(3).

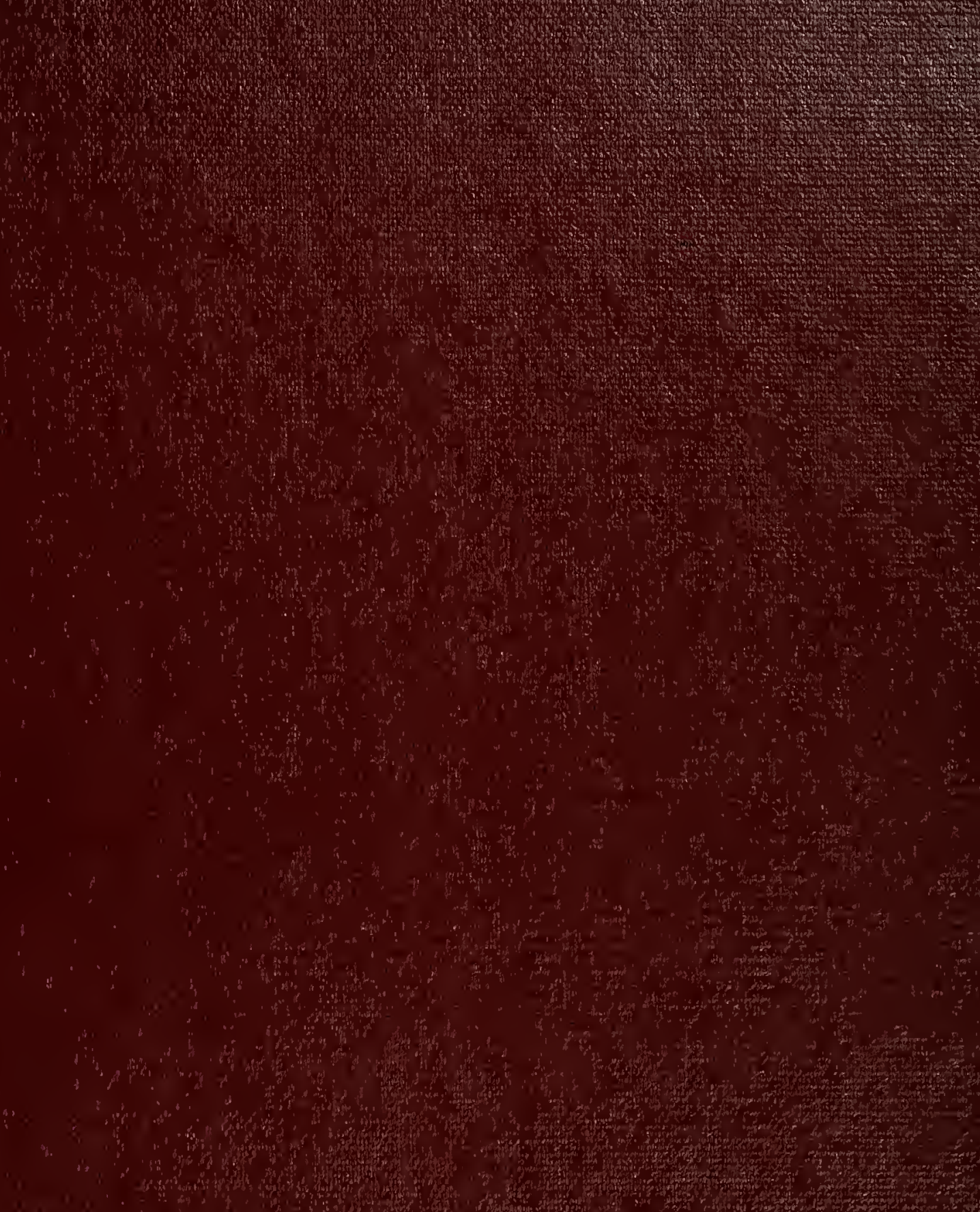

(3)

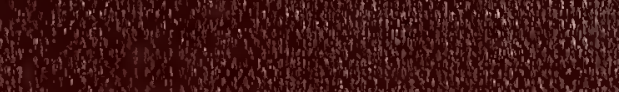







\section{OYA GE}

\section{AUTOUR DU MONDE,}

Exácuté par Ordre ou Roi. 
IMPRIMERIE DE A. FIRMIN DIDOT, IMPKIMEUR DU ROI, RUE JACOR, $\mathrm{N}^{\circ} 24$. 


\section{VOYAGE \\ AUTOUR DU MONDE, \\ (Exáruté par Orore du hioi,}

Sur la Corvette de Sa Llbajesté, La Coquilles, Yrendrent
les années 1822, 1823, 1824 et 1825,

SOUS LE MINISTÈRE ET CONFORMÉMENT AUX INSTRUCTIONS DE S. E. M. LE M ARQUIS

DE CLERMONT-TONNERRE, MINISTRE DE LA MARINE;

Ét publié sous les auspirss

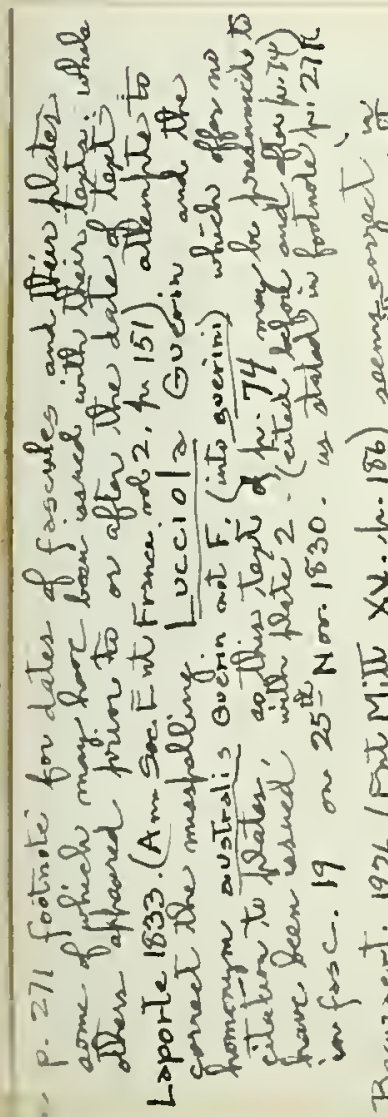

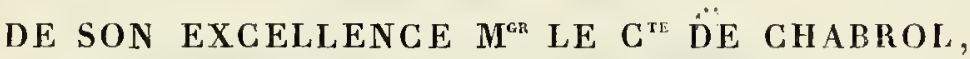
MINISTRE DE LA MIARINE ET DES COLONIES, PAR M. L. I. DUPERREY,

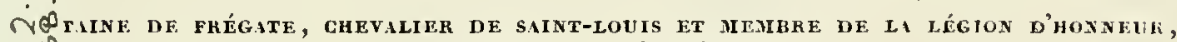

2. COMMANDANT DE L'EXPÉDITION.

Zoologie,

PAR M. LESSON.

Fome Second. $=2^{e}$ Pertie.

\section{PARIS.}

ARTHUS BERTRAND, LIBRAIRE-ÉDITEUR, RUE HAUTEFEULLE， ${ }^{0} 23$.

1830. 



\section{PREMIËRE DIVISION.}

\section{CRUSTACÉS, ARACHNIDES ET INSECTES,}

Par F. C. Guériv Méneville. 



\section{AVANT-PROPOS.}

Le célèbre Latreille, en me chargeant de le remplacer dans la publication des animanx articulés du Voyage autour du monde fait par la corvette de S. M. la Coquille, m'avait imposé une tâche dont je ne m’étais pas dissimulé les difficultés. Pour la remplir convenablement, je résolus d'apporter à cette rédaction les soins les plus scrupuleux, espérant ainsi répondre à l'attente d'un savant que la mort a depuis enlevé à la France, dont il était une des gloires. D’ailleurs javais aussi à cocur de répondre à la confiance dont MM. Duperrey et d'Urville m'avaient honoré, en m'associant à leur collaboration, et je résolus de suivre, autant qu'il était en moi, les traces du premier de ces voyageurs, en donnant à mon travail toute la perfection et l'intérêt scientifique nécessaires, pour qu'il ne demeurât pas au-dessous du grand monument scientifique et national auquel il devait se rattacher.

Afin d'arriver à ce résultat, j'ai dî me livrer à de longues et pénibles recherches; je me suis vu réduit à braver le reproche de lenteur qu'on m'adressait, dans la conscience que cette prétendue lenteur imprimerait un cachet plus durable à mon travail. Maintes fois M. Arthus Bertrand, éditeur de cette vaste et somptueuse publication, s'est plaint de ce qu'il appelait peut-être ma paresse, en me faisant sentir le tort que devait faire an Voyage de la Coquille, celui del'Astrolabe, publié si hâtivement. Mais pouvais-je sacrifier, malgré mon amitié pour l'éditeur, l'intérêt de la science à celui de l’entreprise considérée sous le point de vue commercial? Fort heureusement je trouvai dans M. Ar- 
thus Bertrand un libraire plus jaloux de faire un bon livre, que de livrer au monde savant un de ces ouvrages comme on en produit tant, exécuté avec rapidité et une telle légèreté, que les auteurs y paraissent étrangers aux sciences qu'ils se chargent d'y traiter. Certes, faire figurers, par files et souvent sans pattes, des insectes sur de grandes planches, donner à ceux-ci des noms sans être certain qu'ils n'en aient pas reçu, brocher des descriptions, sans s'inquiéter de celles qu'en ont déjà beaucoup mieux faites une foule d'auteurs, est chose facile; il m'eût suffi de quelques mois pour en produire au moins autant. Le lecteur judicieux verra que telle n'a pas été la marclıe que j’ai suivie; il reconnaîtra que la durée du travail fut motivée par des investigations bibliographiques aussi nombreuses que difficiles et par les comparaisons qu'il m'a fallu faire entre des espèces nouvelles ou des genres inédits et ce qui existait déjà dans la science.

Ici viendrait naturellement se placer cette réflexion que, par le temps employé pour la rédaction de la partie dont j’avais accepté le fardeau, j’ai laissé aux auteurs de plus d'une circumnavigation postérieure le temps de publier leurs récoltes. Il me sera facile de répondre que la science gagnera plus dans un travail longuement élaboré que dans ces publications hâtives écrites sous les inspirations rapides et parfois fugitives du moment; publications où l'auteur semble aspirer à un prix de course plus qu'au succès scientifique. On en jugera par les citations que je ferai tout à l'heure.

Ce n'est pas non plus sans de grands sacrifices que j’ai pu mettre à terme l'histoire des animaux articulés du Voyage de la Coquille; car, ce travail, je l'ai entrepris et achevé par amour pour la science; sans doute si je l'avais écrit comme à la mécanique, qu'on me passe l'expression, j’eusse obtenu des récompenses données avec tant de libéralité à qui sait les enlever de vitesse; mais il m'a fallu prélever sur les travaux qui assurent 
l'existence de ma famille, une part considérable de mon temps pour l'accorder à des recherches ingrates, difficiles, et qui produisent peu d'effet aux yeux de tant de gens, incapables d'apprécier la valeur des livres autrement que par leur grosseur et la promptitude de l'exécution. Il a fallu la passion scientifique dont je suis animé pour me soutenir dans la volonté de terminer consciencieusement mon travail et de contribuer ainsi à une publication honorable pour le département de la marine auquel les sciences naturelles devaient déjà beaucoup.

Il ne faut ni un grand mérite ni beaucoup de temps pour rechercher dans les collections le nom déjà donné à tels ou tels insectes (ce ne sont pas les noms qui leur manquent, soit en France, soit à l'étranger); il n'en faut pas davantage pour décrire enșuite à la hâte ces mêmes animaux : un pareil travail m’a toujours répụgné; il ne sert qu'à entasser pages sur pages, volumes sur volumes. La science, embarrassée par la synonymic obscure qui en résulte, devient un vrai dédale où les bons esprits se perdent, et les entomologistes, aujourd'hui, ne saven vraiment plus comment se débarrasser de cette lèpre qui rend leurs études infinies, pénibles, incertaines, et prépare à ceux qui viendront après nous des difficultés capables de les dégồter de l'étude des sciences naturelles. Un seul fait prouvera ce que j'avance. Le genre Macrothops est inscrit dans l'Astrolabe (partie entomologique, page 210 ), et, à la suite de ce nom générique, je lis la citation du nom de Mac Leay, de même qu'on lit celles de Dejean, Guérin, Gory, etc., etc., sous d'autres noms génériques ou spécifiques; mais que dit un nom sans l'indication de l'ouvrage ou du mémoire dans lesquels l'insecte fut publié? Il ne peut qu'entraîner l'entomologiste qui veut remonter aux sources, à des recherches longues et rebutantes, au bout desquelles il doit encore demeurer daus le doute (I). J'ai en

(1) Comme je l'ai fait pour le genre Scleroderme de Klug, que Latreille avait fait entrer dans tous ses ouvrages, sans dire qu'il était inédit. 
vain feuilleté les ouvrages de Mac Leay qu'on possède à Paris; j'ai en vain écrit à Londres : on m'a répondu que Mac Leay avait décrit beaucoup d'espèces et qu'il en a aussi beaucoup nommé sans les publier, en sorte que je suis contraint à rester dans un doute perpétuel pour ce genre Macrothops, ou je dois enregistrer aveuglément son nom sous une garantie de peu de valeur. Or il est plus expéditif de commencer de suite par là, en se contentant d'avoir recours au tiroir de telle ou telle collection en réputation et en adoptant, sans examen, le nom que l'on trouve sur l'étiquette de l'espèce qui nous paraît identique avec la nôtre, nom que l'amateur a souvent pris dans la boîte d'un autre, lequel le tient lui-même d'mne source semblable : on peut de cette manière avoir publié un volume en deux ou trois mois; mais je suis de ceux qui ne vont pas si vite.

D'autres amateurs, à l'examen superficiel d'un insecte qu'ils n'apercoivent pas au milieu de l'un des cartons d'une collection à peu près classée, trouvent tout simple d'en créer un genre auquel ils ajoutent le Nobis de rigueur, et bientôt ce prétendu genre, orné d'une étiquette de couleur portant son nom barbare en caractères majuscules, est fondé à leurs yeux et pompeusement consacré dans un catalogue. Qu'un naturaliste, pressé de bâcler un pareil ramas de doubles emplois, aille consulter de tels matériaux et les collections qui en fournirent la base, qu'il compare son insecte et qu'il le tronve semblable à celui dont se forme un de ces genres sans consistance, comme, par exemple, les Cilibé, Astrol., p. 262, Diphucephala, p. 200 (I), Sericesthis; p. 206, Geobatıs, p. 215, il n'aura qu'à écrire ses caractères de la sorte: "Les Cilibés ont un peu le port des Peltis et des Thymalus; ils sont propres à l'Océanie et aux îles Moluques, et leurs caractères les éloignent beaucoup des Heleus m? ? Que l'insecte ne ressemble pas à ceux des

(I) J'ai décrit trois espèces appartenant à deux de ces genres, croyant qu'ils seraient caractérisés dans l'Astrolabe. 
collections que l'on consulte, et qu'il soit différent, quoique voisin, de quelques groupes connus, sans plus tarder on en fera encore un genre, tels que Pyronota, p. 213 , Elytruras, p. 40o, Myllorhinus, p. 4 г 8 , etc. etc. etc. Le genre Micronyx(I), par exemple (Astr., p. I 88), scra ainsi caractérisé : "Ce nouveau genre a une assez grande affinité avec les Rutela, les Pelidnota, les Areoda et les Macraspis; mais, d'après la forme des ongles, du clypeum, et le facies général, il ne peut être séparédes Anoplognathides de Mac Leay. "Ou bien enfin, s'affranchissant du préjugé de caractériser, avec autant de détail, les genres nouveaux, on procédera comme pour les genres Pachycolia, $\mathrm{Ba}$ ryscelis, Chrysobalus, Aporhina (Astr., p. 248, 253, 267,3 го), ou autres, en nc leur assignant aucuns caractères. Outre ces observations, dont on pourrait remplir des pages, si l'on avait du temps à perdrc, il existe encore dans les ouvrages faits sur ce modèle une quantité d'inexactitudes, qu'il serait trop long de signaler, et dont les plus saillantes sont relevées dans mon textc aux pages $184,280,278,276$ ct i 95 (voyez une note à la table au sujet de la Libellula bramina). Je me bornerai maintenant à attirer l'attention des entomologistes sur l'énormité de celle qui se trouve aux premières pages de l'Astrolabe, par exemple à la page 23 , dans laquelle on trouve la description de l'Arnidius Marginatus Leach, tandis que le même insecte cst décrit unc seconde fois au verso, sous le nom de Carenum Cyaneum! Je me suis assuré dc ce fait curieux et caractéristique en voyant lindividu de la collection de M. Dupont ct cclui du muséum de Paris.

Ce n'est point ainsi que j’ai procédé; j’ai eu la naïveté de croire que, pour fonder un genre nouveau, il fallait comparer d'abord

(1) Schonuherr a donné aussi ce nom à un genre de Charançons (Generre el spec. Curcul. t. 3, p. 423). Est-ce par modestie ou inattention que M. Boisduval, en corrigeant les épreuves de cet ouvrage, ne l'a pas changé, puisqu'il avait déjà caractérisé et publié un autre genre sous le même nom? 
toutes les espèces qu'on voulait y faire entrer, avec celles des genres qu'on suppose voisins; j’en ai toujours disséqué la bouche, et sourent celle des genres avec lesquels je les comparais; jai cru surtout qu'il était utile de faire connaître les raisons déterminantes de mes nouvelles coupes, et, enfin, j'en ai formulé les caractères avec des détails suffisants pour quon les reconnût autant que possible sans le secours des collections où ils sont entassés.

Il en a été de même pour mes espèces; je ne me suis pas borné à dire sèchement et sans autre préambule: Tel insecte, auquel je donne tel nom, est noir, à pattes rouges, à élytres bleues avec une bande transversejaune : à présent tâchez de voir avec lequel de ceux déjà décrits il a le plus de ressemblance. Il n'y manquerait que d'ajouter avec le grand Corneille :

"Devine, si tu peux, et choisis, si tu l'oses. "

J'ai voulu mener mon lecteur du connu à l'inconnu, et je lui ai dit, après avoir cherché dans le plus grand nombre d'auteurs que jai pu consulter: Tel insecte a beaucoup de ressemblance avec telle espèce que vous connaissez bien ou qui est décrite et figurée dans tel ouvrage, mais elle en diffère sous les points de rue suivants: dans l'espèce que je vous cite pour exemple les pattes sont toutes rouges, dans la mienne la base des cuisses est noire en dessous; dans celle que vous connaissez la bande des élytres touche aux bords, dans la mienne elle n'y arrive pas tout à fait, etc., etc.; et, après avoir fait ainsi ressortir les caractères différentiels de mon insecte, après l'avoir ainsi isolé de ses congénères ( $\boldsymbol{I})$, je l'ai décrit presque minutieuse-

(1) "Pour établir une espèce nouvelle, il faut, avant tout, la distinguer de toutes les espèces décrites, et, pour cela, il est nécessaire de les connaitre toutes, soit en nature, soit d'après des descriptions. La même règle s'applique à la formation d'un genre; elle exige autre chose qu'une différence vague et superficielle : il faut trouver un caractère certain, qui distingue le nouveau genre 
ment et de manière à ne pas permettre qu'il soit confondu avec quelque insecte que ce soit. Cette façon de procéder est, à la vérité, beaucoup plus longue, puisque, pour s'assurer qu'une espèce est nouvelle, il faut comparer toutes celles du même genre et feuilleter souvent un grand nombre d'ouvrages; quelquefois même, pour m'assurer que mon espèce appartenait certainemeut au genre auquel je la rapportais, il m'a fallu examiner ses caractères génériques comparativement et faire l'anatomie de sa bouche. La même manière de procéder a été appliquée à la formation des genrés nouveaux; on verra dans mon texte, aux pages $17,27,71,79,213,247$, par exemple, que j’ai été obligé de faire de nouveaux tableaux des familles pour y introduire un genre et lui assigner sa place naturelle dans la série zoologique. Ces travaux, en général peu appréciés d'un certain nombre d'acheteurs de livres ou méprisés par des prétendues sommités de la science, qui, soignant plus leur renommée que leurs ouvrages, portent uniquement leurs vues aux places lucratives, ces travaux, dis-je, n’ont été faits quavec prudence et lenteur, après un grand nombre de dissections exécutées sous la loupe; des faits bien établis, qui me conduiront peut-être à la cécité, comme le malheureux Savigny, en sont le résultat que jose donner pour incontestable; mais, du moins, jaurai la consolation d'avoir rempli honorablement la tâche que je m'étais donnée, et d'avoir fait un travail que je crois digne du grand et bel ouvrage auquel ont concouru des savants dont l'exemple me commandait de travailler en conscience.

Comme le nombre de feuilles mis à ma disposition était limité, je me suis abstenu d'y perdre l'espace avec de ces prétendus

de tons ceux qui existent déjà. J'en dirai autant de la création des familles, des tribus, des ordres et des classes. "(Burmeister, mém. sur la div. nat. des punaises terrestres (géocorises) considérées surtout relativement à la structure de l'antenne. Revue entom. de Sillocrmann, t. 2, p. 6.) 
coups d'œil géographiques et autres généralités qui ne sauraient être d'aucune utilité pour la science, attendu qu'elles n'eussent pu s'établir que sur un très-petit nombre de faits, recueillis en passant, à la hâte, souvent dans des saisons peṇdant lesquelles les insectes sont encore en nymphes ou à l'état de larves. Sans ètre de la secte des incrédules, je n'ajoute aucune foi aux assertions de ces voyageurs qui, parce qu’ils n’ont pas trouvé de fastueux insectes dans un pays, où eux-mêmes déclarent n'avoir demeuré que peu de jours à une seule époque de l'année, viennent nous dire que ce pays ne produit que peu ou pas d'insectes. Il est évident que si l'on passait seulement une année dans le même lieu, on changerait d'opinion ou que, du moins, on aurait quelque raison à avancer des faits moins incertains : je citerai à l'appui de mon opinion une observation de M. Gay qui, ayant habité le Chili cinq années sans trouver un seul individu d'un Mélasome (le Gyriosomus lavigatus que jai publié dans le Magasin de zoologie, 1834. cl. 1x, pl. 103), en a pris en quantité pendant le cours de la sixième. J'aurais pu reproduire ici quelques-unes des notes recueillies par M. d'Urville à la suite des relâches quil a faites à Sainte-Catherine, à Callao, à Payta, etc.; mais les raisons que jai exposées plus haut me décident à m'en abstenir. En général, on ne saurait trop se prémunir contre ces auteurs sédentaires ou ambulants, qui veulent s'ériger en législateurs, sauf à voir, peu après, leurs ordonnances conspuées par le bon sens public.

On sera peut-être surpris de trouver que la presque totalité des Lépidoptères portent dans mon texte des noms qu'ils n'ont pas sur mes planches, publiées depuis sept aus( (1); cette différence vient de ce que le naturaliste qu'on chargea de publier l'entomologie de l'Astrolabe, ne tenant aucun compte des travaux qui ne sont pas les siens, et voulant avoir l'insigne honneur de

(1) Voyez, à la page $17 \mathrm{I}$, le tableau de la publication des livraisons de la $\mathrm{Co}$ quille et l'époque de celle de l'entomologie de l'Astrolabe. 
placer son nom à la suite de celui d'un papillon, a mieux aimé créer des difficultés pour les naturalistes que d'adopter des noms qui pour tout autre existent en possession d'état dans la science, que j'avais eu le droit d'imposer à ces mêmes Lépidoptères sur des planches somptueusement colóriées, publiées deux ans avant le texte de $M$. Boisduval, et qui conséquemment eussent équivalu pour tout autre à une description complète. Quand un nom d'espèce ou de genre est donné dans une collection seulement, comnie on n'est pas tenu de le deviner, on n'est point blàmable en l'ignorant, et chacun demeure dans son droit de publier cette espèce ou ce genre (1); mais quand des espèces sont figurées dans un ourrage dont le texte demeure sous presse, que leurs figures sont reconnues bonnes ou seulement suffisantes, leurs noms doivent être respectés, nul n'a le droit d'embrouiller la synonymie en les changeant. Linnée, le grand législateur de l'histoire naturelle, foudroie par avance, dans son style concis, de pareils abus : je pense donc que, le code du professeur d'Upsal sous les yeux, on ne saurait assez blâmer la conduite de l'auteur de l'entomologie de l'Astrolabe; pour moi, qui crois entendre mieux les intérêts de la science, je n'ai pas cru devoir tenir à faire prévaloir mes noms, quoique j'en eusse le droit; j’ai même adopté ceux que leur substitua M. Boisduval, montrant ainsi à quel point je craindrais d'encourir le reproche d'embrouiller la synonymie.

Je ne terminerai pas cet avant-propos sans remercier MM. Lesson, Serville, Lefebvre, Chevrolat et Gory, pour les belles espèces qu'ils mont communiquées; en effet, ces natu-

( I) “Je remarque que plusieurs naturalistes s'empressent, comme par une anticipation titulaire, de donner des noms à quelques coupes qui leur paraissent devoir former de nouveaux genres, sans se donner la peine d'en établir les caractères. Ce ne sont que de simples indications, et qui n'imposent aucune loi." (Lítreille, Nouv. Dict. d'hist. nat., nouv. édit. , t. 23, p. I92; et Mac Leay, Hora entom., édit. Lequien, p. 24.) 
AVANT-PROPOS.

ralistes ont pu se procurer beaucoup d'insectes que $\mathbf{M}$. d'Urville n'avait pas pris et qui ne font point partie des collections qu'il remit au inuséum. M. Percheron voulut bien maider aussi,en mouvrant sa riche bibliothèque et en rédigeant pour moi la description d'une partie des Hémiptères Géocorises; je le prie d'en recevoir mes sincères remercîments.

Paris, ce 15 novembre 1838 .

Guérin Méneville.

Nota. Lasignature I n'existe pas, elle devait se composer de l'Avant-Propos qui, formant deux feuilles au lieu d'une, porte les signatures $A$ et $B$. 


\title{
CHAPITRE XII.
}

\section{CRUSTACÉS ET ARACHNIDES :}

\author{
Par F.-E. Guérin.
}

Conne le nombre des espèces nouvelles que nous décrivons dans ce chapitre est assez borné, nous n'avons pas cru devoir faire une division distinctc pour chaque ordre; nous n'établirons donc que deux grandes sections corresponrlantes aux deux classes traitées ici.

$\$ I$.

\section{CRUSTACÉS.}

I. OCYPODE DE D'URVILLE, Ocipode Urvillei. Guér.

O. Testâ rhomboido-quadratâ, brachïs incequalibus granulatis. Oculorum pedunculis ultra ipsos oculos in spinam productis; spinâ glabrâ, minutissimá.

PLANCHE I, fig. $\mathbf{x}$.

Il est de forme carrée, un peu plus large que long; son chaperon est étroit, avancé, arrondi en avant et infléchi; son bord antérieur est sinué, terminé en pointe aux angles, rebordć et finement crénelé. Les bords latéraux sont d'abord parallèles et droits jusqu'au tiers de la longueur de la carapace, ils se rapprochent ensuite un peu vers le bord postérieur qui cst coupé transversalement. Le dessus de la carapace est un peu bombé, finement granulé; les régions ne sont pas saillantes, mais ellcs sont assez bien marquées par des lignes enfoncées. Les yeux sont très-grands, logés dans deux grandes fossettes très-larges, surtout en dessous, et bordées d'une petite carène crénelée; ils sont terminćs par une pctite pointe conique, arrondie au bout et ayant à peine lc cinquième rlc la longueur totale de l'œil.

Vorage de la Coquille. - Z. Tom. II, Purtie II. ${ }^{\text {re }}$ Div. 
Les pinces sont inégales, la droite étant plus grande; celle-ci a le premier article triangulaire ayant l'arête supérieure arrrondie et peu chagrinée, et les deux arêtes inférieures dentées et épineuses. Le second article est très-lombé extérieurement, denté en dehors, avec une épine aiguë en dedans. La main est comprimée, granulée, dentée en scie en dessous et sur le bord supérieur, avec les doigts pointus garnis de dents comprimées et assez tranchantes en dedans. La pince gauche est beaucoup plus petite, sa main est plus étroite et les doigts sont plus longs et moins courbés.

Les pattes sont longues, comprimées, garnies en dessus de petites stries courbes qui les font paraître écailleuses; celles de la seconde paire sont les plus longues; viennent ensuite les troisièmes, les premières et les dernières qui sont les plus courtes et dont le premier article est moins large. Leur ongle est cannelé dans la longueur, garni de poils noirs en delıors, et légèrement aplati. De Taïti.

La fig. I représente l'Ocypode de d'Urville de grandeur naturelle.
a. Sa main de droite.
id.
b. Un des tarses grossi.

2. GÉI.ASIME TÉTRAGONE, Gelasimus tetragonon. Ruppel.

\author{
Fuppel. Besch. und. abbildung. etc., p. 25 , pl. v, f. 5, mâle. \\ Cancer tetragonus. Herbst. t. I, p. 257 , pl. XX, f. 100, femelle. \\ Cancer marinus, minor, vociferans. Seba. Thes., t. III, pl. XIX, fig. I 5 ? femelle. \\ Cancer tetragonus, Fabr., suppl. ent. syst., p. 341, n. 26?
}

PLANCHE I, fig. 2 et 3.

Nous avions considéré l'individu mâle que nous avons figuré conıme une espèce distincte de celle dont nous donnons les citations plus hant: mais depuis que notre planche est gravée, plusieurs naturalistes se sont occupés de la distinction des espèces de ce genre difficile, et tout récemment, M. Ruppel a confirmé l'observation qui prouve que les femelles diffèrent des mâles parce que leurs deux pinces sont petites et égaleś, en sorte que les figures de Herbst et de Séba que nous avions cru appartenir à des espèces différentes de l'individu figuré dans notre planche, n'en sont que des femelles: l'examen d'un grand nombre d'échantillons de la même espèce nous a fait reconnaître que les pinces des mâles varient beaucoup pour la grandeur, poir la longueur des doigts et pour les dents dont ils sont armés; ainsi l'individu à doigt immobile simplement dentelé dont nous avons figuré la main droite, pl. I, fig. 3 , ne diffère pas d'ailleurs du gélasime tétragone; ainsi le nom de gélasime semblable que nous lui avions donné doit être supprimé.

Ces gélasimes ont été trouvés sur les côtes de l'île Borabora. Il paraît que cette espèce habite aussi plusieurs autres parties des Indes Orientales. Le Muséum en possède de Java et du Bengale; elle se trouve aussi dans les mers d'Afrique, et en a été rapportée par M. Ruppel. 


\section{TRAPÉZIE GYMODOCE, Trapezia cymodoce. Gú́r.}

Cancer cymodoce, Herbst. Cancr., t. II, ${ }_{2}{ }^{\mathrm{e}}$ part., p. 22 , pl. LI, f. 5, Aud. Egypte. pl. V, f. 2. Trapezia dentifrons. Latr., Encycl. mélh., t. X, p. $695, \mathrm{n}^{\circ} \mathrm{I}$.

\section{PLANCHE I, fig. 4 .}

Cette jolie espèce est aussi propre aux mers de l'Inde et à celles d'Afrique.

La fig. 4 représente un màle de grandeur naturelle.

a. La partie antérieure de son corps pour montrer linsertion des antennes et la bouche.

$b$. Une des pinces un peu grossie.

c. L'extrémité d'une patte pour montrer les brosses transversales de poils placées sous les tarses.

d. Antenne intermédiaire grossie.

e. Antenne externe grossie.

$f$. Queue du mâle grossie.

g. Queue de la femelle grossie.

h. $i$. k. l. m. n. Les pièces de la bouclıe grossies.

Les individus qui proviennent dı voyage ont été trouvés en pleine mer entre la Nouvelle-Hollande et les îles des Amis.

\section{CYCLOCARCIN, Cýclocarcinus ${ }^{1}$. Guér.}

Le crustacé qui fait le sujet de cette nouvelle coupe générique, a une forme orbiculaire qui lui donne quelque ressemblance avec les mâles des pinnothères et avec quelques leucosies, mais il ne peut être rapproché ni des uns ni des autres à cause de ses pieds-mâchoires extérieurs qui ressemblent à ceux des crabes et des potamophiles. Il ne peut être confondu avec le genre crabe, parce que sa carapace n'est pas arquée en avant comme dans les espèces de ce genre, et qu'elle est aussi longue que large, tandis qu'elle est tonjours plus large dans les crabes; il s'en éloigne encore par sa queue qui est de sept segnents bien distincts dans lindividu mâle que nous décrivons, tandis qu’il n'y en a que cinq dans les premiers. 11 ne peut être confondu avec les trapézies à cause de la forme du test; il en est de même des thelphuses auxquelles il ressemble par ses pieds-mâchoires extérieurs, mais dont il est éloigné à raison de la forme de la partie antérieure de sa carapace qui est avancée, tandis qu'elle est presque tronquée dans ceux-ci.

Les caractères que nous assignons à ce genre sont:

Antennes extérieures courtes, cylindrico-coniques, insćrées en dehors des fossettes oculaires, vers l'angle externe de la cavité buccale, ayant le premier article aplati et en-

' De Kúxdes, cercle, et Ka.pirves, cralic. 
clavé dans la carapace, et les autrcs cylindriques, diminuant de grosseur et de longueur.

Antennes internes insérées presque sur la ligne médiane, placées transversalement dans leurs cavités, celles-ci étant ovales. Pieds-mâchoires extérieurs occupant une cavité carrée; leur second article grand, large; le troisième de même largeur, de moitié moins long, de forme pentagone, ayant l'angle interne supérieur tronqué, et donnant attache, vers son sommet, aux trois derniers.

Yeux petits, portés sur dcs pédicules gros, courts, pouvant se coucher dans les fossettes, et insérés assez près l'un de l'autre au milieı du bord antérieur et de chaque côté du chaperon.

Pinces de la longueur du corps, un peu plus épaisses que les pattes.

Pieds cylindriques de la longueur du corps, terminés par un tarse un peu crochu, conique, sans sillons ni épines.

Carapace orbiculaire, tronquée en arrière, assez bombée, avec les bords latéro-postérieurs un peu coupés et aplatis; et le front un peu avancé et légèrement fendu au milicu ct infléchi.

Abdomen replié, composé de sept feuillets distincts dans les màles.

Ce genre ne se compose jusqu'à présent que d'une espèce; nous pensons que l'on trouvera dans les collections d'autres crustacćs qui pourront s'y rapporter. Quoique nous n'ayons pas cherché à le rapprocher d'une manière rigoureuse et au moyen d'un tableau, des genres avec lesquels il a le plus d'affinitć, nous croyons pouvoir le placer dans le voisinage des trapézies et des thelphuses, nous ne faisons en cela que suivre l'opinion de M. Latreille à qui nous avons montré lia figure de ce crustacé. On ne pourra être arrêté définitivement sur sa place que lorsque l'on aura revu tous les genres de la tribu des quadrilatères et de celle des arqués; $c^{\prime}$ cst un travail auquel "les limites de cet ouvrage ne nous ont pas pernis de nous livrer.

\section{CYCLOCARCIN PINNO'THÉROIDE, Cyclocarcinus pinnothe- roides. GuÉr.}

C. Rotundatus, subglobosus. Clypeo sinuoso, inclinato, chelis paululùm inaqualibus. Testâ fuscâ, flavo-maculatâ.

Au premier aspect on prendrait ce petit crabe pour un mâle de pinnothère. Il n'a pas plus de six millimctres de long sur autant de large; il est de forme arrondie, un peu déprimé aux bords latéro-postérieurs, avancé antérieurement en un petit chaperon sinué et abaissé. Sa carapace est bombée, lisse sans sillons distincts pour indiquer les régions, et elle présente seulement deux petites bosses peu élevées au milieu des bords latéraux. Sa couleur est d'un brun rougeâtre; elle est couverte de taches jaunàtres, arrondies, placées régulièrement de cliaque côté; on en aperçoit une un peu plus grande au centre, et cclles qui se trouvent au bord postérieur sont moins marquées 
et effacées même en arrivant près de ce bord; nous avons compté en tout vingt et une de ces taches grandes et petites.

Les pinces sont un peu inégales, fortes, à peu près de la longueur de la carapace. La gauche est un peu plus forte que l'autre. Leur main n'est pas beaucoup plus longue que l'article qui la précède, elle est bonıbee, presque aussi haute que longue; les dcigts sont courts, crochus avec des dents arrondies très-visibles. Les pattes sont assez courtes, cylindriques; les deux premières paires sont de la longueur du corps, les suivantes diminucnt successivement et très-peu: elles sont terminées par un petit crochet épais, courbé et peu aigu. Les yeux sont assez rapprochés, portés sur de courts pédicules.

L'individu qui est sous nos yeux est un mâle; sa queue est composée de sept tablettes; elles vont en diminuant à partir de la troisième qui est la plus large; elles sont égales en longueur, et la dernic̀re est triangulaire à côtés arrondis.

Cette espèce a été trouvée sur les còtes de l'île de Waigiou.

\section{PINNOTHÈre VILI,OSULE, Pinnotheres villosulus. Guér.}

\section{P. testâ subquadratâ, globosâ, villosâ; fronte emarginatâ; pedibus primis et secunclis cequalibus : ceteris paululum brevioribus : interiori parte chelarum clente paululum prominenti.}

Linclividu que nous avons sous les yeux est une femelle; sa carapace a un peu plus de sept millimètres de long sur autant de large; elle est de forme carrée à angles très-arrondis, globuleuse, molle, couverte d'un duvet court, serré et brun sur toute sa surface; son chapcron est un peu avancé, un peu échancré au milieu. Les ycux sont assez rapprochés, placés de cliaque côté du rostre, portés sur de très-courts pédicules. Les autcnnes intermédiaires sont logćes dans des fossettes ovales; elles sont placées obliquement à l'axe du corps et se dirigent sur les còtés et en haut. Les piedsmâchoires extérieurs sont insérés à une très-grande distance l'un de l'autre, et ne se touchent que par leur sommet. Leurs trois premicrs articles sont nuls; lc quatrième est très-grand, plus large à l'extrémité, un peu avancé au milieu antérieur et donnant attache aux cinquième et sixième qui sont courts, étroits et très-ciliés aux bords. Lc plus grand est garni de poils très-serrés en dedans et aux bords. Les antennes extérieures sont très-courtes, composées de cinq articles avant le filet qui est lui-même très-articulć. Le prcmier articlc est soudé à la carapace et sépare les yeux, des fossettes des antennes intcrméliaires; les autres sont ovoïdes, tronqués aux deux bouts, et vont cn diminuant d'épaisseur; les antennes dépassent de très-peu le bord antérieur de la carapace.

Les pinces sont de la longueur du corps, égales, peu robustcs; la main, en y comprenant les doigts, est aussi longue que les deux articles précédents rćunis; les doigts sont crochus, finement dentés cn dedans et ayant chacun à leur base une dent pen saillante ct arrondie. Les pattes sont assez fortes, courtes; les premières et les secondes 
sont presque ćgales, moins longues que la carapace; les suivantes diminuent un peu de longueur. Ces pattes ainsi quc les pinces sont couvertes du duvet brun qu'on observe sur le corps; elles sont de plus ciliées sur leurs bords. La queue est très-large, de sept tablettes, dont les deux premières très-étroites, les autres presque égales; leur milieu est un peu élevé en saillie arrondie; elle est aussi garnie du neême duvet brun.

Cette espèce diffère essentiellement du Pinnothère Mytilorum et des espèces de Leach que M. Latreille lui réunit, parce que ceux-ci ont le corps glabre, parce que leurs antennes intermédiaires sont placées transversalement dans leurs fossettes, et parce que leur seconde paire de pattes est beaucoup plus longue que les autres. Elle a bien de la ressemblance avec l'espèce figurée dans le grand ouvrage sur l'Égypte, pl. VII, f. I. Mais celle-ci est plus grande; ses antennes internes sont placées transversalement comme dans le Mytilorum. Ses pieds-mâchoires ne sont pas si larges, et la dent de la base du doigt inférieur des pinces est très-forte.

Notre Pinnothère a été pris sur les côtes de l'île de Timor. On n’a conservé aucune notc sur le lieu où on l'a trouvé.

\section{SÉSARME, Sesarma. SAY.}

Ce genre, établi par Say dans le Journal de l'Académie des Sciences de Philadelphie, t. I, p. 73 , avait été abandonné par son auteur et réuni aux grapses; M. Milnes Edwards vient de le reprendre et lui a donné des caractères certains et d'une valeur suffisante pour qu'il soit désormais impossible de ne pas l'adopter. Ces caractc̀res seront publiés dans un ouvrage qu'il prépare et dont il a bien voulu nous montrer le manuscrit.

L'espèce que nous allons décrire a été examinée par lui et rentre parfaitement dans le genrc Sésarma tel qu'il l'adopte.

\section{SÉSARME TRAPÉZOIDE, Sesarma trapezoidea. Guér.}

S. tesiâ rubrâ, flavo-maculatâ, trapeziformi, posterius latiori, complanatâ, utrinquè pilosá. Fronte quatuor plicis truncatis; marginibus anterioribus et lateralibus bidentatis. Pedibus planis, rubris, flavo-fasciatis.

La plus grande largeur de sa carapace se trouve vers le tiers postérieur et est égale à sa longueur; la forme de cette carapace est celle d'un trapèze, elle est plus étroite antérieurement; son front est un peu avancé, divisé en quatre lobes tronqués et presque égaux dont lès latéraux sont un peu plus avancés que les intermédiaires. Les cavités oculaires sont grandes et occupent clıacune le quart de la largeur anté- 
rieure de la carapace; leur angle externe ne s'élève pas à la hauteur du front, il est terminé par une pointe aigüe et un peu avancée. Au-dessous de cette pointe et sur les côtés du test, se trouve une petite dent peu saillante, arrondie. Les bords latćropostérieurs de la carapace sont coupés obliqnement et sont un peu plus grands que le bord postérieur qui est transversal. Le dessus de la carapace est très-peu bombé, les rćgions en sont bien marquées, élevées; tout ce dessus est lisse et les bords seuls sont garnis de poils conrts et serrés; sa couleur est d'un rougeâtre vineux un peu violet, on observe de petites taches jaunes irrégulières, surtout en arrière. Le front est un peu plus ronge; il est rabattu dans toute sa largeur et terminé par une crêtc aiguë qui couvre l'inscrtion des antennes intermédiaires. Les côtés en dessous et vers la bouche sont assez bombés, ils sont couverts d'un duvet jaunàtre et très-serré. Les piedsnıâchoires extérieurs laissent, commc dans les Grapses, un hiatus assez grand entrc eux : leur troisième article offre une crête élevée qui le traverse obliquement de l'angle postéricur externe à l'angle antérieur interne. La queue de la femelle que nous avons sous les yeux est très-grande, ronde et composée de scpt tablettes.

Les pinces sont courtes, petites, égales, un peu rugueuses, avcc les doigts terminés en cuiller. Les pattes sont grandes, très-aplaties, garnies de rugosités, surtout au premier article, qui présente vers l'extrémité et en dessus une forte dent crochue. Le second article a quelques cannelures peu marquées. Les ongles sont longs, crochus au bout, et garnis de très-petites épines. La couleur des pattes est la même que celle du clessus de la carapace; elles ont des bandes transverses sinuées et souvent interrompucs, de coulcur jaune.

Cette espèce ressemble beaucoup à la Sesarma tetragona de M. Edw. et de Lamarck, conservée au Musćum; mais celle de Lamarck est d'égale largeur en avant et en arrière, et son front ne présente pas de lobes distincts comme dans la nôtre. Les dents antérieures des côtés de la carapace de la Sésarme tétragone sont beaucoup plus fortes et plus aiguës que celles de notre espèce.

La Sésarme trapézoïde a été trouvéc sur les côtes de lîle de Taïti.

\section{GRAPSE CRÉNELÉ, Grapsus crenulatus. GuÉr.}

G. testâ rubenti, complanatâ, subquadratâ : utrinquè deflexâ, tridentatâ, a'entibus crenulatis. Fronte transversali, paululum rotundá. Manibus aqualibus, lcevibus, introrsum pilosis. Pedibus marginibus ciliatis.

Cette espèce s'éloigne des Grapses proprement dits par quelques caractères qui nous sembleut assez importants pour autoriser, plus tarl et quand on aura d'autres espèccs analogues, à faire unc nouvelle coupe générique; il serait possible qu'elle entràt dans le gcnre pseudlo-grapse établi par M. Milnes-Edwards; mais, comme nous n'avons fait que jeter un coup-d'œil sur son manuscrit, il nous est impossible d'avoir une certitude 
à cet égard, e'est pourquoi nous laissons provisoirement notre crustacé dans le genre Grapse.

Il est un peu plus large que long; sa longueur est de vingt-trois millimètres et sa plus grande largeur de vingt-six. Sa earapaee est de forme earrée, tronquée en avant et en arrière, avee les eòtés arrondis; la surfaee supérieure est finement ehagrinée, avee les régions bien marquées; les lignes qui marquent la séparation des régions eordiale, génitale et hépatique, forment an milieu la figure d'une $H$. Le front s'abaisse un pen, il est terminé par une erête saillante, un peu arrondie. Les fossettes oeulaires sont assez grandes, plıs en arrière, terminées à l'angle externe par une épine aignë. Les yeux sont de grandeur ordinaire, ils atteignent presque l'épine latérale de leur fossette.

Les eôtés de la earapaee sont arrondis, garnis de deux dents après eelle qui termine les fossettes des yeux; la dernière de ees dents se trouve vers le milieu de ee bord latéral, l'autre est plaeée entre eelle-là et eelle du eoin des yeux. Ses bords sont en ontre finement erénelés, un peu relevés. Le bord postérieur est transverse.

Le dessous de la carapaee, vers la bouehe, est assez bombé, garni de poils eourts et peu serrés. La bouehe oeeupe un espaee earré : les pieds - mâehoires extérieurs laissent entre eux un espaee ouvert assez considérable, mais pas tant que dans le Grapsus pictus; leur seeond artiele n'est pas rétréei en haut, eomme dans ee grapse, il reste d'égale largeur et se trouve rétréei à sa base. Le troisième artiele diffère eneore plus du même dans l'espèee à laquelle nous le eomparons; il est plus large que long, arrondi à ses angles, éehaneré au bord antérieur pour reeevoir les autres artieles, et il porte vers les bords latéraux, et de elaque eôté, une petite élévation qui laisse son milieu en ereux.

Les pinces sont presque égales, assez grandes, épaisses, lisses; la main est bombée en dessus, avee les doigts de sa longueur, eourbés, terminés en euiller et ayant des dents arrondies et assez nombrenses en dedans; les parties de ees pattes qui regardent le corps sont garnies de longs poils très-minees et soyenx, il y en a surtout un paquet eonsidérable et eireonscrit en ovale à la partie interne des mains.

Les pattes sont moins aplaties et moins larges que dans le Grapsus pictus, elles sont lisses, leurs deux premiers artieles sont garnis à la tranehe externe ou supérieure de longs poils très-serrés, le troisième artiele a de ces longues franges de poils à la tranehe supérieure et inférieure; les tarses sont aussi longs que l'artiele qui les préeède, ils sont légèrenteut cannelés en dessus et peu garnis de poils.

Notre individu est un mâle; il ressemble un peu au Grapsus octo-dentatus de la eollection du Muséum, mais eelui-ei’a quatre dents anx bords latéraux, il est plus bombé que le nôtre, ses bords ne sont pas un peı relevés et sa earapace est plus large postérieurement, tandis que le eontraire a lieu dans notre espèce. Sa couleur est rougeâtre.

Il a été trouvé dans les mers de la Nouvelle-Hollande.

\section{CRIOCARCIN. Criocarcinus ${ }^{3}$. Guér.}

Un erustaeé fort remarquable, qui n'avait été vu que par Séba et Linneus et dont on

¿ De Kpiòe, bélier, et Kapxives, crabe. 
n'avait fait depuis que copier la figure, nous a donné l'occasion d'établir ce nouveau genre. Au premier aspect il se rapproche des Micippes par son front qui est abaissé et terminé par un chaperon ou bec denté; mais il s'en éloigne par la saillie que font ses yeux hors de leurs fossettes, et surtout par l'insertion du deuxième article de ses antennes latérales ${ }^{\mathrm{r}}$.

En étudiant l'arrangement des genres que M. Latreille a présentés dans la dernière édition du Règuc Animal, nous avons cherché à placer notre nouveau genre dans le voisinage de ceux qui ont le plus de caractères communs avec lui, et nous avons dî apporter quelques modifications anx caractères de ceux-ci pour y intercaler le nôtre; le tableau ci-joint est destiné à faire mieux ressortir ces caractères et la place que le genre Criocarcin doit occuper dans la méthode de M. Latreille.

I. Longueur des deux pieds, n'excédant guère celle du corps.

A. Serres (des nâ̂les au moins) notablement plus grosses que les pieds. Pédicules oculaires très-courts.

Les g. Mithrax, Acanthonix, Pise et Péricère.

B. Serres (nıème des mâles) à peine plẽ śnaisses que les pieds suivants; pédicules oculaires moyens ou grands.

a. Pédicules oculaires susceptibles de se cacher dans leurs fossettes.

I. Deuxième article des antennes latérales naissant de l'extrémité du premier. Test n'étant pas incliné en avant. Yeux ne dépassant pas les épines qui entourent les fosscttes oculaires, etc.

Genre Mä̈a. Leach.

2. Deuxième article des antennes latérales naissant de l'extrénité du premier; test incliné en avant; yeux dépassant de beaucoup les épines qui entourent leurs fossettes, etc.

Genre Criocarcinus. Guér.

3. Deuxième article des antennes intermédiaires naissant du bord interne et plus bas que l'extrémitć du précédent; test fortement incliné en avant; yeux ne dépassant pas les épines qui entourent les fossettes oculaires, etc.

Genre Micippe. Leach.

४. Pédicules oculaires ne pouvant pas se retirer dans des fossettes.

Genre Sténocionops. Ratr.

II. Longueur des premières paires de pieds excédlant de moitié celle du corps.

Les genres Camposcie, Halime, Hyas, Libinie.

\footnotetext{
' On sait que le premier artiele de ees antenues est toujours soudé au test, et coneourt le plus souvent à fermer infí rieureweut les fessettes orulaires.

rogage de In Coquille. - 7. Tom. 11, partie 11. $1^{\text {te }}$ Div. 
La seulc espc̀ce, type de notrc nouveau genre, n'avait pas été revue depuis Séba et Linneus, comme nous l'avons dit plus haut. Fabricius a fait mention de ce crustacé dans son Entomologie systématique en copiant Linnće; Herbst semble avoir copié la Gygure donnée par Séba en ajoutant la phrase de Linnée, et une description plus étendue qui nous paraìt faite sur celle de Linnée et sur la figure de Séba; enfin on a encore copié Séba dans l'Atlas de l'Encyclopédie méthodique, mais beaucoup mieux que ne l'avait fait Herbst.

Les caraetères du genre criocarcin peuvent être exprimés ainsi :

Corps ovalairc; front penché cn avant; pédicules oculaires longs, insérés au-dessous de deux prolongements en forme de cornes; pouvant se cacher entièrement dans deux fossettcs formées par le bord inférieur de ces prolongements du test, par le bord externe du premier article des antennes latérales et par la base de deux grandes épines du test.

Prenier artiele des antcnnes externes terminé en haut par deux épines, point dilaté à l'extérieur' cn lame transverse ; le seeond article inséré à l'extrémité du précédent entre les cieux épines et plus près de l'épinc interne; ce second article long, atteignant le milieu de la longueur du rostre; troisième article de moitié moins long que le précédent, ccs deux articles garnis de ehaque côté de longs poils raides. Fouet des antcnnes allant eu diminuant, un peu plus long que les deux articles précédents réunis, et eomposè d'un grand nombre de petites articulations; ces antennes latérales ayant leur deuxième article insérć à la hauteur de la base des ycux, ct entre cctte base et linsertion des antenncs intermédliaires.

Antennes intermédiaires insérées dans deux fossettes triangulaires placćes sous le rostre, à la hauteur de l'insertion du deuxième des articles intermédiaires, de forme ordinaire.

Espace compris entrc les fossettes des antennes intermédiaires et la bouche, d'une hauteur égale au tiers de sa largeur, se relcvant en une petite crête qui borde la bouche en avant.

Pieds-màchoires extérieurs occupant un espace trapézoïdal, plus large et un peu arrondi en avant; leur premier article, petit, triangulaire; le second, le plus grand de tous, fortement ćchancré à son bord supéricur externe, denté en scie au bord intérieur. Le troisième article de forme carrćc, inséré dans l'ćchancrure externe du précédent, plus large que lui, offrant à son angle supérieur interne une profonde échancrure dans laquclle s'insère le quatric̀mc article, qui est assez grand, aplati, tronqué et un peu dilaté au bout. Quatric̀me article moins long que le précédent, cylindrique; le cinquième ua peu plus long, eylindrique, plus mince et terminé par un faisceau de poils. Flagre aussi long que son support, qui occupc un espace de moitié moins large que le deuxième artiele du pied-màchoire.

Queuc (dans la femelle) trèz-large, eomposéc de sept tablettes, les trois premières étroites, ćgales; les trois suivantes grancles, soudées entre elles et ne laissant voir que les sutures, la dernière également grande, mais pouvant se mouvoir.

Serres à peine plus épaisses que les pieds. Main plus longue que l'article qui la précède. 
Pattes des deux premières paires égales et de la longucur du corps. Les troisièmes et quatrième allant en diminuant, tarscs terminés par un crochct aigu.

\section{CRIOCARCIN A SOURCILS. Criocarcinus superciliosa. GuÉr.}

C. testâ tuberculatâ, spinosâ et villosâ; antrorsùm angusta et inclinat $\vec{a}$; fronte bidentata ; spinis ocularibus porrectis, apice trifido; oculorum pedunculis elongatis; manibus brevibus, inernibus.

Cancer superciliosus, Linn., Syst. nat., t. II, p. $1047, n^{\circ} 45$. Mus. Lud. ulr. 444-15. Fabr., Ent. syst., t. II, p. 46 I , $n^{\circ} 77$. Herbst Krabben ersterband., p. $227, n^{\circ}$ I 17 , pl. XIV, fig. $8 \mathrm{~g}$.

Cancer araneus, crustaceus, cornulus, amboinensis, Seba, Thes., t. III, tab. 18 , I. I 1. Maia superciliosa Latr., Expl. des pl. de l'Encycl. méth. el atlas, pl. CCLXXVI, fig. 4 .

Ce crustacé est long de trois centimètres et demi, et large d'un peu plus de denx centimètrcs ; sa carapace est ovalaire, rétrécie en avant, garnie dc tuberculcs de différente grosseur et de poils raides, crochus au bout ; ses régions sont bien marquées, ct l'on remarque de chaque côté et un peu cn avant un enfoncement profond à la séparation des régions branchiales et hépatiques supérieures. La région gétritale, qui est placée en avant et un peu au-clelà du milieu de la longueur du corps, porte au nilieu unc forte épine un peu courbée, dirigée en avant et arrondie au bout. A partir de ccttc épine jusqu'à l'extrémité antérieure, la carapace s'abaisse par une courbe régulière sans coupure brusque, comme cela a lieu chez les micippes; lc front descend plus bas que le dessons du corps, il est terniné par deux épines divcrgentcs cn forme de fourche. Les yeux sont portés sur deux proéminences avancées en forme de cornes transvcrsales, dirigćes un peu en avant, terminées par trois épines, dont deux en dessus et une au-dessous de l'antérienre. Cette épinc antérieure est la plus grande, clle esi dirigće en dehors, en avant et en haut, et terminée par un petit bouton lisse; l'autrc cst plus petite, dirigée en dehors ct en arrière; enfin, cellc de dessous, qui est placée sous l'antérieure, est à peu prc̀s égale à la précédente, elle est dirigée en dehors et en bas. La distance comprise entre ces deux cornes, prise de l'extrémité des épines antéricures et supérieurcs, est égale à la largeur du corps. Les ycux sont insérés dans unc fossctte au-dessous et cntre les trois épines, leur pćdoncule les dépasse de la moitić dc sa longueur; il est cylindrique, de la même largeur, et terminé par İœil qui est ovalairc et pas plus gros que son pćdoncule.

En arrière et un peu au-dessous des supports des ycix, ct tout-à-fait sur les bords latéraux de la carapace, on olsserve dcux grandes épincs courbes, horizontales, dirigées un peu en avant, terminées par un pctit bouton lisse, ct ayant à leur bord antćrieur leux petits tubercules arrondis et qui les font pariître comme dentćcs; ces ćpines sont cncore placces plus hant que celle du milieu de la région génitale; les régions branchinales sont très-grandes, bonzlsées, séparćes des autres par un sillon qui devient pro- 
fond à leur séparation d'avec la région génitale: elles portent en arric̀re et vers le quart de la longueur du eorps, une grande épine plaeée sur le eôté, dirigée en dehors, en arrière et un peu en haut, terminée par un bouton lisse et ayant quelques petits tubereules peu saillants en dessus. Beaueoup plus bas, presque au bord de la earapaee et dans son milieu, se trouve de ehaque eôté une épine beaueoup plus petite, arrondie au bout et dirigée en avant. Enfin, le bord postérieur de la carapace est sinué, un peu prolongé au milieu où l'on voit une épine plaeée au eentre du bord postérieur, et dirigée en haut et en arrière.

Les pinees sont eourtes, minees; leur longueur est bcaucoup moindre que eelle du eorps, elles sont lisses; leur dernier artiele ou le poignet n'est pas plus épais que les préeédents; sa longueur, y eompris les doigts, égale eelle des deux artieles préeédents réunis. Les doigts sont eourbés en dedans, tranehants intérieurement avee de petites dentelures pen saillantes.

Les premières et seeondes pattes sont de la longueur du eorps, plus longues que les pinees; les suivantes sont un peu plus eourtes, et les dernières sont les plus eourtes de toutes. L'extrémité de leur premier artiele est garnie de trois tubereules saillants; le sccond artiele est de moitié plus eourt, de forme ordinaire; le troisième est de la longueur du premier, eylindrique et plus mince; enfin, le tarse est de moitié moins long que l'artiele préeédent et terminé par un ongle pointu et eroehu. 'Toutes ees pattes sont eouvertes de poils roides, en partic droits et en partie eroehus. Le dessous présente deux épines plaeées à l'extrénité du premier artiele des antennes et deux gros tubercules de chaque eôté de la bouehe. La queue de la femelle que nous déerivons est trèslarge et vient toueher à la lase des pieds et de la bouehe; elle est eouverte des mêmes poils crochus et bordée de eils eourts et très-serrés.

L'individu que nous déerivons était dans l'alcool; sa couleur est jaunâtre; il était couvert de gros fueus, de polypiers et d'autres eorps étrangers qui s'étaient attaehés à ses poils eroehus. Il a été pris sur les eôtes de l'île de Bourou. Celui de Séba venait d'Amboine.

\section{HYMÉNOSOME DE GAUDICHAUD, Hymenosoma Gaudichaudii, GuÉR.}

I1. testâ oblongâ, ovatâ, explanatâ; rostro porrecto, utrinquè dentato, oculis prominentibus; manibus gracilibus, lcevibus. Pedibus elongutis, inermibus, tarsorum hamulis longis, apice uncinatis, posticè ciliatis.

\section{PLANCHE II, fig. 12 à 18.}

Cette petite espèce n'a que sept millimètres de long sur six de large; son test est très-aplati, de eouleur de corne et presque transparent : son rostre est avaneé, garni au milieu de sa longueur, et de ehaque eôté, d'une petite dent peu saillante. Les yeux sont insérés à la base de ce rostre, dans une éehanerure peu profonde; ils sont assez 
saillants, plus gros que leur pédloncule et globuleux. Les antennes intermédiaires sont tout-à-fait eachées sous le rostre; leur premier artiele est grand, dilaté en dehors; le seeond est petit, les deux snivants, plus grands, sont égaux en longueur, et le dernier est terminé par denx filets articulés conme à l'ordinaire. Les antenncs externes sont insérées au-dessous des yeux; lenr premier article, ou eelui qui est confondu avec le tronc, n'est nullement visible; la tige saillante est composée de cinq artieles, dont le premier est de grandeur moyenne, le second de moitié plus long, le troisième encore plus long, et enfin les deux suivants très-petits et plus minces; le dernicr se termine cn cône, il est prolongé par un filet très-mince, sétifornıe, ne laissant voir aucune artieulation, et garni de poils courts. Les pieds-mâehoires extérieurs sont larges; leur premier article est très-pctit, soudé avec le suivant; eelui-ci est grand, entier et prolongé en haut à son bord internc qui est presque droit. Le troisiène article est aussi grand que le précédent, tronqué à ses angles supérieurs, un peı plus large quc le préećdent dans son milieu; le quatrième article est beateoup plus petit et plus étroit, s’insère au milieu de la troncature de l'angle interne; le cinquième est presque de moitié plus eourt que le quatrième, plus étroit, cylindrique; enfin le sixième est un peu eourbe, un peu plus long que celui qui précède, plus étroit au bout et arrondi. 'Tous ces articles sont garnis de longs cils en cledans. Le fouet a une tige un peu plus longue que les trois premiers articles des pieds-mâchoires, son second artiele est de plus de moitié plus eourt, enfin le flagre est remplaeé par de longs poils. La queue de la femelle que nous décrivons, est très-large, presque roude, et composée de cinq tablettes dont les denx antérieures très-étroites, et les trois suivantes larges et égales.

Les pinces sont un peu plus longues que le corps, égales : la main, y compris les doigts, est aussi longue que les deux premiers articles réunis, elle n'est pas plus épaisse que ces articles, sans poils ni épines; les doigts sont un peu erochus an bout et ciliés en dedans.

Les pattes sont simples, sans épines aux articulations; les premières sont les plus grandes, les autres vont en diminuant jusqu'aux dernières. Les tarses sont longs, un peu crochus, ciliés en dedans. Cette hyménosome ressemblc beaucoup à l'lygm. Mathcei de Latreille, mais dans eelle-ci le rostre est court, large, tronqué et aplati; les yeux ne le dépassent pas, et sont cachés ainsi que les antennes intermédiaires et les quatre premiers articles des antenıes latérales; cette dernière espèce a de plıs les cuisses garnies d'une épine à leur extrémité supérieure et à leur articulation avec l'article suivant. Enfin l'hyménosome de Mathieu diffère encore de la nôtre par sa forme qui est transversale, e'est-i-dire qu'elle est plus large que longue.

Le seul individu rapporté par M. Lesson a été trouvé sur les côtes de la NouvelleHollande.

La fig. I 2 représente l'hymenosoma Gaudichaudï très-grossie, on voit au-dessus le trait indiquant sa longueur.

fig. 13 , partie extérieure très-grossie et vue en dessous.

$\mathbf{1 4}$, antennc externe très-grossie. 
15 , antenne interne très-grossie.

ı6, uı des pieds-mâchoircs très-grossi.

17, l'une des pinces très-grossie.

I 8 , un tarse très-grossi.

\section{HYMÉNOSOHE DE LEACH, Hymonosema Leachii, Guér.}

H. Testâ transversali, explanatâ, rostro tridentato, dentibus aqualibus, rotundatis. Oculis prominentibus, distantibus. Antennis detectis, paulim elongatis. Chelis incequalibus, manibus densis, suprà rotundatis. Pedibus elongatis, tenuibus, femoribus apice unispinosis.

Hymenosoma Leachi, Guér., Iconog. du règne animal, crustacés, pl. X, fig. 2.

Cette cspècc se rapproche un pcu de l'hymenosoma orbicularis de M. Desmarest, mais elle en diffère cependant par plusieurs caractères très-apparents, tels que la forme du corps, lc rostrc et surtont la grosseur de ses mains. Son corps est long de dix miliimètres, et large de près de douze, ce qui lui donne une forme transversale; il est aplati, avec quelqucs sillons presque effacés indiquant les régions; les côtés du corps sont brusquemcnt baissćs, mais très-ćtroits, ils sont terminés en avant et sous les yeux par nnc petite dent très-peu élevée. Le front est large, peu saillant, et composé de trois dents égales ne formant point un rostre avancé; les yeux sont gros, saillants et dépassent un peu les dents du fiont; ils sont placćs dans des échancrures formées par la dent terminalc des côtés du test et les dents extcrnes dı front; ils sont assez distants entre eux. Les antenncs sont très-saillantes au-delà des dents du front; les intermédiaires sont de forme ordinaire, un peu plus longues que le pédoncule des externes; celles-ci ont le second article court, les denx suivants d'égale longueur, le cinquième beaucoup plus petit, cylindrique, ct le dernier encore plus petit, conique, terminé par une longue soie inarticulée. Les pieds-mâchoircs extérieurs ont leurs deuxième et troisième articles presque égaux, le second article est fortement tronqué à son angle antérieur interne, et présente une figure hexagone à côtés presque égaux. Le troisième est également tronqué à l'angle internc et supérieur'; les trois clerniers articles sont à peu près égaux en longueur, mais vont en diminuant de largeur. Le fonet extérieur est comme dans l'hymenosoma Mathai.

La queue dc notre individu, qui est un mâle, est de forme triangulaire, terminée en pointe et conıposée de cinq feuillets; le premier est le plus large de tous et le plus étroit; il est séparé du second par une petite languette très-étroite et qui semble former une sixième tablette rudimentaire; la seconde tablette est moins large, à côtés parallèles, deux fois moins étroite; la troisième est un peu moins longue, aussi large à son insertion avec la précédente, mais diminuant et ayant ses côtés coupés très-obliquement; 
la quatrième est de la largeur de la précédente, avec les côtés parallèles. Enfin la dernière est triangulaire. Cette queue est couverte de légères granulations.

Les pinces sont grandcs, inégales, beaucoup plus longues que lc corps, surtout la droite qui est la plus grande; leurs deux premiers articles sont de forme ordinaire, arrondis, robustes; la main est grande, très-épaisse, bonbée en dcdans et en dehors; lisse; les doigts sont finement deutelés intérieurement, et le supérieur ou celui qui est mobile, a une dent plus forte et séparée des autres vers sa base.

Les pattcs sont assez longues, toutes les cuisscs sont terminées à leur extrémité silpérieure par une petite dent; ces pattes vont en diminuant de longueur depuis les premières; elles sont terminées par un tarse long, crochu et cilié en dessous.

Cette espèce a été trouvée sur les côtes de la Nouvelle-Hollande.

\section{Genre EURYPODE, Eurypodius, GuÉR. ․}

Antennes externes longues, insérées au-dessus des yeux, ayant leur pédoncule formé de trois articles égaux. Les intérieures beaueoup plus courtes, avec leur filet interne, ou le plus petit, de sept articles. Yeux pćdonculés, non rétractiles. Épistône transversal. Troisième article des pieds-mâchoires extérienrs plus long que large, et profondément échancré à son. bord interne et supérieur.

Test triangulaire, rétréci en avant et terninć par un rostre bifide. Serres égales, plus grandes dans les mâles, et à mains comprimées et allongées. Pattes longues, dćcroissant de longuenr depuis la premic̀re paire, et ayant le métatarse dilaté. Queue de sept tablettes dans les deux sexes.

La bouche de cc crustacé est composée d'unc lèvre supćrieure, d'une languc ou lèvre inférieure, de deux mandibules très-dures et pierreuses, ayant trois tubercules saillants sur leur bord tranchant, et un palpe de trois articles inséré sur leur partie dorsale; et de cinq paires de pieds-mâchoires de formes variées. Le premier pied-mâchoire, ou celui qui se trouve immédiatement au-dessus des mandibules, cst membraneux, il est composé de trois pièces principales, ciliées du côté intérieur; le second est également composé de trois pic̀ces, mais beaucoup plus courtes; elles sont aussi membraneuses et ciliées intérieurement, et elles sont attachécs à un large appendice arrondi, transparent et diversement plissé dans sa surface. Le troisième pied-mâchoire est encore membraneux, il est également composé de trois pièces, mais il est de plus accompagné d'un palpe flagelliforme long, et terminé par un filet cétacé et velu extérieurement; cc piedmàchoire est attaché à une longue pièce mcmbraneuse et ciliée qui se trouvc placée audessus des branchies. Le quatrième pied - mâchoirc commence à être corné, il se compose de deux tiges, une interne et l'autre externe, ce dernier est lc palpe flabelliforme, il est beaucoup plus long que la tige interne, et terminé par un filet sétacé. La tige interne est composée de six articles, dont le troisic̀me est le plus grand; les trois suivants

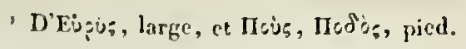


sont presque égaux entre enx, et le clernier est terminé par des épines aiguës et de longs poils. Enfin les einquiènes pieds-màelıoires, ou ceux que l'on nonime pieds-mâehoires extérieurs, sont également eomposés de deux tiges, l'interue est de six artieles dont le premier est très-eourt, soudé avee le seeond qui est très-grand, deux fois plus long que large, avee son bord interne prolongé vert le laut, et arrondi. Le troisième artiele est un peu plus long que large, rétréei à sa base, aussi large que le préeédent, et prolongé à son bord supérieur et interne qui est profondément échaneré; e'est dans eette éehancrure que s'inżèrent les trois derniers artieles qui sont beaneoup plus petits, presque eylindriques, et vont en dininuant de grosseur. Le palpe lagelliforme est plus court, son fouet est eomposé d'un grand nombre d'artieles, et velu à l'extérieur. La cavité bueeale est presque earrée, un peu plus longue que large; son bord antérieur laisse entre lui et la base des antennes un espaee transversal, que M. Latreille a nonmé epistome ou sur-bouehe.

Les antennes sont insérées très-près l'une de l'autre et sur la même ligne. Les extérieures sont distantes entre elles et de la longueur de la moitié du eorps, leur pédoneule est composé de trois articles égaux, dont le premier est soudé à la earapace, et ferme extérieurement les eavités des antennes internes; le filet de ees antennes est plus long que ee pédoneule, sétaeé et composé d'un grand nombre d'articles très-eourts. Les antennes internes ne sont séparées que par une lame terminée en pointe saillante en dessous du rostre, elles sont plus eourtes que le pédoneule des extérieures et logées dans deux petites eavités profondes: leur pédoneule est également composé de trois artieles, et elles sont terminées par leux filets dont l'un, épais à sa base et effilé à son extrémité, est eomposé d'un grand nombre d'artieles eourts, ayant de longs poils à leur partie intérieure; l'autre, beaucoup plus eourt, n'est eomposé que de sept articles presque égaux.

Les yeux sont saillants, très-gros à leur base, plus étroits dans leur milieu et renflés à l'extrémité; ils sont de longueur médioere, et la eavité dans laquelle ils sont insérés n'est pas plus grande que leur base et parfaitement ronde, ee qui ne leur permet pas de se eoneher dans eette eavité, eomme eela a lieu dans les espèees à yeux rétraetiles : ees yeux sont insérés sur les eôtés du test, au-dessus et vers le tiers supérieur du premier article des antennes externes.

La earapace est triangulaire, deux fois plus longue que large, arrondie postérieurement, et terminée par un rostre eomposé de deux pointes dirigées en avant, eonniventes surtout à leur extrémiié et infléehies en dessous. A la base de ces deux pointes ét en dessous, est une forte épine dirigée en bas et recourbée à son extrémité, e'est eette épine qui partage la cavité des antennes internes en deux parties égales. Les régions stomacale, branehiale, eordiale et hépatique sont parfaitement marquées et portent des tubereules terminés en pointe assez saillante.

Les serres du mâle sont de la longueur du eorps, fortes, avee la main et les doigts un peu eourbés en dedans. Celles de la femelle sont beaueoup plus eourtes que le eorps et plus grêles. Ces serres sont eouvertes de longs poils raides sur lcurs diverses arêtes interues. 
Les pattes ambulatoires sont aussi plus grandes dans les màles que dans les femelles; elles vont en dćcroissant de longueur jusqu'à la dernière paire. Leur trochanter est trèscourt, recourbé et renfé cn dessous; la cuissc est la pièce la plus longue; clle esı̀ paṛfaitement cylindrique et légèrement velue; la jambe est plus étroitc à sa base, de moitié moins longue que la cuisse. Le métatarse cst presque aussi long que la cuisse, dilaté inférieurement et ayant sa plus grande largcur au delà dı milieu et vers l'extrémité : cet article est bordé inférieurement de poils raides et asscz longs; il y cn a aussi à la partie supérieure et internc. Le tarse ou l'ongle est grand, courbć en dedans ct couvert d'un duvet court et raide; il se replie contre le bord dilaté du métatarse ct atteint presque la moitié de sa longueur; sa pointe est très-aigüe, dure et cornće.

L'abdomen des deux scxes est composé dc sept tablettcs ; celui du mâlc est très-étroit ; ce sont surtout les deux prcmières tablettes qui sont les plus ćtroites, la troisième est plus large, la quatrième l'cst encore plus, et lcs suivantes vont en décroissant jusqu'à la dernière qui est arrondie à l'extrémité. Cette tablette attcint à peine la hauteur de linsertion des serres. Celui de la femelle forme un ovale presque rond et très-court; scs trois dernières tablettes sont les plus longues, et la dernière atteint la base des picds - mâchoires. Cette queue couvre tout le plastron et touche dans son contour la base des hanches de toutcs les pattes.

La seule cspèce que nous connaissions, et qui nous a servi à établir cc genre, a été rapportée des îles Malouines par MM. Lesson et Garnot. En la dédiant au plus célèbre entomologistc de notre époque, nous ne faisons que remplir un devoir bien doux, puisqu'il nous donne l'occasion de montrer publiquement toute la reconnaissance que nous devons au savant qui a bien voulu guider nos premiers pas dans l'étude de la science à laquelle il a fait faire de si grands progrès.

\section{EURYPODE DE LATREILLE. Eurypodius Latreillii. GuÉR.}

E. testâ triangulari, tuberculatâ, villosâ, spinis duobus utrinque subter oculos; rostro bifido; manibus elongatis, compressis; pedibus elongatis, articulo quinto dilatato ciliato.

Ce crustacé est long de plus de trois pouces; sa plus grande largeur, qui est vers la partie postérieure de la carapace, est de près dc deux pouces. Sa carapace est velue, les poils. sont crochus à leur extrémité, raides, ct très-rapprochés entre eux; c'est à ces poils crochus que s'attachent dcs matières ćtrangères qui couvrent le corps de ces crustacés. Les bords de la carapace sont sinueux; on voit surtont de chaque côté, et en dessous des fossettcs oculaires, dcux épincs courtes, courbées, et dont la postérieurc a sa pointe dirigée en avant et vers les ycux. Les cavitćs oculaires n'ont point de fissure à leur pourtour. Le rostre forme à peu près le cinquième de la longucur de tout le corps. Les pattcs sout velues, le métatarse et le tarse surtout sont couverts d'un duret 
très-serré qui les rcnd veloutćs. Dans l'état frais, cc crustacé doit êtrc d'une couleur brune verdâtrc; dans l'alcool, il prend une teinte fauve-jaunâtre, approchant de la couleur cannelle. C'cst sous cette couleur quc nous l'avons représenté.

\section{EXPLICATION DES FIGURES.}

Fig. I. L'Eurypode de Latreille, réduit.

2. Partie antérieure de la carapace, vue en dessous, pour montrer l'ensemble extćrieur de la bouche et linscrtion des antennes et des yeux.

3. Plastron du mâle pour montrer l'abdomen composé de sept tablettes.

4. Idem chez la femelle.

5. Antenne interne grossie.

6. Pied-mâchoire cxtérieur ou de la cinquic̀me paire grossie.

7. Pied-mâchoire de la deuxième paire.

8. Idem de la premième paire.

9. Màchoire de la secondc paire.

10. Idem de la premic̀e paire.

II. Mandibule avec son palpe de trois articles.

\section{Genre CAPHYRE. Caphyra ${ }^{\mathbf{I}}$ Guér.}

Quoique la tribu des Notopodes ne contienne encore que peu de genres, on a été obligć, deptiis la publication de la dernic̀re édition du Règnc animal, d'y apporter de grands changements en en retirant les Homoles et les Ranines, et en y introduisant deux nonveaux geures dont l'un est détaché des Dorippes de Fabricius, et l'autre formé avec un crustacé entièrement neuf pour la science.

C'est à M. Roux de Marseille que l'on doit l'établissement de ces deux coupes génériques; il ne s'est pas laissé emıorter par le désir de faire des genres à tout prix, comme on le fait malheureusement trop souvent dans des pays voisins, il a employé, pour les siens, des caractères positifs et, conıme il le dit fort bien, d'une importance beancoup plus grande que ceux que l'on emploie actuellement dans la formation des genres. La découverte d'un très-petit crustacé, rapporté de la Nouvelle-Irlande par les naturalistes de l'expédition autour du Monde de MI. le capitaine Dıperrey, nous forçant d'introduire encore un genre dans la tribu des Notopodes, nous avons été obligé de revoir les caractères de tous ceux qui la composent pour faire entrer le nôtre à sa place naturelle et près de ccux qu'il doit avoisiner. Nous avons suivi la méthode de M. Latreille, prćsentée tout récenument daus le premier volume de son cours d'Entomologie, ct c'est l'arrangement adopté par cc célèbre entomologiste que nous reprołluisons ici; les modifications que nous y apportons ne consistent que dans le changement de place des genres Etluse et Cymopolie. Nous avous cru devoir employer ln forme de tablean

' Caphyra, fille de l'Océan. 
pour présenter nos divisions, et faire mieux ressortir la différence et les affinités qui existent entre les geurcs qui nous occupent; c'est du reste une méthode géuéralement employée, et que l'on pent considérer comme le juste nilieu entre les figures et les descriptions.

$6^{\mathrm{e}}$ tribu. Notopodes, Notopoda. Latreille, cours d'Entomologie, $\mathbf{1} 83$ r.

I. Test orbiculaire ou ovoïde, globuleux.

A. Les quatre derniers pieds insérés sur lc dos; corps globuleux orbiculaire.

Genre Drosie, Dromia, Fabr.

в. Lcs deux derniers pieds sculs insérés sur le dos; corps un peu aplati, ovoïle, évasé presquc en forme de cœur renversé, et tronqué postérieurement.

Genre Dinowìne, DJnomene. Latr.

II. Test presquc carré, un peu plus ćtroit à sa partie antérieure, aplati en dessus.

^. Les deux derniers piedls seuls insérés sur lc dos.

Genre Crmopouie, Cymopolia. Roux.

B. Les quatre derniers pieds insérés sur le dos.

I. Tous les pieds seniblables.

Genre Cарнута, Caphytra. Guer.

2. Les quatre premicrs pieds beaucoup plus grands que les suivants.

a. Antcnnes latérales insérées au-dessus des intermédiaires. Yeux portćs sur des pédicules courts.

Genre Dorippe, Dorippe. Fab.

b. Antennes latéralcs insćrées all-dessous des intermédiaires; yeux portés sur de longs pédicules.

Genre Étuuse, REthusa. Roux.

On voit que notre genre ne pouvait ètre confondu avec ancun de ceux de Fabricius et de Roux; scs caractères gćnériques peuvent êtrc exprimés ainsi :

Antennes extérieures assez courtes, sètacćcs, insérćes au-dessus des intcrmédiaircs, et aux angles extérieurs de la cavité buccale; leur premicr article soudé au test, allongé, terminé en pointc aiguë à l'angle externe et supérieur. Le sccond article beaucoup moins long, ovoïde. Le suivant de même forme et de même longueur. Les autres beaucoup plus petits et allant en climinuant dc largeur, vus en dcssus; le second article seul dépasse lc test.

Antennes internes insérées sons le chapcron dans des cavités transvcrsales : leur prcnier article ou celui qui reste dans ces cavités, grand, triangulaire, les dcux autres de forme ordinaire. Yeux portés sur des pédoncules courts, gros, pouvant se cacher en partie dans lcs fossettes oculaires, insérés dcrrière les antenues latérales. Pieds-mâchoires extérieurs ciliés, le deuxième articlc élargi, un peu avancé et arrondi à son extrémité supéricurc interne. Le seconcl presque aussi large à la base quc le précédent; aussi 
haut que large, tronqué obliquement à l'angle supérieur interne, et tronqué earrément en hant et derrière linsertion des trois derniers artieles. Pinces eourtes, égales et de grandeur moyenne dans les femelles. Pieds semblables, diminuant un peu de longueur à partir des premiers, terminés par un croehet reeourbé en cledans et velu. Les deux dernières paires relevées sur le dos. Carapace glabre, quadrilatère, un peu plus large que longue, un peu avaneée et sinuée au bord antérieur, tronquée earrément en arrière; à régions presque effaeées, très-peu eonvexes en dessus. Abdomen replié, lisse, eomposé de sept feuillets dans les femelles. Nous ne savons rien sur les mœurs de ees erustaeés.

\section{CAPHYRE DE ROUX. Caphyra Rouxii. Guer.}

C. testâ glabrusculâ, virescente luteâ, utrinquè tridentatâ, fronte prominulâ, sinuosâ. Chelis spinosis, pedibus apice ciliatis.

Ce ernstaeé est très-petit; sa longueur, y eompris les premiers segments de la queue qui débordent le eorps avant de se eourber, est de six millimètres. La earapaee n'a que quatre millimètres et demi de long sur un peu plus de einq millimètres de large. Elle est un peu bombée en dessus, lisse, d'un vert jaunâtre; son front est avaneé, un peu éehaneré au nilieu, sinué en avant et de chaque eôté cle l'éehanerure; on voit au-dessus de l'insertion des yeux une petite proéminenee en avant de laquelle sort le troisième artiele des antennes latérales. Derrière eette petite dent arrondie sont les fossettes oeulaires qui sont terminées en arrière par une forte dent aiguë; les eôtés de la earapaee sont un peu eourbés, garnis de trois épines, en y eomprenant eelle qui termine les fossettes oculaires. Ces épines sont rapproehées, aiguës, dirigées haut; la clernière arrive à peu près au milieu de la longueur cles eôtés, et il part de sa base un sillon courbe qui s’avanee vers le eentre du bord postérieur de la earapaee. Ce bord est eoupé earrément, un peu sinué au milieu, et aussi large que les eôtés jusqu'aux yeux. Les antennes déhordent la earapace de presque la moitié de sa longueur. Les pinees sont à peu près de la longneur de tout le eorps; lenrs mains, en y comprenant les doigts, sont aussi longues que les deux premier's artieles; le promier est triangulaire avee les deux tranehes inférieures épineuses. Le suivant beaueoup plus eourt; le poignet allongé, un peu comprimé latéralement avee sa carène supérieure armée de trois épines aiguës, en dents de seie, et dirigées vers les doigts. Ceux-ei sont eourbés, aigus et garnis en dedlans de dentelures peu saillantes et arrondies; les pattes sont un peu grêles; les premières sont de la longueur du eorps, les autres un peu plus eourtes; leurs artieles sont eylindriques, le dernier est cilié de ehaque eôté et terminé par un tarse du tiers de sa longueur, eroehu et eilié en dedans. La queue du seul individu femelle que nons possédions est très-large, presque orbieulaire; les trois premiers segments sont plus étroits et paraissent en dessus; les autres, recourbés en dessous, sont à peu près le double plus larges que le troisième. Le dernier est triangulaire. 
Nous pensons que ce petit crustaeé n'atteint pas une plus grande taille, car sa queue est garnie d'œufs, ce qui annonce qu'il est adulte. Il a été trouvé à la Nouvelle-Irlande. Nous l'avons dédié à M. Roux comme un témoignage de toute notre estime.

\title{
CÉNOBITE COMPRIMÉ. Conobita compressa. Guér.
}

\author{
C. testä coriacea ; thorace utrinque complanato, parallelogrammiformi, \\ oculis brevibus, pedibus complanatis.
}

La carapace de cette espèce est entièrenent cornée, mais d'une substance moins solide vers les bords des régions branchiales; la région stomacale ou le corselet est oblongue, un peu granulée, presque parallélogramme, sa plus grande largeur est une fois et demie dans sa longueur, à partir du milieu elle se rétrécit un peu en avant pour se terminer cle chaque côté, et en dehors de l'insertion des yeux, par une dent un peu avancéc; l'espace compris cntre ces dents, ou le chaperon, est coupé droit transversalement. Le dessus de ce corselet est légèrement convexe, ses faces latérales sont coupées carrément, planes, comme comprimées. La région cordiale est rétrécie vers l'arrière, et les régions branchiales sont beaucoup plus larges que le corselet, ayant chacune un sillon profond et arqué et plusieurs autres petits sillons ramifiés postćrieurement et sur les côtés. La suture qui sépare le corselet de ces régions est droite, transverse; les bords de la carapace et ses côtés ont des poils blonds assez courts et peu serrés. Les pédicules oculaires sont courts, et atteignent à peine le milieu du $4^{\mathrm{e}}$ article des pédoncules des antennes externes; ils n'ont pas la moitié de la longueur du corselet; ils sont très-aplatis latéralement; mesurés de la crête supérieure à l'inférieure, ils ont une largeur égale à la distance comprise entre l'extrémité de leur écaille basilaire et leur terminaison; ces écailles hasilaires sont triangulaires, un peu échancrées extérieurement; leurs pointes se rencontrent sur la ligne médiane et forment ainsi une dent assez aiguë entre les pédicules oculaires; cette dent arrive au tiers de la longueur de ces pédicules. Les yeux sont d'un noir luisant. Les antennes latérales ont les articles de leur pédoncule comprinés latéralement; le premier est en forme de croissant, avancé en dessus, et donnant attache, par sa partie postérieıre, au suivant qui est triangulaire avancé en dessous et garni de quelques poils à sa pointe inférieure; le troisième article sinsèrc à la base de cet article, il semble prendre attache dans une échancrure profonde laissée par lcs deux pointes snpérieure du premier et inférieure du second, il est arrondi et dépasse à peine ces deux pointes; le $4{ }_{4}^{\mathrm{e}}$ article a denx fois la longueur de ces trois premiers, il est un peu courbé à la base et il donne attache à un filet articulé qui a plus de trois fois sa longucur.

Les antennes intermédiaires atteignent presque la longueur des latérales, leurs $2^{e}$ et $3^{e}$ articles sont égaux en longucur, mais le $3^{\mathrm{e}}$ est plus mince que le précédent et termine par deux filets articnlés dont le supérieur, qui a plus de la moitié de sa lon- 
gueur, est glabre, terminé un peu en massue, arrondi au bout, et dont le second out l'inférieur est plus grêle, moitié moins long et terminé par quelques poils.

Les pattes, quand elles sont dirigées en avant, se recouvrent en partie les unes par les autrcs ; elles sont comprinuées et présentent des parties aplaties destinées à recevoir exactement les portions des pattes qui viennent s'y appliquer. Les troisic̀mes pattes sont les plus longues, les pinces ensuite; celles-ci sont presque d'égale longueur; la gauche étant un peu plus grosse, leur face interne est coupée droit, la face externe du second article et dn poignet est un peu convexe, tanclis que le même côté du premier article est plat, ce qui forme une tranche fort aiguë au bord supérieur de ces pattes; il en est de mêmc pour le premier article des secondes pattes, mais aux troisièmes on ne voit plus ce méplat, car aucune autre patte suivantc ne devant s'appliquer contre elles, elles sont restées un peu convexes. Les piuces sont garnies de très-petites épines dirigées en avant et moins visibles à mesure qu'on recule vers la base de ces pattes; le bord supérieur et interne du poignet est garni d'ıne frange de poils blonds très-fins et trèsserrés. Le doigt nobile a en dessus et vers le dedans des crêtes formées par des séries de petites épines rougeàtres. Le poignet de gauche est très-dilaté en dessous et postérieurement, l'antre l'est beancoup moins. Les deux autres paires de pattes sont peu granuleuses, si ce n'est au dernier article qui porte en dessus et en dessous des séries longitudinales de petites épines rougeâtres; leur second article a une dilatation en forme de dent placée inférieurement sur leurs tranches supérieure et inférieure, et les parties intérieures qui ne sont pas destinées à être appliquées immédiatement contre les pattes précédentes, sont garnies de poils blonds assez clair-semés. Les quatrièmes pattes sont très-courtes, cachées en partie sous les bords de lil carapace; leur extrémité dépasse à peine la suture qui sépare le corselet des autres régions; le dernier article est fort avancé en dessous, cet appendice est arrondi, presque entièrement couvert par les granılations qui s'observent dans tous les pagures; le crochet terminal qui forme une espèce de pince, cn s'opposant à l'appendice du dessous, est plus court que lui, un peu courbé, toutes ces parties ont des poils fins, blonds et assez longs sur leurs bords; les dernières pattes sont plus longues qne les précédentes; elles atteignent la même suture; leur dernier article est en pince et presque entièrement couvert de graunlations en dehors. L'abdomen est mou, ses fausses pattes sont longues, très-ciliées, ses trois derniers segments sont cornés, le premier transverse, arrondi en avant, le second transverse et un peut plus étroit; ces deux segments ont un sillon assez profond au milieu. Le dernier est aussi long que large, rétréci postérieurement, ayant cette partie plus molle et ciliée sur les bords. Les appendices latéraux sont insérés sur le segment du milieu, très-inégaux, le gauche étant le plus grand.

Cette espèce remarquable a été trouvée à Payta. 
PAGURE à ANTENNES COURTES. Pagurus brevicornis. Guér.

\author{
P. Thorace triangulari, pediculis oculorum eâdem longitudine quam an- \\ tennis medianis, antennis externis brevibus, fere longioribus quam oculis. \\ Chelis anticè explanatis.
}

Cette petite espèee est remarqual)le par plusieurs earaetères tels que la longueur des yeux, l'aplatissement de la face antérieure des pinees: la brièveté des antennes extérieures et la forne triangulaire et rétréeie en arrière du eorselet. Il est blanehâtre. La région stomaeale de la carapaee, ou le eorselet, est de forme triangulaire, ses côtés sont plus longs que le bord antérieur, son extrénité postérieure ne se termine pas tout-àfait en pointe, elle est tronquée transversalement; le loord antérieur, ou le eliaperon, est tronqué presque droit; les eôtés sont eoupés ollliquement pour reeevoir les antenues externes; on voit au milieu une petite pointe avaneée, les autres régions de la earapaee sont membraneuses, son bord postérieur est éehancré en cœur. La base des yeux est garnie d'une petite écaille en forme de virgule très-minee; la longuenr des pédieules oeulaires égale la largeur de la partie antérieure du eorselet; ils sont eylindriques, minees, leur épaisseur formant à peu près le einquième de leur longueur. Les antennes antérieures sont eourtes, ayant à peine deux fois la longueur des pédieules oenliares; leur premier artiele est très-petit, transverse, triangulaire; le seeond, également transverse, est dilaté extéricurement en une grosse épine velue au bout; l'épine mohile qui s'insère sur eet artiele est deux fois plus longue que le troisième; elle est arrondie au bout, garnie de longs poils; le seeond artiele est euurt, arrondi, beaueoup plus étroit; le quatrième est long, aplati, à peu près de la longueur des trois premiers réunis, son extrénité atteint presque aux trois quarts de la longueur de l'ceil; le filet multiarticulé est de moitié plus long que les quatre artieles basilaires pris ensemble, sa saillie au-delà des yeux est à peu près de la longueur de eenx-ei.

Les antemnes intermédiaires sont de la longueur des yeux, et terminées, eomme à l'ordinaire, par deux filets artieulés, dont l'interne, plus long que l'externe, est renflé ¿t sa base et garni extérieureuent de longs eils.

Les pinees sont égales, très-aplaties sur le devant et garnies de poils serrés seulement sur cette faee antérieure. L.a faee postérieure est arrondie et sans poils. Elles sont garnies de petites épines aiguës, eourtes, dont la pointe, qui est noire, déborde un peu les poils, les doigis sont terminés en euiller et leur pointe est d'un noir vif.

I.es deux paires de pattes suivantes sont presque de la même longueur, aplaties latéralenent; leur faee intérieure, ou eelle qui est tournée vers l'animal, est garnie de très-petites épines coniqunes et noires, ave: des séries de poils fins ct très-serrés; la fiee externe présente un petit sillon lougitudinal garni de petits poils. Les bords de ees pattes sont tranehants et garnis de longs poils très-serrés et dirigés vers l'extrémité; be ernelıet ou l'ougle est noir, croelıu et assez aigu. Les 4 pattes atteignent à peine 
l'extrémitć du premier article des pattes précédentes quand ellcs sont dirigćes en avant, leur dernier articlc n'a pas son bord postćrieur avaneć, et ne forme pas ainsi une espèce de doigt opposable au crochet tcrninal, conınıe cela a licu dans d'autres pagures; il est tcrminé par uı ongle erochu, garni intérieurement de petites granulations qui correspondent à d'autres granulations placées sur l'article préećdent et à sa partie extćrieure. Lcs pattcs de la $5^{\mathrm{e}}$ paire sont asscz longues, plus grêles, insérées un peu plus bas quc les précćdentes et sortant du dessous du bord postéricur de la carapace; leur premier article, celui qui vient après le trochantcr, est le plus long de tous, les deux suivants sont presque égaux avec le dernier terminé par une pince, dont le eôté extérieur des doigts et une très-petite portion du poing sont granulés. L'abdomen est membraneux, très-mou, garni de fausses pattes minces et d'une longueur égale à sa largeur; les derniers segments sont cornés, composés de trois pièces, dont la dernière est échancrée sur les côtés; les appendicess latéraux sont très-inégaux, celui de gauche ayant la pièce supérieure aussi longue que les trois pic̀ces eornées de l'abdomen prises ensemble, eelui de droite étant quatre ou einq fois plus petit. Nous ne connaissons pas la patrie de ce pagurc.

\title{
GRIMO'TÉE SOCIALE. Grimotea gregaria. LEACH.
}

\author{
Grimotea gregaria, Leach, Dict. sc. nat., t. XVIII, p. 5o. Desm., Consid. sur la \\ classe des crust., p. 287. \\ Galathea gregaria, Fabr., Ent. syst., t. II, p. 473 .
}

PLANCHE III, fig. I.

Cettc espc̀ce est très-remarquablc par sa couleur et par le nombre immense d'individus que l'on trouve rassemblés dans certaines mers. Notre collaborateur M. Lesson l'a observée dans la rade dc Callao, au Pérou, elle y était si abondante que lesêaux de la mer en avaient contraeté une apparence sanguinolente. Déjà Banks, dans son voyage avee le capitaine Cook, avait observé le même phénomc̀ne; suivant ce naturaliste, la mer en était tellement couverte qu'elle en paraissait rouge commc du sang.

La fig. I. représente ce crustacé grossi.

I. $a$., sa grandeur naturelle; r. $b$., partie antérieure, vue en dessous pour montrer la bouche; x. c., pied-mâchoire, extérieur grossi; I. d., mandibule grossie. 


\section{POPCELlane VIOLETTE. Porcellana violacea. Guer.}

P. testâ orbiculatâ, violaceâ, complanatâ, subloevi, posticè subemarginatâ, chelis leviter granulatis, dentibusque nullis, manibus latis, cligitis rectis sine dentibus.

PLANCHE III, fig. 2.

La longueur de la carapace est égale à sa largeur; elle est aplatie, presque lisse, ou n'ayant que de fines et eourtes stries transversales plus marquées sur les eôtés, de forme arrondie, légèrement éehanerée en arrière, terminée en avant par un rostre court, abaisşé, et arrondi au bout. Les fossettes oeulaires sont peu profondes; les yeux sont eourts, saillants : Les antennes extérieures sont plus longues cue le corps, eomposées à leur base de trois artieles, dont le premier court, plus gros que les autres et dépassant à peine les bords du test; le second deux fois plus long, plus étroit et un peu eourlsé, et le troisième très-court, en forme de nœud: le filet terminal est allongé, multiartieulé et velu. Les pinces sont presque égales, aplaties, à mains très-larges, trèsfinement granulées. Les doigts ne présentent aueunes dents en dedans. Les pattes sont eourtes, aplaties, lisses, leurs trois derniers artieles seulement sont velus. Les ongles des tarses sont assez visibles, un peu erochus. Les pattes postérieures sont petites et repliées sous les bords postérieurs du test; elles sont très-velues au bout.

La eouleur de eette poreellane, dans l'alcool, est d'un rougeâtre tirant sur le jaune; une note et un dessin pris par M. Lesson sur les lieux et d'après l'animal vivant, nous font eonnaître que sa couleur était d'un violet éelatant à reflets d'un beau bleu d'azur. Cette espèee est excessivement eommune sur les roehers de la presqu'ŝle de Talcaguana au Chili; les plus gros individus ont près de deux déeimètres et demi de longueur.

\section{PÉNÉE SÉTIFÈRE. Pencus setifcrus. Guer.}

Manibus nullis, pedibus utrinquè sex didactylis, antennis longissimis. Limn.

Cancer setiferus, Linn., Syst. nat., t. II, n. $1054, \mathrm{n}^{\circ} 78$.

Astacus fuviatilis americants, Seba, Thesaur., 1. III, p. 4I, t. I 7. f. 2.

Astacus seliferus, Encycl., art. Ecrevisse, p. 343.

Palamon sulcatus, Latr., expl. des pl. de l'Encycl., p. 3, pl. 29 r , fig. 2.

Il est évident que l'espèee déerite par Linné et figurée par Séba appartient au genre Pénée, et eette eonviction est d'autant plus grande chez nous, que nous voyons M. Laroyage de la Coquille. $-\mathrm{Z}$ Tom. II, partic II. $2^{\text {re }}$ Dir. 
treille du même avis, puisqu'il a rapportć (à tort pour l'cspèce) la figure 2, pl. 291, de l'atlas de l'Encycl., qui est copiée de Séba, au genre Pénée en la rapportant au palcemon sulcatus qui est de ce genre. Nous ne pensons pas qu'on doive, comme l'a fait M. Latreille, considérer cette figure comme appartenant à un Penceus sulcatus; car il n'y a aucune trace de sillons sur lc dos, et il est probable que le dessinateur n'aurait pas été plus avare de ces sillons qu'il ne l'a ćté des pattes et surtout des pattes caudales qu'il met au nombre de six. D'aillcurs l'habitat de Linné s'oppose à ce qu'on range son espèce avec le sulcatus, puisqu'il dit que son $C$. setiferus vient des Incles; et quoique l'on ne doive pas ajouter beaucoup de foi aux habitats de Séla, il est cependant probable quc son espèce n'était pas d'Europe. Olivier (art. Palæmon, tom. VIII, p. 66o, Encyclopédie) cite la figure de Herbst, pl. 34, fig. 3, sous son palcemon setiferus, $\mathbf{n}^{\circ} 4$. Il cite aussi en synonymie la figure de Séba, pl. $\mathbf{1} 7$, f. 2 , et ne fait en cela qüimiter Herbst qui a rapporté son espc̀ce à celle de Linné et de Séba.

L'espèce de Séba ne peut être confondue avec la figure de Herbst; car dans cette dernic̀re les filets des antennes interméciiaires sont aussi longs quc le pédoncule, ce qui la range dans la secondc division de Latreille (article Pćnée, Encyclopédie), tandis que l'cspc̀ce de Sćba, ayant les filcts des antcnnes intermédiaires très-courts, irait se ranger dans la première division de Latreille.

La description du Penaus mondon de Fabricius, Supplément à l'entomologie systématique, page 408, convient parfaitement à l'espèce figurée par Herbst, et nous n'hésitons pas à y rapporter cette figurc.

L'individu que nous considćrons comme le $C$. setiferus de Linné est long de près de six pouces. Le thorax est beaucoup plus large en arrière, il ne présente pas de sillon creusé dans son milieu, mais on voit un peu avant son hord postérieur, commencer une crête arrondie peu élevée d'abord, et qui va en augmentant pour former plus loin une carène aiguë, très-élevée et terminée par un rostre long, un peu relevé à sa pointe, armé de neuf dents en dessus et d'une seule en dessous. La partie du rostre qui déborde le thorax forme à peu près les deux tiers de sa longueur; l'épine du dessous est placée vers la pointe à peu près au tiers de sa longueur; les neuf du dessus conımencent au tiers antérieur du thorax, et vont en se rapprochant jusqu’à la dernière qui se termine un peu en arric̀re de l'endroit du dessous où est sitıée l'unique épine inférieure : l'intervalle des dentelures de dessus est cilié, il n'y a que la basc du rostre qui ait des cils en dessous. Les bords antérieurs du thorax sont armés cle deux dents très-petites, une à l'angle extérieur et au-dessous des yeux, se prolongeant en arête jusqu'à la seconde, qui est placée un peu en arric̀re, plus bas et à quelque distance du bord; de cette demière il part un sillon qui descend en arrière et se prolonge en avant, le long de la petite arête envoyée par l'épine du dcssous des yeux; un autre sillon aussi court et allant se terminer insensiblement, part égalemont de cette épine intérieure et remonte un peu vers la carène.

Les yeux sont grands, très-globuleux; les pédoncules des antennes internes sont épais à leur base, triangulaires, creusés au milieu pour recevoir les yeux, et n'atteignant pas la longueur du rostre; les deux filets antennaircs sont beaucoup plus courts quc leur 
pédoncule, inégaux, l'externe étant le plus long. Celui-ei est aplati à la base et se rétréeit brusquement pour devenir cylindrique aux deux tiers de sa longueur. L'extérieur est aplati dans presque toute sa longueur. En avant des yeux et au côté interne du pédoncule des antennes supérieures, on obscrve de ehaque eôté unc lane eiliée, plus étroite à sa base, arrondie en spatule au bout, et dépassant à peine la longueur des yeux. Les écailles des antennes externes sont un peu plus longues que le rostre; elles sont trèseiliées intérieurement, et leur bord externe offre près de l'extrémité une petite dent. Le filet de ees antennes a plus de deux fois la longueur de l'auimal.

Les picds-mâehoires extéricurs, aecompagnés de leur grand flagre en pennc, sont longs; leur extrémité, terminée en pointe, atteint la moitié de la longueur des écailles des antcnnes externes. Les trois paires de pieds en pince vont en augmentant de longueur de la première à la troisième; la quatrième et la cinquième paires sont plus courtes que la troisième, elles sont terminées par une pointe un peu aplatie et carénée au milieu; la dernière est plus longue que la préeédente.

Les anneaux de l'aljdomen sont de forme ordinaire, fortement cilićs sur leurs bords; le quatriène est plus eomprimé sur les côtés que les précédents, il a sur son milieu une carène peu élevée qui eommenee à sun tiers antérieur; le einquième est un peu plus comprimé, il a une carènc qui pareourt toute la longueur de son dos; le dernier, presque aussi long que les denx précédents, a une earène beaucoup plus aiguë parcourant aussi toute son étenclue dorsale, et se terminant en arrière par unc petite pointe eourbée en bas. Le feuillet supérieur est de la longueur de cc dernier anneau; il est terminé cn pointe aiguë, eilié, mais sans aueune dentelure sur les bords, et il est marqué d'un sillon longitudinal profond et élargi au milien. Les feuillets latéraux sont plus longs, les extérienrs surtout; ils sont ciliés à l'intérieur et ne présentent aucunes dentelures à leurs bords externes.

Ce pénée diffère du monodon de Fabr. par ses antennes supérieures qui ont les filets beaucoup moins longs que le pédoncule, et par le rostrc qui n’a pas trois dents en dessous.

Il diffère du P. monoceros Fabr. paree qu'il a une dent sous le rostre, tandis que celui-là a le rostrc sans dents en dessous. Enfin il diffèrc du planicornis parce que ses antennes supérieures sont de forme ordinaire, tandis qu'elles sont courtes et comprimées dans eelui de Fabr. Lc pénće cannelé, Pal. canaliculatus d'Oliv. Encycl. p. 66o, qui se trouve dans la mer des Indes, ressenble beaueoup au nôtre; mais il en diffère par les dents des eôtés antérieurs du eorselet; dans le nôtre il n'y a qu'une très-petite dent au-dessous et à l'angle extérieur des yeux, tandis qu'Olivier en mentionne une fort grandc à eet endroit; la petite dent plaeée à peu de distance dı rostre dans le P. canaliculatus, n'cxiste pas ehez le nôtre. Enfin dans le P. d'Olivier, le feuillet supérieur et intérieur de la queue est un peu épinenx sur les còtés, tandis que dans le nòtre il est tout à fait sans épines.

Notre individu a étć trouvé à la Nouvelle-Irlandc.

Couleur jaunàtre dans l'alkool. 


\section{PÉNÉE VETU. Pencus villosus. Guér.}

P. rostro porrecto, suprà octo dentato, subtùs lavi, thorace lavi, piloso, tribus spinis utrinquè et anticè armato, abdomine piloso, segmentis tribus ultimis carinatis, pedibus posterioribus articulo tertio basin emarginato.

Pena us villosus, Guér., Iconogr. du règne animal, crustacés, pl. XX, fig. I.

Le rostre atteint à peine la longueur des écailles antennaires; il est étroit, presque droit, armé de huit dents en dessus et inerme en dessous. Les côtés antérieurs du thorax sont armés de trois épines très-petites : la première sous le rostre, devant les yeux; la seconde, un peu plus forte, placće plus bas et au bord antérieur, au-dessus de l'insertion des antennes latérales; et la troisic̀me placée en arrière, presque sur la même ligne que la précédente, et communiquant avec elle par un sillon peu profond; ce mĉme sillon se prolonge un peu en arrière en se dirigeant cn haut, il est aussi marqué vers le bas et forme une ligne courbe dirigée vers la partie antérieure. 'Tout le corps de ce pénée est garni d'un duvet fin et serré qui a disparu sur les parties saillantes, mais qui s'observe très-bien dans les plus légers enfoncements de la carapace et de l'abdomen. Les antenıles externes sont très-longues; l'extrémité de leurs écailles ne dépasse pas la pointe du rostre. Le pédoncule des antennes intermédiaires arrive aussi à la même longueur, et les deux filets inégaux qui le terminent sont un peu plus courts que ce pédoncule. L'abdomen est comprimé, ses trois derniers anneaux le sont plus que les autres, ils portent une carc̀ne aiguë et dorsale. L'écaille in termédiaire de la nageoire caudale est aiguë; elle a sur son milieu un sillon profond, ses bords sont ciliés, et elle est légèrement velue sur les côtés; les écailles latérales sont velıes, beaucoup plus longues, surtout les extérieures; elles sont ciliées à leurs bords internes. Les pattes sont de forne ordinaire, il n'y a que les dernières qui offrent une particularité remarquable; leur troisième article présente, à sa base et en arrière, une ćchancrure assez profonde.

De la Nouvelle-Irlande.

\section{PALÉMON ORNÉ. Palamon ornatus. Oliv.}

Palamon ornatus, Oliv., Encycl., insectes, t. VIII, p. $660, \mathrm{n}^{\circ} 5$.

Nos individus varient un peu de taille, mais ils se rapportent bien à la description d'Olivier; cependant ancun ne nous a présenté 9 dentelures en dessus, ni 4 en dessous du rostre; à l'égard dı nombre des dents du rostre, nous tronvons un individu qui en a seulement 6 en dessus et 2 en dessous; un autre en a 8 en dessus et 2 en dessous; enfin un troisième en a 8 en dessus et 3 en dessous; nous pensons que toutes ces variations ne doivent pas constituer des espèces distinctes, tout au plus pourrait-on en faire une 
pour le troisième individu où les feuillets des antennes intermédiaires dépassent notablement l'extrémité du rostre, ce qui n'a pas lieu dans les précédents.

Ces Palémons viennent de Waigiou.

\section{PALÉNON AUSTRAL. Palcemon australis. Guér.}

\section{$P$. rostro ferè eâdem longitucline quam testâ, subascendente, suprà duodecim} dentato, spinis lateralibus thoracis per seriem ordine digestis.

Il est long de près de six décimètres, depuis le bout du rostre jusqu'à l'extrémité de la queue; son rostre a presque la longueur de la carapace; il est un peu relevé en avant, armé de douze dents distribuées à des distances presque égales dans toute sa longueur et cn dessus, et en ayant quatre en dessous. Son thorax est lisse, arrondi, sans carènes ni sillons; le bord antérieur est armé d'une épine aiguë, dirigée en avant; on en aperçoit unc autre en arrière de celle-là, placée sur la même ligne, et non plus bas, comme chez les espèces européennes. Les filets des antennes sont très-longs, minces; l'écaille des antennes externes est plus courte que le rostre et n'atteint qu'à la hauteur de sa quatric̀me dent du dessous. L'abdomen est lisse; ses derniers segments n’ont pas de sillon en dessus. Les lames caudales sont plus longues que l'intermédiaire, ciliées au bord. Les pattes sont toutes grêles, de forme ordinaire.

Cette espèce a été trouvée sur les còtes de lî̀le de Taïti.

\section{HIPPOLYTE DE LEACH. Hippolyte Leachii. GuÉr.}

H. rostro lato, ascendente, apice truncato et emarginato, utrinque sexdentato, margine antico thoracis spinato subter oculos. Thorace lavi, abdomine gibboso, laminẩ medianâ caudce apice trispinosâ, manibus chelarum elongatis.

Cette perite espèce n'a pas plus de trois dćcimètres de longueur, la queue étendue, son corselet est court, épais, arrondi en dessus, fortement échancré en arrière. Le rostre est à peu près de sa longueur, courbé, rclevé en avant; il a en dessus six dents aiguës, dont les quatre premières sont placées sur le dos; la quatrième arrivant au-dessus des fossettes oculaires; les deux autres sont plus petites, placécs sur la partie saillante du rostre, à une assez grandle distance l'une de l'autre; la dernic̀re très-près du bout. L'extrémité du rostre est tronquée et échancrée; le dessous est très-large à la base, garni dc six dents très-fortes, courbes, dirigées en avant, dont les quatre premières sont plus rapproclıées et plus fortes. Les yeux sont assez gros, saillants. Le premier article des antennes intermédiaires est armé d’une ćpine simple et assez aiguë. Les pieds-11âchoires extćrieurs ont leur troisième article plus de quatre fois plus long que le second, mince, terminé en pointe et ayant trois petitcs épines au còté intcrne de son extrémité. Les premières pinces sont courtes, n'atteignant pas l'extrćmité des lames 
antennaires; leur main est cylindrique, allongée, sa longueur est plus du double de celle des doigts. Les pinces suivantes sont presque deux fois plus longues; avec leur dernière pièce de la longueur des précédentes, composée de six ou sept petits articles. Les autres pattes sont de forme ordinaire. L'abdomen est épais, court, bossu et lisse. Les feuillets latéraux sont de forme ordinaire, ainsi que lïntermédiaire qui est terminé par trois petites épines et qui en porte quatre sur le dos.

Cettc espèce a été trouvée sur les côtes de lîle de Strong ou Oualan; elle diffère des trois espèces d'Europe appartenant à la même division, par le rostrc et par la forme des mains.

\section{ALPHÉE DE IOTTIN. Alpheus Lottinii. Guér.}

A. thorace eâdem longitudine quam abdomine, chelâ lavẩ maximâ, laevi, digitis simplicibus, pedilus cylindraceis, exilibus, spinä supra oculos, margine anteriori thoracis super oculos porrecto.

\section{PLANCHE IIl, fig. 3.}

Il est long de près de trois centimètres, sa carapace forme la moitié de cette longueur; elle est lissc, très-échancrée en arrière, terminée en avant par un petit rostre, court et courbć en bas. Ses yeux ne sont pas saillants, ils semblent placés dlans l'épaisseur du test et nc se voient que par transparence; il y a au-dessus d'eux une petite épine dirigéc en avant. La nain de droite a le poignet allongé, cylindrique. Les piedsmâchoires extérieurs ont leurs deux derniers articles aussi larges que le précédent; ils sont ensemblc de la longueur du premier, et le second est de moitić plus court que le troisième. Le pédoncule des antennes extérieures est à peine de la longueur des écailles latérales de ces antennes, ce qui établit une différence entre cette espc̀ce et celle d’Égypte, qui est figurée pl. 9, fig. 4, et dans laquelle ce pédoncule dépasse notablemont l'extrémité des lames externes. L'abdomen est très-comprimé sur les côtés en arrière; les lames natatoires latérales sont grandes, de forme ordinaire, et lintermédiaire est oblongue, tronquée au bout, armée de chaque côté de deux petites épines; elle est presque deux fois plus longue que large, tandis que cette lame est à peine plus longue que large, dans l'cspèce citéc plus haut. Les pattes sont assez longues, sans épincs et à articles cylindriques. Cette espèce a été trouvée à la Nouvelle-Irlande. Sa couleur est d'un jaune verdâtre dans l'alkool.

\section{ALPHÉE LISSE. Alpheus lavigatus. Guér.}

A. thorace breviori quam abdomine, pedibus cylindraceis, exilibus, spinis supra oculos nullis.

Cct individu, auquel il manque les pinces, est long de près de quatre centimc̀tres; sa carapacc est beaucoup plus courte que l'abdomen, peu échancréc en arrière, ayant 
un très-petit rostre en avant et poirit d'épine au-devant des yenx. Le pédoncule des antennes extérieures n'est pas plus long que lenrs lames latérales; les pieds-màchoires extérieurs sont allongés, leurs deux derniers articles sont aussi longs que le précédent; le second est de plus de moitié plus court que le suivant. La lame intermédiaire de la nageoire est arrondie en arrière, sans épines latérales et simplement ciliée; elle est à peu près deux fois plus longue que large. Les lames latérales sont de forme ordinaire. Les pattes sont allongées, à articles cylindriques et sans épines. La couleur de cette espèce est jaunâtre dans l'alkool. Elle a été trouvée sur les côtes de l'ìle de Tinor.

En terminant la description des salicoques du voyage, nous devons consigner quelques observations que nous avons été à même de faire en travaillant ces crustacés comparativement avec d'autres espèces qui n'appartenaient pas à la mêrne expédition.

Nous avons reconnu que beaucoup de genres chez lesquels on croyait que lcs antennes internes n'ont que deux filets, en ont récllement trois. Les deux filets internes, inégaux en longueur, sont soudés ensemble jusqu’à l'extrémité chez quelques-uns, tels que les pandales, etc.; dans d'autres, comme les alphées, hippolytes, pontonies, etc., ces filets quoique soudés dans toute leur longueur, ont cependant leur extrémité libre, mais seulement dans un cspace très-court qui ne comprend que deux ou trois articles au plus. Nous avons donc pensé qu'il sera nécessaire de modifier les caractères généraux des divisions établies dans les salicoques, et nous sommes d'accord en çela avec notre célèbre maître M. Latreille à qui nous avons communiqué nos observations à ce sijet. Voilà l'ébauche des divisions qu'on pourrait établir :

I. Antennes intermédiaires de trois filets libres.

g. Palémon, lysmate, athanas, etc.

2. Antennes intcrmédiaires ayant trois filets dont deux inégaux, soudés ensemble jusqu'à leur extrémité, ou ne laissant qu'un très-petit espace libre.

g. Alphée, hippolyte, pontonie, etc.

3. Antennes n'ayant que deux filets, tous deux libres.

g. Pénée, etc.

Nous aurions pu faire sur ces bases une nouvelle classification pour les salicoques, mais sachant que MI. Edwards s'occupe de ce travail, nous nous en sommes abstenu, et n'avons voulu que consigner une observation qui pourra devenir utile par la suite. 
SQUILLE DE CERISY. Squilla Cerisii. Roux.

S. clypeo anteriori trispinoso, corpore suprà, segmentis duobus ultimis exceptis, lavi, spinis duabus mobilibus posticè terminato.

Squilla Crisii, Roux, Crust. de la Méditerr., pl. v.

PLANCHE IV, fig. $\mathrm{I}$.

Nous avions d'abord considérć la squille dont nous donnons la description, conme appartenant à une espèce distincte de celle que M. Roux décrit sous le nom de squilla Cerisï, et nous nous étions fondé, pour la distinguer de cette dernière, sur la présence des deux épines mobiles qui terminent la queue au milieu, et dont M. Roux ne parle pas dans sa description; mais ayant reçu depuis la squilla Cerisï de Sicile, nous avons reconnu que les épines mobiles avaient échappé à l'observation de M. Roux, mais qu'elles existcnt évidemment, et que l'on ne peut la séparer de celle que nous avions nommée Squilla Lessonii. Un fait assez remarquable cst l'habitat de cette espèce, qui se trouve dans les mers de la Corse, de la Sicile et de l'Amérique.

Le corps de cette belle espèce est long de cinq à onze centimètres, d'un vert jaunâtrc luisant très-uni, à l'exception des deux derniers anneaux. La pièce recouvrant le support des antennes et des yeux, ou le bouclier antérieur, est de forme triangulaire à angles latćraux tronqués, et terminée en avant par une épine assez longue et aiguë. Ses angles latéraux ont aussi une petite épine dirigée de chaque côté. Le bouclier céphalique, cclui qui vient après la pièce dont uous avons parlé, est très-élargi postérieurement, arrondi, assez lombé. Tous les segments tlıraciques et abdominaux ont leurs bords arrondis, ils sont lisses sur toute leur surfacc. Le pénultième article abdominal porte six épines partant chacune d'une petite élévation; les deux latérales internes sont plus petites et plus hautes. Le dernier segment porte en dessus onze lignes élevées, et son contour est muni de six épines, dont les deux intermédiaires et postérieures sont en forme de stylets mobiles et coniques. On voit une petite épine entre les pointes latérales, et un tubercule à la basc externe de celles du milieu. Les griffes ont trois dents, dont les deux inférieures plus courtes que la supérieure. Les yeux sont transversaux comme dans la squille mante et les autres espèces de la même division.

Cette squille, quoique très-voisine de la stylifera de Lamarck, s'en éloigne par la forme de la pièce qui recouvre la base des yeux et la base des antennes. Les yeux sont semblables à ceux des autres squilles, tandis que dans la stylifère ils sont droits, arrondis en avant et non transverses. Le dernier segment de la queue est aussi bien différent. M. Lesson l’a trouvée à Payta. 
ÉRICHTHE. Erichtlues. Latr. Smerdis. Leach.

Ce genre, établi d'abord par Latreille et Lamarck, et ensuite par Leaeh, sous le nom de Smerdis, ne se composait, jusqu'à présent, que de quatre espèees; les voyageurs en ont rapporté un bien plıs grand nombre, et les recherclics de MII. Quoy et Gaymard, Garnot et Lesson, D'Urville, Dussumier, Reynaud et Leschenault, ont porté ee nombre à plus de douze; notis en préparons unc monographie qui sera bientòt terminée, et nous allons présenter iei provisoirement le tablean des divisions prineipales que nous avons établies dans ee genre eurieux.

I. Corps linéaire, bouelier au moins deux fois plus long que large, abdomen allongé, souvent plus long que le bouclier et jamais plus eourt.

a. Corps eylindrique. Erichthus narwal, cylindricus et Rouxii Guér.

b. Corps aplati. Erichthus Latreillii. Guér.

II. Corps eourt, bouclier presque aussi large que long, abdomen court, jamais plus long que le bouclier.

Erichthus spinosus, longispinus, globulosus, Dussumierii Guér. et Erichthus armatus, Leaeh. brevidens Latr. Vitreus Fab. et vulgaris Leaeh.

\section{ÉRICHTHE NARWAL. Erichthus narwal. GuÉR.}

E. Scuto antice trispinato; lateribus brevissimis, mediana longiori medio scuto fere requali. Spinis posterioribus eadem longitudine. Ultimo abdominis segmento longitudine quan latitudine majori, postice subangustato, et utrinque tribus spinis postice longioribus.

PLANCHE IV, fig. 2, 3, 4.

Il est long de près de trois eentimètres; son eorps est allongé, aplati; son houclier est étroit, avee les bords latćraux rcpliés en dessous, et sans ćpine au milicu : la largeur de ee bouclier est presquc trois fois dans sa longueur, en n'y eomprenant pas les épines; il cst armé, en avant et de chaque côté, d'une épinc eourte ; mais son loord antérieur se prolonge au milien en unc grande épine droite, presque aussi lougue que ce bouelier et armée en clessous et à la base de trois petites dents aiguës. Les bords postérieurs sont également terminés elıaeun par deux épines, dont l’inférieure très-petite et la supéricure très-grande, mais un peu moins longue que eelle qui est en avant. Les poignets des pinces sont allongés avec le eroehet terminal de la même longueur et peu reeourbć. Les scgments de l'abdomen sont terminés postéricurement en pointe aiguë, l'avantdernier présentc au milieu deux petites dents. Le dernier segment est un peu plus long que large, armé de trois épincs plaeées de ehaque eôté, dirigées en arrière, et dont les

rogage dela Coquille. - Z. Tom. II, Part. II. ${ }^{\text {re }}$ Div. 
postérieures sont très-grandes. Les appendices natatoires de ce segınent sont au moins de sa longueur.

Cette belle espèce a été trouvée dans les mers de la Nouvelle-Guinée.

\section{ÉRICHTHE DE LATREILLE. Erichthus Latreillii. Gú́r.}

E. scuto apice antico trispinato; lateribus spinis brevioribus, mediana medio scuto aquali; spinis posterioribus anteriori minoribus. Ultino segmento abdominis quadrato, tribus utrinque spinis brevissimis.

\section{PLANCHE IV , fig. 5, 6,7 .}

Cette espèce atteint environ deux ccntimètres et demi de longueur; son corps est allongé, cylindrique; son bouclier est juste deux fois plus long que large, replié sur les côtés avec les bords antérieurs latéraux de ces replis échancrés à partir du milieu; les épines latérales de son extrénité antérieure sont très-courtes, le rostre ou l'épine intermédiaire, quoique longue, n’a que la moitié de la longueur du bouclier : les bords postérieurs sont armés chacun de deux épines dirigées en arrière, l’inférieure est très-courte, la supérieure la plus grande, est d'une longueur à peu près égale au tiers de celle du bouclier. Les poignets des pinces sont moins allongés que dans l'espèce précédente, le doigt terminal est de la même longueur et peu courbé. Les segments de l'abdomen sont arrondis aux bords postérieurs, l'avant-dernier est plus étroit, et présente au milieu deux petites dents. Le dernier segment est un peu moins long que large, garni de chaque côté de trois épines petites, dont les postérieures sont un peu plıs fortes; son bord postérieur est tronqué transversalement; les lames natatoires de ce segment sont courtes, et atteignent à peine aux deux tiers de sa longueur.

Cette espèce a été trouvée dans la mer qui baigne l'île de Timor et les îles voisines.

\section{ALIME TÉTRACANTHURE. Alima tetracanthura, Latr.}

A. scuto postice elato; tribus antico apice spinis; mediana majori, spina ucuta in utroque angulo posteriori. Cauda ad apicem elata, ultimo segmento tam lato quam longo. Postice quadridentato et utrinque leviter granulato.

PLANCHE IV, fig. 8 à 13.

Cette espècc, qui est la plus grande connue jusqu'à présent, est longue de près de cinq centimètres, depuis le bout du rostre jusqu'à l'extrémité de sa queue; sa plus grande largeur est d'un centimètre. Son test est oblong, plus étroit en avant, ayant la plus grande largeur vers le tiers postérieur, et se rétrécissant un peu ensuite; sa largeur est presque deux fois dans sa longueur. Son bord antérieur est terminé par trois épines aiguës, dont l'intermédiaire est la plus grande; elle a presque la longueur du pédoncule des antennes intermédiaires. Les deux épines latérales sont un peu divergentes et atteigncnt à peine la hauteur de l'insertion des yeux. Les bords du test sont penchés en toit de 
chaque côté, et l'on voit en dessous de petites épines courtes; ses angles postérieurs sont armés chacun d'une épine un peu moins longue que le rostre, et le bord est profondément échancré; on observe au-dessus de cette échancrure une saillie peu élevée au sommet de laquelle est une petite épine, dirigée en arrière. Les yeux sont très-saillants, globuleux, portés sur un pédoncule qui ne paraît composé que d'un article. Les antennes externes sont insérées au-dessous et plus bas que les internes, elles sont composées d'une lame extérieure, ovale, allongée; portées sur un pédoncule de deux articles, et d'un filet articulé, inséré sur le premier article, moins long que la lame externe, et n'atteignant qu'aux deux tiers de sa longueur. Les antennes internes ont leur pédoncule plus long que le rostre, composé de trois articles, dont le premier est le plus grand, et les deux autres égaux; le dernier est terminé par trois filets inégaux. Les pinces sont grandes, épaisses; leur poignet, ou l'article sur lequel vient s'appuyer la griffe, est armé à sa base cle trois épines dont une impairc et plus grande, et deux plus haut, placées sur la même ligne. Ce poignet s'élargit après ces épines, et sa largeur est un peu plus de trois fois clans sa longueur; le crochet terminal est moins long, un peu renflé au milieu, terminé en pointe courbée en dedans; cette pointe atteint, quand le doigt est plié, les deux épines placées au bord interne du poignet. Lil qucue est à peine de la longueur du test, en n'y comprenant pas le rostre, elle est terminée par uı article aplati, un peu plus long que large, et armé postérieurement de six épines courtes, placées à des hauteurs différentes. Les lames natatoires qui dépendent de cet article terminal sont assez grandes, et atteignent presque la deuxième paire d'épines de cet article.

On a trouvé cette belle espèce dans la mer, près de la Nouvelle-Guinée; M. Latreille lui avait donné, dans la collection du Muséum, le nom que nous lui conservons.

\section{PHYLLOSOME DE FREYCINET. Phyllosoma Freycinetii.}

Antennce exteriores fere duplici longitudine pediculorum ocularium. Clypeus anterior majori latitudine superius; in obtusa acie inferius desinens.

PLANCHE V, fig. 3 .

Cctte espèce remarquable est longue de trois centim. et demi, et large de dix-huit millim. Ses antennes externes ont 14 millim. de long, et dépassent les yeux de plus de la moitié de leur longucur. Le premier bouclier est plus large antérieuremcnt, arrondi à ce point, et terminé en arrière en pointc. La bouche cst située dans le milieu de la longueur du premier boucljer; elle est très-éloignée des deuxic̀mes mâchoires et des picds-mâchoirs, et semble isolée ct tout-à-fait séparée des autres pièccs. Les premiers pieds-mâchoirs sont assez grands, divisés en trois lobes, dont l'intermédiaire plus long et les autres ćgaux, ce qui lui donne à peu près la forme d'un trèfle; l'extrémité des deuxièmes piedsmàchoirs atteint à peine la bouche, tandis que, dans les espèces précédentcs, elle la 
dépasse toujours. La queue est presque de la longueur du second bouclier, les angles postérieurs de ses segments sont terminés en pointe aiguë, surtout ceux du dernier, et lès feuillets externes de la nageoire ont une petite épine en dehors et vers l'extrémité postérieure.

Ce crustacé a étć trouvé par $M$. Lesson dans les mers de la Nouvelle-Guinée, en août 1823 .

\title{
PHYLLOSOME A I.ARGES CORNES. Phyllosoma laticorne.
}

Antennce exteriores latissima. Corpus decolor, diaphanus.

\author{
Cancer cassideus, Der naturforcher, Cahier $17, \mathrm{pl} .5$. \\ Phyllosoma laticorne, Leach. Journ. de phys. \\ Phyllosoma laticorne, id. Voy. de Cranch. \\ Phyllosoma laticorne, Latr. nouv. Dict. d'hist. nat. \\ Phyllosoma laticorne, id. Encycl. méthod, t. io, p. I I9, pl. 354, fig. 4. \\ Phyllosoma laticorne, Desm. cons. sur les crust. p. 255, pl. 44 , fig. 7 .
}

PLANCHE $\mathrm{V}$, fig. I.

Cette belle espèce, la plus grandc que nous connaissions, a plus desept centimètres de longueur; sa plus grande largeur est de cinq centimètres. Ses antennes externes ont à peine douze millinètres de long; elles sont aplaties comme le reste du corps, l'une seule pièce large $\mathrm{cn}$ bas, se dilatant extérieurement en une pointe qui remonte vers la tige principale; celle-ci est un peu éloignée à sa base, et se termine en pointe. Les antennes internes sont de la même longueur; leur pédoncule est formé de trois articles égaux, ct le terminal porte deux filets de même longueur, dont l'externe est plus épais et courbé en dehors, mouvement que suit l'interne. Les yeux dépassent de beacoup la longueur des antennes; ils sont dc forme ordinaire. Le premier bouclier est plus large en avant qu'en arrière; son bord antérieur est presque droit, et le postérieur finit en un lobe arrondi.

La bouche est très-saillante et situće, comme à l'ordinaire, au tiers postérieur du preniicr bouclier. Les deuxièmes mâchoires sont grandes, bilobées en avant, et ayant le lobe postérieur un peu plus long que le premier. Les preniers pieds-mâchoirs sont assez grands, leur lobe antérieur est peu apparent, le médian est long, de la mêne largeur dans toute son étendne, et arrondi à l'extrémité; enfin le lobe postéricur est de même longueur, mais plus de deux fois plus large, et dirigé en arrière. Les deuxièmes piedsmâchoirs sont longs, et leur extrémité dépasse la hauteur de la bouche; ils sont composés de trois articles, outre la hanche; le premier article est long, le second, le plus court de tous, et le troisième, un peu plus long, est terminé, comme à l'ordinaire, par 
un crochet recourbé, oppasé à dc longs poils raides. Ces pieds-mâchoirs n'ont pas de fouet au premicr article, comme on en a observé aux espèces précédentes; on voit seulement vers le tiers postérieur de cet article un petit appendice arrondi au bord, et qui semble articulé à sa base; c'est cette petite pièce qui semble tenir ici la place du grand flagre des précédents. Les troisièmes pieds-mâchoirs sont très-grands, et leur extrémité dépasse la hauteur des yeux. Ils sont composés de quatre articles, dont les trois preniers sont presque égaux, et le dernier beaucoup plus court; comme dans les deuxic̀mes piedsmâchoirs ils sont dépourvus de flagre, et cette pièce est remplacée par un petit appendice semblable à celle que nous avons clécrite plus haut. Ces quatre articulations sont munies de longs poils dans toute leur étendue, mais l'extrémité interne de l'avant-dernier, en face de larticulation du dernier, donne attache à uı groupe de 7 à 8 poils plus gros et plus courts que les autres, terminés en massue, et garnis à leur côté interne, qui est en regard avec ce dernier article, d'un rang de petites épines recourbées et raides; cette particularité, que nous n'avons pas observée aux espèces de la division à laquelle appartient l'espèce précédente, existe chez toutes cèlles de ce groupe.

Le second bouclier est dcux fois plus large quc long, profondément échancrć en arrière, ce qui lui donne la forme d'un croissant renversé. Les pattes ont près de deux fois la longueur du corps; les premières sont les plus courtes, et ne dépassent pas de beaucoup les troisièmes pieds-mâchoirs. Mais les quatre autres paires sont d'égale longneur; les crochets qui les terminent sont d'inégale grandeur; ceux des premières pattes sont petits; ils sont quatre fois plus longs aux trois paires suivantes, et petits ì la dernière. Toutes ces pattes sont munies d'un grand fouet partant du premier article, et nous n'avons pas observé de ces petits corps lamclliformes à la base des hanches, comme il en existe aux espèces dc la division précédente.

La queue est large à sa base, et va en diminuant vers l'extrémité ; son premier segment est deux fois plus long que les suivants. Ils sont tous transversaux, dilatés en pointe arrondie à lcurs angles postérieurs. Les quatre premiers donnent attache à deux lames natatoires qui semblent formées d'une seule pièce divisée en deux lobes à l'extrémité, et dont le lobe interne a une petite échancrure en dehors. La lame intermédiaire de sa nageoire terminale est presque carrée, un peu plus large en haut et légc̀rement échancrée en arrière, les lames latérales sont conformées comme à l'ordinaire.

Ce bel individu a été trouvé par M. Lesson dans les mers de la Nouvelle-Guinée, le 3 septembre 1823 . Leach l'a reçu de mors d'Afrique. 


\title{
PHYLLOSOME PONCTUÉ. Phyllosoma punctata.
}

\author{
Antennce exteriores angustissima. Corpus diaphanum, rubro cribroque \\ punctatum.
}

Phyllosoma punctata, Lesson. 'Journal manuscrit de son Voyage.

\section{PLANCHE $\mathrm{V}$, fig. 2.}

Nous ne connaissons cette espc̀ce que par le dessin que M. Lesson en a fait en mer; elle a trois centimètres de long; son bouclier antérieur estlarge de 12 millim., et ce qui n’a été observé dans aucune de nos espèces, le bouclier postérieur est beaucoup plus large, ayantau moins deux ccntim. dans sa plus grande largcur. Il ne paraît pas échancré postćrieurement, et la queue est petite. Le premier est oblong, presque aussi large en avant qu'en arrière; le second est ovale transverse. Les yeux paraissent avoir leur pédiculc aussi long quc le prenier bouclier, et les antennes sont représentées très-petites. Tout le corps est transparent, d'un blanc satiné; il est couvert, dans toute sa surface, d'une infinité de petits points d'un rouge carmin, assez vif. Les yeux paraissent être d'un jaune orangé.

Cct individu a été pris dans l'Océan ćquatorial, à 2 degrés de latitude sud, par M. de Blosseville, officier de la corvette la Coquille, et dessiné par M. Lesson. Nous regrettons que l'individu n'ait pas étć conservé.

\section{PHYLIOSOME DE DUPERREY. Phyllosoma Duperreyi.}

Antennce exteriores lata. Clypeus fere rotundus, postica parte emarginatus.

\section{PLANCHE V, fig. 3.}

Il est long de plus de quatre centim. et large de trois centim. Ses antennes externes ressemblent beaucoup à celles du Laticorne, mais elles sont un peu moins larges à la base; leur extrémité atteint presque la hautcur dcs yeux. Les antennesinternes sont aussi longues que les yeux; leurs filets terminaux sont recourbés en dehors, et l'interne, beaucoup plus ćtroit, cst plus long que l'extérieur. Le bouclier antérieur est presque aussi long que large, de forme carréc, avec les bords arrondis et la partie postérieure échancrée. Les deuxièmes mâchoires sont très-grandes, avec le lobe externe antérieur, prolongé et pointu, et le lobe postéricur, grand, recourbé en dedans. Les premiers pieds-mâchoirs sont assez grands, divisés cn deux lobes, dontl'antérieur pointu et le postćrieur presque carré. Les deuxièmes pieds-mâchoirs dépasscnt la hautcur de la bouchc; et les troisièmes sont d'une longueur presque double de celle du premier bouclicr quils dépassent de beaucoup. Les pre- 
mières pattes sont moins longues que les pieds-mâchoirs; les trois paires suivantes ont à pelı près la mème grandeur; toutes ces pattes sont armées d'épines aux articulations, et leurs divisions sont garnies de poils de diverses grandeurs. Les pattes postérieures sont petites, elles dépassent un peu la longueur de la queue. Le bouclier postérieur est beancoup moins large que le précédent, presque carré; la queue est de la même largeur à sa naissance; elle diminue d'une manière très-sensible postérieurement, et ses segments sont traversaux. Les appendices des quatre premiers sont assez longs, bifides à l'extrémité, et ne présentant pas de traces d'articulations; leurs deux branches sont accolées l'une contre l'autre. La lame intermédiaire de la nageoire terminale est plus large que longue; les côtés descendent presque droit, se terminent par un petit angle aigu, et son bord postérieur, circonscrit entre ces deux angles, est arrondi et sinueux de chaque côté. Les lames des côtés sont grandes, de forme carrée et à angles arrondis.

Cette belle espèce a été trouvée, au port Jakson, par les naturalistes de l'expédition commandée par M. le capitaine Duperrey.

\section{Explication des détails de la planche 5.}

Fig. 1. a. Bouche du Ph. laticorne.-b. Premiëre machoire.-c. Une de ses trois épines terminales.-d. Extrémité des troisièmes pieds-machoirs. - $e$. Undes poils barbelés placés au côté interne.

Fig. 2. A. Cinquième patte dı Ph. Duperreyi.-B. Extrémité de la première patte.

Fig. 3. A.Extrémité antérieure du premier bouclier du Ph. Freycinetii.-B. Extrémité de l'antenne externe.

$\oint$ II.

\section{AR ACHNIDES.}

\section{ANDROCTONE VARIÉ. Androctonus variegatus. Guér.}

A. Oculis duodecim, manibus elongatis, sublavis, corpore pedibusque obscure flavo, , brunneo maculatis, cauda corpore longiore, lineis granulosis elevatis.

Magasin de Zoologie, classe VIII, fig. 2.

Ce scorpion est long d'environ quatrc centimètres; sa queue forme un peu plus de la inoitié de cette longueur. Le céphalothorax est allongé de forme trapézoïde, plus étroit en avant, échancré au bord antérieur, ayant un sillon profond au milieu et inégal sur toute sa surface. Les deux gros yeux du centre sont situés un peu ell avant du milieu, 
sur une éminence, et dirigés sur les côtés. Les autres yeux sont placés tout-à-fait aux angles antérieurs et latéraux; chaque groupe est composé de cinq yeux dont les trois plus gros sont égaux, placés tout-à-fait au bord du thorax, sur une élévation ovalaire : en dedans cle ces trois yeux et sur le bord interne du tubercule qui les supporte, on observe deux autres yeux de moitié plus petits, situés un peu plus bas, le postérieur plus près ct au-dessous du dernier des trois gros; lautrc plus loin et entre l'avant-dernier ct le dernier des précédents. Lcs segments de l’abdomen sont transverses ct présentent unc petite carène au milieu. Le dernier, ou celui qui précède la queue, en présentc trois. Les anneaux de la queuc vont cn augmentant de longreur jusqu'au dernier; ils sont creusés en sillon au inilieu, lcurs arêtes latćrales supérieures sont trèssaillantcs, crénelées et terminécs en arrière en une petite pointe saillante. Les deux premiers anneaux ont, sur les côtćs et au-dessous de l'arête dont nous venons de parler, trois petites arc̀tes longitudinalcs. Lcs anneaux suivants n'en ont que deux, et le dernier n'en a plus qu'unc. Nous n'avons pas vu la cupule à vcnin, l'individu unique recueilli par M. Durville, en ayant ćté privé par accident. Les pinces sont un peu plus longues que le corps, grêles; l'avant-dernier article est un pen élargi an milieu, il porte cn dessus trois côtes lisses, et en dedans plusieurs petites dents. La main est grêle avec lcs doigts courbćs en dedans, ayant presque deux fois la longueur du poignet. Les pattes sont allongées, aplaties. La couleur générale de ce scorpion est d'un jaune obscur, tout son corps en dessus cst marqué de petitcs marbrures noiràtres, les pattes et les pinces sont comme annelées par des taches de la même couleur. La queue est plus uniforme de couleur. Enfin le dessous est plus pâle et très-peu tacheté.

Cc scorpion appartient évidemnient au genre androctone de MM. Emprich et Ehremberg, nous avons très-lien vu les cinq yeux placés dans chacun des groupes latéraux: on apercoit aux environs de ces ycux de petits tubercules luisants, ce qui a fait penser à M. Latreille que les auteurs ci-dessus cités auraient pu prendre de ces tubercules pour des yeux lisses (voy. Cours d'Ent., t. I, p. 48 r). M. Latreille dit plus loin (p.482) qu'il ı’a jamais vu de scorpion offraut 12 yeux. Cclui que nons venons de décrire présentant ce caractèrc d'une manièrc évidente, pourra détruire tous les doutes du savant français, et servira à démontrer toute l'exactitude des observations de MM. Emprich et Ehremberg.

Cetie espèce curicuse a été trouvée au port Praslin dans la Nouvelle-Irlande; elle était sous des pierres.

\section{BUTHUS DU PÉROU. Buthus Peruvianus. Guér.}

B. Oculis octo, thorace rubescenti, abdomine nigricanti, cauda flava corpore longiore lineis elevatis granulosis, chelis flavis, apice brunneis, subtus pedibusque flavis.

Cctte espèce a près de six centimètres dc longueur, sa queue est beaucoup plus Jongue que le corps; le cćphalothorax est d'un roux fauve, très-élargi en arrière ct 
présentant aux angles postérieurs deux sillons obliques qui viennent finir vers la ligne médiane au bord postéricur. Il est finement chagriné, son milieı est creusé par un sillon profond interrompu au nilieu pour former un tuberculc place à égale distance des deux extrémités, et portant les gros yeux du centre. Le bord antérieur présente deux échancrures pour recevoir les chelières. Les yeux latéraux sont placés un peu au-dessous des angles antérienrs, très-près du bord, chaque tubercule cn porte trois disposés en triangle ayant le sommet vers le bord cxtérieur. Ces trois yeux sont égaux en grosseur, ils ne se touchent pas. Les segments de l'abdomen sont transverses, finement granulés, un peu arqués en arrière, et ayant chacun au milieu une faible impression. Leur couleur est noirâtre avec les bords d'un rougeàtre pâle. Les segments de la quene sont oblongs, ils vont en augmentant de longueur jusquau dernier', qui forme une cupule très-renflée, surmontée d'une épine à venin courbe, au moins aussi longue que la cupule elle-mème. Cette queue est d'un janne doré, chaque anneau porte supérieurement deux arètes granuleuses d'aborả parallèles, et qui viennent se rapprocher de la ligne médiane vers l'arrière; leur milieu est un peu creusé par un léger sillon, les côtés ont de légères arêtes à peine inégales, mais non granuleuses; il y en a trois aux deux premiers, et deux aux suivants, en n'y comprenant pas l'arête supérieure; l'avant-dernier segment présente en dessous une arête granuleuse bien marquée, les autres sont lisses en lessous. Les pinces sont de la longueur du corps, d'un jaune semblable à celui de la queue, leur second segnient offre des arêtes granuleuses, le troisième est un pen renflé en dedans, lisse et arrondi en dehors. La main est globuleuse, presque lisse, avec les doigts lisses, cle la longueur du poignet, et d'un brun roussâtre; les pattes sont aplaties, lisses, très-peu velues, et d'un jaune pàle. Le dessous du corps est plus pàle que le dessus.

Cet individu a été trouvé mort sur' la route sablonneuse de Callao à Iima.

\section{BUTHUS CRAN. Buthus Cran. GuÉr.}

B. Ocnlis octo, corpore totus flavo, chelis lavibus, thorace antice angusiore, linea longitudinali impressä; pedibus elongatis, complanatis et villosis.

Il a environ quatre centimètres ct demi de longueur, il est entièrement et uniformément d'une couleur jaune brunàtre saturée de rous, semblable à la couleur de la cire brute. Les hords du céphalothorax et de l'abdomen paraissent un peu plus pàles. Le céplıalothorax cst très-étroit en avant, il acquiert près dı double en largeur à son lord postćrieur; ce bord est sinueux reborlé; le bord antérieur est également lobé, un peu avancé au milieu. Le sillon méclian est très-profond, interrompu par le tubercủe rles yeux : celıri-ci est placé au milicu de la longueur du céplıalothorax; les yeux latéraux sont placés un peu au-dessous des angles antérieurs, chaque tubercule cn porte rois placés au hord et sur une ligne arquéc dont la courbe est cu dehors, mais non pas en triangle comme on le voit chez le B. Peruvianus : ces yeux sont égaux et se tonchent 
entre eux. Les segments de l'abdomen sont transverses, rebordés, leur milieu présente une petite fossette peu marquée, le dernier segment porte au milicu du bord postérieur deux petils tubercules mieux marqués que dans le $B$. Peruvianus. Les deux premiers segments de la qucue ont étć cassés, les suivants et la cupulc à venin sont semblables à celle dı B. Peruvianus. Les pinces sont à peu près de la longueur du corps; leurs premiers articles ont quelques còtes peu visibles; le poignet est ovalaire, un peu globuleux, lisse ; les doigts sont assez forts, de la longueur du poignet. Les pattes sont grandes, aplaties, et leurs derniers articles sont garnis sur deux tranches de longs poils blanchâtres.

On a trouvé cette espèce à Payta dans les lieux secs et pierreux au bord de la mer. - Au rapport de M. Durville, il est connu dans le pays sous le nom de Cran que nous lui avons conservé; sa piqûre est peı redoutée, et ne produit qu'une légère inflammation.

\section{BUTHUS A BANDES. Buthus Vittatus. Guér.}

B. Oculis octo, corpore levigato, fusco, segmentis nigro-marginatis, cauda crassa, corpore longiore, segmentis anticis subquadratis, profunde sulcatis, lineis elevatis, granulosis. Chelis pedibusque pallidioribus.

Il est long de quatre centimètres; le céphalothorax est d'un brun roussâtre, lisse, rétréci elı devant, sillonné au milieu, avec deux impressions latérales postérieures, presque parallèles aux bords postérieurs. Les yeux du centre sont placés un peu au-dełà du milieu, vers la partie antérieure; les groupes d'yeux latéraux sont placés au bord du céphalothorax, très-près et sous les angles antérieurs; ils sont au nombre de trois, presque égaux, les postérieurs un peu plus petits, et disposés sur une ligne presque droite le long du bord. On voit unc large bande noire au bord antérieur et une bordure étroite de Ja même couleur au bord opposé. Les segments de l'abdomen sont transverses, lisses, luisants, et leur bord postérieur présente une bande noire, un peu dilatée au milieu. Ces seguments abdominaux ne présentent aucune impression sur la ligne médiane. La queue est épaisse; son premicr segment est plus large que long; les deux suivants sont carrés, et les autres allongés; elle est d'un brun rougeâtre-luisant, très-creusée au milieu, garnie en dessus et de chaque côté, d'une ligne élevée, granuleuse. Les bords latéraux sontarrondis, et ne présentent que de légers vestiges d'une ligne élevée. La cupule à venin est peu globuleuse, à épine moins longue, crochue et noire au bout. Les pinces sont à peine aussi longues que le corps, lisses, d'un testacé rougeâtre; les mains sont un pen en forme de cour, avec les doigts plus courts que le poignet. Les pattes sont aplaties, d'un jaunc sale, légèrement variées de brunâtre.

M. Durville a trouvé ce scorpion au Chili, dans la baie de la Conception; il se tronve dans les montagnes de Penco, sous les pierres; les renseignements qu'il a pris à son sujet s'accordent à le faire considérer comme peu dangereux. 


\section{SÉGESTRIE A TÊTE ROUGE. Segestria ruficeps. Gú́r.}

S. Thorace pedibusque brunneo rufo, thorace apice coccineo, mandibutis nivide virilibus, apice rubris; abdomine fuscescenti.

Cette belle espèce a le corselet long de 8 millimètres; elle ressemble beaucoup, pour la forme et la taille, à la ségestrie des caves, si commune en Europc; mais elle cn diffère par la belle tache rouge du devant de son céphalothorax et par la conleur rouge-bruı de tout son corps; ses pattes sont grandes, velues, plus obscures que le céphalothorax avec les articulations rougeâtres. L'abdomen paraît lırınàtre, soyeux; il est très-réduit par la dessiccation; ses mandibules sont fortes, d'un beau vert brillant avec le bout rouge et la griffe noire.

Cette espèce a été prise à Sainte-Cathcrine du Brésil, en octobre. Dans son journal M. Durville la note comme ayant été trouvée sous des feuilles.

\section{DRASSE DYSDÉRIFORME. Drassus dysderiformis. Guér.}

D. Thorace, mandibulis pedibusque ferrugineo-rubris, villosis. Abdomine flarescente, piloso.

Si cette araignée n'avait pas huit yeux, et n'entrait pas parfaitement dans le genre drasse, on ne pourrait la distinguer de la Dysdere érytrine des anteurs: sa longueur est de douze millimètres; son corselet est rétrćci en avant, lisse, faiblement velu, et d'un rouge ferrugineux assez vif. Ses mandibules sont de la mème couleur, velues, avec les crochets bruns. Les pattes et les palpes sont d'un ferrugineux plus jaunâtre, couvertcs de poils jaunes. L’abdomen est d'un jaune pâle, mat, soyenx, couvert de petits poils bruns dirigés en arrière; ceux de sa base sont dirigés en avant, ct lui forment une petite couronne hérissée. Les filières sont un peu rougeàtres, assez saillantes; le dessous de l'ablomen présente à sa base une tache olsscure.

Elle a été trouvée à Dorey, dans la Nouvelle-Guinée.

\section{ÉPEIRE GRACIEUSE. Epeira grata. Guér.}

E. Mandibulis thoraceque ferrugineis, abdomine globoso, aurantiaco, lateribus posticrque nigro-maculato, sup; in verticem lineola nigra, ramosa. Pedibus pallide rufescentibus; tibiis apice nigris, posticis fasciculato-villosis.

La longneur de cette jolie espèce varie de buit à dix millimètres; le céphalothorax est d'un ronge ferrugineux ainsi que les mandibules et les pattes; celles-ci ont l'extrémit: 
des tibias d'un beau noir velouté, à poils très-eourts, à l'exeeption des jambes postérieures qui présentent à ee point un faiseeau de poils noirs, raides, et qui les font paraître eomme en massue. L'abdomen est très-globuleux, prolongé et arrondi en avant; sa partie supérienre est d'un bel orangé brillant, avee les eôtés plus pâles, variés de taches noires. Son extrémité présente une grande taehe noire, arrondie, dans laquelle on observe quatre petites taehes jaunes, dont les supérieures plus visibles. Le milieu offre une ligne noire, longitudinale, renflée au milieu, et envoyant de chaque eôté trois ou quatre petites branehes eourtes et dirigées en arrière; ees lignes sont bordées d'une teinte jaune, plus pâle que l'orangé dans lequel elles tranehent.

De la Nouvelle-Guinée.

\section{GASTÉRACANTHE DE LEPELIETIER. Gasteracantha Lepelletierii. Guér.}

G. Thorace nigro-violaceo, subquadrato. Abdomine flavo, transverso, suboctogono, sexspinoso, spinis incequalibus, violaceis, gracilibus, basi crassioribus; ambitu punctato. Pedibus palpisque sanguineis, apice dilute brunneis.

Encycl. méth. Art. Ulobore, t. ro, p. 763.

Cette espèee est très-élégante ; son eorps est long de neuf millimètres et large d'autant en ne eomprenant pas les épines de l'abdomen. Le eorselet est très-luisant, d'un noir à reflets violets; les pattes et les palpes sont d'un ronge brique avee l'extrémité des tarses brunâtre. L'abdomen est transversal, un peu bombé, de forme hexagonale; ses quatre angles postérieurs portent une épine épaisse à la base et rétréeie brusquement en pointe aiguë, au-dessus des deux latérales qui sont les plus longues, et qui atteignent presque trois millimètres de longueur, il y en a de ehaque eôté une autre très-petite, eonique et dirigée un peu en avant. Toutes ees épines sont déponrvues de poils; les deux latérales sont très-rapproehées entre elles; les postérieures sont plus éloignées des latérales qu'elles ne le sont entre elles. Le dessus de eet abdomen est jaunàtre, marqué de vingtdeux points noirs (et non vingt-trois, eomme nous l'avons dit dans l'Eneyelopédie), dont dix-huit placés autour et quatre au milieu. Le dessous est jaunâtre, ridé avee l'abdomen très-saillant, et garni d'un anneau noir.

Cette espèee a été trouvée dans les bois, aux environs de la rade de Cayelé, dans lîle de Bourou; on la trouve aussi à Taïti, Amboine et autres îles voisines. 
GASTÉRACANTHE A ÉPINES ROUGES. Gasteracantha rubrospinis. Guér.

G. Thorace nigro, subquadrato; abdomine albescenti, transverso, deplanato, subovali, sexspinoso; spinis subaqualibus, turbinatis, rubris. Pedibus nigris; femoribus ferrugineis.

Cette gastéracanthe est longue de sept millimètres et large de dix; elle ressemble beaucoup à la G. Lepelletierii, mais son corselet n'a pas de reflets violets; son abdomen est plus large proportionnellement à sa longueur; il est très-aplati en dessous, d'un blanc un peu jaunâtre, entouré du même nombre de points noirs, et ayant son bord antérieur peu arqué. Les six épines sont coniques, et diminuent insensiblement d'épaisseur pour se terminer en pointe aiguë; elles sont courtes, les latérales n'ayant que deux millimètres de longueur, de couleur rouge brique, et garnies de poils noirâtres; les latérales sont aussi distantes entre elles que les postérieures; les pattes sont noires avec les cuisses rouges jusque près du genou.

Trouvée dans les bois, près le havre d'Offak, dans l'île Waigiou; elle se tient dans des toiles suspendues aux arbres.

\section{GASTÉRACAN'THE FASCIÉE. Gasteracantha fasciata. GuÉr.}

G. Thorace nigro, subquadrato; abdomine nigro bifasciato, luteis, convexo, subovali, sexspinoso, spinis subrequalibus, rubris. Pedibus nigris; femoribus ferrugineis.

Cette espèce est longue de neuf millimètres et large de onze ; elle ressemble beaucoup a la g. rubrispinis, et pourrait bien n'en être qu'une variété; cependant elle en diffère en ce qu'elle est un peu plus grande, d'un jaune plus ou moins rougeâtre; que son abdomen est convexe, et surtout par la présence de deux bandes noires, transversales, interrompues, et dont l'antérieure est plus large; les deux individus que nous avons sous les yeux varient un peu entre enx, l'un armé d'épines un peu plus grandes, à sa bande antérieure interrompue seulement au milieu. Dans l'autre, la couleur est moins vive, et la bande antérieure est trois fois interrompue; le dessous des deux est noir taché de jaune.

Elles ont été prises dans l'île de Guam, l'une des Mariannes. 


\section{GASTÉRACANTHE DE THEIS, Gasteracantha Theisï. GuÉr.}

G. Thorace nigro, subquadrato; abdomine rotundato, octogono, subgloboso, nigro, flavo variegato. Ambitu punctato, sexspinoso; spinis nigro-rur bescenti, denticulatis, incequalibus. Pedibus rufo-brunneis.

Ccite belle espèce est longue de huit millimètres et large de sept; elle est bien distinctc des deux précédentes par la forme de son abdomen qui n'est pas transversal ct dont la largeur cst égale ả la longueur. Son corselet est tout noir, luisant. Ses pattes sont d'un noirâtre tirant au ferrugineux. L'abdomen est noir avec des taclıes d'un beau jaune qui varient beaucoup pour la forme et l'étenduc; dans les individus où ces taches sont le mieux marquées, elles semblent représenter à peu près un oiseau vu sur le dos et les ailes étendues : cet abdomen présente huit côtés égaux, les six postérieurs portent chacun une ćpine à leurs angles; les deux antéricures sont les plus petites, elles sont parfaitement coniques; les deux suivantes sont les plus grandes, leur longueur est d'un peu plus de deux millimètres, les postéricures sont un peu plus courtes; ces quatre épincs commencent par être cylindriques et deviennent ensuite brusquement coniques ; elles sont toutes garnies de petites spinules courtes et dirigées en dehors. Ces épines sont toutes placécs à des distances ćgales entre elles.

De la Nouvelle-Guinée. Nous avons dédié cette especce remarquable à M. Charles de Théîs, élève de M. Walkenaer, et qui, après ce savant, connaît le mieux les Araclunides.

\section{GASTÉRACANTHE RHOMBOIDE, Gasteracantha rhombö̈dea. GuÉR.}

G. Thorace nigro, subquadrato; pedibus fuscis. Abdomine flaro, subtus nigro variegato, suprà complanato, trunsverso, sexspinoso. Spinis incequalibus duabus lateralibus approximatis; ambitu punctato, punctis inferioribus quatuor mujoris.

Cette espèce est longue de sept millimc̀tres et large de neuf. Son abdomen est toutà-fait transversal, au noins deux fois aussi largc que long, non compris les épines. Il est aplati, arrondi en avant, anguleux en arric̀re. Les épines sont noires, les latérales sont très-inégales, les supérieures étant très-pctites, coniques, les suivantes cylindriques et pointues au bont, longues d'un peu plus de deux millinètres, velues; les deux postérieures très-éloignées des précédentes, de moitié plus petites et coniques. Le dessus de cet abdomen est d'un beau jaune d'ocre, marqué des points noirs ordinaires, mais cn ayant quatre plus gros, suivant unc ligne parallèle au bord antérieur placée au-lessus des grandes épines latérales. Lc thorax, les palpes et les pattes sont noirs.

De l'Ile de France. 


\section{GASTÉRACANTHE EN CROISSANT, Gasteracantha lunata. Guér.}

G. Thorace nigro, subquadrato; abdomine complanato, transverso, antice emarginato aut intius arcuato, colore croceo, nigro punctato : sexspinoso, spinis incequalibus nigris. Pedibus palpisque nigris.

Cette epèce est longue de sept millimètres et large de donze; elle est très-remarquable par la forme arquée de son abdomen, ses angles latéraux se relèvent en avant ct sont un peu plus avancés quc le milieu; le bord postćrieur est presque parallèle au précćdent, un pen plus ćlargi au milieu. Sa longneur est presqne trois fois dans sa largeur : les épincs sont velues, noires, les latérales antérieures sont trc̀s-petites, coniqucs, les suivantcs sont beaucoup plus grandes, cylindriques, brusquement terminées en pointc, velues, non pas placées comme chez toutes les espèces quc nous avons décrites, à l'angle postérieur, mais cntre cet angle, qui est arrondi, et l'épine antérieure dont elle est très-rapprochée. Les deux épines postérieures sont plus pctites, coniques, placées à une très-grande distance des précćdentes et également velues; les points arrondis du dessus de l'abdomen sont grands, et de couleur noire. Le corselet, les pattes et le dessous de l'abdomen sont noirs.

Cettc araignée ressemble beaucoup à celle que Fabricius a nommée $A$. fornicata, mais elle en diffère essentiellement par la coulenr des épines qui, dans celle de Fabricius, sont rouges, ct par le dessous qui est noir, tandis que Fabricius décrit la sienne comme ayant le pectus jaunâtre.

Elle a été prise dans lî̀le de Timor.

\section{GaSTÉRACANTHE D'AUdOUIN. Gasteracantha Audouinii. Guér.}

G. Thorace nigro, subquadrato; abdomine flavo, nigro-punctato, transverso, latcribus attenuatis, bispinosis, postice inermi, rotundato; spinis lateralibus incequalibus, anticis minutissimis; posticis magnis, cylindraceis, villosis. Pedibus ferrugineis, apice brunneis.

Elle est longue de scpt millimètres, et large dc neuf sans comprendre les épines; son abdomen est d'une formnc ovale transverse, étroit, rétréci et tronqué de chaque côté, armé de deux épines dont l'antérieure très-petite, conique; la postćrieure beaucoup plus grande, noirâtre, ćpaisse, cylindriquc, comne arrondie au bout, mais ayant une petitc pointe conique cachée dans les poils; sa longuenr est de trois millimètres. Le bord postérieur de cet abdomen présente lcs vestiges de deux pointes postérieures, mais elles sont réduitcs à detux pctits tubercules. Le dessus est jaune avec les points ordinaires 
noirs. Le dessous est noirâtre avec quelques taehes pâles. Le eorselet est noir; les pattes sont ferrugineuses avee l'extrémité plus obscure.

Cette espèce a été trouvée dans l'île d'Amboine; nous la consacrons à notre confrère M. Audouin, qui prépare une Monographie de ce genre remarquable.

\section{SALTIQUE JOLI. Salticus Lepidus. Guér.}

S. Thorace brunneo; palpis, mandibutis margine antico thoracis viridi-ceneo, nitido. Abdomine parvo, aureo. Pedibus anterioribus validibus, brunneis, nitide virescenti, subtus nigro fasciculatis, tarsisque flavis. Pedibus posterioribus favis, brunneo maculatis; cateris pallide brunneis, nigro-villosis.

Mag. de Zoologic, classe VIII, fig. 3.

Cette espèee remarquable est du petit nombre de celles qui sont ornées de couleurs métalliques; elle est longue d’environ huit millimètres, son corselet est brun, trèsbombé; vu en devant il présente une forme earrée, les yeux forment un are au-dessous duquel on voit une belle bande d'un vert métallique des plus brillants formée par des poils eourts, dirigés en bas, eolorés en vert, cliangeant au bleu ou à l’argenté suivant le jour. De ehaque eôté des deux gros yeux mitoyens et sous les yeux qui suivent et qui sont plaeés un peu plus haut, on voit une bande de poils verts métalliques plus étroite que la préeédente, et qui en est séparée nettement par une ligne noire. Les mandibules sont également garnies des mêmes poils verts brillants, ainsi que le devant des palpes. L'abdomen est très-petit, arrondi, d'un jaune soyeux, garni ver's les bords d'écailles métalliques d'un doré verdâtre à reflets argentés. Les pattes antérieures sont beaueoup plus épaisses que les suivantes, presque aussi longues que eelles de la troisième paire, d'un brun rougeâtre à reflets enivreux et dorés. Les cuisses sont garnies en dessus de poils noirs, raides, assez longs; la partie interne des articles suivants offre des faiseeaux des mêmes poils noirs, ainsi que la moitié inférieure et antérieure des tarses; le reste de ees tarses est d'un jaune pâle, avee les erochets noirs. Les pattes suivantes sont grêles, eelles de la seconde paire sont rougeàtres, plus courtes que les préeédentes, garnies de poils noirs, mais plus elair-semés; leurs tarses sont plus pầles. Les troisièmes pattes sont les plus longues de toutes, leur eouleur est la même que dans les précédentes. Les quatrièmes sont les plus eourtes de toutes, pâles, taehetées de brun.

Cette charmante espèce a été trouvée à Dorey, dans la Nouvelle-Guinée. 


\title{
CHAPITRE XIII.
}

\section{INSECTES :}

\author{
Par F. - E. Guérin.
}

SI.

COLÉOPTÉRE.

CICINDÈLE DE LA'I'REILLE. Cicindela Latreillii. Gún. - Nigro-anea; thorace angustato, subcylindrico; elytris sericeis, violaceo-argenteo-micantibus, basi rubro-quadrinaculatis; punctis tribus lunulaque apicis albis. Pedibus nigro-ceneis, tibiisquc flavis. -L. I I mill., l. 4 m.--Atlas, Inseetes, pl. I, fig. 5.

Sa tête est d'un noir verdâtre, avee les yeux très-saillants. Le labre est de la même eouleur, un peu plus large que long, terminé au bord antérieur par une petite saillie arrondie, sans dents. Les mandibules sont très-grandes, noires et n'ayant que la base jaune. Les palpes sont jautâtres, avee l'extrémité brune. Les antennes sont filiformes, noires. Le corselet est de la eouleur de la tête, étroit, eylindrique, un peu rétréei et un peu rebordé aux cleux extrémités, avee une légère impression longitudinale en dessus. Sa largeur est presque dans sa longueur. Les élytres sont presque deux fois plus larges à lenr" base, un peu élargies en arrière, d'un noir soyeux à reflets violets argentés. On voit à leur base quatre petites taelıes rougeâtres virgulaires eourtes, dont les deux internes sont plaeées obliquement de ehaque eôté de l'éeusson qui est noir; les secondes sont longitudinales et plaeées entre les premières et l'angle huméral vers lequel elles se prolongent en are en avant. Vers le tiers antérieur de elaque élytre on trouve un trèspetit point jaunàtre plaeé presque au milieu, mais un peu plus près de la suture que dı bord externe; plus bas que le milieu de l'élytre on voit deux autres points jaunàtres plaeés transversalenent, réunis par une petite ligne ferrugineuse; ces points sont plaeés sur le bord extérieur de l'élytre, le point externe touehe presque ee bord, e'est le plus petit, l'interne est un peu oblong, dirigé obliquement vers le bas, plus grand, et atteignant à peine le milieu de l'élytre. La lunule postérieure est étroite; elle eoumenee à la suture, et longe le bord postérieur de l'élytre jusqu'à l'angle externe. Le dessons du eorps est noirâtre, avec quelques reflets verdâtres au thorax. Les euisses sont noirâtres, 
un peu velues, rcnflées à leur lase. Les jambes sont jaunes, avcc l'extrémité et les tarses noirâtres.

- Cette espècc paraît très-rase, elle a été trouvée unc sçule fois au port Dorey, à la Nouvelle-Guinée; nous la dédions au plus célèbre entomologiste de l'époque, en témoignage d'adniiration et de reconnaissance.

M. d'Urville a rapporté plusieurs autres espèces du genre Cicindèle; comme elles ont été décrites par M. Dejean dans le Species des Colćoptères de sa collection, nous renvoyons à cet ouvragc en nous bornant à présenter les noms de ces espèces avec la citation des figures que nous en avons données.

Cicindela decem-guttata, Fab.; Dej., Sp., t. 2, p. 420 ; Nob., Atlas, Ins., pl. I, fig. I.

Cette espèce nous a préscnté une variété, trouvée à Bourou, dans laquelle la quatrième tache ne se lie pas avec la troisième, et dont la cinquic̀ne tache est beaucoup plus grande. L'espèce type, et qui se rapportc à.la description de M. Dejean, a été prise à Amboine.

Cicindela Durvillei, Dej., Sp., t. 5, p. 224; Nob., Atlas, Insectes, pl. I, fig. 2. De Dorey, Nouvellc-Guinée.

Cicindela tortuosa, Dej., Sp., t. I, p. 87; Nob., Atlas, Insectes, pl. I, fig. 3. De Payta, an Pérou.

Cicindela tuberculata, Fab.; Dej., Sp., t. 2 , p. 43ı; Nob., Atlas, Insectes, pl. I, fig. 4. Du Port-Jakson et de la Nouvelle-Zélande.

Cicindela upsilon, Mac.-Leay; Dej., Sp., t. I, p. I26, et t. 2, p. 414. De la NouvelleHollande.

Megacephala carolina, Fab.; Dej., Sp., t. I, p. 9. De Lima.

Therates labiata, Fab.; Dcj., Sp., t. I, p. I58. Du Port-Praslin, à la Nouvelle-Irlandc, Bourou, Offack, la terre des Papous, et Dorey, Nouvelle-Guinée. Elle répand unc odeur de rose anälogue à celle du Cer. moschatus. Trouvée en aon̂t.

Therates basalis, Durv.; Dej., Sp., t. 2, p. 437 ; Nob., Atlas, Insectes, pl. I, fig. 6. De Dorey.

Tricondlyla aptera, Oliv.; Dej., Sp., t. 2, p. 438; Nob.; Iconogr. du Règne animal, Insectes, pl. III, fig. 3. Du Port-Praslin, Offack et Dorey. Elle habite les troncs d'arbres, et marche avec agilité; lc frottement du corselet rend un petit bruit. Trouvée en août ct septembre.

Cymindis australis, Durv.; Dej., Sp., t. I, p. 449; Nob., Atlas, Insectes, pl. I, fig. 7 . i) la Nouvelle-Hollande.

LÉBIE POSTICALE. Lebia posticalis. GuÉr. - Flavo-ferruginea, clytris striatis, fascia postica sinuata, nigra. Subtus pedibusque flavo-ferrngineis. - L. 10 mill., 1. 5 m. - Atlas, Insectes, pl. I, fig. 8, A. B.

Cette cspèce a quelques rapports avec le Carabus corticalis de Fabricius (Lebia corti- 


\section{ZOOLOGIE.}

ealis, Dej.). Sa tête et son corselet sont lisses, d'un ferrugineux un peu pâle. Les élytres sont striées, luisantes, rebordées, de la même eouleur, avec une large bande transverse noire, sinuée en avant et en arrière, et oeeupant presque toute leur partie postérienre, depuis le milieu jusque près de l'extrémité. Le dessous, les antennes et les pattes sont d'un ferrugineux pâle. Cette espèce rentre dans le genre Lia, établi par Esehscholtc dans son Atlas du Voyage de Kotzebue; elle a, comme les espèees de ee gemre, lavautdernier article des tarses bilobé, et les erochets dentelés en dessous; ses palpes présentent aussi les earactères de ce genrc. Elle a été trouvée à la Nouvelle-Hollande.

ANTARCTIE BRILLANTE. Antarctiu nitida. Guér.-Oblongo-ovata; capite thoraeque nigro-subaneis, elytris lavilus, nitentibus nigro-eupreo mieantibus. Pedibus nigricantibus, tibiis, tarsis, antennisque brunneo-ferrugineis.-L. 7 mill., l. $3 \mathrm{~m}$.-Atlas, Insectes, pl. I, fig. го.

Sa forme est ramassée, peu allongée, à côtés presque parallèles; la tête et le corselet sont d'un noir à reflets bleuâtres; ee dernier est transverse, un peu plus large que long, de la mêue largeur à ses deux extrémités, un peu arrondi sur les côtés, avec les impressions latérales postérieures, et une intermédiaire, peu marquées. Les élytres sont lisses, brillantes, sans stries, ou n'en ayant que de léger's vestiges à peine visibles à la loupe; leur couleur est bronzée, noirâtre, à reflets très-brillants verts-rouges ou bleus. Le dessous du eorps est noir, ainsi que les cuisses; les jambes, les tarses et les antennes sont d'un ferrugineux obscur. Cettc jolie espèce a été trouvée aux îles Malouines.

Antaretia blanda, Dej., Sp., t. 3, p. 529; Nob., Atlas, Insectes, pl. 1, fig. 9. De ha Conception, au Chili.

Antarctia flavipes, Dej., ibid., p. 533 ; Nob., id., pl. I, fig. $\mathbf{3} 3$. De la Coneeption.

Antaretia malachitiea, Dej., ibid., p. 534; Nob., id.; pl. I, fig. I4. Des îles Malouines.

Antaretia chilensis, Dej., ilid., t. 5, p. 805. Du Chili.

Antaretia femorata, Dej., ibid., t. 3, p. 535. Du Chili.

GEOBæNUS D'AUSTRALIE. Geobanus Australasice. GuÉr.-Ovatus; supra piceosubaneus, elytris tenue striatis, interstitio lavibus. Subtus, antennis articulo primo, basi tibiisque pallide flavis.-L. 7 mill., $1.3 \mathrm{~m}$.

Sa tête est triangulaire, plus étroite que le eorselet, d'un brun assez foncé, à reflets un peu cuivreux; le corselet est de la mêne coulenr, plus large que long, très-pen élargi sur les côtés et en avant, lisse, avec clenx fossettes postérieures bien marquées. Les élytres sont un peu plus pâles, lisses, avec des stries régulières, peu enfoneées, lisses; les interstiees ne présentent aucuus points enfoneés; on voit quelques légères impressions au bord postérieur. Ce geobærnus diffère essentiellement de la seule espèee décrite par MI. Dejean, tant par l'hahitation que par d'autres caractères faciles à saisir. Il a été trouvé à la Nouvelle-Hollande, sous les pierres. 
ACUPALPE BRUN. Aeupalpus piceus. Gứr.-Oblongus, nigro-piceus. Thorace subquadrato, rubro marginato, utrinque foveolato, foveis subviridibus. Elytris lavigatis, striutis, striis laevigatis; subtus ater, antennarum basi, pedibusque pallide ferrugineis. -L. 6 mill., l. 3 m.-Atlas. Insectcs, pl. I, fig. 12.

Sa tête est petite, lisse, noirâtre; les palpes sont pâles; les antcnnes sont brunes avec le premier et le second article pâles. Le corselet est un peu plus large que long, de forme carrée, avec les angles et les bords latéraux arrondis, sa couleur est noirâtre avec les bords ferruginenx; son disquc est un peu convexe, lisse, luisant, les fossettes sont assez bien narquées, un peu granuleuses et d'une couleur plus noire, à reflets verts et bleus. Les élytres sont un peu plus larges que le corselet, lisses, noirâtres avec l'extrémité plus brune; ellcs ont des stries lisses, bien marquées; et leurs bords sont un peu ponctués surtout en arrière. Le dessous du corps est noir. Les pattes sont d'un pâle ferrugineux. Il a étć trouvć au Port-Jakson.

TRECHUS DE LA SOLEDAD. Trechus soledadinus. GuÉr. - Alatus, ovalis, gibbosus, brunneo-pieeus, lavibus; thorace subcordato, utrinque foveolato, foveolis granulatis; elytris obsoletissine striatis, rotundatis, marginatis. Femoribus antennisque basi ferrugineis. - L. 5 mill., l. $2^{\frac{1}{2}}$ m. - Atlas, Inscetes, pl. I, fig. 15.

Son corps est convexe, épais, à formes arrondies, entièrement d'un brun foncć luisant; la tête est petite; le corselet est un peu en cœur, tronqué en avant ct en arrière, arrondi sur les côtés, et un peu plus étroit postérieurement. Les élytres forment un ovale assez court; elles sont rebordées, luisantes, lisses, avec quelques légers vestiges de stries plus apparentes vers la suture. Les cuisses sont d'un ferrugineux tirant au brun; les jambes et les tarses sont couleur de poix, ainsi que le dessous du corps. Il a étć trouvé dans la baie de la Soledad, aux îles Malouines.

TRECHUS D'AUDOUIN. Trechus Audouinï. Gú́r. - Apterus, elongatus, depressuls, rufo-piceus; capite magno; thorace cordato; elytris oblongis, subparallelis, lavigatis, obsoletissime sulcatis; antennis basi, pedibusque testaceis. - L. 5 mill., l. 2 nr. - Atlas, Insectes, pl. I, fig. 16 .

Son corps est entièrement d'un brun ferrugineux, un peu plus clair aux bords des élytres. La tête est forte, avec deux sillons longitudinaux au nilieu. Le corselet est allongé, de la largeur de la tête cn avant, rétréci en arrière, rebordé, avec les côtés presquc droits. On n’aperçoit pas de fossettes latćrales en arrière, mais son disque présente un sillon médian et longitudinal, bien marqué. Les élytres sont allongées, parallèles daus une partie de leur longueur, rebordćes, lisses, luisantes; on voit à la loupe des traces presque effacées de côtes assez distantes et un peu plus visibles vers la suture. 
Les pattes et les autennes sont d'un ferrugineux pâle. De la baie de la Soledad, aux Malouines.

BEMBIDION (LEIA) DU PORT JACKSON. Bembidium (Leia) Jacksoniensis. Guér. - Supra anelum; thorace transverso, subcordato; elytris oblongo-striatis; striis punctatis, apice flavo-quadrimaculatis. Pedibus antennisque rubro-brunneis. - L. 4 mill., l. $1 \frac{1}{2} \mathrm{~m}$. - Atlas, Insectes, pl. I, fig. 17 .

Sa couleur en dessus est d'un bronzé brillant; sa tête est petite, lisse, à reflets verdâtres. Les antennes sont pubescentes, d'un brun rougeâtre et plus pâles à leur base. Le corselet est de la même couleur, un peu plus large que long, rétréci en arrière, lisse et peu luisant. Les élytres sont oblongues, garnies de stries ponctuées, et ayant chacune à leur extrémité deux taches jaunes, dont la dernière termine l'élytre, et est bilobée en avant, et l'antérieure placée un peu au-dessus et vers le bord externe est plus petite et presque triangulaire. Le dessous du corps est d'un noir bleuâtre; les pattes sont d'un roussâtre un peu brun, avec les tarses plus pàles. Il a été trouvé au Port-Jakson.

DYTISQUE BORDÉ DE JAUNE. Dytiscus flavocinctus. Guḱr. - Brunneo-niger, capite transverso, ore, duabus maculis rubro-flavis. Thorace lavi, marginibus lateralibus linea transversa flavis. Elytris ovatis, margine punctisque rubro-flavis. Antennis pedibusque quatuor anticis ferrugineis, subtus brunneo ferruginess. - I. 13 mill., 1. 8. m.-Atlas, Insectes, pl. I, fig. r8.

Sa forme est ovale, un peu plus élargie en arrière. Le dessus est d'un brun obscur presque noir, lisse, assez luisant. La tête est large, le labre et le front sont ferrugineux ainsi que deux petites lignes transversales, courbées en arrière; le corselet est bordé de jaune des deux côtés, et présente au milieu une petite ligne transverse et maculaire de la même couleur. Les élytres sont bordées de jaune depuis l'épaule jusque près de leur extrémité. Cette bordure envoie un petit rameau crochu au-dessous de l'épaule, elle se dilate un peu plus bas que le milieu, et se termine par une autre dilatation arrondie. Entre cette dilatation et l'angle postérieur sutural, il y a une très-petite tache jaune. Leur bord antérieur présente à chacune deux taches jaunes dont l'extérieure virgulaire; il y a trois autres taches oblongues placées un peu plus bas que le milieu de l'élytre, celle du milieu étant un peu plus haut que les deux autres; enfin on aperçoit, vers l'extrémité et devant la dernière dilatation de la bordure extérieure, une petite tache oblongue oblique; le dessous est d'un brun ferrugineux ainsi que les pattes postérieures, les quatre pattes antérieures et les antennes sont d'un ferrugineux clair. Il a été trouvé à Dorey, dans la Nouvelle-Gunée.

Dytiscus lavigatus, Oliv. Notre individu a été trouvé à Lima; il constitue une petite variété chez laquelle les élytres présentent une tache rougeâtre à leur extrémité postérieure, 
COLYMBĖTE LINÉE. Colymbetes lineatus. GuÉR. - Ovatus, fuscus, thorace margine ferrugineis, elytris oblongis, striatis, subtus antennis pedibusque pallidioribus. - L. 6 mill., l. 3 m. - Atlas, Insectes, pl. I, fig. 19.

Son corps est ovale oblong; sa tête est brune avec le vertex d'un ferrugineux pâle. Le corselet est transverse, brun avec les côtés d'un ferrugineux brunâtre fondu avec la couleur dominante. Les élytres sout brunes, allongées et garnies de stries longitudinales bien marquées. Les antennes et les pattes sont plus pâles. Trouvé à Amboine.

GYRIN STHIOLÉ. Gyrinus striolatus. GuÉR. - Nigro-ceneus, ovatus, caruleo virescenti micans, elytris subtiliter transverse striatis, postice unidentatis; subtus pedibnsque nigris, posticis apice ferrugineis. - L. 16 mill., $1.8 \mathrm{~m}$. - Atlas, Insectes, pl. I, fig. 20.

Son corps est uu peu bombé, lisse, peu luisant, d'un noir bronzé à reflets bleus et verts; les antennes sont noires; le corselet est rebordé; les élytres laissent une partie de l'abdomen à découvert, elles sont rébordées jusque près de l'extrémité postérieure où le sillon marginal vient former nne petite dent obtuse; leur surface, vue à la loupe, présente une infinité de petites stries courtes, transverses, qui les font paraître comme écailleuses. Le dessous et les pattes sont noirs. Les quatre pattes postérieures ont leur extrémité et les tarses garnis de poils rougeâtres. Il a été pris au port Jakson.

STAPHYLIN APICICORNE. Staphylinus apicicornis. GuÉr.-Nigro-carnleus; capite transwerso, lavigato punctato; ore, mandibulis basi ferrugineis. Antennis basi rufis, medio nigris apice flavis. Thorace oblongo, postice rotundato, angulis anticis acuminatis, supra laerigato, vage punctato. Elytris bruneo-ceneis micantibus, subrugosis, villosis. Abdomine marginato, sabrugoso, villoso. Pedibus ferrugineis. - L. I 5 à I 7 mill., $1.4 \mathrm{~m}$. -Atlas, Insectes, pl. 1, fig. 2 I.

Ses antennes sont remarquables par les couleurs qui les ornent. Leurs trois articles basilaires sont rouges, les cin q suiviuts noirs, et les trois derniers d'un jaune d'ocre. Tout son eorpa est d'un noir à reflets bleus; les parties de la bouche, la base des mandibules et les pattes sont d'un rougeàtre ferrugineux; ses élytres sont d'un beau cuivreux rouge à reflets violets. Il a été trouvé à la Nouvelle-Guinée.

Staphylinus erytlerocephalus. Fab. Du port Jakson.

pÉDĖre A ÉLYTRES VIOLETTES. Paderus cyanipennis. Guér. - Ater, nitidus, elytris rugosis, eiongatis, cyaneis; antennis brunneis, basi ferrugineis. Pedibus atris. L. 9 mill., l. 2 m. - Atlas, Insectes, pl. I, fig. 22.

Tout son corps est $d^{\prime} u n$ noir brillant; sa tête est ponctuée, arrondie, un peu velue; 
les antennes sont brunes, pubescentes, avec les trois premiers articles rougeâtres; le corselet est globuleux, luisant, parsené de quelques points, un peu velu. Les élytres sont oblongues, rugueuses, d'un beau violet brillant. L'abdomen est noir, ruguenx, un peu velu, rebordé. Les pattes sont assez grêles, noires. Il a été trouvé à Lima, au Pérou.

PÉDĖRE AUSTRẠL. Paderus australis. Gúk.--Rufus, capite, apice abdominis pedibusque nigris; elytris cceruleis. - L. 6 mill. $\frac{1}{2}$, l. 2 m.- Atlas, Insectes, pl. I, fig. 23.

Cette espèce ressemble beaucoup au Pcederus riparius de notre pays; sa taille est la même, ainsi que la disposition de ses couleurs; mais les pattes sont entièrentent noires, tandis qu'elles sont ronges, à genoux noirs dans l'espèce européenne. Ce pédère a été pris an port Jakson.

ALÉOCHARE HÉMORRHOIDALE. Aleochara hoemorrhoïdalis. Gü̇.--Nigro-carulea; antennis fusiformibus; capite, thorace elytrisquc crebre punctatis. Abdomine nigro; apice ferrugineo. Pedibus atris. - L. 5 mill., 1. 2 m. - Atlas, Insectes, pl. I, fig. 24.

Cette espèce est grande dans son genre. Tout son corps est d'un noir bleu, peu luisant, ponctné. L'extrémité seule de son abdomen est d'un rouge ferrugineux. Elle a été trouvée au port Jakson.

BUPRESTE PRILLANT'. Buprestis radians. GuÉR. - Viridi-aurea; thorace, lateribus, arcuatis, maculis duabus impressis, magnis, aureis, nitidissimis; elytris serratis, lineis circa decem, paulum elevatis, interstitiis punctatis. Subtus pedibusque viridi-auratis. L. 27 mill., 1. $9^{\frac{1}{2}} \mathrm{~m}$.

Il ressemble beaucoup an $B$. smaragdula d'Olivier; mais il est un peu plus large, proportionnellement, d'un vertbrillant, tandis que c'cst le vert bleuâtre qui domine dans le B. smaragdula; la tête des deux espèces est déprimée en avant, et présente un petit sillon longitudinal; les antennes sont ćgalement noires avec les deux premiers articles verts. Le corselet de notre espèce est à peu près trapćzoide comme dans l’autre; mais chez le nôtre, il est sensiblement arqué sur les côtés, irrégulièrement ct peu granuleux en dessus, et prćsentant dcux larges fossettcs presquc lisses et dorées, tandis que dans l'autre espèce, ce corselct a les côtés droits, qu'il est régulièrement et fortement rugucux, et que ses fossettes latérales sont petitcs, irrégulic̀res, pelı apparentes et garnies des mêmes points enfoncés qu'on observe sur tout le corselet. Les élytres de notre espèce sont un peu plus larges en arrière, tandis que lc contrairc a licu dans le smarugdula; elles présentent huit ou dix lignes longitudinales, très-rapprochées, peu élevées, plus apparentes vers la suture, dans les intervalles desquclles on voit de petites fossettes peu profondes, qui sont elles-mêmes ponctnées. Ces élytres présentent un tout autre caractère dans le $B$. smaragdula; elles n'ont clıacunc que trois lignes élevécs, en n'y comprenant pas celle que bordent les élytres; 
ees lignes sont plus saillantes, d'une eouleur plus blcuâtre; leurs intervalles sont très rugueux, avec des points cnfoneés, dorés. Les pattes de notre espèee sont d'un beau vert, doré, très-brillant, tandis que eelles de l'autre sont d'un vert bleuâtre, un peu bronzées, ainsi que le dessous du corps; ce dessous, dans notre espèee, est d'un bean vert doré.

Ce beau bupreste a été trouvé au port Praslin, dans la Nouvelle-Irlande. M. le comte Dejean l'avait pris pour le smuragdula d'Olivier, mais ayant étudié avee soin la deseription d'Olivier et trouvé dans la collection de M. Chevrolat le véritable smaragdula, nous avons pu les eomparer, et reconnaitrc des différenees cntre eux. Nous en avons un individu beaueoup plus grand, venant de Bourou, (long de trente-deux millimètrcs) qui nous paraît être la fémelle, et que M. Dcjean a considéxé comme une espèce distincte (B. loevipennis de sa eolleetion); sa couleur est la mêmc, à l'exeeption des rcflets de ses élytres qui sont plutôt cuivrés que dorés. Les lignes de ces élytres sont aussi nombreuses, mais presque effacées; elles nc se manifestcnt que parce qu'elles sont bien lisses et sćparées entrc elles par dcs lignes de points enfoneés qu'on voit beaucoup mieux chez le mâle; dans celui-ci, le dernier segment présente une échancrure large en forme d'U, tandis que dans la femelle, eette éehancrure est plus petitc et en forme de V.

Nous avons découvert dans Voet, t. I, pl. 49, fig. ro, une bonne figure du Buprestis smaragdula d'Olivier. Cette figure ne parait pas avoir été eneore eitée.

BUPRESTE A FOSSETTES DORÉES. Buprestis auro-foveata. Gún. - Viridi-aurea, nitidissima; thorace, lateribus arcuatis; maculis duabus magnis impressis nitide aureis. Elytris serratis, costis tribus elevatis, viridibus; interstitiis aureo foveatis. Subtus pedibusque aureo-viridibus. - L. 28 mill., , l. 10 m. - Atlas, Inseetes, pl. II, fig. 2.

Cette magnifique espèee ressemble bien plus au B. smaragdula que notre B. brillant, mais elle en diffère par le eorselet qui présente les deux belles fossettes dorées et presque lisses dont nous avons parlé au sujet du bupreste brillant, et par les élytres sur lesquelles on observe trois véritables eôtes lien plus élevées que les lignes du $B$. smarag$d u l a$, et dans les intcrvalles desquelles on voit des fossettes dorées, irrégulières, eireonserites par des élévations vertes et vermieulaires. Il a été trouvé à Dorey, dans la NouvelleGuinée. Sa longueur est de vingt-neuf millimètres.

Buprestis scutellaris. Fabr. (g. Belinota. Esch.). De Bourou.

Buprestis bimaculata. Lin., Fab., Oliv. De Bourou.

Buprestis bimaculata. Var. $\beta$. Schon. app. ad syn. Ins., t. $\mathrm{I}, 3^{\mathrm{e}}$ p., pag. $12, \mathrm{n}^{\circ} \mathbf{1} 68$. De Bourou.

Buprestis leucosticta Kirly, stellulata. Dalm., Du Port-Jaekson. 
BUPRESTE A DOUZE GOUTTES. Buprestis duodecinguttata. Guér. - Cylindrica, nigro-carulea, subtiliter punctata. Thorace transverso, flavo-marginato : elytris posticc subacuminatis; punctis rotundatis deccm flavis. Subtus utrinque flavo quinque maculata. Antennis pedibusque caruleis. - L. I I mill., I. $4 \mathrm{~m}$.

Ce joli petit Bupreste ressemble un pen an Chrysosticta dc Kirby. Sa couleur est bleue foncée, plus noire en dessus; il cst très-finement ponctué; ses élytres sont rétrécies à partir du tiers postérieur, arrondies et finement denticulées au bout. Le corselet présente de chaque côté une bande jaune, plus largc postérieurement; les élytres ont chacune cinq petites taches rondes de la même conlcur, disposées ainsi : une an bord antérieur près de l'écusson; une autre aux trois quarts antérieurs dessous la précédentc, et plus près de la suture que du bord externe; une autre un peu au-dlessous du milieu, près du bord externe; deux un peu plus petites, et presque à la même hauteur; l'extérieure un peu plus bas. Enfin la cinquième près de l'extrémité et de la suture. Lc dessous est d'un bleu plus brillant; il y a de chaque còté cinq taches jaunes, dont la première cst grande, placée sur le métathorax; la seconde, également grande, est placée sur le premier segunent de l'abdomen; les trois antres beaucoup plus petites occupent le bord extérieur des trois segments qui suivent. - Du port Jackson.

BUPRESTE A ÉLYTRES GUIVRÉES. Buprestis cupreipennis. Guér.-Subtiliter rugosula; capite thoraceque viridibus; elytris rubro-cupreis, apicc subtiliter denticulatis. Antennis, corpore subtus, pedibusque viridibus. - L. 10 mill., $1.3 \mathrm{~m}$.

Son corps cst assez aplati, sa tête est verte, finement rugueuse, très-aplatie en avant. Le corselet est vert, transversal, très-finement rugueux, un peu plus large en avant, penché de chaque côté vers la tête, avec un petit sillon oblique près du bord. Les élytres sont d'un beau rouge cuivré, très-finement rugueuses, presque parallc̀les jusqu'aux deux tiers postérieurs, rétrécjes ensuite, et terminées par des dentelures très-fines. Les antennes, les pattcs et le dessous du corps sont d'un vert brillant et lisse. - Il a été trouvé au port Jackson.

BUPRESTE DE KIRBY. Buprcstis Kirbyi. Guśr. - Sub-dlepressa, capite thoraceque nigro-violacco, punctatis. Elytris striatis, obscurc carulcis, flavo trimaculatis. Subtus pedibusque caruleo vircscens. - L. 15 mill., l. $5 \frac{1}{3} \mathrm{~m}$.

Sa tête est petite; le corsclet est d'un violct noirâtre, transversal, un pell bombé, rétréci en avant, très-ponctué, avec les angles postérieurs aigus. Les élytres sont d'un bleu un peu noiràtre, luisantes, striécs, avec des points dans les intervalles; leur extrémité est terminée par une petite épinc; elles sont marquées chacune de trois taches transverses d'un jaune orangé, arrondies vers la suture ct ne la touchant pas tout-à-fait :

Voyage de la Coquille. Z Z. Tom. II, Partie 11. $\mathrm{r}^{\mathrm{re}}$ Div. 
lẹs deux antérieures sont réunies au bord externe; la première occupe tout le bord antérieur, la seconde est presque au inilieu, la troisième est sćparée des précédentes, placée près de l'extrémité des élytres. Le dessous et les pattes sont d'un bleu brillant tournant au verdâtre; les antennes sont d'un vert noirâtre. - Du port Jackson.

BUPRESTE CHILIEN. Buprestis chilensis. GuÉR. - Depressa, oblonga, viridi-nitens; capite thoraceque punctatis, albo-villosis; elytris striatis, flavis, nigro-maculatis. - L. 20 mill., l. $8 \mathrm{~m}$.

Ce joli Bupreste appartient probablement au genre Conognatha proposé par M. Eschscholtz dans l'atlas du voyage de Kottzebue (première livraison, page 9), et dans lequel il place comme types les Buprestis equestris de Fabricius, et Amoena Kirby. Ses antenues sont plus longues que la tête, d'un vert noirâtre. Le corsclet est transverse, arrondi sur les côtés, rétréci en avant, très-ponctué, avec des poils blancs assez rares; il est d'un vert bleuàtre à reflets violets, avec trois fossettes peu marquées au cìté postérieur. Les élytres ont des stries longitudinales de petits points enfoncés, entre lesquelles s'élèvent des còtes peu saillantes et moins marquées vers la base; elles sont presque parallèles, un peu élargies en arrière, d'un bcau jaune foncé de gomme-gutte, luisantes. Leur suture est finement bordée de noir. Il y a une bande longitudinale noire partant de l'anglc huméral, se dirigeant un peu en dcdans, et qui se recourbe ensuite en dehors pour se terniner au bord extérieur un pcu avant le milieu de la longueur de l'élytre. Cette bande laisse une tache jaune oblongue au bord antéricur externe. Au-dessous du milieu de l'élytre il y a une bande sinneuse ct interrompue, composée de trois taches, une au bord postérieur de chaque élytrc et l'intermédiaire triangulaire, commune aux deux, formée par deux prolongements de la suture. Au-dessous de cette bande, il y en a une autre plus large, entic̀re, arrondie en arrière, anguleusc en avant; enfin l'extrémité de chaque élytre est terminée par une petite tiche noire, commençant avec la bande précédente par le point noir de la suture. Le dessous et les pattes sont d'un beau vert brillant. - Il a été trouvé à la Conception, au Chili.

BUPRESTE JOLI. Buprestis bella. GuÉr.-Depressa, capite nutido, rufo-cupreo; thorace transverso; medio lavigato, cupreo, lateribus viridibus, punctatis. Elytris lavigatis, violaceis, basi et sutura punctato-viridibus, vittis lateralibus punctatis rubro-aureis. Antennis nigris, articulo primo viridi; corpore subtus pedibusque viridibus._-L. 12 mill., I. 5 n. - Atlas, Insectes, pl. II, fig. I.

Cette espèce est l'une des plus brillantes $d u$ genre. Sa tête est d'un rouge cuivreux très-brillant. Le corselet est d'un beau vert de chaque côté, ponctué, avec lc milieu lisse et cuivreux. Les élytres sont d'un beau violet luisant, lisses dans cette partie seụlement; elles ont une bande étroite verte et ponctuée à la suture, leur base est également verte ct ponctuée, et l'on voit au bord extérieur une large bande ponctuée 
et d'une superbe couleur d'or à reflets rouges très-brillants. L'extrémité des élytres est terminée par une troncature allant de dedans en clehors, et qui leur fait faire un angle rentrant. Elles sont très-finement denticulées au bord externe. Les antennes sout noirâtres avec le premier article vert. Le dessous du corps et les pattes sont verts. - Ce charmant Bupreste a été pris à la Conception, au Chili.

Buprestis albivittis. Germ., Ins., sp. nov., p. 39. — De Sainte-Catherine, au Brésil. Ce Bupreste a été nommé Marginicollis dans les collections.

PTÉROTARSE. Pterotarsus. Guér.—Atlas, Insectes, pl. II, fig. 3. A à F.

Nous avions d'abord pensé que l'insecte qui fait le sujet de cette nouvelle coupe entrait dans le genre Galba de M. Latreille, et nous lui avions donné ce nom dans la planche du voyage où nous l'avons figuré; mais depnis ce temps, M. Latreille a publié la partie entomologique dans la nouvelle édition du Règne animal, et nous avons pu nous assurer, par la comparaison des caractèrcs de notre insecte avec ceux que ce savant assigne à son genre Galba, que cette espèce ne peut entrer dans ce genre, et qu'elle nécessite l'introduction d'une coupe particulière.

Dans le tome IV, page 450 du Règne animal, M. Latrcille partage les Élatérides en deux grandes divisions, dont l'une renferme les genres qui peuvent loger leurs antennes dans des cavités, et l'autre ceux qui sont privés de cette faculté. Dans la première division il établit deux sous-divisions, la première pour ceux qui ont les antennes reçues dans des rainures pratiquées immédiatement sous les bords latéraux du corselet (voyez notre pl. II, fig. $3 b$ ), filiformes et simplement en scie, et où les articles des tarses sont toujours entiers sans prolongement, en forme de palettes en dessous; la seconde sous-division reuferme les insectes qui ont les antennes logées de même en partie dins les rainures longitudinales des bords latéraux dı présternum (voy. notre pl. II, fig. $7 i$.), ou dans des fossettes situćcs sous les angles postérieurs du corselet. Dans cette division, les tarses ont souvent de petites palettes formées par le prolongement des pelotes inférienres.

On voit par l'exposé des caractères présentés par M. Latreille, et en examinant les figures portant le $\mathrm{n}^{\circ} 3$ dans notre IIe planche, que notre genre appartient évidemment à la division qui doit avoir les antennes caclées dans des rainurés du corselet; qu'il apparticnt à la première sous-division par la situation de ses rainures, ct à la secondc par le prolongement inférieur de ses tarses. Il vient donc détruire ces deux sous-divisions et se placer entre elles. Voici les caractères que nous assignons à ce genre.

Corps convexe cylindracé (fg. 3). Mandlibules terminées par trois dents inégales. (fig. 3. B C ). Dernier article des palpes plus grand, tronquć obliquement à l'extrémité et terminé en liachc (fig. 3. D). Antenncs flabelliformcs ayant le premier article allongé (fig. 3. A), et se logeant, dans le repos, dans deux fossettes profondes situées sous les bords latéraux du corselet (fig. 3. F). Pattcs petites, tarses ayant leurs $2^{e}, 3^{e}$ ct $4^{e}$ articles entiers, prolongés en dessous en palettes allongées formées par le prolongcinent inférieur cles pelotes (fig. 3. E.). 
Le nom que nous avons assigné à ce genre nous a été proposé par notre célèbre maître M. Latreille, à qui nous avons montré l'insecte qui fait le sujet de cette notice. Les caractères que nous lui avons assignés plus haut le distinguent bien nettement des Galba et des Eucnemis, et il ne peut être confondu avec les Adelocera et les Lissomus, à cause de ses tarses, de la situation des fossettes et de ses antennes ${ }^{\mathrm{I}}$.

P'TÉROTARSE MARBRÉ. Pterotarsus marmoratus. Guér. -Cylindricus, nigro ccerulescens; thorace globoso, tuberculato, antice profonde emarginato, postice acuminato; elytris punctatis, obliqne sulcatis, apice spinosis, maculis nigris sericeis. Tarsis ferrugineis._L. I5 mill., I. 5. 1n. - Galba marmorata. Atlas, Insectes, pl. II, fig. 3.

La tête est petite, peu saillante, insérée dans une profonde échancrure du corselet. Celui-ci est un peu plus large que les élytres, très-ghlobuleux, très-penché sur les côtès, garni de gros tubercules arrondis. Les élytres sont allongées, plus étroites en arrière, terminées à la suture par une petite épine aiguë. Elles ont chacune quatre lignes élevées obliques, dirigées vers la suture, et des taches d'un noir velouté mat, dont les dernières en forme de bande transverse. - Cet insecte remarquable a été trouvé à la NouvelleGuinée.

A DELOCÈRE OBSCUR. Adelocera caliginosa. Guén. - Brunneo-subcastanea, villosa; tharace punctato, postice truncato, angulis posticis acuminatis; elytris crenatostriatis, lateribus rubescentibus. Antennis pedibusque brunneo rufis.-L. I3 mill., $1.4 \mathrm{~m}$. - Atlas, Iusectes, pl. II, fig. 7 .

Il a beaucoup de ressemblance avec l'Elater fuscus de Fabricius, qui a été trouvé à A mboine par Labiliardière, mais il est impossible d'acquérir une certitude à son sujet à cause de la brièveté de la description de cet auteur. La tête est de forme carrée, petite, insérée dans une échancrure du corselet. Celui-ci est à peu près aussi long que large, rétréci en avant, arrondi sur les côtés, bombé, avec des points enfoncés très-serrés et des poils courbés, courts, d'une couleur pâle. Les élytres sont profondément striées, avec l'intervalle de ces stries coupé par de petites lignes élevées transverses. Leurs côtes sont garnies de putits poils courbés qu'on observe sur le corselet. La couleur de ces élytres est brune, avec le bord extérieur un peu roussâtre. Les pattes sont petites et peuvent être reçues dans deș cavités du dessous du thorax; elles sont d'un brun roussâtre. Les antennes sont presque fauves, avec le premier article grand, comme on le voit dans la figure 7 B. - Cet insecte a été pris au port Jackson.

\footnotetext{
x C'est par' erreur que nous avons (Iconographie du R. A. Ius., pl. 12, fig. 2-3) renversé l'ordre de ees deux geures, en nommant Galba le Ptérotarse, et vice versa; nous avions suivi en rela la méthode d'Eschscholtz, présentée dans un tableau inédit: nous avons préféré, el rédigeant cet article, suivre la méthode publiée dans le Règne aninal par le cẻlèbre entomologiste français.
} 
TAUPIN A ÉPAULETTES. Elater scapularis. Gú́rin. - Capite thoraceque atris; thorace oblongo, convexo, punctato, medio impresso, angulis posticis spinosis; elytris punctato-striatis, rubro-castaneis, angulis anticis suturaque nigris. Corpore subtus pedibusque brunneo-castaneis. - L. 15 mill., 1. $3 \frac{1}{2} \mathrm{~m}$.

La tête est aussi large que le corselet, transverse, noire, ponctuée. Les palpes sont avancés, terminés en hachc. Les antenncs sont noires, pubcscentes, de la longueur de la tète et du corselet réunis, filiformes; le corselet cst de moitić plus long que large, bombé, un peu plus rétréci en avant, sillonnè au milieu, ponctué, d'un noir luisant, avec ses angles postćrieurs prolongćs en pointes assez allongées; l'écusson est noir, ovalaire longit udinal; les élytres sont luisantes, allongées, striées, très-fincment ponctuées avec des rangées de points plus enfoncés au fond des stries; vus à la loupe, ces points paraissent disposes par trois. Ces ćlytres sout d'un rouge marron couleur de terre de Sienne brûlée; leur suture est noirc ainsi qu'une très-petitc partie de leur bord extérieur, et il y a unc tache noire oblongue, placéc à l'angle externe et antérieur et ne formant pas le quart de leur longueur. Le dessous du corps est d'une couleur narronrongcâtre, avec le milicn du corsclet noir depuis le mcnton jusqu'à l'extrémité de l'épine postérieure. Lẹs pattes sont noirâtres avec les jambes et les tarses plus roussâtres. - Ce Taupin a èté trouvé au port Jackṣon.

TAUPIN CLAIRVOYANT. Elater perspicax. GuÉRrN. - Castaneus, glaber; capite minuto, fronte plana, subrugosa; antennis thorace brevioribus; thorace sub-quadrato, gibboso, lateribus rotundatis, angulis posticis acuminatis; postice maculis duabus rotundatis supra infraque flavis. Elytris substriatis elongatis, parallelis; postice sub-dilatatis. Corpore subtus pedibusque rufo-castaneis. - L. 17 mill., $1.5 \mathrm{~m}$.

Cette cspècc diffère essenticllement de toutcs celles de la même division par ses élytres qui s'élargissent un peu en arrière, tandis que le contraire a lieu chez les autrcs. Sa tête est très-pctite, avec lc chaperon transverse, et le front un pcu rugueux. Le corselet est deux fois plus large que la tête, aussi long que large, un peu plus étroit en avant, avec les angles postérieurs prolongés en épines. Les taches lumineuses sont grandes, rondes, occupant tout l'angle postérieur et touchant aux bords; elles paraissent en dessous. Les ćlytres sout deux fois et demie plus longues que larges, luisantes, à peine striées, rebordècs, un peu plus larges et arrondies au hout. Sa couleur est uniformément d'un narron un peu rougeâtre. Le dernier segment de l'abdomen est séparé du précédent par une membrane jaunàtre. - On l'a trouvé près de la Conception, au Clinili; il voltige sur les arbrisseaux.

TAUPIN EXOPHTALAE. Elater exophltalmus. Gú̉rix. - Elongatus, brunneus, griseo-pubescens, capite magno, transverso; fronte concava, rugosa; oculis prominentilus. Anternis villosis, tloorace longioribus. Thorace sub-quadrato, antice producto, rotundato; 
lateribus subrectis, angulis posticis spinosis; postice maculis duabus rotundatis, minutis. Elytris sub-parallelis, striatis, subtiliter punctatis, postice paulo dilatatis. - L. 20 mill., 1. $6 \mathrm{~m}$.

Cctte espc̀ce est surtout remarquable par la grosseur de ses yeux : sa tête est plus large que le corselet, avec le chaperou petit, arrondi, saillant. Les antennes sont aussi longues que la tête et le corselet pris ensemblc. Le bord antérieur du corselet se prolonge eu avant au-dessus de la tête et touche aux yeux; ce corselet est presque aussi long que large, un peu rétréci en avant, avec les côtés presque droits, peu convexe et très-finement granulé en dessus. Les angles postérieurs sont prolongés chacun en une épine aiguë divergentc. Les taches lumineuses sont rondes, petites, placées à une distance assez notable des bords latéraux et postéricurs. Les élytres sont presque trois fois plus longues que larges, un peu élargies vers l'arrière, et arrondies au bout. Le dessous, les pattes et les antennes sont d'un marron plus clair. - Trouvé à Sainte-Catherine, au Brésil ; il vole le soir près des haies et jette un éclat très-vif.

Elater Hunteri. MAK-Leay. - Du port Jackson.

CEBRION A ÉLYTRES ROUGEATRES. Cebrio rubripennis. Gú́rux. - Niger, elytris fusco-ferrugineis. Capite parvo; antennis filiformibus, articulo primo elongato, secundo brevissimo, caeteris elongatis aqualibus. Thorace gilboso, punctato, trapeziforni, postice sinuato, angulis acutis. Elytris convexis, elongatis, striato-punctatis, sub-villosis. -L. I I mill., l. 4 nı. (Genre Anelastes? Kirby.)

Cet insecte est en assez mauvais état ; il a perdu ses palpes et presque tous ses tarses. Son corps est plus épais que chez le Celrio" gigas; le corselet est étroit en avant, de la largeur de la tête, élargi en arric̀re, avec les côtés presque droits. Toute sa surface est couverte de points enfoncés très-serrés, à l'exception d'une ligne longitudinale un peu enfoncće, lisse et luisante, qu'on observe au milieu. L'écusson est presque carré. Les élytres sont presque parallèles, convexes, avec les angles huméraux arrondis et un peu saillants; leur largeur est un peu plus de deux fois dans leur longueur; elles sont couvertes de points enfoncés ct irréguliers, qui sont plus gros dans le fond des stries. Leur couleur est marron-ferrugineux, couleur de terre dc Sienne brûlée. Les antennes et les pattes sont brunes. Les tarses postérieurs sont filiformes. - Du port Jackson.

CALLIRHIPIS DE DEJEAN, Callirlipis Dejeanii. Latr. Règne anim., t. IV, p. 460. -Elongatus, castaneus, villoso-murinus; capite par'o, fronte prominula. Antennis ferrugineis, corpore panlo brcviorilus; thorace transverso, anice rotundato, postice truncato sinuato, linea longitudinali punctisque duobus impresso. Elytris subparallelis, punctatis, postice attenuatis, costis tribus antice subolsoletis, basi fossulis impressis. Scutello rotundato. - L. 18 raill., 1.6 m. - Atlas, Ins., pl. II, fig. 4 .

Les figures détaillćes que nous avons données de ce bel insecte nous dispensent d'une plus longue description. Voici l'cxplication de ces figures. - 4. Le C. Dejeanii de 
grand. nat. 4. $a$. sa tête grossie avec une antenne. 4. $b$. tête vue en dessous. 4. $c$. màchoire droite grossie, avec son palpe. 4. $d$, e. l'un des tarses grossi. - Ce magnifique insecte a été trouvé une seule fois à Amboine.

\section{Genre LYCUS, Lycus. Fab.}

Quoique M. Latreille ait déjà partagé ce groupe d'insectes en deux sous-genres, il nous a paru encore susceptible de division, depuis que les voyageurs ont rapporté un grand nombre d'espèces nouvelles qui ne rentrent pas exactement dans les coupes établies. Un jenne entomologiste, M. Delaporte, avait essayé, dans un mémoire cncore inédit, de former quelques genres nouveaux aux clépens des Lycus de Fabricius; nous avons aussi examiné cc grand genre, et nous avons reconnu qu'il est parfaitement naturel, et qu'on doit même y réunir les Omalises. Nous l'avons donc conservé tel que Fabricius l'a formé, nous bornant à le partager en coupes dont plusieurs correspondlent à des genres étalılis par M. Latreille ou par M. Delaporte; ces coupes ayant des noms, nous avons pensć qu'il fallait que toutes en eussent; ainsi elles pourront être considérées toutes comme autant de genres, si le nombre des espèces vient à s'augmenter par la suite.

Le geure Lycus, dans Fabricius (Syst. Eleuth.), se conıpose de 38 espèces; Schonherr en mentionne 6o; nous avons déjà vu dans les collections du Muséum, de MM. Gory, Percheron, Reiche et Desmarcst, 34 espèces nouvelles; ces 34 espèces, jointes aux 6o connues, forment un total de 94 . Nous les avons réparties dans onze divisions de la manière suivante :

I. Bouche portée à l'extrémité d'un prolongement rostriforme plus long que l'espace de la tête compris depuis le vertex jusqu'à l'insertion des antennes.

1. Troisième article des antennes au moins deux fois plus long que les suivants, ceuxci serriformes ${ }^{3}$ dans les deux sexes; élytres dilatées clıez les mâles.

$$
{ }^{\text {re div. (Lrcus. F.) }}
$$

2. Troisième article des antennes à peine plus long que les suivants; antennes pectinécs ${ }^{2}$ chez les màles; élytres parallc̀les dans les deux sexes.

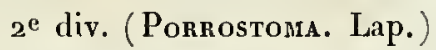

II. Bouche portée à l'extrćmité d'un prolongement rostriforme à peine aussi long que l'espace de la tête compris depuis le vertex jusqu'à l'insertion des antennes.

1. Dcuxième article des antennes aussi long ou plus long que large.

3e div. (Dictyoptera. Lat.)

- Les antennes en seie ou serriformes ont lenrs articles terminés intérieurement par un angle aigu.

2 Les autenues pectinées ont leurs arlicles terminés intélieurement par nu petit prolongement à peine de la longueur de l'arlicle qui le supporte. 
2. Deuxième article des antennes beaucoup moins longque large.

A. Quatrième article des antennes plus long que le précédent.

a. Dernier article des palpes maxillaires fortement sécuriforme. Antennes en scie dans les dcux sexes.

$4^{\text {e div. (Calopteron. Lap.) }}$

b. Dernier article des palpes maxillaires cylindrique et arrondi au bout. Antennes flabellées ${ }^{x}$ dans les mâles. 5e div. (Coptorhives. Nob.)

B. Quatrième article des antennes égal au précédent.

a. Palpes maxillaires aussi longs ou'plus longs que le bec; leur premier article apparent.

6e div. (Metriorhynchus. Nob.)

6. Palpes maxillaires plus courts que le bec; le premier article caché.

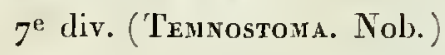

III. Tête n'étant point prolongée en bec.

1. Second article des antennes aussi long ou plus long que large.

A. Troisième article des antennes à peine plus long que lc second.

8e div. (Omalisus. Fab.)

B. Troisième article au moins deux fois plus long que le second.

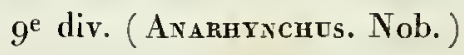

2. Second article des antennes beaucoup moins long que large.

A. Antennes seulcnient pectinées dans les mâles, io div. (ODontocrrus. Nob.)

B. Antcnnes flabellées dans les màles.

1 y div. (Ciadophorus. Nob.)

Les espèces appartcnant à ces divisions seront décrites dans un mémoire plus étendu que nous avons préparć et qui sera publié sous pcu dans les Annales de la Société entnmologique de France. Nous ne donnerons ici que l'indication des espèces rapportées par les voyageurs de la Coquille.

LYGUS APICAL, Lycus (Calopteron) apicalis. Nов. Revis. du g. Lycus, Ann. de la Snc. ent.-Ater; thorace croceo, medio nigro. Elytris ochraceis, apice nigris. Femoribus basi flavis. _ L. I 7 mill., 1. 8 m. _ De Sainte-Catherine, aı Brésil.

LYCUS PARALLĖLE, Lycus (Metriorhynchus) parallelus. Noв. Ibid. - Ochraceus; subtus ater, flavo-maculatus; capite, antennis pedibusque nigris, femoribus basi flavis. Elytris apice infuscatis. - L. 15 mill., 1. 4 n. - D'Offack, terre des Papous.

1 Les antennes flabellées ont le rameau interne de chaque artiele beaueoup plus long que cet article mème. 
LYCUS PORTE-SELLE; Lycus (Metriorlynchlus) ephiopiger. Guér. Ibid. -Oblon, gus, ater. Elytris ochraceis parallelis posticc nigris. - L. 16 mill., 1. $4 \mathrm{~m}$. - De Dory Nouvelle-Guinée.

LYCUS FUNESTE, Lycus (Metriorynchus) funcstus. Guér. Ilid. — Oblongus, ater; thorace elytrisque infuscatis; ely tris parallelis, lineis elcvatis subflavis. Alis nigris. — L. 19 mill. , I. 5 u1. — De Dory, Nouvelle-Guinée.

LYCUS BEAU, Lycus (Cladophorus) formosus. Guér. [bid. - Ater, thorace, elytris postica partc croceis. - L. I 4 mill., l. 4 m. - De Dory, Nouvelle-Guinée. - Cladophorus dimidintus. Atlas, Ins., pl. II, fig. 9 .

LYCUS SUTURAL, Lycus (Cladophorus) suturalis. Gúér. Ibid. _.. Elongatus, ater. Thorace subtus, elytrorumque margine suturali rufis. - L. I I mill., 1.3 m. - De Dory, Nouvelle-Guinée.

LYCUS A COL ROUX, Lycus (Cladophorus) ruficollis. Guér. Tbid. - Linearis, rllfescens; elytris abdomineque apice nigris. Femoribus apice, cruribus tarsisque nigris. Antennis infuscatis. - I. ro mill., l. 2 m. - D'Offak, terre des Papous. - Atlas, Ins., pl. II; fig. 8 .

LYCUS A COL JAUNE, Lycus (Cladophorıs) collaris. GuÉr. Ibid. - Totus ater. Thorace favo. Metathorace subtus puncto unico rufio.-L. 10 mill., 1. 3 m. - De Dory, Nouvelle-Guinée.

LAMPYRE DE PANZER, Lampyris (Photinus. Lap.) Panzcri. Guér. - Ovata, nigra. Antennis flabellatis, thorace maculis duabus anticis triangularibus, elytrisque humeris et fascia media lata flavis. Corpore pedibusque atris. - L. 16 mill., 1. 10 m.

Cette espèce ressenble beaucoup au Lainpyris flabellata de Fabricius, figuré par Voet, col. 1 , tab. 48, fig. 5 ; mais elle en diffère parce que la bande jaune, placée au delà du milieu des élytres, est plus large; par le janne, qui est aux angles antéricurs des élytres ou aux épaules clans notre espèce, tandis qu'il occupe le tour de l'écusson et ne va pas jusqu'aux angles huméraux dansle fabellata; le corps de cette dernière espèce est testacé, d'après la description de Fabricius, tandis qu'il est tout noir dans notre exemplaire. - Il a été pris à Sainte-Catherine, au Brésil.

LAMPYRE APLATI, Lampyris (Pliotinus, Lap.) deplanata. Guér. - Subovata, nigra; thorace semicirculari, flavo, disco nigro; antennis flabellatis nigris. Elytris nigris fascia lata flava. Corpore pcdibusque atris. - L. 14 mill., $1.7 \mathrm{~m}$.

Le corps, lcs pattes et les antennes sont noirs, le corselet cst large, arrondi en avant, trouqué en arrièrc, jaunc avec une tache noire centrale triangulaire large à la base et finissant en pointe à l'extrémité médiane du corsclet. Les élytres sont un peu élargies sur 
lcs eôtés, très-noires, avec une large bande jaune placée avantle milieu et envoyant du jaune jusqu’aux angles huméraux. Les ailes sont noirâtres. - De Sainte-Catherine, au Brésil.

LAMPYRE DE DELAPORTE, Lampyris Laportii. Guér. - Oblonga, fusca; antennis ramosis; capite obtecto, elytris lateribus exterioribus Ravis. Pedlbus fuscis, subtus flavis, tarsis flavescentibus, apice fuscis. - L. 12 mill., 1. $4 \mathrm{~m}$.

Cette espèce est très-voisine de eelle à laquelle nous avons donné le nom de Cladophorus lateralis, dans le Magasin d'Entomologie, $n^{\circ}$ i 1 . A cette époque nous n'avions pas encore bien séparé les Lycus des Lampyres, et nous avions eonfondu notre espèce avec une division des Lycus à laquelle nous avons donné le nom de Cladophore. Notre Lampyre de Delaporte est tout-à-fait brun; ses élytres sont légèrement rugueuses, la bande jaune qui règne sur leurs còtés extérieurs commence à l'épaule, où elle est très-mince, va ensuitc en s'élargissant jusqu'au milieu de la longueur de l'élytre, et se termine en pointe vers les trois quarts desa longueur. Les élytres sont un peu séparées à leur extrémité : les pattes sont brunes, leur tranche inférieure est jaune. Les tarses ont-les deux ou trois premiers articles jaunâtres, les autres sont bruns. - On a trouvé cette espèce a Sainte-Catherine, au Brésil.

LAMPYRE LATÉRA L, Lampyris ( Aspisoma. Lap.) lateralis. FAB. Syst. eleuth. t. II, p. 106.

LAMPYRE AUSTRAL, Lampyris (Lucciola. Lap.) australis. Guer. Ferruginea; thorace transwerso; capite, antennis elytrisque nigris, tarsis infuscatis. Abdomine segmentis duobus ultimis flavis, cateris nigris. - L. 1о mill., $4 \mathrm{~m}$.

Cette espèce ressemble beaucoup au Lampyris italica; sa tête est grosse, noire, avec les antcnnes filiformes, courtes, à peine aussi longues que la tête et le corselet. Le corselct est ronge-ferruginenx, deux fois plus large que long, arrondi en avant, ne recouvrant pas entièrement la tête, rebordé et très - finement rugueux. L'écusson est triangulaire, de la même coulcur. Les élytres sont oblongues, noires, rebordées, finement rugneuses, avec deux petites stries élevées, peu visibles, placées près de la suture. Le dessous dı thorax est ferrugineux, les pattes sont de la même couleur, avec l'extrémité des jambes et les tarses bruns. Les premiers segments de l'abdomen sont brunâtres, le quatrième très-noir, et les deux derniers jannes. - Il a été pris au port Praslin, à la Nouvelle-Irlande.

LAMPYRE MARGINIPENNE, Lampyris (Lucciola. Lap.) marginipennis. GuÉr. - Ferruginea, thorace transverso, capite antennisque nigris. Elytris nigricantibus, lateribus exterioribus ferrugineis. Subtus pedibusqueferrugineis, tarsis apice fuscis. Segmento ventrali antepenultimo flavo, penultimo emarginato. - L. 7 mill., 1. 2 m.

Il est très-voisin du préeédent ; sa tête est noire, grosse, à peine couverte par le corselet. Les antennes sont de la longueur du corselet et de la têtte. Le corselet est presque 
deux fois plus long que large, r'ouge. L'écusson est rouge. Les élytres sont rebordées, finement rugucuses, noirâtres, avec le bord extérieur bordé d'une ligne mince, ferrugineuse, qui n'atteint pas leur extrémité; tout le dessous est ferrugineux, l'avant-dernier article de l'abdomen est échancré en arrière, eelıi qui le précède est seul jaune. Les trois derniers articles des tarses sont brunàtres. - Trouvé à Offak, tcrre des Papous.

LAMPYRE A COL ROUGE, Lampyris (Lucciola. Lap.) ruficollis. GuÉr. - Ferruginea, thorace subquadrato, antice truncato, capite atro; antennis atris filiformibus: elytris elongatis, nigris, abdomine toto flavo, apice trilobo. - L. 6 mill., l. 2 m:

Cette petite espècc est encore très-rapprochée des précédentes; sa tête est assez grosse, noire; les antennes sont un peu plus longues que le eorselet et la tête. Le corselet est prcsquc earré, un peu plus large que long, rcbordé, d'un rouge-fcrrugineux et tronqué droit en avant et en arrière; l'écusson est petit, rouge. Lcs élytres sont oblongues, un peu rebordées, d'un noir luisant et prcsque lisses. Le dcssous du thorax est rouge : l'abdomen est entièrement jaune luisant, avcc l'extrémité terminée par trois lobes dont lintcrmédiaire est un peu échaneré au milieu. Les ailes sont noirâtres, les pattes sont fauves avec les derniers articles des tarses un peu bleuâtres. - De la Nouvelle-Guinée.

LAMPYRE A BOUT BRULE, Lampyris (Lucciola. Lap.) prceusta. Escr. - Entomographien, p. $57, \mathbf{n}^{\circ} 3$ o (Berlin, 1822 ).

Cette espc̀ce a beaucoup de rapport avcc le $L$. vespertina de Fabr.; il serait possible que ce fût la même.

TÉLÉPHORE A BOUT BRULÉ, Telephorts preastus. GuÉR. - Oblongus, luteus; antennis nigris articulo primo flavo; oculis nigris. Elytris apice nigris, tarsis brunneis. -L. 8 nill., I. $2 \mathrm{~m}$.

La tĉte est transversale, aussi large que le corselct; les yeux sont très-saillants. Le corsclet est presque carré, un peu plus largc que long, aplati; les élytres sont très-peu pubescentes, avec une ligne un peu enfoncée près de la suturc et le bord extérieur rebordé; le noir de leur extrémité n'occupe qu'un cinquième au plus de leur longueur. - De la Nouvelle-Guinée.

TÉLÉPHORE A ÉLYTRES POINTUES, Telephorus acutipennis. GUÉR. - Oblongus, obscure luteus, antennis brunneis, articulo primo basi flavo; oculis nigris. Elytris brunneis, attenuatis, sutura margineque obscure-flavis. Pedibus flavis, genibus tarsisque fuscis. - L. 9 mill., 1. $2 \mathrm{~m}$.

Les élytres dc ce Téléphore sont trc̀s-mollcs, plus étroites au bout et même roulées sur elles-mèmes; ellcs paraissent avoir deux lignes élevées, et toute leur surface est cou- 
verte d'un duvet très-fin. Leur couleur est brune, avec le bord extérieur, l'extrémité et la suture jaunâtres. Le dessous du corps est jaunâtre, les ailes sont brunes. - De Bourou.

TÉLÉPHORE DE SCHOEFFER, Telephorus Schofferii.Gú́R. - Elongatus, nigricans; capite, thorace femoribusque ferrugineis. - L. 8 mill., 1. $2 \mathrm{~m}$.

Ses antennes sont filiformes, presque aussi longues que le corps, brunes, avec la base du premier article rougeâtre. La tête est assez large, rouge, avec les yeux noirs. Le corselet est transverse, de forme presque carrée, un peu rebordé. L'écusson est triangulaire, rouge. Les élytres sont d'un noir un peu bleuâtre, avec les épaules trèsprononcées; elles sont lisses, luisantes : le thorax et l'abdomen sont noirs en dessous; les pattes sont noirâtres, avec les cuisses et les hanches ferrugineuses. - Du port Praslin. Nous lc dédions à l'entomologiste qui a le premier établi le genre.

TÉLÉPHORE DU CHILI, Telephorns chilensis. Guḱr.-Oblongus, nigro-subcceruleus, thorace rubro, disco maculis arcuatis nigris. - L. 9 mill., $1.3 \mathrm{~m}$.

Il ressemble un pen au Telephorus fuscus; ses antennes sont noires, un peu plus longues que la moitié du corps; le corselet est aplati, aussi long que large, luisant, rcbordé, garni de poils bruns; son disque présente une tache noire transverse qui envoie deux rameanx arçués vers le bord antérieur. Les élytres sont rugueuses, velues, d'un noir tirant un pcu sur le bleuâtre; le dessous et les pattes sont de la même couleur. - De la Conception, au Chili.

TÉLÉPHORE A ANTENNES DLLATÉES, Telephorus dilaticornis. GuÉr. - Oblongus, ater; antennis articulis basi dilatatis: thorace rotundato, flavo, margine et linea longitudinali nigris. - L. 3 mill., l. $3 \mathrm{~m}$. - Atlas, Ins., pl. II, fig. 5 .

La figure que nous donnons de cette espèce et les dćtails qui l'accompagnent nous dispensent d'une plus longue description; elle a été trouvée à la Conception, au Chili.

TÉLÉPHORE TRANSVERSAL, Telephorus transversalis. GuÉr. - Ovatus, stramineus; capite nigro, flavo-maculato, antennis atris, elongatis; thoraee subquadrato, marginato, lavigato, nigro-maculato. Elytris lavigatis, ovatis, complanatis, vitta transversali ultra medium nigra. Thoraeis subtus nigro, flavo-maculato; abdomine favo, pedibus anticis flavo-brumneis, posticis flavis, tarsisque brunneis. - L. I 1 mill., 1.5 m.

Sa tête est un peu avancée en bec, noire, avec les bords extćrieurs des mandibules et deux taches au dessus des antennes, jaunes. Les antennes ont un peu plus de la moitić de la longueur du corps; le dessous du thorax est noir avec quelques taches jauncs sur les côtés. Les ailes sont noires. Les élytres sont un peu divergentes à l'extrémité , et leur bande noire transverse est un peu sinueuse.-Du Brésil (SainteCatherine ). 
'TÉLÉPHORE JOLI, Telephorus pulchellus. GuÉr. - Oblongus, antennis et capite nigris. Thorace ovato, antice nigro-cyaneo, postice fulvo; elytriselongatis, pubescen s, rugosis, viridibus. Corpore subtus flavo, nigro-maculato; pedibus nigris. - L. I 3 mill., $1.4 \mathrm{~m}$.

Cette belle espèce paraît avoir été nommée par Mak-Leay, mais nous n'avons pu trouver à Paris l'ouvrage dans lequel il l'a décrite : il se pourrait qu'il n'eût assigné ce nom que dans sa collection; aussi, dans le doute, nous avons cru devoir donner une courte description de ce joli insecte. - On le trouve à la Nouvelle-Hollande. Il porte le nom de Cautharis pulchella dans les collections.

SILIS BORDÉ, Silis märginalis. Gvír. - Oblongus, atcr; antennis et capite atris; thorace sanguineo, transverso, postice bidcntato; elytris brunneo-nigris, subrugosis, lateribus linea angustata flava. - L. 6 mill.; $1.2 \mathrm{~m}$.

Ce petit insecte appartient bien certainement au genre Silis établi par Megerle, les antennes sont filiformes, presque anssi longues que le corps. Le corselet est luisant, arrondi en avant, avec deux échancrures sur les côtés, dont la postérieure est la plus profonde : cellc-ci est terminée en arrière par une lame arrondie, courbée en avant et formant presque l'échancrure dont nous venons de parler. La ligne jaunâtre qui borde les élytres extérieurement, est très-étroite au bord huméral, et s'élargit un peu au milieu pour se terminer en pointe avant d'atteindre l'extrémité. Le dessous du corps et les pattes sont noirs. - Trouvé à Sainte-Catherine, au Brésil.

'TYLOCÈRE A GRANDES AN'TENNES, Tylocerus antennatus. Guér. - Oblongus, luteus; capite, oculis palpisque flavis; antennis corpore longiores, articulo primo inflato, flavo; cateris brunncis. Thorace subquadrato, marginato, lateribus pellucido; elytris villosis, brunneo-flavis, sutura et marginibus pallidioribus. Pedibus elongatis, flavis, genibus tarsisque brunneis - L. 12 mill., 4 m,

Cordylocera antennata. Noв. - Atlas, Ins., pl. II , fig. 6.

I.orsque nous avons fait graver notre planche, nous n'avions pas encore pu nous procurcr l'ouvrage de Dalnuan (Analecta entomologica), et ignorant qu'il avait fait le genre Tyloccrus avec un insectc rle la Jamaique analogue au nôtre, nous avions été frappés des caractères quc nons observions dans notre espèce, et nous en avions formé notre gcnre Cordylocère. Nous adoptons actuellement le nom donné par Dalman; l'espèce qu'il a décritc diffère de la nồtre d'une manière notable, tant par la couleur que par Ic lieu d'habitation. Nous avons vu, dans la collection de M. Gory, deux espèces indiennes appartenant à ce genre, ct qui lui ont été envoyées de Londres; l'une d'elles porte une étiquette sur laquclle est inscrit le nom de genre Allocorinus Hoppe; il est probable que ce naturaliste a aussi établi un genrc avec cet insecte sans connaitre l'ouvrage de M. Dalmau. 
Genre LAIUS, Laius. Gú̇r.

Nous établissons ce nouveau genre pour un petit insecte très-voisin du Paussus flavicornis de Fabricius, que Dalman a reconnu appartenir au genre Malachius ou du moins en être voisin. Notre insecte diffère des Malachius par ses antennes, dont le premier article est au moins deux fois plus long que le troisième, tandis que dans les Malachius c'est à peine si le même article est un peu plus grand. La description que Fabricius donne de son Paussus flavicornis. convient presque à notre insecte; mais it dit que le corps est noir, tandis que celui du nôtre est tont bleu; il clit que la tête et le thorax de son espèce ont des poils cendrés, nous n'observons rien de semblable; enfin les élytres sont brillantes dans son insecte, chez le nôtre leur couleur est d'un bleu mat, à peine luisant. Dalman (Analecta entomol., p. so3 et s04) a reconnu le premier que l'insecte décrit par Fabricius se rapprochait des Malachius; il a vu l'espèce décrite par Fabricius, et a pu vérifier que les articles des tarses sont au nombre de cinq.

LAIUS BLEU, Laius cyaneus. GuÉr. - Oblongus, cyaneus, antennis brevibus, articulo primo, secundo et tertio ferrugineis. Thorace postice angustior, lateribus rotundato, antice truncato; elytris lavibus, elongatis; subtus pedibusque cyaneis. - L. 5 mill., l. 2 m. - Atlas, Ins., pl. II , fig. ro. - De la Nouvelle-Guinée.

Nous rapportons à ce genre l'espèce décrite par Fabricius sous le nom de Paussus

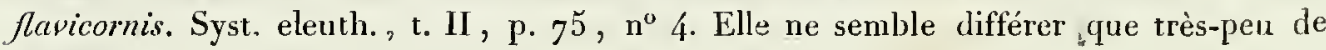
là nôtre.

MALACHIE JOLI, Malachius bellulus. Gự́r. - Capite cyaneo; antennis pedibusque nigris. Subtus cyaneus; thorace rufo rotundato, postice subangustato, elytris rugosis cyaneis nitidis, vitta transversali maculaque apicali rufis. - L. 5 mill., , $1.2 \mathrm{~m}$.

Cette jolie petite espèce a quelque affinité avec le $M$. Laetus; mais ellc en diffère par la disposition des couleurs. La bande transverse de ses élytres est placée un peu plus bas que le milieu, elle est un peu sinueuse, dilatée aux bords. La petite tache de l'extréunité touche à la sutıre et forme avec celle de l'élytre opposèe une petite lunule. Les ailes sont enfumées. - Du port Jackson.

Necrobia rufipes. FAB. - Nous avons deux individus de cette espèce; l'un provient du port Jackson ; l'autre de la Conception, au Chili.

Necrobia ruficollis. FAB. - De la Conception.

Hister speciosus. $\mathrm{P}_{\mathrm{A} \text { Y }}$. Monogr. - De la Nouvelle-Hollande.

ONTHOPHAGE AUSTRAL, Onthophagus australis. Gú́r. - Thorace mutico : clypeo lamina erecta; lateribus hujus lamince cornibus duobus integris. Capite thoraceque subviridibus, corpore, pedibus elytrisque nigris. - L. 20 mill., $1.6 \mathrm{~m}$.

Cet Onthophage ressemble beaucoup à l' $O$. Dama de Fabricius; mais il en diffère par 
la couleur de son corps qui est noire, avec le corselet et la tête verdàtres, et surtout par la forme de ses cornes : dans le Dama, elles ne sont pas réunies par une petite lame élevéc, et chacune d'elles présente au còté externe une petite dent placée vers l'extrémité; dans notre espèce, les cornes sont entières, et lintervalle qui les sépare est rempli par une petite élévation en forme de lame, dont le milieu est un peu échancré. Les élytres denotre insecte sont striées; sa tête est ponctuée, avec les antennes jaunes. - De la Nouvelle-Hollande.

\section{Genre ORYC'TOMORPHE, Oryctomorphus. GuÉr.}

L'insecte qui sert de type à ce nouveau genre offre beaucoup d'analogie avec les Oryctes, surtout avec ceux de l'ancien continent, tels que les $O$. Silenus, Orion, etc., insectes qui ne pcuvent rester dans le même genre que les Oryctes nasicornis, boas, rhynoceros, etc.: en effet, dans ces dernières espèces, les antennes sont très-courtes, avec les articles intermédiaires entre la massue et le premier presque égaux, plus courts que larges; leur chaperon couvre presque les mandibules, qui sont épaisses et peu saillantes, tandis que dans les O. Sylenus, Orion, etc., les mandibules sont aplaties, dilatées en dehors et très-suillantcs; ces insectes ont bien à peu près la uıême antenne que les espèces dont nous avons parlé précédemment, mais leırs tarses antérieurs présentent une particularité remarquable que nous avons observée, quoique modifiée, dans notre genre Oryctomorphe; les crochets de ces tarses sont inégaux, extrêmement courbés, l'externe étant plat, large, et en forme de lanière crochue, tandis que dans les Oryctes nasicornis et autres, ces croclıets sont égaux et de forme ordinaire. Dans notre nouveau genre, la mềme différence s'observe dans les crochets des tarses antérieurs; mais le plus grand est bidenté au bout : il diflère anssi des autres Oryctes en ce que ses antennes sont plus longues, avec les $2^{\mathrm{e}}, 3^{\mathrm{e}}, 4^{\mathrm{e}}$ et $5^{\mathrm{e}}$ articles beaucoup plus longs que larges, cylindriques, tandis quc les deux suivants sont très-courts, dilatés en dedans comme pour commencer à former des lames, et que cenx qui forment la massue terminale sont très-allongés comme dans certains hannctons. Nous allons comparer ces caractères dans les trois genres que uous sonınies obligés de former avec les Oryctes.

I. Chaperon bilobé rccouvrant les mandibules, qui sont arrondies, épaisses et non dilatées sur les côtés.

a. Antennes courtes, à peine aussi longues que la tête, avec les $3^{\mathrm{e}}, 4^{\mathrm{e}}, 5^{\mathrm{e}}, 6^{\mathrm{e}}$ et $7^{e}$ articles très-courts, presque égaux. Crochets de tous les tarses égaux, simples.

Genre Oryctes. Illig.

b. Antennes allongées, plus longues que la tête, avec les $2^{\mathrm{e}}, 3^{\mathrm{e}}, 4^{\mathrm{e}}$ et $5^{\mathrm{e}}$ articles allongés, les $6^{\mathrm{e}}$ et $7^{\mathrm{e}}$ courts et dilatés en dedans. Crochets des tarses antérieurs très-inégaux, l'externe plus grand ct bifide.

Gente Oryctoxorphus. Giér. 
II. Chaperon ne recouvrant pas les mandibules; celles - ci dilatées au côté extérieur. Antennes courtes, avec les $3^{\mathrm{e}}, 4^{\mathrm{e}}, 5^{\mathrm{e}}, 6^{\mathrm{e}}$ et $7^{\mathrm{e}}$ articles très-courts, presque égaux. Crochets des tarses antérieurs très-inéganx, l'externe plus grand, aplati, tronqué et entier an bout.

Genre Oryx. Guér.

ORYGTOMORPHE A DEUX TACHES, Oryctontorphus binaculatus. GuÉr. - Ferrugineo-piceus, capite tuberculato; antennis elongatis decem-articulatis. Thorace inermi, antice sub-excavato, punctato, nitido; scutello triangulari. Elytris elongatis, punctatis, basi rubro-bimaculatis; corpore subtus pedibusque villosis.-- L. 25 mill., $1.8 \mathrm{~m}$. - Atlas, Ins., pl. III, fig. 3 .

Cet insecte curieux parait être une femclle; il est probable que le mâle, comme dans l'O. Silenuls, offre quelques inégalités au corselet, et une corne sur la tête : du reste, il paraît que ses mocure sont les mêmes : il a été trouvé mort dans des pelouses arides; c'est toujours ainsique rous avons trouvél'O. Silenusà Toulon. La figure que nous donnons de cet insecte nous paraît suffisante pour nous dispenser d'une description plus éten. due. - Il a été trouvé à la Conception, au Chili.

SCARABÉE GÉDÉON, Scarabaus Gedeon. Livn. Syst. nat., p. 55 r , ${ }^{\circ}{ }_{2} .-$ ScHon. Syn. ins., t. I, p. 3, no $^{\circ}$.

L'individu rapporté par M. d'Urville a été pris au port Praslin, dans la Nouvelle-Irlande; il ressemble entièrement aux individus Ggurés jusqu’à présent, à l'exception de la corne de sa tête, qui n'offre pas au milieu et en dessus la clent qu'on voit chez les espèces rapportées de Java et du Bengale, et décrites par les auteurs. Dans notre échantillon, cette dent n'existe pas, et la corne est uniformément courbée. On pourrait ne considérer cette différence que comme une variété locale : cependant si la femelle offrait aussi une différence notable, on serait obligé d'en faire une nouvelle espèce; nous proposerons alors de lui donner le nom de Scarabaus Ulysses. Guér.

SCARABÉE AGEON, Scarabceus Ageon. Fab. Oliv. Lat. Voy. de Humboldt., Zool., t. I, p. 182, pl. 17, fig. 6. Voyez notre Atlas, Ins., pl. III, fig. 2.

Nous avions figuré cette espèce, croyant trouver dans l'allongement de ses pattes antérieures un caractère suffisant pour la séparer des autres scarabées, et pour la placer dans le genre Agacéphale de Manerheim; mais les parties de la bouche, en tout semblables à celles des Scarabées proprenient dits, nous ont déterminé à le laisser dans le genre Scarabée. - Il a été trouvé à Lima, sur la côte du Pérou.

SCARABÉE A PATTES LARGES, Scarabaus latipes. GuÉR. - Oblongus, nigro-piceus; capite inermi, antice rotundato; thorace antice excavato cornuque brevi antico, recto. Scutellum triangulare. Elytris striato-punctatis, apice lcevissimis. Corpore subtus 
ferrugineo-brunneo, piloso; pedibus anticis apicc dilatatis.-L. 24 mill., I. 12 m. - Atlas, Ins., pl. III, fig. I.

Il ressemble un peu à un Oryctes pour la forme; sa tête est peqiite, mutique, arrondie en avant et finement granulée en dessus; elle est reçue dans une échancrure du corselet. Les antennes sont très-courtes, brunes. Lc corselet est plus large que long, arrondi sur les côtés, tronqué presque droit cn arrièrc, avec une dépression profonde en avant et une petite corne droite au milieu de son hord antéricur. Toute sa surface est finement ponctuce, et le fond de l'excavation est plus rugueux. L'écusson est triangulaire. Les élytres sont oblongues, arrondies au bout, très-luisantes, avec une ligne de points qui règne tout du long des côtés de la sıtture, et plusieurs autres stries de points obliques et n'atteignant pas jusqu'à leur extrémité. Les pattes antérieures sont remarquables par leur extrémité dilatée, avancće, creusée en cuiller en dessous, ayant deux dents très-obtuses au còté externe et une fortc épine en dedans; les tarses sont insérés sous le prolongement terminal. Les autres pattes sont fortes, garnics de dentelures et d'épines comme dans les autres espèces. Le dessous du corps est d'un ferrugineux brunâtre, garni de poils roux. - Il a été pris au port Jackson.

SCARABĖE COURT, Scarabaus curtus. "GuÉr. - Nigro-brunncus, ovatus, antice angustior. Capite cornu brevi, clypeo marginato; thorace nigro lavigato, marginato, antice submucronato; scutello triangulari; elytris rufo-brunneis, postice sub-dilatatis, profunde punctato-strialis, postice lateribusque punctatis. Corpore subtus brunneo-rufo; villoso abdomine articulo ultimo basi Ravo. Pedibus validis, anticis extus tridentatis.-L. 20 nill., I. $12 \mathrm{~m}$.

Ce Scarabée offre une forme conique plus large en arrière. Sa tête porte une petitc corne un peu courbée en arrière; le chaperon est rebordé, tronqué transvcrsalement en avant, arrondi aux angles. Le corselet est presque noir, échancré en avant pour recevoir la tête, élargi en arrière, avec le bord postérieur un peu sinué, et les côtćs rebordés et garnis en dessous de poils rougeâtres. Sa partie antérieure offre une petite dépression au milieu dc laquelle on observe une petite ligne intprimée. L'écusson est petit, triangulaire; les élytres sont plus larges en arrière, d'un brun rougcâtre, luisantes, avec une ligne enfoncée et ponctuée près de la suture et régnant jusqu’à leur. extrémité; on voit ensuite six ou sept autres lignes très-cnfoncées à la base, diminnant vers l'extrémité, garnies de points dans leur longueur; et les bords externe et postérieur sont ponctués irrćgulièrement. Les pattes sont de forme ordinaire, les antérienres offrent trois dents olutuses au còté externe. Le dessous est plus rougcàtre avec des poirits fauves. - Du port Jackson.

\section{Genre BRACHYSTERNE, Brachysternus. Gú́R.}

Ce genre présente les plus grands rapports avec les Anoplognathes; mais il en diffère par l'absence d'une pointe saillante au sternum du mésothorax, par la formc de ses royage de la Coquille. - Z. Tom. II. Parlie II. $\mathrm{I}^{\mathrm{re}}$ Dir. 
palpes, et surtout par les crochets des tarses, dont l'un est bifide, ce qui n'a jamais lieu chez les Anoplognathes; voici les caractères essentiels de ce genre:

Antennes (fig. 4 B) de dix articles, le premier conique, épais, le second beaucoup plus petit, également épais ; les quatre suivants allongés, presque cylindriques, diminuant un peu de longueur jusqu'au septième, qui est en forme de croissant, plus large que long, et qui donne attache à une massue lamellée allongée, formée de trois articles. Mandibules très-comprimées, courtes, cornées, cachées dans la bouche, et ne laissant voir qu'une tranche étroile à l'extérieur. Labre (fig. $4 \mathrm{~A}$ ) mince, triangulaire, son angle antérieur dirigé en arrière et touchant l'angle correspondant du milieu de la lèvre inférieure. Mandibules (fig. 4 C) courbées et arrondies au bout, mutiques, avec le bord supérieur externe un peu creusé en gouttière. Palpes (fig. $4 \mathrm{C}$ ) maxillaires filiformes, avec le dernier article ovalaire, renflé au nnilieu; lèvre inférieure presque carrée, un peu avancée au milieu; palpes labiaux courts, insérés de chaque côté dans une échancrure supérieure des bords latéraux, composés de trois articles, dont les deux premiers courts et le dernier ovalaire, plus grand que les deux précédents. Tête presque carrée, avec le chaperon arrondi en avant, rebordé; yeux ronds, un peu saillants. Corps un peu convexe, ovalaire. Écusson distinct, presque triangulaire, à côtés arrondis. Élytres recouvrant des ailes. Extrémité de l'abdomen découverte dans un très-petit espacc. Sternum du mésothorax présentant un petit tubercule qui n'atteint pas la base des cuisses. Pattes peu fortes, jambes antérieures tridentées au còté externc. Tarses assez longs, avec les quatre premiers articles allongés, coniques, le cinquième plus grand, courbé, renflé et terminé par deux crochets inégaux, dont l'interne est le plus petit, et dont l'externe est bifide au bout. On voit par tous ces caractères que notre nouveau genre diffère bien sensiblement des Anoplogñathes, et quil ne peut entrer ni dans le genre Lencothyreus, ni dans celui d'Ambyltherus, qui en sont les plns voisins. Le nom que nous lui assignons vient des mots grecs Bpayus, court, et oréprov, sternum.

BRACHYSTERNE VERT, Brachysternus prasinus. GuÉr. - Oblongo-ovatus, nitidus; crpite thoraceque viridibus, punctatis; thorace linea impressa longitudinali. Elytris viride-lutescenti, striato-punctatis; corpore subtus, antennis pedibusque rubro-viridibus micantibus, albo-villosis. - L. 20 mill., I. 10 m. - Atlas, Ins., pl. III, fig 4.

Cette espèce est d'un joli vert tirant un peu sur le jaune, surtout aux élytres; sa tête est un pen plus longue que large, ponctuée, avec le chaperon rebordé et rongeâtre au bord. Le corselet est plus étroit que les élytres, plus large en arrière qu'en avant, sinué śur les bords latéraux et avancé en arrière au milieu; son disque est ponctué et présente au milieu une ligne longitudinale enfoncée. L'écusson est petit, vert. Les élytres sont ovales, très-brillantes, avec des stries de points assez peu enfoncés. Les ailes sont transparentes, avec les nervures brunàtres. Le dessous du corps, les pattes et les antennes sont d'un rouge cuivreux, avec des reflets verts; toutes ces parties sont garnies de poils très-blancs, courts, à l'exception du métatlorax, où ces poils sont longs et duveteux. - Ce joli insecte a été trouvé à la Conception, au Chili. 
Genre HADROCÈRE, Hadrocerus. Gú̉́r.

L'insecte qui forme le type de ce nouveau genre ressemble au premier coup d'ail à un hanneton, et ce n'est qu'en étudiant avec soin sa bouche qu'on voit des différences notables qui ne permettent pas de le classer dans ce genre et dans ceux qui ont été établis à ses dépens. Voici les caractères que nous lui avons observés :

Antennes (fig. $8 \mathrm{~B}$ ) de neuf articles, le premier très-grand, conique; le second petit, ovalaire, renflé; le troisième allongé, presque cylindrique; le quatrième presque égal au second, renflé; les cinquième et sixième très-dilatés extérieurement, cupuliformes, beaucoup plus larges que longs; et les trois derniers formant une massue lamellée, oblongue et étroite; labre très-petit, caché sous le chaperon; mandibules (fig. 8. 2) en forme de feuillets, très-minces, pointues au bout, cachées. Mâchoires (fig. $8 \mathrm{~A}$ ) courtes, épaisses, comprimées, avec leur lobe terminal très-court, comme tronqué, sans dents, garni de poils roides. Palpes maxillaires longs, insérés près de l'extrémite des mâchoires, de quatre articles; le premier très-court ; le second long, cylindrico-conique; le troisième plus court, de mème forme; le quatrième plus long que le second, renflé au milieu et surtout au còté interne, et un peu tronqué au bout. Menton (fig. $8 \mathrm{~A}$ ) trèsproéminent, avancé, plus long que large, arrondi an bout, avec la languette peu saillante, et portant des palpes filiforntes courts. Tête presque carrée, avec le chaperon transverse, rebordé, un peu arrondi en avant. Corps allongé, cylindracé ; écusson triangulaire; élytres recouvrant des ailes et laissant très-peu de l'extrémité de l'abdomen à découvert. Point de saillies sternales sous le corps. Pattes assez fortes, avec les tarses longs, à articles cylindrico-coniques, allongés, et dont le dernier est terminé par deux crochets égaux et bifides (fig. $8 \mathrm{C}$ ).

On voit par l'ensemble de ces caractères, que notre genre diffère notablement des Pachypus par le nombre des articles des antennes et par les crochets des tarses, qui sont simples dans ces insectes. Il ne peut être confondu avec les Amblytherus, chez lesquels le chaperon est très-saillant et va se joindrèà la lèvre inférieure, comme dans les Anoplognathes. Enfin il est éloigné des Macrodactyles, hannetons et autres genres voisins, par l'absence des dents aux màchoires. Son nom est forıné de ḋọós, épais, renflé, et de xśpxs, antenne.

HADROCÈRE A ÉLYTRES MARRON, Hadrocerus castaneipennis. Gú́r. - Oblon_ sus, sub-cylindricus; capite thoraceque nigro-2irescenti, punctatis, nitidis; elytris castaneis, striatis, striis profunde punctatis. Corpore subtus, pedibusque brunneis. - L. 10 mill., 1. 4 m. $\frac{1}{2}$. Atlas, Ins. , pl. III, fig. 8 .

Son corps est allongé, glabre, luisant : la tête est d'un noir à reflets verdâtres, avec le milieu un peu rougeâtre. Les antennes sont d'un brun-rougeâtre; le corselet est presque aussi long que large, arrondi sur les côtés, convexe, ponctué. Les élytres sont fortement striées, avec des points au fond de chaque strie. Les pattes antérieures ont la jambe 
munie de deux dents au côté externe; tous les tarses sont plus longs que les jambes. - De Saintc-Catlıerine, au Brésil.

CERASPIS DU PÉROU, Ceraspis peruvianns. Goér. -Oblongus, subcylindricus, castaneus, flavo-villosulus; thorace subhexagono, postice bidentato; scutello oblongo, ovali, albo-tomentoso. Elytris elongatis, taevigatis, villosis. Subtus, pedibusque concoloribus ; tarsis elongatis. - L. 1o mill., , 1. 4 m. - Atlas, Ins., pl. III, fig. 7 .

Cette espèce appartient bien évidenment au genre Ceraspis établi par MM. Lepelletier de St-Fargeau et Serville; mais il parait que ces entomologistes n'ont pas suffisamment examiné les antennes de ces insectes, car ils leur donnent dix articles, tandis que nous n'en avons jamais vu que neuf dans quatre espèces que nous avons observées, et parni lesquelles il se trouve le Ceraspis pruinosa de ces auteurs : nous avons aussi trouvé tous les croehets des tarses bifides: pcut-être n'avons-nous vu que des femelles. Quoi qu'il en soit, notre espèce offre bien tous les autres earaetères des Cercaspis, et surtout eelui qui est le plus visible et qui consiste en trois dentelures au bord postérieur du corselet. Sa tête est petite, presque carrée, converte de poils très-serrés et jaunàtres. Le eorselet est aussi long que large, ses côtés forment un angle au milieu, ce qui lui donne une forme lhexagonale assez bien prononcée. Il est couvert de poils jaunes roides, courts, dirigés vers le milieu, et venant former par leur jonction une petite crête longitudinale sur la ligue médiane. L'écusson est oblong, blanc à cause du duvet serré dont il est eouvert; il offre à sa base trois petites éehancrures pour recevoir les dents de la base du corselet. Les élytres sont allongrees, un peu élargies au milieu, couvertes de poils trèsconrts jaunâtres. Le dessous et les pattes sont également velus. La couleur de toutes les parties du corps est d'un marron clair. Les tarses sont plus longs que les jambes, armés de deux crochets bifides et égaux. - De Lima, au Pèrou.

\section{Geure LIOGENYS, Liogenys. GuÉRIN.}

Ce genre est intermédiaire entre les Apogonies et les Géniates de Kirby: il tient des premiers par ses antennes composées de dix articles, et des seconds par ses mâchoires, dentées en dedans, et par l'extrémité de ses mandibules, qui est échancrée; vọici les earactères de ce genre:

Antennes (fig. 6 B) de dix articles, le premier grand, épais au bout, un peu dilaté en dehors; le seeond plus petit, de la mềme forme; le troisième égal au seeond, conique; le quatrième plus eourt, conique; les $5^{\mathbf{e}}, 6^{\mathrm{e}}$ et $7^{\mathrm{e}}$ encore plus eourts, dilatés en dedans; le $7^{\mathrm{e}}$ le plus large de tous; massue composée des trois derniers articles formant les feuillets, ovale, oblongue, un peu pointue. Chaperon échancré en avant ; labre avancé en un angle qui tend à se rapproeher de la lèvre inférieure; mandibules (fig. 6 D) arquées, bidentées au bout, eornées; mâehoires (fig. $6 \mathrm{~A}$ ) fortes, avec le lobe terminal tronqué au bout, armé en dedans de trois fortes dents crochues; palpes maxillaires (fig. $6 \mathrm{~A}$ ) très-grands, insérés presqu'à l'extrémité des mâehoires, ayant le pre- 
mier article court, le second au moins trois fois plus grand, cylindrique, un peu renflé au milieu ; le troisième plus court, plus épais; le quatrième beaucoup plus grand, presque anssi long que les deux précédents, très-renflé, ovoïde, presque pointu au bout. Menton ou lèvre inférieure presque carrće, un peu échancrée au milieu, avec les palpes labiaux très-petits et insérés aux angles latéraux et antérieurs. Corps épais, convexe; corselet transversal avec les bords latéraux arrondis. Élytres oblongues, recouvrant des ailes et laissant l'extrémité de l'abdomen à nu. Pattes assez fortes, avec les tarses plus longs que les jambes, ayant leurs articles (fig. $6 \mathrm{E}$ ) allongés et obconiques, les antérieurs ayant leurs quatre premiers articles dilatés dans les mâles, tous les crochets (fig. 6 C) égaux, ćlargis au bout et bifides. Le nom de ce genre vient des mots dexios, nu, Yśvos, menton.

LIOGENYS MARRON, Liogenys castaneus. GuÉR. - Rufo-castaneus, supra lavigatus, subtus flavo-pilosus; capite antice depresso, clypeo bifido; thorace transverso, lateribus rotundato, bifoveato, subrugoso. Scutello rotundato. Elytris punctatis, lineis tribus sub-elesatis. Pedibus elongatis, antice tibiis tridentatis, lavigatis. - L. 15 mill., 1. 7 m.-Atlas, Ins., pl. III, fig. 6 .

Cette espèce ressemble un pcu à un hanneton de nos pays; sa couleur est marron clair ; son corps est luisant en dessus, garni de longs poils jaunâtres en dessous. Ses pattes sont médiocres, avec les tarses allongés. Les jambes antérieures ont trois dents peu saillantes au côté externe. - De la Conception, au Chili.

Nota. Cet insecte doit avoir de grancls rapports avec le Melolontha palpalis d'Escholstz (Entomographien 1822 , pag. 17 ), mais il en diffère, si sa description est exacte, par les palpes maxillaires; dans son espèce il décrit ainsi ces palpes : "Palpis maxillaribus articulo ultimo maximo, excavato. Je u'ai rien observé d'excavé dans les palpes de mon échantillon. Celui d'Escholstz venait aussi de la Conception.

\section{Genre HÉTERONYX, Heteronyx. Gú́rin.}

Ce nouvcau genre se rapproche beaucoup des Dasyus de Serville, des Sériques et des Diphucéphales de Macleay, à cause de ses mâchoires armées de dents très-fortes et arquées; mais il en est distingué par les crochets de ses tarses, qui ne sont pas tous bifides, par la massue de ses antennes qui est ćpaisse, aussi longue que large, et par ses palpes maxillaires obconiques, caractère qui n'a pas encore été observé dans les Lamellicornes : nous placerons ce genre entre les Dasyus et les Sériques, en le caractérisant de la manière suivante :

Antennes (fig. 9 B) de neuf articles, le premier grand, obconique, peu renflé; le second, moitié plus court, ovoïde; le troisième, de la longueur du précédent, beaucoup plus mince, presque cylindrique; les quatrième, cinquième et sixième, beaucoup plus courts, obliques, les deux dcrniers un peu pointus en dedans; mașsue composée des $7^{e}, 8^{e}$ et $9^{e}$ articles, épaiśse, un peu plus longue que large, avec le dernier article 
anguleux, de forme carrée; chaperon triangulaire à augles arrondis; labre très-petit, lamelliforme; mandibules peu arquées, terminées par une seule pointe et ayant vers le milieu de leur longueur un petit tubercule arrondi. Mâchoires (fig. $9 \mathrm{~A}$ ) épaisses, droites, avec le lobe terminal tronqué au bout, et armé au còté interne de cinq fortes dents presque droites. Palpes nuxillaircs áutssi longs que les mâchoires, insérés presque à la hauteur de la troncature du lobe terminal, composés de quatre articles, dont le premier est petit, conique; le second, aussi long que le dernier, obconique, mince; le troisième un peu plus court, épais; le deruier allongé, encore plus épais, plus large, et tronqué obliquemient à son extrémité. Menton ou lèvre inférieure presque carrée, avec les palpes labiaux très-petits', insérés sur ses côtés antérieurs et repliés en ayant et contre elle. Corps épais, cylindracé, plus étroit en avant; élytres oblongues, recouvrant des ailes et ne laissant qu'une très-petite portion de l'abdomen à nu. Pattes longues, aplaties, avec les tarses beaucoup plus longs que les jaunbes, grêles, à articles allongés et obconiques; les antérieurs (lig. 9 C) terminés par deux crochets éganx, simples; les intermédiaires ( fig. $9 \mathrm{D}$ ) et postérieurs (fig. $9 \mathrm{E}$ ) ayant aussi deux crochets égaux, mais armés sous la pointe d'une très - petite dent difficile à voir. Jambes antérieures profondément tridentées au côté extérieur. Le nom de ce genre vient des mots š̃spos, autre, différent, et z̈vü, ongle.

HÉTERONYX AUSTRAL, Heteronyx australis. GuÉR.-- Oblongo-avatus, castaneus, punctatus, villosus, clypeo rotundato, antice cmarginato. Thorace transverso; scutello minuto, triangulari. Elytris elongatis, convexis, apice rotundatis. Pedibus villosis; tarsis gracilibus. - L. I I mill., I. 5 m. - Atlas, Ins., pl. III, fig. 9 .

La figure que nous donnons de cet insecte nous dispense d'une plus longue description. - Il a été trouvé à la Nouvelle-Hollande.

\section{Genre PSEUDO-SÉRIQUE, Pseudoserica. Gú́r.}

Nous avions d'abord voulu placer cet insecte dans le genre Sérique de Macleay, afin de ne pas trop multiplier les genres; mais nous nous sommes convaincus depuis quill est impossible d'associer un insecte à antennes de neuf articles, à mandibules bifides au bout, à menton arrondi, etc., avec les Sériques, qui ont des antennes de dix articles *, des mandibules courtes, entières et triangulaires, un menton en carré long, etc. Nous nous sommes donc décidés à former cette nouvelle coupe qui va se placer immédiatement avant le genre Sérique, et que nous caractérisons de la manière suivante:

Antennes ( fig. 5 B ) de neuf articles, le premier grand, renflé au bout; le second ovoïde, plus court; les deux suivants de la même longueur, obconiqnes; le cinquième

* Il est probable que M. Latreille n’a pas observé l'antenne de la Serica variabilis, à laquclle nous avons trouxć dix arlicles. ( Voycz notre Iconographie du Rẻgne animal, Inscetcs, pl. XXIV bis, fig. $12 d$ ); car ce savant dit (Règne animal, $2^{e}$ éd., t. IV, p. 565 , note 2 ) n'en avoir compté que neuf. Nous u'avours pas eu occasion d'exáminer les deux autres espéces cilées dans cette note. 
long, presque eylindrique; le sixième très-court, élargi en dedans; et les trois derniers formant une massue aplatie assez longue. Chaperon infléchi ; labre saillant, bilobé ; mandibules (fig. $5 \mathrm{D}$ ) assez longues, courbées, bidentées au bout, avec une très-petite dent arrondie plaeée plus bas et au côté interne. Mâchoires (fig. $5 \mathrm{~A}$ ) courtes, à formes carrées, ayant le lobe terninal interne armé de six dents aiguës, croehues, dirigées en haut et cn dedans. Palpes maxillaires plus longs que les mâchoires, ayant leur premier artiele court, les trois antres presque égaux en longueur, avec le dernier un peu renflé au milieu. Menton ou lèvre inférieure ovalaire, plus large au milieu, arrondi en avant, avec les palpes labiaux insérés sur les còtés, petits et courbés sur le bord antérieur. Corps oblong, cylindracé, plus large en arrière, avec le corselet presque aussi long que large; élytres recouvrant des ailes et ne laissant pas apercevoir l'abdomen en dessus. Pattes assez fortes, assez courtes, avec les tarses (fig. $5 \mathrm{E}$ ) un peu plus longs que les jambes, et ayant tous leurs eroelıets égaux et bifides (fig. $5 \mathrm{C}$ ). Jambes antérieures ayant trois dents eourtes et arrondies au eôté extérieur.

PSEUdOSÉRIQUE MARBRÉE, Pseudoserica marmorea. Gúr. - Oblonga, postice latior; brunnea, viridi micans; maculis albis villosis, irregularibus. Clypeo rotundato, punctato, antice subemarginato ; tlorace subquadrato, gibboso, argute punctato, angulis posticis acuminatis. Scutello rotundato, albo-villoso. Elytris argute punctatis, substriatis. Corpore subtus pedibusque castaneis. - L. 13 mill., , $1.6 \mathrm{~m}$.

Serica marmorea, Atlas, Ins., pl. III, fig. 5. - Trouvée à Sainte-Catherine, Brésil.

ELCHLORE CHLORO'TIQUE, Euchlora clelorotica. Gún.-Ovata, convexa, supra flava, nitida. Capite punctato; clypeo transverso, marginato; thorace punctato, trapeziformi, postice subsinuato, lateribus paulo arcuatis.s Scutello triangulari, punctato. Elytris elongatis, punctato-striatis, humeris sub-elevatis. Thorace subtus albo-vil: loso; abdominis segmentis brunneo marginatis; pedibus concoloribus, tarsisque brunneis. - L. 13 mill., 1. $7 \mathrm{~m}$.

La forme générale de cet insecte est ovalaire, plus étroite en avant; il est entièrement d'un jaune d'ocre luisant. La tête est petite, à peu près aussi longue que large, ponctuée, avec une petite ligne transverse marquant la séparation du chaperon. Les yeux sont assez saillants, noirs. Le corselet est plus étroit en avant, un peu plus large que long en arrière. L'éeusson est assez grand, triangulaire, avec les eôtés un peu arrondis. Les élytres sont oblongues, arrondies sur les còtés, avee un grand nombre de stries formées par des points irréguliers et peu enfoneés. Leurs angles liuméraux sont un peu élevés, plus lisses; il y a aussi une élevation moins marquée vers leur extrémité; la partie de l'abdomen qui déborde en dessus est d'un brun jaunàtre. Le dessous du thorax est jaune, garni d'un duvet blanc. Les segments de l'abdomen sont jaunes, bordés de brun. Les pattes antérieures sont ternimées par une pointe avaneée, arrondie au bout; elles n’ont point de dents au eôté externe. Les autres pattes ont deux épines inégales à l'extrénité. Tous les tarses sont d'un brun rougeâtte. - Trouvé à Amboine. 
EUCHLORE LUCIDULE, Euchlora lucidula. Gún. - Ovata; capite, thorace, scutclloque obscure viridibus, punctatis. Elytris croceis, subviride-micantibus, striato-punctatis. Corpore subtus, pedibusque ochraceo-ferrugineis, subviride-micantibus. -- L. I I mill., l. $6 \mathrm{~m}$.

Cette petitc espèce a un peu l'aspect d'unc Anisoplia; sa têtc est ponctuée d'un brunverdâtre couleur olive, ainsi que le corselet et l'ćcusson. Les antennes et les palpes sont d'un jaune-fauve. Les élytres sont d'un jaune tirant au fauve-obscur, avec des reflets un peu verdâtres, et la suture un peu plus sombre ainsi que les bords huméraux; elles sont luisantes, avec des stries fornıées par des points enfoncés. L.e dessous du corps est d'un jaune d'ocre un peu rougeâtre, peu veln, avec quelques reflets veris; les pattes sont de la même couleur. Les jambes antćrieures sont terminćes par une pointc avancée, arrondie au bout, et elles présentent extérieurement unc petitc clent olltuse. L'extrémité de l'abdomen offre une petitc bande transverse noirâtre. - Trouvé à Bourou.

ANISOPLIE DU PÉROU, Anisoplia peruviana. GUÉr. - Ovata, obscure lutea, capite, disco thoracis elytrisque maculis nigris. Corpore subus flavo nigroque variegato. - L. Io mill., $1.5 \mathrm{~m}$.

Cette espèce a beaucoup de rapports avec celle de notre pays pour la taille et les couleurs ; sa tête est noirâtre, arrondie, avcc le chaperon un peu avancé, rebordé et arrondi en avant. Les parties de la bouche et les antennes sont d'un jaune-fauve. Le corselet est transversal, échancré en avant, finement ponctué, d'un jaune-fauve, avec le disque marqué d'une grande tache carrée noire, qui ne laisse que les bords latéraux, et une petite tache transverse au milieu du bord postérieur, jauncs. L'écusson est triangulaire, ponctué, noir, avec une petite tache jaune au milieu. Les élytres sont d'un jaune tirant sur le fauvc, avec la suture et le bord extérieur noiràtres; elles présentent antérieurement et un peu au-delà du milieu, trois petites taches noires disposées transversalement, de forme carrée, l'interne ou suturale placée un peu plus bas que les deux autres; il y a une autre tache noire vers. l'extrémité de l'élytre, et quelques petites taches pen marquées un peu plus haut. Ces élytres sont luisantes et garnies de stries formées par des points enfoncés. Le dessous du corps est noirâtre avec des taches et les bords des anneaux jaunàtres. Les pattes sont jaunes avec l'extrémité des jambes noire. Les jambes antérieures n'ont qu'une petite dent arrondie avant lc prolongement terminal. - Trouvé à Lima, au Pérou.

DIPHUCÉPHALE CO̊LASPIDIOÏDE, Diphucephala colaspidioïdes. Guén. - Melolontha colaspidioïdes. Gyllenhal, in Schonherr, syn. ins. t. I, part. 3. Append. p. Iо , $\mathrm{n}^{\circ} \mathbf{1} 40$.

Cet insecte porte une foule de noms dans les collections. 'T'ous ceux qui l'ont reçu ont arlopté des noms qui semblent venir de Macleay; ils se sont fort peu inquiètés de savoir si des auteurs l'avaient déjà décrit. - Du port Jackson. 
DIPHUCÉPHALE FOURCHUE, Diplucephala furcata. Guér. - Oblonga, viridianea, aut viridi-rubra, nitida; fronte plana, subruyosa; clypeo producto, bifurcato, erecto; thorace suliquadrato, lavigato, antice coarctato, lateribus rotundatis, utrinque obsoletissine impresso. Elytris rude striato-punctatis, punctis confertissimis; corpore subtus pedibusque cinereo-villosis; tarsis cyaneis, aut viridi-cyaneis.-L. 9 ou 10 mill., l. $3 \frac{1}{2}$ ou $4 \mathrm{~m}$. - Iconographie du Règne animal, Ins., pl. XXIV bis, fig. 13.

11 est plus grand que le D. colaspidoides; le mâle est un peu plus grand que la femelle; sa tête est aussi longue que large, aplatie en avant, finement rugueuse, trèsbrillante : le chaperon est très-avancé, très-profondément échancré au milieu, avec ses lobes arrondis sur les côtés, relevés, et formant comme deux petites cornes pointues, mais non aiguës au bout. Le corselet est aussi long que large, rétréci en avant, lisse, terne, conme velonté, avec les angles postérieurs assez aigus, les bords antérieur et postérieur presque droits, une très-petite saillie arrondie aux côtés, vers le milieu de leur longueur et à l'endroit où il commence à se rétrécir. Le milieu du corselet présente un petit sillon longitudinal pen marqué, et l'on voit de chaque côté une petite dépression aussi très-peu enfoncée. L'écusson cst petit, triangulaire, lisse, un peu déprimé au milieu. Les élytres sont parallèles, rebordées, environ deux fois aussi longues que le corselet, fortement rugueuses, avec les angles huméraux et l'extrémité postérieure relevés, presque lisses ; leur rugosité est formée par des points enfoncés, dlisposés presque en séries longitudinales régulières, très-rapprochées, et ne laissant pas de lignes élevées bien manifestes entre eux; on voit cependant, à une certaine distance de la suture, une petite côte lissc, un peu saillante, et la trace d'une seconde côte parallèle, placée sur la partie de l'élytre qui commence à s'abaisser sur le côté. La partic découverte de l'abdomen est triangulaire, avec l'angle postérieur arrondi, plus avancé que dans la femelle. Le dessous du corps est garni d'un duvct cendré, ainsi que les pattes; les tarses sont bleus ou d'un vert-bleu; les antérieurs et intermédiaires ont leurs articles dilatés. Dans les antérieurs ce sont les $2^{\mathrm{e}}, 3^{\mathrm{e}}$ et $4^{\mathrm{e}}$.articles qui sont les plus larges, et dans les intermédiaires ce sont les $\mathrm{I}^{\text {er }}$ et $2^{\mathrm{e}}$ seulement ; ces tarses sont fortentent ciliés des deux côtés. (Voyez Iconogr. du Règne animal, Insectes, pl. 24 bis, fig. $13 e, 13 d$ ) Les jambes antérieures sont terminées en dehors par unc dilatation un peu aiguë; elles n'ont point de dents externes.

La femelle (Icon. du liègne anim., Ins., pl. 24 bis, fig. 13) est un peu plus petite; l'échanciure de son front (voy. Icon. du Règne anim., Ins., pl. 24 bis, fig. 13 a) n'est pas si profoule, et les espères de corncs sont courtes, arrondies et point ćlevées; les pattes sont un peu moins rolustes; les tarses antérieurs ne sơnt point dilatés, et l'extrémitć déconverte de l'aludomen n'est pas si prolongée en arrière. La couleur de ces insectes est d'un beau vert brillant dans quelques individus, avec les pattes rouges-cuivrées. Dans d'autres tout le corps est cuivrenx-rouge très-lorillant, avec des reflets verts; il y en a qui n'ont pas mème ces reflets.

La Dijhucéphale colaspidoìle diffère de notre espèce par son clıaperon, qui est peu échın-

rojaǵe de la Coquille. - Z. Tom. II, Part. II. Ire Div. 
cré, avee les côtćs droits et tronqués angulcusement; par son corselet, qui est transversal et deux fois plus large que long, et par les pattes antérieures qui ont en dehors une dent bien marquée. — Nos individus ont été pris au port Jakson.

\section{Genre LIPARETRUS, Liparetrus. GứnıN.}

Nous plaçons ce nouveaı genre en tête d'une division des Mélolonthides, formée par Latreille (Règne anim., nouv. édit., tome IV, page 56), et renfermant les genres Dasyus, Scrique, Diphneéphale, Macrodactyle, etc. Comme dans les genres de cette division, notre insecte offre neuf articles aux antennes, des dents aiguës aux mâchoires, les crochets des tarses égaux, ete.; mais il en est bicn distingué, paree que tous ces crochets sont simples, tandis que, dans les genres que nous venons de citer, ces croehets sont en tout ou en partie bifides; la proportion des artieles des antennes et d'autres caractères distiuguent suffisamment ee genre.

Antennes de neuf articlcs; le premier long, eonique, renflé au bout; le second de moitié moins long que le premier, également renflé au bout; les deux suivants courts, presque cylindriques, formant à eux deux une longueur égale à celle du précédent; les cinquième et sixième un peu plus courts, dilatés en dedans; les trois derniers formant une massue épaisse, courte et renflée. Labre transversal, largement éehancré en avant, caché par la saillie du ehaperon, qui est transverse. Mandibules courtes, triangulaires, aplaties, ayant le sommet arrondi et la base interne un peu membraneuse et velue. Mâchoires courtes, épaisses, terminées en dedans par quatre dents fortes et assez aiguës. Palpes maxillaires insérés très-haut, au niveau du bord antérieur des mâchoires, composés de quatre articles, dont le premier très-eourt, le second plus grand, obconique, le troisième de même forme un peu plus grand, et le dernier, le plus grand de tous, ovalaire, allongé, un peu plus renflé et arrondi au bout. Lèvre inférieurc presque carrée, avec les bords latéraux un peu arrondis, un peu échanerée en avant; palpes labiaux assez longs, insérés sur les eôtés de la lèvre, courbés sur le bord antérieur, et composés de trois articles presque cylindriques. Tête petite, presque carrée, avec les yeux un peu saillants. Corselet transversal, arrondi sur les côtés. Écusson petit, triangulaire. Élytres eourtes, ne eouvrant que la moitié de l'abdomen, arrondies au bout, se touchant dans toute leur longueur. Abdomen épais. Pattes assez grêles, de grandeur ordinairc; tarses grêles, plus longs que les jambes, à articles allongés, renflés au bout, terminés par deux crochets aigus, simples, assez allongés. Nous avons conservé à ce genre le nom de Liparetrus, qu'il porte dans des colleetions.

LIPARETRUS DISCIPENNE, Liparetrus discipennis. GuÉr. - Subquadratus ater, villosulus. Elytris obsoletissime striatis, ochraceis, margine nigris. Pedibus anticis tarsisque ferrugineis. - L. 7 mill., 1. 3 m.-Atlas, Ins., pl. III, fig. го.

Tout son eorps est lisse, mat; les élytres présentent quelques légères traces de stries; leur surfaee est d'un beau jaune d'ocre, avec tous les bords noirs; le bord antérieur 
ayant le noir un peu plus large que sur les eôtés. Les jambes antérieures sont prolongées extérieurement, et au bout elles n'ont aueune dent, et ne présentent qu'une épine au eôté interne près de linsertion du tarse. - Du port Jakson.

CÉTOINE TACITURNE, Cetonia taciturna. Guér. - Opaca, supra brunneo-virescente, capite immaculato. Thoracc, latcribus abo-cinctis, disco quadripunctato; scutello oblungo; elytris albo-variegatis, apice acuminatis. Corpore subtus flavo-tomentoso, medio nigro-nitido; pcdibus nigro-virentibus nitidis. - L. 19 mill., l. 9 m. - Atlas, Ins., pl. III, fig. 12.

Nous possédons deux indiviclus de eette espèee, appartenant à des loealités un peu différentes : l'un, pris dans l'île de Bourou, est d'une eculeur tirant plus sur le brun que sur le vert; les taehes blanchâtres des élytres ne eommencent qu'au milieu; elles sont régulières, en forme de stries courtes et transverses. C'est cet individu qui a été figuré. L’autre, qui provient d'Amboine, offre uné eouleur plus verte; il a sur les élytres, outre les marques figurées sur eelles du préeédent, un nombre assez eonsidérable de petits points ronds, plaeés irrégulièrement entre la base et le milieu des élytres. Le dessous des deux variétés est eouvert d'un duvet jaunâtre très-eourt et serré; il n'y a que le milieu du thorax et eelui des anneaux de l'abdomen qui en soient dépouillés, et qui présentent alors des taches noires luisantes, transverses et déeoupées au bord.

CÉTOINE PAPOUE, Cetonia papua. Gúr. - Olscure viridis, nitidissima; fronte bicornuta; thorace postice producto, scutellum tegente. Elytris elongatis, postice subattenuatis, subtilissime transversim rugosis, punctatis. Corpore subtus viridi; sternum antice productuma pedibus concoloribus.-L. 34 mill., l. 16 m.- Atlas, Ins., pl. III, fig. I I.

Cette belle espèee a été trouvée à Offaek, dans la terre des Papous : elle fait partie du genre Lontaptera dans la méthode adoptée par MIM. Gory et Pereheron, qui ont présenté à l'Institut une monographie du grand genre Cétoine. Comme elle sera déerite avee détail dans ee beau travail, nous nous bornons iei à la figure que nous cn avons donnée.

Cctonia Ookerii. Swartz in Seh., syn. ins., t. I , $3^{e}$ partie, app., page $49, n^{0} 74$. - Du port Jakson.

Cetonia turrida. Fabr., syst. eleuth., t. II, page $152, n^{\circ}$ 83. - Cetonia fasciolata. Esehseholı, Enthomographien, Berlin, 1822, page 25, $\mathrm{n}^{\circ}$ 10.

Il est évident pour nous que MI. Esehselıoltz n'a pas reeonnu sa Cétoine dans Fabricius, quoique cet anteur l'ait déerite bien exactement, et renvoie à des figures qui ne penvent laisser aueun doute. Notre individu, eomme eeux d'Esehseholtz, Fabrieins Olivier, ete., a été trouvé au Brésil ; c'est unc espèce assez commune dans ee pays. 


\section{Genre PROACIS.}

Ce genre a été établi par Eschscholtz, dans le $3^{\mathbf{e}}$ cahier de son Zoologischer Atlas, sur deux insectes trouvés par lui à la Conception, au Chili. L'espèce principale sur laquelle il a pris ses caractères, et quil a figurée, nous a été rapportée de la même localité par les naturalistes de la Coquille. Nous l'avons représentée dans notre pl. IV, fig. I, n'ayant pas alors connaissance du travail de MI. Eschscholtz, ouvrage qui était encore inconnu en France. Nous nous sommes empressés d'adopter le genre formé par le naturaliste allemand, et nous ne ferons que citer ici la description qu'il a donnée de cette espèce, après avoir présenté quelques considérations générales sur le genre.

Les Proacis sont à l'Amérique ce que sont les Zophosis à l'ancien continent; ils en tiennent la place dans le nouveau monde, offrent les mêmes habitudes et le même facies. Ce genre, que son auteur place à tort dans la tribu des Blapsides, se rapproche bien plus des Erodius que des Nyctelia. Nous cn connaissons actuellement six espèces, toutes propres à l'extrémité de l'Amérique; nous allons donner la liste de ces espèces :

$I^{\circ}$ Prodcis rufipes, Eschscholtz, Zoologischer Atlas, $3^{\text {e }}$ cahier, p. 6, pl. XIV, fig. 2.

$2^{\circ}$ Proncis sulcata, Esch., loc. cit., p. 7 .

$3^{\circ}$ Proacis submetallica, Nob. Mag. de zool.

$4^{\circ}$ Proacis cucullata, Nob. Mag. de zool. n. g. Cucullatus. Lacord. Ann. sc. n. t. 20, p. 286.

$5^{\circ}$ Proacis ursina, Nob. Mag. de zool. n. g. Ursinus. Lacord. Ann. sc. n. t. 20, p. 286.

$6^{\circ}$ Proacis dilaticoldrs, Lacord. Ann. sc. n. t. 2o, p. 285, figuré dans notre Mag. de zool., année $\mathbf{8} 834$.

Le Proacis rufipes est de petite taille, tout noir, avec trois lignes longitudinales blanches sur chaque élytre; nous avons donné des figures détaillées de sa tête, des parties de sa bouche et de son tarse antérienr, dans notre Atlas, Ins. pl. IV, fig. I A, B, C, D.

\section{Genre NYCTOZOILE, Nyctozoilus. Guér.}

Ce nouveau genre est voisin des Nyctelia de Latreille; mais il en diffère d'une manière très-nette par la forme de son labre, par sa lèvre inférieure, et par beaucoup d'autres caractères non moins importants. Voici le signalement que nous lui donnons :

Labre très-étroit, transversal, point échancré en avant.

Mandibules un peu avancées, grosses, bidentées à l'extrémité.

Màchoires courtes, ayant le lobe extérieur arrondi au bout, cilié, et le lobe interne plus court, également cilié, mais armé à son extrémité in terne d'une épine cornée. (Cette épine a été oubliée dans notre planche IV, figure 2, C.)

Palpes maxillaires de quatre articles : le premier très-court; le second grand, un peu renflé vers l'extrémité; le troisième de moitié moins long, et le quatrième de la longueur du second, très-dilaté en hache et tronqué intérieurcment. 
Lc̀vre inférieure petite, en forme de cœur, très-rétrécie en arrière, à angles latéraux arrondis, avec la languette trc̀s-saillante, et laissant l'insertion des palpes labiaux entièrement à découvert.

Palpes labiaux courts, de trois articles, avec le dernier en forme de hache.

Antennes presque filiformes, avec les deux premiers articles égaux, courts, un peu coniques, le troisième plus de deux fois plus long, un peu renflé à son extrémité; les $4^{\mathrm{e}}, 5^{\mathrm{e}}, 6^{\mathrm{e}}$ et $7^{\mathrm{e}}$ de moitić moins longs, un peu coniques, et les quatre derniers plus courts, renflés et comme grenus. - Voyez pour ces détails pl. IV, fig. $2 \mathrm{~A}, 2 \mathrm{~B},{ }_{2} \mathrm{C}$, $2 \mathrm{D}$.

NYCTOZOILE ÉPAIS, Nyctozoilus obesus. GuÉr. - Ater, capite transverso, oculis obsoletis, thorace transverso, lateribus rotundato, angulis acutis. Elytris costato-reticulatis, punctatis. - L. 20 mill., l. I I m. - Atlas, Ins., pl. IV, fig. 2.

Cet insecte est entièrcment noir, peu luisant. Sa tête est reçue dans une légère échancrure du corselet; clle est aplatie en dessus, arrondie en avant, avec deux petits rebords devant les yeux pour recouvrir l'insertion des antennes: les mandibules et le labre sont assez saillants, avec quelques cils rougeâtres. Les antennes sont de la longueur du corselet et de la tête. Le corselet est transversal, presque deux fois plus large que long, arrondi sur les còtés, un peu plus étroit en avant, avec les angles antérieurs et postérieurs un peu aigus; il est assez bombé, rebordé; son milieu offre quelques sillons enfoncés, sinueux, et il a de chaque còté, vers les angles postćrieurs, un enfoncement assez profond. L'écusson est très-petit, arrondi et transversal; les élytres sont bombées, ovales, arrondies sur les côtés, et embrassent l'ilbdomen. Elles ont chacune trois côtes élevées lisses ct sinueuscs, cntre lesquelles il y a d'autres petites ćlévations ou réticulations également sinueuses, transversales, anastomosées entre elles, et formant un réseau trèssaillant. Le dessous du corps est finement réticulé. Les pattes sont assez petites, simples, avec les tarses de grandeur ordinaire et garnis de brosses rousses en dcssous. Ce bel insecte a étć trouvé à la Nouvelle-Hollande.

NYC'TERINUS THORACIQUE, Nycterinus thoracicus. Escrscuoltz, Zoologischer Atlas, $3^{\mathbf{e}}$ cahier, p. 13 , pl. I4, fig. 7 .

La figurc publiée par Eschscholtz n'étant pas accompagnée de détails, nous avons pensć que ceux que nous donnons dans notre planche IV, avec l'espèce type du genre, seraient agréibles aux entomologistes. La figure 3 offre l'insecte de grandeur naturelle; la figure $3 \mathrm{~A}$ prćsente sa bouche vue en dessous et très-grossie. On voit sa tête et ses antennes grossics, figure $3 \mathrm{~B}$; la figure $3 \mathrm{C}$ cst cclle d'un tarse antérieur, ct $3 \mathrm{D}$ celle d'un tarse postérieur. - Notre individu a ćté pris à la Conception, au Chili. 


\section{Genre AMMOPHORE, Ammophorus. Guér.}

Ce genre est très-voisin des Nycterinus de M. Eschscholtz; mais il en diffère d'une manière bicn notable par ses antennes et par d'autres organes essentiels. Voici les caractc̀res que nous lui assignons :

Labre trc̀s-ćtroit, peu visible, insérć dans une ćchancrure du bord antérieur de la tête.

Mandibules fortes, peu saillantes, creusées cn cuiller, et faiblement bidentées à l'extrémité.

Mâchoires courtes, tcrminées par deux lobes presque égaux, armés chacun d'une forte dent cornée, et très-ciliés.

Palpes maxillaires de quatre artieles, épais; les trois premiers presque égaux, le dernier sécuriforme.

Lèvre inférieure de forme hexagone, un peu plus longue que large, à angles peu arrondis, avec la languette saillante et les palpes labiaux à découvert.

Palpes labiaux courts, triarticulés, avec le dernier article en hache.

Antennes grenues, presque perfoliées, de la même grosseur dans toute leur longueur. Le premier article court, le second encore plus court, le troisième presque aussi long que les deux premiers réunis; les suivants eourts, grenus, avee le dernier tronqué à l'extrémité.

AMMOPHORE DU PÉROU, Ammophorus pertvianus. Gut́r. - Ater, capite subquadrato, punctato; thorace transverso, punctato laterilus rotundato; elytris ovatis, costatis, interstitiis transverse crenulatis. - L. 8 mill., 1. 3 m. -Atlas, Ins., pl. IV, fig. 4 .

Il est entièrement noir, peu luisant. Sa tête est à peu près carrée, un peu dilatée sur les còtés et en avant des yeux, échanerée antérieurement avec deux petites impressions au-dessus de l'insertion des antennes. Le labre, les mâchoires et les palpes sont rougeâtres; les antennes ont une fois et demic la longueur de la tête; elles sont tronquées au bout, grenues. Lc corselet est un peu plus large que long, arrondi sur les côtés, plus étroit en arrière, bombé, avec les angles un peu aigus. Son milieu offre un sillon longitudinal assez largc et peu marqué, avec une légère impression de chaque côté; toute sa surface est couverte de gros points enfoncćs. L'écusson est invisible; les élytres sont oblongues, parallèles, cylindroïdes; elles ont chacune sept ou huit côtes élevées, dans l'intervalle desquelles on remarque des points enfoncés, transverses et assez profonds. Le dessous du corps est fortement ponctué; les pattes sont d'un noir tirant sur le rougeâttre; les jambes antérieures sont aplaties et dilatées en dehors; les tarses sont courts, grenus, bruns, avec des poils rougeâtres. Dans la figure $4 \mathrm{C}$, qui représentela mâchoire de cet insecte, on a oublié de graver les deux crocliets cornés qui arment chacun des lobes. La figure $4 \mathrm{~A}$ représente la partie antérieure dc sa tête grossie. Dans la figure $4 \mathrm{~B}$, nous avons montrć sa bouchc vue en dessous, et ses antennes; on a oublié de graver la ligne d'articulation de la lèvre inférieure avec le menton. Cet insecte a été pris à Payta, au Pérou. 


\section{Genre PSAMMÉtTiQUe, Psammeticus. Latrejlete.}

Ce genre a été établi par Latreille, sur l'inseete même que nous avons figuré, et qu'il a trouvé au Muséum. C'est dans ses familles naturelles du règne animal qu'il en est fait mention pour la première fois. Il l'a caractérisé avec plus de détail dans le Dictionnaire classique d'histoire naturelle, article Piméliaires. Les caractères qu’il lui assigne sont les suivants :

"Antennes point perfoliées; la plupart des articles turbinés; le troisième beaucoup " plus long que les suivants; le onzième ou dernier très-distinct, aussi grand que les pré" cédents (subovoìde, court); tĉte et corselet un peu plus étroits que l'abdomen, presque " carrés; celui-ci subovalaire.

"Genre établi sur des insectes du Chili."

Dans la deuxième édition du Rìgne Animal, Latreille ne fait que répéter ces caractères, en employant d'autres formules.

Nous ne connaissons qu'une espèce appartenant à ce genre; c'est :

Le PSAMMÉTIQUE A COTES, Psammeticus costatus. GuÉr. - Ater, capite magno, deplanato, hexagono; thorace cordato, angulis anticis posticisque acutis, medio carinato; elytris undecim carinatis, omnino valde rugosis. - L. I 4 à 18 mill., 1. 5 à 7 m.Atlas, Ins., pl. IV, fig. 8.

La couleur naturelle de cet insecte est noire; mais il est, comme les Asides et quelques Opatres, couvert et incrusté de terre, ce qui le rend gris et ne laisse de noir que les parties saillantes nettoyées par lc frottement. Sa tête est grande, anguleuse en devant, coupée carrément au bord antérieur, plus large an milieu, avec un petit rebord pour recouvrir l'insertion des antennes; sa surface est granuleuse, avec une élévation médiane partant du milieu de sa lonģueur et se terminant au bord antérieur. Les mandibules ne sont pas du tout saillantes quand elles sont fermées; leur extrémité est bidentée, avec le côté externe un peu sillonné. La lèvre inférieure est transversale; les quatre palpes sont terminés par des articles tronqués au bout, mais pas en hache. Les antennes sont à peine de la longueur du corselet et de la moitié de la tête, noires, grenues. Le corselet est en forme de cour, un peu échancré en avant, tronqué carrément en arrière, avec les quatre angles très-aigus. Sa surface est fortement granuleuse, avec une còte élevée et longitudinale au milieu. On ne voit aucune trace d'écusson. Les élytres sont de la largeur du corsclet à leur base ; elles s'élargissent ensuite beaucoup, et vont se terminer en quene peu saillante. Leur surface est granuleuse, et elles ont chacune trois côtes élevées un peu crénelées, entre lesquelles on cn observe une plus petite, formée de petits grains élevés; ces élytres embrassent entièrement les côtés de l’abdomen, qui est noir, fortement ponctuć. Les pattes sont assez grandes, noires, grenues. Les tarses ont quelques cils roux. - Cet insecte a été trouvé à Lima et à Payta, au Pérout. 


\section{Genre HÉLIOFUGE, Heliofugus. Guér.}

Le Mélasome qui a donné lieu à l'établisscment de ce nouveau genre vient encore du Chili; il ressemble beaucoup aux Misolampes; mais il en diffère cependant par le quatrième article des antennes, qui, d'après Latreille, est égal au troisième dans les Misolampes, tandis que, dans notre insecte, cet article est beaucoup plus court. Dans les Misolanpes, la lèvre inférieure est presque carrée, à peine plus large à l'extrémité, aussi longue que large; tandis que, dans le genre Héliofuge, elle est transversale, ou beaucoup plus large que longue, étroite à la base et plus large à l'extrémité. Voici les caractères que nous assignons à notre nouveau genre :

Labre arrondi, saillant, transversal, inséré sur une troncature du bord antérieur de la tête.

Mandibules fortes, peu saillantes, bidentées à l'extrémité.

Màclıoires courtes, ayant le lobe externe grand, arrondi, cilié; l'externe très-petit, étroit, terminé par un onglet peu visible et cilié.

Palpes maxillaires assez longs, de quatre articles, le premier court, le second deux fois plus grand, le troisième plus court, et le dernier grand, fortement sécuriforme:

Lc̀vre inférieure transversale, un peu plus large en avant, avec la languette très-saillante, arrondie, et laissant l'insertion des palpes labiaux à découvert.

Palpes labiaux assez courts, de trois articles, les deux premiers presque égaux, le dernier un peu en hache, arrondi.

Antennes de onze articles, le premier assez grand, le second court, le troisième de la longueur des deux premiers réunis, le quatrième de moitié moins long que celui qui le précède; tous ces articles cylindriques et un peu renflés vers l'extrémité, ainsi que le cinquième et le sixième; les articles suivants aplatis, s'élargissant jusqu'au dernier, qui est un peu plus grand, arrondi et très-obtus au bout.

HÉLIOFUGE DES SABLES, Heliofugus arenosus. Gú́r. - Ater, ore, apice antennarum tarsisque rufo-brunneis; thorace cordato, globeso; elytris striato-punctatis, postice acuminatis. - L. ro mill., l. $4 \mathrm{~m}$. -- Atlas, Ins., pl. IV, fig. 6.

Il est tout noir en dessus et en dessous; sa tête est arrondie, tronquée en avant, ayant un sillon transversal près du bord antérieur, avec les palpes, les mâchoires et l'extrémité des antennes ferrugineux. Celles-ci sont de la longueur de la tète et du corselet réunis. Le corselet est un peu plus large que long, très-arrondi sur les còtés, un peu plus étroit en arrière, bombé et trés-finement ponctué, vu à la loupe. L'écusson est excessivement petit, transversal et arrondi. Les élytres sont allongées, plus larges que le corselet, presque parallèles et peu arrondics sur les còtés, jusqu'aux deux tiers de leur longueur, terminées ensuite brusquement en pointe, soudées et embrassant les côtés de l'abdomen; clles ont chacune neuf stries assez profondes et ponctuées. Les pattes sont de grandeur moyeune, assez grêles, sans épines; les tarses sont simples, avec un duvet ferrugineux cn dessous. L'insecte grossi est représenté dans notre planclie IV, figurc 6. La figure $6 \mathrm{~A}$ représente sa tête vue cn dessous; on la voit en dessus avec les antennes grossies, à la 
figure $6 \mathrm{~B}$. Enfin les $\mathrm{n}^{\text {os }} 6 \mathrm{C}$ et $6 \mathrm{D}$ représentent un tarse antérieur et un tarse postérieur grossis. Cet insecte vient de la Conception, au Chili. Nous possédons une autre espèce du même geure, qui a été trouvée à Monte-Video; c'est notre Heliofugus striatus, publié dans le Magasin de Zoologie.

TÉNÉBRION A COTES, Tenebrio costatus. Gú́r. - Ater, capite prodlucto, thorace rotundato, angulis posticis quadratis; elytris valde costatis, interstitiis punctulatis. L. 20 mill., l. 8 m. - Atlas, Ins., pl. IV, fig. 5 .

Ce Ténćbrion n'est pas aplati comme les espèces de rotrc pays; il a plus de rapports avec celles qu'on trouve à Cayenne et au Brésil. Sa tête est avancée, plus longue que large, arrondie en avant, finement rugueuse; les antennes sont grenues, presque aussi longues que le corselet et la tête réunis. Le corselet est un pcu plus large que long, plus étroit en arrière, arrondi aux angles antérieurs et sur les côtés, avec ses angles postérieurs aigus. Son bord postérieur est coupe droit, rebordé, avec une double bordure : son disque est asscz bombé , finement ponctué avcc deux fossettes au milieu, êt trois autres fossettes peu marquées au borl postérieur. L'écusson cst perit, arrondli en arrière. Les élytres sont oblongues, plus larges en arric̀re, pointues à l'extrémité. Elles ont chacune sept còtes assez élevćes, lisses, entre lesquelles on observe de petites impressions transverses; la deuxic̀ne côte, à partir de la suture, est plus ćlevće à sa naissance. Le dessous du corps est noir, ponctué. Les pattes sont de grandeur moyenne. Cet insecte a des ailes. Il a été trouvé près de Lima.

Nous avons figurć sa tête grossie et vue en dessus dans notre planche $1 \mathrm{~V}$, figure $5 \mathrm{~B}$. La figure $5 \mathrm{~A}$ représente sa bouche très-grossie et vue en dessous.

\section{Genre NYCTOPÈTE, Nyctopetus. GuÉr.}

Ce genre, qui a beaucoup de rapports avec les Hégètres, à cause de sa lèvre intérieure recouvrant lcs màchoires et presque cntièrement les palpes labiaux, ne peut cependant pas être confundu avec lui, parce que son labrc est saillant ct point recouvert par le bord antérieur de la têtc, et que ses antenncs sont en scie; mais il en est surtout éloigné par la présence d'ailes, comme dans les Ténébrions. Nous croyons donc devoir le placer près des Ténébrions, à cause de cette circonstance, en lui donuant les caractères suivants :

Labre transverse, saillant, un peu écháncré en avant. Mandibules fortes, saillantes, bidentécs au bont, avec un sillon an còté externe. Mâchoires assez grandes, à lobes inégaux, l'extéricur plus grand, cilié au bout, l'nnterne plus court et plus étroit, cilié et arné d'un onglet corné. Palpes maxillaires assez courts, de quatre articles, le premier petit, lesecond plus grand que le troisième, qui est égal au dernier, celui-ci tronqué obliquement en dedans en forme de hache. Lèvre inférieure très-grande, en demi-cercle, couvrant tout-à-fait les mâchoires, la languette, et presque les palpes labiaux, qui sont courts, terminés par un articlc un peu en lache.

Vo)agr de la Coquille. - Z. Tom. II, partic II. $\mathrm{i}^{\mathrm{re}}$ Div. 
Anteunes presque filiformes, en scie; le premier artiele assez grand, un peu courbé; le sccond petit, eonique; le troisième presque aussi grand que les deux premiers; les autres de moitié plus courts, allant en s'ćlargissant depuis le quatrième jusqu'au neuvième, dilatés en seic en dedans; le dernier effilé au bout, en forme de toupie.

Ce genre se compose de trois espèees, toutes propres au Chili:l'nne, qui nous a servi de typc, a étć trouvée à la Conception; les deux autres ont étć rapportées des environs de San-Yago par M. Galy.

NYCTOPÈTE TÉNÉBRIOIDE, Nyctopetus tenebrioïdes. GuÉr. - Ater, capite rotundato, thorace quadrato, transverso; elytris punctulatis lateribus depressis. - L. 13 mill., I. 6 m. - Atlas, Ins., pl. IV, fig. 7 .

Sa tête est noire et petite, arrondie en avant, fincment ponctuée; les antennes sont noires, presque de la longueır du eorselet et de la tête. Le eorselet est transversal, plus étroit en avant, ąrrondi sur les eôtés, un pen avancé en arrièreà son bord postérieur, avee lés quatre angles assez aigus; il est un peu bombé au milieu, finement ponctué, avec une petitc inpression pcu marquće de chaque côté et sur le bord postérieur. L'éeusson est petit, triangulaire; les ćlytres sont ovalcs, plus larges que le eorsclet à leur base, d'une couleur noire un peu brunâtre, rebordées, avee des côtes effacées, dont les deux du nilieu de l'élytre sont uı peu plus saillantes. Le dessous du corps est lisse, sans poils ni duvet, de la couleur des élytres; les pattes sont courtes, brunes. On trouve des ailes blanchàtres sous les élytres.

La figure $7 \mathrm{~B}$ de la planchc IV représente la tête de ectte espèce, grossie et vue en dessus. On voit cettc même tête plus grossie et préscntée en clcssons figure 7 A. La figure $7 \mathrm{C}$ offre unc mandibule isolée. Enfin on voit en $7 \mathrm{D}$ une mâchoire très-grossie et isolćc; on a seulement oublié de faire sentir le crochet eorné qui se trouve à l'extrémité du lobe interne. - Cet inseete vient de la Conception, au Chili. Les deux autres espèces appartenant à ee genre sont déerites dans le Magasin de Zoologie, année 1834 .

OPATRE APLATI, Opatrum complanatum. GuÉr. - Ater, thorace transverso, angulis anticis posticisque acutis; elytris leviter rugrsis, striis attenuatis. - L. 8 mill., 1.4 m. - Atlas, Ins., pl. IV, fig. Io.

Il est d'une eouleur uniforme, enfumée, terne; sa tête est petite, ponctuée, élargie en avant des yeux, avec les antennes insérées sous le rebord que forme cette dilatation, et le bord antérieur fortement échancré. Les antennes sont brunes. Le corselet est transversal, éehancré en avant, plus étroit, arrondi sur les côtés, avee le bord postérieur peu sinueux et les quatre angles très-aigus. Son disque est aplati, fincnent rugueux. L'écusson est petit, transverse, très-lisse et un peu luisant. Les élytres sont plus larges quc le eorselet, arrondics au bout, finement rugueuses : vues à la lonpe, elles présentent de faibles traccs de côtes longitudinales effacécs. Le dessous et les pattes sont noirs. - Cet insecte a été pris à Bourou, dans les Moluques. 
OPATRINE STRIÉ, Opatrinus striatus. GoÉR. - Ater, capite thoraceque transversis, leviter punctatis; elytris striato-punctatis : subtus brunneus. - L. 6 mill., l. 2 m. $\frac{1}{2}$. Atlas, Ins., pl. IV, fig. I 2.

Ce petit inseete ressemble beaueoup à l'espèee qu'on rapporte au Blaps prınctata de Fabrieius et de Sehonnerr, et l'on ne pourrait pas les distinguer, si notre iuclividu n'offrait pas une différenee notable dans ses tarses intermédiaires. Dans eelui qui est généralement eonnu sous le nom d'Opatrinus punctatus, les tarses intermédiaires ont les deuxième et troisième artieles dilatés (voy. notre Leonogr. du Règne anim., Ins., pl. 29, fig. I 4 b), tandis que dans notre espèce le troisième artiele seulement est dilaté en eœur, avee le prenier, le seeond et le quatrième très-petits et triangulaires. Notre Opatrinus striatus est allongé, d'un noir peu luisant; sa tête est petite, de forme hexagone, avee les angles arrondis, aplatie, finement ponetuée : ses yeux sont assez grands. Les antennes ont à peine deux fois la longueur de la tête; tous leurs artieles sont obeoniques, avee les trois derniers plus gros et grenus. Le eorselet est transversal, un peu plus étroit en avant, eoupé earrément antérieurement et postérieurement, arrondi sur les eôtés, très-finement ponetué, vu à la loupe. L'éeusson est très-petit, arrondi. Les élytres sont de la longueur du eorselet, presque parallèles, arrondies an bout; elles ont ehaeune dix stries ponetuées, et leur surface, vue à la loupe, est eouverte de trèspetits points. Le clessous du eorps est aussi finenent ponetué; les pattes sont noires, quelquefois d'un brun rougeâtre; garnies de poils très-eourts, avee les jambes antérieures plus larges à l'extrémité et tronquées obliquement. - Ce petit Opatrine a été pris aux environs de la Conception, au Chili. Nous en avons vu un qui venait de Monte-Video; enfin un autre individu nous a été donné par M. Gay, qui l'avait pris aux environs de San-Yago.

Nous avons représenté la tête, la bouche et les tarses de eet inseete dans notre planehe IV, figure I2 A, B, C, D, E.

\section{Genre PHYTOPHILE, Phytophilus. Gúér.}

L'inseete qui a donné lieu à l'établissement de ee genre ressemble, au prenier eoup d'œil, à un Helops caraboïdes des environs de Paris; mais, quand on examine sa bouelue, on trouve des différenees si notables, qu'il est impossible de le placer dans le même genrc. Les Hélops ont une lèvre inférieure assez petite, earrée, laissant les màehoires presque entièrement à déeouvert, ainsi que la languette; tandis que chez linseete qui nous oceupe, eette même lèvre est grande et reeouvre entièrement toutes les parties de la lrouche.-Dans notre inseete, les antennes sont aussi très-différentes de eelles des Hélops. Voiei les caraetères que nous assiguons à ee nouveau genre:

Labre saillant, un peu éehancré en avant, plus large que long. Mandibules avancées épaisses, terminées en euiller au bout. Màehoires petites, terminées par deux lobes inégaux, eiliés, dont l'externe, tronqué obliquement, est le plus grand. Palpes maxillaires 
un peu plus longs que les mâehoires, de quatre artieles; le premier très-petit, le second grand, plus épais à l'cxtrémité; le troisième plus court que le préédent, eonique; et le dcrnier dc la longueur du seeond, mais élargi au bout, tronqué obliquement et fortement séeuriformc. Lèvre inférieure grande, transversalc, insérée dans une grande échancrurc du menton, reeouvrant entic̀rement la languette et les nâchoires, et ne laissant voir que les derniers articles des palpes maxillaires.

PHYTOPHILE HÉLOPIOIDE, Plytophilus helopioïdes. GuÉr.-Brunneo-metallicus, lavigatus, leviter punctulatus; pedibus antennisque rufis. - L. 8 mill., 1. 4 m. - Atlas, Ins., pl. IV, fig. 9 .

Cet inseete est de forme ovale, un peu bo̊mbé. La tête et lc corselet sont d'un noiràtre tirant au violet. La têtc est petite, ponctuée; les antennes sont brunes, ayant une fois et demie au plus la longueur de la tête. Le corselet est transversal, plus étroịt en avant, arrondi sur les eôtés, ponctué, coupé droit en avant, et un peu lobé au bord postérieur. L'éeusson est très-petit, triangulaire; les élytres sont un pcu plus larges que le eorselet à la base, presque parallc̀les, arrondies au bout, d’un brun-verdàtre un peu métallique, luisantes, avee dc faibles stries eomposées de petits points enfoncés. Le dessous est de la même eoulcur, ponctué. Les pattes sont d'nn ferrugineux foneé. - Cet insecte vient de Lima.

Nons ayons rcprésenté sa tête, en dessus et grossie, sous le nº 9 B. La figure 9 A présentc sa bouchc vue en dessous pour montrer la lèvre inférieure; enfin nous avons donné une figure d'une màehoire avee son palpe sous le $n^{\circ} 9 \mathrm{C}$.

ADÉLIE A COL DILATÉ, Adelium dilaticollis. Guér.-Nigro-ceneum subtus nigrum; thorace rotundato, transverso, marginato; elytris striis valde impressis. — L. 19 mill., 1. 7 m. -Atlas, Ins., pl. IV, fig. 11 .

Le eorps de eette belle espèce est noir, avec la tête, le eorselet et les élytres d'un noir bronzé tirant sur le violet. La tête est petite, arrondie en avant, aplatie, avee deux impressions courbes partant des ycux et se dirigeant vers le bord antéricur : les anternes sont de la longueur de la tête et du corselet, noires, grcnues et pubeseentes. Le corselet est plus large que les élytres, très-arrondi sur les eôtés, rebordé, plus étroit en arrière, plus large que long, ćehaneré en avant pour recevoir la têtc, aplati avec un sillon parallèle au bord, de ehaque eôté, et un sillon longitudinal au milieu. Sa surface est entièrement lisse. L'éeusson cst petit, triangulaire. Les ćlytres sont moins larges que le eorselet à leur base; ;elles s'élargissent un peu vers leur tiers postéricur, et se terminent en pointe obtusc; leur surfaee est lisse, et elles ont ehaeune neuf sillons lisses, assez profonds. Les pattes sont assez grandes, avee l'extrémité des jannles et le dessous des tarses garnis d'un duvct roussâtre. - De la Nouvelle-Hollande.

Comme ectte espc̀ee s'éloignc un peu des Adélies par sa forme, nous avons eru devoir figurcr les parties de sa bouche, afin de montrer qu'elle a bien tous les caraetères de ce genre. La figure I B présente sa tête grossie et vue en dessus : on voit son dessous 
avec la lèvre inférieure, sous le $\mathrm{n}^{\circ}$ I r $\mathrm{A}$; enfin sa mâchoire, avec le palpe maxillaire, est représentće figure I I $\mathrm{C}$.

AMARYGME CHANGEANT, Amarygmus mutabilis. Guér. - Cupreus, corpore convexo, pedius corporeque infra nigricantibus, tibiis tarsisque rufo-villosis. - L. I I mill., l. 7 m. $\frac{2}{2}$. - Atlas, Ins., pl. V, fig. I.

Il est de forme ovale, bombé, avec la tète et le corselct penchés en avant. La tête est d'un noir violet, ponctuée, enfoncée dans le corselet jusqu'aux yeux; son chaperon est très-avancé, arrondi; il porte un labre saillant, transversal, cilié. Les mandibules sont grandes, insérées près de la naissance du claperon et des antennes, bidentées au bout. Les yeux sont grands, très-rapproehés sur le vertex, embrassant la base des antennes; celles-ci ont presque deux fois la longueur du corselet et de la tête; elles sont noires, composées d'articles obconicues, grossissant à partir du septième article, aplatis depuis cet article jusqu'au dernier. Le corselet est ćgalement d'un noir violet, presque deux fois plus large que long, beaucoup plus étroit et échancré en devant, arrondi sur les côtés, faiblement lobé en arrière, bombé, luisant ct couvert de points enfoncés, assez forts. L'écusson est petit, triangulaire. Les ćlytres sont d'un noir verdâtre à reflets rouges et violets, trèsbrillantes, lisses, avec huit lignes longitudinales de points enfoncés, assez forts, et distants entre cux. Le dessous du corps est noir, avec les pattes de la même couleur; les jambes sont un peu épaissies au bout, garnies d'un duvet fauvé, ainsi que le dessus des tarses. - Cette jolie espèce vient de Bourou, dans les Moluques.

AIIARYGUE A COL VIOLET, Amarygmus iodicollis. Guér. - Oculis fere contignis. Ater, thorace violaceo; capite elytrisque violaceo-viridentibus; antennis corporeque infra nigricantibus. -- L. I I mill., 1. $6 \mathrm{~m}$.

Cette espècc est très-voisine de la préeédente; mais elle en diffère par la couleur, et surtout par ses élytres, qui sont ponctuées, avec les stries formées dc points plus fins et plus serrés. Sa tète est verte, avec les yeux presque contigus. Les antennes sont noires, ayaut plus de denx fois la longueur de la tête et du corselet, plus grêles que dans l'espèce précédentc. Le corselet est trapézoïle, très-étroit en avant, un peu arrondi sur les côtés, d'un violet luisant et très-finement ponctué, vil à la loupe. L'écusson est trèspetit, triangulaire, violet. Les élytres sont plus allongées que dans l'espèce précédente, de la largeur du corselet à la base, s'élargissant de suite, et restant parallèles jusqu'aux deux ticrs de leur longueur, endroit où elles commencent à diminuer pour se terminer en pointe arrondie. Elles sont couvertes de très-petits points enfoncés, visibles à la loupe; lcurs liuit stries de poiuts enfoncés sont plus rapproehées, formées de points très-serrés entre cux. Le dessous est noir. Les pattes sont plus grêles, noires, avec la base des cuisses fcriugineuse. - Cette jolie espèce vient d'Amboine. 
AMARYGME CUIVREUX, Amarygmus cupreus. Guén. - Ovatus, viridi-aneus, elytris punctato-striatis, pedibus corporeque infra nigricantibus. - L. 12 mill., I. $7 \mathrm{~m}$. Atlas, Ins., pl. V, fig. 2.

Cette espèce ressemble beaucoup à notre $A$. Mutabilis pour la forme : sa tête est d'un noir bronzé, ponctuée, avec les yeux bicn moins rapprochés que clans les espèces précédentes. Les antennes sont noires, filiformes, très-peu renflées vers le bout. Le corselet est trapćzoïde, lissc, d'un cuivreux à reflẹts jaunes. L'écusson est petit, triangulaire, d'un bronzć plus foncé. Les élytres sont plus larges que le corselet à la base, arrondies sur lis côtés, lisses; clles ont chacune neuf stries de points enfoncés. Le dessous est noir, faiblement ponctué. Les pattes sont assez longues, noires, lisses, sans poils ni duvet. - Cette espèce a été trouvée à Dory, dans la Nouvelle-Guinée.

Nous avons représenté sa tête grossie et vue en dessus, figure $2 \mathbf{B}$; on voit sa bouche représentéc en dessous, fig. $2 \mathrm{~A}$. La figure $2 \mathrm{C}$ offre la mâchoire et le palpe maxillaire; l'antenne est représentéc sous le $n^{\circ}{ }_{2} \mathrm{D}$. Enfin les figures $2 \mathrm{E}, \mathrm{F}, \mathrm{G}$, représentent ses tarses.

HÉLOPS BLEU, Helops ccerulescens. GuÉR. - Nigro-cceruleus; thorace subquadrato; elytris subparallelis, profunde striato-punctatis. Tibiis anticis arcuatis. - L. 16 mill., 1. 6 m. 1/2. -Atlas, Ins., pl. V, fig. 3 .

Ce bel insecte cst oblong, presque cylindrique, d'un beau bleu foncé luisant. Sa tête est petite, aussi longue que large, avec unc impression en croissant entre les yeux; elle cst finement ponctuée, vue à la loupe. Le corselet est de forme carréc, un peu plus large que long, arrondi aux angles antćrieurs, coupé droit en avant, un peu sinueux au bord postćrieur; sa surface est luisante et parait lisse; mais, vue à la loupe, on y aperçoit dc petits groupes de points enfoncés, placés irrégulic̀rement. L'écusson cst trèspetit, triangulaire. Les élytres sont plus larges que le corselet, arrondies aux épaules, avec unc petite bosse de cliaque còté, presque parallèles, arrondies postérieurement: elles sont lisses et offrent cliacune huit stries de gros points enfoncés. Le dessous est d'un noir un pcı bleuâtre, avec les pattes grandes, à cuisses renflées; les jambes antérieures sont arquées, les intermédiaires le sont aussi un peu; mais les postérieures sont droites. - Cette espèce vient de Bourrou, dans les Moluques.

\section{Genre GYPHONOTE, Cyphonotus. GuÉr.}

Le magnifique insecte qui nous a servi pour établir ce genre avait été pris par M. d'Urville pour un Curculio. Il sc rapproche un peu des Sphénisques, et possède aussi quelques caractèrcs des Sténotrachèles; mais l'ensemble de son organisation ne permet de le classcr dans aucun de ces genres, et nous a déteruiné à en former une nouvelle coupe, à laquelle nous assignons les caractères suivants : 
Labre très-large, transversal, presque droit en avant, aussi large que le chaperon. Mandibules fortes, saillantes, tronquées obliquement et tranehantes au bout. Mâchoires courtes, ayant le lobe interne eourbé en cledans, très-petit, arrondi au bont et cilié, et le lobe externe quatre fois plus grand, eourbé en dedans, bossu extérieurement, arrondi, et également cilié. Palpes maxillaires très-grands, de quatre articles, le premier eourt, eylindrique, articulé obliquement avee le seeond, qui est plus de trois fois plus long, renflé à l'extrémité. Le troisième petit, obeonique, et le quatrième immensément grand, aussi long que les précédents réunis, très-large, obliquement tronqué en dedans, et fortement sécuriforme. Lèvre inférieure allongée, plus étroite à sa base, avee une languette très saillante, plus large, avancée au milieu, et portant les palpes maxillaires, qui sont courts et terminés par un grand article en forme de eoupe, formant le demi-eercle, et tronqué presque carrément. Antennes filiformes, et ne grossissant un peu qu'it partir du huitième artiele, eomposées d'artieles eylindriques à la base, et obeoniques à l'extrémité, avec le dernier de forme ovoüle, et un peu plus grand que les précédents.

Ce genre a été adopté par M. Gay, dans l'édition anglaise du Règne Animal; il donne une bonne figure cle notre espèce, tome I, pl. 124, fig. 2. M. Gay en a trouvé une ou deux autres espèces aux environs de San-Yago; elles font probablement partie de la collection du Muséum.

CYPHONOTE DROMADAIRE. Cyphonotus dromadarius. Guér. Nigro-caruleus; thorace cylindrico; clytris acuminatis, 4 costatis; in interstitiis valde reticulatis, costis duabus mediis basi in altum produc tis. Capite duabus, thorace quinque vittis albis sericeis. Elytris maculis quadratis, vel elongatis sericeis albis, inter reticulis. - L. 19 mill., $1.5 \mathrm{~m}$. -Atlas, Ins., pl. V, fig. 4.

La forme de eet insecte est allongée et élégante; sa tête est avancée, penehée, noire et ponctuée, avee les yeux grands, bordés d'une ligne blanehe formée par des poils trèseourts. Les antennes sont'ì peine de la longueur de la tête et du eorselet. Le eorselet est allongé, cylindrique, un peu plus long que large, un peu plus rétréci en avant, coupé earrément à ses deux exîrémités, d'un noir bleuàtre à reflets violets, avee einq lignes longitudinales formées de poils blanes, dont trois sc voient en dessus, les deux autres bordant lc eorselet sur les eôtés. L'éeusson est petit, triangulaire. Les élytres sont d'un noir bleu à reflets rouges et violets, plus larges que le eorselet, presque parallèles, rétrécies en arrière et terminées elacune par une pointe aiguë. Elles ont chaeune deux eôtes très-élevées : les premières, eelles qui viennent imnédiatement après la suture, offrent à leur base une dilatation élevée, comprimée, qui rend linsecte comme bossu. Entre claque côte il y a de petites élévations longitudiıales et transversales, qui forment un large réseau à mailles plus on moins earrées, le fond de ehaque espaee de ee réseau est garni d'un duvet servé et blane, ce qui fait paraitre l'inseete tout varié de taches blanehes de formes anguleuses, et qui deviennent des espèces de bandes lougitudinales vers l'extrémité. Le dessous du corps est noir, avee des tachés blanches à la base 
des pattes, et sur les eôtés de ehaque segment de l’abdomen. Les pattes sont allongées, noires, assez grêles. - Ce bel inseete a été trouvé à la Coneeption, au Chili.

Nous avons représenté, sous le $\mathrm{n}^{\circ} 4 \mathrm{~B}$, sa tête grossie, pour montrer le labre et la saillie que font les palpes maxillaires. La figure $4 \mathrm{~A}$ présente sa tête, vue en dessous, pour montrer les parties de la bouehe en plaee. On voit la mâchoire très-grossié sous le $\mathrm{n}^{\circ} 4 \mathrm{C}$. Son antenne est représentée figure $4 \mathrm{D}$; enfu la figure $4 \mathrm{E}$ donne l'aspeet de cet inseete quand on le voit de profil.

LAGRIE GENTILIE, Lagria pulchella. Gú́r. - Cupreo-violacea, antennis rufis; capite, thorace elytrorumque basi late pilis uuratis opertis, maculis nitentibus in elytris. - L. I m mill., l. 5 m. - Atlas, Ins., pl. V, fig. 5.

Cette jolie espèee a la tête arrondie, un peu plus forte que le eorselet, finement rugueuse, noiràtre, avee un duvet jaunâtre eourt. Les antennes ont presque deux fois la longueur de la tête et du eorselet; elles sont fauves à leur base et noirạtres à l'extrémité. Le eorselet est un peu plus long que large, plus étroit que la tête en avant, un pelı renflé sur les eôtés, et plus large en arrière; il est de forme eylindrique, finement rugueux et couvert d'uı duvet jaune un peu luisant. L'éeusson est petit, triangulaire. Les élytres sont deux fois plus larges que le eorselet à leur base, élargies en arrière, et terminées en pointe arrondie. Toute leur surfaee est eouverte de gros points enfoneés; elles sont d'un beau violet luisant, avee la base et l'extrémité garnies du mème duvet jaune qu'on olsserve sur le eorselet. Le jaune de leur base forme une bande transverse, coupée obliquement sur ehaque élytre, et produisant un angle rentrant vers l'éeusson; le jaune de l'extrémité n'est pas si bien limité, et va en se fondant jusqu'au milieu de l'élytre. On observe, depuis ee nilieu jusqu’à l'extrémité, des taehes rondes, plus luisantes, dépourvues de duvet. Le dessous du eorps et les pattes sont noirs. Cette espèee élégante a été trouvée à Dory, dans la Nouvelle-Guinée.

LAGRIE MARRON, Lagria castanea. Gúr. - Castanea; thorace, capite pedibusque obscurioribus; capite vertice valde impresso; thorace lavi, elytris valde striato-punctatis. — L. ro mill. $\frac{1}{2}, 1.4$ m. - Atlas, Ins., pl. V, fig. 6 .

Sa tête est arrondie, bossue en arrière, avee un sillon longitudinal sur le vertex seulement. Sa eouleur est rougeâtre; elle est lisse et luisante. Les palpes et les antennes sont de la même eouleur; ees dernières sont presque deux fois plus longues que la tête et le eorselet réunis. Le corselet est earré, eylindrique, très-lisse et luisant, avee un avaneement en forme de eol pour servir d'insertion à la tête; sa eouleur est beaucoup plus foncée que celle de la tête et des élytres. L'éeusson est extrêmement petit, peu visible. Les élytres sont d'un brun rougeâtre, allongées, plus larges que le eorselet à leuı. base, presque parallèles, terminées en pointe arrondie; elles ont ehaeune neuf stries formées par des points enfoneés; l'espaee qui sépare elhaque strie est lisse; mais on y voit de distanee en distanee de petites stries fines et transverses et quelques poils roides. Le dessous du eorps et les pattes sont de la eouleur des élytres. - Cette espèce vient d'Offae, à la terre des Papous. 
HÉLÉE OVALE, Helceus ovatus. GuÉr.-Niger; capite producto, thorace angulis anticis productis, sese invicem decussantilus, in capite foraninatis; carina media elevata; angulis posticis recurvis; elytris spiniferis, costis plurimis panctisque impressis. - L. I5 mill., I. 9 m. - Atlas, Ins. pl. V, fig. 7 .

Cette curieuse espèce est eourte, de forme ovale, assez bombée. Son corselet est plus large que long, un peu rę́tréci en avant, avee les angles antérieurs prolongés chacun en une pointe courbée en dledans, se croisant sur la ligne médiane, et laissant un trou a travers lequel on voit la tête; les bords de ce corselet sont un pen relevés, bordés ; ses angles postérienr's sont prolongés en une pointe assez eourte, un peu eourbée en dedans; sa surface est terne et très-finenıent rugosule, et il y a au milieu une côte longitudinale saillante, un peı plus élevée en arrière. La tête est petite, entièrentent cachée sous le prolongement du corselet, qui ne la laisse voir que par le trou dont nous avons parlé. Elle est avaneée, rugueuse, avee les yeux un peu rapproehés entre eux vers le milieu du vertex. Son bord antérieur est un peu échancré et clonne attache à un labre transverse, saillant, échancré et eilié en avant. Les palpes maxillaires sont saillants, assez eourts, teruinés par un article fortement sécuriforme; les antennes sont plus courtes que le corselct, un peu grenucs et terminées par einq articles plus gros, courts, presque transverses, dont le dernier est le plus grand de tous. L'éeusson est assez grand, un peu sinuenx sur les côtés, arrondi au bout. Les élytres sont de la largeur du corselet, à leur naissance; elles s'élargissent un peu en s'arrondissant, et se terninent en une pointe très-obtuse : elles ont chaeune, près de l'écusson, une côte élevée, tranchante et étroite, qui va se terniner à la suture vers le tiers antérieur de la longueur. Une autre còte, également tranelıante et élevée, vient ensuite; elle n'est pas beaucoup plus longue que la précédente, mais elle se eontinue en une série d'épines plates et tranchantes jusqu'au bout. Entre la suture, qui est ćpineuse, et cette espèee de eòte, on observe une ligne d'épines ou de tubereules moins élevés. Les côtés des élytres, à partir de la seeonde côte, offrent encore deux espèces de tubercules épineux et, près du bord, d'autres tubercules placés saus ordre. Le bord de ces élytres est relevé en gouttière, et tonte leur surface est garnic de points enfoncés dans l'intervalle des tubercules. Le dessous du corps est fimement rugueux, les pattes sont simples. - Cet insecte remarquable vient de la Nouvelle-Hollande.

CILIBE ÉCHANCRÉ, Cilile emarginatus. GúÉn. - Ater; capite rotundato, transwerso; thorace transverso, prope caput emarginato, laterilus reflexo, in elytris producto. Elytris margine reflexis, punctatis, sex-carinatis. - L. 15 mill., I. 9 m.

I cst d'un noir terne; sa tête est petite, aplatie, avec une petite saillie sur les còtés et le hord antéricur un peu ćelıaneré. Le labre est très-court, inséré dans cette échancrure, cilié, échancré. Les antennes sont presque anssi longues que le corselet, grenues, avee les quatre derniers articles un peu plus épais. Le eorselet est transversal, beaucoup plus étroit en avant, sinué en arrière, fortement échaucré en avant, avec les quatre

Voyage de la Coquille. - Z. Tom. II, Part. II. $\mathrm{I}^{\text {re }} \mathrm{div}$. 
angles arrondis et toute sa surface fincment granulcuse et terne. L'écusson est triangulaire, deux fois plus large que long, peu visible. Les élytres sont ovales, un peu plus larges au milieu, terninées en une pointe très-obtuse; toute leur surfacc est couverte de points enfoncés; la suture est un peu élevée, lisse; elles ont ehaeune trois côtes peu élevécs, surtout les extérieures, qui sont très-peu saillantes. Leur bord est relevé en gouttière. Le dessous est noir, lisse, avec les pattes simples. - Cette espèce vient aussi de lia Nouvelle-Hollande.

NO'TOXE A QUATRE TACHES, Notoxus (Anthicus Payk.) quadrimaculatus. Gúr.r. - Ater; thorace cordato, elytris villosis, maculis quatuor rotundatis remotis albis. Antennis clavatis basi rufescentibus, pilosis. - L. 3 nill. $\frac{1}{2}, 1.1$ m. $\frac{1}{2}$. - Atlas, Ius., pl. V, fig. 8 .

Ce joli petit insecte, qu'on prendrait au prenier abord pour une Anthie en miniature, devra peut-être former un genre propre, quand on aura nieux étudié la tribu des Anthieides, à laquelle il apparticnt. Sa tête est petite, assez large aux yeux, rétrćeie et arrondie cn avant; le labre est transversal, faiblement échaneré; les mandibules sont assez avancées, terminées par deux dents inćgales, aiguës. Les màchoires sont terminées par deux lobes inégaux, ciliés; le plus petit interne, l'extcrne bossu, arrondi. Les palpes maxillaires sont assez courts, composés de quatre articles, le premier très-petit, peu visible, les second et troisième plus grands, cylindriques, obconiques, le dernier de la longueur des trois précédents réunis, allongé, un peı renflé au milieu, un peu plus étroit et tronqué obliquement au bout et en dedans. La lèvre inférieure est un peu plus longue que large, arrondie et plus large en avant, un peu éehancrée sur les côtés, aver une languette de sa grandcur, qui donne inscrtion à deůx grands palpes labiaux, beaucoup plus longs que les maxillaires, ayant lcur premier artiele le plus eourt, grêle, le second également grêle et eylindrique, deux fois plus long, et le dernier plus long que les deux précédents réunis, très-renflé au unilieu, fortement sécuriforme. Les antennes sont plus longues que la tête et le corselet réunis, filiformés jusqu'au milieu de leur longueur, où les artieles grossissent iusensiblement et se terminent par un article ovoïde, rétréci à la pointe. Le corselet est en forme de eœur, tronqué en avant et en arrière, luisant et garni de quelques poils roides. Les élytres sont un peu plus larges, parallèles, luisantes et velues, avee quatre grandes taelies jaunes placées vers leur base et vers l'extrémité. Lc dessous du corps est noir. Les pattes sont assez longues; leurs cuisses sont noires, avec les jambes et les tarses d'un rougeâtre ferrugineıx. - Ce petit insecte a ćté trouvé à Amboine.

Nous avons figuré, sous le nै 8 B., sa tête grossie et vue en dessus; la figure 8 A présente sa têtc vue en dessous pour montrer les parties de la bouehe. Sa mâchoire, trèsgrossie, est représentée sons le n 8 C. Enfin les n"s 8 D, E, F, indiquent ses tarses antéricurs, intermédiaires et postérieurs. 
OEDĖMĖRE LIVIDE, OEdemera livida. OLIv._Flavida, sericea; oculis nigris, elytrorum circuitu pallidiore. - L. I5 mill., 1. 4 m. - Atlas, Ins., pl. V, fig. 9.

OEderzera Forsterii. Escr. Entomographien, etc.

Cette espèce cst fort allongće, d'un jaune soyeux pâle; sa tête est étroite, avec la bouclie avancée; les mandibules sont brunes et les yeux noirs, ronds et assez grands. Les antennes sont filiformes, au moins deux fois plus longues que la tête et le corselet réunis. Le corselet est allongé, un peu bombé, plus ćtroit en arrière, arrondi sur les còtés, avec une faille inpression au milieu et vers le bord postérieur; sa surface est entièrencnt couvertc d'un duret court, serré, formé de petits poils couchés. L'écusson est petit, triangulaire. Les élytres sont plus larges que le corselet, parallèles, arrondies au bout, lisses, couvertes du même duvet soyeux dont nous avons parlé au sujet du corselet, avec la suturc et le bord extcrne plus pâles. Le dessous du corps et les pattes sont d'un jaune pàle. Les cuisscs postérieures ne sont pas renflécs. - Cette OEdémère a été trouvée dans l'ìle de Taiti.

CIS'TELE VELUE, Cistela pilosula. GuÉR.-Brunnea, ovata, sericea; subtus corpore pallidiore; antennis serratis; thorace trapeziformi. - L. 6 mill., 1. 3 m.-Atlas, Ins., pl. V, fig. 10.

Cettc petite Cistèle est ovalaire, d'un brun ferrugineux. Sa tête est petite, finement ponctuée, couverte de poils courts et jaunàtres. Les antennes sont de moitié plus longues que la tête et le corselct, filiformes et d'un brun plıs foncé. Le corselet est de forme trapézoïde, très étroit en avant, un peu sinué en arrière, avec les angles postérieurs très-aigus. 11 est ponctué et couvert de poils jaunàtres très-courts. L'écusson est trèspetit, triangulaire. Les élytres sont de la même couleur, faiblement striées, couvertes de points enfoncés et de poils jaunes et roides conme ceux du corselct. Le dessous du corps est plus pàle, d'un ferrugineux jaunàtre, ainsi que les pattcs.-Cict insecte vient de Bourou, dans les Moluques.

CISTĖLE JAUNE, Cistela lutcola. Gúér. - Lutea, antennis serratis; ano, tibiis, tarsis antennisque fuscis. - L. Io mill., l. 4 m. - Atlas, Ins., pl. V, fig. I 1.

Cettc espèce resscmble lseanconp, au premicr coup d'ocil, à notre Cistèle sulfureuse; mais ellc cn diffère par le corselet, par la forme des élytres, etc. Elle est d'un jaune couleur de gomme gutte; sa tête est étroite, allongée, avcc la bouche très-avancẻe en nuseau. Les yeux sont bruns, ainsi que les antemnes, qui ont plus de la noitié de la longueur du corps et sont filiformes, légèrement en scie. Le corselet est aussi long que large, arrondi en avant, tronqué droit cn arrière, avec une faible impression transverse au bord postérieur. Sa surfice n'est pas granuleusc, mais clle n'est pas lisse ct semble dépolic. L'ćcusson est triangulaire, bien visilble. Les élytres sont un peu plus larges que le corselet, un peu arrondies sur les côtés et à l'extrénité; leur surfacc est un peu plus polie que celle du corselet, et elles ont chacune neuf stries formées de petits points 
enfoncés. Le dessous du corps est jaune avec les deux derniers anneaux de l'abdomen d'un noir luisant. Les pattes sont assez grandes, simples, avec les cuisses jaunes et les jambes et les tarses loruns. - Cette Cistèle vient d'Amboine.

MÉLOÉ CHILIENNE, Meloe chiliensis. GuÉr. - Atra, antennis simplicibus; thorace cordato, transverso, apice truncato; elytris valde reticulatis. - L. 16 mill., l. 7 m. Atlas, Ins., pl. V, fig. 12.

Elle est d'un brun foncé presque noir; sa tête est, comme dans toutes les espèces de ce genre, penchée, portée sur un cou étroit, hossue en arrièrc; elle est granuleuse. Les antennes sont un peu plus longues que la tête et le corselet réunis; elles sont filiformes, composées d'articles un peu épais, mais simples. Le corselet est transversal, renflé sur les côtés, rugueux, avec une impression transverse vers son bord antérieur. Les élytres sont plus larges que le corselet, grandcs, recouvrant les deux tiers de l'abdomen, arrondies, fortement réticulées. L'abdomen est finement granulé; les pattes sont grandes et comprimćes. - Cette belle espèce vient de la Conception, au Chili.

STÉNOCÈRE, DE GARNOT, Stenocerus Garnotii. GuÉr."-Fuscus, tomentosus; capite sordide albido; thorace vittis lateralibuc, cruce medin corollam tetrapetalam mentiente, anaculisque elytrorum sparsis sordide albidis; elytris lineis nigris intermptis; subtus sordide albidus. - L. 14 mill., 1. 5 m. - Guérin, Iconogr. du Règne animal, Ins., pl. 36 , fig. 3 .

Cette jolie espèce est reconnaissable, au premier coup d'œil, par la fleur à quatre pétales qui est dessinée nettement au milieu de son corselet; son corps est un peu déprimé, d'un brun de bistre; son rostre est plat, d'un blanc jaunàtre, avec les inandibules noires, saillantes. Les yeux sont grands, réniformes, obliques. Le dessus de la tête est de la couleur du rostre et d'un brun foncé en arrière. Le corselet est un peu plus large que long, beaucoup plus étroit en avant, tronqué carrément en avant et en arrière, aree les côtés presque droits; il cst brun en dessus, avec une bande longitudinale d'un blanc jaunâtre de chaque côté, derrièrc laquelle on voit plusieurs petites taches de la même couleur; le milieu est occupé par quatre taches ovales, bien circonscrites, placées en croix, et formant une petite fleur; on voit denx autres petites taches au bord postérieur. Les élytres sont plus larges que le corselet, un peu plus étroites en arrière, avec des séries longitudinales de taches alternativement noires et d'un blanc jannàtre. Les pattes et les antennes sont ferrugineuses : le dessous du corps est d'un blanc jannàtre.-Cette espèce vient de Dory, à la Nouvelle-Guinée. Nons l'avons dédiée à notre ami M. Garnot, l'un des zoologistes du voyage de la Coquille.

BÉLUS BRUN, Belus brunneus. GuÉr. - Linearis, elongatus, castaneus; thorace rugosulo-punctato; elytris rugosulis; sultus albidus; abdomine nigro, lateribus albis. - L. 13 mill., , 1.2 m. 
Cette petite espèce est étroite, allongée, d'une couleur marron ferrugineux. Son rostre est avancé, cylindrique, droit, luisant. Les antennes sont ferrugineuses; les yeux sont saillants, ovalaires. Le corselet est plus large que long, plus étroit ell avant, arrondi sur les côtés en arrière, rugueux ct ponctué avec quelques poils blanchâtres et trèscourts au milieu. L'écusson est grand, pointu en arrière; les élytres sont parallèles, rétrécies postérieurement, mais point terminées en queue, comme dans le Belus bidentatus; elles sont rugueuses et offrent quelques petites tachies blanchâtres formées par des petits poils placés près de la suture. Le dessous de la tête et du thorax est blanchâtre; l'abdomen est d'un noir luisant, avec les côtes blanchâtres. Les pattes antérieures sont plus grandes avec les cuisses très-renflées. - Cet insecte vient du Port-Jakson.

BRENTHE BICOLORE, Brenthus bicolor. Guér. - Niger; rostro antennisque brunneis. Capite, thorace, elytris apice sanguineis. Pedibus nigro-fuscis. (Fom.) - L. I7 mill., l. 2 m. $\frac{1}{4}$. - Atlas, Ins., pl. VI, fig. 11.

Cette jolie espèce, dont nous ne connaissons que la fentelle, est ćtroite et allongée, comme les espèces du même genre; sa tête est bombée, portée sur un cou en forme de bouton, rouge, avec la base dn rostre de la même couleur; le reste, à partir des antennes, est d'un brun de bistre. Ce rostre, avec la tête, est à peu près de la longueur du corselet; il est un peu courbé, cylindrique, et il présente un sillon assez profond partant de la naissance des antennes, et se terminant à lá hauteur des yeux. Les antennes sont à peu près de la longueur du rostre, prise des yeux à l'extrémité; elles sont brunes, composées d'articles serrés, terminées par un article un peu allongé: elles sont insérées au tiers de la longueur du rostre, vers sa base. Le corselet forme la moitié de la longueur des élytres; il est étroit en avant, renflé sur les côtés et en arrière, cylindracé, avec un profond sillon au milieu, qui n'atteint pas les extrémités. Les élytres sont parallèles, uII peu rétrécies cn arrière, tronquées et formant une échancrure au bout; elles sont cannelées vers la suture, et le reste de leur surface est garni de séries longitudinales de points enfoneés. Elles sont d'un brun foncé presque noir, avec l'extrémité rouge. Le dessous du corselet et de la tête est ronge, lisse. Lé dessous du métathorax et de l'abdomen est noir et ponctué; l'extrémité de ce dernier est également rouge. Les pattes sont noires, avec les cuisses renfées. Les antérieures sont un peu plus grandes.

Cet insecte a été trouvé à Dory, dans la Nouvelle-Guinée. Nous avons représenté sa tête sous le $\mathrm{n}^{\circ}$ i $\mathrm{A}$.

BRENTHE DE LA NOUVELLE-GUINÉE. Brenthus nova-guineensis. GuÉr.-Nigro-brunneus; antennis apice sub-clavatis, perfoliatis. Thorace rugoso, ovato, longitudinaliter sulcato. Elytris elongatis, profunde striato punctatis, linea flava prope suturam. Pedibus Lrunneis, femoribus basi mfescentibus. - L. 9 mill., I. 2 m. - Atlis, Ins., pl. VI, fig. I3 (la tête.)

Cette petite espc̀ce est d’un brun noirâtre foncé avec quelques reflets métalliques. Sa têtc est de forme carrée, portée sur un cou en forme de nœud bien distinct; elle est très-finement ponctuée avec un sillon longitudinal profond au milien. Le rostre est à 
peine plus long que la tête et le con réunis; il est presque droit, sillonné au milieu, et donne attache, vers le milieu de sa longueur, aux antennes; celles-ci ont à peu près la longueur de la tête ct du rostrc réunis; elles sont un peu perfoliées, un peu renflées au bout, avec les trois derniers articles plus grands. Le corselet est ovoïde, plus étroit cn avant, renflé et arrondi sur les côtćs, profondément sillonné au milicu, rugueux en-dessus et en-dessous. L'écusson est très-petit, peu visible. Les èlytres sont parallèles, un peu rétrécies à l'extrémité et tronquées obliquement; elles ont chacune neuf côtes élevées, étroites, entre lesquelles on observe de gros points enfoncés : les trois prenières côtes, à partir de la suture, sont plus larges et atteignent le bout de l'élytre; les suivantes se terminent un peu avant son extrémité ; c'est sur la troisième côtc qu'on obserrc une bande étroite, jaune, qui vient se terminer avant l'extrémité, à l'cndroit où se termincnt les côtes les plus courtes. Le dessous du corps est de la couleur du dessus, fortement ponctué ; les pattes sont courtes, fortes, noirâtres et ponctuées; la base des cuisses est rougcâtre.

Ce Brenthe a été trouvé à Dory, dans la Nouvelle-Guinée.

\section{Genre LEPTORHYNQUE, Leptorhynchus. GuÉr.}

Ce genre est très-voisin des Bélorhynchus de Latreille, et nous ne l'en aurions pas distingué, ne possédant qu'un mâle, si notre ani M. Gory ne nous avait pas prêté une femellc, provenant aussi de la Nouvelle-Guinée. En examinant le mâle et en suivant les earactères que Schoenherr assigue à son genre Bélorhynchus, on ne trouve pas de différences assez notables pour être autorisé à faire un nouvcau genre. Mais, quand on vient à examiner la femelle, on voit que ses antennes ne sont pas insérées juxta basin rostri, comme le dit Schoenherr, mais au milieu de la longueur de ce rostre. Les articles de ces antennes, la forme des tarses et plusieurs autres parties du corps distinguent aussi ce genre des Bélorhynchus. Voici les caractères que nous lui assignons:

Antennes longues, assez minces, insérées vers le bout du rostre dans le mâle, et au milieu seulement dans la femelle. Ces antennes sont composées de onze articles, le premier plus épais, ovoüde au bout, le second plus court, obconirgue, le troisième de la longueur du prenier dans la femelle, plus long dans le mâle, cylindrico-conique, les suivants diminuant insensiblement de longueur, obconiques dans le unâle, beaucoup plus courts et presque grenus dans la femelle, les trois derniers allongés, plus épais dlans la femelle, grçles et plus longs dans le mâle. Rostre du mâle plus long que le corselet et la tête jusqu'aux yeux, droit jusqu'à l'insertion des antennes, un peu courbé à partir de ce point, un peu renflé au bout; celui de la femelle moins long que le corselet seul, droit, brusquement rćtréci à partir de l'insertion des antennes, sans renflement au bout. Tête obconique. Corselet étroit en avant, sillonnć au milieu. Élytres allongées, linéaires, un peu aplatics en dessus. Pattes assez grandes, avec les cuisses en massue, les antérieures un peu plus grandes que les suivantes. Jambes terminées en dedans par un petit onglet plus narqué dans la fenelle; tarses allongés, fortement ciliés en dessons, ayant le prenier article plus long que les trois suivants réunis, le second très-eourt, le troisième de mème grandeur, bilobé, et le dernier aussi long que les deux précédents, en niassue, et terminé par deux crochets assez forts. 
LEPTORHYNQUE ÉTROIT, Leptorhynchus angustatus. GứR. - Fusco-niger, elongatissimus, cylindricus; elytris apice maribus dilatatis, vittis duabus longitudinalibus; tibiis, tarsis antennisque pallide rufis. (Mas.)-L. 34 mill., 1. 3 m.-Brenthus angustatus. Nов. Atlas, Ins., pl. VI, fig. г 2.

Cette espèce est très-curieuse à cause de sa longueur extraordinaire; sa couleur est entièrement d'un bruı foncé presque noir; la tête est linéaire, deux fois plus longue que le corselet, cylindrique, un pen renflée à sa basc jusqu’aux yenx, qui sont placés au quart de sa longueur, légèrement courbée au bout. Les antennes sont insérées de chaque côté et près de l'extrémité du rostre, presque de sa longuenr, prise de l'extrémité jus qu'aux yeux, filiformes, et terminées par un article plus long que celui qui précède. Le corselet est assez, court, plus étroit en avant, un peu arroncli sur les côtés, tronqué en arrière, lisse, avec un profond sillon longitudinal au milien. Les élytres sont presque aussi longues que la tête et lc corselet réunis, linéaircs, parallèles, cylindriques, de la largenr du corsclet dans toute leur longueur, un peu dilatées cn dehors, ct échancrées au bout. Leur surface est cannelée vers la suture, avec des strics de points enfoncés; elles ont chacune, près de la suture, une ligne orangée, longitudinale, ćtroite, bordée en dedans par la cannelure suturale, et n'atteignant pas tout-à-fait l'extrénité postérieure. Le dessous du corps est noir, ponctué. Les pattes sont assez longues, brunes, avec les jaubes d'un brun plus ferrugineux. Les cnisses sont renflées à leur extrémité; les jambes sont terminées en dedans par une petite ćpine. Les tarses sont allongés, avec le prenier article plus long que les trois derniers réunis; ils sont garnis en dessous de longs cils blanchàtres.

La fèmelle ressenble complétement au mâlc pour la forme du corps, mais son rostre est bien plus conrt. Le bout de ses élytres eat un pen plus étroit et armé de chaque côté d'une très-petite épine courbe. - Ce joli insecte a été trouvé à Dory, dans la Nouvelle-Guinée.

Nous avons donné une figure grossie de son antenne, sous le $n^{\circ}{ }_{12}$ B. L'un de ses tarses est représenté fig. $12 \mathrm{~A}$.

\section{Genre MYRMACICĖLE, Mjrntacicelus. Cunvrolat.}

Nous avions d'abord adopté, pour ce nouveau genre, le nom de Rhynolaccus, que MI. Latreille lui avait assigné dans sa collection; mais notre ami MI. Chevrolat ayant appris que Schoenlıerr avait employé ce mot pour désigner un autre genrc, voulut bien nous en avertir, ct nous proposa de joindre notre insecte à un travail plus étendu qu'il avait cntrepris sur quelques genres voisins des Cylis; nous nous sonmes empressés, dans l'intérèt de la science, de céder à ce désir, et M. Chevrolat a donné à notre genre le nom de Myrmacicelus, en lui assignant les caractères suivants:

Intonne primo secundoque articulis cequalibus, sequentibus octo, inter se in funem connexis; clava velutina et cylindrica in mare, tanquam in Cylade. In fomina ovali triar- 
ticulata (forsan quatuor articulis) prino majore. Rostrum inflexum, subrectum, teres. Caput rotundatum, antice attenuntum, dimensione thoracis. Oculi immcrsi, fere connexi, supra rotunduti. Thorax subcylindricus, in medio valde convexus, strangulatissimus basi et circuatns, apice rotunde trnncatus. Elytra brevia, ovata, subcompressa. Pedes validiusculi, breviusculi. Femoribns maxime clavatis, cameratis. Tibuis rectis, snbcylindricis, arcuatis ortu (genubus haud emarginatis supra), apice subtruncatis. Tarsis latis, latescentibus usque ad apicem. Articulo primo subconico, inflato, secundo breviorc, triangulari, planiusculo, tertio bilobo, quarto omnino secluso in pracedenti.

Ce genre vient immédiatement après les $C_{y}$ las.

MYRMACICÉE BISTRIE, Myrmacicelus bistriatus. Chevrolat. - Atro nitidus, glaber, thorace subelongato, in medio convexo, basi coarctato. Elytris pyriformibus, lateribus compressis, margine bi-striatis. (Fxmina.)

Myrmacicelus formicarius. Chevr. - Ann. de la Soc. entom., t. II, p. 359 (texte.) Myrmacicelus bistriatus. Cnevr. Ibid., pl. i5, fig. B.

Rhinolaccus formicarius. Latr. Figuré dans notre atlas, pl. VI, fig. 7.- L. 4 nill. I /2, I. $\mathrm{m}$ m. 2 l3.

Trompe presque du double plus longuc que la tête, climinuant de grosseur jusqu’à l'extrémité, scabrcıse en avant des yeux, et en dessous dans sa longueur. Tête convexe, rétrécie en avant. Yeux séparés seulement en dessous par une ligne enfuncée. Corsclet cylindroïle, subitcment atténué ct cerclé à sa base, légèrement granuleux à cette place, et échancré latéralement en dessous en demi-cintre; la partie antérieure marquée en marge, près des còtćs, d'une petite ligne. Écusson nul. Élytrcs du double pius larges à la base que le corselet, coupées obliquement aux épaules, avancées en la forme d'un V'sur la place de l'écusson, s'élargissant au-delà du milieu, ayant chacune, près de la marge, deux stries formées de points, commençant aux pattes médianes, et terminées avant l'extrémité de la suture. Trochanters grêles à leur naissance, longs et coniques. On apcrçoit une dent très-petite à l'extrémité postérieurc des cuisses, lorsque les pattes sont étendues. Jambes droites, nédiocres, rugueuses et légèrement renflées prc̀s des tarses, terminées par des soies roicles et courtes. Quatrième article des tarses nuni de deux crochets aigus, cintrés sur eux-mêmes. (Chevr.) - Cet insecte vient du Port-Jakson, à la Nouvelle-Hollandc.

ATERPE A SOURCILS, Aterpus superciliosus. Gvén. - Niger : capite ante oculos fulvo-superciliato. Thorace albo irrorato. Elytris vittis narginalibus albis suturan versus 4.-dilatatis. Corpore subtus allido. - L. r7 mill., I. 6 m._Atlas, Ins., pl. VI, fig. r.

Il est allongé, noir. Sa tête est verticalc, enfoncée dans le corselet jusqu'aux yeux, avec le rostre court, épais, rugueux. Le labre est visible, saillant, un peu échancré en avant. Les mandibules sont saillantes, triangulaires, fortes. Les màchoires sont terminées par un seul lobe triangulairc, tronqué obliquement cn dedans avec des dents aiguës 
sur ce còté. Le palpe maxillaire est très-petit, en forme de tubercule et cntouré de longs poils roides. La lèvre inférieure est insérée dans une échancrurc profonde du menton; elle est un peu plus longue que large, et porte à sou extrémité deux palpes labiaux très-courts, et qui sont composés de trois articles. Les antennes sont insérées dans deux échancrures larges et assez profondes, plucées de clıaquc côté et sur le devant du rostre; elles sont un pen plus longues que la tête, coudées, avcc les deux preniers articles du funicule plus longs, obconiques, les $3,4,5$ et 6 e grenus, et la massue ovale, un peu pointuc, composée de quatre articles distincts. Les yeux sont assez saillants, arrondis; on voit, entre enx et sur le front, dcux petites élévations arrondies en formc de cornes, garnies de cils bruns, qui forment de véritables sourcils au-derssus des yeux. Le corsclet est plus long que large, cylindriquc, renflé au nilieu, arrondi sur les côtés, uI peu avancé sur la tète en avant, et présentant, en face des tubercules de la tète, deux petites élévations oblongues. Sa surface est couverte de profondes inipressions comme un dé à coudre; au fond de chacune d'elles on voit un gros poil blanc, épais et court. Le bord postérieur est garni des mè̀nes poils blancs, mais plus serrés et firrmant unc espèce de lande. L'écusson est très-petit, blanc, triangulaire. Les élytres sont ovalaircs, très-bombées, rétrécies et penchées à l'cxtrémité, couvertes d'impressions irrégulières, comme dans un gros dé à coudre. Leurs bords latéraux sont garnis d'un grand nombrc de gros poils blancs, épais, courts et ressemllaut plutòt à des écailles; cette bordure blancluc se prolonge sur les élytres en quatrc bandes transversales, cn suivant le fond des impressions; la première, située is l'épaule, n’avance pas jusqu'au milieu de l'élytre; la secondc, vcrs le quart antérieur de la longueur, est avancée an-delà du milieu, et formće d'un seul rang d'impressions. Les deux suivantes sont placées à égales distances de la seconde et entre elles; elles sont composées de deuxx rangs diunpressions et viennent atteindre la suture. Enfin l'extrénité est marquée de quelques taches blanches. Le dessous est noir, parsemé irrégulièrement des mêmes poils blancs. Les pittes sont noircs, assez grandes, couvertes d'un mélange de poils noirs et de poils blancs, plus courts et plıs épais.

Cet insecte vient de la Conception, au Chili. Nous avons figuré sa tête sons lẹ $n^{\circ} 1 \mathrm{~A}$. La fig. I B représente sa bouche vue en-dessous; sa mâchioirc est fiğurće sous le $n^{\circ} 1 \quad \mathrm{C}$.

GE்ONÉMUS A STRIES PONCTUÉES, Geonemus striatopunctatus. Guér. - Luteorubescente, elytris striis, punctis nigris elongatis, vittis quatuor brevibus longitudinalibus, atomisque quibusdam albis. Rostro, pedilus abdomineque pallidioribus, tenuiter nigropunctatis. - L. 25 mill., l. 10 m. - Atlas, Ins., pl. VI, fig. 2.

Ce beau clıarançon est rétréci, épais en avant; son corps est très-bonbé avec les élytres renflées et elcvées en arrière. Sa tête cst de moitié plus courtc que le corselet, un peu aplatie en dessus. Les yeux sont un peu obliques, très-peu saillants, un peu ovalaires. Le rostre est cleux fois plus long que la tête, épais, rcnflé au bout, d'un gris finement ponctié de noir, ainsi que la tête, avec un sillon longitudinal au milieu, et un sillon le chaque còté, nieux marqué, partant de chaque œil, et se terninant insensiblement 
un peu avant linsertion des antennes. Les fossettes des anternes sont profondes, bien limitées; elles commencent sur les côtés et à la partie supérieure du rostre, se courbent de suite et vont abontir immédiatement au-dessous des yeux. Les antennes sont grises, longunes et grêles; leur promier article est renflé au bout, son extrémité atteint le bord postérieur de l'oil quand l'antenne est repliée en arrière. Le funicule est composé d'articles obconiques, beancoup plus longs que larges; la massue est brune, grêle, composée de quatre articles. La bouche est noire, l'extrémité supérieure du rostre forme un triangle noir luisant. La lèvre inférieure est tronquée carrćment en avant, arrondie en arrière; les mandibules sont fortes, courtes, creusées en dedans. Le corselet est presque cylindrique, un peu rétréci en avant, rugucux, d'un gris jaunâtre dans les enfoncenıents produits par les rugosités, très-peu lobé derrière les ycux. Les élytres sont ovales, trèsbombées, et élevées en arrière; leurs angles huméraux sont à peine saillants, leur partie postérieure n'offre aucune callosité ou bosse, commc on l'observe dans uotre genre Eupholc; elles sont bcaucoup phis larges au milien quà leur naissance. Leur couleur est semblable à celle du corselet; elles ont chacune neuf stries formćes par de gros points enfoncés, dont le fond est noir; on observc entre la deuxième et troisième strie, en partant de la suture, une lignc blanche naissant du bord antérieur de l'élytre, et se terminant vers le tiers de sa longueur; en deliors de l'extrémité postérieure de cette ligne, on voit deux points blanes, placés, le premier entre la $3^{\mathrm{e}}$ et la $4^{\mathrm{e}}$, et le second, plus petit, entre la $4^{\mathrm{e}}$ et la $5^{\mathrm{e}}$ strie ; on trouve, sur la même liggne et au tiers postérieur de l'élytre, deux taches blanchics peu limitées; il y en a une autre de chaque côté sous chacun des angles huméraux, et une petite sur la même ligne, vers le milieu de l'élytre. Le dessous du corps est du même gris jaunâtre que le dessus, les côtés des segments de l'abdomen ont une bande blanchâtre. Les pattes sont grandes, avec les cuisses renflćes. Elles sont de la couleur du reste du corps, mais un peu plurs pâles, arec une quantitć de petits poils noirs et conrts. Les tarses sont larges, avec le troisième article profondément bilobé.

Ce bel insecte vient de Dory, à la Nonvelle-Guinée; il appartient évidemment au genre Géonénuus de Schœenherr, comme nous nous en sommes assurés en le comparant à une autre espèce de cc genre, envoyée à M. Chevrolat pạr MI. Schoenherr lui-même. Nous pensons que l'espèce fignrée par M. Boiscluval, dans la pl. 7 , fig. 8 du. Voyage de l'Astrolabe: et avec laq̣uelle il fait son genre Chlorolope, appartient aussi aux Géonénųs.

Nous avons figuré, sous les $\mathrm{n}^{\mathrm{os}^{\mathrm{S}}} 2 \mathrm{~A}$ ct $2 \mathrm{~B}$, sa tête vue de profil, et l'extrémité de son rostre vue en dessous et très-grossie, pour montrer les parties de la bouche.

\section{Genre EUPHOLE, Eupholus. GoÉnis.}

Nous avions placé les espèces avec lesquelles nous formons ce nouveau genre, avec les Géonémus de Schoenherr; naais, en suivant la méthode de ce célèbre entomologiste, nous avons bientôt reconnu que les caractères de ces insectes ne cadrcnt pas avec ceux de son genre; il aurait donc fallu modifier les caractères qu'il lui assigne, 
pour $\mathrm{y}$ introduire nos espèces, ou bien faire un nouveau genre à côté de celui-ci. Nons avons pris ce parti, quoiqu’à legret, car les genres établis sur des différences aussi faibles que celles qui servent de base au nôtre, sont difficiles à caractériser, et surtont à reconnaître et à limiter.

Notre genre Euphole diffère des Géonémus par les antennes, qui sont beaucoup plus épaisses, et dont l'extrénité du scapus, ou premier article, vient aboutir à peine au bord antérieur des yeux, quand ces antennes sont pliées cn arrière. Dans notre nouvcau genre, les yeux sont bien plus saillants que chez les Géonémus, le corps est déprimć et non bombé comme dans ce dernier genre; les épaules sont saillantes, avec les élytres calleuses vcrs l'extréunité, cc qui na pas lieu dans les Géonémus. Enfin, dans notre genre, les fosseltes des antennes sont peu limitées, effacées bien avant d'avoir atteint le dessous des yenx; la forme du corps est plus cylindrique quovalaire. Voici avec les caractères essentiels que nous assignons à ce genre :

Antenncs longues, ćpaisses ; scapus court, renflé au bout, atteignant à peine les yeux. Articles du funicule grenus, presque égaux, les premiers un peu plus allongés. Massue épaisse, renflée au milieu, pointuc au bout, et composée de quatre articles, dont le premier est le plus grand. Rostre court, épais, renflé au bout, presque droit. Yeux ronds, saillants. Corsclet tronqué en avant et en arrière, très-peu avancé et arrondi sur les côtés antérieurs et sous les yeux. Élytres oblongues, subcylindriques, avec les angles lıméraux renflés, calleuses, et ensuite comprimées vers l'extrémité. Pattes grandcs, épaisses, avec les tarses larges, aplatis.

Ce genre, tel que nous venons de le caractériser, se compose jusqu’à présent de quatrc espèces propres à la Nouvelle-Guinée et anx grandes Indes. Ce sont des insectes assez grands, ornés des couleurs les plus fraiches et les plusbrillantes, et qui sont encorc très-rares dans les collections.

EUPHOLE DE GEOFFROY SAINT-HILAIRE, Euphulus Geoffroyi. Guínin. - Viridi-glauco metallico. Antennarum clava nigra; thorace, apice elytrisque cyaneis; elytris vittis quinque transversis uigris, tertia ultimaque ad suturam interruptis.

L. 26 mil., l. по m. - Geonemus Geoffroyi. Gúñıv. - Atlas, Ins., pl. VI, fig. 3 et $3 \mathrm{~A}$.

Cette espèce est une des plus belles parmi les Charançons; sa tête et son rostre sont couverts de très-petites écaillcs l'uu beau vert brillant, avec l'extrémité du rostre, un profond sillon longitulinal, les yeux ('t le hord postérieur de la tête d'un noir luisant. Le corselet est très-étroit en avant, renflé au milieu et ensuite parallèle sur les còtés, un peu dépriné en dessus, avcc un sillon longitudinal; il est entièrement d'un beau bleu de ciel, avec les bords antérieur et postérieur vcrts. Le dessous tire sur le vert. Les élytres sont plus larges que le corselet à leur uaissance, presque parallc̀les jusquaux deux ticrs de leur longueur, avec une callosité au bout, ct l'extrémité comme comprimée latéralenıent; leur dessus est peu bonıbé, comme déprimé. Elles sont d'un beau vert 
brillant, for rué par une multitude de petites écailles, jusqu'aux deux tiers de leur longueur; le reste de leur extrćmité est d'un beau bleu de ciel comme le corselet, avec le bout comprimé d'un vert doré : le bord antérieur et la suture sont d'un noir luisant. Il y a, au quart antérieur et au milieu, deux landes noires transversales, assez larges, dentelées, partint du bord des élytres, ct s'élargissant un peu à la suture. Entre la première et la secoude bande, il y en a une antre beaucoup plus courte, qui ue touche ni au bord extérieur ni à la suture; on en observe une semblable, à une égale distance, derrière la deuxic̀me grande bandle, sur la limite du vert; cette bande, qui s'approche un peu plus de la suturc que celle que nous venons de décrire, sépare le vert du bleu : les callositćs, placées assez en arrière de cette bande, sont tcrminées par unc très-petite bande noire. On compte, sur chaque élytre, neuf stries formées de gros points enfoncés et distants les uns des autres. Le dessuus du corps est d'un beau vert doré; l'abdouncn a ses denx premiers segments très-larges, séparés par une bande transverse noire, luisante, sinuée en arrière. Les deux autres segments sont beaucoup plus étroits, ils ont chacun deux taches noires plus larges en avant, atteignant le bord postérieur, et laissant les côtés et le milieu verts. Le dernier segment est triangulaire, avec la base noire. Les cuisses, les jambes et les tarses sont d'un beau vert doré; les cuisses sont épaisses, renflées. Le dessous des tarses est d'un brun jaunâtre.

Ce magnifique insecte vient de la Nouvelle-Guinée; nous l'avons dédié à l'un de nos plus grands zoologistes.

EUPHOLE DE SCHOENHERR, Eupholus Schoenherrii. GuÉr. - Viridi-glauco semimctallico; antennarum clava, elytris vittis transversis quinque, ultima accentifera, nigris. Thorace, vittiv duabus in elytris, genubusque cyaneis. - L. 25 mill., l. г m.

Cette espèce ressemble beaucoup à la précédente, et l'on pourrait croire qu'elle n'en est qu'une variété, si les bandes noires qu'elle a sur les élytres n'étaient pas placées d'une manière toute différente. Sa forme est presque senblable, mais l'extrémité de ses élytres est plus allongée et plus comprimée. Le noir du sillon longitudinal du dessus du rostre n'est pas seulement restreint an fond de ce sillon, il s'étend sur les côtés et forme une bande noire, large, renflée au nilieu, et se terminant en arrière des yeux. Les antennes ne diffèrent pas de celles de l'Euphole de Geoffroy. Le corselet présente la mêne forme; mais il est presque tout vert, n'ayant que son milieu d'une couleur bleue fondue avec le vert. Les élytres sont de même forme, à l'exception de l'extrémité, qui est un peu plus allongée; elles offrent les mêmes stries de gros points enfoncés; leur bord antérieur est également noir, naais elles ont trois bandes transversales, entières. La première est placée plus près du bord antérieur que dans l'espèce précédente; elle est sinueuse et dentée, un pcu plus étroite, et l'espace compris entre elle et le bord antérieur est d'un beau vert. La seconde est placée au milien de la longueur des élytres; elle est moins sinueuse, également large dans toute son étendue, avec l'espace qui la sépare de la première d'un beau bleu de ciel. La troisième est placée 
plus près de la seconde, environ an tiers postérieur; elle vient presque toucher à la suture, et l'espace qui se trouve entre elle et la seconde est d'un beau vert; enfin, on voit, immédiatement après le calus ou la bosse de chaque côté des élytres, une tache en forme de croissant oblique, dont la convexité touche le calus; toute la partie postérieure des élytres est verte, à l'exception de l'espace compris entre la dernière bande et les taches en croissant, qui est bleu. Le dessous du corps est semblable à celui de l'espèce précédente. Les pattes sont vertes avec l'extrćnité des cuisses d'un beåu bleu. Le dessous des tarses est d'un gris blanchâtre. - Cette supperbe espèce vient aussi de la Nouvelle-Guinée. Nous l'avons dédiée au plus célèbre entomologiste de la Suède.

ELPHOLE DE CHEVROLAT. Eupholus Chevrolatii. Guír. - Viridi-micans; rostro valde sulcato, longitudine thoracis. Antennarum clascl fusca. Thorace sub-conico longitudinaliter sulcato. Elytris brevibus, fascïs quinque nigris, ultima valde arcuata. Sulco rostri maculisque abdominalibus, eodem colore. - L. 15 à 18 mill., l. 8 ou 9 mill.

Cette espèce est très-voisine de la précédente, mais elle en diffère par la taille, la coloration, ct surtout par une saillie longitudinale et postérieure des élytres (callosité) qui est noire et réunit les troisième, quatrième et cinquième bandes entre elles : elle en diffère encore par la troisième bande noire, qui se courbe en approchant de la suture, et va presque toucher la quatrième. La trompe de cet insecte est avancée, profondément sillonnée jusqu'au-delà des yeux; son extrémité est éclıancrée et déprimée. La tête est petite, convexe, avec un petit sillon longitudinal sur le front, noir comme celui du rostre. Les yeux sont arrondis, peu saillants. Les autennes sont épaisses, couvertes d'écailles vertes, avec quelques poils pâles, avec la massue d'un brun pâle. Le corselet est coupé droit aux deux extrémités, plus long que large, rétréci en avant et un peu atténué sur les côtés; il a, latéralement et près de la tète, un pli assez marqué, comme les cspèces qui précèdent, et se prolongeant en-dessous. Il est entièrement couvert d'écailles très-petites, d'un vert luisant, avec le bord postérieur noir. L'écusson est punctiforme et caché en partie. Les élytres sont plus larges que le corselet, avancées un peu angulairement vers les épaules, élevées au dessus de l'écusson. Les épaules ont lcurs angles saillants coupés obliquement. Clıque élytre a neuf stries longitudinales formées de gros points enfoncés et assez distants entre eux. La première strie, en partant de la suture, se réunit en arrière au. sillon de la marge; la seconde se réunit à la neuvième ; la troisième finit à la callosité de l'élytre; les quatrième et cinquiène sont séparées par une côte élevée qui finit aussi à la callosité. Les fines écailles qui couvrent les élytres sont toutes du même vert luisant. Le bord antérieur des élytres est noir et forme la première bande; la seconde bande est placéc un peu en arrière; elle est sinueuse, prolongée jusqu’à la marge, sans atteindre le bord extérieur ni la suture : elle offre sur le bord extérieur une dent avancée vers l'angle luméral, et son extrémité interne est tronquée et un peu prolongée vers l'écusson. La troisiène bande est située en arrière, au-clelà du milieu, rapprocliée de la quatrième, courbée et se réunissant, vers la suture, avec cette dernière: outrc ce point de réunion, elles se touchent encore au moyen d'un angole sur la còte qui les traverse, et sc termine à la callosité. Ia 
quatrième bande est presque droite ; elle est aussi rćunie à la cinquième pa: la côte élevée et noire dont nous venons de parler. Enfin la cinquième bande forme, sur l'extrémité penchée dc chaque élytre, un croissant ou plutôt un cercle un peu ouvert sculenent en arrière. Lcs élytres sont comprimées à l'extrémitć. Le prenier segment de l'abdomen est marqué de chaque côté d'une tache allongée, noire, qui n'atteint pas le hord postérieur. Lés deuxième et troisiène segments sont traversés latéralement par une bande noire qui se termine par un point dc chaquc côté du quatrième. Les pattes sont vertes, avec les jaubes antérieures arquées et munies d'une saillie épineuse à leur extrémité interne. Le dessous des tarses est garni de brosses jaunâtres; les croclıts sont roblustes et noiràtres.

Cette belle espèce vient d'Anıboine. Nous l'avons dédiée à notre ami MI. Chlevrolat, l'entomologiste de France qui connaît le mieux les Charançons, comme un témoignage public de notre reconnaissance pour les nombreuses conimunications d'espèces rares qu'il a bien voulu nous faire dans lintérèt de notre travail.

EUPHOLE DE CUVIER, Eupholus Cuvierii. GuÉn. - Viridi glauco, leviter metallico, antennarum clava nigra. Thorace macula utrinque cyanea. Elytris vittis quinque longitudinalibus nigris, media suturali a capite ad extrenum elytrorum dacta.-L. 20 mill. I. 7 m. - Geonemus Cuvierii, Atlas, Ins., pl. V1, fig. 4 .

Cette superbe espèce est l'une des plus rares du genre; sur les trois expéditions qui ont touché à Dory, il n'y a que les naturalistes de celle du capitaine Duperrey qui en aient rapporté un seul indıvidu. Son corps est plus allongé et plus étroit que daus les espèces précédentes. Sa tête et ses antennés sont absolument semblables à celles de l'Eupliole de Geoffroy; seulement le sillon longitudinal de la tête n'est pas noir au fond, mais garni en entier des écailles vertes qui colorent tout l'animal. Le corselet est plus étroit en avant, un peu arrondi au milieu, presque droit ensuite. Il est d'un beau vert, avec unc large bande longitudinale bleue de chaque còtć, et un sillon profond, assez large, et d'un noir luisant au milieu. Les élytres sont d'un beau vert, avec quelques reflets bleus; elles sont un peu plus larges que le corselet, avec les épaules coupées obliquement, presque parallèles, et un peu arrondies sur les côtés, rétrécies au bout, à partir des callosités, avec neuf stries peu narquées, formées par de très-petits points enfoncés ; leur suture est noire et luisante; on voit sur cliacune deux larges landes longitudinales d'un beau noir luisant, l'une placée en dessus et n'atteignant pas l'extrémité postérieure, l'autre placée sur le côté, au-dessous de la saillie humérale et du calus postérieur. Le dessous du corps est d'un beau vert; les deux premiers segments de l'abdomen. sont plus grands, séparés par une bande noire. Les troisième et quatrième sont très-ćtroits, d'un vert plus doré, avec une bande noire à leur base; le dernier est triangulaire, arrondi cn arrière, a vec deux très-petites taches noires à la base. Les pattes sont très-grandes, fortes, avec lès cuisses renflées; les tarses sont un peu bleuâtres, avec le dernier article noir; leur dessous est garni de brosses jaunàtres.

Nous avons dédié cette espèce rare au plus grand naturaliste de notre époque. 
Genre CYLYdRORHINE, Cybjdrorhinus. Guér.

Ce genre est très-voisin des Molyt es de Sehœnlıerr, à eause de sa forme et de ses earaetères géuéraux; mais il en diffère cependant par ses antennes et par la forme de sa tête. Voiei les earaetères que nous lui assignons:

Antennes de onze artieles, assez épaisses, de la lorgueur de la tête et du eorselet rémins. Le premier article en massue, plus épais au bout, atteignant les yeux et pouvant se eacher en partie dans une rainure du rostre dirigée vers le milieu des yeux. Deuxième, troisième, quatrième et einquième artieles obeoniques, diminuant de longueur; les sixième, scptième et luitième eneore plus eourts, presque grenus. Massue oblongue, ovale, eomposée de trois artieles très-distinets, dont le clernier est de la longucur du précédent, terminé en pointe; rostre un peu plus long que la tête, épais, penehé, un peu plus épais au bout, avee une côte élevée au milieu et l'extrémité uı peu déprinée en dessus. Front large, lombé. Yeux arrondis, plaeés sur les eòtés, un peu saillants. Corselet court, arrondi sur les eòtés, un peu plus étroit en avant. Élytres plus larges, ovales, eonvexes; point d'ailes. Pattes de grandeur médivere, avee les cuisses en massne; tarses aplatis, fortement eiliés en clessous, avee le pénultième article bilobé. Abdomen entièrement eouvert en dessus par les élytres. - L'individu que nous déerivons vient de la Nouvelle-Hollande; e’est la mème espèce qui a été déerite et figurée dans le Voyage de Freyeinet sous le nom de Charanęon galonné. Nous avons vu l'individu qui a servi à eette cleseription; il porte une étiquette indiquant qußil a été trouvé aux îles Malouines; nous pessons qu'il y a eu erreur dans eette indication; car les espèees d'inseetes tronvées dans ees îles par M. d'Urville étaient en général petites et avaient une physionomie alpine, tandis que notre Charanęon a bien plus de rapports de physionomie avec les inseetes de la Nouvelle-Hollande.

CYLYDRORHINE RUBANÉ, Cyljorrorhimus lemniscatus. Guér. - Ovalis; sericeobruneus, vittis thorace duabus lateralibus, elytris plurimis, una suturale, atomisque quibusdam albo-griseis. - L. 20 mill., I. $9 \mathrm{~m}$.

Curculio lemniscutus. Quoy et Gaym., Voyage autour du monde de Freyeinet, Zoologie, p. 549 , pl. 82 , fig. 4.

Cet insecte est épais, ovalaire, brun, eouvert d'un duvet serré et très-eourt, de couleur euivreuse. Sa tête est entièrement brune avee un pen de duvet euivreux près des yeux. Le eorselet est un peu plus large que long, peu éclianeré en avant, arrondi sur les eôtés, plus large en arrière; il est moins eouvert de duvet que les élytres; ses bords latéraux en dessus sont oeeıpés ehaeun par une bande blanehe, arquée, parallèle au bord, avee un point brun dins son milieu. Les eôtés en dessous ont également des taches blanches formées par le même duvet. L'éeusson est petit, blane, ainsi que la suture. Les élytres ont sur les eòtés trois bandes longitudinales peu arrêtées, formées par un duvet blane et quelques taehes de la mème eouleur vers la partic postérieure. 
La bande blanche, qui borde les élytres, quand on regarde linsecte en dessus, est maculaire et interrompue. Le dessous du corps est noiràtre, avcc des taches blanches vagues, formées par le même duvet serré. Les pattes sont brunes, avec les jambes couvertes d'un poil jaunàtre très-court. - De la Nouvelle-Hollande. -

\section{Genre PSOMÈLE, Psomeles. Guér.}

Ce nouveau genre, qu'on ne peut que rapprocher des Sciobius de Schœnherr, en diffère cependant par des caractères assez trauchés, pour qu'il soit inụtile d'énumérer ici toutes ces différences; les principales sont dans Ia forme dı eorps et du corselet, dans celle des antennes, et surtout de la proportion de leurs articles, etc. Voici les caractères que nous lui assignons :

Antennes très-longues, grêles; scapus plus allongé que le rostre et la tête, renflé au bout; funicule beaucoup plus long que le scapus, composé d'articles filiformes et obconiques, allongés, dont les premiers sont les plus longs. Massue allongée, étroite, peu distincte du reste du funicule. Rostre très-court, épais, plane en dessus. Yeux arrondis, assez saillants; corselet allongé, avec les côtés peu arrondis. Élytres oblongues, plus étroites à l'extrémité, asscz bombées. Pattes grandes.

PSOMÈLE EN DEUIL, Psomeles luctuosus. Gú́r. - Ater, complanatus, navicularis, maculis quibusdam in elytris lateralibus albis - L. 9 mill., $1.4 \mathrm{~m}$.

La forme générale de ce Charançon est allongée, étroite en avant et en arrière; il est entièrement noir; sa tête est courte, avec un rostre à peine plus long, aplati en dessus, rugueux, un peu élargi, droit. Les antennes sont presque de la longueur da corps et insérées tout-à-fait à l'extrémité de ce rostre; leur premier article atteint presque le milieu du corselet, celui-ci est un peu plus long que large, cylindrique, un peu arrondi sur les côtés, tronqué carrément en avant et en arrière, ponctué sur toute sa surface, avec de faibles taches blanclies aux quatre coins, formées par des poils courts et peu serrés. Les élytres sont un peu plus larges que le corselet à leur base, renflées sur les côtés, rétrécies et terminées en queue en arrière; leur surface est garnie de points enfoncés assez serrés; elles ont clıacune deux petites taches blanches, oblongues et longitudinales près de la suture, quatre taches plus grandes, arrondies et diminuan ${ }^{t}$ d'étendue vers l'arrière, sur les còtés des élytres, et quelques petits poils blancs vers le tiers postérieur. Les côtés des élytres, le dessous du corselet et de l'abclomen sont variés de blanc; les pattes sont grandes, toutes noires, avec les cuisses renflées. Les tarses sout aplatis, avcc le quatrième article plus grand et bilobé. - Cet insectc vieut de lìle de Taiti.

AMYCTÉRE GRENU. Amycterus granosus. Guér. - Ater, thorace granifero; elytris rugosis, plicato-tuberculatis, tuberculis internis elevatioribus seriatis; pedibus gracilibus. —L. 17 mill., 1. $7 \mathrm{~m}$.

Il est entièrement noil, nuat; le rostre est très-court, très-épais, échancré au bout, avec deux còtes élevées cn dessus. Les yeux sont très-petits, ronds. Le corselet est beau- 
coup plus étroit que les élytres, arrondi sur les côtés, un pen plus large en avant, couvert de petits grains ronds très-serrés, lisses. Les élytres sont ovales, oblongues, avec les angles huméraux avancés, luisants; elles sont rugueuses, avec de gros tulereules assez rares, rangés très-imparfaitcment en séries, et dont les postérieurs et ceux qui sont plus près de la suture sont les plus forts. Les pattes sont plus grêles que dans les espèces suivantes; le dernier segment de l'abdomen présente au milieu une petitr fossette au centre de laquelle il y a un petit tubercule ovale, lisse et luisant. - Il vient du Port-Jakson.

AMYCTERE A VERRUES, Anycterus verrucosus. Guér. - Niger; thorace granulifero, tuberculato, interstituis nullis; elytris seriation verrucoso-tuberculalis. - I. 23 mill., 1. $8 \mathrm{~m}$.

Il est entièrement d'un noir terne; son rostre est très-court, très-épais, fortement échancré en avant, lissc, avec deux còtes un peu élevées. Les ycux sont très-pelits, à fleur de tête. Le corselet est un peu plus large en avant, arrondi sur les côtés, couvert de gros grains ronds, luisants, plus forts en dessus, et ne laissant pas entre eux d'espaces lisses et longitudinaux. Les élytres sont un peu plus larges que le corselet, presque parallèles, convexes, rugueuses, avec de gros tubercules arrondis, quelquefois ovales, lisses, plus forts que ceux du corselet, et rangés en séries imparfaites, mais cependant assez faciles à suivre, surtout sur les còtés. Les paties sont de grandeur moyenne, avec les articles des tarses peu dilatés en cœur; les postérieures sont insérées à une plus grande distance entre elles; le dernier segment de l'abdomen est plus grand que les autres; il présente une fossette profonde au milieu, avec deux tubercules saillants. Du Port-Jakson.

AMYCTÈRE DE KRRY, Amycterus Kirbyi. GuÉr. - Ater; thorace rugoso; ely tris sulplicato-rugulosis, subcostatis, costis externis interruptis; sutura carinaîa antice furcata. Audomine vitta tomentosa ferruginea. - L. 17 mill., $1.7 \mathrm{~m}$.

Il est entièrement d'un noir peu luisant; son rostre est très-court, très-épais, peu échancré au bout, avec trois petites côtes peu élevées et luisantes. Le corselet est un peu plus large en avint, arrondi sur les côtés, fortement rugueux, mais non grenu; les élytres sont presque parallèles, un peu arrondies sur les còtés, avec la suture élevée et divergente vers l'écusson: chaque élytre offre, près de la suture, une ligne de tubercules oblongs, peu saillants; il vient ensuite une còte élevée, formée de tubercules réunis vers la base et plus séparés postérieurement; deux tubercules isolés ct placés au milieu de l'élytre, et cinq autres lignes de tubercules moins élevés et phus séparés entre eux, et plaeés sur les côtés. Les pattes sont de grandeur moyenne, avec les jambes épincuses en dedans, échancrées au bout et en dessous, et terminées par deux épines courtes et divergentes; l'abdomen est lisse en dessous, avec une large bande longitudinale, ferrugirieuse, placée au milieu et formée par un duvet très-court et très-serré. - Cette espèce vient du Port-Jakson; nous l’avons dédiée au célébre entomologiste qui a fait connaitro le premicr une espèee de ce genre curieux.

Voyage de la Coquille. Z. T. II, Part. II. ${ }^{\text {re }}$ Div. 
Geure ACANTHOLOPHE, Acantholopluts. Schonher r, Manuscrit.

Ce genrc n'était pas encore publié quand nous avons donné cet article à l"impression, cepcndant M. Boisduval, cliargć par M. Schœnlerr de surveiller l'impressiou de l'ouvrage de ce savant, nous a assurć qu'il était établi dans le manuscrit qui s’imprime actuellcment ( 15 décembre 1833 .)

Le genre Acantholophe se rapproche beaucoup des Amycterus de Schœnherr. Mais ses antennes longucs et grêles l'cn distinguent d'une inanière bien nette.

ACAN'HOLOPHE HÉRISSÉ, Acantholophus echinatus. Guér. - Fuscus, subtomentosus; thorace cchinato, linca media pallida; elytris rugosis, spinis tuberculatis triscriatis; capite bi-cristato. - L. 18 mill., 1. $6 \mathrm{~m}$.

Ce bel insecte est de forme oblongue; il est d'un brun enfumé, couleur de sépia ou de bistre, et couvert d'un duvet court et serré, dc la même couleur. Son rostre est court, très-ćpais, avec une petitc ćlévation au bout et de chaque côté pour protéger l'insertion des antennes, et une crêtc rclevée, aplatic et échancrée au bout, placée de claque côté et au devant des ycux. Le corselet est aussi long que largc, rugueux, avec dix petits tuberculcs en dessus, laissant un enfoncement longitudinal, quelquefois d'une couleur plus pàle, ct trois tubcrcules latéraux de chaque côté; le premier court, comme ceux du dessus, le second placé au nilieu de la longueur du corselet, lc plus grand de tous, bifide et un peu recourbé en arrière, au bout; le troisième moins grand et ne formant qu'une seule épine. Les élytres sont un peu plus larges que le corselet vers leúr milieu, fortcment rugucuses; elles ont chacune trois sćrics longitudinales de gros tubercules spiniformes coniques, plus longs vers l'extrémité postérieure de l'élytre; la séric la plus rapprochée de la suturc est un peu plus courte que la scconde série, qui n'atteint cepcndant pas l'extrémité ; la troisième série atteiut à peine le milieu de l'élytre et n'est composée quc de quatre tubercules, tandis que les deux autrcs en ont au moins huit chacune. Les côtés des élytres sont dépourvus de ces épines et n’ont que des espèces de stries formées par les rugosités. Les pattes sont de grandeur inoyenne; les tarses sont composés d'articles un pcu en cœur. - Cet insecte se trouve au Port-Jakson.

\section{Genre SPHOEROPTĖRE, Spheropterus. GuÉR.}

L'insecte avcc lequel nous établissons ce nouveau genre ressemble beaucoup aux $\mathrm{Hy}$ phantes et aux Otiorhynques de Schœnhcrr, et pourrait à la rigueur être placé dans ee dcrnier genre; mais, si l'on veut suivre la métlode de ce célèbre entomologiste, on doit l'cn séparer, parce que ses antennes diffèrent de celles de ces deux genres, en ce qu'elles ont onze articles au lieu de douze qu'on trouve dans ces derniers, par la grandeur du premier article, qui est égal au fonet ou funicule, qui estcourbé, ćpais, de la mème largeur dans toủte sa longueur, tandis que, dans les deux genres que nous citons, ce premier article est plus court que le funicule, toujours plus ou moins renflé au bout, et droit. Dans notre genre. 
le funicule est composé de sept articles égaux, allongés, cylindriquẹs, et in peu rcnllés an bout, tandis que, dans les Otiorhynques et les Hyphantes, le funienle est composé de deux sortes d'artieles, les deux premiers étant toujours plus grands que les suivants, qui sont quelquefois grenus, d'autres fois obeoniques, mais janais égaux aux deux premiers. La massue ehez notre insecte est allongée, pointue, de trois artieles très-peu distincts, dont le premier forme la inoitié de la Iongueur; dans les Otiorhynques, cette massue est plus ou noins ovoïde, composée de quatre articles bien distincts, dont le premier ne forme que le tiers de la longueur. Voici les caractères que nous assignons à ce nouveau genre, qui viendra se placer entre les Otiorliynques et les Hyphantes:

Antennes presque de la longuenr du eorps, avee le premier article d'égale épaisscur dans toute sa longueur, eourbé, aplati, atteignant beaucoup en arrière des yeux sur le corselet. Tous les articles du funicule égaux, cylindriques, renflés au bout; massue oblongue, étroite, pointue, de trois articles, dont le premier plus grand que les derniers réunis. Rostre assez court, un peu épaissi au bout, avee une fossette antennaire eourte, ćlargie on arière, peu profonde et peu linitée. Yeux arrondis, pen saillants. Corselet très-convexe, avec les còtés arrondis, sans lobe avancé sous les yeux. Élytres rćunies, ovales, très-bombées : cuisses renflées vers l'extrémité, sans aueune dent.

SPHÉROPTĖRE A LIGNES BLANCHES, Spharopterıs albo-lineatus. Guén. - Atcr, thorace granulato; elytris valde punctato-striatis, thorace vittis, elytris procedentibus quatuor albis; elytris duobus transversis alterisque posticis marginalibus apice curvatis; femora desuper albo-vittata. - L. $8 \mathrm{~m} ., 1.4 \mathrm{~m}$.

Il est entièrement noir, peu luisant; son rostre est un peu plus long que la tête, prise du thorax aux yeux; il est cylindrique, un peu déprimé en dessus, plus épais au bout, granuleux, avee une impression en chevron entre les yeux, et quel ${ }_{\text {ques }}$ poils très-eourts au milieu. Le front est lisse. Les antennes sont noires, avee des poils noirs et gris, mélangés. Le eorselet est globuleux, aussi large que long, fortement granulé, couvcrt de petits poils blimes, assez serrés, qui ne laissent que trois bandes longitudinales, noires, formées par des parties moins couvertes de poils. Les élytres sont courtes, ovalaires, bombées, finement rugueuses, avec des stries longitudinales de points enfoncés. Elles ont ehaeune à la base deux bandes longitudinales, blanehes, formées par des poils serrés, qui atieignent le nilieu de leur longueur, une bande transverse, blanehe en arrière et au bord, à partir du uilieu, une ligne blanche qui longe leur bord postéricur et vient se recourber un peu vers la suturc. Leddessous est noir, parsené de petits poils blaucs. Lcs pattes sont noires, avee une bande de poils blanes au-dessus des cuisses et au eòté externe des jaunbes. - Cet insecte élégant est eomuun à Dory, dans la Nouvelle-Guinée.

ALCIDE BOUT BRULÉ, Alcides pratustus. GuEn. - Custaneus, corpore cylindrico, capite pedibusqus nigris; thorace, elytris abdomineque subtus pulvcrnlento-sulplureis, êlytrorum apice fusco. _ L. 17 nill., 1. 6 m. - Ieonographie du Règne aniunal, Insectes, pl. XXXVIII, fig. 6 . 
Cette belle espc̀ce est allongée, cylindrique, avec le dessus du corps un peu déprimé; son rostrc est long et lisse, ainsi que sa tête; ces deux parties sont d'un noir luisant. Le corselet est beaucoup plus large quc long, de moitié plus étroit en avant, fortement lobé en arrière, granulć, d'une couleur brune rougeâtre, mais garni d'un fin duvet d'un jaune doré. L'écusson est très-petit, mais visible; les élytres sont parallèles, arrondies au bout, finement rugueuses et striées; elles sont d'un brun rougeâtre jusqu'au milieu de leur longueur, jannes ensuite, avec l'extrémité noire. Le dessous du corps est d'un beau jaune doré; les pattes sont noires, luisantes; les antérieures sont les plus grandes, avec les cuisses renflées, armées en dessous d'une épine courte; les jambes sont arquées, terminées par une épine crochue, ct ayant, vers leur base et en dedans, une petite dent peu saillante. Les pattcs intermédiaires sont plus courtes, conformées de même; les postérieures sont cncore plus courtes. - Ce bel insecte vient aussi de la Nouvelle-Guinée; il nous a étć communiqué par M. Lcsson.

ALCIDE ÉLÉGANT, Alcides elegans. Gurr.-Ater, elongatus, thorace vittis duabus latis marginalibus; elytris fascia transversa, vitta laterali, ad thoracem incipiente postice ad suturam oblique ducta albis. _ I. I I mill., 1. 3 m. _Atlas, Ins., pl. VI, fig. 6, A, B, C.

Il est entièrement d'un noir luisant; son corps est allongé, cylindrique; sa trompe est très-penchée, plus longue que le corselet, cylindrique, lisse. Les antennes sont petites, grêles, avec la massue assez forte. Lc corselet est pluș étroit en avant, un peu plus long quc large, ponctuć, arrondi sur les côtés, coupé droit en arrière, bordé de ehaque côté d'une bande blanche plus large postérieurement, et formée par un duvet trc̀s-court ${ }^{3}$. Ces élytres sont parallc̀les, arrondies en arric̀re, lisses, avec des stries de petits points enfoncés; clles ont la base un peu prolongée en avant en deux petits lobes arrondis, et recouvrant lc bord postćrieur du corselet. A une pctite distance de la base, on aperçoit unc petite bande blanche uı peu en chevron, et formant l'angle vers l'écusson. Chaque élytre a une autre bande qui prend naissance sur les côtés du métathorax, entre les secondes et troisièmes pattes, remonte sur les côtés de chaque élytrc, s'arrondit, et va se terminer à l'cxtrémitć postérieure; il y a au bord une pctite strie blanche en arrièrc; le dessons du prothorax a une bande blanchc au milieu; l'abdomen a son second segment finement bordé dc blanc. Les pattes antérieures sont plus grandes que les autres, avec les cuisses armées d'une forte épine en dedans; les autrés pattes sont plus courtes, mais conformées de même.

Ce joli charançon vient de la Nouvelle-Guinée.

TYLODE HUMÉRAL; Tylodes humeralis. Guḱr. - Ater, rugosus, rostro depresso; thorace elytris ad extremum coarctatis; basi macula alba longitudinaliter trilineata; tarsi "nnteriores ciliati. Articulo ultimo subtus albo. - L. 14 à 19 mill., l. 4 à 6 nì.

(1) G'est par erreur qu'on a reprèsenté une bande blanche transverse et aı bord postérieur du corselet, dans notre figure 6 . 
Cryptorkynchus humeralis. Latr. Atlas, Ins. pl. VI, fig. 8, 8 A, 8 B.

Cet insecte, comme on le voit par les mesures ci-dessus, varie assez pour la taille. Il est entièrement noir, d'une forme extraordinaire, avec un corselet plus gros que les élytres, et les pattes antérieures beaucoup plus grandes que les autres. Sa tête est petite, presque cachée sous un prolongement arrondi du bord antérieur du corselet; les yeux sont tout-à-fait à fleur de tête, un peu ovalaires, en partie cachés sous le corselet. Le rostre est presque aussi long que le corselet, penché, aplati, un peu renflé en avant, fortement rugueux cn dessus, avec lesantennes insérécs, un peu au-delà du milieu et vers l'extrénité, dans des fossettes obliques qui vont aboutir bien plus bas que le bord inférieur des yeux. Les antennes sont assez courtes, peu ćpaisses; leur premier article n'atteint pas les yeux; les second tet troisième sont allongés, obconiques; les autres sont presque grenus; la massue est courte, renflée, composée de trois articlcs. Le corselet est très-étroit en avant, beaucoup plus large et plus bombé que les élytres en arrière, arrondi sur les côtés, fortement granuleux, percé d'une quantité de grosses fossettes comme un dé à coudre et tronqué carrément en arrière. Les élytres sont plus étroites, oblongues, trc̀s-bombées au milieu, avcc leur bord antérieur plus bas que lcur milieu, rétrécies en arrière, soudées entre clles, et embrassant l'abdomen. Elles sont couvertes de sept lignes longitudinales de gros tubercules spinifornes, rangés en striès qui leur donnent un aspect fortentent réticulé. On voit à la base de chacune et vers le bord extérieur trois taches longitudinales, formées par un duvet blanc très-court et très-serré, dont la plus extérieure cst la plus petite. Le dessous du corps est moins rugucux que le dessus; le corselet offre un profond sillon pour loger le rostre. L'abdomen est très-étroit. Les pattes sont insérées très-près les unes des autres; les antérieures sont rugueusês, démesurément grandes, avec les cuisses renflées, les jambes arquécs, terminées par deux épines crochues dirigées en dedans; on voit entre l'épine du bord extérieur ct celle du bord interne un petit toupet de poils très-rapprochés et roides, qui est dirigé en dehor's et semble, au premicr aspect, former une épine opposée à l'extérieure; ce qui fait l'effet d'une petite pince au bout de clıque patte. Les pattes intermédiaires sont presque de moitié plus petites, avec les janbes moins arquées; les postćrieures sont un peu plus grandes, avec les jambes droites. Les tarses de toutes les pattes sont aplatis; leurs deux premiers articles sont allongés, le premier étant le plus long de tous; le troisième article est plus large, bilobć, bordé de cils blancs très-courts. Les tarses antérieurs senls ont leurs deux premiers articles garnis de longs cils noirs de chaque côté. - Cet insecte vient de la Conceptiọn, au Chili; il nous a été rapporté aussi de San-Yago par M. Gay.

TYLODE DE GAY, Tylodes Gayi. Guén. - Infumatus, rugosissimus; macula trivittata elytrorum basi, articnlo penultimo tarsorum flavo. Tarsis anterioribus haud ciliatis. -L. 14 mill., l. 5 m. $\frac{1}{2}$.

Ce Tylode ressemble beancoup au précédent, et pourrait être considéré comme n'en étant qu'unc variété, si la rćticulation de son corselet et de ses élytres n'était pas toute 
différente; il est entièrement d'un brun foncé; son rostrc est trc̀s-peu rugueux, presque lisse au bout. Le corselet est couvert de points enfoncés; mais ils sont plus pctits et plus serrés que chez le précédent, et cc corselet n'est pas plus large que les ćlytres. Cellcs-ci sont bombées, tronquées carrément en avant, avec les angles huméraux aigus; elles sont garnies de lignes de tubcrcules plus petits, plus serrés, cntre lesquels on en voit quelques autres plus petits; ce qui donne à ces élytres un aspcct tout différent de cclles de l'autre espc̀ce. On voit de chaque côté, et au bord antérieur, trois taches jaunes, formées par un duvet court, et semblables à celles qu'on observe au Tylodcs humeralis. Les pattcs antéricures sont plus grandes que les autres, mais pas d'une nanièrc dispioportionnée. Les tarses antérieurs ne sont pas ciliés de poils si longs. - Cette espèce nons a été donnée par M. Gay, qui l'a trouvée près de San-Yago, au Chili.

TYLODE LATÉRAL, Tylodes lateralis. GuÉR. - Ater, rugosus, rostro subdepresso; thorace rugoso et punctato, sub-globoso. Elytris tuberculato-costatis, intcrstitiis profunde punctatis, linea elongata apicem non attingcnte cum puncto humcrali, albis. Tibïs anticis incurvatis in extremitate. - I. 17 nill., $1.5 \mathrm{ml} . \frac{1}{2}$.

\section{Cryptorhynchus lateralis, Atlas, Ins. pl. VI, fig. 9 .}

Cctte espèce cst plus allongée que les précédentes; elle est entièrement noire; sa tête et sôn rostre sont un peu rugueux. Son eorsclct est très-rćtréci en avant, un peu plus large que less élytres en arrière, avec une légère fossette au milieu et en avant; il est fortement rugucux, et tronqué carrément en arrière. Les élytres sont brusquement tronquécs en avant, allongées, bombécs, rétrécies postérięrement; elles ont chacune huit fortes côtes rugueuses, dans l'intervalle desqquelles il y a des fossettes assez profondes. Entre la troisième et la quairic̀me còte, on voit un espace uni, garni d'un duvet blanc très-serré et très-court, et formant de chaque côtć unc bande blanche parallèle à la suture, et qui n’atteint pas l'extrémité de l'élytre. Il y a, en dehors de cette bande et à la base de l'élytre, une seconde tache blanche très-courte. Les pattes antérieures sont plus grandes que les autres, avec les janbes arquées et terminćes par lcs épines et le faisceau de poils que nous avons observés dans les dcux autres espèces. Les autrcs pattes sont plus courtes. Les tarses sont semblables à ceux des autres espèces; unais les antérieurs n'ont pas lés grands cils qu'on voit au Tylodes humeralis. - Cet insecte vient de la Coneeption, au Chili.

MÉCOPUS A TROIS LIGNES, Mecopus trilineatus. Guér. - Nigrn-fuscus; thorace fulvescentc trilineato; elytris albidis, brunneo strigulatis, lateribus fasciaque oblique fuscis; subtus niger, lateribus albido varicgatis. Perlibus anticis elongatissimis. Thorace subtus antice bi-spinosus. - L., sans la trompe, ro mill., l. $4 \mathrm{~m}$. - Guérin, Iconogr. du Règne animal, Ins., pl. VIII, fig. 339.

Cet insecte a une forme très-rcnarquablc; son rostre est noir, recourbé, presque de la longueur du corps, cylindrique à la base, aplati au bout, rugneux sur les côtés 
et en dessous, presque lisse en dessus, et donnant insertion, près de son extrémité, aux antennes, qui sont assez eourtes et noires. La tête est noire, globuleuse, entièrement oeeupée par les yeux, qui se touchent sur la ligne neédiane et dians. toute son étendue. Le eorselet est un peu plus large que les élytres, árrondi sur les eôtés, transversal, plns étroit en avant, d'un noir velouté, avec trois lignes longitudinales ferrngineuses en dessus, et plusieurs lignes blanehes sur les eòtés et en dessous. De ehaque côté, au-dessous et en avant des pattes antérieures, on voit unc épine mince, aiguë, dirigée en avant et arteignant environ au tiers de la longueur du rosire. Les élytres sont rétrécies en arrière, un peu aplaties en dessus, striées, d'un blane varié cle fauve, avec le bord extérieur et une bande obliqque au-delà du milieu et n'allant pas jusquàa la suture, d'un noir velouté. Le dessons est d'un beau noir de velours, avec les eôtés rayés de blane. Les paties sont grandes, surtout les antérieures, qui sont presque deux fois plus longues que le eorps, grêles, avec le premier artiele des tarses très-long. Les euisses postérieures ont deux petites épines courtes, plaeées sous l'extrémité. - Cet individu vient de la Nouvelle-Irlande; nous en avons un autre qui a été trouvé à Rawack, et qui nous semble n'en être qu'une variété. Les trois lignes du dessus de son eorselet sont blanches au lieu d'ètre ferrugineuses; la base de ses élytres, au lieu d'être blanche, eomme dans lindividu déerit ei-dessus, est noire, avec les épaules et la suture seulement blanchâtres. Le dessous et les tarśes sont entièremont semblables à l'individu préeédent.

Nous avons sous les yeux la figure du Rhynehène Doryphore de MM. Quoy et Gaymard, publiée dans leur Voyage de l'Uranie, planche LXXXII, figures 9 et xo. Cette espèee est très-voisine de la nôtre; elle doit en différer, si la figure est exaete, en c'e qu'elle a des bandes longitudinales, blanehes, sur des élytres brunes.

Genre ARACHNOPE, Arachnopus. Gứr.

Ce nouveau genre est très-voisin des Cleogonus, Ocladius et Orobitis de Sehœenherr; mais il en diffère d'une manière notable par ses antennes, par les yeux, ete. Dans les trois genres auxquels nous le comparons, les antennes sont.brusquement terminées par une massue ovale, renflée, tandis que, dans notre genre, l'antenne va en grossissant insensillenent. Notre insecte, ainsi que les Ocladius et les Orobitis, a les yeux séparés, plaeés en avant de la tête, et de chaque côté de la trompe, tandis que les yeux sont eontigus dans les Cleogronus; mais il diffère des trois genres susmentionnés par l'insertion de ses antennes, qui se trouve vers l'extrémité du rostre, eomme dans les Cleogonus. Voiei du reste les earactères que nous assignons à ce nouveau genre :

Antennes courtes, assez épaisses, insérées vers le bont rlu rostre; le premier article aussi long que le funieule, un peu renflé à son extrémité; les second et troisième allongés, obeoniques; les suivants eourts, devenant insensiblement plus épais jusqu'au neuvième; les dixième et onziène diminuant et se termiuant ell points arrondis. Rostre long, eylindrique, courbé, ayant deux sillons obliques sur les eòtés, l'un pour 
reeevoir le prenier artiele des antennes, dirigé en dessous, l'autre partant des yeux et venant finir insensiblement vers l'insertion des antennes. Lèvre inférieure linéaire, mandibules saillantes, bidentées. Yeux de grandeur moyenne, peu saillants, placés à la base du rostre, et dirigés en avant. Corselet très-étroit en avant, très-élargi en arrière, arrondi sur les eôtés, ayant en dessons un faible sillon impropre à reeevoir entièrement le rostre dans le repos. Élytres eoniques en arrière, assez bombées. Pattes très-grancies, avee les euisses un peu renflées et armées d'une petite dent en dessous. Tarses eourts, larges, aplatis, avee l'avant-clernier artiele en eœur et profondément bilobé.

Ce nouveau genre doit être plaeé entre les Cleogonus et les Ocladius; il se eompose de deux espèees dont l'une est publiée dans le voyage de l'Astrolabe sous le nom d'Archarias à pieds longs, pl. VII, fig. 22.

ARACHNOPE A BANDE, Arachnopus striga. GUÉr. - Ater, antice posticeque attenuato, fascia interrupta alba ad basin elytrorum. Pedibus utrinque albo-ciliatis. - L. 15 mill., $1.6 \mathrm{~m}$.

Chryptorlynacus striga. Latr. Atlas, Ins. pl. VI, lig. 5.

Il est d'un noir peu luisant; sa forme est tout-à-fait rhomboïde, c'est-à-dire qu'il est étroit en avant et en arrière, et large au inilieu. Sa trompe, avee la tête, forme presque le tiers de sa longueur; elle est eourbée régulièrement depuis sa base, lisse, avee quelques granulations près des yeux. Le eorselet forme un peu moins de l'autre tiers; il est un peu plus long que large, eonique, tronqué aux deux extrénités; il est uniformément rugueux, terne, ou peu luisant. Les ély tres sont de la largeur du eorselet à leur naissanee; elles s'élargissent un peu aux épaules, et se terminent de suite en un eône presque semblable à eelui que forment le eorselet et la tête sans le rostre; elles sont soudées, rugueuses, et leur base est mảrquée d'une bande blanehe transverse, assez étroite, formée par des écailles très-eourtes et serrées. Le dessous du eorps est plat, lisse. Les pattes sont grandes, insérées à une distanee notable les unes des autres, les postérienres étant attaehées toutà-fait sur les eôtés du eorps, sous le bord des élytres. Les enisses sont grandes, rugueuses, un peu renflées vers l'extrémité, avee une petite dent en dessous, et une rangée de eils blanehâtres, et très-sêrrés de ehaque eôté. Les jambes sont un peu arquées, avee une earène traneliante sur leur eôté externe, et un ongle eroehu à leur extrémité; elles ont de ehaque eôté une bordure de longs eils pâles. Les tarses sont courts, larges et plats, eomme à l'ordinaire. - Ce singulier inseete a été trouvé à Dory, dans la NouvelleGuinée.

Nous avons représenté, figure $5 \mathrm{~A}$, l'extrémité de son rostre, vu en dessous, pour montrer les mandibules et sa lèvre inférieure.

PRIONE DE LIMA. Prionus (Mallodon Serv.) Lima. Goértv. - Castuneus, capite thoraceque rugosis; angulis posticis acutis, recurvis; lateribus serratis. Elytris basi mgosis; scutello cordato, longitudine impresso. - L. 4 déeim., 1. 12 mill. - Atlas, Ins., pl. VII, fig. I. 
Il ressemble beaueoup an Prionus faber de notre pays; mais il est plus petit et moins large. Il est entièrement d'un brun marron, un peu plus foncé sur la tête et le eorselet. Sa tète est assez petite, fortement rugueuse, avee une impression longitudinale et régulière au nilieu. Les mandibules sont peu saillantes, bidentées au bout. Les palpes sont eourts, inégaux, avee le dernier artiele tronqué obliquement. Les yenx sont grands, réniformes, plus rapproeliés entre eux en dessous qu'en dessus. Les antennes de la seule femelle que nous possédions sont filiformes, à peine de la longueur de la moitié du corps. Le eorselet est transversil, un peu plus large en arrière, presque deux fois aussi large que long, finement dentieulé sur les bords latéraux, avec les angles postérienrs un peu prolongés et relevés en une petite pointe aplatie. Son bord antérienr est un peu éehancré, garni de eils jaunes; le bord postérieur est sinueux, également bordé de cils de la mème eouleur; toute sa surfaee est assez plane, rugueuse, avee un sillon longitudinal et le milieu lisses. L'écnsson est assez grand, finement rugueux, en forme de eœur, avee un sillon longitudinal au milieu; il est très-saillant et eomme posé sur les élytres. La base des élytres est un peu plus large que le corselet; elles sont allongées, parallèles dans toute leur longueur, rebordées, arrondies en arrière, avec les épaules un peu saillantes et arrondies. Elles sont fortement rugneuses à leur base, mais ees rugosités deviennent plus fines vers la partie postérieure. On voit sur ehaque élytre les traees de quatre eôtes peu élevées et peu visibles; le dessous du thorax est garni de poils jannàtres; l'abdomen en est tout-à-fait dépourvı; il est lisse, luisant, et se termine par un oviduete saillant, allongé, un peu élargi et tronqué au bout. Les pattes sont de longueur noyenne, eomprimées, avee l'extrémité des jambes tronquée, un pen élargie et terminée par plusieurs petites épines peu saillantes. Les tarses sont peu dilatés, garnis de brosses jaunes en dessous. - Cet insecte a été pris à Lima.

DISTICHOCÈRE FERRUGINEUSE, Distichocera ferruginea. GuÉr.-Corpus nigrum, subtus pilis argenteis nitidum. Capite macula frontali, thorace vittis duabus elytrisque dense piloso-ferrugineis. $-\mathrm{L}$. 22 mill., $1.6 \mathrm{~m}$. $\frac{1}{\mathrm{a}}$.

Cette belle espèee appartient évidemmeut au genre que Kirloy a établi, dans les Transaetious de la Société linnéenne de Londres, sous le nom de Distichocère. Sa tète est un peu allongée, rétréeie en avant, armée de deux eourtes mandibules, avee les palpes maxillaires filiformes, noirs. Les yeux sont bruns, grands, réniformes. Les antennes s'insèreut dans une éehancrure antérieure de eeux-ei; elles sont noires, un peu plus longues que la moitié du eorps, avee les quatre premiers artieles obeoniques, et les suivalnts un peu plus larges, fourehus au bout, avec le dernier ovoïde allongé. La tête est entièrement noire, avee une large taehe ferrugineuse sur le front, qui atteint de ehaque côté la base des antennes et se prolonge en avant jusquau labre; eette taelie est formée: par un duvet eourt et très-serré. Le corselet est un peu plus large que long, tronqué carrément aux deux extrémités, arrondi et un peu siuné sur les eôtés. Il est noir, avec le dessous garni d'un duvet blane luisant; il a de chaque eôté, en dessus, une large. bande longitudinale formée par un duvet ronge. L'éeusson est assez grand, arrondi,

Vojage de la Coquille. $-\mathrm{Z}$. Tom. II, partie II. $\mathrm{x}^{\text {re }}$ I iv. 
noir. Les élytres sont plus larges que le corselet à leur base, rétrécies en arrière, tronquécs ct arrondies au bout. Elles ont chacune quatre côtes peu élevées, obliques, avec le conmencement d'une autre petite côte près de l'écusson; ellcs sont entièrement couvertes par un duvet court et serié, d'un rouge ferrugineux. Le dessous du thorax et de l'abdomen est noir, couvert d'un duvet blanc argenté; le bord postérieur des segments dc l'abdomen est d'un ferrugineux obscur; le dernier segment est entièrement à découvert en dessus. Les ailes sont à peine plus longues que les élytres, transparentes. Les pattes sont noires, luisantes, de grandeur ordinairc, avec l'extrémité des cuisses renflée. Les tarses antérieurs sont un peu dilatés; les autres sont filiformes, av ec le premier article plus allongé. - Cet insecte vient de la Nouvellc-Hollande.

\section{Genre TMÉSISTERNE, Tmesisternus. Latr.}

Latreille a établi ce genre, dans la nouvelle édition du Règne animal, avec les insectes mêmcs quc nous allons décrire, et il y a rapporté, avec raison, les trois Callidium publiés par Fabricius sous les noms de Variegatum, Lineatum et Sulcatum, qui sont assez bien figurés dans Olivier. Nous pensons qu’il faut aussi rapporter à ce genre lcs insectes auxquels M. Boisduval a donné les noms d'Ichtyosome admirable et à huit points dans les $8^{e}$ et $9^{e}$ planches du voyage de l'Astrolabe; en sorte qu'avec les trois que nous allons décrire, nous aurons vu sept espèces de ce genre, toutes propres à l'Australasie. M. Boisduval en a décrit une dizaine d'espèces provenant des collections de Paris; il est probable qu'il en existe d'autres dans les collections du continent, et surtout dans celles des entomologistes de l'Angleterre, si riches en espèces australasiennes.

TMÉSISTERNE A TROIS BANDES, Tmesisternus trivitatus. GuÉR. - Ater, flavotomentosus. Thorace elytrisque punctatis. Elytris fasciis tribus allis transversis, postica obsoleta. - L. I 8 mill., l. 5 m. $\frac{1}{2}$ - - Atlas, Ins., pl. VII, fig. 12.

Timesisternus bizonulatus. Guér., Icon., Règne anim., Ins., pl. 45, fig. 7.

Il est rétréci en avant et en arrière. La tête est allongée, un peu rétrécie en arrière, noire, ponctuée, avec un sillon longitudinal au milieu; elle a en dessus plusieurs taches irrégulic̀res formées par un duvet très-court, d'un jaune d'ocre. Le corselet est transversal, plus étroit, et tronqué carrément en avant, lobé ell arrière; toute sa surface est ponctuée et garnie de taches irrégulières jaunes, comme celles de la tête. L'écusson est rond, lisse. Lcs élytres sont plus larges que le corselet, un peu rétrécies en arrière, tronquées obliquement et terminées par deux petites épines très-courtes; elles ont de gros points enfoncés qui vont en diminuant vers l'arrière, et toute lcur surface est couverte du même duvet jaune qu'on observe sur le corselet et sur la têtc. Elles ont de plus trois bandes transverses étroitcs, formées par un duvet blanchâtre; la première, un peu courbée, est placée au tiers antérieur; la seconde, beaucoup plus courbée en arrière et un peu sinueuse, se trouve au ticrs postérieur; enfin, entre celle-ci et l'cxtrémité, on en observe une très- 
petite, plus on moins effacée selon les individus, plus sinueuse que la précédente. Le dessous du corps est varié du même duvet jaune, avec lc milieu lisse, noir ct luisant; le dernicr segment de l'abdomen est tronqué au bout, avec unc petite épine de chaquc còté. Les pattes sont de grandeur moyenne, avec les cuisses très-lenflćes, brunes, couvertes d'un duvct jaune pâle. Les jambes ont un duvet plus doré, ainsi que les tarses, qui sont peu dilatćs. - Cet insecte a été trouvé à Dory, dans la Nouvelle-Guinće.

TMÉSISTERNE MARBRÉ, Tmesistermus marmoratus. Guér. -. Aneo-fuseus, atomis maculisque fusco-griseis, sparsis; macula communi làve, elvtromum basi, fascïs duabus latis irregularibus posticis nigris, in ultima punctis quatuor fulvo-griseis. - L. I 5 mill., 1. 4 m. -Atlas, Ins., pl. VIJ, fig. 13 .

Sa forme est scmblable à celle du précédent; la tête cst un peu rétrécie en arrière, noire, couverte d'un duvct jaune; il y a une petite ligne longitudinale noire au milieu, et une autre plus petite au-dessus des yeux de chaque côté. Lcs ycux sont grands, comylétement divisés en deux par l’insertion des antcnnes; celles-ci sont de la longueur du corps, noirâtres, filiformes, avec quelques petits cils roides cn dessous. Les palpes sont courts, filiformes, fauves. Le corselet cst un pcu plus large que long, tronqué, droit en avant, un peu sinueux cn arrière, plus étroit en avant, arrondi sur les còtés. Il est couvert de duvet jaune, avec trois lignes longitudinales noires, placées l'une an milicu, et les deux autres sur les bords latéraux; on observe en dessus de gros points enfoncés, noirs. L'écusson est arrondi, velu. Ises ćlytres sont un pell plus larges que le corselct, parallèlcs jusque vers leur extrémité, tronquées obliquement de dehors en dedans au hout, avcc l'angle extćrieur épineux; elles sont noires, couvertes de points enfoncés assez distants, avec une côte peu élevée, parallèle à la suturc, et aboutissant presque à l'angle postérieur épineux. Toute leur surface est garnie de duvct serré, court ct jaune, placé par petites taches très-rapprochécs; les espaces laissés uus, et qui sont par conséquent noirs, forment d'abord une grande tache commune arrondie, luisante, trés-lisse, et sans points, immédiatemcnt après l'écusson. Les angles huméraux ont deux petites lignes courbes, qui ne dépasscnt pas la grande tache commune; il y a, tout-à-fait au bord de l'élytre, et presque en dessous, deux taches noires, l'unc sous l'angle huméral, l'autre au tiers antérieur; on observe, un peu avant le tiers postérieur de l'élytre, une grandc lsande noirc assez largc, sinncuse, avec une dent dirigée cn haut de chaque côté et sur le bord de chaque élytre; cette bande est courbée vers l'arrière ; cntre clle et l'cxtrémité on trouve sur chaque élytre deux taches d'un jaune un peu fauve, bien distinctes dı jaune qui couvre l'insecte; celles qui touchent à la suture sont de forme un peu triangulaire; elles sont précédées en haut d'une tache noire assez grande; lcs taches jaunes fauves du bord des ćlytres sont placées un peu plus bas que les précédentes, arroudies, précédées aussi d'une petite tache noire; leur dessous cst bordé d'une bande noire assez large. Le dessous du corps cst varié d'un grand nombre de petites taches jaunes, le milieu seul est lisse, luisant ct noir. Le dernier segment de l'abdomen est un pcu jame à l'extrémité; il a une petite tache jaune correspondante à celle des élytres de chaque 
còté; son extrémité est largement tronquée, très-peu épineuse aux anglcs, et couvcrte de poils assez longs. Les pattcs sont noirâtres, avec les cuisses trc̀s-renflées; les tarses sont d'un brun ferrugineux. - De Dory, Nouvelle-Guinće.

TMÉSISTERNE UNIPONCTUÉ, Tmesisternus unipunctatus. Gú́r. - Flavo-griseus, macula communi elytrorum basi nitida, punctata fascïsque quatuor obliquis tenuibus nigris._L. I I mill., $1.3 \mathrm{~m}$. $\frac{2}{2}$.

Cettc petitc cspc̀ce ressemble beaucoup à la précédente, et l'on pourrait la considérer comme n'en étant qu'une varićté, si les bandes noires de ses élytres n'étaient pas toutcs différentes, trìs-étroites, et si la coulcur du duvct qui couvre tout son corps n'était pas d'un jaune différent et bcaucoup plus pâle. Sa tête est entièrement couverte de duvet jaune, avcc une petite ligne noire au milieu, et unc autre devant les ycux. Les antennes sont un peu plus longues que le corps, filiformes, avec les premiers articles noiràtres, et les suivants d'un brun ferrugincux. Le corselet est transversal, plus étroit en avant, ponctué, couvert d'un duvet très-scrré qui entre même dans les points enfoncés, avec trois lignes longitudinales noircs et étroites. L'ćcusson est arrondi, jaune. Les élytres sont un peu plus larges que le corselet, presque parallèlcs, un pcu arrondies sur les côtés, ponctućes, couvertes uniformément de duvet jaune serré, et qui ne forme pas des petites taches commc dans l'espèce précédente. Il y a derrièrc l'ćcusson une grande tache peu luisante, fortement ponctuée, arrondie, avec un petit angle de chaque côtć et en arrière. Les angles huméraux ont quelques petites lignes noires; une prcmic̀re bande ćtroite descend obliquement de la tache commune au bord externe de chaque élytre; il y en a une autre très-courbe placée vers le tiers postérieur, étroite et très-peu sinueuse. Entre cellc-ci ct l'extrémité, il y en a deux autres plus étroites, très-sinucuses, avec des angles aigus; l'cxtrémité des élytres est tronquée carrément, avec une trc̀s-petite trace d'épine à l'angle extcrnc. Le dessous cst uniformément couvert de duvet jaune, à l'exception de la lignc médianc, qui est noire et luisante. Lcs pattes sont ćgalement couvertes de duvet de la même coulcur, avcc lcs cuisses trc̀s-renflées; les jambes et les tarses sont un peu ferrugincux, également couverts de duvet. - Ce petit Tmesisterne vient du Port-Praslin, près dc la Nonvelle-Guinée.

TRAGOCÈRE A DEUX BANDES, Tragocerns bifasciatus. Gućr. - Thorace nigro, flavo-marginato; elytris truncatis bidentatis, castaneis, flavo bicinctis, apice nigris, lineis quatuor elevatis, villosis. Pedibus brunneis, tarsis nigris. - L. I6 mill., $1.5 \mathrm{~m}$. -Atlas, Ins., pl. VII, fig. 3.

Cette espèce est très-voisine de cellc que Donovan a décrite et figurée sous le nom de Prionus bidentatus, et que nous avons représentéc dans notre Iconogr. du Règne anim., Insectes, pl. 45, fig. 8; mais elle en diffère par sa taille, qui cst bien plus petite, par sa couleur et par les deux bandes jaunes bien marquées de ses élytres. Voici la description donnée par Donovan : “ Thorace submarginato, inermi, niger, villosus; elytris castaneis, 
"flavo nebulosis, apice lidentatis, lineis quatuor elevatis. - Long. I pouce. "Cet auteur en a publié unc autre espèce sous le nom de Prionus fasciatus, mais ses élytres sont arrondies au bout, et sa longueur est de 13 lignes.

La tête de notre Tragocère a deux bandes, est petitc, noire, ponctuée, un peu velue, avec des poils gris. Les yeux sont jauıes, bordés de poils roides en arrière, fortement échancrés en haut ponr recevoir les antennes; celles-ci sont un peu plus longucs que le corps, noires, filiformes, à articles obconiques, assez fortes. Le corselet est en forme de trapèze, un peu plus large que long en arrière, plus étroit en avant, un pcu sinueux sur les còtés, tronqué presque carrément à ses dcux extrémités, d'un noir mat, finemcnt chagriné. Il est bordé en arric̀re d'unc bande formée par des poils d'un jaune doré, qui se continue sur les côtés jusque vis-à-vis l'inscrtion des antenncs. Le bord extérieur et le dessous sont garnis de poils blanchâtrcs. L'écusson est triangulaire, lisse, noir. Lcs élytres sont un peu plus larges que le corselet à leur base; clles sont presque parallèles, fort peu rétrécies à l'cxtrémitć, tronquées carrément, avec une très-petitc ćpine à chaque angle de la troncature. Elles ont chacune la suture un pen élevéc, et quatre côtes dont la secondc ct la troisième attcigncnt l'extrémité, tandis que la première, la plus rapprochée de la sutnrc, ne faii que s'en approcher, et que la quatrième sc confond avec la troisième avant le tiers postéricur de chaque élytre; le bord externe de celles-ci est profondément éclıncré vers la base; leur couleur est marron ferrngincux passant au noir, profond vers lc milieu; on observe au tiers antérieur une bande transversale formće par des poils jaune-dorés, qui n'atteint pas la suture, et qui est suivie, un peu plus bas, de deux taches suturales peu marqućes. Au tiers postérieur il y a unc autre bande jaune, beaucoup plus large, sinuée sur les bords, un peu plus étroite vers la suture, mais la touchant. Toute cette partie postérieure des élytres est garnie de poils noirs assez longs. Le dessous de l'abdomen est d'un marron fcrrugineux, avec des taches latérales alternativement noires et jaunes. Le dessous du thorax est noir, velu. Les pattes sont d'un brun marron, avec les tarses noirs. - Cette espèce a étć tronvée au Port-Jakson.

LAMIE GRANULEUSE, Lania granulosa. GuÉr. - Oblonga, convexa, atra, griseotomentosa; capite subrugoso, thorace antice posticeque plicato, medio transverse tuberculatn. Elytris apice subrotundatis, seriatim-tuberculatis; abdomine flavo-variegato, seymento ultimo impresso. Pediuus griseo-variegatis. - L. 36 mill., l. $14 \mathrm{~m}$. - Atlas, Ins., pl. VII, fig. 8 .

Celte Lamic est voisine, quoique plus grande, de la Lamia vermicularis de Donovan; elle est allongće, cylindriquc, noire, toute couvcrte d'un très-court duvet gris jaunâtre. Sa tête est fineıent rugueusc, avcc un espacc plan, carré, situé entre les yeux, la base des antennes et le labrc. Les antennes sont filiformes, moins longues que le corps, noires. Le corsclet est un peu plus liargc que long, plissé transvcrsalement en avant et eu arrière, rugucux au milieu, avec quelques gros tubercules transverses. L'écusson est arrondi, assez grand. Les élytres sont plus larges que le corsclet, avec les angles huméraux saillants, arrondis. Elles s'élargissent très-peu vers leur ticrs postérieur, se rétré- 
cissent ensuite, et leur extrémité est un peu tronquée obliquement, avcc les angles arrondis. Toute leur surface est couverte de tubercules luisants, arrondis, assez distants, rangés en séries, et beaucoup plus gros vers leur base. Le dessous du corps est varié de noir et de jaunâtre, ainsi que les pattes, qui sont fortes et assez courtes. Le dernier scgment de l'abdomen présente en dessous une large fossette arrondie.-Ce bel insecte vient de la Nouvelle-Hollande.

LAMIE DE D'ORBIGNY, Lamia Orbignyi. Guér._Griseo-metallica, elytrorum apice obscuriore, vittis duabus parvis in humeris; macula media ovata, fascia obliqua dentata desinente, albo-griseis. - L. I 7 mill., 1.9 m.-Atlas, Ins., pl. VII, fig. 6 .

Sa tête est noire, ponctuée, couverte d'un fin duvet jaunâtre, moins penchée que dans les autres Lamies, rétrécie en avant et en arrière, un peu eoncave, et ayant un sillon au nilieu. Les yeux sont assez saillants, profondément éehancrés par l'insertion des antennes; eelles-ei ont plus de la longueur du corps; elles sont grises, filiformes; un peu ciliées en dessous, avec le premier article très-renflé et ovoïde. Le corselet est transversal, un peu aplati, brun, rugueux, garni de duvet jaunâtre très-fin, avec une petite ligne élevée, lisse au milieu. Il est plus étroit et un peu échancré en avant, élargi sur les côtés au milieu, avec une courte épine pointue de chaque côté à ce point; son bord postérieur est un peu sinueux, un peu plus large que le bord antérieur. L'écusson est transversal, arrondi en arrière, blanchâtre, avec un point noir au milieu. Les élytres sont plus larges que le corselet à leur base, rétrécies insensiblement en arrière, un peu aplaties, tronquées carrément à l'cxtrémité, avec l'angle externe saillant et presque épineux; elles sont d'un brun noiràtre, couvertes dc points enfoncés assez gros et trèsrapprochés, et garnies d'un duvet jaunâtre très-fin et très-serré; leur base est marquée, de chaque côté et aux angles huméraux, d'une tache blanche; on en voit une autre au milieu des élytres, arrondie, eommune et coupée en deux par la suture; cette tache s'appuie en arrière sur une large bande blanche sinueuse ct dentelée, derrière laquelle les élytres sont d'un brun plus foncé. Le dessous du corps est noirâtre, garni d'un très-fin duvet jaunâtre. Les pattes sont dc la même couleur. Les cuisses antérieures sont trèsrenflées et très-fortes, armées en dedans et au milieu d'une crête ćlevèe et finement dentelée. Les jambes sont un pell,arquécs; les jambcs intermédiaires et postérieures sont droites, avec une petite saillie au côté externc. Les tarses sont assez dilatés. - Cette espèce vicnt du Port-Praslin, à la Nouvelle-Irlande, nous l'avons dédiée à notre ami M. Alcide d'Orbigny, qui vient de faire un voyage de sept ans dans l'Amérique méridionale.

LAMIE RUgOSUle, Lamia rugosula. Guén. - Atra, cylindrica, thorace rugosulo, tuberculis quatuor minutis. Elytris undique granulis elevatis seriatis. -L. I5 nill., $1.5 \mathrm{~m}$. -Atlas, Ins., pl. VII, fig. 9 .

Cet insectc appartient, ans aucun doute, au groupe naturel de Lamies, auquel 
Dalman a donné le nom de Dorcadion; M. Boisduval le place dans le genre Parmena, formé par Mégerle, genre établi sur des caractères de fort peu d'importance.

Son corps est entièrement d'un noir terne, cylindrique, oblong, un peu plus étroit aux deux extrémitćs; la tête est verticale, veloutée ; les yeux sont réniformes, profondément et largement échancrés par la base des antennes; celles-ci sont presque de la longueur du corps, filiformes, avec le premier article plus épais. Le corselet est un peu plus large que long, finentent rugueux, un peu velouté, rebordé en avant et en arrière, avec quatre tubercules peu saillants placés transversalement au milieu de sa longueur, les deux externes étant sur les côtés. Son milieu offre encore quelques légères élévations tuberculeuses, savoir : deux en arrière, deux en avant, et une très-petite au centre. L'écusson est trèspetit, peu visible. Les élytres sont de la largeur du corselet à leur base, ćlargies au milieu, rétrécies et arrondies à l'extrémité; elles sont un peu veloutées, avec des séries longitudinales de petits tubercules pointus, dirigés en arrière, placés assez irrégulièrement près de la suture, formant ensuite des còtes parallèles qui se contournent à la base de l'élytre pour se diriger vers les angles huméraux, où ils vont former une petite crête. Le dessous du corps est un peı velouté, uni. Les pattes sont de grandeur moyenne, avec l'extrémité des jambes garnie d'un duvet jaunâtre, luisant. Les tarses sont peu dilatés, velıs en dessous. - Cette espèce vient de la Nouvelle-Hollande.

GNOME GIRAFE, Gnoma girafa. CuÉR. -Nigra, thorace transversim plicato, cceruleo-micantc, scutello albo; elytris viridi-micantibus, scabriusculis, apice glabrioribus. Scutello albo. Metathorace subtus nigro, immaculato. Pedibus nigro-violaccis.-L. 3 cent., 1. 7 m.-Atlas, Ins., pl. VII, fig. I I.-Cerambjx giraffa, Donovan, Epitome et Sclir., Trans. Lin. Soc., t. VI, pag. I98, tab. 2 I , fig. 8.

Cette grande espèce est bien évidemment celle que Donovan a figurće sous le nom de Giraffa. Sa tête est verticale, assez grande, avec un sillon longitudinal bien marqué sur le vertex. Les antennes sont très-rapprochées entre elles, insérées dans une large échancrure de la partic supérieure des yeux, plus de deux fois plus longues que tout le corps, filiformes, noires. La tête et le corselet réunis forment juste la longneur des élytres; le corselet cst cylindrique, d'un noir à reflets bleus, rétréci au milieu, finement plissé dans toute sa longueur et sans tache; l'écusson est en forme de cœur, arrondi en arrière, entièrement couvert d'un fin duvct blanc argenté. Les élytres sont plus larges que le corselet à leur base, rétrécies ensuite inscnsiblement, arrondies an bout, d'un noir à beaux reflets verts, fortcment granuleuses à leur base jusqu'au-delà de leur nilieu, et finissant insensillement par devenir lisses à l'extrćmité. Le dessous du corps cst sans taches, d'un noir un pen bleuâtre. Les pattes sont très-grandes, d'un noir bleu. Les antérieures sont beanconp plus grandes que les autres, avec les jambes un peu arquées, armées vers l'extrémitć et en dessous d'une petite épine. Les jambes intermédiaires et postérieures ont aussi un pctit tubercule vers l'extrémité, mais il est placé sur le lord externe; les tarses des quatre pattes postérieures sont peı dilatés; les antérieurs, au contraire, lo 
sont beaueoup, et leurs bords sont garnis dle longs eils noirs et asscz roides. - Cette espèce a été trouvée à Amboine et à la Nouvelle-Guinée.

Nota. M. Westwod a fait connaître, dans l'édition anglaise du Règne animal, une grande espèce voisine de celle-ci, et à laquelle il donnc le nom de Gnoma suturatis; elle parait avoir trois lignes sur le corselet, la suture et la base des élytres jaunes. Elle vient de la Nouvelle-Galles du Sud, et elle a été déerite et figurée dlans le t. XV dı The Animal King dom, Insecta, vol. II, pag. 120 , pl. 7o, fig. 2.

GNOME SEMBLABLE, Gnoma affinis. Gú́r. - Nigra, thorace transversim plicato, caruleo-micante, basi striga abbreviata alba; elytris violaceo-micantibus, glabris, basi scabriusculis, albo sex-maculatis. Metathoraee lateribus albo-bimaculato. Pedibus nigrocyaneis. - I. 14 ì 24 mill., l. 4 à 6 m. - Atlas, Ins., pl. VII, fig. 10.

Cettc espèce ressemble beaucoup à la précédente pour la forme; eependant ses élytres sont un peu moins longues, et leurs épaules sont un peu moins saillantes et un peu plus larges. La tête et le corselet réunis sont notablement plus longs que les élytres; les antennes sont an moins deux fois plus longues que le corps. Le corselet est de la même couleur et de mème forme que celui de l'espèce précédente, seulement sa base est marquée d'une petite ligne longitudinale ayant au plus le cinquième de sa longueur, et formée par de très-petits poils blanes. L'écusson est, comme dans la Groma girafa, blane, en forme de cœur et arrondi en arrière. Les élytres sont d'un noir violet très-briliant, granuleuses à leur base à peine jusqu'au tiers de leur longueur, lisses ensuite. Elles ont chacune unc petite tache de duvet blane à l'angle huméral, une autre tache blanche, plus grande, transverse, placée un peu au-delà du milieu, entre la suture et le bord externe, et une autre tache blanche un pen nébnleuse, oblique, allongée, placée à l'extrémité. Le dcssous du corps est d'un noir un peu bleuâtre avee les côtés du inétathorax, sous les angles liuméraux des élytres, marqués de deux taches blanches inégales, allongées et arrondies. Les pattes et les tarses sont conformés comme dans l'espèce précédente. - Nous avons vu deux individus de cette espèce provenant de la NouvelleGuinée, mais de tailles bien différentes; c'est la variété très-petite que nous avons figurée.

Nota. L'espèce qu'Olivier a décrite et figurée, sous le nom de Longicollis, est précisément celle qui a le corselet le plus court; elle a, comme notre Affinis, des taches blanches sur les élytres; mais son corselet n'est pas même de moitié aussi long que les élytres; il a une ligne blanche clans toute sa longueur, au milieu, et deux autres lignes un peu jaunâtres, parallèles et placées de chaque côté. Les côtés du métathorax ef des segments de l'aljomen sont tachés de jaunâtre. Les pattes sont courtes, avec les antérieures très-peu plus grandes que les antres. Les individus que nous avons vus viennent de la Nouvelle-Guinée. 
SAPERDE A POINTS ROUX, Saperda rubro-punctata. Guér.-Nigro-cenea, capile vittis duabus, thorace quatuor, elytris basi duabus punctisque multis ochraceis. - L. 22 mill., 1. 7 m. - Lamia rubro-punctata.-Atlas, Ins., pl. VII, fig. 4.

Cette espèce est fort remarquable en ce qu'elle établit le passage entre les vraies Lamies et les Saperdes auxquelles Fabricius a donné le nom de Gnoma; comme ces dernières, notre espèce a le corselet inerme, strié transversalement; les antennes grandes, les pattes antérieures plus longues que les autres, et le corps rétréci en arrière, avec les épaules saillantes, mais elle en diffère parce que lc corselet est beaucoup moins long et qu'il n'est pas rétréci au milieu.

Notre Saperde est entièrement d'un noir peu luisant; sa tètc est verticale; les yeux sont grands en dessous, assez rapprochés, échancrés en liaut pour donner athache aux antennes, insérées très-près l'une de l'autre sur le laut de la tête, laquelie est échancrée à cet endroit. Les yeux sont complétement entourés d'une large bande ferrugincuse, le labrc est aussi ferrugineux, le vertex a un sillon enfoncé et dcux lignes ferrugineuses qui naissent ensemble au milieu et derrière les antennes, et vont en divergeant en arrière; le bord postérieur de la tête est d'un noir velouté. Les antennes sont presque deux fois plus longues que le corps, filiformes, finement chagrinées, noirâtres. Le corselet est à peu près aussi long que large, rétréci à ses deux extrémités, arrondi sur les còtés, finement plissé transversalement, avec quatre bandes longitudinales ferrugineuses, dont les deux intermédiaires sont les plus rapprochées entre elles. L'écusson est transversal, ferrugineux, avec le centre noir. Les élytres sont beaucoup plus larges que le corselet à leur base, avec les épaules saillantes, arrondies sur les côtés, diminuant insensiblement jusqu'à l'extrénilé, qui est armée d'une petite épine placée un peu en dehors de la suture. Leur surface est fortement ponćtuée et couverte de taches rondcs de diverses grandeurs, formees par un duvet ferrugineux très-serré. Le dessous du corps est également varić de ferrugineux, ainsi que les cuisses. Les pattes antérieures sont plus grandes, avec un petit tubercule sous l'extréuité des jambes; les intermédiaires et postéricures ont aussi un petit tubercule près du bout, naais il est placé en dessus. Ce caractère leur cst comuun avec les Gnoma. _ Cctte espèce vient de Dory, à la Nouvelle-Guinée.

SAPERDE A BORDS BLANCS, Saperda albo-cincta. Gú́r.-Oblonga, atra. Thorace inermi, favo-quadrivittato. Elytris margine exteriore albis, supra flavo-variegratis, lateribus albis. Abdomine albo-maculato, vittis ferrugineis. Pedibus brevibus, cinereotomentosis. —L. I 8 mill., 1. 6 m. - Lamia albo-cincta._Atlas, Ins., pl. VII, fig. 7 .

Cctte espèce pourrait bien être la même que la Saperda collaris de Donovan ; la figure qu'en donne cet auteur se rapporte assez bien à notre individu, seulement ses élytres sont entièrement noires ct bordées de blanc, tandis que la nôtre est en outre tachetéc de jaune. Il pourrait se faire que l'échantillon décrit par Donovan fùt usé et eût perdu les taches james de ses élytres et les bandes transversales de son corselet; dans le doute, nous avons considéré notre espèce commc inédite. Elle est allongée, cylindrique, entiè- 
rement noirc, un peu luisante. Sa tête est très penchće, variée et rayée de jaune. Les antennes sont de la longucur du corps, filiformes, très-eiliées en dessous. Le eorselet est un peu plus large quc long, fincment plissé en travers, presque droit sur les côtés, sans épines ni tubereules, avec le bord antérieur et trois bandes transverses également espaećes, formćes par un duvet très-court d'un jaune d'ocre. L'écusson est petit, arrondi. Les élytres sont plus larges que lc corselet, avec les angles huméraux saillants, arrondis et lisses; ellcs sont parallèlcs, un peu rétrécies et tronquécs au bout, ponctuées dans toute leur étendue, avec des tuberculcs asscz gros à leur base. Leur bord extérieur préscntc unc bandc blanche très-étroite à la base, fortement échancrée sous l'épaule, cnsuite large, et se terminant en pointe au milieu de la troncature. L'extrémité et la suture jusqu'au milicu sont finement bordées de blane; toute la surface des élytres est marquée de petites taehes sinucuses et comme vermiculées, d'un jaune d'ocre. Le dessous du thorax cst varié de jaune et de noir ; les côtés qui correspondent à la partie humérale des élytres où le blane est très-étroit, offrent une large bande blanche qui se réunit au blane des élytres; le dessous de l'abdomen est noir, varié de blanchâtre, avec quatre lrandes transverses ferrugincuses. Les pattes sont courtes, garnies d'un duvet grisâtre. - Cettc Lamie vient du Port-Jakson.

SAPERDE DE LEFEBVRE, Saperda Lefebırï. Guér. - Capite thoraceque albide sericeis. Antennis atris, fronte puncto, thorace macula magna carnleo-nigris. Elytris punctatis, apice truncatis, castaneis, cyaneo-micantibus; fascia lata media nigra, sericea; pectore castaneo violaceo-micante. Abdomine ferrugineo. Pedibus nigris, basi fulvis. —L. I4 ou I 6 mill., 1. 5 à 6 m. - Atlas, Ins., pl. VII, fig. 2.

Cctte jolie cspc̀ce varie un peu pour la taille; elle est épaisse, assez courte, avee le dessus un peu aplati. Ses antennes sont filiformes, noircs, un peu plus longues que le corps. La tête est soyeuse, d'un jaune dorć dains l'un de nos individus, et d'un jaune blanehâtre dans l'autre, avec un point noir et rond au milieu du front. Les yeux sont grands, noirs, éehancrés cn haut pour l'insertion des antennes. Lc eorselet est un peu plus large que long, presque carré, très-peu arrondi sur les bords, jaune, soyeux en dessus, avee une grande tache noirc veloutée qui touche au bord antérieur et atteint le tiers postérieur. Son dessous est d'un ferrugineux clair. L'écusson est transversal, arrondi cn arrière, d'un noir de velours. Les élytres sont d'un marron ferrugineux, avee des reflets très-brillants et violets aux angles huméraux et à l'cxtrémité; leur milieu est traversé par une large bande noirc ct veloutée; lcur surface est couverte de gros points enfoncés, avee une côte un peu saillante partant des angles huméraux, et se prolongeant sur les côtés jusqu'à unc épine située à l'angle externe de leur troncature postérieure. Le dessous du mésothorax et du métathorax est d'un marron plus ou moins foncé suivant les individus; l'abdomen est d'un jaune ferrugineux, avec l'extrémité du dernicr segment brune et velue. Les pattes sont noires, avee le dessous des cuisses ferrugineux. - Cette espèee vient de Dory, à la Nouvelle-Guinée; nous l'avons dédiée à notre ami M. Alexandre Lefebvre, l'un des entomologistes les plus distingués de la capitale, secrétaire et fondatemr de la Soeiété entomologique de Franee. 
SAPERDE GRACIEUSE, Saperda venusta. Gùr.-Azurea, nigro-vittata; capite, antennis, thorace elytrisque fuscis, punctatis, vittis tribus, media communi thorace procedente, metallico-viridibus; ficmoribus fulvis. - L. ro mill., $1.3 \mathrm{~m}$.—Atlas, Ins., pl. VII, fig. 5 .

Cette eharnante petite espèee est d'un noir velouté en dessus, et d'un beau bleu de ciel en dessous. Sa tête est noire, avee le front bleu et deux lignes divergentes de la même eonleur sur le vertex. Le eorselet est presque earré, un peu arrondi sur les eôtés, ponetué, d'un noir velouté, avee trois lignnes longitudinales d'un vert-blen luisant. L'éeusson est arrondi en arrière, vert. Les élytres sont plus larges que le eorselet à leur naissanee, d'un noir velouté, ponetuées, insensiblement rétrécies vers l'extrémité, tronquées et épineuses au bout, avee les còtés droits; leur suture est finement bordée de vert qui se prolonge en une taelıe assez large à leur extrémité; les borils latéraux ont chacun une bande étroite verte qui n'atteint pas l'extrémité postérieure; il y a près de l'éeusson une petite ligne courbe, partant du milicu du bord antérieur de ehaque élytre, un peu plus épaisse en arrière, et dirigée un peu vers la suture. En arrière de ces petites taches on observe un autre point vert plaeé presque au milieu de la longueur de elraque élytre. Le dessous est marqué sur les eòtés du métathorax d'une petite ligne noire presque parallèle aux élytres; il y a quelques petites stries noires aux segments de l'abdomen. Les pattes sont minees, assez grandes, avee les euisses fauves et les genoux noirs; les jambes sont brunes en dessous, et d'un beau bleu de eiel en dessus; les tarses sont également bleus.-CCette espèee a été trouvée au Port-Praslin, à la Nouvelle-Irlande, et à Dory, dans la Nouvelle-Guinée.

M. Boisduval en a déerit une autre, dans le voyage de l'Astrolabe, qui pourrait bien n'être qu'une variété de eelle-ei; ses pattes sont entièrement noires; du reste elle ne diffère pas de la nôtre. C'est sa Saperde à eeinture verte, représentée planehe IX, fig. 20.

CRIOCERE DE GORY, Crioceris Goryi. GuĹn. - Ater, antenns atris, articulis basalibus rufis. Thoracc lavigato, fulvo, medio coarctato. Elytris fulvis, striato-punctatis. Fcmoribus anticis, mesothorace in parte antica, filvis._L. 11 mill., $1.5 \mathrm{~m}$.

Ce Criocère ressemble beaueoup à cclui que Fabrieins a déerit sous le nom de Lema impressı, mais il en diffère ecpendant d'une manière notable par son eorselet, ses euisses antérieures et le devant de son mésothorax qui sont rouges, tandis que, dans le Lama impressa, toutes ees parties sont noires, et qu’il n'y a que les élytres de fauves. La tête de notre Crioè̀re est large, rougeàtre, avec les yenx noirs; son front offre plusieurs petits plis un peu ruguenx. Les antennes sont noires, avee les deux premiers artieles fauves. Le eorselet est fauve en dessus et en dessous, de la largeur de la tète, plus long que large, eylindrique, très-lisse, rétréei au milieu par deux fortes impressions latérales. L'éeusson est petit, triangulaire. Les élytres sont fauves, beaueoup plus larges que le eorselet, bombées, arrondies, très-lișses aux angles hnuméraux et à l'extrémité, rebordées, avee neuf stries formées par des points enfoneés assez rapprochés. 
La partie antćrieure dı mésothorax, jusqu’à l'attache des pattes internédiaires, est rouge; le reste cst noir ainsi que l'abdonen; ces parties sont luisantes, finement ponctuées. Les pattes sont noires, à l'exception des cuisses des antérieures et des genoux des autres qui sont rouges. - D’Amboine. Nous l'avons dédié à notre ami M. Gory.

CRIOCìRE UNIFASCIÉ, Crioceris unifasciatus. Gún. - Fulvus, elytris striatopunctatis, basi apiceque nigro-cyaneis. --L. 7 mill., l. 4 m.

Sa tête est à peine de la largeur du corselet, avec les antennes fauves, un peu brunâtres à l'extrémité, et les ycux un peu obscurs, très-saillants. Le corselet est très-peu plus large que long, très-bombé cn avant, luisant, sans points, avec un sillon transversal assez profond, un peu arrondi ct placé en arrière. L'écusson est petit, d'un rouge brun. Les élytres sont beaucoup plus larges que le corselet, très-luisantes, rebordées, avec neuf strics de points enfoncés, assez distants. Elles sont d'un noir bleuâtre, avec une large bande transversc, un peu plus étroite de chaque côté, placée au milieu, et formant environ le tiers de leur ćtendue. Le dessous du corps ct les pattes sont fauves, un peu velus. - Ccttc jolie espèce vient de Dory, à la Nouvelle-Guinée.

HISPE DE FABRICIUS, Hispa Fabricii. Guśn. - Fulva, elytris nigro-cjaneis; thorace lateraliter quadrispinoso, spinis anterioribus quadrifidis, posterioribus simplicibus. Elytris valde spinosis. - L. 5 mill., I. 2 m.-Iconogr. du Règne animal. Iinsectes, pl. 48, fig. 3 et $3 a$.

Cette petite espèce ressemlle beaucoup à l'Hispa saltatrix de Fabricius, et à celle que H. Boisduval nomme Hispa vaniliorensis, dans le voyage de l'Astrolabe, mais elle en diffèrc d'une manière notable par la forme du corselet et des épines qui s'y insércnt. Dans les deux Hispes que nous citons, les quatre épines du corselet sont placées transversalement et en avant; les latérales sont trifides et les intermédiaires bifides, tandis que dans notre espèce les épines sont toutes latérales; il n'y en a point au milieu; les antérieures sont quadrifides, ct celles qui viennent immédiatement derrière les premic̀res, et qui sont placées sur le côté du corselet, sont simples.

Notre Hispa Fabricii est entièrement d'un rouge de sang. Les antennes manquent, mais le premier article qui reste est rouge. Le corselet est un peu plus large en avant, avec les angles antérieurs un peu saillants; il est assez inégal, avec une impression transverse en arrière; il y a de chaque côté deux épines placées sur les bords latéraux; les antérieures sont composées de quatre pointes ou épines un peu courbes, divergentes, dont un des ranreaux se dirige vers la tête. Les suivantes sont beaucoup plus petites, simples. L'écusson est petit, arrondi, rouge. Les élytres sont deux fois plus larges que le corselet, d'un noir un peu bleuâtre, fortement ponctuées, à épaules saillantes et arnées d'un grand nombre d'épines longues, aiguës, assez grêles, insérées sur toute leur surface.-Cette jolie espèce a été trouvée à la Nouvelle-Guinée. 
HISPE A MOITIE ROUGF, Hispa bipartita. GuÉr.-Sanguinea, antennis atris. Thorace transversaliter quadrispinoso, spinis rufis, lateralibus quadrifidis, intermedius bifulis. Elytris valde spinosis, anticè sanguineis, posticc̀ atris. -L. $5 \mathrm{mill} . \frac{1}{2}, 1.3 \mathrm{~m}$.

Cette jolie espèce est moins étroite que les deux préédentes; les antennes sont presque de la longueur du corps, noires, un peu pubeseentes. La tête est rouge, avee les yeux noirs. Le eorselet est rouge, un peu plus large que long, 111 peu plus étroit et arrondi en avant, avee deux eôtes transverses et un peu élevées au nilieu. Il est armé de quatre épines plaeées transversalement en avant, deux latérales, quadrifides; les deux intermédiaires placées un peı cn avant et bifides. L'écusson est arrondi, ronge. Les élytres sont noires, avec la base rouge jusqu'au tiers de leur longueur environ; elles sont couvertes de longues épines aiguës, rouges dans la partie qui est de cette couleur, et noires sur le reste de leur surfaee. Le dessous du corps est tout rouge. Les pattes sont de la même couleur, mais un peú plus pâles.-Cette espèee vient de Java.

HISPE A COL ROUGE, Hispa fulvicollis. GuÉr.-Sanguinea, antennis atris. Thorace mutico, mgoso. Elytris rugoso-punctatis, sex-spinosis, spinis posticis lateralibus, magnis. - L. 8 mill., 1. $4 \mathrm{~m}$.

Cette Hispe est de forne étroitc en avant, beaucoup plus large en arrière. Sa tête est rouge, avec les yeux et les autennes noirs; le corselet est rouge, rugueux, sans épines, avec une petite fossette peu marquée en dessus. Les élytres sont noires, plus larges que le corselet à leur naissance, beaucoup plus largcs en arrière, rugueuses et ponctuées, avec une forte épine au bord latéral postérieur, trois épines plaeées longitudinalement sur le milieı de chaque élytre, et quelques petits tubercules peı marqués en arrière. Les épaules sont assez saillantes. Le dessous du corps est rouge; les pattes sont de la même conleur. - De Java.

HISPE GENTILLE, Hispa pulchella. GuÉn. - Sanguinea; untennis apice fuscis. Elytris lutcis, valde striuto-punctatis, circuitu maculisque quadratis duobus conmunibus sangnineis.-L. Io mill., 1. 4 111. $\frac{1}{2}$.

Sa tête est petite, ponctuée, un peu avancée en angle aigu sur le front. Les yeux et les quatre derniers articles des antennes sont bruns. Le eorselet est aussi long que large, un peu rétréei en avant, de forme carrée, très-ponctué, avec une petite ligne longitudinale lisse, d'un vert métallique, placée au milieu et n’atteignant pas les lords antérieur et postérieur, et une petite ligne sinueuse de la même couleur, plaeée sur les bords latéraux. L'écusson est petit, arrondi en arrièré, d'un rouge brun foncé. Les élytres sont beaueoup plus larges que le corselet, saillantes et arrondies aux épaules, un peu plus larges en arrière, arrondies au bout, avec dix lignes de gros points enfoneés, et une eòte assez saillante presque an milieu, et un peu plus près de la suture que du bord 
externe. Elles sont d'un jaune pâle, avec le bord externe, la suture, les épaules et l'extrémité d'un rouge carmin vif. On voit sur la suture deux grandes taches carrées, communes, également rouges. Le dessous du corps et les pattes sont d'un rouge carmin vif. -Elle vient de lî̀le Sainte-Catherine, au Brésil.

\section{Genre OXYCÉPHALE, Oxy'cephala. Gứn.}

Le sous-genre que nous établissons sous ce nom avait été indiqué par Latreille, dans la nouvelle édition du Règne animal, de la manière suivante (tom. V, pag. I 43) : "Quelqucs autres Hispes (Monoceros, Oliv.; Porrecta, Scliœn.; Rostratus, Kirby, ete.), remarquables par une saillie en forıne de corne au-dessus de leur tête, forment peutêtre un autre sous-genre. "Nous avons pensé que la présenee d'une corne sur la tête était un earaetère tout aussi peu inmportant que eelui qu'on a assigné au genre Chalèpe; mais nous avons dù suivre l'exemple de notre maître, qui a cru devoir adopter ce genre, et eomme il n'y avait pas de raison pour ne pas se servir d'une épine à la tête plutôt que d'une épine aux jambes antérieures, pour établir un genre, nous avons pensé que le nôtre était tout aussi admissible.

M. Grey, dans l'édition anglaise du Règne animal, a agi comme nous en formant le genre Chelobasis; iei ce n'est plus au front ou à la patte que sc trouve l'épine, c'est au premier artiele des antennes du mâle. Ce genre est publié dans le tom. XV du The Animal Kingdom, Insectes, vol. II, pag. 143, pl. 67, fig. 4, et pl. го I, fig. 4 pour ses détails caractéristiques.

OXYCÉPHALE CORNUE, Oxycephala cornigera. Guér. - Rufa, elytris depressis, valde striato-punctatis, costatis, dimidia postica nigra, vittaque nigra lata, communi, ad scutellum procedente; antennis nigris, articulis duobus primis fulvis. -L. I r mill. $1.4 \mathrm{~m}$.

Oxycephala cornigera, Iconogr. du Règne anim., Insectes, pl. 48, fig. 2.

Sa tête est jaune, sillonnée en dessus, avancée au milieu en une petite corne droite, dirigée en avant, tronquée au bout, creusée par le sillon frontal qui se prolonge jusqu’à son extrémité. Les yeux sont noirs. Les antennes sont longues conme la tête et le corselet, à artieles serrés, un peu moins épaisses au bout, noires, avee les deux premiers articles et l'extrémité du dernier jaunes. Le corselet est de forme earrée, tronqué obliquement aux angles antérieurs, aplati, ponctué. L'écusson est très-petit, triangulaire. Les élytres sont aplaties, allongées, un peu plus larges en arrière, arrondies au bont. Elles ont chacune quatre côtes assez saillantes, entre lesquelles on observe deux rangs de gros points enfoncés. Elles sont d'un jạune d'ocre, avec une large bande postérieure noire, qui ne laisse qu'un très-petit espace de leur extrémité jaune et qui se termine au milieu et se prolonge à la suture jusque près de l'éeusson. Le dessous est très-aplati, lisse, jaune. Les pattes sont jaunes, avec les tarses larges. - Cette curieuse espèce vient du Port-Praslin. 
CRYPTOCÉPHALE SPÉCIEUX, Cryptocephalus speciosus. GuÉr.-Luteus, vertice nigro; thorace fascia transversa nigra; coleoptris punctatis, fascia triangulari communi maculisque duabus apicalibus cyaneis; pygidio, abdomine, metathoraceque fuscis; tarsis antcnnisque nigris. - L. 6 mill., $1.3 \div \mathrm{m}$.

Cryptoccphalus speciosus, Guér., Iconogr., du Règne anim., Insectes, pl. 48, fig. 7 (l'antenne).

Il est court et bombé comme toutes les espèces du même genre; sa tête est ponctuée, d'un noir luisant, avec le front et la bouche jaunes. Les antennes sont dc la longueur de la moitié du corps, noires, aplaties, un peu plus épaisses vers l'extrémité, avec les trois premiers articles tachés de jaune. Le corselet est transversal, très-lisse et luisant, un peu ponctuć en avant, d'un jaune un peu fauve, avec une bande transverse noire, un peu sinueuse, placée au milieu, et n’attcignant pas les bords latéraux. L'écusson est noir, assez grand, triangulaire, trc̀s-lisse, un peu relevé en arrière; les élytres sont à pcine plus larges que le corselet, un peu relevées vers l'écusson, sinucuses au bord, ponctnées, d'un jaune moins roux que le corselet; elles ont, à leur base, une bande d'un noir bleu qui commence par un point huméral, et se dilate ensuite en angle à là suture; l'extrémité postérieure de l'angle formé à la suture atteint presque le milieu de la longueur des élytres. Elles ont, en outre, chacune une grande tache triangulaire de lia même couleur placée sur les côtés et vcrs l'extrémité. Le dessous du corps est d’un noir bleu terne, avec le dessous du prothorax, une tache en arrière du mćtathorax et l'anus d'un jaune pâle. Les pattes sont jaunes, avec l'extrémité des jambes et les tarses noirs. - Ce joli Cryptocéplıale vient du Port-Jakson, à la Nouvelle-Hollande.

CRYPTOCÉPHALE RUDE, Cryptocephalus salcbrosus. Guér.-Rugosus, infumatus, Ravo-livido-sericcus, antonis longissimis, basi rufis. Scgmento abdoninis ultimo valde impresso. -L. 7 mill., 1. $4 \mathrm{~m}$.

Ce Cryptocéphale ressemble beaucoup à celui que M. Wcstvood a nommé Rugicollis, dans le Animal Kingdom, tom. XV, Insectes, vol. II, pag. 1 46, pl. 67, fig. 5, et pl. го , fiğ. 5 pour les détails; mais il en diffère par l'absence de la grande tache noire signalée sur le milieu du corselet de celui-ci. Voici au reste la courte description qu'on tronve de cet insecte dans le Riègne animal anglais cité plus haut. "Brun, rugueux, avec un point noir sur le thorax. Les anteunes des mâles ont deux fois la longueur du corps, tandis que celles de l'autre sexe sont très-courtes - De la Nouvelle-Hollandc. v

Notre Cryptocéphale rude est cntièrenıent d'un brun foncé presque noir, avec un reflet jaune chatoyant, produit par des poils courts et jaunàtres qui couvrent tout le corps. - Du Port-Jakson.

CRYPTOCÉPHALE DE JAKSON, Cryptocephalus Jaksonï. Gú̇.-Cyanens, dcsuper lavis; infra punctato-rugosus; el.tris punctatis. - L. 4 mill., l. 3 m. 
Ce petit Cryptocéphale est entièrement d'un bleu foncé très-luisant. Sa tête est cntièrement enfoncéc dans le corselet, avec le front plat, un peu plissé, et les ycux bruns. Ses antemnes sont un peu plus longues que le corselet, un peu plus épaisses au bout. Le corșelet est arrondi en avant, très-bombé, un peu sinueux en arrière, avec un pctit pli de chaquc còté et vers le bord postérieur. L'écusson cst petit, arrondi, rclevé en arrière. Les élytres sont à peu près deux fois plus longues que le corselet, un peu plus larges à leur base, relevées près de l'écusson, arrondies en arrière, avec les anglcs huméraux un peu saillants et lisses; elles ont des stries longitudinales formées par de gros points enfoncés. Le dernier segment de l'abdomen a sa partic supérieure grande, triangulaire et ponctuée, son dessous offre au milieu une fossette profonde. Le dessous du corps est ponctué, garni de quelques poils courts blanchâtres. Les pattes sont courtes et de forme ordinaire. - Du Port-Jakson, à la Nouvelle-Hollandc. Nous l'avons consacré à la mémoire du général anglais qui a donnć son nom à ce pays.

PODONTIE SPLENDIDE, Podontia splendens. GuÉr.-Oblonga, viridi-aurea micans; thorace quadrato, lateraliter impresso; elytris striatim punctatis, punctis quibusdam latioribus sparsis; inedia postica cyaneis apiceque castaneis; subtus viridi-aurea, abdomine apice testaceo. - L. 16 mill., l. 7 m. - Phyllocharis splendens, Iconographie du Règne anim., Insectcs, pl. 49, fig. 4 .

Ce bel insecte s'éloigne un peu par sa forme des espèces de Podontia dćja connues, ce qui a donné lieu à l'établissement d'un genre nouveau, sous le nom dc Promachus. rifous n'avons pas trouvé de caractères assez tranchés dans cet insecte, pour lc séparer des Podonties, quoique sa forme soit plus allongée, que ses antennes soient plus longues et plus filiformes. Sa tête est lisse, luisante, plus étroite que le corselet, d'un vert-bleu, avcc le chaperon, le labre et les autres parties de la bouchc rougeâtres; le front est largement excavé entre les yeux. Les antennes sont insérées en avant des yeux, distantes à leur insertion; elles sont plus longıes quc la moitié du corps, filiformes, à articles presque ćgaux, d'un beau bleu luisant, avec les deux premiers articles et la base du troisième d'in rouge brun. Le corselet cst transversal, en carré long, avcc lcs quatre côtés presque droits ct parallèles. Il est d'un beau vert luisant à reflets dorés. Ses bords latéraux offrent des impressions profondes formées de gros points irréguliers. L'écusson est assez petit, arrondi, d'un vert luisant et lisse. Les élytres sont presque deux fois plus longues que largcs, d'un beau vert brillant à reflets dorés et de enivre ronge, jusqu'au milieu de leur longueur, passant ensuite insensiblement au plus beau bleu, et se terminant par unc couleur rougeâtre. Elles ont chaeune neuf stries formées par de petits points enfoncés, et offrent, à leur base et sur les côtés, des impressions plus ou moins larges et profondes. Le dessous est lisse, d'un beau vert luisant, avec les trois derniers segments de l'abdomen d'un brun ferrugincux. Les pattes sont assez grandes, robustes, d'un beau vert brillant. Les tarses sont garnis d'un duvet jaunâtre en dessous. - Cet insecte brillant a été trouvé à la Nouvelle-Guinée sur des plantes des lieux bas et humides. 
PODONTIE TRICOLORE, Podontia tricolor. Cnevronat.-Elongatissima, caruleovirescens. Capite, thorace infra, femoribus anticis basi, trochanteribusque rufis. Thorace subquadrato, lavi, foveato et punctato lateribus. Elytris longis, semi striatis, cartuleis, cun tertia parte apicali flava, depressione basali, sulco transversali infra humerum strïsque plurimis profundis. Tribus ultimis segmentibus abdominis flavis._L. 20 mill., $1.9 \mathrm{~m}$.

Cette belle espèce, tout à fait voisine de la précédente, a la tête lisse, déprimée en avant, impressionnée en demi-cercle d'une antenne à l'autre. Le labre est en carré rétréci en avant. Les antenues sont bleues avec le premier article entièrement rouge; le seeond rouge seulement aux extrémités, et le troisième tout rouge. Les yeux sont oblongs, noirs. Le corselet est en carré transverse, un peu marginé et relevé sur les bords, échancré en avant, avec les angles aigus et rougeàtres; il est sinueux et avancé sur l'éeusson, lisse, marqué près des còtés d'enfoncements dans lesquels on voit de gros points profonds, d'un bleu briliant. Un point ronge est placé au-dessus de l'écusson, lequel est arrondi en arrière. Les élytres sont un peu plus larges que le corselet, cinq fois plus longues, parallèles, arrondies toutes deux sur la suture, convexes sur le dos, ayant chacune dix stries ponctuées, faibles près de la suture, très-profondes sur les eôtés. On voit un enfoncement à la base; un sillon transverse, et quelques enfoncements sur les stries. Le tiers apical est finement ponetué, jaune ainsi que les épipleures. La moitié du troisième et les deux derniers segments de l'abdomen sont de cette couleur. Le dessous du corps, les cuisses et les jambes sont d'un vert bleuâtre brillant; la partie postérieure et interne des genoux est rouge, l'extrémité des jambes est creusée extérieurement, eouverte ainsi que le dessous des tarses de poils jaunâtres. - Cette espèee a été prise à Amboine. Elle fait partie de la riche collection de MI. Clievrolat, qui a bien voulu nous donner la description que nous insérons ici. (Genre Promechus, Dej. Catal.)

PHYLLOCHARIS A DEUX BANDES, Phyllocharis bicincta.Guŕr.-Nigro-ccentlea; capite, scutello, elytris, vittis duabus, secunda postica parra, anoque fulvis.-L. I I mill., 1. 5 m.--Iconoggr. du Règne animal, Ins., pl. XLIX, f. 3.

Les antennes sont noires avec les premiers articles seulement d'un bleu luisant. La tête est petite, d'un rouge de sang, luisante, avee une forte impression au milieu. Les palpes sont rouges. Le corselet est près de deux fois plus large que long, un peu sinueux et rebordé sur les còtés, largement échancré en avant, avec les angles postérieurs aigus; il est assez lombé, lisse et très-luisant, du même rouge que la tête. L'écusson est petit, arrondi, d'un noir bleu. Les élytres sont allongées, convexes, à épaules assez saillantes, très-lisses et luisantes, avec des stries formées par des séries de petits points enfoncés. Elles sont d'un heau bleu foncé avec une large bande rouge au mi lieu, et une autre plus étroite placée à leur extrémité et les terminant. Le dessous du corps et les pattes sont d'un noir bleu luisant; les deux derniers segments de l'abdomen sont d'un ronge sanguin.-Cette nouvelle espèce vient d'Amboine. 
CHRYSOMÈLE DE PERCHERON, Chrysomcla Perchcronii. Gún.-Nigro-cyanea, elytris vittis quatuor luteis, secunda interrupta, ad marginem recurva, tertic ad quartam in extremun juncta.-L. 6 mill. $\frac{1}{2}, 1.5 \mathrm{~m}$.

Elle est entièrcment d'un bleu de Prusse foncé, de forme un peu oblongue. La tête et lc corselct sont luisants, ponctués. Les antennes ont le prcmier article d'un noir bleuâtre et les dcux suivants jaunàtres; les autres nous sont inconnus, notre individu les ayant perdus. L'écusson et les ćlytres sont d'un noir bleu trc̀s-luisant; on y voit des stries formées par des points cnfoncés et très-rapprochés entre eux. Elles ont chacune quatre lignes longitudinales jaunes réunies à la base de l'élytre. La prcmière, celle qui est placée à très-peu de distance de la suture, atteint l'extrémité de l'élytre et s'anastomose avcc la quatrième, qui longe le bord extérieur; la seconde vient se réunir à la premic̀re près de l'extrémité, et la troisième, qui ne communique pas aux autrcs en avant, se courbe brusqucment, un peu au delà du milieu de l'élytre, en arrière, et va s'anastomoser avcc la quatrième.-Cette jolie espèce se trouve à Lima, au Pérou: nous l'avons dédiée à notre ami M. A. Percheron, qui s'est fait connaitre par des travaux estimés.

ADORIE SUBHÉMISPHÉRIQUE, Adorium subhemispharicum. GuÉr.-Ovatum, luteum ; clytris convexis, incumbentibus; capite minuto impresso; oculis nigris. Metathorace abdomineque subtus maculis nigris.-L. 13 mill., $1.9 \mathrm{~m}$.

Cette espèce a plutôt l'aspect d'une grosse Coccinelle un peu allongée que d'une Galeruque. Scs élytres sont très-convexes, débordant de beaucoup l'abdomen. La tête est petite, d'un jaune pâlc avec une impression longitudinale au milieu. Les yeux sont noirs. Les antcnnes sont jaunes ainsi que les palpes, qui sont un peu brunâtres au bout. Le corsclet est beaucoup plus étroit que les ćlytres, jaune pâlc luisant. L'écusson est petit, triangulaire. Les élytres sont lisses, beaucoup plus larges, arrondies en avant, transparentes sur les côtes, qui débordent l'abdomen, d'un jaune plus foncé dans la partie qui ne déborde pas. Les pattes sont d'un jaune pâle avec l'extrémité des jambes et les tarses plus foncés. Le dessous du corps est jaune; mais on voit de chaque côté du métathorax, entre les deuxième et troisième pattes, une grande tache luisante d'un noir vif, et de chaque côté des segments de l'ab̉omen un point également noir. -Cet insecte vient de Java.

ADORIE BASALE, Allorium basale. GuÉr.-Sanguineun, ore, thorace sternoque luteis; vertice, scutello, elytris basi late nigris : pedibus fuscis._L. 12 mill., l. 7 m.—Iconogr. du Règne anim. Ins., pl. XLIX bis, f. 1 .

Cette belle espèce est oblongue, un peu convexe; sa tête est rouge avec le vertex noir et les yeux bruns. Les antennes sont longues, noires avec une partie des trois premiers articles rougeâtre. Le corselet est d'un rouge brique, lisse, luisant et trans- 
versal, arrondi sur les côtés, et un pcu plus large en arrière. L'ćcusson est petit, triangulaire, noir et luisant; les élytres sont finement et irrégulièrement ponctuées d'un beau rouge foncé, avec une large bande d'un noir luisant à leur base. Les pattes sont noires avec les trochanters et la base des cuisses fauves. Le dessous du corps est rouge avec une large tache noire au milieu du métathorax, entre les deuxième et troisième pattes. - Cet insecte vient de Dory, dans la Nouvelle-Guinée.

ADORIE POSTICALE, Adorium posticale. GuÉr. - Sanguineum, antennis, elytris oblique ad extremum abdomincque nigris : tibiis tarsisque fuscis. - L. 9 mill., $1.5 \mathrm{~m}$.

La tête est rouge avec l'extrémité des mandibules et du labre noire. On voit une tache brune sur le vertex, entre l'insertion des antennes et un petit sillon longitudinal au milieu. Les antennes ont à peu près les deux tiers de la longueur du corps, elles sont noires, velues, avec les trois premiers articles rougeâtres à la base; nous avons vu une variété de cctte espèce, publiée dans le Voyage de l'Astrolabe, qui avait les antennes entièrement fauves. Le corselet est transversal, arrondi en arrière et sur les côtés avec les angles antérieurs un peu saillants; sa surfaee est lisse et luisante, et il est entièrement rouge. L'écusson est triangulaire et rouge. Les élytres sont rouges, luisantes, entièrement couvertes de petits points enfoncés irrégulièrement semés. Leur extrénité offre une grande tache noire qui en occupe plus du tiers postérieur, est coupée obliquement du bord externe à la suture, ce qui donne à l'ensemble du noir une forme échancrée dont l'angle aigu est en arrière; ces taches n'atteignent pas le bord des élytres, en sorte que tout le bord occupé par les taches noires est cependant rouge. Le dessous du eorps est rouge avec l'abdomen noir; les pattes sont également rouges avec l'extrémité des jambes et les tarses bruns.-De Dory.

ADORIE D'OLIVIER, Adorium Olivicrii. Gúr.-Ovatum, convexum, luteum : thorace pallidiore; oculis nigris, antennis in extremum tarsisque fuscis. - L. 8 mill., $1.5 \frac{1}{2} \mathrm{~m}$.

Cette espèce est un peu plus large que les précédentes; sa tête est d'un jaune pâle a vec les yeux noirs et une forte impression au milieu du vertex. Les antennes sont presque de la longueur du corps, brunes avec les trois premiers articles jaunes. Le corselet est transversal, d'un jaune pâle, coupé droit en avant, arrondi sur les eôtés et ell arrière, lisse et luisant avec deux petites taches transverses, d'une couleur un peu plus foncée au milieu. L'écusson est de la eouleur du corselet, triangulaire. Les élytres sont beaucoup plus larges, d'une couleur jaune plus foncée que celle de la tête et du corselet, fortement rebordées sur les côtés, couvertes de petits points enfoncés, trèsrapprochés et irrégulièrement placés : elles ont chacune une bosse humérale arrondie, luisante et assez saillante. Le dessous du corps et les pattes sont de la couleur du corselet; l'extrémité des jambes et les tarses sont brunâtres. - Cette espece a été trouvée à Amboine, à Bourou et dans l'île de Vanikoro, suivant les naturalistes de l'Astrolabe. 
A la suite de ces deseriptions d'Adorics du Voyage de la Coquille, nous allons faire connaître succinctement deux belles espèces entic̀rement nouvelles, et qui ont étć trouvées à la Cochinchine par MM. Diard et Duvaucel.

\section{Adorium Diardi. Guérrx.—L. I 3 mill., l. 7 m.}

Corps un peu convexe; antennes des deux tiers de la longueur du corps, jaunes. Tête noire avec le bord antćrieur jaune. Corselet lisse, noir; presque aussi long que large, de forme un peu carrée. Ėcusson petit, transversal, jaune. Élytres plus larges que le corselet, d'un rouge acajou avec l'extrémité noire, mais dont le noir est fondu et ne tranche pas brusquement avec le fond; elles ont chacune des stries de points enfoncés très-scrrés. Pattes noires avee les tarses bruns. Dessous noir avec le milieu du métathorax et du mésothorax rouge.

Adorium Duvaucelii. Guér. - L. I 2 mill. l. 7 m.

Jaune. Antennes ayant les dcux tiers de la longueur da corps; corselet transversal, lisse. Écusson jaune. Élytres finement ponctuées, jaunes, ayant chacune à la base une large tachc bleue, arrondie en arrière, occupant plus de la moitié de leur longueur, touchant à la suture, et n'allant pas jusqu'au bord extérieur. Dessous et pattes jaunes.

GALLERUQUE PARTAGÉE, Gallenuca dimidiata. Guér. - Rufa, thorace complanato, transverso, linea transversali impresso. Elytris atris postice rufis; femoribus rufis; tibiüs tarsisque brunneis. - L. 8 mill., 1. $4 \frac{1}{3} \mathrm{~m}$. - Iconogr. du Règnc anim., Ins., pl. XLIX bis, fig. 3.

Cettc belle espèce, qu'il ne faut pas confondre avee la Galleruca dimidiata de Fab. (Ent. suppl., p. $99, \mathrm{n}^{\mathrm{o}} 9^{3}, 4$ ) qui cst une Altise, est entièrement d'un rouge de vermillon, avec les élytres noires depuis la base jusqu'an milieu, dans quelques individus, et jusqu'au tiers postérieur dans d'autres. La séparation du noir au rouge a lieu par une ligne transverse presque droite. La tête est de la largeur du corselet, avec les yeux gros, noirs. On voit entre eux deux petites impressions transverses coupées par une ligne longitudinale qui part du vertex, et va se termincr entre la base des antennes. Le corselet est plus de deux fois plus large que long, arrondi sur les côtés, assez déprimé avec une impression transverse large et profonde oceupant toute son étendue au milieu. L'écusson est rouge; les élytres sont un peu dilatées en arrière, rebordées, lisses avec les angles huméraux très-marqućs. Le dessous est d'un rouge un peu plus pâle. Les antennes sont entièrement d'un rouge pâle, les cuisses sont rouges; les janıbes et les tarses sont bruns.-Cette Galleruque vient de Java.

GALLERUQUE DE BUQUET, Galleruca Buquetii. GuÉr.-Capite thoraceque rufis, antennis flavis. Thorace subquadrato, transverse impresso. Elytris atris, postice macula magua rufa; corpore subtus atro; pedibus anticis brunneis, cateris atris. - L. 7 m., l. $4 \mathrm{~m}$. 
Cette espeee est d'une forme un peu plus raccoureie que la Dimidiata; sa tète est à peu près de la largeur du eorselet, avee les yeux noirs et quelques légères impressions entre les yeux et devant les antennes. Celles-ei sont filiformes, à peine deux fois longues eomme la tête et le eorselet, d'un jaune pâle. Le eorselet est rouge en dessus et en dessous, presque aussi long que large, un peu sinueıx sur les eòtés, un peu plus étroit en arrière, lisse, avee un profond sillon transverse an milieu. L'éeusson est petit, d'un rouge brun. Les élytres sont plus larges que le eorselet à leur base, élargies en arrière, rebordées, lisses dans quelques individus, les mâles, peut-être. On voit unie espèee d'élévation derrière l'éeusson, et deux tubcrcules à chacune, près de la suture, entre l'éeusson et le bord postérieur de eette espèce de bosse qui se termine au tiers de la longueur de l'élytre, près de l'endroit où finit le noir. Les élytres sont d'un uroir luisant, avee tout le bord également noir; elles ont chaeune une grande taehe rouge qui oeeupe toute leur partie postérieure, à l'exeeption des bords, et se termine en are un peu au delà du milieu, en oecupant plus de la moitié de leur étendue. Le dessous du corps est entièrement noir luisant ; les pattes antérieures sont d'un rouge brun, les autres sont entièrement noires.-Cette espèce vient de Java.

GALLERUQUE TERMINÉE DE ROUGE, Galleruca torminata. Gú́r. - Sanguinea elytris atris apice rufis. Antennce rufae; thorace subgloboso, lasigato; femoribus rufis; tibiis tarsisque brunneis.-LL. 6 mill., l. $3 \frac{1}{2} \mathrm{~m}$.

Cette Galleruque ressemble beaueoup à eelle que Fabrieius et Olivier ont nommée Hamorrhoidalis, mais elle s'en distingue par la forme de son corps qui cst plus bombé, par ses antennes qui sont plus eourtes et entièrement rouges, tandis que dans l'Harnorrhoidalis elles ont les trois premiers artieles rouges, les quatre suivants noirs, les deux qui viennent après encore rouges, et les deux derniers noirs. Dans la Galleruca hamorrhoidalis les pattes sont entièrement rouges, tandis que dans la nòtre les euisses seulement sont de eette eouleur, les jambes et les tarses étant d'un brun foneé presque noir.

La tête de notre Galleruque est plus étroite que le eorselet, d'un rouge de sang, avee Ics yeux noirs. Les palpes sont ronges, les antennes sont filiformes, ayant un peu plus de deux fois la longueur de la tête et du eorselet réunis. Elles sont insérées entre les yeux, très-rapproehées à leur base; on voit derrière elles, sur le vertex, une ligne transversale enfoncée qui touche de ehaque eòté le bord postérieur des yeux. Le eorselet est un peu plus large que long, arrondi sur les eôtés, bombé, très-lisse, d'un rouge de sang. L'éeusson est rouge. Les élytres sont lisses, luisantes, rebordées, d'un noir vif, avec l'extrémité marquée d'une taçhe rouge arquée, rcmontant un peu au bord externe et à la suture, et formant à peine le cinquième de leur longueur. Le dessous est entièremcnt rouge; les pattes sont de grandeur ordinaire, leurs euisses sont rouges avee les jambes et les tarses bruns.-Cette jolie espèee vient de Java.

Nota. La Galleruque pulliée par Sahlberg (Periculi entomographici, ete. p. 65, pl.4, fig. 1) sous lc nom de Crioceris apicalis, ressemble beaucoup à la nòtre, mais elle s'en 
distingue par son corselet, qui est deux fois plus large que long, et sur le milieu duquel on voit deux petites fossettes, tandis que le corselet de notre espèce est aussi long que large, lisse ct sans aucune trace de fossettes.-Du reste, ce Crioceris apicalis de Sahlberg a été trouvé à Sierra-Leonc, sur la côte d'Afrique.

GALLERUQUE POSTICALE, Galleruca posticalis. GUÉr. - Flava, elytris maculis duabus posticis ovatis nigris. -L. 6 mill., $1.3 \mathrm{~m}$.

Tout le corps de cette espèce est jaune; la tête est petite, avec une forte impression an milicu; les yeux sont bruns, les antennes sont presque aussi longues que les élytres; le corselet est plus large que long, arrondi sur les côtés, lisse avec une profonde impression transverse au milieu. L'écusson est triangulaire. Les élytres sont très-finement ponctnées, luisantes; elles ont chacune une grande tache ovale noire, occupant leur moitié postéricure, et ne touchant ni au bord ni à la snture. Le dessous est d'un jaune plus foncé avec le bord des segments de l'abdomen jaune pâle. -Du port Praslin, à la Nouvelle-Irlande.

GALLERUQUE DE CARTERET, Galleruca Carteretii. Gúk. - Flava, elytris vittis duabus latis, transversis, nigris, prima basali, secunda posticali.-L. 7 mill., $1.3 \mathrm{~m}$.

La tête est petite, jaune, lisse, avec les yeux très-saillants et noirs. Les antennes sont au moins de la longueur du corps, velues, d'un jaune brunâtre. Elles s'insèrent sur le milieu de la tête et sont contiguës à leur naissance. Le corselet est un peu plus large que long, arrọndi latéralement avec une faible échancrure de chaque côté et une forte impression transverse au nilieu. L'écusson est triangulaire, jaune. Les élytres sont trèsfinement ponctuées, jaunes avec une large bande noire à la base, occupant le tiers de leur longueur, et une autre à l'extrémité, occupant 'aussi un tiers de lcur étendue. Le dessous et les pattes sont jaunes.-Cette espèce vient du havre Carteret, à la NouvelleHollande.

CASSIDE A UN POIN'T, Cassida punctum. FAB.-Flava, elytris fasciis duabus puncto-

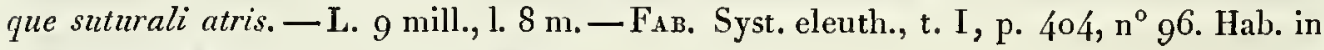
oceani Pacifici insulis. D. Billardière.

Nous avons reçu de la Nouvelle-Guinée deux individus qui appartiennent évidemment à cette espèce et qui en constittent deux variétés fort remarquables. Elles s'éloignent même tellement du type et de la description de Fabricius, que nous nªurions pas hésité à en faire deux espèces distinctes, si nous ne nous en étions rapportés quà cette description, et si nous n'avions pas comparé nos échantillons avee l'individu qui a servi à Fabricius. Nous devons la communication de cet insecte à M. Turpin, qui a hérité des débris de la collection de Labillardière, dans laquelle Fabricius avait décrit et 
étiqueté de sa main toutes les espèces nouvelles alors; nous allons commencer par donner une clescription détaillée de cet insccte afin de pouvoir lui comparer nos deux variétés.

La Cassida punctum de la collection de Labillardière, décrite par Fabricius, est arrondie, peu bombée. Sa tête est petite, entièrement cachće sous le corselet, d'un jaune un peu fauve avec les yeux allongés et noiràtres. Le corselet est arrondi en avant, d'un jaune fauve, avec les contours dilatés d'un jaune pâle et transparcnt. Lc bord postérieur est arrondi, un peu avancé vers l'écusson qui cst petit, triangulaire et jaunc. Lcs élytrcs sont plus larges que le corselet, d'un jaune rougeâtre sur la partie qui recouvre le corps, d'un jaune pâle et transparent sur le large rebord qui les entoure. Leurs angles antérieurs remontent un peu plus haut quc le milieu du corselet, ct la partie qui recouvrc le corps et qui est assez brusquemcnt bombée, offre des sćries peu régulières dc gros points enfoncés. Chaque élytre a, à la base, une large bande noire, un peu sinucuse et dentée en arrière, et qui n'atteint pas la suturc. On voit près dc l'anglc huméral et dans cette bande noire une très-petite tache jaune et une autre en arric̀rc (quc nous verrons, dans l'une des variétés suivantes, envahir tout l'angle de l'élytre). Vers le ticrs postérieur on voit une autre bande noire de la même largeur que la précédente, fortement dilatée en haut et $\mathrm{cn}$ bas sur la partie de l'élytre qui couvre le corps, et n'atteignant la suture que vcrs l'extrémité, où elle se prolonge jusqu'au bout de l'élytre. Dans la partie dilatée de la tache noire on voit une petite tache jaune un peu oblongue. Entre ces deux bandes, au tiers antérieur et sur la suture, on voit un gros point noir commun. Le dessous du corps et les pattes sont jaunes.

\section{Cassida punctum, Var. A.}

Cette variété est tout à fait de même taille et de même couleur générale que la précédente, les stries ponctućes de ses élytres sont les mêmes, mais les bandes antérieure et postérieure ne se prolongent pas jusqu'au bord extcrnc; le noir reste dans la partie de l'élytre qui recouvre le corps; la tache d'cn haut et cellc d'en bas sont rémries et laissent au milieu un espace jaune qui remonte à l'écusson, et au milieu duquel on retrouve le point central; au milien de la tache et en dehors il resie une échancrure qui indique la place de l'espace jaune obscrvé dans l'espèce type.

\section{Cassida punctum, Var. B.}

Encore semblable aux précédentes; dans cettc variété le petit point jaune placé à la base de chaque fascie antérieure est devenu large, le point central se réunit de chaque côté, en formant lui-même une bande transverse, avec les bandes d'en haut et d'en bas. Les petites taches qui se trouvent dans la dilatation des bandes postérieures s'élargissent aussi beaucoup, en sorte que la partie du corps qui recouvre lcs élytres est variée de taches noires et jaunes.-Ces deux variétés ont été prises à Dory dans la NouvelleGuinée. 
ALTISE DE CHEVROLAT, Altica Chevrolatii. Guér.-Flava, nitida; capitc elytrisque nigris; elytris cum sex maculis flavis; femoribus posticis infuscatis. -L. 5 mill., $1.3 \mathrm{~m}$. -. Iconogr. du Règne anim., Ins., pl. XLIX bis, fig. I3.

Sa têtc cst petite, noire, avec les yeux saillants et de la même couleur. Les antennes sont aussi longues que le corps, rougeâtres. Le corselet cst transversal, lisse, arrondi sur les eôtés, d’un jaune pàle avec quelques petites taches nébuleuses un peu plus foneées. L'écusson est petit, triangulaire, noir. Les élytres sont arrondies, lisses et très-luisantes, d’un noir vif : elles ont ehacune trois taches jaune-pâle, savoir : deux au milieu, disposées transversalement et parfaitement rondes, et une autre ovale, un peu réniforme, transverse et placée vers l'extrémité. Le dessous du corps et les pattes sont rougeâtres. Les cuisses postérieures sont très-renflées avec une tache brune en dessous. -Cette jolie espèee vient de Dory, à la Nouvelle-Guinée.

COCCINELLE A FOURCHES, Coccinella furcifera. Gún. - Nigra, thorace elytrisque vitta circumdatis ad suturam furcata, vittaque disco longitudinali-_L. $6 \mathrm{mill} ., 1.5 \mathrm{~m}$. - Iconogr. du Règne anim., Ins., pl. LI, fig. I.

Elle est entièrement noire, lisse, un peu luisante. La têtc a une taehe jaune, transvcrse et sinueuse sur le vertex; le bord antérieur du corselet est jaune, et cette couleur se prolonge un peu sur les côtés et cn trois dents, dont celle du milieu un peu plus longue que les antres. Les élytres sont bordées de jaune depuis l'écusson jusquà leur extrémité. Au bord antérieur ce jaune se prolonge en deux petites dents, l'une près de l'écusson, l'autre un peu plus extérieurement. Il y a sur chaque élytre et près de la suture, une ligne jaune, ćtroite, anastomosée en arrière avec la bordure extérieure, bifurquée en haut et terninée vers le tiers antérieur de l'élytre. On voit au bord externe une autre ligne parallèle à la première commençant à la hauteur de la bifurcation de la ligue voisine de la suture, et n'attcignant pas l'cxtrémité. Le dessous et les pattes sont noirs; on voit deux petites taches jaunes de ehaque côté du métathorax.-Cette espèce est indiquée avee doute eomme venant de la Nouvelle-Hollande.

\section{ORTHOPTËES.}

Genre ACRIPEZE, Acripcza, Gứr.

(De Axpıc, Sauterelle, ct IIš̌n, qui va à pied.)

Linsecte, type de ce nouveau genre, appartient, dans la Méthode de M. Séville, à la troisième grande division dc ses Locustaires, et vient se placcr près des Bradypores et des Éphipigères; il sc distingue faeilement de ees deux genres par la grandeur de ses élytres qui recouvrent l'abdomen, et par la brièveté de ses pattes postérieures. On ne peut le eonfondre avee les Phalangopsis, qui ont les palpes et les pattes très-allongés, 
et dont les pattes de derrière sont très-grandes et tout-à-fait propres au saut. Voiei les caractères essentiels que nous assignons à notre nouvcau genre :

Corps eourt, épais. Tête ovale, moins large que le corselet, avee trois yeux lisses très-aplatis, protégés par des élévations et placés un peu en arrière et entre les antennes. Palpes assez épais, de longueur moyenne; les maxillaires le double plus longs que les labiaux, leur dernier artiele allongé, très-peu élargi et tronqué obliquement au bout. Antennes probablcment fort allongées : l'individu unique en notre possession les avait perdues. Corselet court, avee sa noitié antérieure plissée et arrondie, ct sa moitié postérieure aplatie, ne reeouvrant point les élytres. Élytres en forme d'écailles, grandes, ovales, reeouvrant presque entièrement l'alıdomen. Point d'ailes. Pattes de longueur moyenne, très-peu épineuses; les postérieures à peine plus ggrandes, avee les cuisses trèspeu renflées à leur base. Abdomen gros, terminé par de très-petits appendiees dans le mâle.

ACRYPEZE RÉTICULÉE, Acrypeza reticulata. GuÉR.-Brunneo-livida; capite testaceo, nigro-maculato. Elytris brunncis convexis, valde reticulatis, nigro-bimaculatis. Abdomine nigro. Pedibus testaceis nigro annulatis. - L. 27 mill., 1. io m. -Atlas, Ins., pl. X, fig. 2 , et $2 a$.

La tête de cet inseete est jaunâtre, avee la base du labre, les eôtés du vertex, et quelques petites taches irrégulièrement plaeées, noirs. Le corselet est d'un brun jaunâtre, avee de petites taehes noires et des plis irréguliers transversaux. Les élytres sont de la eouleur du eorselet, fortement rétieulées; elles ont ehaeune deux taelies noires vers l'extrémité, et la droite a la partie reeouverte par la gauehe d'un noir luisant. Le thorax en dessous est'd'un jaunâtre varié de noir. I.es pattes sont également jaunes avec des anneaux noirs.-Cette sauterelle vient dı port Jackson à la Nouvelle-Hollande.

LISTROSCEIE A PEIGNES, Listroscelis pcctinata. GuÉr. - Elongata, viridis; oculis brunneis. Pedibus anterioribus et intermediis valde spinosis.-L. 3o mill., l. $4 \mathrm{~m}$. -Atlas, Ins., pl. X, fig. I et I, $a b c$.

Cette jolie Listroscèle diffère de la seconde espèce déerite par M. Serville, paree qu'elle est entièrement verte, tandis que la sienne est d'un brun assez clair, avee le labre et les palpes labiaux jauncs et les cuisses vertes. La tête du seul individu mâle que nous possédions est ovale, allongée, perpendieulaire, avee les palpes très-grands, séeuriformes. (Voy. fig. I. b.) Les antennes sont très-longues, insérées très-près l'une de l'autre, et séparées par une petite pointe conique formée par le vertex. Les yeux sont saillants, bruns. Le corsclet cst assez. allongé, lobé sur les eôtés, tronqué, un peu arrondi et échaneré en arrière. Les élytres et les ailes sont de la même eonsistanee, d'un vert pâle, avec de fines réticulations peu ruarquées. Le métasternum et le mésosternum sont éehanerés et creusés au milieu, avec les côtés relevés. (Voy. fig. I. a.) L'abdomen est court, terminé dans le màle par une large plaque bifurquée et par deux longs appendices courbés. (Voy. fig. I. c.) Les pattes sont grandes, vertes. Les antérieures ont les

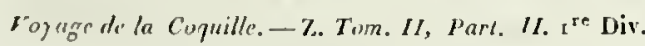


euisses renflées, fortes. Les euisses et les jambes de eelles-ei et des intermédiaires sont armées de deux rangs de longues épines eourbées et divergentes, disposées de ehaque eôté eomme deux peignes. Les pattes postérieures sont plus grandẹs, avee les euisses renflées et de très-petites épines peu visibles. Cet inseete vient de l'île Bourou, l'une des Moluques.

\section{HÉMYPTÉRES.}

SCUTELLERE DE LABILlARDIERE, Seutellera Billardicrii. FABr. - Cyanea, scutello abdomineque testaceis, apiee eyaneis. Fabr., Syst. rhyng., p. $129, \mathrm{n}^{\circ} 4 .-$ Stoll., eimie. pl. 7, f. 48 (genre Callidea, Laporte.)

Nous avons donné une nouvelle figure de eette belle espèee, pl. XI, f. 1, pour mieux faire ressortir les différenees que présente la variété que nous allons déerire. La figure publiée par Stoll est, au reste, si mauvaise que nous eroyons rendre serviee en en domnant une plus exaete. La variété A, figurée dans notre Atlas, pl. XI, fig. 2, diffère de l'espèee type, en ee que le noir-violet de l'extrémité de l'éeusson, qui danș la première oecupe à peine le quart de sa longueur, en oeeupe plus du tiers. Cette même eouleur s'étend et oeeupe les quatre derniers anneaux de l'abdomen, tandis que dans l'individu normal elle n'oeeupe que les deux derniers. - Ces magnifiques inseetes ont été trouvés sur les feuilles des plantes. Le prenier vient d'Offak, terre des Papous; la variété a été prise au port Praslin, dans la Nouvelle-Irlande. L'espèee suivante, et mème la Tetyra imperialis, de Fabricius, ne sont probablement que des variétés de la Seutellère dont nous venons de parler. Nous avons des exemples de si grandes différenees dans la eoloration, ehez la même espèee, que nous sommes presque certain de cette identité spéeifique.

SCUTELLERE ROYALE, Seutellera regalis. FAB. -- Thoraee scutelloque aureis; thorase punctis duobus, scutello maculis duabus caruleseentibns. - Fab., Syst. rhyng., p. $128, n^{\circ} 2$.

Cimex regalis, Fab., Ent. syst., t. 4, p. $80, n^{\circ} 5$.

"Corpus magnum, nitidum. Antennæ nigræ. Thorax lævis, glaber, rufo-aureus, antiee punetis duobus eyaneis et inter hæe maeula obsoleta, rufa. Margo thoraeis postieus eyaneus. Seutellum rufo-aureum, nitidum, maeulis duabus eyaneis, altera ad basin, altera ad apieem. Alæ onnes fuseæ, eosta anteriorum usque ad medium eyanea. Peetus eyaneum, rufo-maculatum. Abdomen rufum, utrinque linea e punetis eyaneis impressis. Anus cyaneus. Pedes eyanei, femoribus basi rufis.»

Cimex regalis, Donov. An epitone ins. of Asia (pl. hemyptera, fig. ${ }_{*}^{*}$ )? 
Variété A. - (Scutellera Peronii.) Guèr. - Atlas, Ins., pl. XI, f. 4.

Nous avions pensé, cn faisant la fignre de eette Seutellère, qu'elle formerait une espèce distincte du Cimex regalis de Fabricius; mais ayant eu occasion de voir plusieurs espèces de Scutellèrcs varier d'une manière extrèmement notable dans les dispositions des taches, nous nous sommes décidé à ne considérer notre Scutellera Peronit que comme une variété de la Regalis, qui n'est probablement elle-mème qu'une variété de la Billardierii. En effet, notre individu a vingt millimètres de longueur sur neuf delarge, eomme l'espèce type figurée par Donovan; mais il en diffère parce que les taches plaeées en avant du corselet, dans la Regalis, sont réunies dans notre variété, et n'en forment qu'une seule assez grande, verte et luisante. L'écusson, qui dans la Regalis offre quatre taehes noires, est tout-à-fait sans taehe dans notre individu; seulement on voit vers la base une légère onde brune, formant un point un peu plus marqué au milieu. Le thorax de l'espèce type est vert-violet taché de rouge; elıez notre individu il est vert sans taches; les cuisses n'ont pas la base rouge, comme dans la Regalis de Fabricius.Cette belle variété vient de l’île de Timor.

SCUTELLÈRE DE BANKS, Scutellera Banksii. Var. Guér. - Cimex Banksii, scutellaris, violaceus; thorace macula anchore-formi; scutello arcubus duobus maculisque tribus ovalibus sanguineis.-Donovan. An epitome ins., of Asia, etc., pl. Hemiptera, fig. *.

Scutellera Schonnherrï, Eschscholtz. Entomographien, p. 99, pl. 2, fig. 1. - Long. i 7 mill., l. I I $\mathrm{m}$.

Cette cspèce varie beaucoup dans la disposition et la grandeur de ses taches rouges. Dans les individus que nous avons sous les yeux, les deux ares rouges de la base de l'éeusson sont fort larges, rémis en arrière, point bifurqués en avant; les trois taches postérieures sont ćgalement réunies, ct forment une bande transverse ondée qui conmunique avec les arcs antérieurs par la ligne médiane. Dans une secondc variété, le rouge commence à oceupcr moins de plaee; les trois taehes postérieures commencent à se distinguer entre elles, mais elles sont eneore réunies. L'cspèce type, figurée par Donovan, présente des taches rouges encore moins étendues; les deux arcs antérieurs sont étroits, bifurqués en lıant; les trois taclıcs postéricures sont bien séparées. Enfin, dans notre quatrième variété, il ne reste plus que de légères traces de rouge; la taehe, cn forme d'ancre, placée au milieu du eorselet, est remplacée par trois petits points ronges. Les arcs de la base de l'écusson sont remplacés par deux lignes courtes, obliques, partant du bord antérieur, et se dirigeant obliqucment vcrs l'extérieur. Il ne reste plus en arrière qu'une petite tache centrale, les latérales ayant disparu.

Dans les trois variétés, le dessous du flonax est bleu, avec le milieu plus ou moins largement taché de rouge; l'ablomen est ronge, avec le bord des anncaux taché de bleu- 
violet. Les antennes et les pattes sont bleues. - Cette belle espèce vient de Java, des grandes îles de la ner du Sud, et même de Manille; ear il est certain pour nous que la Scutellera Schonnherrii, déerite et figurée par Esehseholtz, n’en est qu'une variété, où le rouge a envalii tout l'éeusson. Nous possédons un individu presque semblable; seulement la taehe en forme d'ancre du eorselet est un peu moins développée.

SCUTELLÈRE A TĖTE NOIRE, Scutellera atricapilla. Gún. - Oblonga, rubra; antennis, capite pedilusque atris. Thorace macula prope caput. Scutello fascia transversa

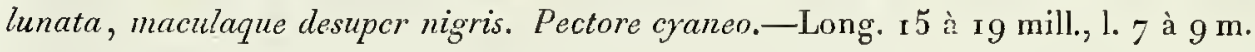

Cette belle espèee varie pour la forme, la taille et lcs taehes; elle nous semble trèsvoisine de la Scutellera sex-maculata, publiée dans le Zoological Miseellany de Leaeh, t. r, p. 36, pl. I 4. Sa tête est d'un bcau noir luisant, aussi longue que large, triangulaire, un peu ruguense, avec la ligne lisse et eireonserite par. deux sillons qu'on voit à presque toutes les Seutellaires. Les antennes sont noires, plus longues que la moitié du eorps dans les mâles, plıns eourtes chez les fernelles, à artieles un peu aplatis. Le eorselet est étroit en avant, très-élargi en arrière, deux fois plus large que long, finement ponetué, avce une grande taehe earrée et noire derrière la tête, et deux taehes noires quelquefois réunies, d'autres fois assez distantes, plaeées au milieu et derrière la taehe antérieure. Ces deux taches disparaissent dans quelques individus; et alors le corselet est tout rouge, avec la taehe antérieure noire, qui persiste toujonrs, mais qui est plus ou moins diminuée. L'éeusson est finemert ponetué; vu obliquement, il offre de magnifiques reflets violets. La basc est plus ou moins largement bordée de noir; il y a deux taehes noires, souvent eonfondues en une grande taehe ovale et transverse, au tiers antérieur et au milieu, et au tiers postérieur, une grande bande transverse, n'atteignant pas les bords, plus ou moins large, remontant quelquefois sur les côtés jusqu'à la hauteur des deux points antérieurs. Le dessous du thorax est noir, à reflets bleus, avee les bords du eorselet rouges. L'abdomen est rouge avee une tache à la base, quatre taehes de ehaque eôté, et trois taehes noires sur le milien du dernier segment; ces trois taehes se confondent quelquefois en une seule grande taehe, d'autres fois elles sont presque effaeées. Les pattes sont entièrement d'un noir bleu.

Var. A. Dessus entièrement rouge sans taehes.

Cette belle espèee a pour earaetère eonstant d'avoir la tête et une tache au bord antérieur du eorselet, noires. - Elle se trouve à Java.

\section{SCUTELLÈRE PAYENNE, Scutellera pagana.}

T. cyanea; scutello abdomineque rufis, cyaneo maculatis. Farr. - Long. I I mill., l. 7 m. - Atlas, Ins., pl. XI, fig. 5.

Tetyra pagana. Fabr. Syst. rhyng. p. $134, \mathrm{n}^{\circ} 29$.

Cimex paganus. Donovan. Epitome. ins. India, pl. Hemiptern, fig. $*_{*}^{*}$ 
Nous n'avions pas encore pu nous procurer l'ouvrage de Donovan quand nous avons représenté cette espc̀ce; et quoiqu'elle fût décrite, nous voulions la figurer, croyant qu'elle ne l'avait jamais été. Cependant, comme le seul ouvrage dans lequel elle soit représentée est fort cher ct fort rare, les entomologistes seront peut-être bien aises de voir cette intéressante espèce figurée dans un livre français. Sa tête est assez petite, arrondie en avant, ponctuée, bleue, avec deux sillons longitudinaux parallèles et assez enfoncés. Les antennes sont noires, peu allongćes. Le corsclet est bleu, finement bordé de rouge sur les còtés, avec une large bande longitudinale rouge, un peu dilatée au milieu et beaucoup plus èlargie au bord postérieur; la surface du corselet est lisse: on voit quelques points cnfoncćs au bord antérieur, et au milieu, où il présente un lćger sillon transverse. L'écusson couvre tout l'abdomen et n'en laisse déborder qu'une petite partie; il cst d'un bcau rouge vermillon, avcc une large tache bleue au milieu de la base, et une autre tache bleuc transverse, sinuée eu avant, profondément échancréc au milicu et en arrière, situće sur le tiers postćrieur. Le dessous du thorax est bleu, avec quelques petites taches rouges à la base des pattes. L'abdomen est rouge, avec cinq taches noires sur les côtés, visibles en partie en dcssus. Les pattes sont noires. - Du port Jakson. M. Lefebvre possède unc variété où le corselet est entic̀rement noir.

SCUTELLÈRE A POINTS ROUGES, Scutellera rubro-punctata. GUÉR. - Ferruginea. Thorrce viridi-irrorato, punctis septem, scutello punctis decem aurantiacis. Subtus testacea, abdomine punctis lateralibus nigris. Antennis pedibusque nigris, fenoribus ferrugineis. - Long. 13 mill., $1.8 \frac{1}{2} \mathrm{~m}$.

Cette espèce ressemble bcaucoup à la Scutellera Fabricii de Linné, tant pour la forme du corps que pour la couleur générale. Sa tête est triangulaire, d'un rougebrun assez foncé, sans taches, avec une petitc élévation longitudinale au milieu. Les antenncs sont noircs. Le corselet est de la couleur de la tête, semé d'une infinité de très-pctits points verts peu apparcnts ; il a de chaque côté trois points orangés, ronds, dont le premier est placé au bord antérieur, tout-à-fait derrière les yeux; le second au milieu, et le troisièmc près du bord postérieur. En avant et au milieu du corselet, on voit uı septièmc point orangé placé au milieu. L'écusson est de la couleur carnélite de la tête, sans taches vertes; il a à la base, et contre le corselet, six points orangés égalcment espacés, et en arrière de ceux-ci, vers le milieu de sa longueur, quatre autre points de la même couleur placés aussi à égale distance entre eux. Le dessous du corps est d'un jaune ferrugineux, avec un petit point noir de chaque côté des segments de l'abdomen. Les cuisses sont rougeâtres, avec les jambes et les tarses noirs. - Cette espèce vient de Java.

SCU'TELLÈRE DES PAPOUS, Scutellera papua. Guŕr. - Nigra, cenea, nitens, pedibus, vittc circumdante, lineis punctisque flavis. - L. 5 mill., 1. 4 m. - Atlas, Ins. pl. XI, fig. 6 ( genre Coptosoma, Laporte.) 
Elle est entièrement arrondie, plate; la tête est transversale, avee le bord antérieur et une ligne transverse au milieu, jaunes. Le eorselet est noir luisant; il a en avant une ligne jaune, arquće derrière la tête, eourbée tout-à-eoup, et se terminant aux bords et près des angles postérieurs; derrière eette ligne on observc deux points jaunes, plaeés vis-à-vis les deux angles qu'elle fait en se eourbant en arrière. L'écusson est dilaté postérieurement, reeouvrant entièrement les élytres et les ailes, d'un noir bronzé très-brillant, entouré d'une ligne fauve, interrompue au milieu du bord antérieur. Le dessous du eorps est également noir, avec des points jaunes au bord des segments de l'abdomen. Les pattes et les antennes sont jaunes et eourtes. - D'Offak, à la terre des Papous. Nous avons vu au Muséum une autre espèee de ee genre beaueoup plus grande et plus belle. Voiei la deseription que nous en avons faite:

SCUTELLÈRE DEBAUDIN, Scutellera Baudini. Gớr.-Noire, tête avec deux points rouges placés de chaque côtć. Corselet noir avee une grande taehe rouge de chaque còté, dans ehacune desquclles est une tache noire. Éeusson noir avee une bande rouge vers la base; eettc bande; dilatée au milieu et en arrière, éehancrée latéralement, avee deux points noirs, placés un de chaque eôté. Derrière eelle-ei il y a une autre bande rouge, sinueuse, arquće en arrière; vers l'extrémité postérieure on voit une autre bande droite, et en arrière de eelle-ci, une petite raie rouge. Le bord postérieur est également ronge depuis le milieu de la longueur de l'éeusson. Dessous noir, varié de jaune; pattes noires à genoux jaunes. - De la Nouvelle-Hollande ? Trouvée par Péron, pendant le voyage autour du monde eommandé par le eapitaine Baudin.

Description comparative des scutellétes de L'inde, voisines de la sc. stokerus, et POUR LA PLUPart confondus avec cette espiee.

A. Abdomen bleu en dessous.

I. Abdomen entièrement bleu.

I. Scut. Praslinia. Guér.-Long. I 8 mill.-Blene à reflets verts. Trois taches au bord antérieur du eorselet; sept taehes arrondies sur l'éeusson, dont la septième postérieure, noires. Thorax en dessous taché de bleu et de vert luisant. Segments de l'abdomen noirs, bordés de vert. Pattes entièrement bleues. - Port-Praslin.

2. Scut. Germarii. Escir.(I) _Long. I I mill.-D’un vert doré. Trois taches noirbleuâtre sur le bord postérieur du eorselet; six taelıes noires, dont l'intermédiaire antérieure triangulaire, les autres arrondies, sur l'éeusson. Dessous bleu, taehé de vert. Pattes entièrement d'un noir bleu. - Ile Luęon.

3. Scut. Eques. Farr. _ Long. I 2 mill. - Bleue à reflets verts. Huit taehes sur le corselet, et huit autres sur l'éeusson, dont l'intermédiaire antérieure bifide, noires. Dessous vert. Abdomen noir, avec les bords verts et des points noirs. Pattes bleues. - De Tranquebar.

1 Entomographien, p. 100, $n^{\circ} 7$, pl. 2, fig. 2. 
II. Abdomen rouge sur les eôtés.

4. Scut. lateralis. Guér. - Long. ro mill. - Bleue à reflets verts. Neuf taehes oblongues sur le eorselet, et quatorze inégales sur l'éeusson, noires. Dessous d'un beau bleu à reflets verts et dorés. Bords latéraux de l'abdomen ayant une large bande rouge, n'atteignant point l'anus, marquée de quatre points noirs. Pattes bleues. Antennes noires. - De Java.

B. Abdonen jaune ou rouge en dessous.

I. Bords supérieurs de l'abdomen rouges.

5. Scut. Stokerus. F F arrondies sur le corselet, sept ovales sur l'éeusson, grandes et noires. Dessous dı thorax jaune, taehé de vert sur les eôtés. Abdomen jaune, avec une taehe it la base, l'anus et quatre points de ehaque eòté, noirs. Bords rouge vermillon; euisses jaunes, avee l'extrémité bleue; jambes et tarses bleus.-Du Bengale.

6. Scut. Patricius. Farr. - Long. 8 mill. $\frac{1}{2}$. - Bleue à reflets verts; une ligne dorsale et qquatre taehes de elaque eôté sur le eorselet, neuf taches sur l'éeusson, noires. Dessous du thorax jaune, avee des taches vertes sur les eôtés, et les angles latéraux rouges. Abdomen jaune avee une taehe à la base; l'anus et quatre lignes obliques et eourtes, de ehaque côté, noirs. Bords latéraux et supérieurs rouges. Cuisses rouges avec l'extrémité bleue; jambes et tarses bleus. - De Tranquelar.

7. Scut. Buquetii. Gúx́n, - Long. 16 à 17 mill. - Verte, brillante. Six petites taehes sur le eorselet et sept sur l'éeusson, noires. Dessous du thorax vert, son bord et la base des pattes, rouges. Aldomen rouge vif au milieu et sur les côtés en dessus, avec une large bande verte, dans laquelle est un double rang de taehes noires de ehaque eôté. Cuisses rouges avec les genoux noirs; pattes et tarses noirs. Bord externe des élytres rouge. - De Java.

II. Bords supérieur's de l'abdomen bleus.

8. Scut. Stollii. Wouf. - Long. I 3 mill. - Bleue à reflets verts; six taehes arrondies sur le eorselet, huit sur l'éensson, noires. Dessous du thorax jaune, avec trois taehes violettes de ehaque eôté. Abdomen jaune, avee les côtés d'un vert pourpré, et einq taehes noires de chaque côté. Cuisses jaunes, avee le bout bleu; jambes et tarses bleus. Bord externe des élytres, rouge. - Des Indes orientales.

9. Scut. anrata. Gúér. - Long. 13 à 15 mill. - D’un vert-doré brillant à reflets rouges. Six taches sur le eorselet, et sept sur l'éeusson, dont l'intermédiaire allongée et eordiforme, noires. Dessous du eorselet vert-doré, avee de petites lignes jaunes aux sutures. Abdomen jaune, aree une grande taclıe à la base, 
une autre à l'extrémité et quatre points latéraux noirs; le bord externe d'un bleu vert. Pattes bleues, avec les trochanters jaunes. - De Java.

Io. Scut. excavata. Guér. - Long. I 5 mill. - Verte-bleuâtre, une excavation triangulaire au bord antérieur du corselet, noire au fond, et sept taches noires. Huit taches noires sur l'ćcusson, les antérieures latérales plus petites, l'intermédiaire allongée, et les autres très-grandes, arrondies et ovales. Dessous du thorax vert, a vec de petites lignes jaunes aux sutures. Abdomen janne, largement entouré de vert, avec des points noirs sur les còtés. Cuisses jaunes à la base, avec leur moitié verte. Jambes et tarses verts. - De Java.

11. Scut. dilaticollis. Guér. - Long. io à I 2 mill. - D'un vert bleu; corselet dilaté de chaque côté, avec six taches noires. Sept taches rondes sur l'écusson, et une intermédiaire, antérieure, grande et cordiforme, noires. Dessous du corselet vert, avec quelques petites lignes jaunes aux sutures. Abdomen jaune orangé, avec une tache à la base et l'anus noirs, et les bords verts, marqués de deux rangs de points noirs. Cuisses orangées avec les genoux verts. Janbes et tarses d'un noir vert. - De Java.

Nota. Quand nous ne donnons pas une description particulière des élytres, c'est qu'elles sont brunes avec la côte d'un noir bleu ou vert. Les ailes, chez tontes, sont transparentes, avec l'extrémitć brune.

SGUTELlÈRE DE PRASLIN, Scutellera Praslinia, Guér. - Long. I 7 mill., 1.8 m. - Atlas, Ins., pl. XI, fig. 3.

Son corps est allongé, parallèle dans la moitié de sa longueur, brusquement rétréci ensuite, triangulaire antérieurement, de forme naviculaire. L'écusson s'étend jusqu'à l'extrémité des élytres, sans rétrécissement brusque des côtés; elle est entièrement d'un bleu indigo clair, avec le disque de la tête, du corselet et de l'écusson, et le bord des segments inférieurs vert doré, se fondant avec le bleu. Sur le corselet sont trois taches, deux latćrales, une médianc vis-à-vis dı vertex; sur l'écusson sept taches, six latérales, disposées sur deux rangs longitudinaux de trois chacune, une mćdiane située à l'extrémitć: toutes ces taches, ainsi que de larges bandes sur les segments de l'abdomen et les antennes, noires. Du Port-Praslin, à la Nouvelle-Irlande.

\section{SCUTELLÈRE LA'TÉRAIE, Scutellera lateralis. GuÉr.}

Cette petite espèce est de forme plus globuleuse et plus courte que les suivantes; elle est très-bombée, longue de 9 à ro millimètres, et large de 6 à 6 et demi. Sa tête est de forme triangulaire, arrondie au bout, ponctuée, avec deux sillons longitudinaux 
au milieu. Elle est verte, luisante, avec les côtés et l'espace compris cntre les sillons d'un beau bleu de Prusse. Les antennes sont noires. Lc corselet, d'un bleu vert, est très-bombé et trc̀s-large en arric̀re, ponctué, avec les angles latćraux postérieurs assez saillants; il a, en dessus et en avant, deux taches noires oblongnes, placées transversalement, et se dirigeant un peu obliqucment vers l'extrémité d'une ligne médiane et longitudinale, dont l'cxtrémitć atteint lcur hauteur et qui va se terminer au bord postérieur. De chaque côté de cette ligne l'on voit trois taches longues, obliques, n'atteignant pas le bord postérieur. L'écusson est de la couleur du corselet, ponctuć. Il a trois bandes transverscs de taches noires ainsi disposécs : cinq au bord antéricur, dont les latérales en forme de croissant; quatre vers le milieu, dont les deux intermédiaires beaucoup plus grandcs; trois en arrière de celles-ci, presque rćunies par une faible marque brune; deux encore plus en arrière, et souvent une très-petite tache transverse à l'extrémité postérieure. Le dessous du corps cst de la couleur du dessus. Il y a de chaque côté de l'abdomeı une large bande rouge, commençant trc̀s-près de sa base, ct terminée près de l'anus; elle occupe la moitié du premier segment, le second, troisième et quatrième, et la moitié dı cinquième; elle est marquée de quatre points noirs, placés au bord des segments et indiquant les stygmates. Les pattes sont de la couleur du corps. Les élytres sont brunes et les ailes transparentes avec l'cxtrémité seulement enfumée. - De Java.

\section{SCU'TELLÈRE DE STOKER, Scut. Stokerus. FaBR.}

Cette espèce, dont nous avons vu un grand nombre d'individus, est tonjours du Bengale et de la Chine, et non de Java et des îles de l'Inde. Sa longueur est de s a à I 3 millimètrcs, et sa largeur, à la base de l'écusson, de 6 et demi à 7 mill. C'est cclle de toutes qui a la forme la plus raccourcie et la plus ramasséc. Sa tête est d'un bcau vert bleu, avec une tache noire sur le vertex, prolongée en une ligne longitudinale, circonscrite par deux petits sillons enfoncés. Les antennes sont de moitié moins longues que le corps, noires. Le corselet est un peu plus large que l'écusson à ses angles postérieurs, coupé droit et point dilaté sur les côtćs. Il est d'un beau bleu un peu vert, arcc trois grandes taches noires et arrondies près du bord antćrieur, trois autres tachcs beaucoup plus grandes et rondes prc̀s du bord postérieur et sur la ligne de ses angles latéraux, et une tache plus petite et noire, sur chacun de ces angles saillants; en tout 8 taches. L'écusson est un peu plus étroit que le corselet, de la même couleur, fortement enfoncé cn dessus, à sa base; il a trois grandes taches noires, ovales et transverses de chaque còté, et une autre grandc tache ovale et longitudinalement placée au tiers antérieur et sur la ligne médiane. Les élytres sont d'uu brun foncé, noires à la côtc, avec la mcmbrane tcrminale d'un brun enfumé. Les ailes sont transparentes jusqu'anx deux tiers de leur longueur, avec l'extrémité d'un brun enfumé. Le dessous du corps est jaune; les côtés du corselet ont de grandcs tachics vertes, avec une tache vermillon sous les angles latéraux. Le milieu du premier segment de l'abdomen offre une tache brune plus ou moins large, et de chaque 
côté une tache noire ronde. Les trois segmenis suivants ont aussi une tache noire de cliaque côté; ce qui fait quatre taches sur chaque bord de l'abdomen. Le dernier segment est entièrcment noir, et les bords latéraux de l'abdomen, au-delà des taches noires et cn dessus, sont d'un rouge vermillon vif. La trompe est jaune. Les pattes sont de grandeur moyenne; leurs cuisses sont jaunes jusqu'aux trois quarts de leur longueur, d'un noir bleu aux genoux. Les jamlbes sont d'un bleu foncé presque noir, ainsi que les tarscs. - Cette espèce varie pour la couleur générale, qui est quelquefois rougeâtre, à reflets bleus. Les taches sont quclquefois plus pctites. Le dessous du thorax a moins de vert dans quelques indiviclus. La tache du milieu du premier segment de l'abdomen est quelquefois presquc nulle.

\section{SCUTELLÈrE DE BÜQUET, Scut. Buquetii. Guír.}

Cette espèce a une forme un peu plus allongée que la Scut. Stokerus; elle est longue de 16 à 17 millimètres, et largc de 8 à 8 et dcmi à la base de l'écusson; elle est en dessus d'un vert clair, luisant, avec des reflets violets dans quelques individus. La tête est assez petite, triangulaire, avec les yeux bruns et très-saillants. Elle a au milieu une petite élévation lisse un peu dilatée en arrièrc, circonscrite par deux petits sillons enfoncés; c'est cette ligne qui est noire dans la Scut. Stokerus et dans d'autres cspèces: ici elle est dı miême vert que le reste de la tête. Les antennes des mâles ont á peu près la moitić de la longueur du corps; cclles des femelles sont un peu plus courtes : elles sont noires, avec leurs articles aplatis, comme dans les autres espèces. Le corselet est de forme ordinairc, presque droit, ou un peu échancré sur les còtés, ponctué. Il a de chaquc côté et en avant, une impression à fond noir, placée obliquement, et quatre petites taches rondes et noires un peu au-delà du milieu. Dans quelques individus, on voit une tache oblongue rouge entre les deux impressions antérieures; dans d'autres, on ne voit plus que les deux taches des côtés, sur la ligne des quatre qui se trouve près du milieu. L'écusson est un peu enfoncé à sa base, couvert d'un grand nombre de petits points enfoncés, avec une ligne longitudinale au milieu, dépourvue de points et faiblement marquée; il a de chaque côté trois pctites taches noires, rondes, et une plus petite au milieu et près de l'extrémitć. Le dessous du thorax est rouge, avec de grandes taches vertes ct rćunies sur les còtés. Les côtés du corselet sont bordés de rouge, lequel se voit un peu de dessus. L'abdomen est d'un beau rouge vermillon, avec les côtés largement bordés de vert; on voit au bord extérieur du vert, quatre gros points noirs, et en dedans de cenx-ci, quatre taches noires moins bien circonscrites. Le bord tout-àfait externe est rouge, mène vu en dessous. La trompe est noire et rouge à la base. Les cuisses sont rouges, avec une très-petite portion des genoux rerte. Les jambcs et les tarses sont d'un vert foncé. - Cette belle espèce vient dc Java.

On trouve dans Donovan $\left(^{*}\right)$ la figure dine cspèce assez voisine de celle-ci, et qu'il appelle Cimex costatus. Elle a, comme la nôtre, le bord des élytres rouge; mais ses

(") An Epitome of the inseets of Asia, etc., pl. des Hémiptères, fig. * " * 
pattes sont entièrement rouges, et elle n'a que deux grandes taches sur le corselet et quatre sur l'écusson, d'un noir bleuâtre.

\section{SCUTELLÈRE DOREEE, Scut. aurata. GUÉR.}

Cette espèce ressemble beaucoup à la Scut. Stokerus pour la forme et la grandeur. Sa longueur est de I 5 à ı 5 mill. et demi, et sa largeur, derrière le corselet, de $8 \mathrm{~m}$. environ. Sa forme est un peu plus oblongue; elle est un pen moins carrée en arrière. Sa couleur en dessus est un beau dorć vert à reflets rouges. La tête est triangulaire avec une ligne longitudinalc noire, conme dans la Scut. Stokerus; mais elle n'a pas le vertex noir. Les antennes sont noires, presque de la longueur des deux tiers du corps. Le corselet a. huit taches noires comme dans la Stokerus; mais elles sont plus petites, stirtout les latérales, qui disparaissent presque dans quelques variétés. L'écusson est comme dans la Stokerus; il n'a aussi que sept taches, mais plus petites, presque rondes, avec celle du nilicu plus grande, triangulaire et allongée. Le dessous du thorax est d'un beau vert bleu, à reflets métalliques très-brillants, avec quelques petites lignes jaunes à la suture des segments. Le dessous de l'abdomen est jaune, avec une large tache carréc, oceupant le nuilieu des deux premiers segments et d'un noir bleuàtre; le dernier segment et l'anus sont également d'un noir bleuâtre à reflets dorés. Les côtés de l'abdomen sont occupés par quatre grandes taches bleues, réunies et formant bande. Le bord extérieur et la partie visible en dessus, qui est rouge dans la Scut. Stokertes, est ici d'un beau bleu, à reflets métalliques et verts dans quelques individus. J'ai observé les deux sexes de cette espèce ; ils sont entièrement semblables, à l'exception des antennes, qui sont plus longues chez les mâles. - Cette Scutellère se trouve exclusivement à Java, et non au Bengale et à la Chine, comme la Stokerus.

\section{SGUTELLÈrE EXCAVÉE, Scut. excavata.Guín.}

Cette belle espèce cst d'un bleu vert brillant, de forme oblongue, moins rétrécie en arrière que les précédentes, avec les côtés plus parallèles. Sa longueur est de 15 millimètres, et sa largeur, à la basc de l'écusson et au tiers postérieur, de 7 mill. Sa tête est assez grande, triangulaire, avec les yeux saillants et noirs: elle a au milieu la ligne longitudinale signaléc aux autres espèces. Cette ligne est noire. Les antennes sont plus longues quc la moitié du corps, dans le seul mâle que nous possédions. Le corselet cst à peine plus large que la tête en avant, ćchancré de chaquc còté, avec les angles latéraux saillauts. De derric̀re les yeux il part deux petites eôtes élevées qui viennent se joindre à angle aigu au tiers antéricur, et qui circonscrivent une fossette assez profonde, triangulaire, et d'un noir unat. On voit de chaque côté une petite fossette oblique, ovalaire, à fond noir, comme celles que nous avons signalées à la Scut. Buquetii. Derric̀re l'angle postéricur de la fossette du milieu, sur la partie la plus saillante du corselet, on voit un assez gros point noir ct rond : de claque côté, et à la hauteur des fossettes latérales, il y a deux petites taches rondes, placées l'une derrière l'autre; les 
angles latéraux sont un peu noirâtres. L'écusson a trois taches de ehaque côté : les deux premières sont de moitié plus petites, rondes; les suivantes sont aussi rondes, mais très-grandes; les dernic̀res sont ovales, plaeées transversalement. Derrière celles-ei et près de l'extrćmité, il y en a une autre ovale et transversale, plus petite, et au milieu et près de la basc, on en voit une assez grande, de forme triangulaire et prolongée en arrière. Le dessous du thorax est d'un beau vert luisant, avec la base de la tête et les sutures finement bordées de jaune. L'abdomen est jaune, très-largement bordé de vert, avee la base noire. Les eôtés offrent chaeun quatre gros points noirs. Les euisses sont jaunes jusqu'au-delà dı milieu, vertes ensnite, ainsi que les jambes et les tarses. Les élytres sont brunes avec la eôte d'un noir bleu et l'extrémité enfumée. Les ailes sont transparentes avee le bout brun. - De Java.

\section{SCUTELlÈrE A CORSELET DILATÉ, Scut. dilaticollis. Guér.}

Cette pctite espèee a un peu la forme et la eouleur de la Scut. Stokerus, mais sa longueur n'est que de ıo à 12 millimètres, et sa largeur, à la base de l'éeusson, de 5 et demi à 6 . Le dessus est d'un bleu luisant plus ou moins verdâtre; la tête est large, triangulaire, avee les yeux saillants et la ligne du milieu noire. Les antennes sont noires : eelles des mâles sont au moins aussi longues que le eorps, celles des femelles sont plus eourtes; leurs deux derniers artieles sont un peu plus élargis que dans les autres espèees. Le eorselet est aussi large que la tête en avant, brusquement élargi ensuite par une petite dilatation minee, arrondie, en forme de lame un peu tranehante, plaeée de ehaque eôté. Il n'offre pas, eomme dans la Scut. Stokerus et dans les autres espèees voisines, une dépression en avant; il est uniformément bombé, plus large que l'ćeusson, et presque deux fois plus large que long; sa surfaee est lisse ou très-faiblement pointillée, vue à une forte loupe. Il a deux lignes transversales, eomposées ehaeune de trois taehes arrondies assez grandes; les dilatations sont noires au milieu. L'éeusson a sept grosses taches ar'rondies et noires, et unc grande tache triangulaire vers la base, très-large en avant, un peu éehanerée sur les côtés, avee une petite ligne verte au milieu dans quelques individus; la taehe postérieurc est plaeée au milieu et près dc l'extrémité. Le dessous du thorax est d'un beau vert brillant, avec de petites lignes jaunes aux sutures. Le rostre est vert, avec la base de couleur orangée. L'abdomen est dun beau jaune orangé vif, avec une tache earrée, noire à la base, et l'anus noir-bleu. Les eôtés sont verts, avec deux rangs de quatre points noirs plaeés de ehaque eôté. Les cuisses sont d'un jaune orangé vif, avee les genoux seulement, les jambes et les tarses d'un vert blelı. - Cette jolie espèce, bicn earaetérisée par les dilatations de son eorselet, vient de Java.

La Tetyra senator, de Fabricius, que nous avons vue dans la eolleetion de Bose, va eneore dans ee groupe. Elle est un peu plus grande que la préeédente, d'un beau bleu noir, avee une bande formant la moitié antérieure du eorselet, la base de l'écusson, une bande au milieu, communiquant avec unc tache terminale, d'un beau vert doré très-brillant. En dessous, la moitić antérieurc du thorax est d'un vert doré, lc reste est d'un bleu noir. L'abdomen est noir, avee unc bande denteléc de ehaque eôté, d'un beau 
rouge vermillon, et l'extrémité verte. Les cuisses sont d'un rouge vermillon, avec lcs jambes et les tarses noirs. - Elle vient d'Amboine, et a été rapportée par Labillardière.

\section{Genre SCUTIPHO̊RE, Scutiphora. GuÉn.}

Ce nouveau genre ressenıble beaucoup à celui que M. Delaporte a établi sous le non de Calidea, dans sa classification des hémiptères, insérće dans notre Magasin de zoologie; mais il s'en distingue d'une manière notable par ses antennes. Voici le caractère que nous lui assignons :

Corps allongé; tête triangulairc avec les yeux saillants. Antennes de cinq articles; le premier court, le second très-long, courbé; le troisième trc̀s-petit, en formc de point, et les deux derniers égaux, ne formant pas ensemble les deux tiers de la longueur du second. Extrémité du suçoir dépassant un peu la base des pattes postérieures. Tarse ayant le premier article aussi long que les deux suivants réunis, avec le troisième armé de deux crochets et d'une petite pclote bifide.

SCUTIPHORE PEINTE, Scutiphora picta. Guír. - Viridi-cyanea desuper, virta margincali thorace, antice, maculis duabus scutello antice, ochraceis; infra ochraceis maculis lateralibus in segmentis inferioribus, genuis, tibiis, tarsisque cyaneis; antennis nigris; articulo primo basi fulvis. - L. 15 mill., larg. 7 m. - Atlas, Ins., pl. XI, fig. 7 .

Son corps est allongé, naviculaire, bleu mêlé de vert. Le corselet a une bande marginale, placée au bord antérieur, d'un rouge brique; on voit deux tachics de la même couleur, presque contiguës, à la base de l'écusson. La partie inférieure du corps, la moitié du premier article des antennes, et les trois quarts des cuisses, sont d'un rouge couleur de brique, avec des taches bleucs sur les parties latérales de chaque scgnient. Les genoux, les jambes et les tarses sont de la même couleur; les antennes sont noires, un peu moins longues que le corps. - Cet insecte a été trouvé au Port-Jakson et au PortWcstern, à la Nouvelle-Hollande.

PENTATOME DE FALlEN, Pentatoma Fallenï. Gúr. - Lutea, griseo-variegata, capite viridl; thoracis spinis bifidis cyaneis. Scutello in extremum albo; elytrorum membrana fusco maculata; abdomine nigro; pedibus luteis. - L. 12 mill., $1.6 \mathrm{~m}$. - Atlas, lins., pl. XI, f. 8.

Elle cst un peil oblongue, sa tête est rugueuse, presque carrée en avant, allongée, d'un vert foncé luisant, avec quelques petites taches de rouille sur le vertex. Les ycux sont très-saillants, bruns. Les antennes sont presque aussi longues que la moitié du corps, d'ın jaune pâle. Le corselet est étroit en avant, élargi et armé sur chaque côté d'une forte ćpine pointue, sous l'extrémité dc laquellc se tronve une très-petite dent. On voit anssi une très-petite épine aux angles antéricurs, tout-à-fait sous les yeux. Le 
bord antérieur est lisse, jaune, avec quelques taches brunes, et une bordure de points enfoncés, noirs, derrière la tête. Le reste de sa surface, derrière les taches antérieures, est jaune, criblé de petits points bruns, plus serrés sur le milieu. Cette couleur devient plus foncée vers les ćpines latérales, qui sont noires. L'écusson est asscz grand, jaune piqué de points noirs; il a une grande tache arrondie et noirc à la base; il est brun vers l'extrémité, qui est arrondie et d'un blanc jaunâtre poli. Les élytres sont jaunâtres, finement piquetées de brun, avec la membrane brune, marquée de deux taches transparentes, l'une extérieure, l'autre en dedaus. Le dessous du thorax est brun tacheté de jaune; l'abdomen est d'un noir brun, avec les côtés tachés de jaune pâle; les pattes et le rostre sont jaunâtres. - Cette espèce vient de Dory, à’la Nouvelle-Cruinée.

PENTATOME DE SCHELLEMBERG, Pentatoma Schellembergii. Guír. - Lutea, griseo variegata; thoracis spinis nigris. Scutello apice acuto, albo. Abdomine luteo virescente. - Long. 1 I mill., I. 5 m. - Atlas, Ins. pl. XI, f. 9.

Cette Pentatome est plus allongée que la préeédente, d'un brun rougeâtre en dessus, jaunâtre en dessous. La tête est assez allongée, avec des points très-serrés, noirs au fond et formant quatre lignes longitudinales. Les antennes sont d'un jaune un peu fauve. Les yeux sont jaunâtres, et les yeux lisses, très-brillants et rouges. Le corselet est plus de deux fois plus large que long, mesuré d'une pointe à l'autre; il est jaune sur les bords antérieurs et postérieurs, couvert de points très-serrés, bruns au fond; ses épines latérales sont fort aiguës, noirâtres. L'écusson est allongé, aigu à l'extrémité, couvert de points enfoneés bruns; il a quelques taches nébuleuses jaunâtres, avec le milieu brun et l'extrémité d'un blanc jaunâtre. Les élytres sont couvertes de petits points bruns, avec une faible tache nébuleuse près de l'extrémité, et la membrane uı peu transparente, enfumée et à nervures brunes. Les côtés de l'abdomen qui débordent les élytres sont jaunes, avee des tachcs obliques noires, assez espacées entre elles. Le dessous est d'un jaune livide, ponetué de petits points bruns, påles; le milieu est lisse, et les angles des segnıents aigus et noirs à la pointe seulement. Le rostre est d'un jaune pâle, et les pattes de la même couleur. - Du Port-Jakson.

PENTATOME DE WOLF, Pentatoma Wolfi. GuÉr. - Nigra, desuper punctata; vittis caput, thoracem, scutellum, marginenque elytrorum anterioren circumdantibus, fulvis. Corpore infra rubro livido, punctato. Antennis pedibusque nigris. - Long. 10 mill., l. 5 m. - Atlas, Ins., pl. XI, f. 10.

Son corps est ovalaire oblong; sa tête est allongée, ponctuée, d'un noir luisant, avec trois lignes longitudinales rouges. Les antennes sont noires et les yeux d'in brun rouge. Le corselet est un peu plus de deux fois plus large que long, arrondi sur les còtés, sans épines latérales, très-ponctué, noir, avec les bords et une bande longitudinale au milieu, rouges; il y a une bande nébulcuse d'un jaune rougeàtre, placée transversalement au milieu. L'écusson est grand, un peu bombé à sa base, ponetué. Son 
extrémité, un pcu arrondie, atteint assez au-delà du milieu de l'abdomen. Il est rouge, avec deux grandes taches triangulaires noires à sa base. Les élytres sont noires, avec le bord extérieur taché de rouge; leur membrane est noire, avec l'extrémité brune et un peu transparente. Les côtés de l'abdonıen, qui débordent les élytres, sont rouges, sans taches. Le dessous du corps est d'un jaune rougeâtre, avec des points noirs sur les côtés dı thorax et de l'abdomen. Les pattes sont noires, avec la base des cuisses jaunâtre. Le reste est rougeâtre. - De Bouron, l'une des îles Moluques.

PENTATOME DE GERMAR, Pentatoma Germarii. Gú́n.-Thorace valdc, humeris, anoque spinosis, viridis: scutello, elytrorum membrana, anoque infumatis. - Long. 15 mill., larg. 8 m. 一 Atlas, Ins., pl. XI, fig. I ז.

Cette espècc a le corselet triangulaire, transversal; il est ćchancré pour recevoir la tête, très-dilaté à la hauteur des épaules cn deux épincs aiguc̈s; il s'échancre postćrieurement pour recevoir l'écusson : celui-ci est presque aussi large que long, atteignant à peine le milicu de l'abdomen, qui est terminé par quatre épines, dont les extérieurcs beaucoup plus longues que les autres; entièrement d'un vert d'herbe, avec l'écusson, la pointe des épines du corselet, les mcmbranes des élytres, la partie anale et les tarses enfumés. Dans les individus desséchés, le vcrt passe au jaunâtre. - Prise à Bourou, dans les îles Moluques.

PENTATOME DU POR'T JAKSON, Pentatoma Jaksoniensis. GuÉr. - Viridi-lutea, vittis thorace, scutelloque pallidioribus; scutelloque in cxtremum ochraceo maculato. - Long. 8 mill., larg. 4 mill. - Atlas, Ins., pl. XI, f. 12.

Le corps est ovalaire, forternent pointillé, plat, entièrement d'un vert jaunâtre; la tête, deux bandes transversales sur le corselet, et une autre courbe sur l'écusson, plus pâles. On voit un point couleur d'ocre à l'extrémité de ce dernier. Membrane des ailes légc̀rement enfumée. Antennes et tarses fauve clair.

Cette Pentatome a beaucoup de rapports avec lc Cimex rubro-fasciatus de Fabricius. Syst. Rlıyng., p. I go, $\mathrm{n}^{\circ}$ 8o. Mais elle a l'extrémité de l'écusson rougeâtre, ce que Fabricius ne mentionne pas dans son espècc. - Du Port-Jakson.

PENTA'TOME APLATIE, Pentatoma complanata. GuÉr. - Corpore depresso, valde punctato, thorace scrrato, humeris spinoso, viridi-pratense; antennis pedibusque luteis; antennis nigro anmulatis. - Long. 20 mill., larg. to m. - Atlas, Ins., pl. XI, f. 13 .

Cette espèce a lc corps très-aplati et fortcmcnt ponctué; la tête cst avancée, enfoncée postérieurcment dans une profonde échancrure du corselet. Celui-ci est triangulaire, dentelé en scie des deux côtés de la tête, dilaté en une épine méplate, relevée, aiguë à la hautcur des épaules. L'écusson est droit à son bord antèrieur, triangulaire, aigu. L'abdomen est ovoïde, légèrement foliacć sur les côtćs, dćpassant les élytres. Tout 
l'insecte en vert pré, avec les impressions des points vert-grisâtre; une ligne légèrerement relevće sur l'écusson, lcs pattes et les antennes jaunâtres; les extrénités des quatre derniers articles des antennes, un petil point à l'extrémité des fémurs, noirs. Tarses et épines du corselet brun clair. - De Sainte-Catherine, au Brésil.

PENTATOME RACCOURCIE, Pentatoma crassula. Guér.-Viridis; elytrorum pars crustacea, livida, puncto marginali infumato. - Long. 9 mill., larg. 6 m. - Atlas, Ins., pl. XI, f. 14 .

Cette espèce est très-raccourcie, et large à proportion de sa longueur. L'écusson est large, arrondi et blanchâtre à son extrémité : le reste de sa formc n'offre rien de remarquable. Elle est verte; la partie inférieure du corps plus pâle, surtout au milieu de l'abdomen. Les ćlytres, excepté le bord antérieur qui est vert, sont livides, avec un point enfumé touchant la bordure verte. La partie membraneuse de l'élytre est enfumée à sa jonction avec la partie crustacée. - Offak, terre des Papons.

\section{Genre AGAPOPHYTE, Agapophyta. Guér.}

Ce nouveau genre est voisin des Pentatomes pour la forne généralc du corps; mais il s'en distingue au premier coup d'œil par ses antennes, qui n'ont que quatre articles, par son rostre très-court et dépassant à peine la base des premiers pieds, tandis qu'il atteint au-delà des troisièmes dans les Pentatomes. Voici les caractères que nous assignons à ce genre :

Antennes longues, de quatre articles : le premier court, assez fort; le second, trèslong, cylindrique; les deux suivants éganx entre eux, formant ensemble la longueur des deux premiers. Bec court, dépassant à peine la base des premières pattes. Tarses de trois articles; le deuxième, le plus court, le troisième ayant une membrane entre les crochets.

Ce genre est mentionné dans l'Essai d'une classification systématique des Hémiptères, que M. Delaporte a inséré dans notre Magasin de zoologie. Il est placé près du genre Dinidor, fondé par Latreille.

AGAPOPHYTE A DEUX POINTS, Agapophyta bipunctata. GणÉR. - Lutea seu in visum viridis; in utroque elytro punctum nigrum. - Long. 16 mill., larg. 8 m. Atlas. Ins., pl. XI, f. I5.

Corps assez plat, allongé. Tête triangulaire ayancée. Corselet hexagone, fortement échancré vis-à-vis dc l'écusson; celui-ci est deux fois plus long que la largeur de sa base, légèrement bi-épineux à son extrémité; la jonction de la partie coriace à la partie membraneuse de l'élytre est fortement sinueuse. Le rostre est très-court, dépassant peu les premic̀res pattes. Le premier segment abdominal s'avance en pointe dans une échancrure du sternum. Entièrement fauve, peut-être verte sur le vivant, avec un petit point noir au milieu de chaque élytre. - Port-Praslin. 
Genre PLATYCORIS, Platycoris. Gúr.

Ce nouveau genre est fort voisin des Phloca et des Dryptocephala de MI. de Laporte, et il vient se plaeer entre ees deux genres, si l'on suit la méthode exposée par cet entomologiste dans notre Magasin de Zoologie. Comme les Phloca, il n'a que quatre artieles aux antennes ( $\mathbf{r})$, tandis que les Dryptocephala en ont cinq; eomme ces derniers, la tète est déeoupée, et les antennes-s’insèrent dans des éehanerures formées par les déconpures extérieures. Voici les caractères que nous assignons à ee nouveau genre.

Antennes cylindriques, assez longues, de quatre articles dont le premier eourt, le deuxiène quatre fois plus long, les deux suivants égaux, aussi longs ensemble que le seeond. Téte découpée en avant en quatre lobes, dont les deıx du milieu plus larges et arrondis, les latéraux plus courts, aigus, laissant entre eux et ceux du milieu un espaee assez grand dans lequel s'iusèrent les antennes. Rostre assez long, atteignant la base des pieds postérieurs. Tarses de trois artieles, dont le sccond est peu distinet; le premier grand, épais, eylindrique; les deux suivants, soudés, moins longs à eux deux que le prenier'; erochets simples, sans menbrane intermédiaire. Corps aplati en dessus; écusson grand. Élytres allongées, avee la membrane peu distinete, étroite. Des ailes rudimentaires impropres au vol.

PLA'TYCORIS BORDÉE DE ROUGE, Platycoris rubro-marginata. Guér. - Nigra. Marginata, maculata, et irrorata rufo colore. - L. Io mill., l. 5 mill. - Atlas, Ins., pl. XI, fig. 16.

Cette espèee offre un facies tout partieulier : son corps est très-plat et représente un ovoïde dont la partie la plus large est au milieu de l'abdomen, tandis que la tête en forme la partie étroite; sa tête est plus large que longue, le chaperon est bifoliaeé fendu, relevé sur les eôtés; le corselet est transversal en forme de trapèze et éehaneré, pour recevoir la tête, il est droit vis-à-vis l'écusson. Celui-ei est plus long que large, rouge au bout. Les élytres ne couvrent pas l'extrénité de l'abdomen, la partie membraneuse est très-restreinte, longitudinale. Cet inseete est noir bordé de rougeâtre avec des bandes de eette couleur sur le eorselet et les élytres, et einq tachés sur les eôtés de l'abdomen; le rostre, les hanches, la prenière partie des fenurs et des tibia, et la base des deux derniers articles des antennes sont fauves; on voit des atomes de eette eouleur répandus sur tout le dessus du eorps. — Trouvée au Port-Jaekson.

(s) C'est par erreur que nous avons indiqué 5 articles aux antennes de la figure XVI, pl. II de notre atlas; de nouvelles observations, faites avee une trés-forte loupe, nous ont fait reconnaitre quili n'y a réellement que 4 articles aux antennes.

Vojagre de la Coquille. - Z. Tom. II, Part. II. I ${ }^{\mathrm{re}}$ Div. 
PLATYCORIS A DEUX POINTS, Platycoris bipunctata. GuÉr. - Lutea, valde punctis nigris impressa. Thorace scutelloque transversis rugis. Elytris puncto luteo. Pedibus luteis, femoribus apice brunneis. - L. I r mill., 1.8 in. $\frac{\frac{1}{2}}{2}$ - Atlas, Ins., pl. XII, fig. 3 .

Cctte espèee, que nous rangeons avee doute dans notre genre Platycoris, en diffère surtout par l'épaisseur de son corps et par la forme de sa téte; les antennes sont mutilées, ee qui nous empèehe de eonnaître le nombre de leurs artieles. La tête est brune, saillante, rugueuse, triangulaire, aplatie, et arrondie en avant, avee les yeux très-saillants et deux yeux lisses très-distants. Le corselet est assez bombé, cn forme de trapèze, deux fois plus large cn arrière, avee les côtés presque droits; son bord antérieur est eoupé droit, et les angles présentent chaeun une petite saillie plaeée derrière les yeux; sa surfaee est brune, fortement elagrinée avee toutes les saillies des rugosités d'in ferrugineux foncé. L'éeusson est également chagriné; sa couleur cst la même; il eșt très-grand, triangulaire, assez bombé. Les élytres sont grises piquetées dc jaune, avee un point jaunâtre assez gros au milieu; leur membrane est très-étroite et réduite, eomme dans la Platycoris rubro-marginata, à un très-petit lambeau nembraneux brun. Les bords de l'abdomen, laissés à déeouvert par les élytres, sont marqués alternativement de noir et de rouge. Le dessous du eorps est brun. Les pattes sont jaunes avee l'extrémité seulement des euisses brunes. - Cette eurieuse punaise vient du Port-Jaekson, à la Nonvelle-Hollande.

HALYS A POINTS JAUNES, Haly's flavo-punctata. GuÉr.-Brunnea, atomis innumeris luteis sparsa. - L. 20 mill., l. $10 \mathrm{~m}$. - Atlas, Ins., pl. XI, fig. I7.

La tête est avaneée plutôt arróndie antérieurement que triangulaire; les yeux sont très-développés, le eorselet légèrement épineux à sa partic lıunérale; droit à son bord postérieur; la gaînc du rostre est épineuse à sa partie antérieure, eelui-ei dépasse les jambes postérieures; eette espèee est d'un brun noiràtre entièrement parsemée d'atomes jaunàtres, mais ees cleux eouleurs sont tellement mélangées que peut-être devrait-on regarder la eouleur jaune eomme le fond; elle est en outre eouverte de points cnfoneés très-prononeés, mais seulement dans les endroits bruns; les points jaunes aequièrent plus de développement et sont d'une eouleur plus fauve en plusieurs endroits; on en remarque surtout deux vis-à-vis du vertex, trois à la base de l'éeusson, un à son extrémité et un sur le disque de elıqque élytre: au-dessous du eorps, la eouleur jaune forme une taehe médiane sur ehaque anneau de labdomen; et deux petites taehes sur les bords de ehaeun d'eux. Les pattes, le rostre et les parties inférieures de la tête sont marquées de lignes longitudinales de la même couleur, et le premier artiele des tarses presque tout entier est également jaune. - Elle a été rapportée du Port-Jaekson.

HALYS DE WINTHEM, Halys Winthemiii. Gú́r. - Livida. Thorace, scutello postice, elytris virescentibus, panctis innumeris nigris sparsis; in insectis vivis viridi-auratis. L. 22 mill., $1.8 \mathrm{~m}$. - Atlas, Ins., pl. XI, fig. I 8 . 
Cette espèee est allongée; la tête, d'égale largeur partout, est bi-foliacée à son extrémité, avee le labre légèrement saillant. Les yeux sont plus que deni-sphériques, comme détachés de la tête; le corselet, fortement échaneré, est d'abord arroudi sur les eôtés, finement dentelé, il s'avanee ensuite brusquement à droite et à gauche pour former une épine aiguë; il est presque droit à son bord postérieur; l'éeusson est presque deux fois plus long que large, plus élevé avee l'extrémité aiguë. L'abdomen est légèrement dentelé sur les eôtés; la gaine du rostre est épineuse à sa partie anterieure, celur-ci dépasse de beaucoup les pattes postérieures; la tête, la partie antérieure du corselet de l'écusson, et les parties inférieures sont d'un jaune livide; la partie postérieure du corselet de l'éeusson, les élytres sont verdâtres, tout le dessus du corps et la partie inférieure de la tête sont couverts de points enfoncés noirs, mais qui dans le vivant sont d'un beau vert métallique; on en retrouve toujours quelques traces, même dans les animaux dessechés, particulièrement en arrière des yeux; tous les tibias sont en outre largement bi-annelés de noir.-D'offak terre des Papous. Il en existe une variété plus pâle qui a été trouvée à Dory.

TESSARATOME A ANTENNES JAUNES, Tessaratoma favicornis. GuÉr. - Nigrocuprea, valde rugosa; antennis, elytris maculisque octo in thorace infra; fulvis; in elytris vitta longitudinalis nigra: membrana rubro-cuprea. - L. 32 mill., 1. 17 nı. - Atlas, Ins., pl. XII, fig. 2.

Cette espèee est une des belles découvertes que l'on doit aux derniers voyages autour du monde; MI de Laporte, dans son Essai d'une classification des Hémiptères, a créé avee elle le genre Onchomeris; mais la publication des planches de eet ouvrage étant de beaucoup antérieur au sien, j’ai dû décrire eette espèce sous le nom que je lui avais imposé en la figurant; sa tètc est très-petite à proportion de la grancleur du corps; elle est en forme de fer de lance très-éerasé, le eorscilct est presque demi-circulaire antérieurement, échancré pour recevoir la tête, échancré anssi, mais peu profondément pour recevoir l'écusson; ce dernier est allongé aigu; tous deux sont fortement ehagrinés et, ainsi que la tête, d'une eouleur noire bronzée; les élytres se recouvrent exactement à leur extrémité, paraissent alors très-allongées en forme d’un triangle suivant la forme de l'éeusson; tout le corps est noir-vert dessus et dessous, les antennes, le bord de la tête, la gâne du rostre, les élytres et 8 taches sur la partie inférieure du thorax, sont fauves; sur le fauve des élytres est une bande d'un noir vert, prenant de la partie humérale et s'étcndant jusqu’à la membrane; eclle-ei est grande à nervures parallèles, d'un brun euivreux rougcà tre.-Cette belle espèce vient de la Fouvelle-Guinée.

\section{Gexre méGyMène, Megymenum, Guér.}

MI. Serville avait séparé, dans sa colleetion, une espèce de la famille des Cimicites, voisine des Aradus, mạis en différant notablement par la forme du corps et des élytres. Nous avons reeonnu que notre nouveau genre appartenait à cette coupe, et nous nous 
sommes empressés d'adopter le nom que M. Serville lui avait assigné; non pas paree qu'il était dans sa collection, mais parce qu'il fait partie d'un travail encore inanuscrit de ce savant entonologiste. Voici les caractères que nous assignons au genre Megymennm.

Antcnnes beaucoup moins longues que le corps, composées de quatre articles aplatis; le premier court, inséré devant les yeux, sous le chaperon ct ne le dépassant pas; lc second, le plus long de tous, un peu plus étroit à la base. Les troisième et quatrième réunis, un peu plus longs que le second; le troisième oฑalaire, un peu plus large que l'extrémité du précédent; le quatriène plus étroit que le troisième, terminé en pointe. 'Tête armée de chaque côté, et en avant des yeux, d'une épine aiguë, deux ocelles. Rostre logé dans une fossette du thorax, atteignant à peine les secondes pattes, corselet transversal, armé en avant d'une épine placée de chaque côté, et tout à fait derrière les yeux. Écusson assez grand, ne recouvrant pas tout l'abdomen. Élytres ayant leur portion membraneuse très-étendue, recouvrant des ailes plus courtes. Pattes fortes avec des tarses de trois articles, dont le premier est grand, le second très-petit, et le troisième aussi grand que le premier, armé de deux erochets simples. Bords de l'abdomen dentelés.

MÉG YMÈNE DENTÉ, Mcgymenum dentatum. Guér.-Brunneum. Elytrisnigro-reticulatis, mombrana flava apice brumea. Capite depresso, cum spinis duabus. Lateribus thoracis valde dilatatis, antice spinosis. Lateribus abdominis obtuse-dentatis. - Long. 20 mill., I. I 2 m. - Atlas, Ins., pl. XII, fig. I.

Cette espèce est entièrement d'un brun de suie terne; ses antennes sont un peu aplaties, à peine aussi longues que la tête et le corselet réunis. La tête est plate en dessus; elle offre une petite épine au-dessus des yeux. Le corselet est transverse, de la largeur de la tête en avant, armé d'une petite épine courbe placée de chaque côté au bord antérieur et derrière les yeux; il est finement rugueux, et offre en avant un sillon transverse et deux impressions assez marquées placées derrière la tète; ses còtés présentent deux grands lobes arrondis et dirigés en avant; son bord postérieur est un peu arrondi. L'écusson est assez grand, arrondi en arrière, et atteint presque la moitié de la longueur de l'abdomen. Les élytres sont assez développées, avec la partie membraneuse grande, jaune, coupée de nervures brunes, et ayant l'extrémité interne également brune, ce qui produit une grande tache au milieu et derrière l'écusson, quand elles sont fermées. Les bords de l'abdomen dépassent assez notablement les élytres, ils ont des dents arrondies, alternativement grandes et plus petites. Les pattes sont assez fortes avec les cuisses à peine dentées en dessous et les jambes aplaties. - De Dory, Nouvelle-Guinée.

MÉG YMÈNE CUIVRÉ, Megymenīim cupreum. GuÉr. - Cupreo-obscurnm. Membrana elytrorum lateo-brunnea. Thorace lateribus quadratis. Lateribus abdominis denticulatis. L. I5 mill., 1. 9 m.

Tout son corps est d'un brun rouge brillant, couleur de cuivre rouge. Sa tête est aplatie avec le chaperon creusé au milieu. Les antennes sont aplaties, noires. Le corselet est transversal, aussi large que la tête, et armé de deux petites épines placées sous les yeux, 
en avant; il a de ehaque eòté deux dents assez saillantes dont les antérieures ne remontent pas en avant, et sa surface est rugueuse, garnie antérieurement de einq tubereules issez forts avee une fossette au milieu, et plus en arrière. L'écussoin est grand, terminé en pointe arrondie; il atteint presque le milieu de la longueur de l'abdomen. Les élytres ont leur portion membraneuse très-étendue, d'un jaune sale un peu lorunâtre en arrière. Les pattes sọt assez fortes avec les euisses assez fortement dentées en dessous et les jambes peu aplaties. - De Java.

GONOCÈRE A COLLIER, Gonocer'us collaris. GuÉR.-Luteus, vitta in thorace transversali pallidiore : punctis multis brunneis; clytrorum membrana fusca. - Long. $8 \mathrm{~m}$., 1. 3 m. - Atlas, Ins., pl. XII, f. 4.

Cette petite espèce a beaueoup d'analogie avee quelques Corées de notre pays; le eorselet est épineux à ses angles et légèrement dentelé après l'épine, avant de rejoindre l'écusson. L'inseete est entièrement d'un jaunâtre fauve, avee beancoup de points bruns: une large bande jaune traverse le eorselet au-dessus des deux épines latérales. Les eôtés de l'abdomen, qui débordent les élytres, sont alternativement jaunes et bruns. Le dessous est jaune tacheté de brun. Les pattes sont assez grêles, jaunes.—De Dory, à la NouvelleGuinée.

CORÉE ROUILLÉ, Corcus rubiginosus. GUÉR.-Obscure ferrugineus; subtus pallidior. Thorace triangulari, antice nigro-bimaculato. Capite fusco. Antennis basi apiceque fuscis. Femoribus posticis incrassatis, subtus unidentatis. - Long. 19 mill., I. $7 \mathrm{~m}$.

Il est entièrement d'un rouge de rouille, forcé en dessus, plus pâle en dessous. Les antennes sont presque de la longueur du eorps, avee le premier et le dernier articles bruns. La tête est brune, finement ehagrinée. Le corselet est de forme triangulaire, finement ehagriné en dessus, un peu rebordé et dentieulé sur les eôtés, avee une ligne élevée, transverse sur le bord postérieur, et deux taehes brunes en avant. L'éeusson est triangulaire, équilatéral. Les élytres sont très-finement ehagrinées; leur portion membraneuse est d'un brun un peu métallique. Les pattes sont de la eouleur du dessus, les euisses antéricures et intermédiaires sont peu fortes, armées en dessous et vers l'extrémité d'une dent assez petite. Les euisses posterieures sont fort renflées, armées d'une large dent en dessous; leurs jambes sont un peu arquées en dehors avee un angle assez fort en dedans et au milieu de leur longueur, elles sont dentelées depuis ee point jusqu'à l'extrémité. Les eôtés de l'abdomen en dessus sont marqués, à la suture des segments, d'une petite trie jaune.'Tout le dessous est d'un ferrugineux jaunâtre. - Du port Jackson, à la NonvelleHollande.

ANISOSCÈLE ENFUMÉ, Anisoscelis infumatus. Gú́n. - Viridi-opacus, ochraccus infra. Antennis flavo-annulatis. - L. 15 mill., 1. 4 m. - Atlas, Ins., pl. XII, fig. 5.

Cet inseete appartient au genre Anisoscelis proprement dit, de la métlode de M. de Laporte; il est entièrement d'un noir verdâtre en dessus; sa tête est avaneée, finenıent ru- 
gucuse avec les yeux saillants. Les antennes sont insérées devant les yeux, au milieu de l'espace compris entrc eux et l'extrémité. Elles sont de la longueur du corps, d'un noir vcrdâtre, et les deuxième, troisième et quatrième articles ont un petit anneau jaune à la base. Le corselet est de forme triangulaire, de la largeur de la tête en avant, avec une petite épine derrière les yeux, assez plane, aigu de chaque côté en arrière; l'écusson est triangulaire, assez petit. Les élytres sont allongées; vues à la loupe elles semblent semées, ainsi que le corselet et la tête, d'une infinité de petits poils fauves: elles ont au milieu trois petits points fauves placés transversalement : un au milieu, au commencement de la partie membraneuse et un de chaque côté, ou surur chaque élytre. L'abdomen est rouge en dessus, avec les bords découverts par les élytres marqués de taches noires carrées. Le dessous est ferrugineux. Les pattcs sont de la même couleur, grêles, avec: les jambes annelées de brun. Les cuisses postérieures sont un peu plus fortes, finement ćpineuses en dessous et vcrs l'cxtrémité. Le rostre atteint la moitié de la longueur du corps, et clépasse un peu l'insertion des pattes postérieures De Sainte-Catherine, au Brésil.

\section{Genre LEP'TOGLOSSE. Leptoglossus. Gứr.}

L'insecte avec lequel nous fondons ce genre, offre tous les caractères du genre Anisoscelis, tel que le conçoit M. de Laporte, mais ces caractères sont très-exagérés : ainsi la tête est beaucoup plus allongée et étroite; mais ce qui le distingue encore plus, e'est l'excessive longueur de son rostre qui atteint presque l'extrémité de l'abdomen.

LEPTOGLOSSE A COL DILATÉ, Leptoglossus dilaticollis. Gux́r. - Brunneo-ruber. Capite conico, rostro longissimo, thorace antice concavo, dilatatissimo serratoque lateribus; tibiis posticis foliaceis, in elytris vitta tenui transversâ, antenuis, pedibus, corporeque infra fulvis. - L. 35 mill., l. ro m. aux ćpaules - Atlas, Ins., pl. XII, fig. 9 .

Cet insecte offre un caractère très-remarquable dans la longueur de son rostre; sa tête est allongée conique, le corselet présente la forme d'une portion de cercle de même épaisseur ; ses cxtémités arrondies et dentées, s'avancent bien au delà de l'insertion de la tête, environ jusqu'à la hauteur des yeux; toute sa partie supérieure présente en outre beaucoup de points enfoneés. Lc reste du corps est allongé, beaucoup plus étroit que le corselet; l'écusson est triangulaire presque équilatéral; les pattes postérieures sont très-développées, les fémurs sont légèrement claviformes, dentés en dessous, les tibias sont foliacés, la foliole ovale sans aucune ćchancrure en dedans, bidentée en dehors. Tout linsecte est en dessus d'un brun rougeàtre avec une ligne transverse jaune au milieu des élytres. La partie inférieure du corps, les pattes, les antennes sont beaucoup plus claires._Brésil, du midi de la capitainerie de Saint-Paul.

ANISOSCÈLE ROUGE, Anisoscelis rubricatus. GuÉr,_Viridi-niger. Thorace, scutello; elytrisque rubris, nigro adspersis. - L. 18 mill., , l. 7 m. -Atlas, Ins., pl. XII, fig. 7. 
Cette espèce appartient au genre Stenocephalus de M. de Laporte ou à celui de Cerbus fondé presque en même temps par M. Hahn. Cependant sa tête est plus large que longue, un peu plus courte que dans les autres Pachymeria que nous avons sons les yeux; la saillie du milieu, qui est formée par le tranchant d'une lame verticale, est un peu moins avancée et les yeux sont plus saillants. Cette tête est brune avec les yeux jaunâtres. Le corselet est de forme triangulaire avec les angles latéraux postérieurs saillants et les côtés droits. Les bords antérieur et postérieur sont jaunâtres; toute sa surface est finement rugueuse, d'un ferrugineux vif tacheté de noir. L'écusson est de la même couleur, triangulaire. Les élytres sont aussi de la mème couleur avec la membrane noirâtre tachée de blanchầtre sale au milieu. L'aldomen est vert noir avec lcs bords rouges. Le dessous du corps, les pattes et les antennes sont d'un vert noir. Les cuisses postérieures sont épaisses, courbées, épineuses en dessous avec un sillon longitudinal en dedans et en delıors. Les jambes postérieures sont un peu aplaties, un peu renflées en dedans et au milieu, et arnées depuis ce point, de denticulations assez marquées au côté interne; les antéricures et intermédiaires ont deux ou trois petites dents au-dessous de leur extrémité.-De Sainte-Catlıerine au Brésil.

ANISOSCÈLE FÉMORÉ. Anisoseclis femoratus. GúR. - Lygaeus thorace serrulato, femoribus posticis incurvis dentatis, tibiisque posticis compressis. Fab. - L. 28 mill., 1. $9 \frac{1}{2}$ m. -Atlas, Ins., pl. XII, fig. 6. Le mâle (sous le nom d'A. Stollii), et pl. XII, f. 8. La femelle (sous le nom d'A. suralis).

Lygaeus femoratus. Fab., syst. rhyng., p. 205, n` 1o, Ent. syst., t. 4, p. г37, no 10.

Nous n'avions pas reconnu cette espèce quand nous avons fait graver notre planche, et ce n'est que depuis peu de temps que, ayant étudié de nouveau le genre Ly'gacus de Fabricius, et aidé d'un grand nombre d'espèces et d'individus, nous avons pu nous assurer que l'individu qui porte sur la planche le nom de Stollii se rapporte parfaitement au Lygaus femoratus de cet entomologiste, et que notre $A$. Suralis n'en est que la femelle. D'après sa description on voit qu'il n'a connu que le mâle dont les cuisses sont très-fortes, courbées, garnies de forts tubercules sur toute leur surface, avec deux grandes épines en dessous, dont l'une est au milieu de la longueur, et l'autre, à près d'une ligne au delà, et vcrs l'extrémité. Dans la femelle, les cuisses postérieures sont beaucoup moins fortes; elles ont cinq épines en dessous; leurs jambes sont largenent foliacées, la membrane occupant presque toute leur longueur extérieurement, et ayant deux dents pen aiguës, tandis qu'au côté interne elle n'occupe que le tiers antérieur et que le reste de la jambe est dentelé. Pour tout le reste, la femelle ressemble au mâle.

Nous avons fait les figures de notre planche d'après des individus provenant de SainteCatherine, au Brésil. Nous en avons reçu d'autres de Tampico, au Mexique, ils sont entièrement semblables aux premiers, mais leurs antennes et lenrs pattes sont d'un ferrugineux un peu plus obscur. 
ANISOSCÈLE A GROSSES CUISSES, Anisoscelis maeromerus. Gúr.-Obseurus, thorace scrratulo, postice. subspinoso. Antennis, pedibusque anticis branneis. Femoribus posticis, clavatis, incurvatis, apice serratis, unispinosis, tibiisque apice subfoliatis. Abdomine basi quadrispinoso-L. 20 mill., $1.6 \mathrm{~m}$.

Cette belle espc̀cc est entièrement d'un brun presque noir en dessus. La tête est courte, un peu plus large que longue, d'un brun moins foneé. Les antennes sont plus longues que le corps, d'un brun ferrugineux, avee le dernier article un peu arqué, plus long que le précédent. Le eorselet est rugueux, finement denticulé sur les côtés, qui sont droits, plus long que large, penché et étroit en avant, avec les deux angles postérieurs aigus mais peu saillants. L'éeusson est strié transversalement, aigu en arrière avec une petite taehe jaurie à la pointe. Les élytres sont un peu plus étroites en arrière. Le dessous du corps et les quatre pattes antérieures sont d'un brun moins foncé que le dessus. Les quatre cuisses antérieures sont même plus pâles à leur base, et lenr extrémité offre cn dessons une assez forte épine; leurs jambes sont simples. Les pattes postérieures sont de la couleur du dcssus du corps, très-arquées vers leur base, rugueuses, ayant une bosse denteléc en dessous vers l'extrémité, et une assez forte dent tout à fait près du bout, Leurs jambes sont eomprimées, un peu dilatées à l'extrémité et extérieurement avec deux dents peu saillantes en dedans et au bout. Les côtés du thorax offrent entre l'insertion des seconde et troisième pattes, deux petites taches blanehes, dont l'antérieure est la plus grande. Les deux premiers segments de l'abdomen portent, de chaque eôté, une forte épine courbée en arrière, et que l'on voit même quand on regarde linnsecte en dessus._Cet insecte entre dans le genre Pachymeria, et vient de Dory, à la Nouvelle-Guinée.

ANISOSCĖLE ABDOHINAL, Anisoscelis abdominalis. GuÉr. - Obscurus; thorace serratulo, subspinoso. Antennis apice flavis. Femoribus posticis clavatis, incurvatis, inermibus; tibiis postieis intus valide unidentatis. Abdomine ferrugineo, basi tuberculis tribus obtusis validis, apice nigris._L. 26 mill., $1.8 \mathrm{~m}$.

Il est plus long que le précédent; ses antennes sont plus courtes que le corps, d'un brun noirâtre, avec le dernier article jaune, un peu plus foncé au bout. Le corselet est rugueux, distinctement dentelé aux bords. L'écusson est rugueux, triangulaire, sans tache au bout. Les élytres sont allongées; la ligne de séparation de leur portion membraneuse est légèrement tẹintée de jaunâtre. Toutes les pattes sont d'un brun foncé. Les quatre cuisses antérieures sont armées en dessous, et à l'extrémité, de deux petites dents ; les postérieures sont très-fortes, courbées à leur base, très renflées, ruguenses, sans dents ni épines en dessous; leurs tibias sont comprimés, un peu arqués en dehors avec une forte dent aiguë en dedans et vers le milieu de leur longueur. Le dessous du corsclet et l'abdomen sont d'un rougeàtre ferrugineux; le premier segment de l'abdomen présente trois gros tubercules transverses noirs au bout. Le milieu du second segment 
concourt à former celui du milieu en s'élevant considérablement; cctte portion est un peu plus eourte et un peu échanerée au bout. - Ce bel insecte, qui appartient au genre Pachymeria de M. de Laporte, vient d'Amboine.

ANISOSCÈLE A ÉLYTRES BLEUES, Anisosceliscocruleipennis.GuÉr.—Corpus aneum; antennis atris, articulo ultimo fulvo. Tiliis quatuor anticis tarsisque favis. Femoribus posticis elongatis, tuberculatis, incrassatis, subtus spinosis. Abdonine lateribus fulvis. - L. 19 mill., $1.5 \mathrm{~m}$.

Cette espèce, que nous rangeons encore dans le genre l'achymeria, commence à avoir des caractères des Nematopus; sa tête est transversale, peu avancée, et ses antennes sont terminées par un article plus long que le précédent; elles sont d'un noir bleu avec le dernier article d'un ferrugineux obseur. Le corselet est finement rugueux, peu élevé en arrière, plus étroit en avant. Bleu foncé ainsi que l'écusson, qui est triangulaire. Les élytres sont de la même couleur avee le côté externe finement bordé de rouge. Les quatre pattes antérieures sont de forme ordinaire; leurs cuisses sont bleues et armées en dessous de deux petites épines; les jambes et les tarses sont jaunes; les pattes postérieures sont bleues avec les tarses seulement jaunes; les cuisses sont très-longues, renflées, rugueuses, épincuses en dessons; les jambes sont simples, un peı comprimées. - Cette punaise vient de Bourou, dans les Moluques.

NÉMATOPE A TÈTE JAUNE, Nematopus flaviceps. GuÉr. - Capite, thorace, vitta, pedibus corporeque infra, luteis; thorace, elytris, scutello, corpore supra, femoribusque posticis, viridi-aneis. - L. 15 mill., 1.4 m. - Atlas, Ins., pl. XII, fig. 10.

La tête est transverse, les yeux très-saillants, les antennes presque aussi longues que le corps; lc corselet est plat trapézoïdal, creısé en gouttic̀re dans son milieu, avee une forte impression transverse à son extrémité; l'écusson est allongé aigu; les fémurs postérieurs sont un peu épineux. La tête, la première partie dı corselet, les quatre pattes antérieures, le commencement des fémurs, les tibias et les tarses postérieurs, et la partie inférieure du corps, sont d'an jaunâtre-fauve; le corselet, l'écusson, les élytres, le corps en dessus, deux bandes le long des segments inférieurs du thorax et les fémurs postérieurs sont d'un vert-doré; je sompconne que lorsque cet insecte est vivant, il y a d'autres parties vertes qui ont disparu; les antennes sont brunes. - Cette jolie espècc a été trouvée à Offak, terre des Papous.

ALYDE A CORNES ANNELÉES, Alydus annulicornis. Guén. - Brunneus, subtiliter luteo-sericeus, antennis pallido-annulatis, corpore lineis maculisque luteis lateribus vittato. - L. 19 nill., 1.3 m. - Atlas, lns., pl. XII, fig. x 1.

La tête est avancée triangulaire, les yeux très-saillants; le corselet est presque carré, épineux à scs angles postérieurs; le corps est très-comprimé ; les fémurs postérieurs, 
renflés sur toute leur longueur, sont dentés en dessous; tout le eorps est brun terne, couvert d'un duvet très-court, jaunâtre; les trois derniers anneaux des antennes sont annellés et jaunâtres. Du rostre partent dcux bandes de la même eouleur qui s'étendent le long de la tête, du eorselet et de l'abdomen jusqu’à son extrémité; sur le mésothorax et le métathorax ces bandes prennent la forme de taches. - D'Offak, terre des Papous.

LEPTOCORISE JAUNATRE, Leptocorisa flavida. GuÉr. - Corpore elongatissime flavidlo, infra pallidiore. - L. I 5 mill., I. 2 m. - Atlas, Ins., pl. XII, fig. 12.

La tète est conique, très-allongée. Le eorselet est plat, presque carré, plus long que large; tout l'inseete est fauve, finement ponetué, avee les parties inférieures du eorps et le eommeneement des trois derniers anneaux des antennes plus pâles, et deux points bruns aux angles postérieurs du eorselet.--De Bourou, aux îles Moluques.

LYGEÉ ROUGE-NOIR, Lygans atrorufus. GứR. - Niger, thorace maculis duabus lateralibus, elytris et abdomine duabus maculis basalibus magnis sanguineis. Elytrortun membrana puncto albo. - L. 9 mill., I. $3 \frac{1}{2}$ m. Atlas, Ins., pl. XII, fig. I3.

Cette petite espèee, d'un noir mat, est eouverte d'un duvet très-eourt. Surr le eorselet sont deux taehes marginales et latérales rouges de sang qui paraissent s'allonger sur la base des élytres; sur les élytres, et dans la même position, on en yoit deux autres, ainsi que des deux còtés de la base de l'abdomen en dessous; on remarque en outre un point blanc sur la membrane des élytres. - De la Nouvelle-Guinée.

LYGÉE A AILES ENFUMÉES, Lygaeus fuscipennis. - Croceus; scutcllo, elytris, pectore, pedibus, antennis oculisque fuscis. - L. I1 I mill., 1. 4 m. - Atlas, Ins., pl. XII, fig. 14.

La tête, le corselet, l'abdomen sont d'un beau jaune de safran. Les antennes, les yeux', l'écusson, les élytres, la poitrine et les pattes sont enfunıés. - Rapporté du Port-Praslin.

LYGÉE DE 'TAITI, Lygaus tä̈tensis. Gú́r. - Castaneus; thorace elytrisque anticè pallidioribus : corpore infra fulvo, rostro, antennis pedibusque infumatis. - L. $23 \mathrm{~m}$., l. $3 \mathrm{~m}$. - Atlas, Ins., pl. XII, fig. 15.

Les eonleurs de eette espèee sont peu tranchées : en dessus elle est d'un brun rougeâtre, plus elair à la partie antérieure du eorselet et à la base des élytres; les parties inférieures du eorps sont fauves, et paraissent d'un rouge assez vif par plaees; la membrane des élytres est jaunâtre et transparente vers l'extrémité; le rostre, les antennes et les pattes sont bruns. - De Taïti.

LYGÉE PÉRUVIEN, Lygceus peruvianus. Guén. - Capite thoraceque posticè croceis; clytris abdomineque luteis; rostro, antennis, thorace anticè, scutello, elytrorum membrana, 
maculis duabus, singulo segmento abdominis infrà, pcdibusque, nigris; subtus vittis maculisque albis. - L. 16 mill., $1.6 \mathrm{~m}$.

Dysdercus peruvianus.-Atlas, Ins., pl. XII, fig. I6.

La tête et la plus grande partie postérieure du eorselet de cet insecte sont couleur de safran; la partie eoriace des élytres ainsi que l’abdomen en dessous sont jaunes; le rostrc, les antennes, l'écusson, la membrane des élytres, la poitrine, les pieds, et deux taehes sur chaque anneau abdominal sont noirs; on voit sous le thorax et l'abdomen plusieurs bandes transversales et quelques taehes blanches. Sa tête est très-bombée sur le vertex, oì je n'ai pas aperçu d'oeelles. - De Payta au Pérou.

RÉDUVE TUBERCULÉ, Reduvius tuberculatus. GuÉr. - Luteus, thorace sex-tuberculato, abdomine foliaceo, suprà viridi-aeneo, reflexo, infrà infumato. - L. 27 mill., I. 5 m. - Atlas, Ins., pl. XII, fig. 17 .

Cette belle espèee, qui appartient au genre Harpactor de M. de Laportc, a la tête cylindrique, allongée, les yeux très-éloignés du eorselet. Celui-ei est partagé en deux parties par une impression transversale; sur la première partie sont deux tubereules droits, et sur la seconde il y en a deux autres au milieu et deux en arrière, vis-à-vis des angles de l'écusson; les angles du corselet sont en outrc terminés en épine mousse; l'écusson est eourt, muni de deux tubercules à la suite l'un de l'autre; l'abdomen est foliacé, relevé droit sur les eôtés, formant en dessus comme une large gouttière où sont couelhées les élytres : tous les pieds sont longs, entièrement fauves. La base des élytres, l'abdomen en dessus et en dessous, excepté la partie anale, sont fortement enfumés; la partie foliacée de l'abdomen est d'un vert bronzé. - Cette espèce remarquable vient de la Nouvelle-Guinée.

RÉDUVE A VENTRE BLEU, Reduvins cyaniventris. GuÉr. - Castaneus, thorace quadritulerculato, abdomine foliaceo, reflexo, viridi-cyaneo-metallico. - $\mathbb{L}$. 2 I mill., l. 4 m. - Atlas, Ins., pl. XII, fig. 18.

La tête est allongée cylindrique; la première partie du corselet est très-courte, bi-épineuse; la seeonde partie est bombée, ayant scs angles terminés en épines mousses, et deux tubercules vis-à-vis des angles de l'éeusson; eelui-ci est armé d'un tubereule placé près de son extrénité. Lialodomen est foliacé, relevé brusquement sur les côtés, formant une gouttic̀re où sont couehées les élytres; tout le corps est d'un brun marron avee l'abdomen d'un beau bleu métallique passant au vert. - Cette belle espèce vient du Port. Praslin ; elle rentre aussi dans le genre Harpactor.

RÉDUVE A ÉLYTRES BLANCHA'TRES, Reduvius albipennis. Guḱr. - Cyaneus, thorace grloboso, nitido. Femoribus basi, segmentis abdominalibus infra, coccineis. Elytris lutcis. - L. 12 à 15 mill., 1.4 à $5 \mathrm{~m}$. 
Son corps, scs antennes et ses pattes sont d'un beau bleu luisant, à l'exception de la moitié antérieure des cuisses, d'une bande transvcrse placéc sur le milieu des quatre premiers scgments de l'abdomen et d'une petite strie placée sous ses bords latéraux, qui sont d'un beau rouge vermillon. Les élytres sont entic̀rcment d'un jaune pâle et ne couvrent pas tout l'abdomen. Le corsclet cst trc̀s-bonıbć, divisé cn quatre grosses bosses par deux impressions profondes qui se croisent au nilicu. La tête est petitc, insérée à la partie inféricure du corsclet. - Cette jolie espèce vient de Java; clle fait partie du genre Ectrichodia de M. Serville.

CIGALE A POCHE. Cicada perulata. Gú́r. - Obscure-ferruginea, capite et ihorace albo nigroque variegatis; lateribus abdominis sacco pallido, pulvere argenteo induto. Pediobus favis, nigro maculatis. - L. 35 mill., enverg. 1 I décinı. - Atlas, Ins., pl. X, fig. 5 . et 5 . $a$.

Cettc Cigale cst trc̀s-voisine de la C. Saccata de Fabricius, mais elle en diffère par plusieurs points et surtout par la présence d'une ligne longitudinalc jaune placée au milieu du prothorax; la tête est transversale, deux fois plus large que longue, noire, tachéc de janne; le labre, vu cn dessus, est péu saillant, un peu échancré et jaune au milieu. Les yeux sont saillants, jaunâtres et ponctués de brun. Le prothorax est d'un ferrugineux foncé avec les bords latéraux et postćrieur jaunes. [la de fortes impressions obliques et longitudinales, et les bords qui avoisinent la bordurc jaune sont d'un brun plus ou moins noir, ainsi qu'une bande longitudinale placée au milieu et dans laquelle est inscritc une bande jaune. Le mésothorax est bombé, lisse, terminé en arrière par les élévations en forme de croix qu'on observe aux espèccs de la mème division; il est de la couleur dı prothorax, et il présentc en avant quatre taches noires triangulaires, dont les intermédiaires, qui sont les plus courtes, sont bordécs de ferrngineux jaunàtre ; le milieu offre une tache également noire, transverse, placée en arrière dans l'impression médiane, et prolongée en avant en une pointe aiguë qui n'atteint pas le bord antérieur; les deux impressions postérieures latérales qui contribuent à former les élévations en croix dont nous avons parlé plus haut, sont jaunàtres et garnies d'un fin duvet blanc. Le métathorax est très-pcu visible et couvert de duvet blanc. L'abdomen est noir avec le bord postérieur des segments rouge foncé couleur d'acajou ; il porte de chaque côté une large poche, prolongée en arric̀re jusqu'aux deux tiers de sa longueur, arrondic au bout, d'un jaune pàle et couverte d'une poussière blanche farineuse. Ces poches ont, en dessous, une ouverture ovalaire, oblique, formée supérieurement par le bord postérieur des opercules, qui sont très-peu développés et précédés d'une petite ćpineinsérée près des hanches des pattes postérieures. Les élytres et les ailes sont transparentes avec les nervures d'un brinferrugireux foncé ; la còte est composée de trois nervures; elle est jaunc, jusqu’à son anastomose et au delà du milieu, avec lc bord externe ferrugineux et l'interne noir. Il y a vers le bout de l'élytre aux anastomoses des deux cellulcs externes deux petites taches enfumées pent visibles. Les ailes inférieures sont égalcment transparentes avec les nervures jaunes. Le dessous du corps est jaunâtre saupoudré de blanc; il y a une largc bande noire et longitudinale sous le milieı 
de l'adbomen. Les pattes sont jaunes variées de noir, surtout les antérieures, qui ont les jambes entièrement noires. Nous avons représenté cette cigale, vue en dessous, sous le $n^{\circ} 5$ A. - Du Port-Jackson.

CIGALE VIDÉE, Cicada exhausta. Gú́r. - Pallideflava; abdomine vesiculoso, diaphano, brunneo irrorato, segmentorum margine rhodino. Alis hyalinis, nervulis flavis. Long. 22 mill., enverg. 5 décim. - Atlas, Ins., pl. X, fig. 6.

On ne peut rapprocher cette espèce que de la Cicada vacua de Stoll. (Cic. pl. XII, fig. I 8.) Mais elle en diffère par la taille et par la couleur. Notre cigale vidée est entièrement d'un jaune pàle; sa tête est petite, un peu arrondie en avant, transverse, avec les yeux saillants. Le prothorax est un peu plus large que la tête, élargi brusquement et bordé de rougeâtre en arrière; il a des impressions longitudinales et obliques assez enfoncées. Lc mésothorax est lisse taché de brunâtre; enfin le métathorax est assez grand, échancré en arrière, avec une fossette profonde de chaque côté, dont le bord antérieur est strié et bordé de rose. L'abdomen est gonflé, tramsparent et vide; chaque segment est bordé d'un fin liséré rose et couvert d'un grand nombre de petites taches brunes. Les élytres et les ailes sont transparentes, à nervures jaunâtres. Les opercules du mâle que nous décrivons sont petits, arrondis, légèrement teints de rose et précédés d'une petite épine. Les pattes sont de la couleur du corps.

De Burou aux Moluques.

CIGALE DE EYDOUX, Cicada Eydouxii. Gú́r. - Ferruginea, capite flavo nigroque variegato; prothorace linea longitudinali et limlo laterali flavis. Mesothorace et abdomine maculis latis nigris. Lamellis abdominalibus rubris, latis. Alis hyalinis, maculis brunneis super nervulos. - Long. 4\$ mill., enverg. II décim.

C'est une des grandes espèces du genre; sa tête est transversale, d'un jaune un peu fauve, tachée de marques noires anguleuses. Le prothorax est beaucoup plus large que long, d'un rouge ferrugineux coulcur d'acajou. Son bord postérieur est jaune, et l'on voit au unilieu une ligne longitudinale assez large de cette couleur, laquelle est bordée de noir. Lc mésothorax et le métathorax, réunis, sont également ferrugineux; le mésothorax est lisse; il a, au milieu et au bord antérieur, deux taches noires coniques, larges à leur base, prolongées jusqu'au milieu de sa longueur et arrondies en arrière; ces deux taches sont finement bordées de jaune. En dehors de ces taches, on voit me large raie noire commençant au bord antéricur, descendant jusqu'au bord postérieur, s'arrondissant en arrière, remontant au milieu en une pointe qui va se terminer dans l'espace laissé par les dcux taches du milieu. Le métathorax, profondément creusé, est noir dans ses sillons et jaune sur les parties saillantes. L'abdomen est gros et court, de la couleur dı thorax; le premier anneau est très-grand, presque entièrement noir, à l'exception du milieu qui est rougeâtre. Les suivants sont plus étroits, marqués de larges taches noires qui, dans les postérieurs, forment une bande à leur base. Tous ces 
segments sont plus ou moins garnis d'un duvet soyeux blanc. Le dessous de la tête et du thorax est varié de noir. Les pattes sont également jaunes avec des lignes longitudinales noires aux euisses et les jambes rougeàtres, à extrémités noiràtres. Les lames abdominales sont larges, plates, d'un rouge livide tirant sur le rose : elles atteignent à peu près la moitié de la longueur de l'abdomen, et se recouvrent un peu sur la ligne médiane. Le dessous de l'abdomen est noir luisant. Les élytres et les ailes sont grandes, entièrement transparentes, avec les nervures jaunàtres et ferrugineuses; et celles de la côte des supérieures noires vers l'extrémité. Les petites nervures transversales du premier tiers des ailes supérieures, celles du second tiers et l'extrémité des nervures longitudinales qui aboutissent au bout de l'aile, sont noires avec la membrane qui y touche légèrement enfumée.

Cette bellc espèce vient du Port-Jackson, à la Nouvelle-Hollande. Nous l'avons dédiée à notre ami M. Eydoux, chirurgien de la marine, qui a parcouru ces contrées d'une manière si fructueuse pour la science.

CIGALE NOIRE ET VERTE. Cicada atro-virens. Guér. - Viridi-obscura. Capite et thorace viridibns, maculis nigris. Segmentis abdominis viridibus, basi nigra. Primo segmento lata macula laterali flava; secundo macula alba : abdomine infra rubro virescente. Elytris et alis vitreis, nervulis flavis viridibusque. - Long. 24 mill., enverg. 8 eentim.

La têtc et le thorax sont d'un vert clair taehé de noir. On voit sur le mésothorax et de chaque côté une tache noire an milieu de laquelle il y en a une autre d'une couleur rougeâtre. Les segments de l'abdomen sont verts avec une large ljande noire à leur base ; le prenier segment est plus grand et offre une grande tache fauve et triangulaire de chaque còté; le second présente aux mêmes endroits une grande tache blanche formée par un duvet trc̀s-fin. Le dessous de la tête et du thorax est d'un vert jaunâtre tirant sur le fauve dans quelques endroits; les pattes sont plus verdàtres. Les lames abdominales sont peu étendnes, de la couleur du thorax. Le dessous de l'abdomen est fauve, garni d'un duvet argenté peu serré: Les élytres et les ailes sont transparente, longues et étroites, à nervures d'un jaune fauve, à l'exception de la moitié antérieure de la côte qui est d'un vert d'herbe; cette conleur verte s'étend même un peu à la base des ailes et forme à cet endroit une petite tache. Cette cigale vient de Java.

CIGALE COULEUR DE SAFRAN, Cicada crocea. GuÉr. - Flava. Capite brunneoobscuro, maculis rubris. Thorace flavo; prothorace et mesothorace duabus maculis latis rubro-brunneis. Abdomine croceo, colore obsoletiore infra. Pedibus flavis, tibïs tarsisque nigris. Elytris et alis hyalinis, nervulis flavis; anticis cum membrana ad nervulas proximata flavo-pallido colorata. - Long. 23 mill., enverg. 5 centim. et demi.

La tête est transversale, très-large et très-courte, avec le chaperon avancé au milieu et triangulaire. Elle est d'un brun foncé et tachée de rougeâtre. Le prothorax est assez 
grand, avec de fortes impressions latérales obliques; il est d'une couleur jaune d'or, et offre de elaque côté une grande tache arrondie d'un brun rougeàtre. Le mésothorax et le métathorax sont jaunes; le mésothorax est presque entièrement occupé par deux très-grandes taches brun rouge, et l'on voit eette mème couleur an milieu de la saillie postérieure produite par le métathorax. L'abdomen est d'un bel orangé vif ; on voit sur la ligne médiane une série de taches brunes peu foncées. Le dessous du thorax est jaune pâle, ainsi que les lames abdominales, qui sont très-petites; les pattes ont les hanches et les cuisses jaunes avec les jambes et les tarses bruns. Le dessous de l'aldomen est d'un orangé plus pâle que le dessus. Les élytres et les ailes sont transparentes à nervures orangées : leur basc est tachée d’orange vif. Les élytres sont légèrement plissées en travers, et leur membrane est tachée, près de chaque nervure, d'une teinte jaune safran transparente.

Cette espèce, qui est assez voisine de la cicada splendidula de Fabricius, vient du Bengale.

CIGALE A COL TACHÉ, Cicada maculicollis. GuÉn. - Ferruginea. Prothorace maculis duabus flavis, brunneo bifasciatis. Mesothorace nigro maculato. Corpore subtus pallidiore. Elytris et alis vitreis, nervulis obscure ferrugineis. - Long. 24 mill., enverg. 6 centim. et demi.

Elle est entièrement d'un rouge ferrugincux foncé, couleur d'acajou. La tête est transverse, avec les yeux jaunes et quelques taches de cette couleur sur le front. Le prothorax offre de chaque côté une grande tache jaune traversée obliquement par denx raies brunes. Le mésothorax a quelques taches nébuleuses noires, et, dans deux légers sillons latéraux, deux faibles raies jaunes produites par un léger duvet. L’abdomen est d'un ferruginetix un peu plus clair avec des traces d'un duvet jaune. Le dessous est un peu plus pâle, avec un duvet assez abondant d'un jaune pâle chatoyant. Les lames ventrales sont très-petites, arrondies. Les pattes sont de la même couleur. Les élytres et les ailes sont transparentes, à nervures de la couleur du corps.

Cette espèce, très-bien caractérisée par les taches de son prothorax, se trouve au Bengale.

CIGale Thalassine, Cicada thalassina. Peren.

Cicada thalassina, Perch., Genera des Insectes, par Guérin et Percheron, ${ }_{\mathbf{1}}^{\text {er }} \operatorname{liv}_{\text {. }} \mathrm{r}^{\circ} 5$, Hémiptères, pl. 2.

Cette belle cigale offre l'aspect d'un papillon, à cause de la distribution de ses couleurs. Voici comment MI. Percheron la décrit : "D'un noir peu intense; bord postérieur du prothorax, une tache tridentée sur le mésothorax et deux latérales, verdâtres; les yeux et la partie avoisinante dc la tête, le rostre, d'un fauvc foncé. Ailes supérieures jaunâtres, ternes avcc les nervures vertes; l'extrémité de l'aile est largement bordée de noir, et l'on voit cn outrc une bandc transverse sur son lisque, et une plus courte près de 
l'extrémité du jaune; les ailes inférieures sont d'un bleu pâle, avec le dernier tiers noir velouté et un point bleu au milieu. "Elle vient des Indes orientales, du Bengale et de la côte du Malabar.

CIGALE DE DUVAUCEL, Cicada Duvaucelï. Guén.

Cicada Duvaucelii, Guérin, Iconographie du règne animal, Insectes, pl. 58, fig. I.

Cette espèce vient se placer près de la précédente, à cause de scs conleurs et deleur distribution; son corps est noir, taché de vert et de rouge en dessus, et entièrement rouge dessous. Les pattes sont annelées de rouge et de noir. Les élytres sont d'un vert jaunàtre transparent, avec la côte et une large bordure à l'extrémité brunes. Les ailes inférieures sont d'un bleu très-léger, avec le bout également brun.

Cette jolie cigale vient de Sainte-Catherine, au Brésil, de la province des Mines, et mêmc des frontières du Paraguay.

\section{Genre APHÈNE, Aphcena. Gú́r.}

Ce genre est fondé avec une partie des Lystra de Fabricius; le nom d'Aplicena

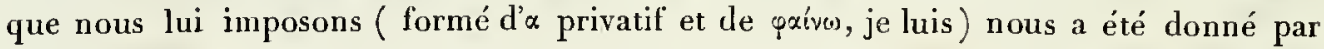
M. Serville, qui avait formé sous ce nom et dans sa eolleetion une division composée de ces insectes et de quelques lystres : voici les caractères que nous assignons à ce genre :

Antennes ayant leur second artiele ovalaire, plus long que large, arrondi au bout, fortement granuleux, avec la soie insérée au côté extérieur de cet article, et non à l'extrénité; cette soie précédée d'un petit article obconique peu allongé. Deux yeux lisses placés un peu en avant et au-dessous des yeux, entre eux et les antennes. Front quelquefois terminé par un petit prolongement dirigé en arrière; espaee compris, à la hauteur des yeux, entre la naissance du frout et la naissance du rostre, plus long que large, aplati et caréné. Labre grand, un peu en forme de cœur. Bec long, de trois articles, atteignant la base des pattes postérieures. Élytres moins larges que les ailes, beaucoup plus longues que larges, ayant une coloration différente. Pattes allongées, épineuses, propres au saut. Prothorax un peu moins larges que le mésothorax, trèspeu échaneré au bord antérieur. Abdomen aplati.

APHÈNE REMBRUNIE, Aphcena fitscata. GuÉk.-Brunnea; basi elytrorum et alarumn viridi, alis pallidis; metathorace supra, thorace omnino infra, punctis duobus in singulo segmento abdominis albis. _ L. 15 mill., enverg. 42 mill. — Atlas, Ins., pl. X, fig. 7 .

Elle est presque entièrement d'un brun roussâtre avee quelques parties vertes. La tête est petite, brune, avee le front prolongé en arrière par une petite saillie en forme de rhombe, carénée sur les bords et au milieu, et représentant assez bien un fer de lance; les yeux sont plus pâles. Le prothorax et le nésothorax sont bruns; le mésothorax offre une petite carène médiane et deux carènes latérales peu élevées. Le métathorax est assez 
grand, brun et couvert d'une substance farineuse blanehe. Les premiers segments de l'abdomen sont bruns, saupoudrés de blane; les quatrième, cinquième et sixième sont bordés en arrière de vert; tous ces segments ont de chaque côté une petite tache blanche. Le dessous est brun avec le thorax saupoudré de blanc. Les pattes sont brunes. Les élytres sont brunes, presque opaques, avec les nervures d'ın brun plus foncé; leur base est lavée de vert. Les ailes sont d'un brun plus transparent, un peu jaunàtre au milieu, à nervures brunes foncées et à base verte en dessus et en dessous. Cette espèee, à eouleurs tristes, a été trouvée à Dory, dans la Nouvelle Guinée. Nous avons reprèsenté sa tête, vue de face, de profil et en dessus, sous les $n^{\circ} 7$. A. B. C.

APHÈNE $\Lambda$ POINTS NOIRS, Aphena nigropunctata. Gún. - Nigro-brunnea. Capite ct prothorace supra ochraccis. Mesothorace obscuro, marginibus posticis rulris. Abdominc rubro, scgmentis basi mucore albo indutis; subtus fuliginoso stigmatibus albis; ano rubro. Elytris rubro-brunncis, flavescentibus apice; in singulo elytro quatuor punctis rotundatis nigris et macula flavida margine posteriore. Alis rubris, duodecim maculis rotundatis nigris, quinque anticis albis, ct lata macula rotundata nigra, in medio caruleata. - Long. 17 mill. Enverg. 46 mill.

- Cette belle espèce a la tête petite, d'un jaune d'ocre, avec le front arrondi en avant, et une petite erête élevée au-dessus de elıaque cil. Le prothorax est de la même eonleur jaune; il est transverse, avec le bord antérieur sinué, et offrant au milieu une crête longitudinale tranchante et élevée. Les pièces de l'articulation des èlytres sont jaunes. Le mésothorax est d'un brun rougeâtre, triangulaire, avec trois carènes, dont une médiane droite et deux latérales courbées. Le métathorax est d'un ronge vermillon avec une grande tache noire de chaque eôté. L'abdomen est large, d'un beau rouge vermillon vif, avee quelques taches transverses sur les premiers anneaux, qui sont eouverts d'une poussière farineuse blanehe. Le dessous de la tête et du thorax est d'un brun rougeàtre, avec une grande tache blanchâtre entre l'articulation des secondes et troisiènes pattes. L'abdomen est presque noir en dessous, avec une fossette blanche sur le bord de chaque segment. L'anus est rouge. Les pattes sont entièrement d'un brun rougeâtre. Les élytres sont d'un rouge sanguin lavé de jaunâtre au milieu, jaune à la base, et d'un jaune safran un peu sale à l'extrénité : elles offrent six points noirs, ronds et de grosseurs différentes, disposés ainsi, savoir : deux gros points à la eôte, occupant à peu près le unilieu de l'espace; un autre gros point vers l'extrémité et au milieu de la largeur de l'élytre, à l'endroit où commenee le jaune safran de son extrémité; un point à la base de l'élytre, moins limité, presque triangulaire et moins gros; un autre vers le bord postérieur et placé au premier tiers de l'élytre en partant de la base, et uu troisième, le plus petit des six, entre eelui-ci et le gros point noir qui est plaeé vers l'extrénité. Outre ces points on en voit plusieurs autres bien plus petits et dispersés sur tonte la partie rougeâtre. On voit au bord postérieur et vers l'extréuité, presque au-dessous du gros point noir le plus éloigné de la base de l'élytre, une taclıe blan- 
clıâtre, de forme carrée; il y a aussi trois ou quatre très-petits points blanchâtres dans la partie jaune du bout de l'élytre. Les ailes sont grandes, sinueuses an bord inférieur, d'un beau rouge vermillon vif avec l'extrémité noire : cette tache noire offre, dans son unilieu, un grand nombre de petites taches carrées d'un joli bleu outremer. Le bord postérieur des ailes est un peu enfumé, et elles offrent sur le disque une douzaine de points noirs de forme ronde ct de grosseur variée, et trois points blancs placés vers le milieu de leur longueur et accompagnés de quelques petites piqùres blanches. Le dessous des élytres et des ailes est de la même couleur.

Cetre espèce vient de Java.

APHĖNE JOLIE, Aphana pulchella. Guér. - - Brunneo-corticina. Mesothorace obscuriore, Abdomine miniato, segmentis basi mucore albo indutis, flavo infra, nigro adsperso, stigmatibus albis et nigris. Pedibus favo anuulatis. Elytris luridis, nigro multi-notatis. Alis rubris, antice flavescentibus, maculis numerosis nigris et quatuor anticis albis, cum apice lata macula rotundata nigra, in medio cululeata. - Long. 15 mill. Enverg. 37 mill.

Cette espèce est un peu plus petite que la précédente, mais elle lui ressemble beaucoup au premier coup d'œil. Elle en diffère cependant d'une manière bien tranchće par : sa tête et son prothorax, qui ne sout pas jaunes co:nme dans la Nigropanctata, par ses élytres tachetées de petits points noirs irréguliers, et par ses pattes jaunâtres annelées de noir. La tête, le prothorax et le mésothorax sont d'une mème couleur jaunâtre piquetée de gris. Le métathorax et l'abdomen sont d'un bean ronge vernillon; on voit sur le métathorax deux très-petites taches noires, et de faibles bandes noires sur les trois premiers segments de l'abdomen : ces segments offrent aussi des traces de duvet cotonneux blanc. Le dessous de la tête et du thorax est d'un brun jaunâtre assez foncé; on voit du blanc entre l'insertion des secondes et troisièmes pattes. Le dessous de l'abdomen est d'un joli jaune d'ocre piqueté de noir. Chaque segment a sur le bord latéral une profonde fossette noire dont le fond est garni d'une poussière blanche. Les pattes sont brunes, annelées de jaune. Les élytres sont d'un jaune safran un peu sale et demi-transparent, plus jaune vers l'extrémité; elles sont couvertes ll'un grand nombre de petits points noirs parmi lesquels on en voit d'un peu plus grands; elles ont, vers l'extrémité et au bord inférieur, une tache carrće blanchâtre, suivie, à l'angle postérieur et externe, d'une tache brune fondue avec les petits points noirs de l'extrémité. Les ailes sont d'un joli rouge vermillon carminé vers leur naissance, et un peu orangé au milieu et du côté du bord antérieur; leur extrémité offre une grande tache noire marquée au milicu de petits points bleus; leur bord postérieur est un peu enfumé, et leur disque présente seize à dix-sept points noirs presque égaux, et quatre petits points blancs placés dans la partie orangée.

Cette jolie espèce, qui ressemble tout à fait à un papillon, a été prise à Java. 
LYSTRE MACULÉE, Lystra macnlata. Guér. - Ochraceo-lurida. Capite, thorace et elytris nigris, flavo-maculatis. Alis nigris, maculis duabus violaceis basi; punctulis duobus albis versus extremitatem. - Long. 17 millim. Enverg. 43 millim.

Le genre Lystre u'est plus pour nous ce qu'il est dans Fabricius; nous l'avons limité, et nous avons présenté ses caractères dans la partie entomologique du Voyage aux Indes orientales, par M. Bélanger (pag. 459).

La tête de cet te espèee est transverse, avec le bord antérieur arqué, rebordé, noir. Elle est noire avee quatre grandes taches jaunes d'ocre. Le prothorax et le mésothorax sont noirs avec de grandes tachesjaunes arrondies et très-linitées. Le métatlıorax est noir et offre de clıque côté une tache rougeâtre. L'abdomen est jaune avec le premier segment, une ligne étroite sur le second, et de très-petits points près du milieu sur les autres, noirs; les còtés des trois premiers segments sont couverts d'une poussière farineuse blanche. Le dessous de la tête est brun avec les antennes jaunes. Le thorax est mélangé de brun, de noir, de jaune et de blanc. Le dessous de l'abdomen est d'un jaune orangé avec quelques petits points blanes. Les pattes antérieures et intermédiaires sont fauves à leur base, avec l'extrémité des cuisses, les jambes, les tarses noirs, et les genoux jaunes; les postérieures sont jaunes avec les tarses noirs. Les élytres sont noires et eouvertcs de taehes rondes et contiguës d'un beau jaune orangé; ces taches sont tellement rapprochées que la couleur jaune domine, et qu'on pourrait plutôt dire que les élytres sont jaunes tachées de noir. Les ailes sont d'un beau noir, avee deux taches oblongues d'un beau violet à leur base. Le dessous des quatre ailes offre les mêmes couleurs que le dessus, mais elles sont beaucoup plus vives.

Cette espèce vient des environs de Rio-Janeiro, au Brésil.

LYSTRE DE SERVILLE, Lystra Scrviliei. Guén. - Brunnca. Metathoracc, clytris nntice alisque ct abdominis basi subrubris; elytris apice hyalinis. Alis in medio longitudinaliter nigro fasciatis, apice hyalinis. Ablomine infra nigricante, marginc laterali et segmentibus postice ochraceis. -- Long. 22 millim. Erverg. 35 millim. - Atlas, Ins., pl. $\mathbf{X}$, fig. 3.

La tête de la Lystra Serwillei est transverse, un peu arquée, vue en dessus, à bords un pcu carénés, d'un brun couleur de poix; le prothorax et le mésothorax sont de la même eoulenr, un peu ridés et granulés, avee quelques petites carènes élevées. Le métathorax est brun mélangé de vermillon. L'ả̉domen est d'un jaune orangé, taché de vermillon à sa base. Le dessons de la tête et du thorax est brun taché de jaune et de noir, avee lüutervalle entre linsertion des pattes intermédiaires et postérieures blanc. Le dessous de l'aldomen cst noir avec les eòtés largement bordés de jaune. Les pattes sont brunes avee des stries longitudinales jaunes. Les élytres sont rougeâtres à la base, brunes et jaunes au milieu, et transparentes à l'extrémité. Les ailes ont la base d'un beau rouge vermillon; une bande courbe brune au milieu, très-étroite vers le bord antérieur et 
s'élargissant beaucoup en se dirigeant vers la base au bord inférieur; leur extrémité est tout à fait transparente avec des nervures brunes.

La figure $8 \mathrm{~A}$ offre la tête de cette Lystre vue de facc. Cette jolie espèce, que nous avons dédiée à l'un des entomologistes les phus distingués de la capitale, se trouve dans l'île Sainte-Catherine, au Brésil.

LYSTRE PALE, Lystra pallida. GuÉn. - Flavo-pallida. Abdomine rubro, punctulis nigris, infra luteo. Elytris pallidis flavo nigroque variegatis. Alis nigricantibus, lunula apicali vitrea. - Long. 18 millim. Enverg. 40 mill.

La tête est transversale, à bords parallèles et arquućs, d'un jaune pâle et brunâtre, avec le bord du front noir. Le prothorax et le mésothorax sont de la cozleur de la tête: le prothorax a deux petites taches noires au hord antérieur; le mésothorax a deux taches noires doubles au bord antérieur, et deux pctites taches noiresà l'angle aigu qui le termine en arrière. Le métathorax est brun varié de noir et de jaune. L'abdornen est d'un beau rouge vermillon, avec les deux premiers articles tachés de raies noires, et une série de six points noirs sur le bord postérieur des autres segments. L'anus est noir. Le dessous du corps et les pattes sont d'un janne pâle, avec lcs tarses sculement bruns. Les élytres sont d'un jaune pâle avec l'extrémité piquetée de brun, qui laisse des taches róndes et pâles, et la base marquée de taches irrégulières d'un brun foncé presque noir. Les ailes sont brunes avec des taches oblongues plus pàles à la base, et une tache ovale transparente vers l'extrémité; la base des élytres ct des ailes est un peu tachée de rouge : leur dessous est semblablc au dessus.

Cette espèce a été prise au Brésil, près de Rio-Janeiro.

LYSTRE EN DEUIL, Lystra luctuosa. Guér. - Nigra. Aldomine rubro-croceo, punctulis nigris, infra luteo. Genubus pedibusque posticis flavis. In extremitate alarum lunula parvula hyalina. - Long. 6 millim. Enverg. 40 mill.

La tête est d'un brun foncé, transversale, arquce et à bords parallèles. Le prothorax et le mésothorax sont de la mềme couleur, finement chagrinés, avec unc petile carènc lisse au milieu, et des élévations lisses et brunes-rougeàtres sur les côtés du mésothorax, qui produisent au milieu un méplat assez sensible. Le métathorax et le prenier segment de labdomen sont noirs; les autres segnients sont rouges, un peu variés de jaunc, avec chacun six points noirs à la base, assez gros sur les còtés, mais petits au milieu. Dessous de la tête et du thorax noir. Dessous de l'abdomen janne-soufre avec un rang de points de chaque côté, et l'anus noir. Les quatre pattes antérieures noires; les postérieures ayant les cuisses noires, les genoux jaunes, les jambes brunes et les tarses noirs. Élytres d'un noir brư foncé, tachées de rouge à la base, d'un brun plus pâle et rougeâtre à l'extrémité, avec quelques traces de points noirs; ailes d'un brun foncé à taches rouges 
à leur insertion, avee deux taches un peu transparentes à la base et une tache assez petite transparente vers l'extrémité. Dessous semblable, mais un peu plus foncé.

Cette Lystre vient du Brésil.

ANOTIE ROUGE, Anotia coccinea. Gux́r. Coccinca. Rostro basi pedibusque fuvo pallidis. - Long. 4 mill. Enverg. I I mill. — Gućrin, Iconographie du règne animal, Inseetes, pl. 58 , fig. 13 .

Cet insecte est entièrement d'un beau rouge carmin pur. Sa tête est très-saillaute, eomprimée sur les côtés, avcc le front bicaréné en dessus. Les antennes sont grandes, d'un rouge un peu jaunâtre, ainsi que les yeux. Le prothorax est très-étroit sur les côtés, arrondi en avaut vers le nilieu. Le mésothorax est grand, lisse, triangulaire, avec une petite earène peu élevée au milieu. L’abdomen est conique. Le dessous due orps est rouge, avee la base du rostre, les lıanches et les pattés d'un jaune pâle. Les élytres et les ailes sont rouges et sans taches.

Cette espèce a été trouvée au Port-Praslin à la Nouvclle-Irlande.

CIXIE A AILES PALES, Cixius pallidipennis. GuÉr. Flavo-pallidus. In capite macula super oculos nigra; mctathorace maculis et margine posteriore segmentorum abdominis nigris. Elytris hyalinis, pallide-flavis, cum macula brunnea in margine. Alis decoloratis, duabus maculis infuscatis in angulo interiore. - Long. 9 mill. Enverg. 24 mill.

La tête est d'un jaune pâle, avec le bord du front ct une petite tache dans l'angle audessus dcs ycux d'un brun noirâtre. Le prothorax est de la mème couleur, très-étroit sur les eôtés, fortement prolongé au milieu et en avant, et ne laissant voir en dessus qu'un petit rebord de la tête ; le mésothorax est également pâle, fortement avancé en avant, avec une carènc de chaque eôté, se continuant en arc de cercle avec lc bord antérieur, et une autre earc̀ne sur la ligne nédiane; en dedans des carènes latérales on voit une petite bande brune. Le métatborax est pâle avec les parties saillantes d'un noir luisant. L'abdomen est jaune; chaeun des segments a une bordure noire très-étroite sur les eôtés et un peu élargie au milieu. Le dessous et les pattes sont pâles. Les élytres et les ailes sont transparentes, avec les nervures jaunes. Lcs élytres paraissent jaunâtres et plus foneées que les ailes, paree que les nervurcs sont plus serrées : elles ont vers l'extrémité et prc̀s du bord antérieur, une petitc taehe brunc peu arrèlée.

Cette espèee a été trouvée au Port-Jackson à la Nouvelle-Hollande.

CIXIE TRANSPAR ENT, Cixius pellucidus. Guér.--Flavo-viridis. Prothorace carinato, bimaculato, nigro. Abdomine tribus lineis obscuris. Elytris hyalinis, reticulatis; macula marginali fusca ante apiccm, et in alis altera macula in angulo interiorc marginis. - Long. 6 mill. Enverg. 7 nill. Guérin, lconographie du règne animal, Insectes, pl. 58, fig. 4 . 
Cette petite espèce ressemble beaucoup au Cixius panorpapennis, et il est difficile de l'en distinguer au premier coup d'oeil; mais elle en diffère par sa couleur oủ le vert dominc, par ses élytres qui sont bien moins cliargées de nervurcs, et par ses ailcs inférieurcs qui n'ont qu'une seule tache brune à leur angle postérieur interne.

La tête est d'un jaune verdâtre, sans taches en dessus. Lc prothorax est de la neême couleur, très-étroit, caréné an milieu avec-une petite tache noire de chaque côté de la carène. Le mésothorax est grand, d'un jaune verdâtre lavé au milieu de brun roussâttre, avec trois petitcs carènes jaunes. L'abdomen est vert avec le milieu et les côtés noirs; ces taches noires, formant des bandes longitudinales, sont bordées d'une couleur fauve fondue avec le vert. Le dessous de la tête est jaunâtre, tricaréné, avec deux bandes brunes. Le clessous du thorax et de l'abdomen est jaunc pâle taché dc brun. Les pattes sont pâles. Les élytres sont entièrement transparentes, à nervures lorunes très-peu serrées; elles ont, au bord antérieur et près de l'extrénité, une tache brune, quadrangulaire et très-limitée. Les ailes offrent à leur angle postérieur et interne une senle tache noire un peu fondue sur les bords.

Cette espèce a été rapportée dc Java.

CIXIE A ALLES DE PANORPE, Cixius panorpapennis. Gúx. Obscure flavls. Capite tricarinato, apice truncato. Abdomine nigro, quatuor seriebus punctorum et margine inferiore segmentorum, flavis. Elytris et alis reticulis confertis brunneis, macula fusca in margine anteriore. - Long. 4 mill. Enverg. 20 mill.

La tête est d'un janne pàle avec le dessus assez largre, coupé angulairement en avant, et ayant deux larges taches brunes qui occupent presque toute la surface. Le prothorax est jaunàtre, taché de brun. Le mésothorax est fauve couleur d'acajou, avec trois carènes élevées, jaunes, bordécs de noir. Le métathorax est fauve taché de noir. L’abdomen est jaune avec une grande tache noire ct luisante an milieu de chaque segment, et deux taches plus petites et noires de chaque côté. Le dessous de la tête est d'un jaune brun, caréné au milieu, avec la carène bordée de noirâtre, et une raie de la même couleur de chaque còté. Le dessous du thorax et de l'abdomen est jaune varié de noir. Les pattes sont pâles. Les élytres et les ailes sont transparentes, à nerrures brunes; celles des élytres sont très-nombreuses ct très-rapprocliées, ce qui leur donne unc légère teinte enfumée; elles ont, vers l'extrémité et au bord antérieur, une petite tachc brune et ronde, bordée de brun jaunâtrc -pâle et peu limitée. Les ailes ont à leur angle interne deux petites taches nébuleuses.

Cette petite espèce a été trouvée au Port-Jackson à la Nouvelle-Hollande; elle se distingue surtout du C. pellucidus, qui en est très-voisin, par la réticulation beaucoup plus serrée des élytres et des ailes.

RICANIE TRIMACULÉE, Ricania trinaculata. Guér. Brunnea. Singulo elytro maculis tribus hyalinis, duabus in margine anteriore et altera in margine laterali. - Long. 7 mill. Enverg. 20 mill. 
Le corps est entièrement d'un brun foncé coulenr de sépia. Le mésothorax offre trois carènes élevées. La base de l'abdomen est blanchâtre, le dessous est d'un lorun moins foncé avec quelques taches blancliâtres et le bord des segments alsdominaux jamnâtre. Les pattes sont d'un brun jaunâtre pâle. Les élytres sont d'un brun luisant tirant utn peu sur le fauve, avec quelques taches nébuleuses plus foncées; elles ont clacune trois taches transparentes triangulaires nettement limitées et disposées ainsi : une au bord antérieur vers le milieu de la longuteur de l'élytre, l'autre très-près de l'extrémité , et la troisième au bord externe vers son milieu, et ayant la pointe dirigée obliquement en haut. Les ailes sont d'un brun enfumé, un peu transparentes.

Elle vient de Dory à la Nouvelle-Guinée.

RICANIE A AILES VIOLETTES, Ricania iodipennis. GuÉr. -Viridis violaceo-variäa. Elytris viulaceis ; alis pallidioribus. -- Long. 5 mill. Enverg. 16 mill.

La tête a trois fortes carènes; elle est verte sur les côtés avec le nilieu violet. Le prothorax est lisse, vert clair, avcc une bande longitudinale violette au nilieu. Le mésothorax est lisse, faiblement caréné en arrière seulement; son milieu est violet et ses bords sont verts. Le métathorax et l'abdomen sont violets tachés de vert, ainsi que le dessous $\mathrm{du}$ corps. Les pattes sont jaunâtres. Les élytres ct les ailes sont d'un beau violet uniforme, plus pâle aux ailes. On voit sur les élytres de petites taches blanches peu marquées, produites par une poussière blanche. Le thorax et l'abdomen portent aussi des traces de cette même poudre farinense.

De Dory, Nonvelle-Guinée.

RICANIE SPLENDIDE, Ricania splendida. Guér. - Flavida. Capite brunneo, costis tribus longitudinalibus ferrugineis. Thorace brunneo, longitudine costato. Elytris luteolis hyalinis, onnino brunneocircumdatis, cum fascia codem colore, margine anteriore ainnexa, postice dilatatu, rotondata, puncto albo notata. Alis omnino vitreis, pallide branneo-marginatis. Long. 9 mill. Enverg. 24 mill. - Atlas, Ins., pl. X, fig. го.

La tête est d'un brun jaunâtre, bordée de jaune pâle. Le prothorax est brun, trèscourt et en forme de demi-cercle. Le mésothorax est de la mềne couleur, fort grand, tricarèné, à carènes rougeàtres. Le métathorax et l'ablomen sont jaunes en dessus ct en dessous; le dessous de la tête et du thorax est brun avec les bords du fiont, le lahre, les hauches et les pattes, jaunes. Les élytres sont transparentes, d'un jaune clair, avec unc large bordure brune, plus étroite au bord postérieur, et envoyant de la còte un rameau courbe qui vient se réunir à une tache ronde située au milieu, et dans le centre de laquelle on voit une tache farineuse blanclse. Les ailes sont transparentes, légèrement lavées de jaune, avec une tache triangulaire au bord antérieur et le hord externe enfunés.

Cctte jolie espèce vient de Dory, à la Nouvelle-Guinée. Les figures $10 \mathrm{~A}$ et in B représentent sa tète vue de face et de profil. 
RICANIE OCULÉE, Ricania oculnta. Guér. - Fusca. Elytris fuscis subdiaphanis. Ocello nigro, pupilla alla; alis diaphanis infumatis. Labro, corpore supra pedibusque luteis. - Long. 7 mill, Enverg. 23 mill. - Atlas, Ins., pl. X, fig. 9 .

Le corps est brun foncé en dessus, avec le métatliorax ct la base de l'abdomen un peu pâles. Le dessous de la tête et les côtćs du thorax sont noirs, le labre, les pattes et le dessous de l'abdomen jaunâtrcs. Les élytrcs sont brunes, avec unc grande tache près de l'extrćmité noire, au milieu de laquelle se trouve un point blanc farineux. Les ailes sont légc̀rement enfumées et un peu plus claires à leur base.

Cette espècc, qui vient de Dory à la Nouvelle-Guinéc, a étć appelée Flata Io par M. Boisduval, dans le Voyage de l'Astrolabe, Entomologie, $2^{\mathrm{e}}$ part., p. 62 r. Il cite notre Ricania ocellata; ce qui prouve qu'il n'ignorait pas le nom que nous lui avions imposé, sur une planche publièc longtemps avant même que les naturalistes de l'Astrolabe fussent revenus de lcur cxpédition. Nous ne pouvons deviner quelles sont les raisons qui ont déterminé M. Boisduval à prendre un autre nom.

RICANIE BORDÉE, Ricania marginella. GuÉr. - Pallide-flava. Thorace viridi, vittis duabus croceis. Elytris postice arcuatis, viridibus, omnino rubro-marginatis, puncto adnexo in margine posteriore. Alis albis. - Long. 7 millim. Enverg. 20 millim.

Guérin, Icónographie du règne animal, Inseetes, pl. 58, fig. 6. -- Voy. de Bélanger, p. 467 .

Cette jolie espèce ressemble, au premier coup d'œil, à une Pyrale. Sa tête est d'un jaune verdâtre, avec le front élevé en une petite corne conique et peu saillantc. Le prothorax et le mésothorax sont d'un vert frais; ils offrent quatre bandes longitudinales convergentes vers la tête, et quelques taches sur les côtés, d'un orangé vif. Le nétathorax et l'abdomen sont d'un blanc jaunâtre mêlé c!e quelques teintes vertes. Le dessous de la tête, les quatre jambes antérieures et l'anus sont d'un brun pâle; tout le dessous du corps, les quatre cuisses antérieures et les pattes postérieures sont d'un vert très-pâle. Les élytres sont falciformes, c'est-à-dire, que l'angle externe de leur bord postérieur est un peu prolongé en bas, de manière à rendre ce bord postérieur court et concave. Elles sont d'un joli vert trc̀s-frais, coupć par un rćseau de ncrvures de couleur orangée; leur contour est bordé d'un liséré roux et dentelé en dedans, très-mince à la côte et au bord externe, et plus large au bord postérieur; on observe vers l'cxtrémité de ce bord, aux deux tiers de la longueur de l'ćlytre, une petite tache rousse arrondie ct qui tient à la bordure postérieure. Les ailes sont d'un blane laiteux à reflets légèrement verdâtres et bleuâtres.

Cette jolie espèce vient de la Cochinchine.

FLATE PYRALE, Flata pyralis. GuÉr. - Albicans. Capite carinato. Elytris albis, nervuits seu maculis transversis brunneo-variegatis. Alis lacteis. - Long. 8 mill. Enverg. 23 millin. - Atlas, Ins., pl. X, fig. 1 r. 
Cette espèee offre les plus grandes ressemblanees avee ees petites Pyralites grises qui vivent sur les éeorees des arbres. Sa tête est assez saillante, étroite, fortement triearénée, d'un gris-jaunâtre pâle, avee deux larges taehes brunes en dessus. Le protlıorax est avaneé sur la tête au milieu, fortement eomprimé sur les eôtés, de la eouleur de la tête, avee quelques points bruns peu marqués. Le mésothorax est plus large que long, pâle au milien, avee les bords bruns. Le métathorax, l'abdomen, en dessus et en dessous, et les pattes sont d'un blane-jaunâtre pâle. Les élytres sont blanehes, avec les nervures brunes; dans plusieurs parties, l'intervalle entre quelques-unes de ees nervures est taehé de brun, ee qui produit des taches sonvent rangées en portion de eerele, en earré ou en triangle, mais d'une manière si eonfuse qu'il est impossible de faire eomprendre la place qu'elles oeeupent d'une manière nette, par une simple description. Les ailes sont d'un blane laiterx sans taehes.

D'Offak, terre des Papous.

EURYBRACHYS RACCOURCI, Eurybrachys abbreviatus. GuÉr. - Niger : abdomine femoribusque postieis rubris. Elytris maeulâ albâ in medio margints. - L. 5 mill. Enverg. 12 mill.

La tête est très-large, noire, avee les yeux bruns. Le prothorax et le mésothorax sont noirs; le premier est très-étroit, arrondi en avant, eoupé droit à son insertion avee le mésothorax, lequel est très-faiblement triearéné, et dont la pointe postérieure et médiane est jaune. Le métathorax est rouge avee le milieu marqué d'une raie noire. L'abdomen est rouge, avee les pièees de l'anus brunes. Le dessous de la tête, du prothorax et du mésothorax, les quatre premières pattes et les jambes et tarses des dernières sont bruns. Le dessous du métathorax, de l'abdomen, et les euisses postérieures sont rouges. Les élytres et les ailes sont noires, avee les nervures rougeâtres; les élytres offrent au bord externe, un peu avant le milieu de leur longueur, une petite taehe jaune, oblique et en earré long.

Du Port-Jakson, à la Nouvelle-Hollande. 


\section{NÉVROPTĖRES.}

LIBELLULE ÉLÉGANTE, Libellula elcgans. Guér. - Luteo-fusca; antennis nigris; abdomine vittis tribus longitudinalibus nigricantibus; alis rufescentibus, apice hyalinis, in medio flavo-rcticnlatis, stygmatibus sulphureis; pedibus spinis nigris. - L. 38 mill. Enverg. 56 mill. — Atlas, Ins., pl. X, fig. 3.

La tête est d'un jaune sale, avec les yeux un peu plus foncés et les antennes noires. Le corselet est velu, de la couleur de la tête, avec les sutures d'articulation des ailes et des pièces du thorax brunes; il est un peu plus pâle sur les côtés et en dessous. Les pattes sont également jaunes, garnics d'épines brunes sur les côtés : elles ont leur côté interne brun, ce qui les rend de couleurs différentes suivant le côté oủ on les regarde. L'abdomen a les cinq premiers segments jaune pâle, à sutures brunes; les suivants sont d'un jaune plus orangé, et offrent trois lignes longitudinales brunes, l'une sur la ligne médiane, les deux autres sur les côtés. Le dessous est de la couleur du dessus, sans taches. Les quatre ailes sont rousses, avec le milieu jaunâtre pâle, et l'extrémité transparente. Les stigmates sont d'un jaune serin pur. La couleur rousse des ailes appartient à toute la membrane, et la partie plus jaune qu'on observe au milieu est produite seulement par la couleur plus jaune des nervures.

Cette espèce a été trouvée à Amboine.

LIBELLULE APICALE, Libcllula apicalis. GoÉr. - Fusca; alis luteo-fuscis, macula rotundata vitrea adnexa margini exteriori, reticulis fuscis; stygmatibus castaneis. - L. 40 mill. Enverg. 6o mill.

Cette Libellule ressemble presque entièrement à celle que Drury a publiée sous le nom de L. Sophronia (t. II, pl. XLVII, fig. 14), et dont Olivier a reproduit la description dans l'Encyclopédie méthodique; mais il est dit positivement dans cette description, que la L. Sophronia a les pattes noires, tandis que dans notre espèce elles sont jaunes. Nous croyons, à cause de ce caractère, devoir la distinguer spécifiquement.

La tête de notre Libellule est jaune, plus pâle en dessous. Les yeux sont plus foncés, presque bruns en dessus, jaunes inférieurement. Les antennes sont noires. Le thorax est d'un jaune foncé tirant sur le brun en dessus, d'un jaune-verdâtre pâle dessous, sans taches. Les pattes sont entièrement d'un jaune tirant sur le roux, avec un double rang d'épines brunes. L'abdomen est triangulaire, avec une arête aiguë en dessus et sur les côtés. Il est de la couleur du corselet en dessus, plus pâle dessous, avec le bord de chaque segment finement marqué de brun. Les ailes sont d'un jaune roux transparent, à nervures brunes, avec le stigmate d'un brun un peu orangé et une tache arrondie 
et transparente au bout. La tache transparente des ailes supérieures atteint le bord inférieur; celle des secondes ailes est entourée de jaune et n'atteint aucun des bords de l'aile. On remarque vers le milieu de leur longueur, sur le bord antérieur, une petite tache pâle, causée par l'absence de nervures dans l'endroit où la eôte est coudée et anguleuse ; depuis ce point jusqu’à la base de l'aile, la côte offre une teinte un peu plus foncée.

Cette espèce a été prise à Amboine.

LIBELLULE BRAMINE, Libellula bramina. Gún. - Brunnea; capite corporeque flavicantibus infrà; abdomine lineis tribus longitudinalibus, rufo-lrunneis; alis brunneorufescentibus, apice hyalinis, reticulis flavis rubrisque, stigmatibus miniatis. - - L. 40 mill. Enverg. 55 mill.

Cette Libellule ressemble beaucoup dans son ensemble à celle que M. Boisduval a décrite et figurée, dans la partie entomologique du Voyage de l'Astrolabe, sous le nom de L. Manadensis, et nous n'hésiterions pas à penser que c'est la même espèce, si la description et la figure en avaient été faites par Séba, ou par quelque naturaliste de la même époque et aussi peu exact; mais eette deseription sortant de. la plume d'un entomologiste aussi savant et aussi connu que l'est M. Boisduval, doit être admise dans la science, et ne peut me laisser aucun doute sur la validité de mon espèce, qui en diffère par beancoup de traits, comme on va le voir en suivant ma description et en la comparant å celle de la L. Manadensis.

La tête et les yeux sont d'un brun tirant sur le fauve en dessus, et d'un jaune assez pâle en dessous, surtout à la bouche. Le thorax est également brun-rougeàtre en dessus; les flancs et le dessous sont d'un jaune-verdâtre. Les pattes sont d'un brun roux et armées d'épines noires. L'abdomen est triangulaire, brun-rougeâtre en dessus, plus pâle en dessous, avec une carène assez aiguë au nilieu, brune, et une ligne également brune de chaque côté. Les ailes sont d'un beau brun-roussâtre en dessus, avec quelques reflets un peu irisés et une légère teinte jaune au nilieu et vers leur base, produite par des nervures jaunes; toutes les autres nervures qui sont dans leur portion colorée sont d'un rouge vermillon vif. L'extrémité des quatre ailes est transparente, avec les nervures brunes, et les stigmates sont d'un beau rouge vermillon, entourés de fortes nervures noires. La base des ailes et la côte offrent quelques taches plus claires, causées par l'absence de nervures. La portion transparente des premières ailes occupe leur extrémité et ne se prolonge pas au bord postérieur; dans les inférieures, le brun se courbe et laisse le bord de l'aile transparent jusque prc̀s du milieu de son bord inférieur. Le dessons des quatre ailes est un pcu plus foncé, et offre des reflets irisés du violet le plus brillant.

Cette espèce diffère donc de la $L$. Manadensis par la présence de quatre stigmates vermillons et par la forme de la partie transparente des ailes inférieures; dans la figure planche XII de l'atlas de l'Astrolabe, cette portion ne se prolonge pas au bord postérieure de l'aile.

Cette espèce a été prise au Port-Praslin à la Nouvelle-Irlande. 
AGRION AUSTRAL, Agrion australis. Guír. - Nigro-viridis; ore, thorace maculis lateralibus et singulo segmento abdominis basi, flavis; pectore pallido; alis leyalinis, reticulis atris, stigmatibus sulphurcis majoribus quam in cateris speciebus. - L. 36 mill. Enverg. 53 mill.

La tête et les yeux sont noirs' avee la bouehe d'un jaune pâle. Le thorax est noir en dessus, d'un jaune pâle dessous, avee les euisses jaunes en dedans, noires en dehors; les jambes et les tarses sont noirs, garnis d'épines brunes. L'abdomen est minee, cylindrique et assez long ; tous ses segments sont noirs, avee la base, sur les eôtés et en dessous, tachée de jaunitre. Les ailes sont transparentes, à nervures noires, avee un grand stigmate rugueux d'un jaune paille mat, entouré de nervures plus épaisses que les autres, et d'un noir vif.

Cet Agrion a été pris à Offak.

MANTISPE GRANDE, Mantispa grandis. Gォ⿺廴́. - Atro-fusca; femoribus anterioribus latis, transversè rugosis, spinis tibiarum ct tarsorum castaneis, antenuis obscurioribus. Alis angustatis, perlucidis, antice rutilis, apicc obscurioribus. L. 20 mill. Enverg. 49 mill. - Atlas, Ins., pl. X, fig. 4.

C'est la plus grande espèee eonnue du genre; la tête est noire, avee les yeux blanehâtres. Les antennes sont plus longues que la tête et le prothorax, grenues et d'un brun roussâtre. Tout le eorps est d'un noir terne; le prothorax est à peine deux fois plus long que la tête, beaueoup moins large que la tête, plus large en avant, plissé en travers, et formant trois lobes arrondis; le mésothorax et le métathorax sont beaueoup plus larges, égaux entre eux, bombés en dessus. L'abdomen est aussi long que le thorax, plus étroit à sa base, un peu en massue. Les pattes antérieures sont grandes, ravisseuses, avee les articulations et les épines et erochets d'un brun-roussâtre. Le poignet, qui est formé par la cuisse, est granuleux et armé en dedans d'une rangée de fortes épines, dont la première est grande; et les autres plus courtes, inégales; le tarse qui termine la jambe offre eneore les traces de einq artieles, il est terminé par un seul croehet. Les autres pattes sont ambulatoires, de forme ordinaire; leurs hanehes et leurs euisses sont noires, les jambes et les tarses bruns; ees tarses sont terminés par deux larges crochets multidentés. Les ailes sont transparentes, à nervures rousses, lavées de jaune fauve beaueoup plus intense vers la eôte. Leur extrénité est terminée par une taehe brune, fondue et transparente; les stigmates sont de la couleur fauve qui oceupe le bord antérieur.

Cette cspèee vient d'Amboine.

La figure $4 \mathrm{~A}$ représente la base et l'extrémité de l'antenne; $4 \mathrm{~B}$ le bout de la jambe et le tarse de la patte postérieure; $4 \mathrm{C}$ un des erochets de ee tarse très-grossi.

MANTISPE RAYÉE, Mantispa vittata. GuÉR. - Fusca; capite suprà carinato; antennis pallidis, apice nigricantibus; abdomine flavo, vittis lateralibus latis duabus 
aliaque media angusta, suprà et infrì, brunneis; pedibus flavis, femoribus anticis apice intus nigris, prima spina flava apice nigra. Alis hyalinis, stigmatıbus fulvis. - L. Io mill. Enverg. 26 mill.

La tête est fauve, avec les yeux verdâtres et les antenncs deux fois plus longues qu'elle, jaunes, fauves à la base et brunes ì l'cxtrémité. Le prothorax est près de trois fois plus long que la têtc, plus étroit, élargi en avant, rugueux et un peu ridé en travers, jaune, avec une large bande fauve de chaque côté. Le mésothorax et le métathorax sont d'un fauve brunâtre en dessus, avec deux raies longitudinales jaunes; ses flancs et le dessous sont jaunes; l'abdomen cst un peu rétréci à la base, rugueux, jaune, avec une ligne longitudinale assez étroite au milieu et une bande très-large de chaque côté, d'un brun un peu fauve. Les pattes antérieures sont ravisseuses, jaunes. Les cuisses ont une grande tache noire occupant tout le còté extérieur, depuis la grande épine du nilieu jusqu'à l'cxtrémité. Les autres épines sont courtes et inégalcs. Les quatre pattes postérieures sont minces et jaunes; leurs tarses sont terminés par de petites pelotes et deux crochcts simples. Les quatre ailes sont transparentes, très-luisantes, très-légèrement teintes de jaune dans lintervalle des nervures qui sont noiràtres; le stigmate est fauve, très-prolongé en arrière et confondu avec la nervure sous-costale qui est très-forte.

Cette Mantispe vient du Port-Jakson.

\section{HYMÉNOPTERRES.}

ICHNEUMION DE GRAVENHORST, Ichneumon Gravenhorstï. Guér. - Niger opacus; segmenibus abdominis dorso sejunctis, primo segmento rubro-obscuro; alis brunneis, macula media rotundata flava. - L. 16 mill. Enverg. 32 mill. - Atlas, Ins., pl. VIII, fig. 6 .

La tête, les antennes et les yeux sont noirs; le vertex porte trois gros yeux lisses jaunes. Le corselet est noir, globuleux, ovalaire, avec un enfoncement séparant le mésothorax du métathorax; le bord postérieur du premier et la moitié postérieurc du second sont d'un rouge sanguin. Les ailes sont demi-transparentes, d'un brun-jaunâtre plus pâle vcrs l'extrémité; les supérieures ont au milieu une tache jaune de forme ronde et touchant à la còte. Le dessous du corselet est noir, aplati au milieu. Les pattes sont noires. L'abdomen est allongé, à segments étranglés à leur base, ponctués, aplatis en dessus. Le premier est rougeâtre, un peu pédiculé, à pédicule bicaréné, avec le bord postérieur trilobé; les autres sont noirs. Le dessous est d'un noir brun. - Mâle.

Cet Ichneumon a été trouvé au Brésil, dans lî̉le de Sainte-Catherine. 
PIMPLA CEINTE, Pimpla cinctator. Gún. - Nigra; capite luteo; thorace pedibusque quatuor anticis ferrugineis; abdomine fasciis quinque flavis, primo segrnento ferrngineo; antennis, pedibus posticis et oviducto nigris; alis nitidis brunneis. - L. I5 nill. Enverg. 26 mill. - Atlas, Ins., pl. VIII, fig. 5.

Il est assez voisin du Pimpla crenator de Fabricius. La tête est fauve en dessus, jaune devant et dessous, avec les yeux grands et noirs. Les antennes sont de la longueur du corps, filiformes, d'un roux brun plus foncé vers l'extrémité. Le corselet est oblong, lisse, bossu et arrondi en dessus, entièrement d'un rouge brique luisant. Les quatre ailes sont demi-transparentes, d'un brun-jaunâtre à reflets dorés, avec les nervures brunes; les supéricures ont, au milieu et touchant à la côte, une tache un peu plus pâle. Les quatre pattes antérieures et les hanches des postérieures sont d'un rouge brique. Les pattes postérieures sont d'un beau noir. L'abdomen est d'un noir vif et velouté en dessus, à l'exception du premier segment qui est bicaréné et rougeâtre à la base; tous ses segments sont ponctués et largement bordés de jaune doré. Le dessous est jaune pàle avec deux lignes latérales de points oblongs noirs. Les filets de l'oviducte sont de la longueur de l'abdomen, noirs.

Il vient du Port-Praslin, à la Nouvelle-Irlande.

JOPPE PEINTE, Joppa picta. Servilue. - Nigra; ore, fronte, pedibus anticis, in thorace numerosis maculis et sex macnlis abdominalibas tarsisque posticis, flavis; abdomine ferrngineo; alis flavescentibus apice brunneis.

Joppa picta. Senv., Guér. - Iconogr. du Règne animal. Ins., pl. IXV, fig. 7. L. 17 mill. Enverg. 33 mill.

Le caractère que Latreille assigne à ce genre, dans son Règne animal, ne nous semble pas exact, lorsqu'il dit que les Joppes séloignent des Ichneumons et genres suivants par les antennes notablement élargies ou épaisșies avant le bout; car ce caractère n'existe que dans le mâle, du moins pour l'espèce dont il est question ici, et que nous avons représentée darıs notre Iconographie. Lindividu qui nous a été prêté par MI. Serville avait les antennes très-manifestement renflées vers le bout, et se rapportait parfaitement au signalement donné par Latreille; mais celui que nous avons actuellement sous les yeux, quoique identiquement semblablc, porte des antennes tout à fait filiformes et effilées vers le bout, sans la plus légère trace de renflement. Il nous semble que le caractère employé par Fabricius, la considération des palpes qui ont le troisième article sécnriforme et les trois suivants filiformes, servirait mieux à caractériser cc genre, en s'appliquant aux deux sexes. Quoi qu'il en soit, notre insecte appartient bien au groupe des Joppa de Fabricius; sa tête est noire en dessus avec le bord postérieur, le front et les parties de la bouche jaunes. Les antennes sont noires, filiformes, presque de la longueur du corps, avec le premier article jaune en dessous. Les palpes sont jaunes, longs, avec le troisième article sécuriforme et les trois clerniers minces, bruns. Le corselet est ponctué, noir, avec deux lignes longitudinales au prothorax, et plusieurs taches carrées aux , 
segments suivants, jaunes. Les côtés et le dessous sont jauncs tachés dc noir. Les ailes sont transparentes, jaunâtres très-pâles, à reflets métalliques dorés très-luisants imitant une lame de talc, et ayant leur extrémité brune. Les quatre pattes antérieures et les hanches des postérieures sont noires en dessus, et jaunes en dessous. Les postérieures sont noires, avec le dessous ct l'extrémité du trochanter, la base de la jambe et les tarses jaunes. L'abdomen est ovalairc, attaché au thorax par un pédicule assez allongé, un peu aplati en dessus, à segments étranglés à leur suture, finement striés en long, d'un fauve foncé couleur de bois d'acajou, avec une tache jaune de chaque côté et près du bord postèrieur des trois premiers segments. Le cinquième segment est tronqué carrément ell arrière, avec une épine assez forte de chaque côté en dessous et aux angles postérieurs externes. Le dessous est jaune avec un rang de points oblongs noirs de chaque còté.

Ce bel insecte a été trouvé au Brésil.

BRACON TRICOLORE, Bracon tricolor. Guér. - Niger; capite et abdomine infrà flavis; thorace pedibusque quatuor anterioribus rubris; alis brunneis, obscurioribus basi, lunula hyalina in nedio; oviducto longissimo. — L. I4 mill. Enverg. 26 mill.

Ce joli Bracon a quelques rapports avec ceux que Falbricius a nommés femorator et defensor. Sa tête est d'un jaune doré avec les yeux, les antennes et l'extrémité des mandibules noiràtres. Le corselet est lisse, luisant, bossu en avant, avec deux faibles impressions en dcssus; il est d'un rouge fauve dessus et dessous avec le métathorax seulement noir. Les ailes sont d'un brun noirâtre plus foncé à la base; les supérieures ont une petite strie transparente et transversale au milieu. Les quatre pattes antérieures sont rouges et les postérieures noires. L'abdomen est noir, luisant, allongé, plus étroit à sa base, et terminé en pointe. Ses segments sont finement ponctués; le second offre en dessus des sculptures anguleuses, et les derniers sont un peu pâles à leur insertion. Le dessous de l'abdomen est jaunâtre. L'oviducte est plus de deux fois plus long que le corps, très - mince et noir. - De Dory, Nouvelle-Guinée.

BRACON ÉPINEUX, Bracon spinator. GuÉR. - Rufus; thorace spina collari recta; abdominis dorso strigoso, duobus segmentibus ultimis postice trispinosis, segmento apicali favo, postice unispinoso; antennis tarsisque posticis fuscis. Alis lutescentibus, apice fuscis. - L. I I mill. Enverg. 24 mill.

Cette espèce est fort curieuse à cause des épines dont elle est armée; elle ressemble assez à l'espèce nommée armator par Fabricius, mais elle en diffère par la couleur de l'abdomen, des ailes et des pattcs. Sa tête est d'un rouge pâle, très-petite, portée sur un cou étroit bien distinct, quoique assez court; les yeux sont grands, ovalaires, noirs. Les antennes sont de moitié plus longues que le corps, filiformes et noires. Le corselct est d'un rouge pâle en dessus et en dessous, très-rétréci en avant, bossu et élevć au milieu. Le prothorax est très-court, en forme de collier; sa partie antérieure est étroite, tronquée carrément pour recevoir lc cou, il est armé, aux angles antérieurs de cette tron- 
eature, de deux tubereules spiniformes assez saillants, et au milieu, près de son insertion avee le segment suivant, d'une forte épine droite, dirigée en haut. Le mésothorax est beaueoup plus grand et plus large, avee deux sillons en avant, qui eireonserivent trois bosses lisses, et une autre hosse en arrière entourée de gros points enfoneés. Le métathorax est transverse, tronqué earrément en arrière, avee les angles postérieurs terminés chaeun par une épine saillante et tronquée au bout. Les ailes sont jaunes, transparentes, avee le bout brun; la moitié du point épais et une taehe située au milieu de l'aile supérieure, et touehant la eôte, sont d'un brun plus foneé. Les pattes sont de grandeur moyenne, rouges, avee l'extrémité des jambes et les tarses des postérieures bruns. L'abdomen est rouge pâle, sessile, plus large que le eorselet, ovale-oblong, pointu en arrière; ses segments sont finement ridés dans le sens de la longueur; le seeond offre une petite bosse de ehaque eôté et en arrière, les troisième et quatrième ont aux angles postérieurs une forte épine dirigée en arrière, et au bord postérieur, au milieu, une épine plus eourte de la foree de eelles du deuxième segment; le-dernier segment est jaune, triangulaire, et terminé en une pointe aiguë au milieu. Le dessous est eoneave; on voit avant l'anus une forte pointe : l'oviduete est très-eourt, et ne dépasse pas la pointe du dernier segment, sous laquelle il est eaché.

Ce eurieux Braeon qui, par la petitesse de sa tête, pourrait eonstituer une division dans le genre, a été trouvé au Bengale.

BRACON VOYAGEUR, Bracon viator. GuńR. - Ruber; antennis brunneis corpore longioribus; thorace lcevigato, antice valdè attenuato; abdomine lavigato, duobus primis segmentis suprà scalptis; oviducto brevi, setis lateralibus nigris; alis brunneis pallidioribus basi, stigmate magno, ovali, favo-aurulento, nigro-marginato. - L. I6 mill. Enverg. 34 mill.

C'est une des grandes espèees de ee genre. Tout son eorps et ses pattes sont d'un rouge foneé vineux eouleur de bois d'aeajou. La tête est petite, globuleuse, avee les yeux pâles. Les antennes sont un peu plus longues que le eorps, fliformes, brunes. Le thorax est allongé, bombé au milieu, très-rétréei en avant et beaueoup moins en arrière, lisse, luisant. Les ailes sont brunes, demi-transparentes avee la base plus pâle. Le stignıate ou point épais des supérieures est grand, ovalaire, d'un jaune d'or; il y a eontre la eôte, en avant et en arrière de ee point, une petite taehe noirâtre fondue. Les pattes sont de grandeur moyenne. L'abdomen est assez long, ovalaire, étroit à sa base, terminé en pointe; les deux premiers segments offrent des élévations longitudinales produites par des sillons fortement ponetués, les autres segments sont lisses et trèsluisants. L'oviduete est de la longueur de l'abdomen, avee le filet intermédiaire rouge et les latéraux noirs et velus.

Ce Braeon vient du Brésil. 


\section{Genre TRACHYPÈTE, Trachypetus. GuÉR.}

Ce genre, suivant la méthode de Latreille, présentée, en 1829 , dans la dernièrc édition du Règne animal (p. 289), appartient à la troisième et dernière division des Ichneumonides, celle qui comprend des espèces à abdomen demi-sessile, à palpes labiaux de quatre et à palpes maxillaires de six articles; il se range dans la premièrc section de ce groupe, parmi ecux qui ont les mandibules bifides ou éehanerées, et qui forment les genres Helcon, Sigalphus et Chelonus. Il se distinguc des deux premiers par son abdomen, ne préscntant quc deux segments en dessus, et des Chelonas, parce quc ceux-ci ont l'abdomen d'unc sculc piècc; on doit done le placer' entre les Sigalphus et les Chelonus, et voici lcs earactères que nous lui assignons:

Antennes sétacées, très-longucs, composées d'un grand nombre d'articles, insérées sur le front entre les yeux et à la même hauteur, filiformes, ayant le premier article assez fort, un peu globuleux, le second très-petit, le troisième eylindrique de la longucur des deux premiers, les suivants égalenent cylindriques, mais allant en diminuant de longueur jusqu'au premier quart, où ils sont courts et eonservent la même forme jusqu'au bout.

Labre inséré dans une faiblc échancrure du chaperon, arrondi en avant, formé de deux lames superposées; la première cornée épaisse, vclue en avant; la seconde attaehée sous cclle-ei, membraneuse, rebordée sur les côtés, prolongée en avant en une pointe qui dépasse notablcment le labre.

Mandibules saillantes, crochues, un peu plus épaisses et bidcntées au bout, cachées en grande partie sous le labre, quand elles sont fermées.

Mâchoires formant unc espèee de bec avec la lèvre inférieurc, couchées sur elle, allongées, courbées en dehors, tcrminécs par un lobe đemi-cornć, ovalaire, cilié.

Palpes maxillaires insérés sur le dos des mâchoires, deux fois plus longs que les labiaux, de six articles filiformes presque égaux, à l'exception du quatric̀me qui est un peu plus long que le cinquic̀me.

Lèvre inférieure cornée, tubuleuse, terminée par deux paraglosses arrondies, formant une échancrure au milieu.

Palpes labianx insérés presque au nilieu de la longueur de la lèvre, dćpassant à peine les paraglosses, composés de quatrc articles filiformes ct égaux entre eux.

Tête de grandcur moycnne, dc formc carrée, avec les anglcs arrondis, plate en avant, attachéc immédiatement au corselet, sans prolongement postérieur en forme de cou; yeux saillants, ovalcs, plaeés sous les angles antćrieurs et supérieurs; trois yeux lisses sur lc vertex. - Thorax bossu, assez gros, rétréei en avant et en arrière. - Ailes supérieurcs ayant une cellule radiale grande, triangulaire, ct trois eellules cubitales; les deux premic̀res quadrangulaires, allongées et égales; la troisic̀me très-grande, occupant tout le sommet de l'aile. Trois ccllules discoildales; la premicre ct la seconde presque égales, quarlrangulaires, placées au-dessous l'unc dc l'autrc; la troisième trc̀s-grande, crminéc par lc bord postérieur dc l'aile. - Abdomen claviforme, ne paraissant com- 
posé que de deux segments; le premier allongé, étroit, un peu élargi en arrière; le second ovalaire, bombé en dessus, concave en dcssous, avec l'extrémité terminéc par un faible prolongenient sillonné vaguement en travers et tronqué au bout. - Pattes allongées. 'Tarses de grandeur moyenne; une pelote entre les crochets du dernier article.

TRACHYPÈTE EN MASSUE, Trachypetus clavatus. Gú́R. - Nigro-cyaneus; antennis longissimis, mandibulis et antennis basi, metathorace et primo segmento abdominis pedibusque ferrugineis; alis flavis apice nigro-brunneis. - L. 17 mill. Enverg. 35 mill. Atlas, Ins., pl. VIII, fig. 7 .

La tête est rugueuse, d'un noir vif à reflets bleus; les yeux sont blanchâtres; les antennes ont presque deux fois la longueur du corps; elles sont d'un brun de plus en plus foncé vers l'extrémité, a vec le quart antérieur ou les premiers articles fauves. Les mandibules sont fauves avec l'extrémité noire. Le prothorax et le mésothorax sont velus, d'un noir luisant à reflets bleus, tant en dessus qu'en dessous; le premier est assez grand; il offre trois bosses élevées, lisses, dans l'intervalle desquelles on voit de gros points enfoncés et allongés; le mésothorax est fortement rugueux, avec une bosse élevée en pointe au milieu. Le métathorax est velu, fortement rugueux, rouge en dessus et noir en dessous. Les ailes sont d'un jaune fauve très-luisant et transparent, avec l'extrémité brune ct les ncrvures ronssâtres. Les pattes sont assez fortes, cylindriques, d'un jaune fauvc, finement velues. L'abdomen est claviforme en arrière, le prenier segment est ponctuć, un peu sillonné au milieu, d'une couleur fauve; le second est deux fois plus long, finement ponctué à sa base, très-lisse et luisant au milieu et en arrière, d'un beau noir violet en dessus et en dessous.

Ce magnifique hyménoptère a été trouvé dans les environs du Port-Jakson, à la Nouvelle-Hollande.

FOURMI MAIGRE, Formica macra. Guér. - Elongata, rufescens; antennis longis, favis, articulo primo rufescente; ore flavo; pediculo elongato; abdomine parvo, brunneo; pedilus gracilibus. - L. Io mill. Larg. au thorax I mill. - Atlas, Ins., pl. VIII, fig. I. - Individu neutre.

Cette espc̀ce appartient à la famille des Atomes, et vient se placer près de celle que Latreille a nommée Formica longinoda (Hist. nat. des Fourmis, pag. 184, pl. XI, fig. 72). C'est la plus grande espèce connne de cette famille : śa tête est globuleuse, d'un fauve brunàtre, avec la partie antérieure et les organes masticateurs jaunes. Le labre est inséré dans une grande échancrure dı front, il est arrondi en avant. Les mandibules sont trèssaillantes, dentelées au côté interne et terminées par une pointe crochue brune. Les antennes sont dc la longueur du corps, insérées ell avant de la tête, près du bord qui donne attache au labre; leur premier article est un peu inoins long que les suivants pris ensemble, d'un roux pâle; les autres sont jaunes, filiformes, et un peu plus épais vers l'extrémité. Les yeux sont tachés de brun. Le prothorax est plus long que les deux autres segments du thorax; il est renflé au milieu, très-étroit en avant et en arrière, 
élevé et un peu bossu au milieu et en dessus. Le métathorax et le mésothorax forment un second nœud plus eonrt que le précćdent, assez renflé; ee eorselet est d'un fanve brunâtre. Le pédieule de l'abdomen est de la même couleur, allongé, très-étroit à sa base, un peu renflé en arrière, brusquement rétréci ensuite, pour donner attache à l'abdomen qui est globıleux, un peu plus brun. Les pattes sont très-longues, grêles, d'un fauve pâle. Les crochets des tarses sont forts et eroehus.

Cette espèee grêle a été trouvée à Offack. Nous l'avons représentée grossie, fig. I A, et nous donnons sa tête vue de faee, fig. I $\mathrm{B}$.

FOURMI A VENTRE NOIR, Formica nigriventris. Gúr. - Fulva; abdomine oculisque nigris; antennis longissimis; thorace elongato angustato; squama rotundata elevata; pedibus longissimis. - L. г nı. Larg. au thorax 1 m. 1/2. - Atlas, Ins., pl. VIII, fig. 4. - Individu neutrc.

Cette jolie espèee est bicn earaetérisée par la eouleur de son abdomen. Sa tête est allongće, fauve, avec les yeux et l'extrémité des mandibules noirs. Les antennes sont fauves, plus longues que le eorps. Le thorax est fort loug, fauve, lisse et étroit, sans étranglement notable au milieu. Le pédicule de l'abdomen est formé d'une petite éeaille fauve, relevée, épaisse, arrondie et tronquée en haut; l'abdomen est ovoïde, un peu effilé au bout, d'un noir velouté. Les pattes sont très-grandes, fauves.

Cetfế fourmi a ćté prise au Port-Jakson; elle est figurée grossie et de profil, fig. $4 \mathrm{~A}$. La fig. $4 \mathrm{~B}$ offre la tète vue de faee et très-grossie.

FOURMI SOYEUSE, Formica sericata. Gúr. - Nigra lutescente-sericea; thorace cubico, antice bispinoso. Squama bispinosa. - L. 1o mill. Larg. au thorax 2 mill. Atlas, Ins., pl. VIII, fig. 2. - Individu neutre.

Cette espèce est extrêmement voisine des Formica relucens et hastata de Latreille, mais elle en diffère par le pédieule de l'abdomen, qui n'est armé que de deux ćpines, tandis que eelui des deux espèees eitées cn a quatre. La tête est noire, eourte, presque ovale, de la longueur du corselet, avee le front avaneé, portant au milieu deux petites carènes saillantes, an côté extérieur desquelles sont insérées les antennes. Les yeux sont situés en arrière et en haut, très-saillants et arrondis. Les antennes sont de la longueur du eorps, noires. Les mandibules sont fortes, triangulaires et fortement dentées en dedans. Le eorselet est eourt, de forme carrée, aplati en dessus, avee les bords tranehants et ceux du prothorax prolongés en avant en deux fortes épines, dont la pointe n'atteint pas les yeux. Le pédieule de l'abdomen est très-court, en forme d'écaille, armé à ses angles externes et supérieurs de deux fortes épines un peu divergentes et un peu courbées vers l'arrière. La tête, le thorax et le pédicule abdominal sont noirs, eouverts. d'un duvet soyeux jaunâtre un peu doré. Les pattes sont grandes, noires, avee un duvet doré sur les tarses antérieurs. L'abdoinen est globuleux, noir luisant.

Cette espèee vient d'Offaek. Nous l'avons représentée grossie et de profil, fig. 2 A. 
Les figures $2 \mathrm{~B},{ }_{2} \mathrm{C}$, offrent la tête vue de face et de profil. La figure $2 \mathrm{D}$ représente le pédicule de l'abdomen grossi.

FOURMi a SIX ÉPINES, Formica sexspinosa. Latr. - Hist. nat. des Fourmis, pag. $\mathbf{2} 6$, pl. IV , fig. $2 \mathbf{I}$.

La fourmi que nous avons représentée pl. VIII, fig. 3, diffère bien de celle que Latreille a décritc, mais cette différence, qui consiste dans la direction des épines $d u$ métathorax, ne nous parait pas assez importante pour motiver la formation d'une nouvelle espèce; nous considérerons donc notre individu comme une variété de la Formica sexspinosa.

Dans la description donnée par Latreille, il est dit, et la figure est d'accord avec cette description, que les épines placées au còté postérieur du thorax sont dirigées du cóté de l'abdomen. Dans notre variété, ces épines, au lieu d'être dirigées en arrière on du côté de l'abdomen, sont dirigées en haut et verticalement, et forment un angle droit avec le dos, comme on le voit évidemment sur notre figure 3 . La figure $3 \mathrm{~A}$ offre le pédicule de l'abdomen, pour montrer les deux épines dont il est armé. Cette fourmi vient d'Offack.

FOURMI AMMON , Formica Ammon. FABr. - Thorace bispinoso; squama petiolari spinis duabus incurvis. - FAs., Ent. Syst., t. II, p. 36o, n$^{\circ}$ 48. - L. 7 mill. I/2. Larg. au thorax I mill. 3/4. - Individu neutre.

Nous donnons ici une description détaillée de cette espèce, pour la distinguer de celle que Latrcille a rapportée à tort à la description de Fabricius. En effet, dans tous les ouvrages de Fabricius, il est dit que le corselet a deux fortes épines en arrière, mais nulle part il n'est parlé d'épines en avant. Dans l'espèce que Latreille décrit sons le nonı d'Ammon (Hist. nat. des fourmis, p. I 32), "le corselet est cubique, un peu cendré. Le premier segment a, de chaque côté et antérieurement, un avancement formé par l'angle;" et plus loin (p. г 33), il dit : "M. Fabricius n’a point parlé dans sa description des deux avancements antérieurs du corselet."

La vraie fourmi Ammon ressemble beaucoup à notre Formica relucens, et à quelques autres espèces voisines décrites par Latreille. Sa tête est courte, globuleuse, noire, avec le front avancé. Les antennes sont noires, plus longues que le corps. Le corselet est noir, couvert d'un duvet soycux doré; il est allongé, en carré long, plat en dessus et sur les côtés à bords supérieurs tranchants; sans épines en avant, un peu rétréci en arrière et portant deux épines dirigées horizontalement vers l'ablomen. Le pédicule de l'abdomen est court, un peu globuleux, rétréci postérieurement et armé en dessus de deux épines courbées en arrière et un peu en dedans, dirigées aussi vers l'abdomen. Les pattes sont grandes, noires. L'abdomen est globuleux, noir, avec quelques traces de duvet doré.

Cette espèce a été trouvée au Port-Jakson, à la Nouvelle-Hollande.

L'individu que nous avons sous les yeux démontre bien évidenment que la description de Fabricius est exacte, et que la fourmi publiée par Latreille forme une espèce très- 
voisine, mais bien distincte de l'Ammon de Fabricius. Nous proposons de donner à cette espèce le nom de Latreillii, en lui laissant la diagnose par laquelle ce savant l'a caractérisée, mais en la modifiant un peu pour rappeler la courbure des épines de l'écaille abdominale. Voici cette caractéristique modifiée :

FOURMI DE-bATREILLE, Formica Latreillii. GúÉn. - Thorace cubico ; spinis quatuor; squama petiolari spinis duabus incurvis.

Syn. Formica Ammon. I Latr., Hist. nat. des Fourmis, p. $\mathbf{I} 32$.

FOURMI A VENTRE SOYEUX, Formica sericeiventris. GuÉR. - Nigro-brunnea; prothoracis in angulo anteriori spinis duabus, mesothorace, metathorace pedibusque compressis; abdomine sericeo-nitido. - Long. I 2 mill. Larg. au thorax 2 mill. - Iudividu neutre.

Cette fourmi avoisine encore la relucens de Latreille et ses congénères. Sa tête est oblongne, d'un noir brun, un peu échancrée en arrière, peu bossue sur le front. Les mandibules sont peu saillantes, fortes, triangulaires, dentées au còté interne. Les antennes sont un peu moins longues que le corps, d'un noir brun, plus roussâtre vers l'extrémité. Le corselet est allongé, noir avec quelques reflets soyeux; le prothorax est court, aplati en dessus, un peu comprimé en arrière avec une petite pointe avancée aux angles antérieurs. Le mésothorax et le métathorax sont comprimés sur les còtés, et tranchants sur la ligne médiane, où ils forment une crête aiguë et un peu arrondie d'avant en arrière. Le pédicule de l'abdomen forme une forte écaille en coin, élargie transversalement en haut, avec le sommet tranchant et un peu courbe. Les pattes sont noires, grandes, avec les cuisses et les jambes très-comprimées, plates, surtout les jambes, qui sont tout à fait en lanes. L'abdomen est globuleux, un peu ovoïde, noir g couvert d'un duvet soyeux d'une teinte argentée un peu jaunâtre et très-luisante.

Cette fourmi a été trouvée à Rio-Janeiro, au Brésil.

FOURAI A ZONES, Formica zonata. Gú̇r. - Brunneo-fulva, marginibus capitis et thoracis, limboque segmentorum abdominalium, luteis. Thorace abdomincque infrà pallidioribus. Alis hyalinis, nervulis brunneo-fulvis._L. I 4 mill. Larg. au thorax, 4 mill. - Individu femelle.

La tête est petite, plus étroite que le corselet, d'un jaune brunâtre varié de fauve en dessus, plus pâle en dessous, avec les joues ou l'espace saillant situé derrière les yeux d'un jaune plus pâle. Les antennes sont courtes, à peine de la longueur de la tête et du corselet, d'un fauve pâle à la base, jaunâtres à l'extrémité. Les mandibules sont fauves, avec le bord dentelé noir; elles sont fortes, de forme triangulaire. Le corselet est d'un jaune sale en dessus, avec les bords et deux bandes longitudinales au milieu d'un fauve brunàtre; le dessous est d'un jaune pâle. Le pédicule de l'abdomen est brun, arrondi avec deux bosses à la partie supérieure; l'abdomen est arrondi, aplati, 
d'un brun un peu roussâtre; les quatre premiers segments sont transversaux et bordés en arrière d'une bande jaune assez large. Les autres segments sont très-petits et cachés dans le quatrième. Les pattes sont de grandeur moyenne, d'un jaune un peu fauve; les ailes sont très-grandes, transparentes, à nervures d'un brun fauve.

'Cette fourmi a été prise au Port-Praslin. Nous n'en avons vu qu'un individu mále.

PONÈRE GRANDE, Ponera grandis. GuÉn. - Nigro-subcyanea; capite sub.quadrato, oculi parvi; mandibulis maximis; thorace globoso, in medio compresso lateribus, pediculo crasso, antice rotundato et postice truncato. Pedibus longis; tarsis anterioribus subtus pilis rnfescentibus. - L. 22 mill. Larg. au thorax, 3 mill. 2/2. - Individu neutre.

C'est la plus grande Ponère connue; elle est entièrement d'un noir vif, avec quelques reflets bleus quand on fait glisser la lumière obliquement sur elle. Sa tête, vue de face, est de forme carrée avec les angles arrondis, et la partie postérieure un peu échancrée. Elle est verticale, peu bombée, avec deux élévations séparées par un sillon au milielı, pour donner attache aux antennes; celles-ci sont un peu plus longues que la tête et le corselet, assez fortes, mais ne grossissant point vers le bout. Les mandibules sont fortes, presque aussi longues que la tête, courbées en dessous vers leur extrémité, avec quatre fortes dents au côté interne, non compris leur pointe et un petit tubercule situé au-dessous d'elle. Les yeux sont petits, placés sur le devant de la tête, un peu en arrière des antennes. Le thorax est plus étroit que la tête, un peu globuleux en avant, comprimé au milieu, lisse et luisant, arrondi sur le dos et tronqué obliquement en arrière. Le nœud ou pédicule de l'abdomen est gros, épais, comprimé sur les côtés, arrondi en haut et en avant, coupé carrément en arrière; l'abdomen est allongé, pointu, avec les deux premiers segments grands, égaux, les autres beaucoup plus courts et diminuant brusquement en pointe aiguë. Les pattes sont grandes, velues, peu comprimées. Les tarses antérieur's sont garnis en dessous d'une brosse de poils fauves.

Cette grande espèce vient du Brésil; elle a été prise dans la province des Mines.

MYRMICE DE LUND, Myrmica Lundii. Gú́n. - Nigra, opaca, villosa, et rugosa; antennis apice lrunneis; thorace oblongo metathorace postice bituberculato; spinis duabus in medio; pediculo primo parvo, bispinoso, secondo latiore, subtus planato, lateribus tuberculato. Abdomine masculi nitido, neutre opaco. - L. Io mill. Larg. au thorax, 2 mill. r/2. - Individus mâle et neutre.

Cette Myrmice est entièrement rugueuse et velue, d'un noir mat. La tête est de la largeur du corselet, dirigée en avant, de forme carrée, un peu échancrée en arrière, avec deux crêtes sinueuses sur le front. Les yeux sont petits, placés sur les côtés; les antennes sont insérées à la hauteur des yeux, distantes entre elles, à peine de la longueur de la tête et du corselet, noires, avec les derniers articles un peu plus épais et 
bruns. Les mandibules sont triangulaires, finement dentelées au còté interne, fauves. Le corselet est plus long que large, rétréei en avant et en arrière, aplati en dessus, avec deux petites pointes au milieu et en arrière du mésothorax, et deux épines assez longues, dirigées en arrière, un peu courbées en bas, situées au milieu du métathorax. Le premier nœud est petit, un peu allongé, étroit à sa base, élargi en arrière, et armé en dessus de deux épines dirigćes en liaut et un peu divergentes; le second nœud est plus court, plus large, aplati en dessus, tuberculé sur les eôtés. L'abdomen est globuleux, avec le premier segment très-grand, le couvrant presque à moitié, et les autres petits et cachés en dessous. Les pattes sont de grandeur moyenne.

Le mâle est de la même grandeur et de la mêne couleur, et ressemble tout à fait au neutre; sa tête est très-petite, arrondie, avec les yeux saillants. Les trois yeux lisses, placés sur le vertex, forment une éminence très-saillante et sont très-forts. Le prothorax est bossu et arrondi en avant, et non aplati eomme dans le neutre. Les deux pointes que l'on voit en arrière du mésothorax de celui-ci, sont remplacées par deux tubercules arrondis. Les épines du métathorax et de la première écaille sont aussi un peu moins fortes. L'abdomen est globuleux, luisant, un peu aplati sur le premier anneau. L'anus offre quatre tubercules saillants. Les ailes sont grandes, à nervurcs jaunâtres; elles sont d'un brun enfumé plus foncé vers le bord antérieur. Les pattes et les antennes sont d'un noir brun.

Cette Myrmice a été trouvée au Brésil; nous l'avons dédiée à M. Lund, savant voyageur suédois, qui a publié, dans le t. XXVLII des Annales des sciences naturelles, des observations fort curieuses sur quelques fournis du Brésil.

MYRMICE GOULUE, Myrmica gulosa. Fasr. - Rufa, abdomine apice nigro; primo segmento contracto. Mandibulis porrectis. $\mathbf{F}_{\mathbf{A B R}}$, Ent. Syst., t. II, pag. $363, \mathbf{n}^{\circ} 55$.

F. castaneo-brunnea; mandibulis capite longioribus; abdominis apice nigro. - LATr., Hist. nat. des Fourmis, pag. 215 , pi. VIII, fig. 49. ( $G^{\text {re }}$ Ecrton. - Latr., Hist. nat. (les Crust. et des Ins., suite à Buffon, t. XIII, p. 258.)

On voit par ces deux descriptions que cette espèce est sujette à varier, puisque l'individu qui a été vu par Fabricius était roux, et que celui de Latreille était d'un brun marron. Fous avons sous les yeux une variété presque noirc, chez laquelle les mandibules, les antennes et les tarses seulement sout roux. La tête, le thorax et le pédicule de l'abdomen sont d'un noir terne et mat, finement rugueux et pubescents, et l'abdomen est lisse et a son premier segment, ou le seeond nœud du pédicule, et les suivants d'un noir vif très-luisant. Cette belle variété a été trouvée au Port-Jakson, à la Nouvelle-Hollande.

Cette espèce fait partie du genre des Myrmices, tel que Latreille le caractérise dans la dernière édition du Règne animal de Cuvier, et, si l'on veut suivrc à la lettre cet ouvrage, on doit la placer dans la division qui comprend " des espèces entièrement semblables aux Myrmices, mais à mandibules linéaires, composant le sous-genre Ecitor.n 
Ce sous-gcnrc Eciton a ćté fondé par Latreille, dans son Histoire naturelle des Crustacés et des Insectes, t. XIII, p. 238. Dans cet ouvrage, il y rapporte les Formica gulosa et hamata de Fabricius. Dans son genera, ces deux espèces sont séparées; l'une ( $\boldsymbol{F}$. hamata) forme la première division du genre Atte, de Fabricius, et l'autre ( $F$. gulosa ) s'en va constituer la première division du genre Мукмсх.

Lcs Hymćnoptères qui vont suivre, du moins ceux qui appartiennent à la famille des Hétérogyncs, ont nćcessité un travail fort long, car la plupart des espèces que nous avions à décrire n'cntraient dans aucun des genrcs établis; il a fallu en créer de nouveaux; et, filèle à nos principcs sur ce sujet, nous avons dû étudier la famille entière des Hétérogynes, et surtout la tribu des Mutillaires, pour y faire entrer nos nouveaux genres et pour les placer à côté des anciens, suivant lcurs affinités. Comme ce travail nous a conluit à fairc passer quelques genres de Fouisseurs dans les Hétérogynes, cettc famille a dû être cxaminée avec soin, ce qui a bcaucoup augmenté notre travail; nous avons donc disséqué les parties de la bouche de tous les genres que nous avons pu nous procurer de ces deux tribus; nous en avons fait des dessins, et, quoique nous ayons reconnu quc les caractères tirés des parties de la bouche sont, chez ces insectes, d'un faible secours dans la distinction des genres, et ne peuvent être employés utilement que pour caractériser des groupes plus généraux, nous avons cependant obtenu des rapprochements qui nous ont beaucoup aidé et viennent appuyer d'autres caractc̀res, plus faciles à saisir, pris dans la forme du corps et des pattes, dans la distribution des nervures dcs ailes, ctc.

Latreille, dans la dernière édition du Règne animal, formc, avec les Hétérogynes qui vivent solitaircment, et dont chåque espc̀ce n'est composée que de mâles ailés et de femelles aptères, une division qui correspond à la tribu des Mutillaires de ses autres ouvrages. Le principal genre de cette division est celui des Mutilles, dont on connaît bien les deux sexes; il y ajoutc.le genre Myrmose, dont on connaît aussi les deux sexes, le genre Myrmecode, que nous croyons devoir considćrer comme composé des individus femelles du genre Thynne, lcs Sclćrodermes de Klugg, qui semblent ne différer que trèspeu des Myrmoses, et les Méthoques, qui sont, d'après des observations récentes, lcs fcmelles du ggenre Tengyre. Les genrcs Doryle et Labide, dont on n’a encore observé que des mâles, forment, dans cettc tribu, une petite section distinguée par l'insertion des antennes, et cette section rentrera probablement dans la tribu des Hétérogynes quand on la connaîtra bien. Les genres Aptérogyne et Psammotherme sont des démembrements des Mutilles.

Connaissant les différences qu'offrent les deux sexes entre eux, dans les Mutilles et les Myrmoses, on pouvait déjà prévoir que ces mêmes différences existaient entre les sexes des autres genres du même groupe; mais l'expérience directe n'était pas encore venuc nous éclairer. On voyait seulement que, dans certains gcnres, on ne connaissait que dcs femelles, tandis que d'autres se composaicnt seulement d'individus mâles; mais on n'avait pas fait assez de recherches pour rapporter ces femelles à leurs vrais mâles, et on les laissait dans des familles séparées. 
Dans ces derniers temps, l'observation que l'on a faite de l'accouplement de la Méthoque ichneunonide avec la Tengyre de Sanvitale, est venue encore montrer combieı les sexes peuvent différer entre eux dans cette tribu : c'est à M. Wcsmaël, savant entomologiste de Bruxelles, que l'on doit cette intéressante déeouverte, et c'est $M$. Vander Linden qui l'a publiée dans les Annales des Seienees naturelles (for dans la deuxième partie de ses Observations sur les Iyménoptères fouisseurs. Ce savant, trop tòt ravi à l'entomologie, avait déjà fait connaître, dans la première partie de cet ouvrage (2), l'opinion de M. Wesmaël, qui soupçonnait que les Méthoques pourraient bien être les femelles des 'Tengyres; et ce qui donnait du poids à cette eonjecture, c'est que ces entomologistes avaient observé qu'on trouvait ces deux genres à la même époque et au même endroit.

L'observation que nous avons citće est encore venue acquérir un nouveau degré de poids par celle qui a été faite quelque temps après par notre ami M. Poey, savant entomologiste qui habite la Havane, dans l'île de Cuba. Il a trouvé dans ee pays une espèce de Tengyre assez rare, dont il a surpris l'accouplement avec une espèce aptère se rapportant très-bien au genre Méthoque. Voici les renseignements quiil nous a adressés à ce sujet : "Me trouvant près d'un mur bàti en terre et exposé au soleil, j’ai pris un individu qui voltigeait près d'un petit trou; quelque temps après, $j$ 'en aperçus un autre qui s'était posé près d'un de ces trous; je le saisis, et ne fus pas peu surpris de lc voir entraîner avec lui une espèce de fourmi rouge avee laquelle il était aceouplé. Je les piquai ensemble, et ce n'est que la douleur eausée par cette piqûre qui les a fait se séparer." Dans une lettre postérieure à eelle-ci, il nous dit : "J'ai acquis de nouveau la eertitude que le couple (Ichneumon et Fourmi) que je vous ai envoyé, était légitimement uni." On voit, d'après ces observations, que l'on doit s'attendre à trouver tôt ou iard les femelles de plusieurs autres genres placés dans la famille des Fouisseurs, et surtout celles des Myzines. Jusqu'ici on avait pensé que quelques espèces de l'Amérique du Nord, dont Jurine a fait son genre Plésie, étaient les femelles des espèces qu'on rapporte de ce pays; mais nous croyons qu'il n'en est rien, et nous appuyons notre opinion sur l'analogie qu'il y a entre l'organisation des 'Tengyres et des Myzines d'un côté, et sur eelle qui existe entre les 'Tiphies et les Plésies de l'autre. Si l'on compare une Plésie, femelle de Myzine suivant Latreille, avee une Tiphie, on verra que ces deux insectes ont des formes robustes comme les Scolies; que leurs pattes sont fortes, à cuisses courbes, à jambes dentées et ciliées, à tarses nıunis de brosses; et, ee qui est à nos yeux la meilleure preuve de leur. analogie avec les Scolies et les Tiphies, e'est que leur's ailes supérieures sont composées de la même manière, c'est-à-dire que leurs nervures ne vont pas aboutir à l'extrémité de l'aile, tandis que, dans toutes les espèees de Myzines et dans tous les autres genres des Mutillaires, à l'exception des Aptérogynes et des Myrmicopsis, qui offrent une anomalie par l'oblitćration d'une grandc partie de leurs nervures, ces nervures se continuent jusqu'au bout de l'aile, en circonscrivant des eellules bien nettement marquées.

(I) Ann. des Sc. nat., t. XVI, p. 48 , 1829 .

(2) Observatians sur les Hym. d'Furope de la famille des Fouisseurs, r re Partie, Extr. du t. IV des Mẻm. de I'Acad. royale des sciences et belles-leltres de Bruxelles, 1827 , et $2^{\text {e Partie, }} \mathbf{1 2 9}$.

Voyage de la Caquille. - Z. Tom. II, Part. II. $\mathrm{I}^{\text {re }}$ Div: 
L'on sera convaineu de la nécessité qu'il y a de conserver le genre Plésie, quoiquon n'ait eneore observé que des femelles, et de le placer près des Scolies et des Tiphies, quand on rélléchira que, daus tous ces genres, les mâles sont beaucoup plus rarcs, surtout dans les Tiphies; en effet, sur une cinquantaine de Tiphies d'Europe que nous avons pu examiner, nous n’avons trouvé que sept à huit mâles, ressemblant entièrement à lcurs femelles pour le eorps et les ailes; et ces mâles n'ont été trouvés que dans l'espéce à pattes noircs ( $T$. morio), tandis que l'espèce à pattes rouges ( $T$. femorata) ne nous a offert que des femelles. Nous aurions même conclu de là que les $T$. morio sont les mâles des $T$. femorata; mais nous avons aussi trouvé plusieurs Tiplia morio femelles, et M. Vander Linden dit positivement qu'il a vu un mâle de la $T$. femorata. Cette différenee dans le nombre des mâles et des femelles existe aussi ehez les Sapyges. Quant aux Méries, nous n'avons eneore vu que des femelles; M. Spinola seul parle des deux sexes.

Puisqu'il y a une telle disproportion dans le nombre des mâles comparé à celui des femelles chez les Tiphies, pourquoi n'en serait-il pas de même pour les Plésies? On doit d'autant plus le penscr, que ces insectes n'ont encore été répandus qu'en très-petit nombre dans nos collections : Jurinc n'avait vu que cinq individus femelles; nous en avons trouvé quatre ehez M. Serville, quatre au Muséum, et un chez M. Percheron. Il n'y a donc rien d'extraordinaire à penser que, sur ces quatorze individus, le hasard n'ait pas fait tronver un mâle, puisque, dans les 'Tiphies, c'est à peine si l'on trouve un mâle sur sept femelles d'espèces différentes.

De ces considérations il résulte pour nous la conviction que les Plésies ne sont pas les femelles des Myzines, et nous le croyons d'autant plus que, si l'on pouvait penser le contraire, il faudrait croire alors quc les Tiphies sont les femelles des Myzines de notre pays, ce qui n'est cependant pas. Du reste, M. Vander Linden, dans la note qu'il a publiée au sujet de la Tengyre, vient encore appuyer notre opinion; car cet entomologiste distingué pense que la femelle de la Myzine eylindrique doit être bien voisine de la Méthoque femelle, et il appelle l'attention des entomologistes du midi de la France sur la Mutilla diadema de Fabricius, dont on ne connaît pas le mâle, et qu'il soupçonne ètre la femelle de cette Myzine ( $\mathbf{r}$ ).

Parmi les Hyménoptères de la Nouvelle-Hollande que nous avons à déerire, il s'en trouve plusieurs espèees qui offrent beancoup d'affinité avec les Myzines, et d'autres avec les Thynnes, genre fondé par Fabricius; mais tous les individus que nous possédons, et ceux que nous avons pu voir dans les collections publiques et particulières de

(r) Cependánt, comme la nature ne se prête pas à toutes nos classifications, prétendues si naturelles, il pourrait arriver que tous ces raisonnements, basés sur des analogies et cependaut fort probables, fussent renversés par le fait de l'accouplement des Myzines amćricaines arec les Plésies du même pays; cela scrail une exception remartquable à la régle que nous avons établie à l'aide de plusieurs faits, et l'on serait alors obligé de relirer ces insecles du gene Myzine et de la famille des Hétćrogynes, ou de modifier la caractéristique de cette famille. L'expérience directe pourra scule nous ćclaircr à cet ćgard; c'est aux naturalistes anćricains ou aux royageurs à tâchıcr de surprendre ces insectes dans laccouplement. 
Paris, sont des mâles à antennes composées de treize articles. On a rapporté du même pays quclques cspc̀ces aptères, tclles que la Tiphie pédestre de Fabricius et la Myzine: aptère d'Olivier, qui offrent toujours des individus femclles dont Latreille a fait le geure Myrmécode. Si Latreille avait connu la diffćrence qui existe entre les deux sexes des Méthoques, s'àl avait réfléchi à celle des sexes des Myrmoses, il n’aurait pas établi ce genre Myrmécode; il aurait peut-être pensé que ces insectes ne peuvent ĉtrc que les femelles des Thynnes, car la différence qu'il y a cntrc clles et les Myrmécodes cst bien moins grande quc celle qu'on trouve entre une Myrmose mâle et sa femelle, et cntre une Tengyre et une Méthoque : cn effet, dans ces deux genres, les mâles sont entièrcment noirs, tandis que les femclles sont en grande partie rouges. Dans les Thynnes et les Myrmécodes, les uns et les autres sont noirs ou bruns, avec l'abdomen taché de jaune; lcs pattes sont fauves, et la différcncc de taille est à peu près la même, c'est-à-dire que les mâles sont environ le double plus grands que leurs femelles. D'après ces rapprochements, nous n’hésitons pas à considérer les Myrmécodes comme étant les femelles des Thynnes, et nous supprimons le premier genre, comme on a déjà supprimé le genre Tengyre.

On voit, par ce qui précède, que nous allons être obligé de faire subir quelques changemcnts à la composition du groupe quc Latreille a formé avec les Hćtérogynes composés de deux sortes d'individus; nous y ferons rentrer quelques genres qu'il plaçait dans la famille des Fouisseurs, tels que ceux de Méthoque, Myzine et Thynne. Nous laisserons dans la première tribu des Fouisseurs, cellc des Scoliètes, tous les Fouisseurs dont les deux sexes sont ailés, qui ont les pieds courts, gros et épineux, les nervures des ailes supérieures n'aboutissant pas à l'extrćmité, etc. Ccllc des Sapygites ne renfermera que les genres Sapyge et Polochres. M. Spinola a donné une bonne description ct une figure accompagnée de détails de ce dernier genre (I), qu'on ne peut placer avec les Mutillaires, puisque la seule espèce connue est composée d’individus ailés dans les deux sexes, ni faire entrer dans celle des Scoliètes, car les nervures de ses ailes aboutissent. toutes à l'extrémité, et les pattcs sont peu robustes, sans épines, et n'ayant nullement l'aspect épais de celles des Scolies et genres voisins. Nous avons, du reste, sous les yeux lc dernier individu restant dans la collection de M. Spinola, et que ce savant a bien voulu nous communiquer, et quoiqu'il n'ait plus les parties de sa bouche, qui, d’après les figures que nous avons citées, pourraient le faire rapprocher des Bembex, à cause de l'allongement du labre, sa forme gćnérale, les nervures de ses ailes, la gracilitć de ses pattes le feraient ranger dans le voisinage des Myzines et des Thynnes, si l'on ne savait pas que ses deux sexes sont ailćs. Nous le laisserons avec les Sapyges, à l'exemple de Vander Linden; peut-être un jour, quand on aura pu faire un nouvel examen de ses caractères et quand on connaitra ses mœurs, pourra-t-on en faire le type d'une tribı distincte.

(r) Faunæ Ligustice fragmenta, authore $M^{* * * *} S^{* * * * *}$, decas prima, in-12, Genur, anno 1805 , mense novembris; et Insectorum Liguriæ species novæ aut rariores quas in agro ligustico nuper detexil, elc. Par Max. Spinola, in- $4^{\circ}$, figg. Genure, 1So6. (Tom. 1, pag. I9, no IX, pl. I, f. VIII, f. A. B. 1,2,3,4.) 
D'après notre manière d'envisager ces insectes, voici comment nous proposons de composcr et de caractériser les tribus des Mutillaires et des Scoliètes (juillet 1 837):

Famille des Hétérogrnes.

$I^{\text {re }}$ tribu. Foruicaines.

Hyménoptères vivant en société et offrrant trois sortes d'individus : des màles et des f́cmelles ailés, et des neutres sans ailes.

Genres Fourmi, Ponère, Odontomaque, Myrmice, Éciton, Atte, Cryptociere, etc.

II tribu. Mutillaires.

Hyménoptères vivant solitairement et n'offrant que des mâles ailés et des femelles aptères (antennes de treize articles dans les mâles et de douze dans les femelles).

Genres Doryle, Labide, Mégalocère, Mutille, Psammotherme, Aptérogyne, Myrmicopsis, Myrmose, Méthoque (Tengyre et Méthoque), Myzine, Rhagigastre, Téléphoromyie, Tachyptère, Agrionyie, Thynne (Thynne et Myrmécode), Thynnoüde, Anthobosque et Elaphroptère.

Famille des Foursseurs.

$I^{\text {re }}$ tribu. Scolıètes.

Hynénoptères à pieds courts, gros et épineux dans les deux sexes, fort ciliés, avec les cuisses arquées près du genou; antennes plus courtes que la tête et le thorax, chez les femelles; nervures des ailes supérieures n'atteignant pas leur extrémité.

Genrcs Scolie, Tiphie, Plésie, Mérie et Paramérie.

II ${ }^{\mathrm{e}}$ tribu. SAPYgites.

Hyménoptères à pieds courts, grêles, simples, sans épines. Antennes aussi longues au moins que la tête et le corselet dans les deux sexes. Nervure des ailes supérieures atteignant leur extrémité.

Genres Sapyge, Polochre.

Les autres tribus n'entrent pas dans le plan de cette révision. Du reste, elles nous paraissent bien caractérisées par Latreille, et nous ne reproduirons pas leur signalement. Nous n'avons présenté les caractères de celles des Scoliètes et des Sapygites que pour mieux isoler nos Mutillaires. Nous allons maintenant passer à l'examen des gcnres de cette tribu; nous essayerons de les grouper au moyen d'un tableau purement artificiel, en nous servant, faute de mieux et à l'exemple de Latreille, de la forme du thorax des femelles divisé en une, deux ou trois pièces dans toutes celles que nous avons vues. Les genres dont les mâles seuls sont connus de nous n'entrent dans ces groupes que par analogie et provisoirement. Du reste, nous n'attachons aucune importance à ce classement des genres entre eux; nous n'avons cherché à les ranger ainsi que pour démontrer la difficulté d'une classification tranchée et bien claire, actuellement que l'on connaît un plus grand nombre d'espèces, et son impossibilité quand ce nombrc se sera encore accru et que l'on possédera plus de nuances intermédiaires entre chaque forme. Nous ne développerons ensuite que les caractères des genres qui ont été trouvés dans les contrées parcourues par l'expédition de M. Duperrey, réservant pour un mémoire que nous insérerons dans notre Magasin de zoologie, les genres européens et africains qui ne doivent pas entrer dans le Voyage de la Coquille. 
I. Mandibulcs trc̀s-grandes, bouchc eachée en entier ou en partie sous lc labre. Mảchoires ct lèvres très-petitcs. Palpes maxillaires de deux articles, les labiaux de trois.

A. Deux cellules cubitales.

g. Dorylus. Fab.

B. Trois cellules cubitales.................... g. Labydus. Jur.

II. Mandibules rudimentaires. Palpes maxillaires de cinq articles. Antennes plus longues que la tête et le thorax $(1) \ldots \ldots \ldots \ldots$ g. Megalocera. Nob.

III. Mandibules de grandeur moyenne. Palpes maxillaires de six articles.

A. Thorax des femelles ne paraissant composé que d'une seule pièce.

1. Antennes des mâles simples.....................

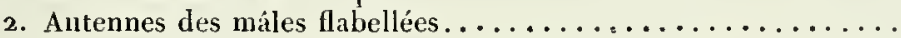

g Mutilla. Lin.

g. Psammotherma. Lat.

B. Thorax des femelles eomposé dc deux pièces distinetes.

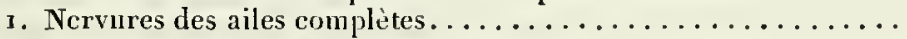

2. Nervurcs des ailes en partie atrophiées.

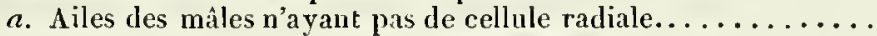

$b$. Ailes des mâlcs ayant une cellule radiale fermée.........

C. Thorax des femelles composé de trois pièces distinctes.

x. Abdomen des máics cyliudriquc, terminé inférieurement par úne grande épine rccourbéc cn lıaut.

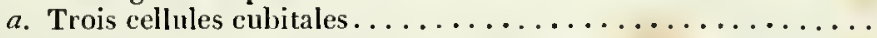

$b$. Quatre cellules cubitales.

†- Première cellılc cubitalc entière et sans appendice.......

++ Premic̀rc cellule cubitale ayant un appendice qui la

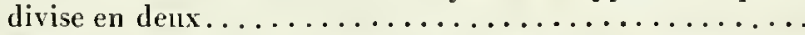

2. Abdomen des mâles aplati, n’ayant point, à l'extrèmité, d'épine recourbée vers le haut (3).

a. Mandibules tridentées.

+ Les deux nervures récurrentes aboutissant aux deuxic̀me et troisième cellnles eubitales..................

++ Lcs deux nervures récurentes aboutissant à la scconde

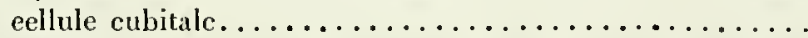

b. Mandibules bidentées. Chaperon très-avaneé entre les mandibules.

† Labre déconvert et saillant.

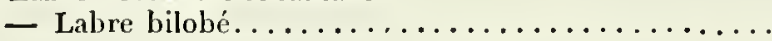

- Labre arrondi.

o. Màchoires non cilićes à leur base. . . . . . . . . .

o o. Mâchoircs très-eiliées à lcur base...........

$\uparrow$ Labre recouvert par le chapcron.

$\times$ Premièrc ccllule cubitale sans appendice........

$\times \times$ Première cellule eubitalc ayant un appendiee.

g. Myrmosa. Lat.

g. Apterogyna.

g. Ayrmicopsis. Nob.

g. Methoca. Lat. (2)

g. Myzine. Lat.

g. Rhagiguster. Nob.

g. Telephoromyia.Nob.

g. Tachypterus. Nob.

g. Agrionyia. Nob.

g. Thynnus. Fabr.

g. Thynnoides. Nob.

g. Anthobosca. Nob.

g. Elaphroptera. N. (4)

(1) Ces genres rentreront probablement dans la tribu des Formicaires, si l'on parvient à đécourrir les mœurs des espéces qui les composent. Nous pensuns qu'il y a des neutres aptères.

(2) Le nom de Méthoque élant antérieur à celui de Tengyre, a été conscrvé à ce genre par M. Vander-Linden; nous avons suivi l'exemple de cet cntomologiste consciencieux.

(3) On aurait pı, à la riguenr, ne faire que denx on trois genres dans celte division; mais la difference d'habitation et quelques caractères, quoique légers, autorisent l'établissement des genres que nous formons. Du reste, on a si peu chassé les Hyménoptères exotiques, qu'il est certain que des genrcs composés actuellement d'une ou de deux espéces, en auront beancoup plus, quand les voyageurs ne se borneront plus à ne ramasser que de gros et brillants Coléoptc̀res.

(4) Nous n'avons pas fait entrer dans ce tableau les deux genres provisoires Diamma et Ammodromus; ils se composent de femclles qui entreront probablement dans les genres déjà conums, quand on les aura mieux observées, el qu'on aura surpris leır accouplement. Quanı au genre Scleroderma de M. Klng, nous pensons qu'il se compose des femelles du G. Epjris de M. Westwood, lequel fait partie de la tribu des Oxyures de Latreille. 
Les premiers genres du tableau qui précède ne figureront pas, comme nous l'avons dit plus haut, dans ce Voyagc, parce que les naturalistes de l'expédition commandće par M. lc capitaine Duperrey n'ont rapporté aucune dc leurs espèces; nous réservons cette partie de notre travail pour un mémoire sur la tribu des Mutillaires, qui paraîtra dans notre Magasin de zoologie, accompagné de nombreuses figures caractéristiques.

\section{Genrc RHAGIGASTRE, Rhagigaster. Guér.}

Les caractères qui distinguent ce genre des Myzines et des Méthoques sont peu nombreux; car la forme de la seule cspèce qui le compose, presque tous les caractères tirés de l'organisation de sa bonche, de ses antennes, etc., nc diffèrent en rien de ce que l'on trouve chez les deux genres citćs plus haut, et l'on ne peut le séparer des Myzines surtout, qu'en employant le caractère qu'offrcnt ses ailes supćrieures et son chaperon. Nous nc décrirons ici que les parties qui distingnent ce genre de ceux auxquels nous le comparons.

Chaperon assez avancé, coupé droit en avant; labre peu saillant, presque droit et à peine échancré au milieu.

Mandibules peu arquées, bidentécs.

Màchoires allongécs; palpes maxillaires de la longueur des mâchoires, près du double plus longs quc les labiaux, composés de six articles presque égaux, cylindrico-coniques, un peu dilatés cn dedans.

Lèvre longue, un peu avancée au milieu et en avant; palpes labiaux courts, de quatrc articles obconiques, dont le premier et le quatrième sont un peu plus longs que les deux intermćdiaires, qui sont égaux entre eux.

Ailes supérieures ayant une cellule radiale grande, allongée, atteignant presque leur extrćmité, quatre cellules cubitales complètes, avec le commcncement d'une cinquic̀me formant une petite cellule entre la première et la seconde, cette petite cellule supplémentaire n'atteignant pas la nervure inférieure.

RHAGIGASTRE UNICOLORE, Rhagigaster unicolor. GuÉR. - Niger, punctatus, pilis albidis indutus; mesothorace quadri-sulcato. Alis hyalinis stygmatibus et nervulis nigris, anticis apice sub-infiuscatis. Abdominis segmentibus sub-coarctatis, postice rugosis.

Long. 19 mill. - Enverg. 3o mill.

Tout son corps, ses antennes et ses pattes sont d'un noir profond et un pen luisant, avec quelques poils bruns. La tête est à peu près de la largeur du thorax, beaucoup plus large que longue, aplatie en avant, fortement ponctuće et comme rugueuse; elle offre, sur le front et entre les yeux, une petite carène élevée et transversale qui n'atteint pas les yeux, et qui est placée un peu plus près des yeux lisses que de l'insertion des antennes. Les yeux sont grands, ovalaires, allongés, à peine un peu échancrés en dedans, d'un jaunâtre brun. Les antennes sont filiformes, à peine de la longueur de la tête et du thorax, composées d'articles cylindriques un peu arqués, comme dans la Tengyra Sanvitali. Le thorax est fortement ponctué; il y a sur le mésothorax deux 
impressions qui vont en divergeant un peu vers le prothorax. L'abdomen est plus long que le thorax et la tête, cylinclrique, à articulations étranglées à leur base. Le premier segment est un peu plus étroit que les autres, fortement éelıneré en dessous et ayant, de ee eôté et à la base, un petit tubereule élevé en forme d'épine. Les autres segments offrent en arrière, ainsi que le premier, une impression transverse assez forte pour simuler un petit artiele intermédiaire. Le dernier segment se termine en pointe en arrière; il cst tronqué en dessus, et présente en dessous une forte épine eourbée et relevée, et à la base de laquelle on voit deux petites dents placées latéralement : tous ces segments offrent quelques points enfoneés sur leur surfaee. Les pattes sont assez courtes, avee les euisses un peu renflées et les tarses grêles. Les ailes sont translueides, à nervures noirâtres; les supérieures sont teintées de brun, surtout vers l'extrémité; elles offrent quelques reflets violets.

Cet inseete vient du Port-Jaekson.

\section{TÉLÉPHOROMYIE, Telephoromyia. Gux́r.}

Tête arrondie, tronquée en arrière, aussi large que lc thorax. Yeux ovalaires, entiers. Trois petits yeux lisses sur le vertcx.

Antennes un peu moins longues que la tête et le thorax, grêles et filiformes, avec le premier article un peu plus épais, le seeond petit, les suivants aussi longs que le premier, eylindriques et droits jusqu'au sixième, et ensuite un peu courbés.

Chaperon à peine avaneé entre les mandibules, offrant au milieu un enfoneement triangulaire, simulant une forte éehanerure. Labre saillant, de la largcur de l'entoncement antérieır du elhaperon, deux fois plus large que long, très-faiblement éelianeré en avant, et eilié.

Mandibules grandes, arquées, tridentées, avee la dent terminale plus longue que les inférieures, qui sont larges et fortes à leur base, et égales entre clles.

- Mâehoires peu allongées, à peine deux fois plus longues que larges, terminées par deux lobes membraneux assez distinets, l'un supérieur, arrondi et eilié, l'autre inférieur et peu saillant en dedans. Palpes maxillaires plus longs que les màehoires, de six articles, le premier très-eourt, les second et troisième plus longs, obeoniques et assez élargis au bout, les trois derniers plus longs, avee les quatrième et einquième un peu dilatés en dedans à leur extrémité, et le dernier presque eylindrique et arrondi au bout.

Lèvre courte, à peine denx fois plus longue que largc, éclranerée latéralement eu arrière, tronquée en avant. Palpes labiaux beaueoup plus courts que les maxillaires, de quatre articles épais, dont le premicr est le plus long, un peu courbé, les deux suivants presque triangulaires, dilatés extérieurement, et le dernier ovoïde.

Ailes supérieures ayant unc cellule radiale allongée, atteignant presque l'extrémité, et quatre ecllulcs eubitales entières; la première est très-longue, et offre, sous le point épais, un commeneement de cinquième cellule, produit par un petit rameau dirigé en derlans de la nervure qui sépare la première de la seeonde eellule eubitale. Première et seeonde nervures réeurrentes atteignant les deuxième et troisième eellules eubitales. 
Pattes de longueur moyenne, assez grêles. Crochets des tarses bidentés.

Abdomen allongé, un peu aplati, rétréci à ses extrémités et simple en arrière.

Nous ne connaissons qu'une seule espèce de ce genre; elle a été trouvée vers l'extrénité de l'Amérique méridionale, au Chili, par M. Gay, et en Patagonie, par MI. A.d'Orbigny.

'TÉLÉPHOROMYIE A PIEDS ROUGES, Telephoromyia rufipes. GuÉr. - Nigra; capite thorace maculis, abdomine fasciis interruptis quinque, flavis; pedibus fulvis; alis hyalinis, margine anteriore ante apicem brunneis. - I. 15 mill. 1/2. - Enverg. 26 mill.

Sa tête cst noire, très-finement chagrinée, avec les yeux bruns. Les mandibules sont jaunes en avant, fauves du côté qui regarde la poitrine et à l'extrémité. L'échancrure enfoncée du milieu du chaperon est largement bordée de jaune pâle, il y a deux taches de cette couleur au-dessus del'insertion des antennes, contre le bord antérieur des yeux, et au milieu du triangle formé par les yeux lisses. Le bord postérieur de la tête, derrière les yeux, offre aussi unc ligne jaune qui part du bord inférieur des yeux et va toucher un petit croissant placé clerrière les yeux lisses. Les antennes sont entièremęnt. noires. Le corselet est finement clıagriné, noir terne. Le protlıorax est très-court, en forme de collier, et porte une tache jaune et allongée de chaque côté. Le mésothorax, qui s'arrondit en avant, offre un croissant jaune, qui part de l'insertion des ailes supérieures, et dont la convexité est vers la tête; le bord postérieur de son écusson est jaune; il y a une grande tache de la même couleur en avant de ce bord, et deux petites taches derrière l'insertion des ailes; les côtés, au-dessous des ailes, offrent une grande tache en crochet et un point rond en arrière. Le métathorax présente de chaque côté une grande tache jaune, courbée en crochet en arrière. Le dessous est noir. Les ptérygodes qui recouvrent l'insertion des ailes sont jaunes. Les ailes sont transparentes, à nervures brunes; les supérieures sont légèrement teintées de brunâtre, avec la còte et le point épais orangés; elles ont, à l'extrémité, et au bord antérieur seulement, une petite tache brune, un peu fondue en arrière et occupant toute la cellule radiale. Les pattes sont d'un fauve un peu orangé.

L'abdomen est noir, un peu luisant, finement ponctué. Le premier segment a une bande jaune et entière près de son bord postérieur; les quatre autres ont chacun une bande semblable, mais elle est interrompue au milieu. Les sixième et septième segments sont noirs. Le dessous des second, troisième et quatrième segments prćsente une tache triangulaire de chaque côté; les autres sont noirs.

De Patagonie et du Chili.

TACHYPTĖRE, Tachypterus. Gứr.

Tête ronde, un peu aplatie en avant, de la largeur du thorax; yeux ovalaires, à peine échancrés en dedans, trois petits yeux lisses. 
Antennes filiformes, à peine de la longueur de la tête et du thorax réunis, ayant le premier article plus fort, un peu tronqué obliquement au bout, le second petit, mais bien distinct, et les suivants égaux entre eux, cylindriques.

Chaperon très-peu avancé, un peu tronqué au milieu. Labre caché sous le chaperon, très-large et transverse, mais fort eourt, un peu arrondi en avant et cilié.

Mandiluules grandes, un peu arquées en dedans, assez ciliées en dehors, terminées par trois fortes dents presque égales.

Mâehoires allongées, avec le lobe terminal assez grand, membraneux, un peu eilić et divisé transversalement par une suture sinueuse. Palpes maxillaires plus longs que la mâchoire, de six artieles inégaux, les trois premiers plus courts que les trois derniers; le premier eourt, les second et troisième plus longs, égaux, un peu obconiques, les trois autres égaux, mais plus longs, moins épais que les premiers et un peu obconiques.

Lèvre moins longue que les mâehoires, eomme tridentée en avant, un peu élargie en arrière; palpes labiaux presque de moitié plus courts que les maxillaires, de quatre articles obeoniques, dont le premier est le plus long, les seeond et troisième presque égaux, un peu plus épais, et tronqués au bout, et le dernier ovalaire allongé, à peine plus long que le précédent.

Ailes supérieures ayant une cellule radiale assez grande, n'atteignant pas l'extrémité, ct quatre cellules cubitales complètes, dont la première est allongée, entière et sans aucun appendiee; les deux suivantes phus courtes et de forme irrégulière, et la quatrième plus grande ct terminée par toute l'extrémité de l'aile. Deux nervures récurrentes aboutissant à la seconde cellule cubitale.

Pattes assez grandes, de force moyenne. Abdomen allongé, rétréci à ses deux extrémités, et terminé en pointe en arric̀re.

On ne connait encore qu'une seule espècc de ee genre, qui se distingue au premier coup d'œil par l'insertion des deux nervures récurrentes.

TACHYPTÈRE FASCIÉ, Tachyptcrus fasciatus. Gú̇́. - Ater, albo pilosus; abdomine fasciis quinque interruptis flavis, anticis et posticis angustioribus; femoribus intermediis et posterioribus rubris; alis hyalinis anterioribus flavescentibus. - L. I 4 mill. Enverg. 24 nill.

La tête est noire, garnie de poils blanes, avec les mandibules tachées de jaune à leur base. Les antennes sont un peu moins longues que la tète et le thorax, filiformes; noires. Le thorax est entièrement d'un noir bleuâtre, fnement ehagriné et garni de poils blancs. Les ailes sont transparentes, à nervures noirâtres; les supérieures ont un léger reflet jaunâtre. Les pattes sont noires à l'exception des cuisses des intermédiaires, et des postérieures, qui sont presqu'en entier l'un rouge brique. L'abdomen est ovalaire, luisant, noir. Le premier segment est plus étroit que les autres; il a une trèspetite tache jaune de claque eôté au bord postérieur. Les second, troisième et quatrième sont à peu près égaux, et portent en arrière, dessus et dessous, une bande jaune interrompue au milieu; le dernier olfre deux petites taclies jaunes à l'anus. 
Cette espèce a été trouvée dans l'île des Kanguroo, à la Nouvelle-Hollande. Il n'en existe qu'un individu dans les collections du Musćum de Paris.

\section{AGRIOMYIE, Agriomyia. GuÉr.}

'Tête rondc, aplatie en avant, de la largeur du thorax. Yeux ovalaires, entiers. Trois petits ycux lisses en triangle $\mathrm{cn}$ avant du vertex.

Antennes filiformes, à peine de la longueur de la tête et du corselet, ayant le premier article plus ćpais que les autres, le second très-petit et peu apparent, et les autres égaux entre eux et cylindriques.

Chaperon très-saillant, rétréci et tronqué au milieu. Labre saillant, de la largeur de la troncature médiane du chaperon, fortement bilobé et cilić.

Mandibules assez allongées, courbées, terminées par deux fortes dents presque égales.

Màchoires peu allongées, à peine deux fois plus longues que larges, avec les lobes membraneux, grands, le supérieur faiblement divisé par une suture transverse, ayant un petit lobule ou une petite échancrure en dedans; l'inférieur peu distinct, arrondi et cilié en dedans. Palpes maxillaires un peu plus longs que les mâchoires, de six articles; le premier le plus court, un peu obconique; le second deux fois plus long, presque cylindrique; les deux suivants égaux entre eux, un peu plus courts que le second, un peu renflés à l'extrémité; et les derniers un peu plus grêles et de la même longueur.

Lèvre de la longueur des mâchoires, plus de deux fois plus longue que large, un peu élargie au milieu, avec les paraglosses assez saillantes, arrondies et un peu ciliées. Palpes labiaux plus courts que les maxillaires, de quatre articles; le premier le plus long, les deux suivants égaux, obconiques, le quatrième ovalaire.

Ailes supérieures ayant une cellule radiale grande, allongée, atteignant presque le bout de l'aile, et quatre cellules cubitales, dont la première, qui est allongée et plus grande, est presque séparée en deux parties égales pạr une nervure qui atteint presque l'cxtrémité postérieure du point épais. Les deux nervures récurrentes aboutissent sous les seconde et troisième cellules cubitales; la plus extérieure est fortement arquée, et vient s'attacher fort près de la seconde cellule cubitale.

Pattes assez grandes, à cuisses un peu renflées, avec les crochets des tarses bifides.

Abdomen ovalaire, rétréci aux extrémités, et offrant un rudiment d'épine relevée au dernier segment.

AGRIOMYIE MACULÉE, Agriomyia maculata. Guér. - Nigra, pilis griseis induta; thorace suprà et infrà et segmentibus abdominalibus quinque primis, flavo-maculatis; alis favo-pallido-hyalinis, pedibus fulvis. - Long. I6 mill. - Enverg. 24 mill.

La tête est noire, finement chagrinée, garnie de quelques poils blanchàtres. Les mandibules sont jaunes, avec l'extrémité noiràtre. Le chaperon est entièrement, jaune, et 
cette couleur s'étend un peu au-devant des yeux, jusqu'à la hauteur de l'insertion des antennes; il y a deux petites taches jaunes au-dessus de l'insertion de celles-ci.

Le corselet est noir, finement chagriné. Le prothorax, qui est très-court, offre en avant un petit bourrelet assez saillant et jaune, et au milieu une ligne un peu sinuée, de cette mêtne couleur, qui part de l'insertion des ailes supérienres et va rejoindre la bordure antérieure au milieu. Le mésothorax a une petite carène élevée de chaque côté; son milieu présente une grande tache jaune carrée; il y en a une autre arrondie au milieu de l'écusson, dont le bord postérieur est encore bordé de jaune. Les ptérygodes des ailes supérieures sont jaunes, et l'on voit en arrière et de chaque côté deux petites taclies. Les côtés du mésothorax ont une grande tache arquée sous les ailes supérieures et une autre plus petite en arrière. Le métathorax présente au milieu une grande tache en fer à cheval, et une autre tache arrondie et assez grande de chaque côté. Les ailes sont transparentes, lavées de jaunâtre, avec les nervures d'un brun jaunâtre et le stygmate orangé. Les pattes sont fauves, peu velues.

L'abdomen est noir, un peu chagriné, avec le bord postérieur des segments garni d'un sillon transversal. Le premier présente au milieu de sa longueur deux taches transverses étroites, qui ne se tonchent pas sur la ligne médiane; les second, troisième et quatrième ont également deux taches, mais beaucoup plus grandes sur les côtés, et plus éloignées entre elles au milieu; enfin lc cinquième offre deux taches linéaires semblables à celle du prenier. Le dessous du premier segment n'a qu'une petite tache au milieu; les second, troisième et quatrième ont de grandes taches à peine interrompues au milieu, et le cinquième n'a que deux petits points. Les sixième et septième anneaux sont tout noirs, et le dernier est terminé en dessous par une trèspetite épine faiblement courbée en haut.

Get hyménoptère vient de la Nouvelle-Hollande.

\section{Genre 'THYNNE, Tlynnus. FABR.}

Ce genre a été fondé par Fabricins dans son Systema Entomologice (1775), avec trois insectes de la Nouvelle-Hollande quil avait vus dans la collection de Banks. Depuis, dans son Entomologia systematica ( $\left.179^{3}\right)$, il y a ajouté une autre espèce de la même collection, mais provenant de l'Afrique, ce qui en a fait monter le nombre à quatre.

Sur ces quatrc espèces, une seule, le Th. dentatus, a été admise par Latreille comme appartcnant à ce genre; car il dit, dans le nouvean Dictionnaire d'histoire naturelle (18 19), que les autres espèces de Thynnes, qui sont au nombre de trois, appartiennent à la tribu des Apiaires. Ainsi, poursuit-il, celle qu'il (Fabricius) nomme échancré, et que j’ai vue dans la collection dc M. Banks, est du genre Stélide, et a été décrite comme nouvelle dans ma Monographie des Anthidics; elle se trouve en Afrique. Les deux autres espèces, dont on peut voir les figures dans Uonovan, me paraissent devoir être placées avec les Cœelioxydes.

On ne pcut cependant admettre encore le jugcment de Latreille sur ce sujet, car il paraîl ne pas avoir connu la note publiée par Kirby, dans l'Addenda du premier volume de sa Monographia apum Anglia (1802), p. 222, dans laquelle ce savant, qui 
a aussi étudié les Thynnes de la collection de Banks, dit positivement que les $T h$. dentatus et emarginatus sont congénères, quc lc Th. integer est douteux, et que le $T h$. abdominalis est un Apiaire.

Nous ferons observer encore que, dans le passage cité plus haut, Latreille se trompe probablement, en disant qu'on peut voir les figures de ces deux dernières espèces dans Donovan; nous avons bien trouvé dans l'Epitome of insects of Asia, etc., deux figures, outre celle du Th. denté, mais ce sont celles du Th. ćchancré et du Th. entier.

Comme nous l'avons dit dans l'introduction de ce Mémoire, nous croyons devoir considérer les Myrmćcodes de Latreille comme étant les femelles des Thynnes, et ici l'analogie vient appuyer fortement nos prévisions. Cependant, comme aucune observation directe ne peut confirmer cette vue, nous croyons devoir séparer, dans les caractères génériques que nous allons exposer, ceux des mâles de ceux des individus femelles que nous leurs rapportons. Nous allons donc caractériser ce genre, comme il l'a ćté jusqu'ici, en nous servant des mâles seulement.

Mâles. - Tctte ronde, un peu aplatie d'avant en arric̀re, de la largeur du thorax; yeux ovales, entiers; trois petits yeux lisses sur le vertex.

Antennes filiformes, plus longues que la tête, de treize articles, ayant le premier article plus fort, tronqué obliqucment, le second très-court, le troisième presque de la longneur du prcmier, un peu obconique, et les suivants un peu plus longs, cylindriques et égaux entre eux.

Chaperon avancé, tronqué ou arrondi en avant; labre saillant, arrondi au milieu et cilié.

Mandibules grandes, arquées, bidentées au bout; mâchoires assez allongées, ayant leurs deux lobes rćunis et n'en fornıant qu'un seul arrondi et cilié, membraneux; palpes maxillaires plus longs que les labiaux, de la longueur des mâchoires, de six articles presque égaux, obconiques, allant en diminuant d'épaisseur, avec les quatrième et cinquième un pcu dilatés en dedans.

Lèvre moins longue que les mâchoires, un peu élargie en arrière, munie de deux larges paraglosses; palpes labiaux de moitié plus courts que les maxillaires, de quatre articles ćgaux, un peu dentés en dedans avec le dernier ovoïde.

Ailes supérieurcs ayant une cellule radiale grande, qui atteint presque l'extrémité, et quatre cellules cubitales allongées, presque égales, avec la première divisée en dedans par un commencement de nervure, qui part du bas de sa séparation d'avec la seconde cellule et se dirige obliquement vers la côte. Les deux nervures récurrentes aboutissent sous les seconde ct troisième cellules cubitales.

Pattes grandes, assez robustes, avec les crochets des tarses bidentés.

Abdomen de sept segments, allongé, un peu aplati, rćtrćci en arrière et terminé par une pointe qui offre quelquefois plusieurs dentelures latérales.

Nous connaissons actuellement (juillet $\mathbf{1} 837$ ) onze espèces mâles de ce genre; elles sont toutes propres à la Nouvelle-Hollande.

Femelles. - Tête de forme carrée avec les angles arrondis, aplatie d'avant en arrière; yeux petits, ovales; point d'yeux lisses sur le vertex. 
Antennes un peu plus longues que la tête, contournées sur elles-mêmes, de douze articles; le premier grand, plus large, tronqué obliquement, de la longueur au moins des trois suivants; le second très-petit; le troisiène, plus long, obconique; le quatrième de même forme, nnais un peu plus court ; les suivants encore un peu plus courts, plus larges que longs, un peu dilatés en dehors, du côté où l'antenne se courbe pour se contourner, et le dernier ovalaire, assez pointu au bout.

Chaperon n'étant point avancé entre les mandibules, avec une petite pointe au milieu, produite par la saillie d'une petite carène longitudinale placée sur la ligne médiane; labre caché, très-court, arrondi et cilié en avant.

Mandibules grandes, aplaties, courbées, ciliées en dessous, rétrécies vers le bout, avec l'extrémité terminée en une seule pointe arrondie.

Mâchoires courtes, élargies en angle au côté externe, ayant en dedans deux lobes membraneux ciliés, dont le supérieur cst le plus petit. Palpes maxillaires très-courts, de six articles; les trois premiers assez grands, obconiques et presque égaux, et les trois derniers rudimentaires, formant au bout du troisième une petite pointe conique ayant à peine le tiers de sa longueur.

Lèvrc plus longue que large, profondément échancrée en arrière, brusquement rétrécie en avant et terminée en pointe au milieu. Palpes labiaux plus grands que les maxillaires, de quatre articles; le premier, le plus grand de tous, cylindrique, courbé; lcs second et troisiène obconiques, presque de moitié plus courts, un peu dilatés en dehors; le quatrième un pen plus long que le précédent, ovalaire et terminé un peu en pointe.

Thorax en carré long étranglé vers le tiers postérieur, coupé carrément sur les côtés et en arrière, et composé de trois segments très-distincts.

Pattes assez grandes, robustes, à cuisses élargies et aplaties, garnies d'épines et de cils; crochets des tarses bifides.

Abdomen allongé, un peu plus large en avant, un peu aplati, rétréci en arrière, de six segments.

Nous n'avons vu en nature qu'une seule espèce de ces femclles; la forme de son albdomen, sa couleur ct les taches jaunes qui l'ornent, ne peuvent faire rapprocher cette espèce que des Thynnus dentalus, variabilis ou affinis. Dans le doute où nous nous trouvons à ce sujet, nonis croyons devoir la rapporter à la plus commune de ces espèces, $T$. variabilis, en attenrlant que des observations directes aient confirmé ou détruit ce rapprochement, que nous ne faisons que par analogie. Nous procéderons de la même manière à l'égard de la Typhia pedestris de Fabr., que nous croyons être la femelle du Th. dentatus, ou du zonatus, et de la Myrmecodes austratıs de Lcach, qui nous parâ̂ı être la femelle du Thynnus annulatus de Kirby, et nous placerons leur description à la suite de celle des mâles.

Nous diviserons les espèces du genre 'Thynne en deux sections, ainsi qu'il suit :

I. Antennes plus courtes que la tête et le corselet réunis, de la même épaisseur jusqu'au bout, à articles cylindriques non rétrécis ni courbés à leur naissance. 
THYNNE DENTÉ, Thynnus dentatus. $\mathrm{F}_{\mathrm{ABR}}$ - - Abdomine atro; segmento secundo, tertio quartoque punctis duobus albis. FaBr.

Thynnus dentatus. - F FBr., Syst. Entomol., p. 36o, $\mathrm{n}^{\circ} \mathrm{I}$ (1775). Cette espèce se trouve reproduite dans tous les autres ouvrages de Fabricius.

Thynnus dentatus. - LATr., Gen. Crust. et Ins., t. IV, p. I I I, et pl. XIII, f. I, 2.

- Donovan, Epitome, avec figure.

- Id. Genera illust. of Ent., part. I, pl. XII, fig. I.

- Roemer, Gen. Ins., t. XXXV, fig. 8.

- Encycl. meth. pl. 382, fig. 8. Copie de celle de Donovan, Épitome.

- Lamarck, Anim. sans vert., t. IV, p. rog.

Cct insecte, qui se trouve encore décrit ou indiqué dans les dictionnaires d'histoire naturelle et dans plusieurs autres ouvrages généraux, est bien distinct de toutes les autres espèces du même genre, et les figures quc nous possédons, notamment celle du Genera de Latreille, qui lui a été envoyée d'Angleterre par Macleay, ne laissent aucun doute à ce sujet, et montrent que la description donnée par Fabricins est trèsexacte. Comme nous n'avons pas vu cette espèce, nous allons reproduire cette description.

Statura et nagnitudo vespa vulgaris. Antenna porrecta, fusca, basi picece. Labium favim, dentatum. Mandibula fave, apice nigrce. Thorax niger, striga antica, lobo postico scutelloque flavis. In medio dorsi lineola duce impressa, abbreviata. Abdomen glabrum, atrum, primo segmento basi, 2, 3, 4, punctis duobus flavis, reliquis immaculatis. Anus denticulis septem parvis serratus.

Habitat in Nova-Hollandia. Museuin Banksianum.

THYNNE ZONÉ, Thynnus zonatus. Gú́R. - Niger; capite, vertice excepto, margine anteriore et posteriore prothoracis, nesothorace in parte posticali, metathorace, tribus primis segmentibus abdominalibus, margine posteriore exceptis, in segmentibus sequentibus maculis duabus, pedibusque, flavis; ano septem spinis instructo. Alis flavo-lyyalinis. - L. 27 mill. Enverg. 48 mill.

La tête est jaune, ponctuée, un peu velue, avec le vertex et le bord postérieur noirs. Les antennes sont noires, à articles cylindriques non rétrćcis ni courbés à leur naissance, et beaucoup moins longues que la tête et le thorax pris ensemble. Le prothorax est noir , finement rugueux, bordé de jaune en avant et en arrière. Le mésothorax est noir, ruguenx, avec le bord postérieur et le dessus de l'insertion des ailes jaunes; il offre deux faibles sillons velus et longitndinaux au milieu, et un sillon transversal en arrière. Le métathorax est entièrement jaune tant en dessus qu'en dessous; le dessous 
de tout le thorax est jaune taché de noir au milieu. Les ailes sont transparentes, à nervures presque noires et légèrement teintées de jaune fauve. Les pattes sont entièrement jaunes, avec les tarses bruns. L'abdomèn est allongé, finement ponctué, avec les prenier, second et troisième segments jaunes dessus et dessous, et bordés de nair en arrière; le quatrième est noir dessus et dessous, avec une large bande jaune au milieu échancrée en avant; le cinquième est également noir, avec les côtés et deux petites taches en dessus jaunes; le sixième est encore noir, avec deux petites taches jaunes et une épine de chaque côté aux angles postérieurs. Ces deux segments sont noirs en dessous, ainsi que le septième qui est petit, noir, bifurqué en arric̀re de son arceau supérieur, avec le dessus de cet arceau fortement sillonné dans le sens de sa longueur, et l'arceau inférieur un peu plus avancé, formant une lame horizontale armée de quatre épines latérales et d'une pointe au milieu.

Comme on le voit, cette espèce est très - voisine de celle que Fabricius a nommée Thynnus dentatus; mais elle en diffère par la coloration de son abdomen.

II. Antennes plus longues que la tête et le corselet réunis, un peu plus minces vers l'extrémité, à articles cylindriques un peu courbés.

'THYNNE VARIABLE, Thynnus variabilis. Kirвт. - Niger; clypeo antice truncato; capite et thorace pilis flavis; marginibus prothoracis, scutello, metathorace et in quinque primis segmentibus abdominalibus quatuor maculis, flavis; pedibus fulvis alis croceis.

Thynnus variabilis. - LeAcH. Mss. Williain Sharp Mac-Leai. Cat. of ins. Collect. bi cap. Kivg., $\mathrm{n}^{\mathrm{O}} \mathbf{1 2 7}$ ( $\mathrm{r}$ ).

Thynnus dentatus. - Jurine. Nouv. Mćth. de class. des Hym., p. 179. - L. 26 mill. - Enverg. 48 mill.

Cette espèce, dont nous avons vu huit individus, nous a offert deux variétés chez lesquelles les taches de l'abdomen sont étendues et confondues ensemble sur les premier, deuxième et troisième segments. Celles des quatrième et cinquième sont un peu plus grandes quc dans les individus ordinaires, mais elles ne se touchent pas; et les sixième ct septic̀me scgments sont entièrement noirs, comme dans les autres, caractère qui semble constant dans cette espèce. Nous avons aussi rcconnu un individu qui, au premier coup d'œil, aurait pu être rangé, comme variété, dans cette espèce, mais qui, par suite d'un examen plus attentif, doit en être distingué, à cause de la forme de son labre et de la coloration en jaune des deux derniers segments de son abdomcn, caractères que nous n'avons trouvés dans aucune des variétés du Thynnus variabilis. Comme la dcscription que donne Kirby de cette espèce ne se rapporte pas en tous points aux individus quc nous possédons, et quiil est probablc quill a décrit une variété qui nous est encore inconnuc, nous allons la reproduire en entier, avant de donner la description des

(1) Il cite, à tort, comme synonyme de cette cspèce lè Thynnus dentatus, Fab. 
individus que nous considérons conme types spécińques et avant de faire connaìtre les variétés quc nous en distinguons, et l'espèce qu'on aurait pu confondre avec les individis types.

Thynnus variabilis ( I). Kırby.-Descr. Ins. Nov.-Holl., Trans. Lin. Soc., t. XII, p. 476. T. rufus, nigro-maculosus, abdomine atro; segmentis quinque anticis suprà et infrà Raso-maculatis. - Long. corp. I 3 lin.

Corpus fire lineare, mollissime sed vix dense fulvo pubescens. Caput flavum; vertice macula magna angulata nigra. Antennce thoracis fere longitudine, sctacece, nigree. Truncus subglobosus, suprà fulpus; anticc fasciis duabus vitta intermedia connexis, nigris, disco nigro; lineolis duabus obliquis rufis, subtus fulvus, spatio inter pedes primi paris et posteriorcs nigro utrinquc fulvo strigoso. Pcdes rufo-fulvi. Alce corpore longiores, fuscescentes. Abdomen ovato-lanceolatum, vel fere cuneiforme, nigrum, segimento primo favo; apice maculis duabus, crucequc, nigris, intcrmediis quatuor nigris; maculis quatuor flavis transversc digcstis. Venter segmentis antice fascia flava, ultimis interruptis, anali mucronato (2).

Actuellement nous allons tâcher de donner une description plus complc̀te de cette espc̀ce, en commençant par les individus que nous regardons comme types.

La tête est un peù plus étroite que le thorax, uı peu aplatie d'avant en arrière, finenent chagrinée, velue, noire; le chaperon et le bord des yeux, cn avant et en arrière, jusqu'aux deux tiers de leur hauteur, sont d'un jaune un peu orangé. Il y a encore deux petites taches de cette couleur entre les antennes; nuais le dessous de la tête, une partie du front an-dessous des antennes et toute la partie supérieure sont noirs; en un mot, il y a plus de noir que de jaune, et il serait inexact de dire que la tête est jaune, tachée de noir. Les antennes et les yeux sont noirs; les antennes sont au moins aussi longues que la tête et le corselet réunis, filiformes ct un peu effilées vers le bout. Les mandibules sont jaunes, avec l'extrémité bidentée, noire. Le chaperon est un peu bombé en avant, avancé, très-faiblement ćchancré ou arqué en dedans, de chaque côté, et coupé droit en avant, ce qui laisse un peu voir le bord antérieur du labre.

Le thorax est grand, bombé, très-finement chagriné, couvert d’un duvet jaunâtre assez épais; il est noir, tachć de jaune (ou jaune taché de noir, car ces deux couleurs occupent à peu près autant d'espace, et ce n'est que dans la variété que nous décrivons plus bas qu'on peut dire exactement qu'il est jaune taché de noir). Le prothorax est court, tronqué au bord antérieur, avec les angles latéraux bicn sentis, un peu arqué au hord postćrieur; il est noir, avec les bords antérieur et postérieur jaunes. Le mésothorax est également noir; le bord postérieur de l'écusson est jaune jusque près des ailes; cet écusson, qui cst assez bombé, offre deux taclıes jaunes placées latéralement et en arrière, et l'on voit, à l'insertion des ailes inférieures, deux petites stries de la même couleur qui vont se réunir en angle aigu juste à l'attache de l'aile. Les ptérygodes ou pièces

(I) $\mathrm{Y}$ adopt this name from the MIss. of Dr. Leach, who observes that this species varies considerably. He possesses four varieties, and M. Macleay a fifth.

(2) Descr. of Several new. species of ins. collected in New-Holland by M. Robert Brawn. Trans. Lin. Soc. T. XII, p. $476, \mathrm{n}^{\circ} 30$. 
mobiles qui recouvrent l'insertion des ailes supérieures, sont également jaunes. Tout le reste de la surface dorsale du mésothorax reste noir; l'on voit de chaque côté, et en avant, deux larges impressions un peu divergentes qui sont occupées par un duvet plus serré et jaunâtre; les côtés du mésothorax sont marqués de deux petites taches triangulaires, l'une située sous les ailes supérieures, et l'autre sous les ailes inférieures, très-près d'elles. Le dessous est entièrement noir. Le métathorax est jaune en dessus, avec le bord antérieur noir; cette bordure noire est très-étroite au milieu, et se dilate en un angle rentrant de chaque côté : le milieu de son bord postérieur, où vient s'insérer l'abdomen, est un peu taché de noir; le dessous est noir et entièrement occupé par les lianches. Les ailes sont grandes, à nervures d'un brun fauve; elles sont teintes d'une eouleur jaune assez foncée, surtout les supérieures. Les pattes sont d'un fanve un peu jaunâtre, avec les hanches noires largement tachées de jaune en avant.

L'abdomen est noir luisant, à peine plus long que la tête et le corselet, plus large en avant, un peu déprimé en dessus, un peu élargi sur les côtés, et terminé en pointe en arric̀re; chaque segment, qui est très-lisse et sur lequel on voit quelques points épars et peu marqués, offre en arrière un petit pli transverse. Le premier est marqué en avant, dans la portion tronquée, de deux taehes d'un janne pâle, placées très-près l'une de l'autre au milieu, et en dessus il a quatre autres taches du même jaune, dont les plus extérieures sont in peu allongées et plus petites, et les supérieures, assez distantes l'une de l'autre, sont d'une forme arrondie, beaucoup plus grandes, et touehent les latérales par leur côté externe. Les quatre segments suivants ont, au milieu, quatre taches semblables, diminuant un peu de grandeur vers l'arrière; le sixième segment n'a que deux petites taches sur les bords, et le dernier est entièrement noir; celui-ci est brusquement penché en bas, arrondi en arrière, garni de quelques gros points enfoneés ; l'arceau inférieur est un peu plus saillant, et se termine en une pointe simple assez courte et droite. Le dessous de l'abdomen est noir; le premier segment a une tache janne triangulaire au milieu; le second offre une grande bande transverse, profondément échancrée en arrière et au milieu, et les troisième, quatrième et einquième ont chacun deux grandes taches de la même couleur.

La variété A diffère du type parce que le jaune occupe la plus grande étendue; on peut dire que sa tête est jaune avec le vertex seulement noir. Les bordures jaunes dı prothorax sont si larges, qu'elles ne laissent plus entre elles qu'un très-petit filet noir. Le mésothorax a toute la partie postérienre jaune, ainsi que les côtés près des ailes, en sorte qu'il ne reste de noir qu'un espace carré situé au milien et an térieurement, entre les ailes supérieures, et encore cet espace est-il occupé par denx taches jaunes allongées, longitudinales, et se touchant au milieu et en arrière. Les côtés du mésothorax sont occupés par de grandes taches jaunes et il n'y a que le dessous qui soit entièrement noir. Le métathorax est tout jaune dessus et dessous; il a seulement deux petites taches noires placées derrière l'éensson du mésothorax. Les hanches sont entièrement jaunes; les ailes ne diffèrent en rien de celles du type.

L'abdomen est luisant; son premier segment est entièrement jaune, avec quatre trèspetites taches noires an bord supérieur de sa troncature antérieure, et trois autres

royage de la Coquille. - Z. Tom. 11, Part. 11. ${ }_{1^{\mathrm{re}}}$ Drv. 
taches transverses près de son bord postéricur. Les second et troisième segments sont encore jaunes, avec le bord postérieur marqué d'une ligne noire étroite, formant trois dents qui remontent vers la base sans l'atteindre, surtout celle du milieu qui est plus courte dans le second segment. Le quatrième segment est noir, avec le bord externe et une large tache jaune de clıaque côté; le cinquième est senblable, mais les deux taches supéricures sont beaucoup plus petites. Le sixième est noir et n'a que les deux petites taches latérales; enfin le septième et dernier est tout noir. Le dessous des quatre premiers segments est jaune, avec le bord postérieur noir, prolongé un peu au milieu. Le cinquième est noir et n'a quc deux taches jaunes triangulaires à la base. Les sixième et -septième sont sans taches et entièrement noirs.

L'individu qui a servi à Jurine pour établir son genre Thynne, n'était qu'une variété de cette espèce; la description qu'il en donne ne permet pas d'en douter.

Le Thynne variable n'est pas rare à la Nouvelle-Hollande, car on en trouve quelques individus dans toutes les collections qui viennent de ce pays.

THYNNE SEMBLABLE, Thynnus affinis. Gǘr. - Niger; clypeo porrecto, antice rotundato; capite et thorace pilis flavis; marginibus prothoracis, scutello, metathorace et in quinque primis segmentibus abdominulibus quatuor maculis, flavis; pedibus fulvis; alis croceis. - Long. 27 millim. Enverg. 53 mill.

Cette espèce est assez semblable à la précédente pour que, au premier aspect, on ne l'en distingue point; mais, après un examen attentif, on voit qu'elle en diffère notablement, en ce que les deux derniers segments de l'abdomen sont tachés dejaune, ce que nous n'avons jamais observć chez l'autre, et surtout par la forme du bord antérieur de son chaperon qui est arrondi et non tronqné en travers, comme dans le T.variabilis.

Sa tête est noire, avec les mandibules, le chaperon, le bord antérieur des yeux, jusqu'ì leur sommet, et les côtés derrière eux, jaunes. Il y a aussi une petite tache jaune au-dessus de chaque antenne. Les mandibules ont le bout noir, on voit une tache triangulaire noire au milieu du chaperon qui est très-bombé en avant, trèsprofondément échancré sur les côtés, et saillant et arrondi en avant, de manière à recouvrir presque entièrement le labre. Les antennes sont semblables à celles du précédent, noires. Le corselet est grand, couvert de poils blanchâtres. Le prothorax est noir, largement bordé de jaune 'en avant et en arrière, avec les côtés entièrement de cette couleur. Le mésothorax est également noir, finement pointillé, un peu luisant; il a dans sa première moitié quatre lignes longitudinales jaunes, un peu convergentes en arrière; la portion qui précède l'écusson est marquée de deux taches ovalaires et grandes, et son bord postćrieur est finement liséré de jaune; enfin l'écusson est jaune en arrière, avec une pctite tache de chaque côté. Les flancs du mésothorax ont de grandes taches jaunes en crochets et le dessous est noir. Le inétathorax est noir, avec une grande tache longitudinale étranglée au milieu et dilatée en haut, placée sur la ligne mćdiane; ses côtés ont aussi une grande tache jaune qui en occupe presque toute l'étendue. Les ptérygodes sont jaunes et ont deux petites taches brunes; les 
ailes ont les nervures d'un brun jaunâtre; elles sont transparentes, et les supérieures sont légèrement lavées de jaune fauve. Les pattes sont fauves, avec les hanches noires presque entièrement occupées par des taches jaunes.

L'abdomen est un peu plus long que le corselet, noir luisant. Le premier segment a une grande tache arrondie en avant et quatre taches en dessus, jaune d'ocre. Les cinq suivants ont quatre grandes tachcs en dessus de la mêmc couleur, et le septic̀ne est entièrement jaune, avec une petitc tache brune au milieu. Ce dernier segment est arrondi en arrière, et son arceau inférieur se termine en une pointe simple et peu saillante. Le dessous de tous les segments est jaune, avec une tache noire de chaque côté.

Ce bel Hyménoptère vient du port du Roi-Georges, à la Nouvelle-Hollande.

THYNNE A AILES OBSCURES, Thynnus obscuripennis. GuÉr. - Niger albopilosus; abdomine supra brunneo-rufescente; alis branneis, nervulis nigris, anterioribus obscurioribus; primo segmento abdominis tricarinato infra et ultimo rotundato, ano spinoso, lateribus unidentato. - Long. 28 millim. Enverg. 55 mill.

Sa tête est de la largeur du thorax, noire, chagrinée et velue; les yeux sont d'un jaune pâle. Les antennes, dont nous ne connaissons que les quatre premiers articles noirs, doivent être entièrement de cette couleur. On voit au milieu de leur iusertion une petite saillie bidentée; le chaperon, qui est tronqué en avant, les parties de la bouche et les mandibules, jusque près de l'extrémitć, sont d'un brun-rougeâtre. Tout le corselet est noir, chagriné et couvert d'assez longs poils blanchàtres ct serrés. Les ailes ont leurs nervures noires; les inférieures ont une très-légc̀re teinte brune enfumée, mais les supérienres sont très-obscures dans toute leur étendue. Les pattes sont noires, velues. L'abdomen est de la largeur du thorax, à peu prc̀s de sa longucur; il est sans poils, finement ponctué, noir, avec lc dessus de tous les segments d'un roux obscur; cette couleur occupe presque entièrement l'arceau supérieur de chaque segment, qui n'a de noir qu'au bord latéral. Le premier segment offre en dessous trois fortes carèncs longitudinales; le dernier est arrondi en arrière en dessus, et terminé en une pointe courte en dessous; la base de ce segment présente en outre une petite dcnt de chaque còté.

Cet insecte se trouvait parmi d'autres individus provenant du voyage de Péron autour du monde; il était sans indication de localité et en très-mauvais état, mais il est probable qu'il a été trouvć à la Nouvelle-Hollande.

THYNNE A VENTRE ROUXX, Thrnnus rufiventris. GuÉR. - Niger, griseo-pubescens; in margine posteriore thoracis fascia lata flava; abdomine pedibusque fulvis; alis croceis nitidis. - Long. 27 mill. Enverg. 50 mill.

Sa tête est plus étroitc que le corselet, velue, noire, fincment chagrinée. Les antennes sont noircs, aussi longues quc la têtc et lc corselet réunis, un peu plus. minces vers le bout; l'intervalle qui sépare leur insertion, le bord des yeux en avant et en 
arrière, le chaperon, la bouche et les mandibules sont jaunes; ces dernières ont seulement l'extrémité noire. Le chaperon est tronqué en avant. Lé corselet est noir, finement chagriné, couvert d'un duvet jaunàtre assez serré. Le prothorax a le bord postérieur largement bordé de jaune. Les côtés de son bord antérienr ont une petite saillie assez avancée et en forme de dent, vue en dessus. Les ptérygodes et les nervures des ailes sont d'un jaune-roussàtre; toute la surface de celles-ci est teinte de cette même couleur, tant aux antérieures qu'aux postérieures. Les pattes sont grandes, d'un jaune un peu roussầtre, avec les hanches seulement noires. L'abdomen est plus étroï et plus long que le thorax, d'un roux un peu brunâtre en dessus et en dessous, à l'exception du premier segment qui offre en dessous une grande tache noire. Le dernier segment a son arceau supérieur arrondi en arrière, et l'inférieur terminé en pointe un peu courbée en haut, de colleur noire.

Ce Thynne vient du Port-Jakson.

THYNNE ANNELÉ, Thynnus annulatus. KIRBx. - T. fulvcscente-villosus; thorace obscure-ferrugineo, nigro maculoso; abdomine flavo segmentis utrinque annulo nigro. Kerby, Descr. Ins. Nouv.-Holl., Transact. Lin. Soc., t. XII, p. 476 . - Long. corp. i 5 lin. I/2.

Corpus nigrum, pube densa satis fulvcscenti vestitum. Caput subtriangulare; ore favo. Clypens favus, postice macula dorsali longitudinali subcampanulata nigra. Antenna nigrae. Truncus oblongus, quadrangulus, fulvus; maculis quibusdam obscuris dorsalibus nigris. Pedes fulvi; coxis posterioribus basi nigris. Alo corporis fere longitudine, fuseescentes. Abdomen lineari-lanceolatum, basi retusum, apice deflexum, flavum; segmentis apice annulisque duobus latere exteriori interruptis, nigris. Pedeo macula nigra. Venter segmentis utrinque lunula, strigaque intermedia, nigricantibus; ultimo spina acuminata armato.

Comme nous n'avons pas vu cette espèce, nous copions textuellement la description qu'en a donnée Kirby, dans son Mémoire sur les insectes de la Nouvelle-Hollande.

THYNNE AUSTRAL, Thynnus australis. Borsd. - Fuscus; capite thoraceque cinereo-villosis; abdomine fulvo nigro sex-annulato; alis diaphanis subfumosis. - Boisd. Voy. Astrol. Zool., t. V, p. 655, pl. I 2 , fig. 2.

Il est d'un brun-noirâtre, avec le corselet et la tête recouverts d'un duvet assez serré d'un gris In peu jaunâtre. Celle-ci est un peu moins velue antérieurement. Les antennes sont noires; les yeux et la bouche sont jaunâtres. L'abdomen est d'un jaune fauve, avec des anneaux noirâtres qui l'entourent complétenient. Les cuisses sont noirâtres, avec les jambes et les tarses d'une couleur jaunâtre. La base de l'abdomen est d'un noir luisant en dessous. Les ailes sont transparentes, d'une teinte légèrement enfumée. Il se tronve au port Western.

N'ayant pas vu cette espèce, nons avons dû reproduire en entier la description qu'en donne M. Boisduval. Nous pensons qu'elle diffère peu du Thynnns annulatus de Kirby, si ce n'est pas la même espèce. 
THYNNE A VENTRE JAUNE, Thynnus flaviventris. Guír. - T. niger pilis albis indutus; clypeo basique mandibularum et quatuor primis segmentibus abdoninalibus flavis; alis hyalinis flavescentilus; ultimo segmento abdominis tridentato. - Long. 17 mill. Enverg. 32 mill.

Tête noire, finement chagrinée, garnie de poils blancs, avec le chaperon jaune et les mandibules fauves à extrémité noire. Thorax noir couvert d'un duvet blanc assez serré. Ailes transparentes à nervures brunes et à cồte très-épaisse; les supérieures légèrement teintées de jaune. Pattes noires, couvertes de duvet blanc. Abdomen noir, avec le dessus des quatre premiers segments d'un jaune orangé. Le dernier segment est terminé par une pointe assez allongée, à la base de laquelle il y a de chaque côté une autre petite pointe.

Cette espèce vient de la Nouvelle-Hollande. Il y en a un seul individu sans antennes au Muséum de Paris.

THYNNE ÉCHANCRÉ, Thynnus emarginatus. FABR. - T. abdomine nigro; segmentis fascia interrupta flava, scutello emarginato. - FABR., Ent. Syst., t. II, p. 24亿, $\mathrm{n}^{\circ}$ 2. - Donova , Epitome Ins., etc., avec figure.

Statura omnino pracedentis (T. dentatus) at paulo minor. Antennce cylindricce, nigra. Caput flavum lineis duabus frontalibus strigaque verticali nigris. Thorax planus, obscure ferrugineus, antice striga flava, posticc strigis duabus atris. Scutellum late cmarginatum. Ahdomen nigrum, primo segnento et ultimo imnaculatis, reliquis fascia in medio interrupta, flava. Anus dentibus septem.

Hab. in NovarHollandia. Mus. Banks.

THYNNE ABDOMINAL, Thyrnus abdominalis. FABR. - Niger, abdonine ferrugineo, scutello emarginato. - FaBr., Ent. Syst. Em. et auct., etc., t. II, p. 245, no 3 (I793).

Medius. Caput nigrum, parum cinereo-pubescens. Thorax niger, scutello plano, emarginato. Abdomen totum ferrugineum, immaculatun ano integro. Ala nigra. Pedes nigri.

Hab. in Africa rquinoxiali; Mus. dom. Banks.

THYNNE ENTIER, Thynnus integer. $\mathbf{F}_{\mathbf{A B}}$. - Ater, abdominis segmentis margine villoso-cincreis, ano integro. - FABR., Syst. Entom., p. 36o, $\mathrm{n}^{0} 3(\mathbf{1} 775)$, et tous ses autres ouvrages.

Thynnus integer. - Dovov., Epitome Ins., etc., avec figure.

Prcecedentibus minor. Antennce nigrce. Caput nigrum, fronte tomento cinereo-pubescente. Thorax ater, immaculatus, scutello truncato, obtuso. Abdonen cylindricum segmentis in medio atris margine omni villoso cinereo. Anus integer, aculeo brevi, recurvo.

Hab. in Nov.-Holl. Mus. dom. Banks.

La Scolia 7 -cincta. - FABR., Ent. Syst., t. II, p. $237, \mathrm{n}^{\circ} 36$, pourrait bien appartenir au genre Thynnus. 
La Typhia radula, FaBr., Ent. Syst. II, 226, $n^{\circ}$ I 1 , est peut-être aussi un Thynnus.

THYNNE A TACHES JAUNES, Thynnus flavo-guttatus. GuÉr. (Thynnus Variabilis? foem. Gúńr.) - Fulvas; antennis basi, mandibulis et abdomine supra nigris, quinque primis segmentis abdominalibus quatuor maculis flavis.

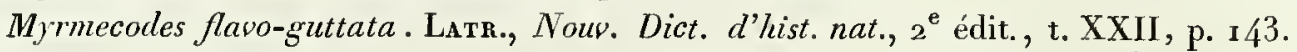
— Long. 23 millim.

La tête est d'un rouge ferrugineux, arrondie, un peu.plus large en haut, aplatie d'avant en arrière, couverte de gros points enfoncés assez distants. Les yeux sont petits, ronds et noirs. Les mandibules sont noirâtres; le premier article des antennes est brun et les suivantș jaunâtres.

Le corselet cst rouge, luisant, couvert de gros points assez distants entre eux; ses côtés sont tronqués carrément, ainsi que le bord postérieur du métathorax; il est un peu noins large que la tête, de la même largeur en avant et en arrière, et plus rétréci au milieu. Le prothorax et le métathorax sont à peu près de même étendue; c'est le mésothorax qui est le plus court et le moins large. Les pattes sont assez grandes, fortes, dentées et velues, avec les cuisses comprimées et épaisses au milieu, et les tarses eiliés ct propres à fouir.

L'abdomen est du double plus large que le corselet, tronqué en avant, un peu rétréci en arrière, un peu aplati et de la forme de celui des Th. variabilis et affinis. Il est composé de six segments. Les cinq premiers sont noirs en dessus, avec le bord un peu fauve, très-luisants; le premier est faiblement ponctué, avec le bord postérieur marqué de quelques plissures; le second est en entier occupé par des stries transverses qui ne vont pas jusqu'aux taches jaunes latérales, les autres sont simplement garnis de petits points cnfoncés très-distants entre eux; ces cinq segments ont chaeun au milieu quatre taches jaunes assez grandes, les latérales sont oblongues et placées près des bords des segments; les intermédiaires, qui se voient seules en dessus, sont rondes. Le sixième et dernier segment est rouge, beaucoup plus étroit, eomme implanté dans le préeédent, brusquement tronqué en arrière, garni de stries qui partent du bord postérieur et suivent son contour parallèlement. Le bord postérieur de l'arceaú supérieur de ce segment est arrondi et avancé au milieu, avec une dent assez saillante de chaque eòté ; l'arceau inférieur est simplement arrondi. Le dessous de l'abdomen est rougeâtre, un peu velu, avee le bord postérieur des segments bordé de cils jaunâtres.

Ge bel insecte vient du Port-Jakson.

'IHYNNE APTÈRE, Thynnus apterus. Gú́R. - Myzine aptera, picea, abdominis segmentis maculis quatuor flavis. OLIv. Encycl. méth. Ins., t. VIII, p. I37.

Cette espèce, que Latreille croit devoir rapporter, comme variété, à sa Myrmecodes flavo-guttata, en semble cependant assez distincte, elle a été décrite par Olivier, dans l'Eneyclopédie méthodique, sous le nom de Myzine aptera. Voilà sa deseription : 
Elle paraît différer peu de la Tiphie pédestre, décrite par Fabrieius dans le Muséum de Banks. Elle est de la grandeur de la Myzine maculée, et l'abdomen est plus renflé. Les antennes sont eourtes, de la eouleur du eorps; le seeond artiele est enchâssé dans le premier et est à peine apparent. Les taches latérales sont un peu plus petites que les deux dorsales. La tête est pointillée. Les yeux sont petits, ovales, un peu distants des antennes. Le eorselet est pointillé, un peu étranglé au milieu par deux lignes transverses, enfoneées. Le sixième anneau de l'abdomen n'a point de taches; il est strié, et terminé par une valvule arrondie et par deux épines plaeées une de ehaque eôté. Les pattes sont eourtes, velues. Les jambes sont un peu épineuses. Elle se trouve à la Nouvelle-Hollande. - Du eabinet de M. Labillardière.

THYNNE PÉDESTRE. Thynnus pelestris. Guér. - Aptera, nigra, Ravo-variegata, thorace compresso. FAB.

Tiphia pelestris. Fab. Syst. Ent., p. 354, n $8 .(\mathrm{I} 775)$.

Mutilla myrmecodes. Lamarcк. Anim. sans vert., t. IV, p. Ioo.

(Thynnus zonatıs? foem. Guśr.)

N'ayant pas vu eette espèce, nous allons transerire la deseription qu'en a donnée Fabrieius dans son Systena Entomologiae, et qu'il a reproduite dans ses publications postérieures.

Antenna breves, nigrce, articulo primo latiore. Caput supra nigrum, fronte flava, snbtus flavun. Thorax latcribus compressus, niger, dorso Ravo, arcu nigro. Pectus flavum. Abdonen Ravun, prioribus quatuor segmentis nigris, fascia lata fava, secunda interrupta; quartum segmentunu nigrum, macula latcruli flava. Anus prominens, deflexus, bivalvis, valvulis ovatis, obtusis aculeoque brcvi, acutissimo. Pcdes breves, Ravi, femoribus compressis, carinatis nigris.

Habitat in Nova-Hollandia. Mus. Banksianum.

THYNNE DE GRAY, Thynnus Grayï. Guér. - Myrmecodes anstralis. Leaeh, Gray, Kingd. Aninu. Ins., t. II, p. 5 I 6, pl. 7 1, f. 3.

(Thyınus annulatus? foem. Gór.)

Voilà tout ee qu'en dit M. Gray: In the geñus Mrrurecodes, of Latreille, we figurc a spccies wich Dr. Leach has named Australis. It fulvous, the head and thorax reddish brown, and the abdomen with transverse arch bands of black. This insect is from NewHolland.

Nous avons été obligé de changcr le nom de cet insecte, parce qu'il y a déjà une espèce nommée Australis par M. Boisduval. 


\section{Genre THYNNOIDE, Thynnoides. GuÉr.}

Les insectes qui composent cc genre ne diffèrent pas beaucoup des vraies Thynnes, mais cependant leur facics et quelques-uns de leurs caractères essentiels autorisent à les cn séparer, au moins comme sous-genre. Voici les caractères que nous assignons à ce groupe :

Tête rondc, un peu aplatie d'avant en arrière, de la largeur du thorax; yeux ovales, entiers; trois petits ycux lisses sur lc vcrtex.

Antennes filiformes, un peu plus longues que la tête et le thorax; le premier article assez long, un peu plus épais à l'extrémité et tronqué obliquement, le second très-court, le troisic̀me moins long que le premier, obconique, les suivants un peu plus longs, égaux entre eux, eylindriques et un peu courbés, les derniers diminuant un peu d'épaisscur jusqu’à l'ex trémitć.

Chaperon avancé, tronqué et un peu échancré au bout; labre saillant, arrondi et cilié en avant.

Mandibules grandes, arquées, bidentées au bout.

Mâehoires grandes, allongées, ayant leurs lobes réunis et n'en formant qu'un seul qui est arrondi au bout, eilié et dilatć en dcdans à la base. Le support de ces mâchoires est corné, arrondi en dedans, et garni de très-longs cils dirigés en dedans et en bas. C'est là le caractère le plus saillant de ce genre; il se retrouve, aussi développé, dans les trois espc̀ces que nous avons examinées. Palpes maxillaires de la longueur des mâchoires, de six articles prcsque égaux en longuenr, obconiques; les trois premiers plus épais, ayant l'extrémité intcrne un peu dilatée en dedans, les trois derniers un peu plus grêles.

Lèvre allongée, arrondie sur les côtés et rétrécie en arrière, avcc les paraglosses assez saillantes, membraneuses et arrondies; palpes labiaux plus courts que les maxillaircs, de quatre articlcs ćgaux, dont les trois premiers obconiques et le dernier ovalaire.

Ailcs supérieures ayant une cellule radiale grande; atteignant presque l'extrémité de l'aile, et quatre cellules eubitales allongées, presque égales, avec la prenière presque divisée en deux par un commencement de nervure vers l'extrémité. Les devix nervures réeurrentes atteignant le dessous des seconde et troisième cellules cubitales.

Pattes grandes, assez fortes, avec les crochets des tarses bidentés.

Abdomen de sept segments, allongé, très-arrondi en dessus, aplati en dessous, avec tous les segments assez fortement ćtranglés à leur base. Anus terminé par une pointe courte, courbée en bas, et deux petits tubercules latéraux.

Nons avons vu, dans la collection du Muséum, dcux espèces aptères ayant de grands rapports avec les femelles que nous rapportons au genre Thynnus, mais dont les palpes maxillaires ont leurs six articles bien développés, et les trois premiers un peu plus épais, eonme chez les 'Thynnoïles. Ne pourrait-on pas penscr que ces femelles appartiennent aux Thynnoïdes? Nous les décrirons à la suite de ce genre, en attendant des observations positives. 
THYNNOIDES A PIEDS FAUVES, Thynnoïdes fulvipes. GuÉr. - Niger, subvillosus, clypeo emarginato, flavo; mandibulis basi flavis; pedibus rubris; alis flavescentibus, nervulis atris. - Long. 2 r mill. Enverg. 34 mill.

La tête est de la largeur du corselet, noire, finement ehagrinée et un peu velue; le chaperon est un peu bombé, jaune jusqu'au-dessous de l'insertion des antennes; cette couleur se prolonge, au bord antérieur, jusqu'à toucher les yeux. On voit au milieu du jaune, et vers le haut, une petite taehe noire fourchue en avant, et, presque au milieu de la longueur de la partie jaune, un petit point noir peu arrêté; ce ehaperon a, de plus, le bord antérieur assez échancré. Les mandibules sont jaunes, avec l'extrémité noire. Le labre est jaune. Les yeux sont bruns. Les antennes sont entièrement noires.

Le corselet est noir, clıagriné, velu; l'écusson du mésothorax est un peu élevé en arrière, avec une faible fossette au milieu de cette saillie. Les ailes sont obscures, lavées d'une teinte brune-jaunâtre enfumée, avec les nervures d'un brun-noirâtre. Les pattes sont d'un fauve obscur, avec les hanches et les trochanters noirs.

L'abdomen est d'un noir bleuàtre, un peu ponctué, avec les segments étranglés à leur base; il est un peu plus étroit en avant et en arrière, velu, avec une rangée de cils assez longs et roides près du bord postérieur de chaque segment, en dessus et en dessous. Le septième a son arcean supérieur arrondi en arrière, rugueux; l'inférieur est plus saillant, terminé par une épine peu longue, à la base de laquelle il y en a deux beaucoup plus petites, ee qui fait paraitre l'anus tridenté.

Cette espèce vient du Port-Jakson.

THYNNOIDE A PIEDS ROUGES, Thynnoïdes rubripes. GuÉR. - Niger, subvillosus; clypeo margine anteriore flavo; mandibulis basi flavis; pedibus rubris; alis fulvescentibus; nervulis obscuris. - Long. 14 mill. Enverg. 24 mill.

Thynnus? rubripes. Atlas, Ins., pl. 8, fig. 9 .

Cette espèce pourrait être considérée comme une variété du Fulsipes, si l'on connaissait d'autres individus de taille moyenne formant le passage entre eux; mais nous ne possédons qu'un seul échantillon de chaque espèce, et la différence de taille est si considérable que ce motif, joint à la coloration de son cbaperon et des ailes, ne nous permct pas de réunir eet insecte avec le Fulvipes; nous allons donc en donner une description particulière. Sa tête est au moins de la largeur du corselet, noire, finement chagrinée et très-peu velne. Le chaperon est jaune en avant, mais cette couleur ne monte pas jusqu'à la base des antennes, et elle est encore échancrée au milieu par le noir qui s'avance sur la ligne inédiane. Le bord antéricur du ehaperon est droit ou à peine échancré, les mandibules sont jaunes, avec le bout noir. Les antennes sont noires.

Le thorax est noir, finement rugueux, un peu velu. L'écusson du mésothorax est moins saillant que chez l'espèce précédente, sans fossette au milieu. Les ailes sont teintées de jaune-roussâtre et moins obscures que chez le Fulvipes, avec les nervures brunes roussâtres. Les pattes sont d'un fauve vif avec les hanches et les trochanters noirs. 
L'abdomen est d'un noir bleuâtre, un peu ovalaire et semblable à celui de l'espèce précédente, mais il n'est presque pas velu, et n'offre pas de rangées de cils au bord postérieur des segments.

Du Port-Jakson.

THYNNOIDE BLESSÉ, Thynnoüles pugionatus. GuÉR. - Niger, albo-villosus; lata macula sanguinea in utroque latere mesothoracis; alis pallide brunneis, nervulis atris. Long. 15 mill. Enverg. 3 o mill. I/2.

La tête est noire, finement chagrinée, couverte de poils blancs, plus longs sur les côtés. Antennes longues, nöires. Chaperon noir, un peu échancré en avant, avec les côtés bordés d'une ligne jaune assez étroite. Mandibules noires, avec le côté interne seulement bordé de jaune.

Le corselet est noir, chagriné, velu; les angles antérieurs du prothorax sont très-saillants et forment, vus en dessus, dcux pointes assez aiguës; l'écusson du mésothorax est plus bombć que chez les deux autres espc̀ccs et même un peu saillant en arrière; les côtés du mésothorax sont occupés par une grande tache sanguine, ovalaire, allongée et oblique. Lcs ailes sont transparentes, un peu enfumées vers le bout des inférieures et sur presque toute la surfacc des supérieures, avec les nervures très-noires. Les pattes sont noires, velues.

L'abdomen est ovalaire, noir, à segments étranglćs, avec l'épine intermédiaire de l'anus un pen plus longue que chez les deux espèces déjà décrites; il est assez garni de poils blancs.

Cet insecte vient de la Nouvelle-Hollande.

Nous croyons devoir placer ici des insectes aptères, qui doivent être les femelles de quelqucs espèces du genre 'Thynnoïde, ou d'un genre qui viendra se ranger près de lui dans le niche groupe. Ces insectes sont tous de la Nouvelle-Hollande: l'un d'eux a été décrit sommairement par M. Westwood, dans les Proceedings de la Société zoologique de Londres, séance du 14 avril 1835 ; il en a constitué un genre distinct que nous adoptons provisoirement; nous reproduisons en entier cette description, et nous la ferons suivre de celle que nous avons faite, au Muséum de Paris, d'un individu mutilé de cette même espèce, et d'une autre qui est encore inédite.

Genus DIAMMA, Westw. (Fam. Mutillida.)

Corpus oblongum, nitidum, apterum. Caput subhorizontale, fere rotundatum. Mandibulce elongata, curvata, graciles, dentibus tribus minutis, internis. Antennce breves, convoluta, ad apieem graeiliores. Thorax elongatus, binodosus. Abdomen elongatum, eonvexum, segmentis basalibus subeoarctatis. Pedes breviuseuli, spinosi. Genus Myrmecodi affine. 
DIAMMA BICOLORE, Diamma bieolor. Westw. - Niger, purpureo cyaneoque nitens; antennis, pedibus, mandibulisque rufis, his ad apicem nigris. - Long. corp. lin. 9 I/2. - Hab. in Nova-Hollandia. In Mus. Westw.

Lindividu que nous avons vu au Muséum de Paris est long de I 7 mill. Sa tête est violette, comprimée d'avant en arrière, lisse et luisante, transversale vue en dessus, avec les yeux ovales; les mandibules sont courbées, fauves, avee l'extrémité noire; on voit deux petites taches rouges entre l'insertion des antennes.

Le corselet est plus de deux fois plus long que large, lisse et très-luisant. Le prothorax est de la longueur des deux autres segments réunis, plus large en avant, bombé en dessus; le mésothorax est fort court, étroit, sillonné en travers au milieu, et formant une espèce de nœud entre le prothorax et le inétatlorax; celui-ci est de la forme du prothorax, mais étroit en avant et plus élargi et tronquué en arrière. Les eôtés du prothorax et du métathorax sont comprimés. Les pattes sont fortes, d'un fauve vif, avec les cuisses un peu comprimées, les jambes et les tarses épineux. L'abdomen est à peine plus long que le corselet, violet, de six segments; le premier plus étroit, globuleux, court, le second brusquement plus large et un peu plus long; le troisième est de la mème grandeur; le quatrième un peu plus court et plus rétréei en arrière, et les cinquième et sixième très-courts et se rétréeissant pour se terminer en pointe; il y a un aiguillon au dernier segment.

De la Nouvelle-Hollande.

DIAMMA ÉPHIPPIGÈrE, Diamma ephippiger. Gǘr. - Apterus, niger, nitidus, lavigatus; mesothorace, metathorace pedibusque fulvis. - Long. 13 mill.

Quoiqu'il nous soit impossible de rapporter cette femelle à l'une des espèces du genre 'Thynnoïde, nous pensons qu'elle pourrait bien appartenir au fnlsipes ou au rabripes. Sa tête est d'un noir luisant, grande, en carré arrondi aux angles, lisse avec quelques points enfoncés; les mandibules sont fortes, bidentées et fauves au bout; le ehaperon est un peu avancé, tronqué carrément en avant, et donnant insertion à un labre presque caché en dessous, transversal, de la largeur de la troncature du chaperon. Les mâchoires ont leur support corné assez allongé, glabre; elles sont terminées par un grand lobe membraneux, paraissant divisé près de l'insertion du pa!pe. Celui-ci est assez eourt, de six articles presque égaux, et d'à peu près la longueur du support corné. La lèvre inférieure est oblongue, aussi de la même largeur dans toute son étendue, arrondie en avant, et donnant attache à deux palpes.courts, de quatre articles égaux. Les antennes sont de couleur fauve, un peu plus longues que la tête, avec le premier article plus gros et plus long que les autres, le second un peu plus court que les suivants, et le dernier ovalaire et un peu plus grand que ceux qui le précèdent. Les yeux sont petits, ronds et placés sur les còtés, et près de l'insertion des mandibules. Le prothorax est plus étroit que la tête, un peu plus long que large, très-rétréci en avant, lisse, avee quelques points enfoncés, et d'un noir luisant dessus et dessous. Le mésothorax est un peu plus étroit, beaucoup plus court, rouge en dessus et en dessous. Le méta- 
thorax est tout rouge, de la largeur du mésothorax à sa base; il s'élargit en arrière, et est à peu près de la grandeur du prothorax, tronqué et brusquement surbaissé postérieuremcnt, avec le bas de la troncature ùn peu prolongé au milieu pour donner attache à l'abdomen. Lcs pattes sont rouges, fortes, à cuisses comprimées, élargies et courbées, avec lcs jambes armées de fortes dents au côté cxterne et les tarses longs et ciliés. L'abdomen est entièrement noir, luisant, avec l'anus fauve; le premier segment est un peu plus ćtroit que les suivants; le dernier est fendu au milieu en dessus; l'arccau inférieur se termine en pointe obtuse.

Cet insecte vient de lîle des Kanguroo, à la Nouvelle-Hollande. Il est unique dans la collection du Musćum de Paris.

Cet insecte ne pourrait entrer dans le genre Myrmécode, tel que le caractérise Latreille; il en diffère essentiellement par le nombre et la grandeur des articles de ses palpes.

On rapprochera probablement de cette espèce le Betlyylus apterus de Fabr., Syst. Piez., p. $238, \mathrm{n}^{\circ} 7$, quand on pourra l'étudier d'après nature pour compléter notre travail nous allons reproduire la description quen donne cet auteur.

Bethilus apterus, niger, pedibus rufis. FAB., Syst. Piez., p. $238, \mathbf{n}^{\circ} 7$.

Statura et magnitudo praeedentium. Caput atrum, immaeulatum. Thorax segmentis tribus, intermerlio angustiore, niger. Abdomen pilosum, nigrum, segmentorum marginibus ferrugineis, nitidulis. Pèdes rufi.

Hab. in Nova-Cambria. Dom. Billiardière.

Genre ANTHOBOSQUE, Anthobosca. GuÉrin.

Têtc rondc, de la largeur du tlrorax, aplatie; yeux ovales, grands, entiers; trois petits. yeux lisses sur le vertcx.

Antennes beaucoup plus courtes que la tête et le thorax, filiformes, un peu effilées au bout, avec le premierarticle très-grand, le second petit, le troisième de moitié moins long que le premicr, obconique; les suivants un peu moins longs, cylindriques, avec les deux ou trois derniers un peu moins ćpais.

Chaperon peu avancé, avec le milieu un peu saillant, échancré. Labre très-petit, caché sous le chapcron.

Mandibules assez grêles, peu allongées, et peu courbées, terminées par dẹx dents assez fortes, dont la supérieure est la plus longue.

Mâchoires assez allongées, à lobe terminal arrondi et cilié, divisé en deux portions par une suture oblique. Palpes maxillaires un peu plus longs que la mâchoire, de six articles presque égaux, un peu obconiques.

Lèvre de la longucur des mâchoires, au moins quatre fois plus longue que large, échancrée aux angles antérieurs pour l'insertion des palpes, ayant les paraglosses et le lobe intermédiairc assez grands, membraneux. Palpes labiaux un peu moins longs que 
les maxillaires, de quatre artieles; le premier plus grand, un peu courbé, un peu épaissi au bout; les deux suivants égaux, obconiques, et le dernier de la même longueur, ovalaire.

Ailes supérieures ayant une cellule radiale grande, n’atteignant pas leur extrémité, et quatre cellules cubitales dont la première cst allongée, entière, sans appendice; la seconde, la plus petite, de forme triangulairc; la troisième grande, quadrilatère, et la dernière plıs petite et terminée par le bord de l'extrémité. Les deux nervures récurrentes s'insèrent au-dessous des seconde et troisième cellules cubitales.

Pattes assez grandes, fortes, avec les crochets des tarses très-arqués et bifides.

Abdomen allongé, un peu plus étroit en avant, arrondi à l'extrémité et assez aplati en-dessus.

ANTHOBOSQUE D'AUSTRALIE, Anthobosca Australasice. Guér. - Nigra; thorace, fasciis tribus abdominalibus interruptis, Ravis; pedibus favo-fuscis; femoribus anticis, nigris; alis hyalinis, anterioribus flavescentibus stigmate flavo.

Myzine? Australasia. Guḱr. - Atlas, Ins., pl. 8, fig. ıo. - Long. 16 mill. Enverg. 23 mill.

Sa tête est noire, finement chagrinée, avec le chaperon et le devant des yeux jaunes. Les mandibules sont fauves, avec une grande tache jaunc au côté externe, et l'extrémité des dents noirâtce. Le front, au-dessus des antennes, est garni de poils blanchâtres assez longs et dirigés en haut. Le thorax est finemcnt chagriné, noir; le prothorax est assez long, transversal, il offre au milieu, en dessus, une grande tache jaune, échancrée au milieu en avant, pointue sur les côtés, et de chaque côté, au-dessus de l'insertion des pattes antérieures, une autre tache jaune arrondie. Le mésothorax est un peu aplati au-dessus; il a, dechaque côté, une petitc carène élevée qui se termine entre l'insertion des premières et secondes ailes, et il offre au milieu une grande tache jaune de forme carrée; l'écusson, qui est peu saillant, présente une tache jaune ovale, sur sa division postérieurc. Les côtés du mésothorax ont encore, sous les ailes supérieures, une petite tache jaune arrondie. Le métathorax est orné de denx taches assez grandes, placées sur les côtés et d'une taclıe plus petite au milieu et en arrière. Les ailes sont transparentes, avec les nervures d’un brun jaunâtre; les supérieures sont légèrement lavées de jaunâtre. Les pattes sont d'un jaune fauve; les euisses des antérieures sont noirâtres à leur base, ct il y a une petitc taehe brune et fondue sous celles de la seconde paire.

L'abdomen est allongé, plus étrọit à la hase, noir peu luisant; le premier segınent est un peu rougeâtre sur les côtés, le second a une large tache jaune de chaque côté, ct touchant au bord antérieur; et les troisième et quatrième en ont chacun une plus étroite, située au milieu, et allant presquc le toucher sur la ligne médiane. Le dessous est entièrement noir.

Cet insccte vient du Port-Jakson. 
Nous croyons devoir placer ici, comme étant très-voisin des deux genres Anthobosca et Ornepetes, un insecte que nous n'avons pas vu, dont M. Westwood n'a donné qu'une courte description, et avec lequel il a fondé un genre propre; voici tout ce qui a été publié à son sujet :

\section{Genre ANODONTYRA, Westw. (Fam. Scoliida.)}

Corpus elongatum : abdomen articulis continuis, oblongo-ovatum, ad apicem inerne. Mandibula dente valido interno ante apiccn armato.

Palpi maxillares elongati 6 labiales 4-articulati.

Alarum nervi fere ut in Tengyra Sanvitali dispositi.

Obs. Tcngyris affinis : statura minus elongata quam in Tengyris ct Myzinibus.

Antenne graciles, $\mathbf{1} 3$-articulatce, articulo $2^{\circ}$ discreto.

Anodontyra tricolor, Westw. - Westw. Proceedings of the Zool. Society. of Lond. Part. III, I835, p. 7 I.

An. nigra; collari antice flavo lineato; segmentis abdominalibus $2^{\mathrm{do}}, 3^{\text {to }}, 4^{\text {to }}$ ad marginem posticum flavo, interrupte narginatis, subtus etian macula parva laterali ejusdem coloris notatis : tibits tarsisque testaceis; alis fulpo-testaceis, ante apicem nubilo fuscescenti notatis.

Long. corp. lin. 8 r/4. Exp. alar. lin. 14 r/2. - Hab. in Chili, In mus. dom. Hope.

\section{ORNEPĖTE, Ornepetes. GuÉr.}

Tête arrondie, déprimée en avant, yẻux ovales, entiers, trois petits yeux lisses.

Antennes filiformes, moins longues que la têtc et le corselet; avec le premier article plus épais, le second très-petit, mais bien apparent, les suivants égaux entre eux, cylindriques.

Chaperon très-saillant, rétréci et bidenté au milieu. Labre petit, caché sous le chaperon, un peu échancré au milieu et cilié cn avant.

Mandibules assez grandes, arquées, bidentées au bout, la dent supérieure plus longue que l'inférieure.

Mâchoires assez courtes, un peu dilatées au côté externe, à peine deux fois plus longues que larges, avcc le lobe supérieur arrondi, cilié, l'inférieur peu distinct et entièrement membraneux. Palpes maxillaires beaucoup. plus longs que les mâchoires, de six articles obconiques et inégaux; le prenier fort court, le second un peu plus long, les troisième et quatrième plus longs que le second, égaux, fortement obconiques et anguleux à l'extrémité internc, les deux derniers plus cylindriques, un peu plus longs.

Lèvre un peu moins longue que les mâchoires, un peu rétrécie en avant, à peine deux fois plus longue que large; palpes labiaux de moitié moins longs que les maxil- 
laires, de la longueur de la lèvre à peu près, avec le premier article le plus long, obconique, et les trois autres épaissis au milieu, les $2^{e}$ et $3^{e}$ dilatés et un peu anguleux au côté externe, et le dernier ovalaire.

Ailes supérieures ayant une cellule radiale très-allongée, étroite et atteignant presque le bout de l'aile; quatre cellules cubitales allongées, dont la première est coupée en dedans par une petite nervure qui n'atteint cependant pas le point épais. Les deux nervures récurrentes vont s'attacher sous les seconde et troisième cellules culitales.

Pattes de grandeur moyenne, peu fortes, avec les crochets des tarses bidentés.

Abdomen allongé, presque parallèle sur les côtés, avec les extrémités rétrécies.

ORNEPÉTE A TÊTE NOIRE, Ornepetes nigriceps. Guír. - Niger, margine anteriore prothoracis, scutello, in abdomine fasciü interruptis sex et limbo inferiori femorum, flavis. Alis hyalino-opacis. - Long. 14 mill. Enverg. 22 mill.

La tête est entièrement noire, très-finement chagrinée et peu velue. Les antennes sont noires. Les mandibules ont une grande tache jaune à la base, et leur extrémité est noire. Le thorax est très-fincment chagriné, un peu velu, noir, avec le bord antérieur du prothorax largement bordé de jaune; le mésothorax a deux pctites carènes élevées devant l'insertion des ailes; son bord postérieur offre une grande tachc jaune de forme carrée, et son écusson est bordé de la même couleur. Les ptérygodes sont jaunes. Les ailes sont demi-transparentes, blanchâtres, à nervures presque fauves. Les pattes sont noires et le dessous des cuisses antérieures est seul jaune. L'abdomen cst noir, peu luisant, finement ponctué; le premier segment offre deux pẹtits points jaunes, situés sur les còtés et un peu en arrière; les trois suivants ont au milieu deux taches allongées et transversales jaunes, échancrées sur les côtés et en avant, et se touchant presque sur la ligne médiane; les cinquième et sixième segments ont leurs taches moins longues et plus arrondies. Le dessous est tout noir.

Cet insecte a été pris au Clıili, par M. d'Urville.

\section{ÉLAPHROPTÈRE, Elaphroptera. Guér.}

Ce genre, entièrement composé d'espèces américaines, pourrait à la rigueur en constituer au moins deux, mais les caractères qu'il faudrait employer, pour arriver à les distinguer, seraient alors si minutieux que nous n'avons pas osé nous jeter dans leur exposition; voici les caractères généraux que nous lui assignons:

'Tête rondc, portée sur un très-faible avancement du prothorax. Yeux ovales entiers. Trois petits yeux lisses sur le vertex.

Antennes filiformes, un peu effilées vers lc bout, plus longues que la tête et le corselet: le premier article plus épais, tronqué obliquement; le second petit, mais bien distinct et détaché du précédent. Les suivants presque égaux, cylindriques, courbés tons dı même còté. 
Chaperon n'étant point avancé entre les mandibules, fortement échancré au milieu, avcc les angles assez saillants de chaque côté. Labre saillant, transverse et ovalaire.

Mandibules grandes, arquées chez les uns, arquées et courbées en dedans et en dessous chez d'autres, terninées dans tous par deux fortes dents, l'inférieure étant large et tronquée chez quelques individus.

Mâchoires courtes, à peine deux fois plus longues que larges, avec le lobe supérieur plus grand, assez corné, divisé en deux parties par une suture oblique et membraneuse. Palpes maxillaires plus longs que la mâchoire, de six articles inégaux; le premier est de plus de moitié plus court que le suivant; le second est obconique, allongé; les troisième et quatrième sont de la longueur du précédent, égaux, tronqués obliquement et très-renflés au bout. Les deux derniers sont égaux entrc eux et de la longueur des précédents; le cinquième est obconique, et le sixième cylindrique et arrondi au bout.

Lèvre courte, moins de deux fois plus longue que large, un peu renflée au milieu, rétrécie en avant et en arrière. Palpes labiaux plus courts que les maxillaires, un peu plus longs que la lèvre dans quelques individus, un peu plus courts chez d'autres, de quatre articles inégaux; le premier long, obconique, les second et troisième égaux, plus courts, renflés au bout, le dernier ovalaire.

Ailes supérieures ayant une grande cellule radiale, allongée, étroite, atteignant presque l'extrémité de l'aile, et quatre cellules cubitales entières, avec la première divisée en dedans par une petite nervure qui ne touche pas tout à fait le point épais en arrière. Les deux nervures récurrentes s'insèrent au-dessous des seconde et troisième cellules cubitales, la seconde nervıre est souvent très-flexueuse.

Pattes grandes, robustes, avec les crochets des tarses bidentés.

Abdomen allongé, un peu plus épais au milieu, rétréci en avant et en arrière, avec lc dernier segment brusquement penchć en arrière et tronqué.

Ce genre se compose d'espèces américaines, qui ont toutes un facies assez semblable.

$\mathrm{I}^{\mathrm{re}}$ Division. Mandibules arquées de dehors en dedans, et pliées d'avant en arrière.

ÉLAPHROPTÈRE MI-PARTIE, Elaphroptera dimidiata. Guér. - Nigra, abdominc laevigato, fulvo, nitido; capite et thorace tomentosis, alis brunneis, sub-hyalinis. Long. 27 à 29 mill. Enverg. 48 à 50 mill.

Myrmosa dimidiata, HaLidaY, Descr. Ins. by. cap. King, trans. Lin. soc., vol. XVII, p. $328, \mathrm{n}^{\mathrm{o}} 46(\mathbf{I})$.

(I) M. Atra ; abdomine rufo; alis cyaneis. Mas. - Long. 13 1/2 lin. alov. $24 \mathrm{l}$.

Mas. Atra, villosa, antennis et pedibus concoloribus; antenne capitis et thoracis longitudine, articulis exterioribus curvatis, unde apex antennarum undulatus evadit. Ala castanex, cyaneo-micantes, abdomen thorace fere duplo longius, badium, nitidum, dorso fere glabrum.

It is possible this may be the Scolia rufiventris of Fabricius, of which there is no figure. It was taken by lieut. Graves in Chili. 
La tête est noire, finement chagrinéc, couverte de poils noirs assez serrés. Lcs antennes sont noires et les yeux bruns. Le corselet est finement clagriné, velu. On voit sur le mćsothorax deux petites carènes latérales, précédées en dedans d'un sillon asscz profond; son écusson porte, au ccntre, une petite élévation un peu fendue an milieu. Les ailes sont demi-transparentes, d'un brun obscur un peu plus foncé au milieu, surtout dans les supérieurcs; lcurs nervures sont presque noires. Les pattes sont grandes, entièrement noires, un peu velues. L'abdomen est plus long que la tête et le thorax, élargi au milieu, rétréci aux cxtrémités, aplati, lisse et luisant, sans poils audessus, d'un rouge fauve avec la base du premier segment noire; chacun de ces segments offre, près du bord postérieur, un petit pli transverse qui semble le diviser en deux articles. Le dernier est brusquement courbć en bas, et cette partie penchée est en carré long, rayée dans sa longueur, tronquće en arrière et un peu échancréc au milieu; l'arceau infërieur se termine en pointe qui déborde un peu au milieu de l'échancrure supéricurc et fait paraître l'anus tridenté.

Ce bel insecte vient du Chili.

ÉLAPHROPTĖRE A AILES PALES. Elaphroptera pallidipennis. Gú́r. - Nigra; abdomine lavigato, fulvo, nitido. Alis lyalinis pallide-flavis, apice violaceo-micantibus. — Long. 24 mill. Enverg. 42 mill.

Cet insecte est un peu plus petit que le précédent, nıais il lui ressemble sous tous les rapports ct pourrait bien n'en être qu'une variété. En effet sa tête, son thorax, les antennes et les pattes sont noirs, velus, et offrent lcs mêmes impressions; l'abdomen est également fauve, lisse et luisant, mais nous ne connaissons pas son dernier segment, qui manque à l'individu unique, sujct dc cette description; il ne diffère donc du dimidiata que par ses ailes qui sont transparentes, légèrement et uniformément lavées de jaune doré luisant et pâle, avec des reflets violets à l'extrémité, et clont les nervures sont d'un brun jaunâtre.

Cette espèce ou variété vient aussi du Chili.

ÉLAPHROPTĖRE NOIRE. Elaphroptera atra. Guér. - Nigra, pilis albis induta. Alis perlucidis, incoloribus, nervulis brunneis, stigmate nigro. - Long. 15 mill. Enverg. $2 j$ mill.

Tout son corps, ses antennes ct ses pattes sont noirs, garnis de poils blancs assez serrés. La tête est aplatie en avant, fincment chagrinéc, avec les ycux brinns. Le mćsothorax est également chagriné, il a de clıque côté une pctite carc̀ne longitudinale, et parallélement à cette carènc, un sillon asscz profond situć en dedans. L'écusson n'offre aucune éninence, les ailes sont incolores, transparentes, à nervures bruncs avec le point épais noir. La première cellulc cubitalc n'cst pas nettement, divisée par une petite nervure, dirigéc cn dedans et partant de la nervure qui la sépare de la seconde, on ne voit que la naissance de cette petite nervure assez bicn indiquée. L'abdomen est aplati, élargi au Voyage de la Coquille. - Z. Tom. II, Part. II. $1^{\text {re }}$ Div. 
milieu, lisse et luisant, garni de poils blancs en dessus; son extrémité postérieure est brusquement penchée en bas, tronquée au bout, et l'arceau inférieur cst terminé par une petite pointe tricuspide qui déborde un peu cette troncature supérieure.

Cet insecte a été rapporté du Chili.

$2^{\mathrm{e}}$ Division. Mandibules simplement arquées.

ÉLAPHROPTĖRE FASCIÉE. Elaphroptera fasciata. Gú́r. - Nigra, capite fascia posticali, margine anteriore thoracis, scutello maculis quinque (duabus longitudinalibus), abdomine fasciis sex latis, flavis; pedibus fulvis; alis fusco-hyalinis. - Long. 23 mill. Enverg. 40 mill.

Sa tête est noire, très-aplatie en avant, chagrinée, avec le chaperon bombé, saillant au milieu, tronqué et un peu échancré, avec les angles latéraux saillants et noirs. Il offre près du bord une lignc jaune qui se prolonge un peu en avant et en arrière des yeux, et qui ęnvoic, au milieu de la bosse du chaperon, un double rameau qui s'arrête, en s'arrondissant, beaucoup avant l'insertion des antennes. On voit encore, au-dessus de l'insertion de ces antennes, au coin supérieur des yeux et aux côtés postérieurs de la tête, derrière le vertex, de petites taches jaunes. Les mandibules sont brunes, avec une grande tache jaune au côté externe. Leur dent inférieurę est simple, sans aucune dilatation interne.

Le corselet est chagriné, noir , couvert.d'un duvet blanchâtre peu épais; le prothorax est arqué avec son bord postérieur jaune. Le mésothorax offre deux petites carènes et deux sillons internes longitudinaux; il a les ptérygodes jaunes et huit taches de la même couleur disposées ainsi : quatre sur la ligne médiane, la plus petite en avant, visà-vis dc l'insertion des ailes supćrieures, une autre un peu plıs grande et ronde, en arrière de celle-ci, la troisième, la plus grande, au milieu de l'écusson, la quatrième, transverse, occupant son bord postérieur. Il y en a deux autres de chaque côté, placées au-dessous dc l'insertion des ailes, et l'on voit une petite crête jaune, formée par deux petites fossettes sous lesquelles s'articulent les ailes postérieures. Les côtés du mésothorax n'offrent qu'une très-petite tache jaune sous l'insertion des premières ailes. Le métathorax est occupé, en dessus, par deux taches longitudinales et un peu sinueuses. Lcs ailes sont transparentes, un peu lavées de jaunâtre, avec les nervures brunes et la cellule radiale occupée par une teinte obscure. Les pattes sont fauves, avec les hanches et les trochanters noirs.

L'abdomen est aplati, rétréci aux extrémités, un peu arrondi sur les côtés, lisse, luisant, avec quelques points enfoncés et éloignés entre eux, et le bord postérieur des segments muni d'un petit pli. Le premier a un petit sillon longitudinal au milieu ct une large bande jaune, vers le bord postérieur et en dessus seulement. Les deux suivants ont leur milieu occupé, dessus et dessous, par une large bande, faiblement échancrée au milieu; les quatric̀me et cinquième ont cette même bande interrompue au milieu, dessus et dessous; enfin le sixième n'offre plus que deux grandes taches latérales, seulement en dessus. Le dernier segment est fortement rugueux et tronqué en arrière.

Ce bel insecte vient de Patagonie. 
ÉLAPHROPTÈRE CORNUE. Elaphroptera cornuta. GuéR. Nigra, capite et thorace flavo-variegatis; abclomine fulvo, macula laterali flava in quatuor primis segnentis, totis tarsis, margine inferiore femorum et tibiarum, flavis. Alis flavo-hyalinis, cellula radiali sub-obscura. - Long. 17 mill. Enverg. 29 mill.

Sa tête est finement chagrinée, noire, un peu velue; les antennes sont noires, plus courtes que la tête et le thorax réunis; les mandibules sont grandes, arquées en dedans, jaunes avec l'extrémité noire. La dent interne est élargie, pen saillante. Le chaperon cst jaune, avec le bord antérieur noir ; il présente, au milieu et au-dessous des antennes, une corne ou pointe saillante noire au bout, dirigée en avant; le jaune du chaperon forme deux grandes taches triangulaires au-devant des yeux, il y a deux taches arrondies audessus de l'insertion des antennes, et une ligne sinueuse, interrompue derrière le vertex, située au bord postérieur de la tête, derrière les yeux.

Le corselet est chagriné, un peu velu, avec le prothorax bordé de jaune en avant et offrant une petite tache oblongue de chaque côté. Le mésothorax a deux petites carènes et deux sillons longitudinaux, son écusson est saillant, occupé par une assez grande tache jaune, par une bande en arrière de celle-ci, et son bord postérieur également jaune. Les ptérygodes sont fauves. Le métathorax a deux taches jaunes ovales, longitudinales et un peu divergentes en arrière. Les ailes sont transparentes, à nervures fauves, lavées de jaunàtre, avec la cellule radiale occupée par une teinte brune qui la dépasse un peu en arrière. Les pattes sont assez courtes, noires, avec la tranche inférieure des cuisses et les tarses jaunes.

L'abdomen est allongé, étroit, aplati, ponctué, presque parallèle sur les côtés, avec la base et l'extrémité un peu rétrécies; son premier segment est noir avec une tache jaune échancrée, de chaque côté et près du bord postérieur. Les autres segments sont fauves; les second, troisième et quatrième ont une tache jaune de chaque côté, et une légère teinte noire au milieu en dessus et en dessous; le dernier est brusquement penché en dessous, rugueux et arrondi en arrière.

Du Brésil.

ÉLAPHROPTĖRE A AILES TACHÉES, Elaphroptera maculipennis. GuÉR. - Nigra, capite, metathorace, in thorace plurimis maculis, in abdomine maculis quinque lateralibus, tarsis, femoribus infra tibiisque basi, flavis. Alis hyalinis, nervulis brunneis, macula apicali brunnea. - Long. 18 mill. Enverg. 23 mill.

Sa tête est finement chagrinée, noire. Les antennes sont plus courtes que la tête et le corselet ensemble, noires et grêlcs. Les mandibules sont jaunes, arquées, avecla dent inférieure très-large, tronquée carrément, et l'extrémité noire. Tout le devant de la tête, jusqu'au milieu des yeux, les côtés en arrière, et deux taches au-dessus des antennes, sont jaunes. Le corselet est finement rugueux, un peu velu; le prothorax est bordé de jaune en avant et en arrière. Le mésothorax a deux petites carènes et deux sillons longitudinaux; il a unc tache jaune au milieu, son écusson est très-bombé en arrière, entièrement 
jaune, ainsi que les ptćrygodes et une petite ligne placée de chaque côté au-dessus de l'insertion des ailes; il y a une grande tache triangulaire sur lcs côtćs et sous les ailes. Lc métathorax est entièrcment d'un fauvc orangé en dessus. Les ailes sont transparentes et incolores avcc les nervures d'un brun jaunâtre; les supćrieures ont la cellule radiale et la troisic̀me cubitale occupćes par une tache brune un peu fondue. Les pattes sont noires, avec le dessous des cuisses, les jambes antérieures et tous les tarses jaunes.

L'abdomen est allongć, aplati, noir, luisant et ponctué. Les cinq premiers anneaux ont, de chaque còté, une largc tache triangulairc à angles arrondis, et d'un jaune orangè assez vif; le dernicr segnent est tronqué en dessus et un peu pointu en dessous.

Cette espèce, qui ressemble tout à fait à la précédente pour la forme et la taille, vient aussi du Brésil.

ÉLAPHROPTÈRE APICALE, Elaphroptera apicalis. GuÉr. - Nigra, eapite thoraceque maeulis flapis. Abdomine apice fulvo, maeulis quinque lateralibus favis; tibiis tarsisque flavo-rufescentibus. Alis hyalinis, nervulis flavis, macula apicali brunnea. - Long. I 3 mill. Enverg. I 8 mill.

La tête est un peu cn carré, arrondie et faiblement échancrée en arrière, finement ponctuée, noire. Elle a le chaperon et le bord antćrieur jaunes; les mandibules sont également jaunes avec l'extrćmité noire, leur dent inférieure est très-large et tronquée en dedans. Les antennes sont noircs, grêles, presque de la longueur de la tête et du corselet. Il y a une tache assez grande, d'un jaune obscur, derrière chaquc oil. Le prothorax, qui est trèscourt, a deux bandes jaunes, l'une au bord antérieur, interrompue au milieu, l'autre entière au bord postérieur. Le mésothorax et le métathorax sont finement ponctués, garnis dc duvet blanchâtre; le mésothorax a une lignc jaune au bord postérieur et une grande tache carrće de la mćmc couleur; on voit une petite tache jaune sous chaque aile; le métathorax offre dcux taches jaunes assez grandes. Les ailes sont transparentes, avec l'extrémité des supérieures un peu enfumée. Les pattes sont jaunes avec les hanches et les cuisses brunes. L'abdomen est noir avec les sixième et septième segments fauves; les cinq premiers segments offrent, dc chaque côté et au milieu de leur longueur, une grande tache jaune de forme presque triangulaire.

Cette jolie espèce vient de la province des Missions, au Brćsil.

A la suite des Élaphroptères nous placerons quelques espèces aptères, toutes américaines, et que nous pensons être les femelles des Élaphroptères que nous avons décrites, ou de quelques autres espèces encore inconnues du même groupe; nous les réunirons provisoirement en un seul genre, ainsi qu'il suit :

\section{Genre AMIMODROME, Ammodromus. Guér.}

Corps allongé, aptère, tête arrondie, presque verticale. Mandibules grandes, courbées, étroites et terminées par une simple pointe. Antennes courtes, arquées et contournées sur elles-mêmes, de douze articles, le premier grand, le second très-petit, 
presque caché dans le précédent, les autres presque égaux. Palpes maxillaires allongés, de six articles, les labiaux de quatre. Corselet divisé en trois segments distincts, comprimé sur les côtés, avec le nœud intermédiaire beaucoup plus étroit. Abdomen allongé, convexe en dessus, un peu aplati dessous, composé de six segments. Pieds courts, épais, très-épineux, à cuisses comprimées et arquées.

AMMODROME FRONTAL, Ammodromus frontalis, GuÉR. - Nigro-piceus, fronte flavo, antennis, pedibus anoque fulvis. - Long. 12 mill.

Sa tête est arrondie, un peu aplatie d'avant cn arrière, finement ponctuée, d'un brun noirâtre, avec le front entièrement jaune. Les antennes sont de la même couleur, ainsi que les mandibules; le corselet est d'un noir brunâtre foncé, très-comprimé sur les còtés, plus étroit au milieu, finement ponctué. Les pattes sont fauves, garnies de poils blancs assez longs, avec les tarses épineux, terminés par deux crochets assez épais et bificles. L'abdomen est plus épais que le corselet, ovoïde allongé, finement ponctué, velu à la base et en dessous, d'un noir assez foncé avec le bord articulaire des segments un peu brunâtre; le segment anal est beaucoup plus petit, tronqué en arrière, à troncature ovalaire et rebordée sur les côtés; on voit à son extrémité un petit oviducte ct au-dessous un aiguillon qui doit piquer comme celui des femelles de Mutilles.

Cet insecte a été trouvé en Patagonie, par M. d'Orbigny; c'est peut-être la femelle de l'Elaphroptera fasciata, ou de la Telephoromyia rufipes.

AMMODROME RUFIPÈDE, Ammodromus ruficeps. GuÉr. - Ater, nitidus; capite maculis duabus; antennis, mandibulis pedibusque fulvis; duobus primis segmentis abdominalibus anoque rugosis. - Long. 15 mill.

Cette femelle ressemble beaucoup à celle que M. Haliday a décrite sous le nom de Myrmecodes scoliceformis, mais elle en diffère par une taille plus petite et par ses pattes qui sont d'un fauve vif. Sa tête est noire, assez grande, un peu velue, finement ponctuée, avec une petite fossette longitudinale en avant du front; elle a, de chaque côté et en dehors de l'insertion des antennes, une grande tache triangulaire fauve. Les antennes sont brunes, avec l'extrémité du premier article, le second et le troisième en grande partie, fauves. Les mandibules sont grandes, arquées, simplement terminées en pointc, ciliées en dehors et fauves. Le corselet est d'un noir vif, luisant, étroit au milieu, comprimé sur les côtés, garni de petits points enfoncés plus visibles en dessus. Les pattes sont fauves, épineuses et couvertes de poils blancs assez longs. L'abdomen est plus épais que le corselet, ovoïde allongé, d'un noir luisant, saus poils en dessus, garni de poils blancs en dessous. Les deux premiers segments sont chagrinés, les suivants sont ponctués, avec la base lisse; le dernier est lisse en dessus, brusquenent tronqué avec cette partie chagrinée et arrondie.

Cet insecte a été trouvé au Brésil et à Corrientes. 
AMMODROME A FORME DE SCOLIE, Ammodromus scoliceformis. Gu Ér. Myrmecodes seoliceformis. - HaLIDAY, Trans. Lin. Soc. vol. xvil, pag. $3_{27}, \mathrm{n}^{0} 45$, (I836). Niger, vitta frontali et antennis testaceis. Fem. - Long. 9 lin.

Fem. Animalculum apterum prosearabai magnitudine, scolice statura, sed thorace angustiore et medio eoaretato. Oeuli minutissimi. Antenna teretes, eonvoluta. Abdominis segmenta duo antica eoriacea. Niger, obscurus, subtus presertim pallido-pnbescens, vitta testaeea, frontem transcurrens, oeulos ineludit. Antennce ferruginece, scapo nigro argenteo-barbato; tibiarum spinula et tarsorum seta rufo-picere. Hab. Chili.

Nota. Cet insecte pourrait bien être la femelle de l'Elaphroptera dimidiata décrite plus haut.

AMMODROME, VARIÉ, Ammodromus varius. GuÉr. - Myrmeeoda varia. Perty, Voy. au Brésil, etc., pag. $\mathbf{3 8}$, pl. 27 , f. го. Nigra, favo-variegata, pédibus fulvis. Long. 4 l. Lat. proth. $2 / 3$.

Animalculum singulare, revera transitum a mutillariis ad tiphias formans, et forsan his propinquius. Caput subglobosum, nigrum, flavo-varium, glabrum, nitidulum; mandibulis ferrugineis; oeulis parvis, prominulis, nigris, oeellis nullis. Thorax mutieus, fusco-niger, humeris flavis; seetionibus tribus valde distinetis. Abdomen satis magnum, elongatum, fuseo-nigrum, lave, ad latera flavo-varium. Subtus fuseo-badia glabra. Antennce ruface. Pedes fulvi, tibiis spinulosis, tarsis elongatis, penicillato ciliatis. - Du Brésil.

\section{Genre SCOLIE, Scolia. Fabr.}

Nous avons sous les yeux quelques espèces de ce genre, provenant de l'Amérique et des îles de l'Océanie, certainement nouvelles et qui, par la disposition des nervures de leurs ailes supérieures, n'entrent pas dans les divisions établies par MMI. Serville et Lepelletier de St.-Fargeau (Encycl. méth. Ins. 'T. X, p. 393). Nous n'exposerons pas ici les caractères des divisions fondées par ces naturalistes; car nous sommes obligés de les modifier, pour pouvoir placer nos espèces nouvelles; voici les divisions que nous proposons de leur substituer :

1. Ailes supérieures ayant quatre cellules cubitales.

$x$. Seconde cellule cubitale n'atteignant pas la radiale.

A. Deux nervures récurrentes.

$a$. Les deux nervures récurrentes reçues séparément par la seconde cellule cubitale. (S. G. Euis. Fab.)

Exemples. Seol. interrupta, eincta. Fab.

6. Les cleux nervures récurrentes réunies avant d'être reçues en un seul point par la seconde cellule cubitale. (S. G. Lracos.)

Exemple. Scol. dimidiata. Guér. 
B. Une seule nervure récurrente. (S. G. Scolia proprement dit.)

Exemples. Scol. procer, flavifrons, bimaculata, rubiginosa. Fabr. capitata. Guér.

2. Toutes les cellules cubitales atteignant la radiale.

A. Deux nervures récurrentes. (S. G. Cosila.)

Exemple. Scol. chilensis. Gućr.

B. Une seule nervure récurrente. (S. G. Ascolr.)

Nous n'en connaissoṇs pas encore.

II. Ailes supérieures ayant trois cellules cubitales.

A. Deux nervures récurrentes. (S. G. Campsomeris. Saint-Farg., mss.)

Exemples. Scol. atrata, variegata, aurea, dorsata, thoracica, collaris (I). Fab. Petitii, Servillci, micans, formosa. Guér. vestita. Klug., etc.

B. Une seule nervure récurrente. (S. G. Lacosi.)

Exemples. Scol. ruficornis, maura, verticalis, nobilitata, bicincta, tridens, sexmaculata, quatuor-punctata, uni-fasciata, histrionica. Fabr. apicalis, apicicornis, maculata, fasciato-punctata. Guér.

On voit que nous n’avons pas voulu employer, pour séparer nos espèces, la considération des appendiees des jambes postérieures ou antérieures, qui sont dilatés en euiller dans quelques espèces, ct spiniformes dans d'autres; nous avons eru reeonnaître que ce caractère se représentait dans diverses sections, et nous pensons qu'on ne devra l'employer que lorsque le nombre des espèces sera tellement accru, qu'il sera nécessairc d'y faire de nouvelles coupures.

Nous avons appris aussi que M. Lepellcticr de Saint-Fargeau devait établir plusieurs genres aux dépens des Scolies, et correspondant aux diverses sections établies dans l'Encyclopédie, et nous avons eu connaissance de plusieurs cspèces (celles de la division II, qui n'ont que trois cellules cubitalcs, et qui forment la subdivision $A$, eomprenant les espèces à deux nervures récurrentes) qui portent le nom générique de Campsomeris. Nous pensons que ces genres ne sont pas nécessaires dans l'état actuel de la science. Le genre Scolie est bien homogène, bicı naturel, et il serait fàcheux de le couper inutilement. Nous avons done conservé leur nom générique de $S c o l i a$ à toutes les espèces, mais pour nous conformer à l'usagc que l'on semble vouloir établir, nous avons placé, à la suitc de nos divisions, des noms de sous-genres, parmi lesquels figure celui de Camipsomcris que nous n'avons cependant vu publié nulle part.

SCOLIE PARTAGÉE, Scolia dimidiata. GuÉr. - Atra, villosa. Quinquc ultimis segmentis abdominalibus ferrugineis. Ano trispinoso. Alis nigro-cyaneis. (Mas.) - Long. 22 à 23 mill. Enverg. 34 à 35 mill.

(1) Cette $S_{c o l i a}$ collaris, et plusieurs autres, telles que la Thoracica, la Dorsata, sont rangées par Fabricius dans son genre Tiphin (Syst. Eleuth., p. $235, \mathbf{n}^{\circ} 20$ ). Il a donoé is la $S_{c}$. collaris la Chine pour habitation. Nous en avons un individu femelle, qui nous vient bien certainement du Sénégal, et qui appartient, sans aueun doute, an genre Scohia. Coequethert a figurè l'individu mème décrit par Fabricius, dans ses Illustr. Icon., pl. XIII, f. 3. 
Cette espèce est très-voisine de la Scolia analis de Fabricius, si ce n'est pas la même; cependant nous n'avons pas osé la rapporter à celle-ci, parce que cet auteur a classé la sienne parmi de petites espc̀ces, ce qui indiquerait qu'elle n'est pas de la taille de la nôtre; de plus, il la compare à sa $S c$. quadripustulata, que nous ne connaissons pas et qui doit être de petite taille, puisquïl l'a mise après la $S c$. nobilitata, qui est de la grandeur tout au plus de la quatuor-punctata. Enfin, dans sa description il dit: Ano hirto, ferrugineo; ce qui semble indiquer que l'extrémité seule de l'abdomen est rouge, et non toute sa moitié postérieure, coinme on le voit chez notre espèce.

La Scolie partagée cst allongée, de forme svelte; son corselet et sa tête sont d'un noir vif, luisants, ponctués ct un peu velus; le métathorax est échancré en arrière. Les antennes du mâle, le seul sexe que nous connaissions, sont au moins aussi longues que la la tête et le corselet, droites, cylindriques et d'un noir mat. Les ailes sont d'un noir violet à reflets luisants bleus; les inférieures sont un peu moins foncées; la côte des supérieures ct toutes les ncrvures sont noircs. Ce qui rend cette espèce curieuse, c'est la manic̀re dont les deux nervures récurrentes se joignent avant d'aller aboutir, par une seule nervure et en un seul point, au-dessous et au commencement de la troisième cellule cubitale. Les pattes sont assez fortes, noires, velues; les jambes antérieures sont terminées par une forte épine crochue, arrondie au bout, creusée en gouttière en dedans; les autres ont deux épines droites et de forme ordinaire. L'abdomen est allongé, ponctué, velu, avec le premier segment un peu plus étroit que le suivant, un peu étranglé en arrière; ce premier segment, le second et la base du troisième sont d'un noir vif à reflets bleus et à poils noirs; les trois quarts du troisième, les quatrième, cinquième, sixième et septième sont d'un rouge ferrugineux assez vif avec des poils fauves. Le septième segment est terminé par trois épines inégales aiguës, assez fines et brunes.

Cette belle espèce a été prise dans lî̀le de Bourou, dans l'Océanie.

SCOLIE A TĖTE ORANGÉE, Scolia capitata. Gứr. - Nigra, nitida, punctata. Capite, antennis, parte anteriore crurum anteriorum, aurantiacis. Alis nigro-cyaneis. (Mas.) Long. I 8 mill. Enverg. 3 I mill.

Cette espèce est très-facile à distinguer; les nervures de ses ailes supérieures la placent à côté de la Scolia flavifrons; comme chez celle-ci, on trouve quatre cellules cubitales et une nervure récurrente aboutissant sous la seconde cubitale; ses antennes et sa tête sont d'un beau jaune orangé vif, ainsi quc le devant des jambes antérieures; tout le corps et les pattes sont d'un noir vif, un peu velus. Le thorax est fortement ponctué. Les jambes antérieures ont une épine spatuliforme, et les autres deux épines aiguës et simples. Les ailes sont noires à reflets bleus et violets. L'abdomen est ovalaire avec le premier segment un peu étranglé en arrière. Le dernier scgment manque.

Cette jolie espèce fait partic de la collection de M. Petit de la Saussaie; il ne connaît pas sa localité, mais il pense qu'elle vient des Indes orientales. Il se pourrait aussi qu'elle fût originaire du Sénégal. 
SCOLIE CHILIENNE, Scolia Chilensis. Guér. - S. Nigra, punctata, pilis atris; antennis, articulo primo excepto, croceis; alis brunneis violaceo-micantibus; tibiis anticis spina curvata intus membranacea armatis; ano multidentato. (Fœmina.) - L. 19 mill. Enverg. $3_{2}$ mill.

La tĉte est arrondie, fortement ponctuée et velue. Les antennes ont lc premier article noir, luisant, avec le bout taché de fauve, et les autres d'un bean jaune orangé. Le corselet est' noir, fortement ponctué, garni de forts poils noirs, avec le milieu du mésothorax marqué de quatre sillons longitudinaux assez enfoncés. Les ailcs sont brunes avec de beaux reflets violets; les supérieures ont une cellule radiale allongée, tenant à la côte jusque près de son extrémité; quatre cubitales atteignant toutes la radiale : la première la plus longue, la seconde la plus courte, plus large en bas; la troisième plus grande, en carré obliquc. Il y a deux nervures récurrentes : la première, presquc droite, atteint obliquement le nilieu de la deuxième cellule eubitale; la seconde, sinueuse, atteint à angle droit le tiers antérieur de la troisième. Les pattes sont fortes, velues, noires, très-cilićes et épineuscs. Les jambes antćrieures ont, à l'extrénité et intérieurement, une forte épine courbee et garnie en dedans d'une petite lame membraneuse. Les épines terminales des autres pattes sont simples et droites. L'al)domen est noir, luisant en dessus, très-garni de poils noirs sur les côtés et en dessous. Le dernier segment est arrondi au bout, très-penché et garni de fortes dents assez nombreuses.

Cette scolie a été trouvée au Chili.

SCOLIE DE PETIT, Scolia Petitii. GuÉr. - Hirta, atra; thorace milgoso; abdomine fasciïs duabus latis fulvis; alis nigris, cyanco-nitidis. (Fœmin.) - L. 43 mill. Enverg. 73 mill.

C'est une des plus belles espèees du genre; elle est plus grande que la Scolia flavifrons et se distingue facilement par les deux belles bandes d'un fauve orangé vif de son abdomen. Sa tête est un peu plus étroite quc le corselct, d'un noir peu luisant, garnie de gros points enfoncés et ayant cn avant, entre les antennes, une brosse serrée de poils noirs et roides. Le corselet est grand, fortement rugueux, un peu velu; le mésothorax offre quelques petits sillons longitudinaux. Les ailes sont grandes, d'un brun noir à rellets bleus très-brillants; elles ont deux nervures récurrentes qui vont aboutir à la secondc cellule cubitale, comme dans toutcs les espèces de la même division. Les pattes sont fortes, velues et épineuses; les jambes antćrieures sont terminćes, en dcdans, par une forte ćpine dilatée et tronquée au bout, courbée, creusée en gouttière et de couleur cornée; les autres jambes sont tcrminécs par deux épines simples. L'abdomen est allongé, lisse, avec les segments garnis au bord postérieur de deux rangs de poils noirs roides et presque spiniformes; les second et troisième segments sont occupés presque entièrement par une large bande d'un bcl orangé vif, arrondie sur les côtés. Lc segment anal est arrondi, convert de petites strics courtes et longitudinales qui lui donnent un aspect rugueux.

rorage de la Coquille. - Z. Tom. II, Part.II. I $^{\text {re }}$ Div. 
Cette magnifiquc espèce vient du Mexique, elle fait partie de la collection de M. Petit de la Saussaye, qui nous l'a comınuniquée avec plusieurs autres insectes précieux qu'il possède seul à Paris; nous nous sommes fait un devoir et un plaisir de la dédier à ce naturaliste zélé, afin d'avoir une occasion de lui témoigner publiquement toute notre reconnaissance pour la génćrosité avec laquelle il a disposé en notre faveur de beaucoup de crustacés et d'insectes rares ct intéressants pour la science; ces communications nous sont d'un grand secours pour nos travaux, et $M$. Petit rend ainsi un nouveau service à la science, en nous mettant à même dc faire connaître des faits nouveaux, qu'il publierait certainement mieux que nous, si ses occupations ne l'en empêchaient pas.

SCOLIE DE SERVILLE, Scolia Servillei. Gúk. - Hirta, atra, immaculata; capite thoraceque valde punctatis; abdomine lcevigato; alis pallide-flavis apice sub-violaceis. (Fœmina.) Atlas, Ins., pl. 8, f. 8. - Long. 28 mill. Enverg. 45 mill.

Cette espèce ressemble beaucoup à la $S c$. atrata de Fabricius, mais elle est bien plus petite, ses ailes sont plus pâles, tout son corselet est fortement rugueux, tandis que dans l'atrata il est lisse et luisant en dessus et au milieu.

La forme de la scolic de Serville est allongée, tout son corps et ses pattes sont d'un noir luisant dans certaines parties, mais sans reflets violets. La tête est de la largeur $d u$ corselet, velue, fortement ponctuée. Les antennes de la femelle sont courtes, noires, contournées. Le corselet cst également velu et ponctué, brusquement tronqué en arrière, avec l'écusson du métathorax un peu saillant et garni de poils. Les ailes sont d'un jaune pâle à la base, avec la côte un peu plus ferrugineuse et l'extrémité d'un brun pâle à reflets un peu violets; les nervures sont d'un brun presque noir, les supérieures ont, comme toutes celles de la même division, deux nervures récurrentes qui vont aboutir sous la seconde cellule cubitale. Les pattes sont fortes, noires, velues et épineuses; les jambes antérieures ont, à lcur extrénité interne, nne forte épine droite d'abord, crochue ensuite, arrondie au bout et creusée en gouttièrc en dedans; les autres n'ont que deux fortes épines droites et aiguc̈s. L'abdomen est assez allongé, lisse, peu élargi au milieu et terminé par une pièce anale arrondie; ses deux premiers segments sont ternes et mats, à l'exception de leur bord postérieur qui est luisant; les autres sont luisants sur toute leur surface. Ils ont tous, en arrière, deux rangs de poils noirs assez longs, couchés sur le segment suivant et formant ainsi une espèce de bande transverse plus terne. Le dessous de ces segments offre quelques lignes transverses et irrégulières formées par des petits points enfoncés.

Lc mâle, que nous trouvons dans la collection de M. Petit, diffère par une taille un peu moindre; il a I 8 millimètres de long; ses antennes sont plus longues que la tête et le corselet, cylindriques, presque droites. Ses ailes sont presque transparentes, d'un jaune pâle, avec le bout un peu enfumé. L'abdomen est allongé, assez étroit, ponctué et velu, avec l'anus arrondi, sans épines, armé seulement de chaque côté d'une petite lame cornée, mais il diffère surtout de celui de la femelle, parce qu'il a le premier segment beaucoup plus étroit, ce qui lui donne un aspect étranglé à la base. 
Cette espèce a ćté prise aux cnvirons de Lima, au Pérou; nous en avons vu un individu en tout semblable, que M. d'Orbigny a trouvé en Patagonie.

SCOLIE BRILLANTE, Scolia micans. Gú́r. - Nigra, villosa; prothorace dense nigro villoso; mesothorace punctato; alis brunneis, violaceo-micantibus, superioribus costa ferruginea; abdominè nitido, cceruleo-nicanti. (Fœemina.) —Long. 2 I mill. Enverg. 34 mill.

Tout son corps est d'un noir vif́, luisant; la tête est lisse avec le vertex sans poils, mais le front est couvert d'une brosse de poils noirs, très-serrés. Les antennes sont noires, courtes et contournées. Le prothorax cst court, comme dans toutes les espèces du mème genre, très-finement chagriné, garni de poils noirs trc̀s̀-serrés et formant une brosse. Le mésothorax est sans poils, luisant, avec quelques sillons et de forts points enfoncés sur le disque; son écussoṇ est lisse. Le mésothorax est lisse, brusquement tronqué en arrière, avec son écusson élcvé et formant au milicu une espèce de bosse pointue. Les pattes sont fortes, noires, velues et épineuses. Les jambes antćrieures sont terminées par une forte épine aplatie, élargie en cuiller au bout et de coulcur cornée. Les ailes sont d'un brun foncé à reflets violets, leur extrémité est plus foncée, et la côte des supérieures est d'un jaune ferrugineux. L’abdomen cst allongé, lisse, avec quelques points enfoncés à la base des segments, et deux rangs de poils roides et peu serrés à leur bord inférieur; il est d'un beau noir chatoyant à reflets irisés violets ou bleus. L'anus est arrondi.

Quoique cette espèce ait beaucoup d'affinité avec la $S_{c}$. Servillei, elle s'en distingue suffisamment par une taille un peu inférieure, par ses ailes d'un brun violet à côte fauve, et par son abdomen à reflets violets. Son habitat est aussi trc̀s-différent, car c'est à Bourou, dans les Moluques, qu'elle a été trouvée. Il y a aussi dans Fabricius (Syst. Piez, p. 224, n" 35) une Scolia cyanipennis, qu'il décrit ainsi : "Atra, immaculata, alis cyaneis. Hab. Tranquebaria." Mais elle doit être petite, car elle est placée près de la quadripustulata, que nous connaissions et qui est d'une taille bien moindre que notre espc̀ce. Du reste, Fabricius aurait parlé de la côte des ailes supérieures, qui est ferrugineuse dans notre individu. Des échantillons rapportés de la côte de Coromandel pourront seuls lever les doutes à ce sujet. Enfin nous trouvons que la description de la Tiphia nigra de Fabricius pourrait peut-être aller à notre scolie; mais la description de Fabricius dit: "Capite thoracisque antice ferrugineo subvillosis", ce qui ne va pas à la nôtre.

SCOLIE THORACIQUE, Scolia thoracica, Gó́r. - Nigra; thorace pilis griscis; alis brunneis, violaceo-micantibus (Fonı.).

Tiphia thoracica, Fabr. Entomol. Syst. Suppl., p. 225, nº 15 à 16. Syst. Piez, p. $225, \mathrm{n}^{\circ} 19$.

Varietas. Thorace antice pilis ferragineis. - Tiphia nigra? F F B., Syst. Ent., 2, 225, 9 . — Long. I 8 à 22 mill. Enverg. 3 I à 38 mill. 
Nous avions déjà décrit cette espèce comme nouvelle, quand nous avons songé à la chercher dans les 'Tiphics de Falricius; nous avons reconnu que c'est bien évidemnent sa Tiphia thoracica, qu'il décrit ainsi: "Atra, thoracc cincrco villoso, alis cyaneis, " ct nous avons pensé que cette découverte valait bien celle d'une espèce nouvelle, aussi allons-nous donner une description plus détaillée de cctte Scolie, pour qu’il ne restc plus de doutc à son sujet.

Ellc doit aussi ressembler beaucoup à la Scolia hirticollis de Fabricius, qui vient de la Nouvclle-Hollande; mais ellc cn diffère, si la dẹscription de cet auteur est exacte, parce que, dans son espècc, les ailes sont testacécs à la base et bleues au bout, tandis que dans la nôtrc, elles sont entièrement d'un brun foncé à reflets bleus. Quoi qu'il en soit, la Scolia thoracica est d'un noir profond; sa tête est lisse, luisante, un peu velue sur le front, avec le vertex sans points enfoncés; le derrière de la tête est garni d'une brosse de poils rudes et cendrés. Les antennes sont noires, courtes, courbées. Le corselet cst fortement ponctué; le prothorax et le mésothorax, jusqu'à l'insertion des ailes, sont couverts de poils gris asscz.longs; le métathorax est brusquement tronqué en arrière, avec son écusson un peu saillant. Les ailes sont entièrement d'un brun noirâtre à reflets bleus et violets; les inférieures sont plus pâles. Les pattes sont fortes, velucs et épineuses, d'un noir vif. Les jambes antérieures sont terminées par une forte épine courbée, arrondie et un peu dilatée au bout, creusée en gouttière. Les autres jambes sont terminées par deux épines aiguës et simples. L'abdomen est assez court, ovalaire, lisse, peu luisant et d'un aspect soyeux; chaque segment a, à son bord postérieur, deux ligncs transverses de poils noirs et roides. L'anus est arrondi en arrière, avec une petite dent de chaque côté.

Il y cn a une variété chez laquelle les poils du corselet, au lieu d'être gris, sont d'un ferrugincux vif. Ne pourrait-on pas la rapporter à la Tiphia nigra de Fabricius?

Cette cspèce vient des Indes orientales.

SCOLIE BELLE, Scolia formosa, Guér. - Nigra, capite thoraceque antice pilis ferrugineis; mctathorace flavo-sericeo; alis flavis, apice infuscatis; costa ferruginea; ab: domine fasciis quatuor anoque ferrugineis; cruribus tarsisque fulvis; pulis ferrugineis. (Fom.).

Scolia formosa. Iconogr. du Règne animal, Ins., pl. 69, fig. 10. -- Long. 25 mill. Enverg. 4I mill.

Sa têtc est un peu moins large que le corselet, noire, ponctuée, entièrement couverte de poils orangés très-serrés. Les antennes sont brunes, avec le premier segment fauve. Le cliaperon et les mandibules sont bruns. Le corselet est noir, ponctué, couvert, jusqu'à la hauteur de l'insertion des ailcs inférieures, de poils orangés très-serrés et couchés. Le reste de sa surface est garni d'un trc̀s-court duvet soyeux, jaunàtre. Les ailes sont d'un jaune safrané, avec la côte et les nervures ferrugineuses, et une petite tache brune ct fondue au bout et vers la côtc. Les nervures des ailes supérieures offrent une anomalie qui pourrait donner quelques doutes sur la section à laquelle cette espèce 
appartient; elles semblent n'avoir qu'une seule nervure récurrente; mais un exanıen plus attentif fait bientôt voir que la seeonde est commencée, qu'elle est plus fine et qu'elle ne parvient pas jusqu'à la seconde cellule cubitale, quoiqu'elle se dirige bien évidemment vers elle. Les pattes sont fauves, avec les cuisses noires; elles sont garnies de poils orangés assez serrés sur les jambes et au côté externe des cuisses, et plus longs sur les tarses. L'abdomen est noir, velouté, avec la moitié postérieure des quatre premiers segments et les deux derniers en entier, d'un beau jaune orangé très-vif; la bande du premier segment est plus étroite et droite en avant; celle du second est un peu échanerée au milieu, celle du troisième est au contraire un peu élargie an milieu, et enfin celle du quatrième est encore droite en avant et aussi étroite que la première. L'anus est arrondi en arrière, avec une petite dent de chaque eôté.

Cette magnifique espèce vient de Port-Praslin, à la Nouvelle-Irlande.

SCOLIE APICICORNE, Scolia apicicornis, GuÉn. - Nigro-brunnea, villosa, rugosula; capite obscure-fulvo; antennis brunncis apice flavis; alis flavidis, apice sub-infuscatis; costa ferruginea (Fœm.). - Long. 29 mill. Enverg. 48 mill.

Elle est un peu moins grande que la Scolia atrata de Fabricius; sa tête est d'un fauve obscur, luisante, fortement ponctuée, avec deux petites fossettes entre les yeux sur le vertex; les mandibules sont brunes, presque noires au bout; les antennes sont d'un brun foncé, avec les trois ou quatre derniers articles jaunes. Le corselet est d'ın brun foncé, chagriné et couvert de petits poils noirs. Le métathorax est lisse, avec des reflets soyeux et chatoyants, produits par un duvet extrêmement fin et serré. Les ailes sont transparentes, d'un jaune pâle, à nervures ferrugineuses, avec le bout un peu enfumé; les supérieures ont à la côte une assez large bande d'un jaune ferrugineux. Les ailes offrent une anomalie curieuse, qui peut donner la mesure de la confiance que l'on doit accorder aux caractères pris de leurs nervures, pour former des genres aux dépens des Scolies : l'aile gauche n'a qu'une cellule cubitale fermée, et pas de nervure récurrente; l'aile droite a sa seconde cellule cubitale bien fermée, et la nervure récurrente est commencée, mais n'atteint pas la cellule cubitale. Cependant nous n'hésitons pas à placcr cette espèce dans la dernière division; car on voit très-bien que le manque de quelques nervures à l'aile gauche ne peut provenir que d'une anomalie. Les pattes sont d'un brun foncé, un peu plus ferrugineuses en dessous, et garnies d'épines et de longs poils presque noirs. Les jambes antérieures ont une épine arrondie au bout, creusée en gouttière et courbée ; les autres ont deux épines aiguës. L'abdomen est d'un brun ferrugineux en dessus, avec la moitié postérieure des trois premiers segments noire; mais cette couleur est fondue insensiblement avec le brun ferrugineux; il est couvert de points enfoncés assez forts et garni, surtout sur les côtés, de poils noirs assez longs ct roides; le dessous est presque tout noir; l'anus est arrondi.

Nous ne connaissons pas exactement l'habitation de cette singulière espèce; elle doit venir des Indes orientales, ou peut-être du Sénégal. 
SCOLIE A BANDES E' POIN'TS, Scolia fasciato-punctata, Gó́r. - Nigra, nitida, villosa et punctata; alis nigro-cyaneis; abdomine segmento primo duobus punctis, tertio fascia lata et quarto fascia minuta, rufis (Fom.). - Long. 22 mill. Enverg. 35 nill.

Cettc espèce doit avoir de l'affinité avec la Scolia quadrifasciata de Fabricius; elle est entièrcment d'un noir vif ct luisant; sa têtc et son corselet sỏnt fortement ponctués, velus. Les ailes sont d'un brun très-foncé à reflets d'un beau bleu luisant, quelquefois violets. L'abdomcn est allongé, lisse, luisant, garni de poils noirs, couvert de petits points enfoncćs; le second segment porte deux points rouges, distants entre eux; lé troisième est presque entièrement occupé par une large bande rouge, et le quatrième offre une petite bande très-mince, presque interrompuc, de la même couleur; l'anus est arrondi, avec.une petite dent de chaque côté.

Cettc Scolie vient des Indes orientales, dc Java, etc. ; elle fait partie de la collection de M. Petit de la Saussaye.

SCOLIE APICALE, Scolia apicalis, GuÉr. - Atra, villosa; antennis flavis, basi nigris; alis brunneis violuceo-micantibus, apice hyalinis (Mas.). - Long. 20 mill. Enverg. 37 mill.

Cettc espèce ressemble beaucoup à la Scolia ruficornis de Fabricius, mais elle en diffère par la taille (I) et surtout par lcs ailes, qui sont transparentes au bout, tandis qu'elles sont cntièrement d'un noir bleu chcz celle-là. Sa tête est un peu plus étroite que lc corselet, fincment ponctuée; les antennes sont longues, droites, jaunes, avec les deux premiers articles noirs; le corselet est également ponctué, velu sur les côtés, tronqué en arrière; les ailes sont brunes, à reflets bleus et violets, avec le bord externe et une petite portion de la côte, au bout, transparents et incolores. Les pattes sont noires, vclues et épineuses. L'abḍomen est allongé, noir, luisant, à reflets bleus, ponctuć et velu; lc premicr seginent est un peu plus étroit; l'anus est arrondi.

Cctte espèce, qui fait partie de la collcction de M. Petit de la Saussaye, est sans indication de localité; elle sc trouvait avec des espèces indicnnes, et semble appartenir à cette partie de l'ancien continent. Peut-être aussi est-elle du Sénégal.

(r) Nous avons su, dans la collection de M. Petit, le mâle et la femelle d'une scolie du Sénégal à antennes rouges, semblable à la $S c$. ruficornis, mais de moitiẻ plus petite : au premier coup d'œil on croirait que c'est la mème espèce arrêtée dans son développement, mais après un cxamen attentif, on recounaît que la petite espèce diffère de la ruficornis par les reflets de ses ailcs qui sont violets et roses, tandis qu'ils sout conslamment d'un beau bleu dans 7 ou 8 individus de la ruficollis mảles et femelles; chez notre petite espèce, l'abdomen esı d'un noir luisant à reflets bleus et riolets trc̀s-rifs, tandis qu'il est d'un noir terne dans l'autre; le corselet, dans la petite espèce, est ponctué en avant, mais irès-lisse et luisant en arrière, tandis qu'il est finement ponctuć partout, chagriné, velu et terne dans les deux scxes de la ruficornis. Toutes ces différences nous ont décidć à sćparer ces dcux petits individus sous le nom de $S c o l i a$ affinis, Guér. Celte espèce derra être placée immédiatemeut après la $S$. ruficornis. 
SCOLIE MACULÉE, Scolia maculata, Guér. - Atra; capite thoraceque Ravo-maculatis, abdomine lateribus maculis quatuor flavis, alis favo-brunneis, anticis costa obscuriore, cyaneo-violaceoque micantibus; pedibus brunneo-fcrrugineis, femoribus obscurioribus (Fœm.). - Long. 18 mill. Enverg. 3o mill.

Sa tête est noire, ponctuée, avec lc bord du chaperon, la base des mandibules, une ligne trausverse sous l'inscrtion des antennes et au milieu du front, et le tour des yeux, en avant et en arric̀re, jaunes. Les antennes sont noires; le corselct est rugueux et ponctué, noir; le prothorax a les côtés entic̀rement jaunes; l'écusson est jaune, ainsi qu'une petite ligne transverse en arrière, un petit point au milieu du métathorax, et une grande tache sur les côtćs; les flanes offrent unc trc̀s-petite tache jaune sous les ailes. Les ailes sont d'un jaunâtre obscur, à nervures noirâtres; les supérieures sont plus foncées, avec la côte presque noirc et des reflets violets ct bleus, surtout vers le bout. Les pattes sont d'un brun ferrugincux, plus foncé et presque noir à la base des cuisses, avec des poils jaunes assez longs. Les tarses sont jaunes, avec l'extrémité de chaque article noiràtre. Le dessous de l'abdomen est noir, luisant, avec le seeond segment rougeâtre, bordé, ainsi que les suivants, de poils serrés et gris.

Hab. ?... De la eollection de MI. de Romand.

PEPSIS DE PETIT, Pepsis Petitii, Guér. - Tomentosa, nigro-corulea; antcnnis . ferrugineis; articulo primo secundoque nigris; alis flavo-sericeis, basi nigris, apice albis (Fœm.). - Long. 24 mill. Enverg. 65 mill.

Ce bel inseete est très-faeile à distinguer et ne ressemble à aucune des cspèces connues: il est d'un noir velouté très-foneé, avee quelques reflets bleus, surtout à l'abdomen. Sa tête est de la largeur du corselet; ses antennes sont longues, enroulées vers le bout, d'un beau jaune orangé vif, avec les deux premiers articles noirs. Le mésothorax offre, entre les ailes, trois petites earènes divergentes. Les ailes sont d'un beau jaune soyeux pâle, comme lavé d'argent; les inférieures sont d'un jaune un pcu plus vif. Les supćrieures ont la base noire, mais ce noir n'occupe qu'une très-petite portion; aux inférieures ce même noir oceupe plus du tiers de leur longueur; il cst fondu et passe inscnsiblement jusqu'au jaune. L'extrémité des quatre ailcs est incolore et transparente. Les pattes sont grandes, robustes, épineuscs et velues; l'abdomen est ovalaire; il offre des reflets bleus très-luisants.

Ce nagnifique Hyménoptèrc a été pris au Pćrou: il fait partie de la eollection de de II. Petit la Saussaye, à qui nous l'avons dédić.

PEPSIS A BORDURE, Pepsis limbata, Guér. - Ceruleo-nigra, capite thoraceque nigro-villosis, antennis nigro-fuscis, articulo primo nigro-carulco; alis rufis, apice et margine interno-fuscis. - Long. 24 mill. - Enverg. 49 mill. (mâle). -- Long. 37 mill. Enverg. 66 mill. (fem.) 
Nous croyons devoir distinguer eette espèee, quoiqu'elle ait bien dc l'affinité avec le Pepsis marginata de Palisot-Bauvois. Nous avons sous les yeux trois individus femelles qui ont moins d'un pouee et demi de long, et un mâle qui a moins d'un pouee, et il nous paraît diffieile de les rapporter à une des plus grandes espèees du genre, à une espèec dont la femelle a deux pouces de long, et que MM. Serville et de SaintFargeau ont déerite dans l'Eneyelopédie méthodique, d'après les individus mêmes rapportés de Saint-Domingue par Palisot-Bauvois. Du reste, la différenee de loealité vient eneore nous engager à ne pas réunir ees deux espèces. Nous avons pu examiner les individus mêmes rapportés par Palisot-Bauvois, dans la belle eollection de M. Serville, que ee savant nous a ouverte avee une libéralité qui prouve un véritable zc̀le pour la scienee, et nous allons tâeher de faire ressortir les caraetères qui distinguent ees deux espèees entre elles, abstraetion faite de la grande différenee de taille de ees inseetes.

Dans le Pepsis marginata, qui a plus de deux pouees de long, la tête et le thorax sont d'un noir pur, sans reflets bleus veloutés, mais sans poils. Le ehaperon est fortement éelıaneré en avant. Le métathorax offre un assez grand sillon longitudinal au milieu, qui va aboutir en arrière à une petite erête élevée et transversale, occuipant le bord postérieur au sommet de la troneature postérieure. L'extrémité de l'abdomen est faiblement garnie de poils bruns. Les ailes sont d'un jaune fauve un peu soyeux et peu luisant, un peu plus pâles vers l'extrémité; l'extrémité des supérieures est oceupée par une bordure d'un brun noirâtre qui atteint, en se fondant insensiblcment, les dernières nervures transversales formant les eellules radiales et cubitales. La bordure des ailes inférieures est plus étroite; les pattes sont d'un noir mat.

Dans notre espèee, au eontraire, la tête et le thorax sont d'un noir bleu; eomme l'abdomen, ils sont garnis de poils noirs assez longs. Les antennes sont d'un noir terne, avee le premier artiele noir bleu; le ehaperon est éehaneré, mais plus faiblement; le métathorax est simple, un peu eonvexe, et n'offre ni sillon ni élévation postérieure; les poils qui garnissent l'extrémité de l'abdomen sont plus nombreux et d'un noir vif. Les ailes sont d'un jaune fauve plus vif, plus rougeâtre; elles sont moins soyeuscs et plus luisantes, et la bordure de leur extrémité est un peu moins large et moins foneée. Les pattes sont d'un beau noir bleu à reflets très-vifs, comme l'abdomen.

Le mâle de notre Pepsis limbata est plus petit que la femelle; sa longueur est à peine de i l lignes ( 24 mill.). Il est en tout semblable, mais ses antennes sont droites et plus longues.

Cette belle espèee se trouve au Chili et au Pérou. Nous en avons donné une bonne figure dans l'atlas du Dictionnaire pittoresque d'histoire naturelle, pl. 47 I, f. 2.

POMPILE DORÉ-SOYEUX, Pompilus aureosericeus, Gú́R. - Brunneo nigroque sericeus; capite brunneo, aureo micante, antennis flavis; prothorace mesothoraceque aureo sericeis; metathorace transverse strigoso; alis flavo-aureis, nervulis fulvis, marginibus pallidioribus; pedibus fulvis, aureo-micantibus; abdomine aureo-sericeo et piloso (Fœm.) - Long. 48 à 5 o mill. Enverg. ro centim. environ. 
C'est le plus grand et le plus beau Pompile que nous connaissions; sa tête est brune, garnie d'un duvet soyeux à reflets d'or. Les antennes, le chaperon, la base des mandibules et les palpes sont jaunes; le thorax est d'un brun noir, couvert d'un duvet soyeux très-serré, d'un jaune luisant à reflets plus dorés au prothorax et au mésothorax. Le métathorax est strié en travers, avec un petit stigmate ovale et oblique de chaque côté. Les ailes sont d'un beau jaune doré, un peu fauve, surtout vers la base, avec l'extrémitć un peu plus pàle. Les pattes sont d'rn jaune fauvc, avec un fin duvet qui leur donne des reflets dorés. L'abdomen est d'ın noir obscur, avec lcs deux derniers segments garnis d'un duvet doré et de quelques poils bruns assez longs.

Ce magnifique insecte vient de Java.

POMPILE DE LEPElletier, Pompilus Pelterii, Guén. - Ater, thoraee villoso, abdomine glabro; untennis, eruribus, tarsis anoque ferrugineis. Alis favo-ferrugineis, basi nigris paululum infuseatis apice. - Atlas, Ins., $\mathbf{n}^{\circ} 9$, fig. 2. - Long. 29 mill. Enverg. 54 mill.

Il est peut-être voisin du Pompilus analis de Fabricius; mais il s'en distingue toujours très-bien par ses jambes et ses antennes fauves. Le Pompilus assimilis du mêmc auteur ne peut non plus être confondu avec notre espèce, car il a un point ferrugineux sur le thorax avant les ailes, et celles-ci sont bleues; mais l'espècc à laquelle il ressemble le plus est son Pompilus eapensis, qui diffère cependant du nôtrc parce quc son anus n'est pas fauve, par sa première nervụre récurrente, qui aboutit presque sous la nervure qui sépare les scconde et troisième cellules cubitales, tandis qu'elle aboutit encore assez loin de cette nervure dans le nôtrc, par la troisic̀ne ccllule cubitale, qui est aussi largc en haut qu'en bas, tandis que dans le nôtre cette mème cellule est un peu plus étroite en haut, et enfin par son habitation.

Le Pompilus Pelterii cst noir, avec la tête, le corselct et la base de l'abdomen garnis de poils noirs assez longs et serrés. Le bord antérieur du chaperon, le labre, la base des mandibulcs et les palpes sont fauves. Les antennes sont d'un jaune fauve, avec les deux premiers articles un peu plus foncés. Les ailes sont d'un beau jaune un peu ferrugineux, à ncrvures fcrrugineuses, avec la base noire et unc très-pctite bordure brune au bout. Les cuisses sonı noires, avec l'extrémitć seulement d'un brun ferrugineux ; les jambes et les tarses sont d'un bean jaune ferrugineux; l'abdomen est glabre, luisant, a vec un faible reflet bleuâtrc; Ic dernier seginent est un peu velu, d'un brun rougeâtre.

Cette cspèce se trouvc à Amboine : nous la dédions à M. Lcpcllctier de St.-Fargcau, qui s'occupe avec succès de l'ćtudc des hymónoptères.

POMPILE DU CHILI, Pompilus Chilensis, Guḱr. - Ater, subpilosus, metathorace transwerse strigoso, basi sub-eanaliculato, alis favo-ferrugineis, apice infuscatis.

Pepsis Lepeletierii, Atlas, Ins., $\mathrm{n}^{\circ}$ 8, fig. 12 (1). - Long. 24 mill. Enverg. 44 mill.

(r) C'est par une erreur de graviure qu'on a mis le nom de Pepsis Lepellierii à cette espèce.

Voyage de la Coquille.-Z. Tom. II, Part. II. $\mathbf{1}^{\mathrm{r}^{\mathrm{re}}}$ Div. 
Il est entièrement noir, un peu velu; l'écusson du mésothorax cst assez saillant, lisse; le métathorax est un peu ridé transversalement en arrière, et offre au milieu une fossette longitudinale assez allongée et assez profonde. L'abdomen présente quelques faibles reflets blcuâtres, et son anus est garni de quelques poils d'un brun foncé. Les ailes sont d'un jaune ferrugineux, avec le bout brun pâle.

Cet insecte vient du Cliili.

POMPILE A DEUX TUBERCULES, Pompilus bitnberculatus, GuÉr. - Nigro-cyaneus, sericeus, nitidus, sub-pilosus; quinque primis et duobus ultimis articulis antennarum nigricantibus, articulo sexto et septimo apice et quinque sequentibus flavo-rufis, metathorace transverse strigoso, fovea longitudinali; alis nigro-brunneis, violacco cyaneoque inicantibus, abdomine segmento secundo infra transverse bituberculato. (Fœm.) - Long. 32 mill. Enverg. 54 mill.

Il ressemble beaucoup au Pcpsis ruficornis de Fabricins, qui est un vrai Pepsis pour les auteurs modernes et dont nous avons vu un individu dans la collection de M. Serville; mais il est un peu plus petit. Tout son corps et ses pattes sont d'un bleu trèsfoncé, soyeux, à rcflets luisants d'un beau bleu vif. Ses antennes ont les deux premiers articles d'un noir blcu, les trois suivants d'un noir brunâtrc, le quatrième a un peu de fauve au bout; le cinquième en a beaucoup plus; les cinq suivants sont entièrement d'un jaune fauve, et les deux dernicrs sont d'un brun noirâtre. Le métathorax est strié en travers; il offre au milieu deux petites carènes longitudinales, assez distantes ct divergeant un peu en arrière, ce qui produit au milieu un sillon assez large et peu profond. L'abdomen est ovalaire, très-luisant; le second segment est muni, en dessous, de deux forts tubercules placés de chaque côtć près du bord postérieur. Les ailes sont d'un brun foncé, avec de beaux reflets violets et bleus.

Ce Pompile vient du Brésil.

POMPILE ICHNEUMONIFORME, Pompilus ichneumoneus, Gó́r. - Brunneo-ferrugineus, opacus, sericeus; mesothorace lincis duabus lnngitudinalibus obscurioribus, alis flavo-brunneis violaceo et cyaneo micantibus, anticis macnla media pallidiore. (Fœm.) Atlas, Ins., $\mathbf{n}^{\circ}$ 8, fig. т3. - L. 22 mill. Enverg. 40 mill.

Cc Pompile, par sa forme plus svelte et par sa couleur, ne peut être comparé à aueune espèce connue. Ses antennes, son corps et ses pattes sont d'une couleur brune ferrugineuse; il est entièrement couvert d'un duvet court, serré et soyeux ; les antennes sont aussi longues que la tête, le eorselet et la moitié de l'abdomen, droites et semblables à cclles d'un mâle de Pepsis. Lc mésothorax offrc deux lignes longitudinales obscurcs, plus larges en avant; son écusson cst assez saillant, avec une fossette en arrière. Le dessous, entre les premièrcs et les secondes pattes, préscnte une grande tache noire. Les ailes sont d'un brun jaunâtre, à reflets très-brillants violets et bleus; 
les supérieures ont, au milieu, une tache demi-transparente, longitndinale et ovalaire, avec le milieu obscur; les inféricures ont la base égalenıent demi-transparente. La première nervure récurrente vient aboutir presquc au-dessous de celle qui sépare les seconde et troisième ccllules cubitales.

Cette espèce vient de la Nouvelle-Guinée.

POMPILE NOIR-BLEU, Pompilus nigro-cyaneus, Gứr. - Ater, sericeus, opacus; thorace valde elevato; abdomine sub-cyaneo, lavigato; alis nigro-brunneis, cyaneo-nitentibus. (Fœmi.) - Long. 18 mill. Enverg. 36 mill.

Son corps et ses pattes sont d'un noir velouté, un peu velus; le corselet est très-ćlevé en avant, et la tête semble attachée plus bas que dans les autres espèces. L'abdomen a quelques faibles reflets bleuâtres; les ailes sont d'un brun foncé, avec de beaux reflets bleus et violets.

Il vient du Chili.

POMPILE A TÊTE VELUE, Ponipilus hirticeps, Gǘr. - Nigro-cyaneus, nitidus; capite thoraceque nigro-pilosis; antennis flavo-rufis, basi apiceque nigris; alis nigrofuscis, violaceo cyaneoque micantibus. — Long. 15 mill. Enverg. 31 mill.

Il est entièrement noir, avec de beaux reflets bleus sur la tête, le prothorax et le mésothorax, sur les pattes et l'abdomen; la tête, le corselet et la base de l'abdomen sont garnis de poils noirs, plus nombreux et plus longs sur le devant de la tête, entre les antennes; celles-ci ont leurs deux premiers articles noirs, les cinq suivants d'un beau jaune orangé vif, les huitième et neuvième jaunes en dessus et noirs en dessous, et les derniers entièrement noirs. Les ailes sont d'un brun foncé à reflets violets et bleus très-luisants et très-vifs.

Ce Pompile se trouve au Chili.

POMPILE A JAMBES JAUNES, Pompilus favipes, GuÉr. - Niger, opacus; alis brunneis, cyaneo nitentibus; abdomine glabro, subcyaneo nitido; antennis fusco-ferrugineis, articulis duobus primis nigris; cruribus tarsisque flavis. (Fœm.) - Long. 15 mill. Enverg. 3 I mill.

Sa tête et son corselct sont d'un noir peu luisant, sans poils; les antennes sont d'un fcrrugineux assez foncé, avec les deux premiers articles noirs; le métathorax est strié transversalement, mais les stries n'atteignent pas jusqu'à l'insertion de l'abdomen. Les ailes sont d'un brun foncé avec de beaux reflets violets et bleus très-luisants; les cuisses sont noires, luisantes, avec les jambes et les tarses d'un beau jaune orangé. L’ąbdomen est noir, lisse et luisant, avec quelques reflets bleus. - Du Chili. 
POMPILE AGRÉABLE, Pompilus blandus, Guér. - Pallide caruleus; alis hyalinis nervulis nigro-brunneis; antennis pedibusque nigris; femoribus posticis rufis. (Fœm.) - Long. if mill. Enverg. 29 mill.

Il n'y a que le Liris maura de Fabricius, qu'il appelait Pompilus maurus dans son Entomologia systemalica, suppl., qui puisse être comparé à cette espèce; mais cct insecte est d'un autre genre : il est noir, ct n'a de commun avec le nôtre que ses cuisses rouges et son habitation aux Indes oricntales. Notre Pompilus blandus est entièrement d'un joli bleu de ciel très-luisant, avec quelques reflets vcrdâtres; le chaperon, le bord des yeux et le dessous de l'inscrtion des antennes sont garnis d'un fin duvet à reflets argentés; les autennes et les pattes sont noires, à l'exception des cuisses postérieures, qui sont d'un rouge sanguin jusque trèsprès de leur extrémité. Les ailes sont transparentes et incolores, à nervures noires.

Ce joli Pompile vient du Bengale.

POMPILE ÁtSTRAL, Pompilus Australis, Guér. - Ater, antennis, capite, vertice excepto, aldomine, primo seginento excepto, fentoribus apice, crucibus, tarsis alisque favis, his apice nigro-fuscis. (Mas. et fœm.) Long. I3 mill. Enverg. 22 mill. Mâle. - Long. 18 mill. Enverg. 29 mill. Feinelle.

Il est trc̀s-voisin de l'Annulatus' et du Luteipennis de Fabricius, mais il en diffère par beaucoup de points. La description du Pompilus bicolor de Fabricius lui irait bien cncore; mais cet auteur dit que son insecte est grand, que ses mandibules sont noires au bout, que le thorax a des denticules postérieurement, que la moitié du second segment abdominal est noire, ce qui n'existe pas dans le rôtre. Sa tête est jaune, ainsi que les palpes et les antennes, avec le vertex entièrement noir chez le mâle, et ayant une seule ligne transverse noire chez la femelle. Le corselct est d'un noir terne, un peu velu sur les côtés, avec le métathorax faiblement ridé en travers. Les ailes sont d'un jaune fauve, un peu plus foncć vers la base, avec une bordure d'un brun assez foncé au bout. Les cuisses sont noires, avec l'extrémité jaune; les jambes et les tarses sont également d'un jaune orangé assez vif. L'abdomen est ovalaire, lisse et un peu luisant; son premier segment est noir, les autres sont d'un jaune fauve en dessus, avec le dessous des deuxième, troisième et quatrième noir.

Il vient du Port-Jakson, à la Nouvelle-Hollande.

** Troisic̀me cellule cubitale beaucoup plus étroite en haut.

POMPILE A VENTRE ROUX, Pompilus rufiventris, GUÉr. - Ater, prothorace, limbo posticali flavo; alis fuscis, anticis violaceo sub-micantibus, capite thoraceque maculis argenteo-sericeis; abdomine rufo-obscuro. (Fœm.) - Long. 16 mill. Enverg. 28 mill. 
Il est très-voisin du Pompilus turcicus de Fabricius; mais il en diffère parce que la bande antéricure du corselct, au lieu d'être cendrée, comme la décrit Fabricius, est d'un beau jaune soyeux. Sa tête, ses antennes, le corselet et les pattes sont d'un noil vif et luisant, avec peu de poils; il y a sur le devant de la têtc, sur les côtés du corselet et en arrière du nétathorax, des reflets argentćs produits par un duvet très-fin et très-serré; le prothorax cst bordé en arrière d'une assez large bande jaune qui est fort arquée avec la convexité cn avant. Les ailes sont brunes, avec les ncrvures noircs, et quelques reflets violets et bleus; la troisième cellule cubitale est rétrécie en avant, comme dans le $P$. viaticus; les inférieures sont plus pâles. L'abdomcn est allongé, un peu comprimé sur les côtés, d'un fauve foncé coulcur d'acajou, avec quelques reflets cendrés et quelques poils noirs.

Cette espècc vient de Buenos-Ayres.

POMPILE LUISANT, Pompilus nitidulus, GuÉr. - Nigro-cyanens, nitilus, metathorace abdomineque dilutioribns, antcnnis pedibusque nigris, alis fuscis. (Fœm.) Long. ro mill. Enverg. I 6 mill.

11 a quelque affinité avec le Pompilus captions de Fabricius; nıais il en diffère par la belle conlcur bleue chatoyante de son métathorax et de son abdomen. La tête, le prothorax et le mésothorax sont noirs, sans poils, avec de faibles reflets bleuâtres; le métathorax, les flancs et l'abdomen sont d'un beau bleu foncé à reflets très-vifs et uu peu violets. Les antennes et les pattes sont noires, les ailes sont brunes, à ncrvures noires; les inférieures sont plus pâles. La troisième cellule cubitalc est rétrécie en hant, comme dans quelques espèces européennes et le Pompilns viaticns entre autres.

Il vient du Chili.

AMMOPHILE OPULENTE, Ammophila opulcnta, Guér. - Atra, sericca, frontc et thoracis maculis lateribus, argenteo'micantibus, alis hyalinis, apice infuscatis, costce et neroulis nigris. (Fom.) - Long. 32 mill. Enverg. 40 mill.

Cet insecte est assez voisin du Pepsis argcntata de Fabricius : il est entièrement d'un beau noir de velours, avec des reflets luisants; sa tête cst un peu plus large que le corselet, aplatie en avant, avec le front argenté. Lcs mandibules sont grandes, d'un noir luisant; les antennes sont également noires, ternes, assez courtes. Le prothorax est petit, avec trois bosses assez distinctes au bord postérieur; le mésothorax a un petit sillon longitudinal au milieu; le métathorax, faiblement strié en travers, prćsente au milieu une petite carènc longitudinale qui va se terminer au bord postérieur. 11 y a, de chaque côtć du thorax, dcux taches rondcs, très-limitées, argcntées et trèsluisantes, qui ressortent et scintillent pour ainsi dire sur un fond de velours noir; les premièrcs de ces taches sont plaeées au bas des côtés du mćsothorax, immédiatement sous l'insertion des ailcs; les deux postérieures, un peu ovalaires ct rćniformes, sur les côtés et en arrière du métathorax, à la naissance des hanches postérieures. Les 
ailes sont ineolores et transparentes, avee le bout un peu enfumé, leurs nervures sont noires; les supérieures ont la eôte assez épaisse et d'un noir vif jusqu'à la eellule radiale. Les pattes sont grandes et d'un noir un peu luisant; l'abdomen est ovalaire, porté sur un pédieule aussi long que la tête et le corselet pris ensemble.

Ce bel inseete vient du Para.

AMMOPHILE RUFIPÈDE, Ammophila rufipes, Guḱr. - Nigra, sub-rugosa, pedibus, alarum squama abdominequc rufis, segmentibus tribus ultimis abdominalibus supra nigris, alis lyyalinis, anticis sub-infuscatis. Atlas, Ins., $\mathrm{n}^{\circ} 9$, fig. $\mathbf{r}$. - Long. I 9 mill. Enverg. 2 I mill.

Il est très-voisin de l'Am. sabulosa, mais il est très-faeile à distinguer. Sa tête est plus large que le eorselet, noire, avee les antennes et les mandibules de la même conleur. Le corselet est très-finement rugueux, peù velu, noir, avec un petit sillon au milieu du mésothorax, et deux impressions longitudinales courbées et latérales au métathorax; l'éeaille qui recouvre la base des ailes est fauve; eelles-ei sont transparentes, un peu enfumées, surtout vers le bout, à nervures d'un brun noirâtre. Les pattes sont fauves, avee les hanehes noires. L'abdomen est fauve, lisse et un peu luisant, avee le dessus des trois derniers segments noir.

Cette espèce vient de Lima, au Pérou.

SPHEX DE DORY, Sphex Dorycus, Gún. - Niger, testaceo-villosus, alis obscure brunneis, flavido-micantibus, basi apiceque obscurioribus; abdomine fulvo, petiolo nigro, tibiis posticis intus fulvo-micantibus. (Fœm.) - Long. 3 I mill. Enverg. 5 I mill.

Sa tête et son eorselet sont d'un noir terne, avee un fin duvet jaunâtre. Le vertex offre en avant un petit sillon longitudinal qui se bifurque en arrivant au premier œil lisse, et longe les deux autres en dehors pour se terminer à leur hauteur. Les antennes sont grandes et noires, un peu renflées au milieu; les mandibules sont grandes, élargies au bout, avee une grosse dent obtuse en dedans et vers l'extrémité. Le mésothoráx offre un petit sillon longitudinal et médian en avant; son éeusson est inarqué par un enfoneement transverse; enfin, le métathorax est arrondi, avec un petit stigmate bien marqué de ehaque eôté. Les ailes sont brunes, à nervures noires, avec la eôte et la base plus noirâtres, et l'extrémité un peu plus foncée que le inilieu; elles sont très-luisantes, avee des reflets jaunes. Les pattes sont noires, luisantes; les jambes postérieures offrent en dedans des reflets soyeux d'un fauve doré. L'abdomen est fauve, luisant, lisse, avee le pétiole assez eourt et noir; l'anus est garni de quelques poils bruns assez longs.

Cet inseee vient de Dory, à la Nouvelle-Guinée.

SPHEX DU PORT-PRASLIN, Sphex Praslinius GuḱR. - Ater, villosus, abdomine 
nitido, glabro, sub-carulco, alis brunneis cyaneo-micantibus. (Fcem.) - Atlas Ins., $\mathrm{n}^{\circ} 8$, fig. 14. - Long. 22 mill. Enverg. 36 mill.

Il est assez voisin du Pepsis cyanipennis de Fabricius, mais il n'a pas, comme celuici, le devant du corselet et l'abdomen cendrés, et il n'est pas américain. Sa tête est noire, finement rugueuse et velue; le front est garni d'un duvet un peu cendré. Les antennes sont assez grandes, noires, ternes. Le corselct est finement chagriné, d'un noir terne, avec des poils noirs assez nombreux et assez longs; le prothorax est si court qu'il est caché par le mésothorax et invisible en dessus. Les ailes sont d'un brun jaunàtre assez foncé, à nervures noires, avec dic beaux reflets bleus; les pattes sont noires, velues, avec les jambes et les tarses garnis d'un court duvet à reflets jaunâtres. L'abdomen est ovalaire, lisse, un peu luisant, avec quelques faibles reflets bleus, son pétiole est assez allongé.

Ce Sphex vient du Port-Praslin, à la Nouvelle-Irlande.

PÉLOPÉE A VENTRE BLEU, Pelopaus cyaniventris, Gú́n. - Nigcr, capite thoraceque villosis, abdomine glabro, nigro-cyaneo nitido, alis brunncis apicc obscurioribus, cyaneo-micantibus. (Mas). - Atl., Ins., pl. 8, fig. I 5. - Long. 3o mill. Enverg. 43 mill.

Il ressemble beaucoup au Pelopaus cyancus de Fabricius, mais il est un peu plus grand, et son corselet est d'un noir pur sans reflets bleus, tandis que dans celui-là tout le corps est d'un beau noir bleu assez vif. La tète et le corselet sont noirs, fincment rugueux, très-velus; l'écusson est assez saillant, un peu échancré au milieu. Les antennes, les mandibules, les palpes et les pieds sont noirs. Les ailes sont d'un brun obscur, avec le bord plus foncé; elles ont de beaux reflets bleus très-luisants. La seconde cellule, au lieu de venir aboutir, avec la première, sous la seconde cellule cubitale, comme dans tous les Pélopées, va s'attacher sous la nervure qui sépare cette seconde cellule de la troisiène; la proportion de ces deux cellules est aussi un peu différente; mais nous pensons que cela ne peut motiver tout au plus qu'une division dans le genre Pélopée. Cette aile établit un passage entre celle des vrais Pélopées et celle des Sphex. L'abdomen est bleu, très-luisant, lissc, avec le pétiole assez court et noir.

Gette belle espèce vient du Brésil; nous cn avons vu des invidus provenant de Maldonalo, sur la còte de la république Argentine.

BEMBEX DE BRULLE, Bembex Brullci. Guér. - Niger, albo-villosus; thorace supra inmaculato; abdomine flavo, fascïs nigris, fascia prima secundaque postice tri-lobatis. Pédibus luteis, fcmorihus basi infra nigris; alis hralinis. - Atlas, Ins., pl. 9,

- fig. 3. - Long. 5 mill. Enverg. 26 mill.

Sa tête est noire, couverte de poils blanchàtres, avec es yeifx oruns. Le chaperon, le labre et la base des mandibules sont jaunes. Les antennes sont noires, avec le premier 
artiele jaune en dessous; il y-a une petite ligne jaune derrière ehaque oeil. Le eorselet est noir, eouvert de poils hlanehâtres; le bord postérieur du prothorax a une très-petite ligne jaune de ehaque eôté; il y a aussi sur les flanes, en avant du mésothorax, une petite tache allongéc jaune. Les ailes sont ineolores, à ṇervures brunes. Les pattes sont jaunes, avee la base des euisses, surtout en dessous, noire. L'abdomen est jaune en dessus, sur les eôtés, et même un peu en dessous de chaque eôté, avee le ventre ou le milieu de son dessous noir. En dessus, le premier segment est noir avee une large bordure jaune en arrière; les seeond et troisième ont une bordure noire à leur base; ee noir forme an milieu trois lobes dont le médian cst plus petit et pointu, tandis que les latéraux sont de forme earrée. Les quatrième, einquième et sixième segments ont une simple ligne noire, étroite et un peu sinuée à la base; l'anus est sans taches.

Il est assez voisin du Bembex americana de Fabricius. Il a été trouvé à la Coneeption, au Chili.

GUÈPE A DEUX TACHES, Vespa bimaculata. Gú́n. - Nigra, sericea; antennis supra fulvis; in segmento secundo abdominis maculis duabus magnis flavo-ferrugineis, alis Ravo-ferrugineis, basi obscurioribus. -. Vespa Alduini, Atlas, Ius., pl. 9, fig. 6. Long. 23 mill. Enverg. \{o mill.

Cette Guêpe a quelques rapports avee les Vespa cincta et affinis de Fabrieius, nais elle est plus petite et n'a pas de taehes brunes sur le thorax. Sa tête est grande, noire, avec les yeux bruns et des taehes d'un ferrugineux obseur sur les eôtés du vertex et derrière les yeux. Lcs antennes sont noires en dessus; leur premier artiele est également noir en dessous, mais les suivants ont ee côtć entièrement fauve. Le eorselet est noir, soyeux et velu. Les ailes sont d'un jaune ferrugineux obseur, avee la base noirâtre, surtout à la eôte et au bord postérieur jusqu'au milieu. Les pattes sont noires avee le dessous des tarses et quelques reflets soyeux et bruns aux jambes. L'aldomen est noir ; son sccond segment porte en dessus deux grandes taches d'un jaune orangé, allant toucher le bord postérieur, se réunissant au milieu cn un seul point, et ayant ehaeune une petite taehe brune en arrière et au inilieu.

Cette espc̀ee a été trouvée dans l'île de Bourou, l'une des Moluques.

ODYNERE A AILES BLEUES, Odynerus cyanipennis. GUÉr. - Niger; capite thoraceque rugosis; clypeo, thorace antice et postice, scutello, primo segmento abdominal, flavis; alis infuscatis, cyaneo-micantibus, anticis costa nigra. (Mâle). - Long. 17 mill. Enverg. 28 mill. - Atlas, Ins., pl. 9, fig. 5.

Sa tête est noire, rugueuse, avec les yeux bruns. Le chaperon est entièrement jaune, tronqué carrément en avant, avec les angles latéraux un peu saillants; le labre est arrondi, saillant et assez long, noir, ainsi que les mandibules et les palpes qui sont allongés. Les antennes sonthoires avee le dessous du premier article jaune. Le eorselet 
est très-rugueux, noir, sans poils; il a deux petites taches jaunes, étroites, transversales, se touchant presque au milieu, au bord antérieur du prothorax ; le métathorax a deux grandes taches jaunes triangulaires sur les côtés de la troncature postérieure, et une autre petite tache transverse derrière l'écusson. Les ailes sont brunes, avec le bord postérieur des infćrieures et l'extrémité des supérieures presque incolores et transparents. Les supérieures ont la côte et la base d'un brun plus foncé, presque noir, et elles offrent des reflets bleus et violets très-luisants. Les pattes sont noires. L'abdomen est noir, presque lisse; le premier segment a, en dessus, une large bande jaune occupant toute la partie qui n'est pas tronquée en avant. - De Payta, au Chili.

ODYNÈRE A PIEDS ROUX, Odynerus rufipes. GuÉR. - Niger, nitidus; alis fuscis cyaneo-micantibus; ore, clypeo apice, articulo primo antennarum infra, macula frontali pedibusque, ferrugineis. Abdomine laevigato. - Long. 16 mill. Enverg. 28 nill.

Cette espc̀ce est très-facile à distinguer; tout son corps est d'un noir vif, sans poils, très-luisant. La tête et le corselet sont ponctués. Le chàperon est rétréci en avant, bidenté, fauve au bout. Les mandibules et les palpes sont également fauvcs; il y a une petite tache de cette couleur entrel'insertion des antennes, et le premier article de celles.ci est fauve en dessous. Les ailes sont obscures; les supérieures sont plus foncées vers la côte, avec de beaux reflets violets et bleus. Les pattes sont fauves, avec les hanches seulement noires. L'abdomen est lisse, luisant, d'un noir vif.

Cétte espèce a été prise dans lî̀le de Taïti.

ODYNÈRE SPLENDIDE, Odynerus splendidus. Guḱr, - Villosus, niger. Capite Alavo-variegato. Antennis flavo-ferrugineis. Prothorace supra, metathorace maculis lateralibus, abdomine fasciis sex latis, ano pedibusque flavo-ferrugineis. Alis flavis apice infuscatis. - Long. 3o mill. Enverg. 47 mill.

C'cst la plus belle espèce que nous ayons jamais vue; sa tête est noire, avec les yeux bruns. Le chaperon et lc labre sont d'un beau jaune orangé : le chaperon a deux fortes dents latérales en avant. Les yeux sont bordés de jaune en avant et en arrière. Les antennes sont entièrement d'un bel orangé vif. Le prothorax est de la même couleur en dessus. Le reste du corselet est d'un bcau noir de velours, avec une grande tache orangée de chaque côté du mćtathorax en arrière. Les ailes sont d'un jaune fauve plus vif vers la côte des supérieures, avec l'extrémité largement bordée de brun. Les supérieures diffèrent un peu de celles des Odynères d'Europe et des deux espèces que nous avons décrites plus haut, parce que leur scconde cellulc cubitale est triangulaire, ayant les deux nervures qui la circonscrivent attachées presque au mème point cn haut, tandis que dans les espc̀ccs ordinaires ces nervures s'attachent à une assez grande distance l'une dc l'autre. Les pattes sont d'une belle couleur orangée, avec les cuisscs noircs jusqu'aux dcux tiers de leur-longueur. L'abdonen est d'un beau noir dc velours, avec tous ses segments largement bordés de jaune orangé vif en dessus et en dessous, à l'exception 
du premier qui est tout noir dessous; l'anus est également orangé. Les derniers segnents de l'individu femelle que nous avons sous les yeux sont rentrés l'un dans l'autre, de manière à ne pas laisser voir le noir de leur base, ce qui rend l'extrćmité de son corps presque entièrement jaune.

Ce superbe insecte vient de la Nouvelle-Hollande.

ODYNÈRE CEINT D'OR, Odynerus aurocinctus. Gúx. - Villosus, niger; clypeo favo brunneo-rsariegato. Prothorace supra, alarum squama, scutello, metathorace maculis tribus, abdomine prino segmento, sequentibus postice pedibusque flavo-ferrugineis. Alis infuscatis, anticis costa obscuriore (fom). - Long. 18 mill. Enverg. 29 mill. Atlas, Ins., pl. 9, tig. 4 .

Il ressemble assez à l' $O$. splendidus décrit plus haut, mais il est de moitié plus petit. Sa tête est noire, veloutée, garnie de quelques poils jaunâtres assez courts. Le chaperon est bidenté, jaune, avec le milieu taché de brun jusqu'aux dents latérales. Le labre est jaune ainsi que les palpes; les mandibules sont grandes et noires. Il y a entre les antennes un petit point jaune qui vient se confondre avec le chaperon. On voit une petite tache de cette couleur derrière les yeux. Les antennes sont entièrement noires. Tout le corselet est d'un beau noir de velours, avec quelques poils jaunâtres, Le prothorax est d'un beau jaune orangé vif. Le métathorax a de chaque côté sur lcs flancs, un peu avant l'insertion des ailes, une tache carrée de couleur orangée. Les écailles des ailes et l'écusson sont de la même couleur. Le métatlıorax a une petite ligne transverse derrière l'écusson, et deux taches en arrière et sur les côtés, de la même couleur orangée. Les ailes sont transparentes, enfumées, à nervures brunes; la côte des supéricures est noirâtre; leurs cellules cubitales sont comme dans l' $O$. splendidus. Les pattes sont d'un jaune orangé presque fauve, avec la base dcs cuisses noire. L'abdomen est noir velouté, avecle premier segment, excepté sa base, et une large bordure postćrieure aux suivants, d'un jaune orangé vif.

Cette espèce vient aussi de la Nouvelle-Hollande.

RHOPALIDIA A VENTRE TACHÉ, Rhopalidia maculiventris. GuÉr. - Fusca, rugosa; clypeolateribus, mandibulis basi, fronte ante oculos flavo-maculatis. Abdomine flavo, segmento primo, et secundo macula magna, insequentibus basi, nigris. Alis hyalinis, subinfuscatis, anticis costa obscuriori. - Long. 16 mill. Enverg. 27 mill. - Atlas, Ins., pl. 9 , fig. 8 .

Ce genre a été fondé par M. Lepelletier de Saint-Fargeau, dans son Histoire naturelle des Insectes hyménoptères, faisant partie des suites à Buffon, publiées par le libraire Roret (t. $\mathrm{I}^{\mathrm{er}}$, p. 538, Paris, 1836 ). Il en décrit deux espèces propres à l’Amérique méridionale; la nòtre est bien nouvelle et se distingue trop par ses caractères et son habitation pour qu'il soit nécessaire d'entrer dans des détails comparatifs. Sa tête est plus large que le corselet, aplatie en avant, d'un brun grisâtre, un peu rugueuse. Les antennes sont noires, avec le dessous un peu ferrugineux vers l'extrémité. Le chaperon a une petite pointe 
au milieu; il offre dechaque còté une petite tache jaune; les mandibules sont également tachées de jauneà la base extérieưre ; on voit encore une petite strie janne peu marquée sur le front, eontre le bord antérieur des yeux. Le eorselet est entièrement d'un brun grisâtre cendré,finement rugueux, terne; la portion déelive du métathorax offre un enfoneement luisant, noir; il a de chaque côté, en arrière, une pointe assez saillante. Les ailes sont transparentes, un peu enfumées, avec la côte des supérieures plus obscure; les. pattes sont noires. L'abidomen est jaune, avec le premier segment, une grande taehe arrondie au milieu du seeond, partant de la base et dépassant le milieu de sa longueur, et la base des autres, bruns.

Cette espèce vient de Dory, à la Nouvelle-Guinée.

EUMÈNE DU PORT-PRASLIN, Eumcnes Praslinia. Guér. -- Nigra, ferrugineovaricgata; abdominis petiolo incurvo, maculis duabus longitudinalibus fasciaque posticali, segmentibus cateris fasciis latis, pedibusque ferrugineis; alis hyalinis nitidis subflavis, costa subferruginea. - Long. 3o mill. Enverg. 43 mill. - Atlas, Ins., pl. 9, fig. 7 .

Cette espècc ressemble presque entièrement à celle que Fabricius a si bien décrite sous le nom de $E$. arcuata; mais elle s'en distingue cependant par ses pattes qui sont entièrement fauves, par les bandes de son abdomen qui ne sont pas interrompues au milieu, et par le dessous du premier segment de l'abdomen, après le pétiole, qui offre au milieu deux grandes taches fauves qu'on ne voit pas à l'espèce de Fabricius.

Sa tête est noire, moins large que le corselet, aplatie en avant, avec une tache orangée au milieu du front, eommuniquant avec le chaperon qui est de la nêtme eouleur; le tour des yeux, en avant et en arrière, est bordé de jaune orangé. Les antennes sont noires. Le prothorax est entièrement d'un jaune orangé vif; le mésothorax est noir, avec une très-petite carène au milieu; ił a, en avant, deux taches arquées, deux petites' lignes au milieu, deux taches sur les écalles des ailes, deux autres sur l'écusson, et une ligne derrière celui-ci d'un jaune orangé; ses flancs ont une grande tache jaune de chaque côté, située sous les ailes supérieures; le mćtathorax est d'un jaune orangé, avec une ligne longitudinale noire au milieu, ne formant pas la croix comne dans l'E. arcuata de Fabricius. Les ailes sont transparentes, d'un jaune obscur, très-luisantes, à nervures brunes, avec la côte d'un jaune un peu plus fauve; les pattes sont entièrement ferrugineuses, avee les hanches et les trochanters noirs, et les artieles des tarses un peu brunàtres. L'abdomen est noir; le premier segment, ou le pétiole, est aussi long que la tête et le eorselet, très-étroit, arqué, un peu plus épais en arrière, avec deux taches allongées et longitudinales, placées de ehaque côté au milieu, et une bande transverse près du bout, d'un jaune orangé vif; le second segment est très-grand, en cloclie, avec une large bande près de sa base et une autre au bord postérieur orangées; les trois suivants sont également bordés de jaune orangé; le dessous de tous ces segments offre une bande plus étroite, interrompue au milieu, et l'on voit sous le second, vers le milieu de sa longueur, deux taehes arrondies de la même couleur orangée. L'anus est noir.

Ce bel insecte vient du Port-Praslin, à la Nouvelle-Irlande. 
Nous avons figuré, planche 9 , fig. $7 \mathrm{~A}$ à $\mathrm{F}$, les parties de la bouche de cette espèce, pour servir de point de comparaison avec celles du genre Ischnogastre. A représente la tête vue de profil pour montrer la saillie du labre et des mandibules. B, la lèvre inférieure surmontée de sa languette et portant les palpes labiaux qui offrent une anomalie, celui de droite n'ayant que trois articles, tandis que celui de gauche en a cinq. C et $D$ offrent l'extrémité de ces deux palpes très-grossie. $\mathrm{E}$, mâchoire portant son palpe de six articles. F, chaperon, extrémité du labre et mandibules très-grossis et vus de face, pour montrer la longueur et les dents des mandibules.

\section{Gcnre ISCHNOGASTRE, Ischnogaster, Guér.}

Suivant la méthode de Latreille (Règ. anim., $2^{\mathrm{e}}$ édit.), ce genre doit se placer entre les Synagres et les Eumènes; car il ressemble au premier deces genres par sa languette divisée en quatre filets longs et plumeux, sans glande au bout, et il avoisine les Eumènes par la forme très-allongée du premier segment de son abdomen. Voici les caractères que nous lui assignons :

Antennes en massue allongée, de douze articles dans le seul individu femelle que nous ayons vu, insérées vers le haut de la tête, devant une échancrure supérieure des yeux, ayant le premier article plus long que les deux suivants réunis, le second court, le troisième plus long que les suivants, qui sont à peu près égaux en longuenr et vont en augmentant d'épaisseur jusqu'au dixième, pour diminuer ensuite et se terminer au dernier en une pointe obtuse. (Pl. 9 , fig. 9 , C.)

Chaperon très-allongé, arrondi au bout, couvrant entièrement le labre. (Pl. 9, fig. 9 , C. D.)

Mandibules allongées, sans dents au côté interne, terminées en pointe peu crochue, à peine plus longues que le chaperon. (Pl. 9 , fig. $9, \mathrm{~A}$, et fig. $9, \mathrm{D}$, où elles páraissent déborder beaucoup plus le chaperon, parce qu'on a figuré celui-ci un peu relevé, ce qui le montre en raccourci.)

Mâcleoires allongées, terminées en pointe, portant chacune un palpe un peu plus long, de six articles, dont les trois premiers, plus longs, atteignent ensemble la longueur de la mâchoire, et les trois derniers courts, presque égaux. (Pl. 9 , fig. 9, E.)

Lèvre inférienre ayant une languette plus longue que les nâchoires, avec le lobe intermédiaire divisé, vers le milieu de sa longueur, en deux longs filets minces et terminés en pointe aiguë, et les deux filets latéraux un peu plus courts, également trèsaigus et ciliés. (Pl. 9, fig. 9, E). Les palpes labiaux doivent avoir quatre articles, comme ceux des Synagres et des Eumènes; mais nous n'arons pu les voir, ils étaient détruits dans l'unique individu que nous avons observé.

Téte allongée, aplatie, avec les yeux longs, échancrés en dedans et vers le haut. (Pl. 9, fig. 9, A, B.) Thorax très-bossu, court. Ailes pliées dans le repos, les supérieures ayant un stigmate assez épais et bien marqué, avec une cellule radiale fort allongée, atteignant presque le bout de l'aile; et quatre cellules cubitales de forme 
carrée, les deux premières beaucoup plus longues que larges, presque égales, la seconde, ayant tous ses côtés parallèles, la troisic̀me et la quatrième égales, presque carrées. Il y a deux nervures récurrentes qui vont s'attacher sous la seconde cellule cubitale, près de ses deux extrémités. (PI. 9, fig. 9, F.) Abdomen très-allongé, avec le premier segment fort étroit, deux fois plus long que le thorax, et les autres beaucoup plus larges, presque égaux (le second n'étant pas cn cloche pour recevoir les suivants), formant une massue ovoïde. Pattes grêles, avec les tarses allongés, terminés par une petite pelote et par deux crochets assez petits et simples.

Nous avions donné depuis longtemps le nom de Sténogaster à ce genre, et ce nom avait été publié dans les planches de ce Voyage, qui ont paru il y a plus de cinq ans. Des entomologistes qui s"inquiètent peu des publications antérieures ayant donné ce même nom à un coléoptère, nous avons dî en chercher un autre; celui que nous employons exprime la même idée.

ISCHNOGASTRE A AILES BRILLANTES, Ischnogaster fulgipennis, Gúr. Niger, nitidus, antennis apice favis; thorace favo, mesothorace et metathorace supra scutelloque, nigris, alis hyalinis, aurco purpureoque fulgentibus, costa alarum anticarum, stiymate, cellula radiali, brunneis. Pedibus quatuor anticis flavis, posticis obscurebruineis, petiolo abdominali longissimo, recto, apice subclavato. - Long. 17 mill. Enverg. 24 mill. — Atlas, Ins., pl. $\mathbf{n}^{\circ}$ 9, fig. 9 .

Ce curieux insecte est surtout remarquable par l'éclat métallique de ses ailes; sa tête est noire, aplatie en avant, avec les yeux bruns; les antennes sont longues, un peu épaissies au bout, noires, avec les deux derniers articles d'un jaune obscur. Le corselet est jaune en dessous et sur les côtés, avec quelques tachcs brunes sur lc prothorax; tout le dessus du mésothorax, les écailles des ailes, le milieu de l'écusson et la base du métathorax noirs; ce dernier offre un sillon longitudinal bien marqué au milieu. Les ailes sont transparentes, à nervures brunes, avec l'extrćmité légèrement enfuméc; la côte, le stigmate et toute la cellule radiale sont bruns; elles paraissent incolores vues dans un certain sens; mais si l'on fait arriver la lunière obliquement, elles offrent les reflets métalliques les plus brillants, dorés, pourprés et mêlés de vert très-lnisant. Les quatre pattes antérieures sont jaunes, avec les tarses bruns; les postérieures sont d'un brun noirâtre; l'abdomen est noir, très-luisant, avec le pétiole de moitié plus long que la tĉte et le corselet, droit, un peu renflé vers le bout; les autres segments forment une massue ovale, pointue en arrière; ils ont leurs bords un peu brunâtres.

Cet insecte a été trouvé à Dory, dans la Nouvellc-Guinée.

ANDRĖNE AUSTRALE, Andrena Australis, Gúr. - Nigra; capite thoraceque fulvo-hirtis, scutello producto, spinoso; abdominc nitido, glaberrimo, pcdibus fulvo-pilosis; alis hyalinis apice subinfuscatis. - Long. I r mill. Enverg. 20 mill. — Atlas, Ins., pl. 9, fig. ro et $\mathbf{r}$. 
Cet insecte s'éloigne assez des Andrènes par les caractères des parties de la bouche, et même par la proportion des cellules de ses ailes supérieures; mais comme nous n'avons eu sous les yeux que deux femclles en assez mauvais état, nous n'avons pas voulu introduire un genre nouveau sur des matérianx aussi incomplets, et nous le laissons dans le genre Andrana jusqu'à ce que l'on ait pu en étudicr de meilleurs individus des deux sexes; nous allons cependant décrire avec soin les diverses parties de sa bouche, pour appeler l'attention des entomologistes; et si plus tard l'on jugeait à propos de distinguer cet insecte des Andrènes, nous proposerions de donner le nom de Mellitidia au geure qu'on pourrait établir avec lui.

Sa tête (fig. 1o, A, B) est arrondie, très-aplatie en avant, avec les yeux grands, placés sur les côtés, très-allongés du haut en bas, entiers, c'est-à-dire sans échancrure brusque au côté interne. Les antennes (fig. 1o, A) sont insérées au milieu de la hauteur du front, de douze articles, le premier fort long, un peu plus mince que les suivants; les second, troisième et quatrième sont courts, un peu obconiques, égaux; les suivants sont un peu plus longs et plus épais, égaux jusqu'au dernier qui est arrondi au bout. Le chaperon (fig. I , A) est peu saillant entre les mandibules, coupé presque droit en avant; le labre (fig. I I, A) est saillant, large à sa base, terminé en une pointe aiguë au milieu, velu sur les côtés. Les mandibules (fig. I I, A) sont assez saillantes, élargies au bout et en dedans, avec trois dentelures arrondies au côté interne. Les mâchoires (fig. I , C, F, G) sont allongées, avec le lobe terninal plié en dessous, court et terminé en pointe. Les palpes maxillaires (fig. I I, D) sont insérés à la base externe de ce lobe, coudés, plus courts quc lui, de six articles presque égaux. La lèvre inférieure (fig. I I, E) est allongée; elle porte à son extrémité une languette pliée en dessous, composée de quatre lanières assez allongćes, ciliées, étroites, terminées en pointe et dont les latérales sont presque du doublc plus longues que les intermédiaires. Les palpes labiaux sont insérés à la base externe de la languette, composés de quatre articles inégaux, assez fortement obconiques, à sommet oblique, dont le premier est presque aussi long que les trois suivants ensemble; ils sont un peu plus longs que les deux lanières externes de la languette, et plus longs que les maxillaires. Le corselet est ponctué, noir, couvert d'un duvet serré et de poils d'un jaune ferrugineux, ainsi que la tête; l'écusson du mésothorax est prolongé en arrière en une pointe mousse assez saillante. Les ailes sont transparentes, à nervures d'un brùn noirâtre, avec le bout très-faiblenent enfumé. Les supérieures (fig. 1o, C) ont la cellule radiale grande ; il y a quatre cellules cubitales très-inégales; la première est plus longue que haute, deux fois au moins plus grande que la seconde; celle-ci est la plus petite; elle est plus haute que longue, à côtés parallèles et formant presque un carré long; la troisième est un peu plus grande que la première, presque du double plus large en bas qu'en haut; enfin la dernière est plus grande, terminée par l'extrémité de l'aile, mais sa nervure inférieure n'est que conmencée. Les deux nervures récurrentes aboutissent, l'une au-dessous du milieu de la seconde cellule cubitale, l'autre au delà du milieu de la troisième cubitale. Les pattes sont noires, garnies de duvet jaune fauve et de poils noirs; le premier article 
des tarses pustérieurs est plus grand que les autres pris ensemble, prolongé en une pointe arrondie à son extrémité supérieure, très-velu. L'abdomen est ovalaire, lisse, d'un noir luisant; il a quelques poils noirs en dessus; ceux de dessous sont plus nombreux et mêlés de duvet un peu fauve.

Cet insecte a été trouvé au Port-Praslin. Nous avons figuré l'extrémité de l'aile de l'Andrcena flessa (pl. 9, fig. 12) pour faire mieux ressortir la différence de proportion des cellules cubitales.

\section{LÉPIDOPTËRES.}

Tous les lépidoptères dont nous allons brièvenient donner la description, sous les noms que leur a imposés M. Boisduval dans l'Entomologie de l'Astrolabe en I832 (1), et plus tard dans les Suites à Buffon de Roret, ont été publiés, plusieurs années avant lui, dans de belles planches coloriées, qui ont paru de I83o à I83 I (2), et certes il est bien reconnu actuellement que des figures coloriées, surtout exécutées avec le luxe et la perfection qui distinguent celles du Voyage de la Coquille, font aussi bien et mème mieux connaître un insecte, et surtout un lépidoptère, que les plus minutieuses descriptions. Il n'en a cependant pas été ainsi aux yeux de M. Boisduval, car il a changé les noms que nous avions imposés à beaucoup de nos espèces, contrairement à toutes les règles établies entre les naturalistes et surtout aux intérêts de la science, qu'il tendait ainsi à embrouiller encore davantage si nous avions voulu exercer un droit incontestable en conservant ici les noms que nous avions donnés à nos lépidoptères.

Voilà comment M. Boisduval cherche à expliquer ces changements de noms, et nous montrerons tout à l'heure, en citant le texte même de M. Boisduval, qu'il pouvait se dispenser de les faire, et qu'en les effectuant il paraît n'avoir cédé qu'au besoin d'ajouter plus souvent son nom à celui de quelques espèces. Voici la note que l'on tṛouve en tête de la première partie de l'Entomologie de l'Astrolabe :

(1) L'Entomologie de l'Astrolabe a paru en arril 1832 , en deux livraisons de planches avec une livraison de texte relatif aux lépidoptẻres. La deuxième livraison du texte, contenant les autres iusectes, a paru en mai 1835.

(2) La livraison 17, contenant les pl. 13, 14 des insectes, a paru le 26 mai 1830.

$\begin{array}{lllll}18 & - & 1,15,16 & - & 1^{\text {er }} \text { septembre } 1830 . \\ 19 & - & 2,17 & - & 25 \text { novembre } 1830 . \\ 20 & - & 3,6,17 & - & 7 \text { mars } 1831 . \\ 21 & - & 12,146 i s & - & 29 \text { mai } 1831 . \\ 22 & - & 5,18 & - & 15 \text { juin } 1831 . \\ 23 & - & 4,20 & - & 25 \text { juillet } 1831 . \\ 24 & - & 11,21 & - & 5 \text { septembre } 1831 . \\ 25 & - & 7 & - & 13 \text { octobre } 1831 . \\ 26 & - & 8 & - & 15 \text { novembre } 1831 . \\ 27 & - & 9,10 & - & 22 \text { décembre } 1831 . \\ 25 & & & \end{array}$


"Avis. Pendant que ce demi-volume était à l'impression, plusieurs livraisons de planches de la partie entomologique de la Coquille ont été publiées. Malgré le désir que j'avais d'adopter tous les noms que l'auteur se proposait de donner aux espèces nouvelles communes aux deux Voyages, et malgré les recherches que j'ai faites à ce sujet, il est arrivé, comme cela n'a lieu que trop fréquemment lorsque deux ouvrages paraissent en mêne temps, que quelques lépidoptères que j’ai décrits se trouvent figurés sous des noms différents. C'est pourquoi je crois qu'il ne sera pas inutile de citer ici ce petit nombre d'espèces. Je regrette beaucoup que M. Guérin n'ait point encore publié le texte, j'aurais pu établir la synonymie d'une manière plus certaine que d'après des figures qui, quoique très-soignées, laissent quelquefois désirer de connaître le dessous de plusieurs papillons diurnes.

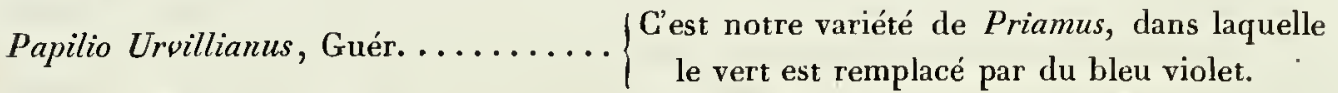
Papilio Euchenor, Guér............ Papilio Axion, nob.

Polyommatus Cleotas, Guér.......... $\begin{aligned} & \text { Argus Pota, nob. L'individu existant au Mu- } \\ & \text { séum était étiqueté Poeta par M: Guérin. } \\ & \text { J'ignore pourquoi il a changé depuis ce nom } \\ & \text { en celui de Cleotas. }\end{aligned}$

Vanessa Amelia, Guér............. C'est la Vanessa Sabina des auteurs.

Nymphalis australis, Guér.......... Mynes Leucis, nob.

Satyrus Klugii, Guér. ............ Satyrus philerope, nob.

Satyrus Duponchelii, Guér. ......... Satyrus Dorycus, nob.

Satyrus Bazochii, Guér. .......... Satyrus cyamytes, nob.

Morpho bioculatus, Guér............ Hyades indra, nob.

Hesperia antipodes, Guér.......... Thymele dichroa, nob.

Hesperia Critomédia, Guér. ......... Thymele odix, nob.

Deileptena Poeyi, Guér............ Hazis mars, nob.

Lithosia Arthus-Bertrand, Guér....... Chelonia Saucia, nob.

Noctua scapularis, Guér............ Agarista frontinus, Donovan.

Cleis posticalis, Guér............ $\left\{\begin{array}{c}\text { Damias melaxantha. Ce lépidoptère est cer- } \\ \text { tainement une nocturne. }\end{array}\right.$

Le docteur BolsduvaL."

On voit d'abord que M. le docteur Boisduval a très-bien su reconnaittre nos espèces, quoiqu'elles ne fussent pas décrites, puisqu'il a si bien réussi à faire figurer nos noms à côté des siens, bien avant que notre texte soit imprimé. D'un autre côté, comme il a eu à sa disposition les individus du Voyage dc la Coquille, qui avaient été rendus au Muséum avec des étiquettes après avoir été figurés, ce qui nous est prouvé par la note qu'il place après le nom du Polyommatus Poeta, il aurait pu lever ses doutes, s'il avait pu y en avoir, au sujet des figures qui, suivant lui seulement, laissent à désirer de connaitre le dessous de plusieurs papillons. Puisqu'il a adopté, à la page 39 , le nom de $P$. Ormenus, donné par nous à un papillon que nous décrivons seulement à présent (1838), 
pourquoi a-t-il donné, deux pages plus loin, le nom d'Axion à notre $P$. Euchenor, en adoptant immédiatement après, p. 4r, notre nom de $P$. Phestus? Pourquoi vient-il relever une de nos erreurs, p. 173 , et montrer encore qu'il a très-bien reconnu les espèces que représentent nos figures, ce qui n’ćtait pas difficile à un entomologiste aussi avancé dans la eonnaissance des lépidoptèrcs, tandis qu'à la page 68 , voulant adopter un de nos noms, quoique le lépidoptère ne soit figuré qu'en dcssus, il tombe malheureusement sur une dc nos erreurs, qu'il ne reeonnait pas, en laissant au Papilio Hylas de Cramer le nom de Corytzes que nous lui avions donné à tort, ce que nous avons reconnu en rédigeant notre tcxte?

Nous pourrions citer cncore beaucoup d'exemples semblablcs, qui montrent jusqu’à la dernic̀re évidenee que M. Boisduval a parfaitement reconnu nos espèces, d'après nos planehcs et d'après les individus qui avaient été figurés et qu'il a vus au Muséum, en sorte qu'il est certain que eet habile Lćpidoptériste, $\mathrm{cn}$ changeant ainsi des noms publiés au moyen de très-bonncs planches, a cédć à un capriee inexplicable. Nous aurions donc, comme nous l'avons dit plus haut, le droit de conscrver à nos espèees les noms qui sont gravés sur nos planches ct de mettrc ceux de M. Boisduval en synonymie; mais nous n’avons pas la puérilité d'attacher unc si grande importance à la gloire dc baptiser quelques insectes, et, pour nc pas apporter une nouvelle confusion dans la synonymie de ces lépidoptères, nous adopterons les noms qu'il lui a plu de donner à la plupart de nos espèccs. Comme elles se trouvent dćjà décrites, nous éviterons un doublc emploi inutile et nous n'en ferons pas de nouvelles descriptions; nous allons nous borner à reproduire les diagnoses données par M. Boisduval, en ne déerivant plus complétement que les espèces qui n'ont pas dît entrer dans son Entomologie de l'Astrolabe.

PAPILLON DE D'URVILLE, Papilio Urvillianus. Guér. - Alis holosericeis supra cyaneo-violaceis, limbo nigro; anticis fascia longitudinali latissima, posticis maculis submarginalibus nigris; his dentatis.

Ornithoptcra Urvilliana. Borsd., Suites à Buffon, Lépid., t. I, p. ${ }_{175}$. - Guḱr., Atlas, Ins., $\mathbf{n}^{0} \mathbf{1} 3$, fig. $\mathbf{r}$ et 2 .

Ce magnifique papillon a étć trouvé au Port-Praslin, à la Nouvelle-Irlande; M. Durville, dans les notes qu'il a rédigćes à la suite de sa relàehe au Port-Praslin, dit que ee lépidoptère vole lentement au sommet des arbres et qu'il se pose sur les feuilles.

PAPILLON AXION, Papilio Axion. Borsd. - Alis dentatis, nigris; fascia cxtus angulosissima, lata, allo-sulphurca; posticis subtus insuper lunula ani fulpa tribusque arculues fulocscentibus. (BossD.)

Papilio Euchenor. Gú́r., Atlas, Ins., ñ 13 , fig. 3.

De la Nouvelle-Guinéc.

Papilion sévìre, Papilio Severus, Cran. - Guér., Atlas, Ins., nº r 4 , fig. r. 11 a été pris à Amboine.

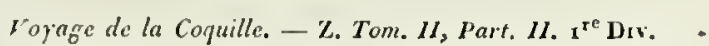




\section{VOYAGE AUTOUR DU MONDE.}

PAPILLON ORMENUS, Papilio Ormenus. Guér. - Alis nigris, anticis fascia apicali submaculari lutescenti vol rufesccnti, posticis fascia subflava lata, extus dentata; posticis subtus nigerrimis, lunulis submarginalibus carulescentibus anguloque ani macula rubesccnte. (Borsd.) - Atlas, Ins., $\mathrm{n}^{\circ} \mathbf{1}$, fig. 3 .

D'Offak, terre des Papous.

PAPILlon PHestus, Papilio Phestrs. Guér. - Alis nigris, posticis fascia discoidali transversa albo-sulfurea nervis divisa, anguloque atrinque ani lunula rubricante; posticis subtus lunulis nuinutis fulvis atonisque carulescentibus. (Borso.) - Atlas, Ins., $\mathrm{n}^{\mathbf{0}} \mathbf{1} 4$, fig. 2. A. B.

Il a été pris à la Nouvelle-Guinée.

PIÉRIDE CHILIENNE, Pieris Chiliensis. GuÉr. - Alis albis; supra apice anticarum late nigris, macula oblonga aurantiaca notatis; subtus posticis anguloque apicali anticarum maculis nigris aliquando luteo adspersis. - Enverg. 55 mill. - Atlas, Ins., $\mathrm{n}^{\mathrm{o}} 15$, fig. 1 .

Antocharis chilensis. Borss., Suites à Buffon, Lépid., t. I, p. 566.

Ses quatre ailes sont d'un blanc un peu soufré; les supérieures ont le sommet peu arrondi, couvert d'un très-large espace noir sinué intérieurement, marqué d'une tache transversale oblongue d'un rouge foncé, arrondie extérieurement et sinuée sur son côté interne; les échancrures sont jaunâtres. Les ailes inférieures sont arrondies, avec un petit lobe en arrière représentant un vestige de queue; elles offrent à l'extrémité une rangće marginale de cinq ou six points noirs. Le dessous des premières ailes présente, outre le dessin du dessus, une rangée marginale de taches jaunâtres. Le dessous des secondes est d'un jaune soufre, parsemé d'une vingtaine de petites taches noires et de quatre ou cinq taches fauvcs.

Cette jolie espèce a été prise aux environs de la Conception, au Chili.

COLIADE DE VAUTHIER, Colias Vauthierï. Guér. - Alis integris, utrinque virescenti-favesccntibus; anticis disco sub-albidis, supra vittis macnlisque conmunis marginalibus nigris, puncto anticarum nigro obsoleto, puncto discoidali ocellari minuto; posticis macılis mefopurpureis punctoque discoillali argenteo. - Enverg. 48 mill. - Atlas, Ins., $\mathrm{n}^{\circ}$ i 5 , fig. 2 .

Cette espc̀ce ressemble tellcment à la Colias Phicomone qu'on pourrait la considérer comme n'en étant qu'une variété locale, quoique sa patrie soit si différente; ses quatre ailes sont un peu moins saupoudrćes de noirâtre que dans la Phicomone, surtout chez la femelle, avec la bordure un peu plus maculaire; le point discoïdal des premières ailes cst un peu plus gros, à peine pupillé en dessus dans le mâle; les nervures des ailes 
supérieures sont noirâtres, surtout chez la femelle; tout le reste est comme chez la P. Phicomonc.

Cette Coliade à plıysionomie si européenne, comme presque tous les insectes du Chili, a été prise dans ce pays, près de la Conception.

ÉMÉSIS IEOSIDA, Emesis Leosida. BorsD. - Alis anticis pallidc fulpis extimo late nigro maculis daabus fulvis, posticis vix snbcaudatis fulvo-forrugineis, lunulis tribus caudaquc nigris; anticis subtus basi fulva maculis tribus lineaque albis, extimo late nigris (apice cxcepto) maculis sex chalybeo-argcnteis; posticis subtus rufo-ferrugineis nervis fascïsque albis, insupcr maculis duabus cxternis lincaque marginali chalybeo-argenteis. (Borss.)

Argynnis pulchra. Gứn., Atlas, Ins., $\mathrm{n}^{\circ} \mathrm{r} 6$, fig. 2 et 3.

Cette charmante espèce a été trouvée au port Dory, à la Nouvelle-Guinée.

DAMIS DE SEBA, Damis Sebce. BorsD. - Alis integris, nigris disco communi albo anticis .ntrinque posticis subtus fascia marginali nitide-cyanea. (Borso.)

Papilio Danis. Cram. - P. Damis, Her вst. - Seba Mus., t. IV, tab. 25, fig. 5, 6, 12, I3, et tab. 37, fig. 5, 6 .

Erycina Damis. Godarn, Encycl., t. IX, p. 577. - Enverg. du mâle 45 mill., de la femelle 5 r mill.

Polyommatus Damis. Gó́r., Atlas, Ins., no I 8, fig. r, 2.

Godard s'est trompé en considérant comme un mâle l'individu quil a décrit dans l'Encyclopédie; nous avons sous les yeux les deux sexes de ce joli papillon, et ils diffèrent beaucoup, mais en dessus seulement.

Le màle est plus petit ( 45 mill. d'enverg.), entièrement noir en dessus, avec les ailes antérieures arrondies au bout; les quatre ailes ont une bande commune discoïdale étroite d'un blanc sale, elles ont en outre la frange entièrement blanche.

La femelle ( 5 I mill. d'enverg.) a les quatre ailes noires en dessus; mais les supérieures ont au bord antérieur et externe une large bande d'un beau bleu nacré, qui se prolonge en se fondant jusquau milieu du bord externe des secondes ailes.

Le dessous dles deux sexes est entièrement semblable et tel que l'a décrit Godard.

Ce lépidoptère a été pris à Amboine, à Rawak, Offak et à Dory, dans la NouvelleGuinée.

DAMIS HYLAS, Damis Hylas. Guén. - Alis caudatis argenteo-caruleis nitidis, marginc tenui nigro, disco communi albo; omnibus subtns fuscis, disco communi albo lineis posticis albis undulatis, posticis maculis marginalibus oblongis nigris, intcrnis argentopunctatis. (Borso.)

Papilio Hylas. Сraм., pl. 363, fig. E. F. 
Polyommatus Hylaïs. Godard, Encycl. méth., Ins., t. IX, p. 654, nº r 26.

Damis coritus. Borso., Voy. de l'Astrolabe, Entom., $\mathbf{r}^{\text {re }}$ part., p. 68.

Polyommatus coritus. Guér., Atlas, Ins., $\mathrm{n}^{\circ} \mathbf{1} 8$, fig. 3 .

M. Boisduval a parfaitcment reconnu ce papillon dans nos planches, quoiqu'il ne soit figuré qu'en dessus; mais il n'a pas aussi bien reconnu l'erreur que nous avions commise en lui donnant un nom nouvean, tandis qu'il est si bien figuré dans Cramer et que Godard l'a décrit assez bien, quoique d'après un individu mutilé.

Nous restituons à cet insecte le nom spécilique d'Hylas, que Cramer lui avait donné et que Godard a cru devoir modifier pour le distinguer du Polyommatus Hylas (Encycl. p. 687). Actuellement qu'il entre dans un genre assez éloigné des Polyommates, il n'y a pas d'inconvénient à lui laisser son ancien nom.

Il a été trouvé à Dory, dans la Nouvclle-Guinée; celui que Godard a décrit venait d'Amboine.

SIMOETHUS LÉOS, Simœthus Leos. Gú́r. - Alis subdentatis, supra fuscis, anticis macula discoidali lata (mas), obsoletissima (fomina), alba; subtus griseo-cinereis, characteribus nigricantibus obsoletis. - Enverg. du mâle 35 mill., dc la femelle 45 mill. Atlas, Ins., $\mathrm{n}^{\circ}$ i 8 , fig. 8 .

Cette espèce ressemble beaucoup au $S$. Pandu de Horsfield (Papilio Symethus, Fabr.), et peut-être n'est-ce qu'une variété locale, mais nous en avons vu trop peu d'individus pour ponvoir nous prononccr à ce sujet.

Les deux sexes de notre insecte diffèrent beaucoup pour la taille et pour la couleur du dessus. Le mâle a le dessus des quatre ailes d'un brun foncé uniforme, avec les supérieures marquées de trois fort petites taches blanchâtres fondues et ne constituant que les traces de la tache des fenellcs.

La femclle a les quatre ailcs en dessus d'un brun moins foncé, surtout à la base. Les premières ailes offrent une large bande blanchc oblique, profondément dentée des deux côtés, partant de la côte près de la base, se dirigeant obliquement vers le bord externe, projetant aux deux tiers de sa longueur une large dent carrée et non échancrée, et suivant ensuite le bord postérieur en se fondant vers la base.

Le dessous des quatre ailes, dans les deux sexes, est d'un gris cendré, un peu jaunâtre uniforme; les supérieures, chez la femelle, présentent la tache blanche $d u$ dessus, mais elle est fondue avec le gris du cóté externe et salie un peu par la couleur dominante. Dans les deux sexes, il y a aux quatre ailes des hiéroglyphes bruns très-bien prononcés et une bordure de points noirs réunis par une ligne sinueuse brune.

Cette espèce ou variété a été prise à Bourou, dans les Moluques. Elle diffère notablement de deux individus du Simathus Pandu venant de Java et de la description donnée par Godard, par les points suivants :

Dans l'espèce de Java, la bande blanche des ailes supérieures, chez la femelle au 
moins, s'étend, en se fondant, jusque très-près de la base, la dent qu'elle projette au côté externe et inférieur, est toujours échancrée au milieu; le dessus des secondes ailes est brun noir vers la còte seulement avec le reste de sa surface cendré bleuâtre, et une liture blanche au milieu. Le dessous des ailes supćrieures est d'un gris jaunâtre avec l'extrémité lavée de ferrugineux; la tachc blanche du dessus est exactement reproduite et nettement limitée par du brun assez foncé à la base de l'aile et du côté de l'extrémité; les hiéroglyphes de ces mêmes ailes sont très-peu prononcés et les points du bord, qui sont presque noirs chez le $S$. Leos, sont ici d'un ferrugineux brunâtre. Les ailes inférieures sont d'un jaunâtre plus pâle et blanchâtrc à la moitié antérieure, lavées de ferrugineux à l'extrémité et vers le bord postérieur, avec des hiéroglyphes roux bordés de brun et unc liture longitudinale brune an milieu, derrière la bande la plus apparente d'hiéroglyphes.

ARGUS POETE, Argus poeta. Guér. - Alis fuscis, anticis lunula nigra discoquc carulescente, posticis fascia submarginali crocea; omnibus subtus albido-cinereis, punctis majoribus nigris; posticis fascia crocea. (Bossd.)

Polyontmatus Cleotas. GuÉr., Atlas, Ins., $\mathbf{n}^{\circ}$ r 8, figg. 4.

Pris au Port-Praslin, à la Nouvelle-Irlande.

HAMADRYADE ZOILE. Hamadryas Zoilus. FAbr., Hub, Boisd.

Nymphalis Nais. Guér., Atlas, Ins., ${ }^{\circ}{ }_{1} 5$, fig. 3.

L'individu que nous avons figuré a été pris à Offak; il se trouve dans beaucoup d'autres lieux de l'Australasie.

CÉTHOSIE OBSCURE, Cethosia obscura. Guér. - Alis subrotundatis dentatis fuscis, serie postica punctorum majorun flavescentium, subtus fuscescentibus, fascia submarginali albida, extus dentata; anticis subtus basi fulvescenti. (Borsd.) - Atlas, Ins., $\mathrm{n}^{0} 15$, fig. 4 .

Cette espècc, qui est bien distincte de toutes celles que l'on connaît, a été prise au Port-Praslin, à la Nouvelle-Irlande.

MÉLITÉE DE GABERT, Melitaa Gabertii. Guér. - Alis fulvis, serie postica punctorun margineque nigris; anticis strigis duabus transversis nigris; subtus luteofulvis. (Bonsd.)

Argynnis Gabertii. Guér., Atlas, Ins., $n^{0} 16$, fig. 4.

Prisc dans lîle de Taiti et dédiée à M. Gabert, l'un des officiers de l'expédition. 
VANESSE AMÉLIE, Vanessa Amelia. GuÉr. - Alis dentatis, supra obscure fuscis, fascia lata media communi flavo-aurantiaca; subtus griseo-flavescentibus, fascia discoidali alba sub-rosea intus recta, extus dentata, serieque postica ocellorum nigrorum iride ferruginea pupillaque violacea. - Enverg. $7 \frac{1}{2}$ centim. - Atlas, Ins., $n^{\circ} 14^{\text {bis }}$, fig. I.

Quoique M. Boisduval ait dit, dans la note placée en tête des lépidoptères du Voyage de l'Astrolabe, que cette espèce n'est que la Vanessa Sabina des auteurs, nous nous permettrons d'avoir une autre opinion, car elle diffère tellement de cettẹ $V$. Sabina, qu'il est on ne peut plus facile de l'en distinguer en la comparant à la bonne description qu'en a donnée M. Godard dans l'Encyclopédie. Nous pensions d'aloord que notre Vanesse n'était autre que l'Algina de M. Boisduval (Astrol. Entom., ${ }^{\text {re }}$ part., p. 1 22); mais nous avons repoussé cette idée en comparant attentivement notre espèce avec la description de cet habile lépidoptériste; car, si nous avions rapporté notre papillon à son espèce, nous aurions dû croire quc la description qu'il a donnée de la $V$. Algina est fausse en plusieurs points importants, ce quil est impossible de supposer de la part d'un entomologiste aussi distingué. Voici du reste la description quill a faite de sa $V$. Algina: "Ailes d'un brun noirâtre, avec une bande discoïlale transverse, d'un jaune fauve (le "mâle), ou blanche (la femeillc); les inférieures ayant une seconde bande marquée de "six yeux; dessous grisâtre, avec la bande discoïdale, et une rangée postérieure d'yeux "à iris fauve et à prunelle violctte."

Il est tout à fait évident que ces mots les inférieures ayant une seconde bande marquée de six yeux, s'appliquent aux deux sexes; or, dans notre espèce, dont nous ne connaissons que le mâle, nous ne trouvons pas de bande postérieure marquée de six yeux; à peinc voit-on, derrière la bande fauve, quatre ou cinq taches un peu plus foncées et qui ne sont visibles qu'à un certain jour. Voici, du reste, la description de notre Vanessa Amelia:

Ailes en dessus d'un brun-noirâtrc, avec une large bande discoïdale d'un beau jaune orangé, natteignant pas l'angle anal, nettement limitée sur ses bords, courbée aux supćrieures et un peu dentće en haut, d̉roite et parallèle aux inférieures; deux ou trois petites taches fondues et jaunes fauves près du sommet des supérieures; bord extcrne des inférieures d'un brun un peu plus pâle, avec une ligne ondulée noiràtre près de la frange, qui est brune, et quelques taches arrondies très-peu visibles près de la bande jaune. Dessous des quatre ailes d'un gris jaunâtre un peu plus pâle à la base, avec une bande conmune discoïlalc blanchâtre légèrement lavée de rose, sans taches ni points, entière au côté interne, dentelée en dehors et atteignant l'angle anal, et ayant à chaque aile, entre cette bande et le bord externe, une rangće de six yeux inégaux noirs, à iris jaunâtre entouré de brun avec une très-petite prunelle violette, à l'exception des deux inférieurs des premières ailes qui n'ont pas de pupille et dont le dernier est plus grand et échancrć des deux côtés. Le bord de l'aile est un peu plus pâle, avec une bordure sinueuse brune prćcédée entre chaque nervure d'une petite tache brune fondue, derrière laquelle il $\mathrm{y}$ a un espace blanchâtre.

Notre espèce diffère de la $V$. Sabina mâle par plusieurs caractères faciles à saisir : 


\section{ZOOLOGIE.}

d'abord la $V$. Sabina a les ailes supérieures plus éehanerées sous le sommet, et les inférieures ont une petite queue, ce qui n’a pas lien dans la nôtre. La bande diseoïdale est d'un jaune moins vif, avee les bords de celle des inférieures séparés du brun du fond par un ton brun ferrugineux fondu. Les trois taehes du sommet des supérieures sont plus grandes, leur bord externe est pâle et un peu jaunâtre, avec une bande foneée et presque maeulaire et une ligne ondulée près du bord, lesquelles se terminent à l'anglè anal en devenant noires et en laissant entre elles une fine strie violette. La frange est alternativement brune et blanehe. Le dessous de la $V$. Sabina est d'un gris eendré avec une bande plus pâle eorrespondante à la supérieure, une ligne de points noirs entourés de fauve très-pàle, plaeće dans une ligne fondue plus foneée ; le bord externe est presque blanehâtre, avee quelques points bruns placés entre les nervures et une ligne extérieure noiràtre, ondulée, peu marquée, et une tache noire à l'angle interne des supérieures et à l'angle anal des inférieures; la base des ailes supérieures offre deux ou trois bandes ondulées transverses un peu plus pâles, et enfin la bande blanchàtre du milieu est eomme saupoudrée, aux supérieures et à la base des inférieures, d'une infinité de petits points noirs.

Nous ne pousserons pas la eomparaison de ces trois espèees plus loin; les notes que nous venons de présenter aideront, nous l'espérons, à les faire distinguer entre elles : si plus tard on reeonnaissait que la $V$. Algina de M. Boisduval est la même que notre Amelia, l'on ne pourrait s'en prendre qu'à lui, et il faudrait alors reconnaître que sa description était insuffisante.

Le Vanessa Amelia a été trouvé à Offak.

NYMPHALE DE GEOFFROY, Nymphalis (Mrnes) Geoffroyi. Guér. - Alis subcaudatis, subvirescenti-albis margine nigro; antieis subtus albis costa apiccque nigris nitidis, apice maenlis quinque sexve albis notato superjectis macula sanguinea; posticis subtus nigris nitidis, eosta sangninea postice flavo eonspersis. (Bolso.) - Atlas, Ins., $\mathrm{n}^{\circ} \mathbf{r} 6$, fig. $\mathbf{I}$.

Cette belle espèce vient du havre d'Offak, terre des Papous; nous l'avons dédiée à M. E. Geoffroy-Saint-Hilaire, le plus grand des naturalistes vivants (avril I 837).

MYNES LEUCIS, Mynes Leucis. BorsD. - Alis anticis nigris serie postica punctorum flavidorum, posticis subeaudatis nigris area diseoidali sulphurea; anticis subtus punctis albis numerosis; posticis subtus basi albo punctatis, arca discoidali, lineisque tribus flexuosis, interruptis, viresccnti-allidis. (Borso.)

Nymphalis australis. Guén., Atlas, Ins., $\mathbf{n}^{\circ} \mathbf{1} 4^{\text {bis }}$, fig. 4 .

D'Offak, terre des Papous.

SATYRE PHLÉROPE, Satyrus Philerope. BorsD. - Alis omnibus supra anticisque subtus fulvis, nigro-variis occllo unico; posticis utrinque (famina) ocellis duobus; subtus cinerco-lutesccntibus (fomince cincreo-violaceis) strigis tribus undulatis nigris. 
Satyrus Klugüi. GuÉr., Atlas, Ins., $\mathbf{n}^{\mathbf{0}} \mathbf{7}$, fig. I.

Des environs du Port-Jakson, à la Nouvelle-Hollande.

SATYRE DE DORY, Satyrus Dorycus. Borsd. - Alis supra fuscis, anticis angulo interno, posticis extus dimidiatim fulvo-aurantiacis; anticis ocellis duobus, posticis tribus, nigris albo-pupillatis; subtus flavo-luteis, intus obscurioribus, vitta transversa rufa; margine dilutiori, ocellis, anticarum 2, posticarum incequalibus 5, adomato.

Satyrus Duponchelii. Gú́r., Atlas, Ins., nº 17 , fig. 3.

Quoique l'espc̀ce décrite par M. Boisduval dans l'Astrolabe (Ent., I ${ }^{\text {re }}$ part., p. ${ }^{152}$ ) nous parût très-voisine de la nòtre, nous n'aurions jamais osé rapporter notre Satyre de Duponchel à la description que M. Boisduval donne de son $S$. Dorycus, si ce savant ne nous avait pas assuré avoir décrit notre espèce, que nous lui avons montrée à cet effet. Voici la description de M. Boisduval, afin de montrer quc nos doutes étaient légitimes. "Alis supra fiscis; posticis dimidiatim fulvo-aurantiacis; anticis ocellis duobus; posticis tribus extremis minutissimis."

Le Satyrus Dorycus a été pris au havre de Dory, à la Nouvelle-Guinée.

SATYRE CYAMITE, Satyrus cyamites. BorsD. - Alis rotundatis, nigris basi late fulvo-ferruginea, ocelloque unico; subtus fuscis strigis tribus obscurioribus, apiceque pallidiori; anticis ocellis quatuor primo, quarto majoribus, posticis sex primo, quinto majoribus. (Borso.)

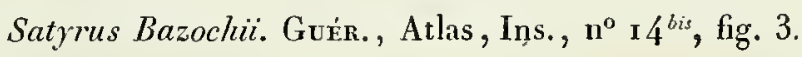

De Dory, à la Nouvelle-Guinée.

SATYRE DU CHILI, Satyrus Chiliensis. GuÉr. - Alis integris, supra nigris, apice anticarum utrinque macula ocellari atra; subtus nigro-rufis, anticis lata macula rubra discoidali, posticis albo nigroque variegatis. - Atlas, Ins., ${ }^{\circ}$ 16, fig. 4-5. - Enverg. 5 centim.

Ce Satyre ressemble cxtraordinairement aux Nègres de nos montagnes, et il vient encore montrer combien la physionomie de l'entomologie du Chili a d'affinité avec celle du midi de l'Europe. Son corps et ses antennes sont noirs, celles-ci ont un peu de fauve au-dessous de la massue. En dessus, les quatrc ailes sont d'un brun noir uniforme sans taches, avec un petit eil noir près du sommet des supérieures, très-peu visible dans le mâle. Le dcsssous est d'un noir roussâtre assez foncé dans le mâle, avec la base des supérieures d'un ferrugineux vif, quelques petites stries noires et grises à la còte, ct un assez gros oil noir près du sommet. Les inférieures sont marquées de lignes ondées, noires, précédécs ou suivies de taches blanchâtres qui forment vaguement delix bandes arrondies, parallèles au bord externe. 
La femelle, que nous avons vue dans la collection de M. Lefebvre, est plus pâle dessus et dessous, avec une large tâche d'un brun roussâtre au milieu des ailes supérieures. Cet insectc a été pris aux environs de la Conception, au Chili.

SATYRE TRISTE, Satyrus tristis. GUE். - Alis paululum dentatis; supra nigro-fuscis. Subtus brunneo-rufis, anticis disco rulescentibus lineis nigris, ad costam, albo griseovariegatis; punctis geminis, ad apicem, nigris, albo-pupillatis, aliquando supra scriptis; posticis, linea latissima alba sinnosissima interrupta, et transversa, intus infraque dentis albis, potius luteola ad medium, crenata, maculaque alba ad marginem anticum terminata, punctis marginalibus albis.

Argynnis tristis. Guér., Atlas Ins., $\mathrm{n}^{\circ}$ 16, fig. 5. — Enverg. 33 millim.

Nous avons ćté induit en crrcur en faisant dessiner notre planche, parce que l'individu unique de la collection du Voyage a été raccommodé, et que l'on a collé les ailes sur un corps d'Argynne: le renflement des nervures des ailes ne nous laisse aucun doute sur le genre de ce lépidoptère. En dessus, ses quatre ailes sont d'un brun noir foncé, un peu dentées, à frange alternativement brune et jaunâtrc. Lc dessous est d'un brun roussàtre, plus vif au milieu des ailes súpérieures, avec quelques lignes brunes, et près du sommet deux taches noires réunies, munies de deux très-petites pupilles blanches. Lcs postérieures ont au milieu une ligne d’un blanc jaunâtre, très-sinueuse, dentée inférieurement, se terminant plus haut que le milieu en une assez grande tache jaunâtre et triangulaire; il y a à la côte, et dans le prolongement de cette ligne blanche, une assez grande tache de la même couleur. Derrière cette ligne, on voit une bande plus pâle que le fond des ailes, dans laquelle on compte quatre ou cinq petits points blancs.

Cette espèce a été prise au Chili.

Nous donnons, à la suite de ces descriptions, la diagnose de deux autres espèces à physionomie européenne, qui ont étć récoltées dans le même pays par M. Eydoux, pendant son voyage sur la corvette la Favorite; elles seront décrites avec détail, et figurées dans la zoologie de ce Voyage.

Satyrus Coctei, Gúér. - Alis integris, laviter sinuosis, mari supra nigro-fiuscis, famina fulvescentibus; subtus brunneis, anticis macula latissima discoidali rubro-fulva, ad apicem macula rotundata nigra (aliquando supra scripta) albo-bipupillata; posticis vitta obsoleta pallidiori versum marginem. - Enverg. 33 millim.

Satyrus Lefebrii, Gún. - Alis integris dentatis rufis; anticis disco rulescente; inaquali vitta marginali crenata ad apicem lutescente, punctis duobus quorum apicali Voyage de ta Coquille. - Z. Tom. II, Part. II. I $^{\text {re }}$ Div. 
maximo (subtus albo bipupillato) nigris. Posticis vitta marginali crenata rubescente, puncto anali nigro notata; sultus anticis similibus, posticis griseo-nigro fuscoque variegatis; vitta marginali superna alba atomis rufis adspersa. - Enverg. 7 centim.

Nous avons dédié le premier de ces lépidoptères à notre ami M. le docteur Th. Cocteau, connu par ses excellents travaux erpétologiques; l'autre porte le nom de notre bon camarade Alex. Lefebvre, dont les entomologistes connaissent suffisamment les titres scientifiques. Nous profitons de cette occasion de le remercier des bons avis et des secours qu'il nous a donnés pour cette publication.

HYADE INDRA, Hyades indra. BorsD. - Alis anticis albis costa apiceque nigris; posticis albis margine nigro macuta discoidali nigra, oculis duolus nigris iride pupillaque coruleis; posticis subtus luteo-albis ut supra ocello nigro pupilla irideque coeruleis ad sostam. BorsD.

Morpho bioculatus. Gú́r. - Atlas Ins., nº 1 7, fig. I.

De la Nouvelle-Guinée.

EURYBIE CAROLINE, Eurybia carolina. Godart. - Encycl. méth. Ins., t. IX, p. 45g. Art. Papillon. Atlas Ins., $\mathbf{n}^{\mathrm{o}} 4^{\mathrm{bis}}$, fig. 2.

Cette espèce a été prise à Sainte-Catherine, au Brésil; nous l'avons représentée parce que, au moment où nous avons fait nos planches, elle n'était figurée dans aucun ouvrage français.

THYMELE ODIX, Thymele odix. Borsd. - Alis fuscis; anticis fascia transversa aurantiaca; posticis fascia lata terminali aurantiaca. Borsd.

Hesperia critomedia. Gúén. - Atlas Ins., nº 18 , fig. 6.

D'Offak, Terre des Papous.

THYMELE A DEUX COULEURS, Thymele dicleroa. Borsd. - Alis fuscis; anticis immaculatis; posticis fascia tcrminali aurantiaca intus acute dentata; abdomine subtus palpisque fulvis. BorsD.

Hesperia antipodes. Guér. - Atlas Ins., n 18 , fig. 7. - De Dory, à la NouvelleGuinée.

AGARISTE FRONTINUS, Agarista frontinus. Doxov. - Alis nigricantibus, fimbria albida; anticis fascia alba transversa lineaque ad extimum nigra; posticis immaculatis; thorace rufescente. BorsD.

Noctua scapularis. - Atlas Ins., $\mathrm{n}^{\circ}$ 19, fig. 2. - Des environs du Port-Jakson. 
AGARISTE HÉMORRHOIDALE, Agarista hamorrhoüdalis. Guér. - Alis nigrofuscis; anticis lineis duabus basilaribus, fasciolisquc mediis duabus abbreviatis, plumbeis, maculaque externa albida; posticis fascia fluwa; omnibus subtus concoloribus; collari anoque fcrrugineis. Boisd. - Atlas Ins., $\mathbf{n}^{\circ} \mathbf{1 9}$, fig. $\mathbf{1 .}$

Cette jolie espèce vient de la Nouvelle-Irlande.

GLAUCOPIDE A VENTRE STRIÉ, Glaucopis strigiventris. GuÉr. - Alis integris, utrinque fuscis, maculis fencstratis albis, basi lutco maculatis. Corpore fusco, antice binis maculis luteis; abdomine lutco supra excisuris nigris strigato. - Atlas Ins., $1^{\mathbf{0}} \mathbf{1 9}$, fig. 8. - Enverg. 33 millim.

Cette espèce est facile à reconnaître aux stries noires qui coupent son abdomen. Ses antennes sont brunes, bipectinécs; sa tête cst petite, brune. Le corselet est de la nême couleur, avec deux grandes taches jaunes sur le devant, au-dessus de la tête, séparées par une ligne étroite noirâtre. Les ailes sont brunes dessus et dessous, avec des taches jauncs à la basc. Les supérieures ont deux bandes transverscs de taches tranśparentes, placées l'une un peu avant le milieu et l'autre vers le bout; la bande apicale est composée de quatre taches inégales dont les supéricures sont les plus petites; la bande du milieu a trois taches et se continue avec une bande de trois autres taches également transparentes placécs au milicu des ailes inférieures. L'abdomeı est d'un jaune d'ocre, avec la suture des segments brunc; le dessous est d'un jaune plus pâle, avec les côtés tachés alternativement de noir et de jaune d'ocre. Les pattes sonit brunes, avec le cóté externe des jambes jaune.

Cette jolie Glaucopide a été prise dans l'île de Sainte-Catherine, au Brésil.

HAZIS MARS, Hazis Mars. BorsD. - Alis subconcoloribus, nigro-violaceis; anticis fasciis punctoquc albis; posticis basi albo maculatis, fasciague subpostica lutea, plus minusve obsoleta; thorace violacco, collariflavo; abdominc rufesccnte; (fomina) posticis disco albo, fascia transversa submarginali lutca. BorsD.

Deileptena Poeji. Gứri. - Atlas Ins., nº 19 , fig. 3.

Cette belle cspècc a été trouvéc à Offak.

\section{Genre PIIALOÉ, Phaloe. Gù̇r.}

Comme nous n'avons pas actucllement assez de matériaux pour bien fixer les caractères de ce nouveau genre, nous allons suivrc l'exemple de M. Boiscluval (Genre $A$ ganaïs, Astrol. Lnt. re $^{\text {re }}$ part., page 248 ), et le caractériser à sit manière, en disant: Les insectes de ce genre habitent lAmérique méridionale, au Brésil, dans la république Argentine, etc. 
PHALOE ENSANGLANTÉE, Phaloe cruenta. Guér. - Alis integris elongatis, utrinque anticis brumneis, maculis luteo-vitreis, ad apicem albis, punctis ad costam versum basin rubro-sanguineis; posticis luteo-vitreis, nervis nigris, lato margine nigro, punctis minutis albis notato. Corpore supra brunneo, subtus albido; thorace capiteque albopunctatis, ano sanguineo. (Mas.) - Atlas, Ins., ${ }^{\circ}{ }_{19}$, fig. 4. - Enverg. 6 ccntim. 1/2.

Callimorpha cruenta. Huвx. Zuträge, etc., n ${ }^{\text {os }} 329,330$.

Ce joli nocturne a les ailes allongées, entic̀res; les supérieures sont d'un brun un peu jaunàtre, avec deux bandes transversales demi-transparcntcs, la première jaune, partant du milieu de la côte et se dirigeant vers l'angle postérieur, la seconde apicale, blanche, vitrée, avec une petite tache jaune près du milicu du bord externe; on voit à la base une autre tache jaune et triangulaire. Enfin la côte, à partir de la base jusqu'à la bande dn milieu, est d'un brun presque noir, marquée de cinq taches d'un rouge de sang. On voit près de l'angle postérieur externe deux on trois petites taches blanches. Les ailes postéricures sont d'un jaune transparent tirant un peu sur le verdâtre, avec les nervures noires; leur extrénité est largement bordée de noir, et il y a dans cette bordure, et près de la frange, cinq points blancs. La couleur des quatre ailes, en dessous, est semblablc en tout à celle du dessus. Le corps cst brun; la tête et le corselet sont inarqués de petites taches blanches; l'anus est d'un rouge dc sang, et le dessous de l'abdomen jaune; les pattes sont brunes en dessus et jaunes au côté inférieur.

Ce joli lépidoptère vient du Brésil ; lïndividu figuré par Hubner est une très-petite femelle, chez laquelle les ailes inférieures ont plus de noir. M. Boisduval possèdc cette même espèce venant de Buénos-Ayres, et d'une taille plus grande.

CHÉLONÉE ASTRÉE, Chelonia astrea. Gú́r. -- Alis anticis albido-murinis, subdiaphanis; costa, macula mcdia apiceque fuscis; basi punctis duobus nigris; posticis albido sub-murinis, subdiaphanis; thorace murino, punctis nigris; abdomine supra rufo (var. albido-cinereo, basi anoque supra rubellis), infra favido, lateribus punctis nigris. Palpis rufis apice nigris. Pedibus griseis, intus rufis.

Sphinx astreus. Drury, t. II, p. 49, pl. 28 , fig. 4.

Chelonia saucia. Bolsd. - Voy. Astr. Ent., I ${ }^{\text {re }}$ Partie, page 2 I 4 .

Lithosia Arthus Bertrand. Guér. - Atlas Ins., nº 19, fig. 5. - Enverg. 7 centin.

Après une comparaison très-attentive de notre lépidoptère avec la description et la figure de Drury, nous avons reconnu, plus que jamais, qu'il est impossible d'en faire une espèce, et nous persistons à considérer notre Chélonée comme une légère variétć du Sphinx astreus de Drury. En effet, il n'y a que la couleur du dessus de l'abdomen qui fasse un peu différer notre insecte de celui de Drury, et encore, chez le nôtre, 
voit-on le rouge s'étendre un peu sur les côtés des segments jaunes, ce qui pourrait faire penser qu'unc circonstance à nous inconnue a pu faire disparaìtre cette couleur sur. les segments intermédiaires. Les côtés de l'abdomen ont les points noirs que Drury a figurés à son Sphinx astreus, mais ces points sont un peu plus petits et cachés dans des replis causés par la dessiccation. Enfin l'habitation de l'espèce de Drury est le Bengale; la nôtre vient d'Offak, dans la Terre des Papous, et l'on sait que bcaucoup d'espèccs de ces deux pays sont identiques. Nous donnons ici, pour que chacun puisse juger notre rapprochement, la description que Drury a faite de son Sphinx astreus, dans ses Illustrations (t. II, p. 49, pl. 28, fig. 4). "Déploie ses ailes presque 3 pouces. Le dessus, les antennes sont en filet, brunes, claires, et plus épaisses au milieu. Les yeux bruns, obscurs. La tête, couleur de crème, tachée de noir, comme aussi le cou, avcc une fente on onverture rougc au milieu, et une tache noire de chaque côté. Le corselct, couleur de crème, taché de noir. L’abdomen écarlate. Lcs ailes supérieures sont transparentes, desquellcs un tiers, près du bout, est opaquc et d'une coulcur de poil claire, qui conrt environ mi-chemin sur le bord antérieur de chaquc aile, où se tronve une raie de la même couleur courant mi-chemin au travers de l'aile. Les bords antérieurs et postérieurs sont couleur de crème obscurc. Les ailes inférieures aussi sont trapsparentes, les bords antérieurs et les coins supérieurs étant couleur de crème obscure. Le dessous, les an-tennules sont extćrieurement blanchcs, mais rouges en dedans, les extrémitćs étant noires. La trompe est repliée. La poitrine blanche, avec une tache noire de chaque côté. Les pieds rouges. Le dessous des cuisses blanc. L'abdomen coulcur de crème, avec une raie blanche étroite de chaque côté, sur laquelle sont plusieurs taches noires. Toutes les ailes paraissent de la même couleur qu'en dessus, sans aucun changement. Je l'ai reçue du Bengale."

La N. Melanthus de Cramer (t. IIl, pl. CCLXXXVI, fig. B.) est voisine de celle-ci. Elle vient de Ceylan.

POLIE PEINTE, Polia picta. Gú́r. - - Alis albidis nigro rubroque variegatis; posticis albidis; anticis subtus costa rubricante. Borsd.

Noctua festiva. Donov, - Epitome of Ins. of New-Holl. - Noctua picta. - Atlas, Ins., $\mathrm{n}^{\circ}{ }_{9}$, fig. 7 .

Cette jolic espèce a été trouvée au Port-Jakson.

OPHIUSE PROPÍCE, Oplizusa propitia. GuÉR. - Alis luteis nigrescenti subconspersis linea communi subpostica fusca; anticis punctis tribus quatuorve fuscis; omnibus subtus vivide luteis fascia postica strigisque duabus discoideis fuscis. BorsD.

Noctua propitia. - Atlas Ins., $\mathrm{n}^{\circ} \mathbf{1} 9$, fig. 6 . 
DAMIAS MELAXANTHE, Damias melaxantha. Borsd. - Alis nigro-violaceis; anticis macula externa aurantiaca; posticis fascia lata aurantiaca fimbriaque nigra; subtus concoloribus, strigis yinlaceis. BorsD.

Clcis posticalis. Gú́r. - Atlas, Ins., n x8, fig. 5 .

Cet insccte a été pris au Port-Praslin. Nous pensons que c'est à tort que M. Boisduval le place dans les nocturnes; s'il n'appartient pas aux diurnes, il doit au moins aller parmi les crépusculaires ou à la suite des uranies.

\section{DIPTËRES.}

\section{Genre LEPTOTARSE, Leptotarsus. Gux́r.}

D'après le nonvelohivage de M. Macquart (I), et en consultant le tableau de sa tribu des tipulaires terricoles, on voit que ce genre ne peut aller que dans la division EE, composée d'espèces ayant le prolongement de la tête épais et pcn allongé. Notre insecte se distingue du genre Pachyrhine qui entre seul dans cette division par le dernier article de ses palpes et par le nombre de ceux des antennes. Voici les caractères que nous lui assignons :

Prolongement de la tête épais et peu allongé (fig. I. A.). Front peu saillant. Les trois premiers articles des palpes (fig. I. C.) cylindriques et égaux, le dernier aussi long que les deux précédents réunis, composé de cinq articles bien distincts dont le premier est le plus étroit, et le dernier plus long que le précédent. Antennes (fig. I. B.) filiformes, de dix articles: le premier grand, eylindrique; les trois suivants, épais, courts, égaux; les quatric̀me et cinquième plus étroits et obconiques; les quatre derniers beaucoup plus étroits, égaux et allongés. Ailes écartées. Cinq cellules postérieures, deuxième pétiolée. Pattes trìs-grêles, avec les tarses au moins deux fois plus longs que les jambes.

LEPTOTARSE DE MACQUART, Leptotarsus Macquartii. Gú́r. - Luteus. Thorace antice, abdomine maculis quatnor triangularibus, nigris; alis infascatis; pedibus brunneis, gracilibus, tarsis longissimis. - Long. $x 9$ mill. Enverg. 44 mill. - Atlas Ins., pl. 20, fig. $x$.

La tête est petite, jaune, avec les yeux et les antennes obscurs. Le prothorax est noir, assez luisant, lisse, avec une tache latérale jaune de chaque côté et en arrière. Le

(I) Hist. nat. des Insectes. Diptères, dans les Suites à Buffon de Roret. 
mésothorax et le métathorax sont lisses, d'un jaune assez vif; l'on voit un peu de brun en arrière de l'écusson du métathorax. Les ailes sont grandes, demi-transparentes, un peu enfumées, à nervures brunes, avec la côte un peu jaunâtre. Les pattes sont très-grêles et très-longues, d'un brun obscur, plus pâles à la base, avec les tarses au moins deux fois plus longs que les jambes, à premier artiele plus long que les quatre suivants. L'abdomen est jaune, lisse ct luisant; le bord postérieur des quatre premiers segments porte une bande noire avancée en avant et en pointe au milieu.

Ce bel insecte a été pris au Port-Jackson.

\section{Genre ÉVANIOPTÈRE, Evanioptera. Gú́r.}

Ce genre est voisin du précédent et doit cntrer dans la même division, car le dernier article de ses palpes est allongé et composé de plusieurs articulations, tandis que dans la division qui comprend les Limnolies, le dernier article des palpes est semblable aux autres, plus court qu'cux et simple. Voici les caractères que nous assignons à notre genrc Evanioptera :

Prolongement de la tête court, épais. Front assez saillant; les deux premiers articles des palpes (fig. 2. A.) cylindriques et égaux, le troisième plus court et épais en dessous, le dernier ou quatrième composé de cinq articulations inégales, dont les deux premières sont les plus longues et les autres grenues. Antennes........ cinq cellules postérieures aux ailes (fig. 2. B.), la dernière plus large. Pattes longues et grêles.

Nous avions d'abord donné le nom de CaLoptène à ce genre; mais M. le comte de Castelnau ayant depuis employé ce nom pour un genre de coléoptères voisins des Lycus, nous avons dû changer le nôtre pour éviter des synonymies.

ÉVANIOPTÈRE FASCIÉE, Evanioptera fasciata. Gún. - Atra. Capite, abdomine basi apiceque favis. Alis nigris maculis duabus basilibus fasciaque transversa favis. Pedibus nigris flavo annulatis. - Long. 18 mill. Enverg. 3o mill. - Atlas Ins., pl. 2o, fig. 2.

Sa tête est d'un beau jaune orangé, avcc les yeux, le premier article des antennes et les palpes bruns. Le corselet est noir et terne; les ailes sont d'un brun foncé presque noir, avec la base, deux taches allongées natteignant pas le milieu, et une bande transverse au delà du milieu, d'un beau jaune orangé. Les pattes sont noires, avec la base des cuisses et une partie asscz grande vcrs leur extrémité, d'un jaune orangé; il y a un peu de jaune au milieu des jambes ct à la base des articles des tarscs. L'abdomen est noir, avec les deuxième, troisième, quatrième ct le dernier segment d'un jaune orangé assez vif.

Cct insecte a été pris dans l'ille de Saintc-Catherine, au Brésil. MI. Wenrood en décrit une seconde espèce du Nepaul. (Soc. Ent., t. IV, p. 68r.) 
PANGONIE DU PORT-JAKSON, Pangonia Jaksoniensis. Gnér. - Flava; oculis thoraceque nigris; abdomine rufo, apice obscuriori, tarsis brunneis. Alis hyalinis basi, costa nervulisque flavis. - Long. 17 mill. Enverg. 28 mill. - Atlas Ins,, pl. 20, fig. 3.

Sa tête est jaune, très-velue en dessous, avec les yeux très-grands, presque contigus en dessus; il y a des ocelles. La trompe est brune, deux fois plus longue que la tête. Le corselet est noir en dessus, avec un peu de duvet jaune doré sur les côtés et le dessous entièrement couvert de grands poils jaunes. Les ailes sont transparentes, avec une petite portion de leur base, la côte et les nervures jaunâtres. Les pattes sont d'un jaune fauve, avec les tarses bruns. L'abdomen est de la couleur des pattes, lisse, luisant, avec l'extrémité un peu plus foncée et tournant au brun (femelle). — Du PortJakson.

3. A. Sa tête vue de profil. 3. B. Antenne. 3. C. Palpe.

PANGONIE DE MACQUART, Pangonia Macquartii. Guér. - Flava. Capite thoraceque supra ferrugineis, oculis nigris. Abdomine apice obscuriori, tarsis pallide brunneis. Alis pallidis, hyalinis, nervulis flavis. - Long. 14 inill. Enverg. 28 mill.

La tête est d'un jaune ferrugineux en dessus, avec les yeux noirs et le dessous jaune pâle et très-velu. Il y a des ocelles; la trompe est deux fois plus longue que la tête, noire, avec le filet supérieur jaune. Le corselet est d'un ferruginetux assez vif en dessus, avec les côtés et le dessous d'un jaune pâle et velus. Les ailes sont transparentes, à nervures jaunes; celles de la côte sont un peu plus obscures. Les pattes sont jaunes, à tarses un peu obscurs. Le dessus de l'abdomen est jaune à la base, avec les trois derniers segments obscurs à côtés plus pâles; le dessous est tout jaune. (Fenelle.) - Du Chilì.

PANGONIE A AILES NOIRES, Pangonia nigripennis. Guér. - Atra. Thorace villoso. Abdomine nitido, lateribus pilis aureis. Alis pedibusque nigris. - Long. 19 mill. Enverg. 45 mill.

Sa tête est très-aplatie d'avant en arrière, transversale, avec la.trompe plus de deux fois plus longue qu'elle, ayant les filets supérieurs rougeàtres : il y a des ocelles. Le corselet est couvert d'un duvet très-serré, et les parties qui en ont été dépouillées offrent quelques reflets rougeâtres et veloutés. Les ailes sont noiràtres, plus foncées à la base et vers la côte. Les pattes sont entièrement noires, un peu. velues. L'abdomen est bombé, très-élargi au milieu, brusquement rétréci en arrière, lisse, luisant et peu velu; les côtés de ses segments postérieurs, à partir du troisième, sont garnis d'un duvet soyeux d'un beau jaune doré. Le dessous est tout noir (femelle). — Du Brésil.

PANGONIE THOraGiQUe, Pangonia thoracica. Guér. - Nigra. Oculis cupreis. Thorace brunneo, pilis densis flavo-pallidis. Alis obscure brunneis. Abdomine nigro, nitido lateribus pilis flavo-albis. - Long. 20 mill. Enverg. 46 mill. 
Elle ressemble entièrement à la précédente pour la forme de l'abdomen et pour la taille, mais sa tête est moins aplatie, et la trompe un peu moins longue. Les yeux sont contigus, d'un cuivreux foneé presque noir. Le corselet est d'un brun jaunâtre, couvert en dessus d'un duvet assez long et très-serré, d'un jaune pâle. Les ailes sont brunes, avec la côte et la base plus obscures. Les pattes sont noires, velues. L'abdomen est noir, luisant, avec les eôtés des segments postérieurs, à partir du troisième, garnis de duvet soyeux d'un jaune un peu doré (mâle). - Du Brésil.

TAON A GOUTTES, Tabanus guttatus. Dovov., Epitome. - Ater; thoracis lateribus lineolisque duabus abdominisque punctis medio quatuor marginalibusque octo albis. (Donov.) - Long. 25 mill. Enverg. 49 mill: - Atlas, Ins., pl. 2o, fig. Io.

L'individu que nons avons figuré est une variété distinguée par l'alssence des points blancs du milieu de l'abdomen. Ses antennes n'ont aucune trace de clent à la base du troisième article.

Ce Tabanus guttatus n’a pas été connu de Wiedemann. - Du Port-Jakson.

TAON LARGE, Tabanus latus. GuÉr. - Ater nitidus. Thoracis lateribus abdominis apice ferrugineo-pilosis. Alis hyalinis, costa nervisque nigris. Abdomine quadrato, planato, pilis nigris lateralibus. - Long. 20 mill. Enverg. 37 mill.

Il est entièrement noir; sa tête est petite, aplatie en avant. Les antennes ont leur troisième article simple, sans dent. Le corselet est noir, avec les côtés garnis de poils serrés d'un rouge ferrugineux, qui s'étendent en dessous et garnissent le bord antérieur sous la tête. Les ailes sont transparentes, avec la eôte et les nervures noires. L'abdomen est aplati, en carré long, avee les côtés parallèles et l'extrémité postérieure tronquée carrément. Il y a de chaque côté une frange de longs poils noirs, et en arrière une autre frange composée de poils d'un ferrugineux vif. Les pattes sont noires. - De la Conception, au Chili.

Genre AGAPOPHYTE, Agapophytus. Guér.

'Ce genre ne peut être convenablement placé que dans la tribu des Xylophagiens et à côté du genre Hermetia; mais il s'en distingue par la forme cylindrique de son corps, par ses antennes et par ses ailes, et ces différences sont tellement tranchées quili serait superflu de les faire ressortir ici. Voici les caractères que nous assignons à ce genre :

Corps allongé, cylindrique; palpes filiformes, de trois articles; le premier court, le second plus de deux fois plus long, cylindrique; le troisième un peú plus court, un peu élargi à sa base, arrondi au bout. Antennes beaucoup plus longues que la tête; prcmier article plus long que les deux suivants réunis, d'égale épaisseur dans toute sa longueur, peu aplati; le second très-court, un peu obconique, le dernier beaucoup plus long, un peu aplati, eomme tordu au milieu, velu, n'offrant pas de traces de divisions. royage de la Coquille.-Z. Tom. II, Part. II. I Ie Div. 
Écusson mutique; abdomen étroit, épais, conique; quatrième cellule postérieure de l'aile étroite et fermée.

AGAPOPHYTE AUSTRAL, Agapophytus Australasice. Gún.r. - Ater. Antennis articulo primo flavo. Alis hyalinis, nervulis nigris, obscure fasciatis. Pedibus anticis flavis, femoribus basi nigris; intermediis et posticis nigris, articulo primo tarsorum flavo. Long. I I mill. Enverg. 2 I mill. - Atlas, Ins., pl. 2o, fig. $x$ x.

Tout linsecte est noir. Sa tête est à peine plus large que le corselet, transversale, avec les yeux un peu rougeâtres : elle offre en avant un profond enfoncement marqué de trois sillons et destiné à recevoir la trompé : celle-ci est coudée, saillante, arrondie au bout, avec une forte échancrure en dessous et près de l'extrémité. Les palpes sont un peu plus courts qu'elle. Les antennes ont au moins trois fois la longueur de la tète; elles sont assez grêles; leur premier article est entièrement d'un jaune fauve et les autres d'un brun noir. Le corselet et l'abdomen sont d'un noir terne. Les ailes sont transparentes, à nervures noires, avec une assez large bande noirâtre au milieu et l'extrémité très-légèrement enfumée. Les pattes antérieures sont jaunes, avec la base des cuisses noire; leurs tarses sont plus longs que la jambe, à premier article plus épais et aussi long que les suivants réunis; ceux-ci deviennent de plus en plus étroits et les deux derniers sont bruns. Les pattes intermédiaires et postérieures sont noires; leurs tarses n'ont pas le prenier article si grand et si dilaté que ceux des premières, mais ce premier article est jaune à șa base. Tous ces tarses ont deux pelotes bien développées à l'extrémité inférieure du dernier article.

Cet insecte vient du Port-Jakson à la Nouvelle-Hollande; il peut être considéré comne établissant le passage entre les Xylophagiens et quelques genres de la tribu des Stratyomides.

La figure i I représente l'Agapoplytus Australasice de grandeur naturelle. I I, A. Sa tête grossie et vue en dessus. I I, B. La mème, vue de profil. I I, C. Sa trompe et un palpe. I ı, D. L'extrémité d'une antenne. i , F, G. Pelotes des tarses.

HERMÉTIE CEINTE, Hermetia cingulalis. Gú́r. - Atra. Maculis lateralibus thoracis et marginibus abdominis viridibus. Alis hyalinis fusco-maculatis. Pedibus nigris, genubus flavis. - Long. I2 mill. Enverg. 26 mill.

La tête est noire, avec les yeux d'un noir verdâtre traversés par une ligne horizontale noire; il y a une tache verte derrière chacun d'eux. les antennes sont plus de deux fois plus longues que la tête, noires, aplaties. La trompe est noire, avec une tache verte en arrière et tout le dessons de la même couleur. Le corselet est noir, peu luisant. Il a une tache verte allongée de chaque côté, se terminant avant l'insertion des ailes, une autre tache de la même couleur, toujours de chaque côté, naais en arrière des ailes, et l'extrémité de l'écusson également verte. Les flancs ont trois grandes taches 
vertes; la première placée au bord antérieur derrière la tête; la seconde un peu avant l'insertion des ailes, et la troisième au bord postérieur. Les ailes sont transparentes, à nervures noires, avec le milieu et l'extrémité tachés de brun. Les pattes sont grêles, noires, un peu velues, avec l'extrémité des cuisses jaune. Les jambes postérieures sont un peu épaissies au milieu. Les balanciers sont jaunes à la base et verts au bout. L'abdomen est noir dessus et dessous, rebordé autour, avec ce rebord vert. - Cette jolie espèce vient de Java.

ODONTOHYIE DE LIMA, Odontomyia Limae. GuÉr. - Nigra. Fronte et dimidio scutelli flavis. Abdomine favo, segmentis quatuor anticis in medio nigro maculatis; pedibus flavis; alis hyalinis. - Long. r 3 mill. Enverg. 22 mill. - Atlas, Ins., pl. 20, fig. 12.

Elle ressemble assez à l' $O$. furcuta de notre pays et doit être placée près de cette espèce. La tête du seul individu que nous ayons pu voir est en partie détruite, mais on voit que le front est jaune, ainsi que les antennes et le bord postérieur des yeux. Le corselet est noir, velu sur les côtés, avec l'écusson saillant ayant sa moitié postérieure jaune et offrant deux petites épines de cette conleur plus courtes, plus rapprochées entre elles et moins divergentes que dans l' $O$. furcata. L'abdomen est jaune dessus et dessous. Lès trois preniers segments ont, au milieu, une grande tache noire triangulaire, dont la pointe est en bas et va se confondre avec la tache suivante, ce qui forme sur les côtés de fortes dents aiguës; le quatrième segment a une tache plus petite, qui n'occupe que la base, et les autres sont très-étroits et sans taches. Les pattes sont jaunes et les ailes transparentes à faibles nervures jaunes. - De Lima au Pérou.

OXYCÈRE TROMPEUR, Oxycera decipiens. Guér. - Nigra. Capite, antennis oculisque Ravis. Thorace sulbrugoso, scutello postice spinisque flavis. Abdomine flavo, supra vitta longitudinali nigra. Pedibus flavis, alis hyalinis nervulis pallidis. - Long. 9 mill. Enverg. 19 mill.

Cette espèce vient montrer que les genres Odontomyie et Oxycère ne sont pas bien nettement tranclıés, car elle semble établir le passage entre eux par ses antennes qui sont munies au bout d'un style plus grand que celles de l'Odontomyia furcata, et cependant plus court que dans l'Oxycera pulchella. Sa tête est un peu plus large que le corselet, jaune, avec les yeux d'un jaune un peu plus obscur et occupant toute la surface. Les antennes sont jaunes, terminées par un style qui a la moitié de la longueur du troisième article. La trompe est saillante et noire. Le corselet est noir, finement rugueux, avec l'écusson saillant, bordé de jaune et armé de deux petites épines de cette même couleur. Les ailes sont incolores, avec de faibles nervures jaunâtres. Les pattes sont grêles, jaunes. L'abdomen est aplati, à côtés parallèles, d'un jaune pâle, 
avec une large bande longitudinale noire placéc au milieu, plus large à sa base, et à son extrémitć, occupant les trois prcmiers segments et la base du quatrième.

Cette cspèce vient du Port-Jakson, à la Nouvelle-Hollande.

LAPHRIE REMARQUABLE, Laphria spectabilis. GuÉR. - Viridi-nitens; thorace antice flavo-maculato. Abdominc cyaneo. Alis infumatis basi flavis. Tibiis anticis intus sericco-flavidis. - Long. 25 inill. Enverg. 44 mill.

Laphria splendida, Gú́r., Atlas, Ins., pl. 20, fig. 7. - 7, A. Sa tête grossie.

Cette bclle espćce a beaucoup de rcssemiblance avec la $L$. cyanea de M. Macquart, et quoiqu'elle soit beaucoup plus grande, nous ne l'cn aurions pas distinguée, si nous ne voyions pas que ce savant a placé la sienne dans une division ayant la premic̀re cellule postérieure des ailes fermée, tandis que chez la nôtre cette même cellule est ouverte, ce qui la placc dans une autre division et nous autorise à en faire une autre espèce. Nous changeons son nom parce que M. Macquart l'a enployé, nous ne savons pourquoi, pour une autre espèce qui vient de Surinam.

La tête de notre $L$. spectabilis est très-aplatie d'avant en arrière, d'un noir verdàtre, avec le front garni d'un duvet doré très-serrć, et les moustaches formées, de chaque còté, de quatre longs poils noirs courbés en bas. Les antennes et la trompe sont noires. Le corselet est très-bombé, d'un beau veri-bleu très-luisant, avec deux grandes taches triangulaires d'un blanc soyeux, formées par un duvet très-serré et placées de chaque côté au bord antérieur. Les côtés du thorax, avant et sous les ailes, offrent aussi quelques petits reflets soyeux. Les ailes sont transparentes, d'un brun enfumé, à nervures noires, avec la base plus pâle et un peu jaunâtre. Les quatre pattes antérieures sont de la couleur du corselet, avec les tarses bleus; les postérieures sont d'une couleur plus bleue, avec les jambes à reflets violets; elles ont toutes de très-longs poils gris, et les jambes antérieures offrent, en dedans et vers le bout, un duvet soyeux d'un blane jaunẩtre. L'abdomen est allongé, à côtés parallèles, un peu aplati; le premier segment est un peu plus large, de la couleur du corselet; les suivants sont d'un beau violet luisant. Ils ont tous sur les côtés des poils noirs assez roides.

Cet insecte a été pris à Amboine.

OMMATIE FAUVE, Ommatius fulvidus. Wied., MacQ.

Asilus Garnotii, Gúxr., Atlas, Ins., pl. 2o, fig. 8. - 8, A. Son antenne grossie.

Nous n'avions pas reconnu cct insecte dans Wiedmann quand nous avons fait graver la lettre de notre planche. Notre individu a été pris à Bourou, dans les Moluques. 


\section{Genre AGONOSOME, Agonosoma. Guŕr.}

Ce genre est très-voisin des Psilopus, mais il s'en distingue par ses antennes, dont le troisième article est plus allongé que les deux précédents, par sa tête qui, vue de face, offre trois lobes beancoup plus développés, dont les latéraux sont débordés par lcs yeux, et dont lintermédiaire porte les yeux lisses et deux grands poils divergents. Voici les caractères esscntiels que l'on peut assigner aux Agonosomes:

Face large. Troisième article des antennes allongé, de forme conique; style inséré à son extrémité, très-long, sans poils. Yeux sans poils; abdomen allongć et cylindrique; pieds longs, grêles; point de soies au-dessous des cuisses postérieures. Quatre cellules postérieures aux ailes.

M. Macquart, n'ayant probablement pas eu connaissance de nos planches du Voyage autour du monde, a donné le nom de Chrysosome à un genre de Muscides, ce qui nous oblige à changer notre nom, quoiqu'il soit publié depuis longtemps dans nos planches.

AGONOSOME FASCIÉE, Agonosoma fasciata. Gú́r. - Viridi-aurata nitida ; oculis rubris; antennis fulvis, stylo nigro; fronte albo-sericeo. Thorace vittis tribus longitudinalibus obscuris; lateribus albo-sericeo, incisuris segmentorum abdominalium nigris. Alis hyalinis costa et lata macula transversa obscuris. Pedilus favis, tarsis nigris. - Long. I 2 mill. Enverg. 20 mill.

Chrysosoma fasciata. Atlas, Ins., pl. 20, fig. 5.

Sa tête est plus large que le corselet, d'un vert-bleu, avec les yeux rouges et le front, au-dessous des antennes, couvert d'un duvet soyeux blanchàtre. Lcs antennes sont fauves, avec l'extrémité du dernier article et le style noirs. La trompe est fauve. Le corselet est d'un beau vert luisant, avec trois bandes longitudinales obscures en dessus, et les côtés garnis d'un duvet soyeux gris blanchàtre. Les ailes sont transparentes, à nervures et côtes brunes; elles ont une petite taclıe à la base, une autre plus grande près du milieı, partant de la côte, interrompue, quelquefois entière, et une grande bande occupant presque tout le bout de l'aile, ne touchant pas entièrement le bord postérieur, ui l'extrémité; toutes ces taches d'un brun obscur. Les pattes sont jauıes, avec les tarses des quatre antérieures noirâtres, et les jambes et tarses des postérieures de la même couleur. L'abdomen est d'un beau vcrt doré, à reflets rouges en dessus, noir dessous, velu, très-luisant. Chaque segment a la base et l'extrémité noires, ce qui produit des bandes transverses étroites à chaque point d'articulation; de plus, on voit sur les còtés des taches blanches soyeuses, produites par un irès-fin duvet.

Ce bel insecte vient de Dory, à la Nouvelle-Guinée.

Nous avons figuré quelques parties caractéristiques de cet insecte. Ainsi la figure 5. A. montre sa tête vue en dessus; 5. B. idcm vue de face; 5. C. idem de profil; 5. D. son antenne très-grossie; 5 . E. son aile. 
294

VOYAGE AUTOUR DU MONDE.

CHRYSOSOME A AILES TACHÉES, Chrysosoma maculipennis. Gú́r. - Viridi-corulescens, nitida. Oculis rubris; antennis obscure ferrugineis, upice, styloque nigris; fronte albo-sericeo; thorace lineis tribus longitudinalibus nigris, lateribus albo-sericeis, incisuris segmentorum abdominalium late nigris. Pedibus flavis tarsis obscuris. Alis hyalinis, nervulis brunneis, fascia lata ante apicem obscura. - Long. 1 I mill. Enverg. 20 mill. Atlas, Ins., pl. 2o, fig. 6 .

Cette espèce ne diffère de la précédente que par les ailes, qui n'ont qu'une seule bande obscure, et par les bandes noires de son abdomen, plus larges et occupant au moins autant d'espace que le vert, ce qui n'a pas lieu chez la première, où le vert domine. Elle vient d'Offak.

BOMBYLIUS AUSTRAL, Bombylius australis. Gú́r. - Atro-opacus pilis albis, fronte favo. Alis brunneis basi obscurioribus. Pedibus flavo-brunneis. - Long. Ir mill. Enverg. 26 mill. - Atlas, Ins., pl. 2o, fig. 4.

Il ressemble un peu au Bombylius minor de notre pays, mais il en diffère par ses ailes, qui sont plus obscures, et par sa trompe pius courte. Sa tête est assez large, noirâtre, avec les yeux un peu métalliques; le front, au-dessous des antennes, est jaune, ainsi que la cavité où s'insère la trompe, garni de poils jaunâtres assez serrés. La trompe est à peine deux fois plus longue que la tête, noire, aplatie et élargie au bout, avec les soies supérieures brunes; les antennes sont également noires. Tout le corps est d'un noir terne, tournant au brun. Le dessus est dépouillé de poils, mais on voit qu'ils ont été enlevés et qu’ils étaient d'un blanc grisâtre, à en juger par ceux qui restent sur les côtés et en dessous. Le bord postérieur de l'écusson est d'un brun fauve. Les ailes sont d'un brun enfumé, avec la base et les environs de la côte plus foncés. Les pattes sont d'un brun jaunâtre.

Ce diptère a été pris au Port-Jakson.

ANTHRAX A UNE CEINTURE, Anthrax unicincta. GuÉr. - Ater. Thorace pilis fulvis. Abdomine lateribus fascia media anoque, flavis. Alis obscure-fuscis, violaceo-micantibus. — Long. 13 mill. Enverg. 3o mill. - Atlas, Ins., pl. 2o, 9 .

Cette espèce a beaucoup de ressemblance avec l' $A$. Tantalus de Fabricius, et M. Macquart l'a même considérée comme n'en étant qu'une variété; mais nous persistons à l'en distinguer parce que, au lieu d'avoir une bande argentée sur le troisième segment, c'est une bande d'un jaune doré qu'òn voit, et l'on n'aperçoit aucune trace des taches blanches placées sur les còtés des sixième et septième segments, dont parle M. Macquart. Du reste, notre insecte est bien plus petit que l'A. Tantalus, car celui-ci a 7 lignes ou près de 17 millimètres de long.

La tête de notre Anthrax est noire, et presque entièrement occupée par les yeux, 
qui offrent une couleur métallique cuivreuse. Le corselet est noir, il parait avoir été entièrement couvert de poils fauves, que l'on voit encore sur les côtés. Les ailes sont d'un brun noirâtre foncé, à nervures noires et à reflets irisés et violets. Elles ont chacune quatre cellules sous-marginales, et cinq petits points bruns peu visibles à l'œil nu. Les pattes sont grêles et noires. L'abdomen est noir, velu. Les côtés du premier segment ont des poils fauves assez longs; on voit une bande transverse de cette même coulenr sur le milieu du troisième segment, et enfin le dernier est entièrement couvert d'un duvet d'un jaune doré. Cette espèce a été prise à Bourou.

La figure 9. A. de notre planche représente la tête de l' $A$. unicincta très-grossie et vue de face; 9 . B. la mêmè tête vue de profil ; 9. C. l'antenne ; 9 . D. l'aile, pour montrer les nervures et les petits points bruns.

ANTHRAX A COTE NOIRE, Anthrax nigrocostalis. GuÉR. - Ater. Thorace lateribus, abdomine basi flavis. Secundo et tertio segmento abdominis albo fasciatis. Alis hyalinis basi costaque nigris. - Long. I 6 mill. Enverg. 4o mill.

Cette espèce est très-voisine de l'A. Tantalus, et ne s'en distingue réellement que par les ailes. La tête du seul individu que nous possédions manque. Le corselet est garni, en avant et sur les côtés, de poils fauves très-sèrrés, qui doivent exister sur toute la surface quand l'insecte est frais. Les ailès sont transparentes, à nervures brunes, avec la base et la côte d'un brun foncé noiràtre; elles ont quatre cellnles sous-marginales. Les pattes sont noires. L'abdomen est noir, velu, avec les côtés de la base des premiers segments garnis de poils fauves. La base des second et troisième segments offre une bande transverse formée d'un dıvet blanc argenté; on voit quelques traces de ce même duvet blanc sur les côtés du septième segment. -- De Bourou.

MOUCHE ROYALE, Musca (I) regalis. Guér. - Viridi-nitens. Capite albo-sericeo, vertice vitta longitudinali nigra. Thorace lineis longitudinalibus obscuris, basi albosericeo. Segmentis abdominalibus postice nigro-marginatis, villosis. Alis hyalinis, nervulis brunneis, macula nigra prope basin. Pedibus nigris villosis. - Long. 2 I mill. Enverg. 46 mill. - Rutilia regalis. Atlas, Ins., pl. 2 I , fig. I.

Cette magnifique espèce est d'un beau vert à reflets dorés et bleus; sa tête est plus étroite que le corselet, assez saillante au milieu, avec l'ćpistome peu avancé; elle est d'un brun noirâtre, couverte d'un très-fin duvet blanchâtre qui lui donne des reflets soyeux et luisants. Les yeux sont d'ın brun à reflets métalliques. On voit, au-dessous de chaque

(1) Nous décrivons sous le nom général de Musca les espèces de Muscides créophiles qui n'cntrent pas évidemmeıt dans les coupes de M. Robineau Desroidy et surtout dans celles de M. Macquart. En nous abstenant détablir pour ces espèces des genres nouveaux, nous évitons des doubles emplois avec ceux que M. Macquard a dủ créer, dans un grand travail sur les Dịtères exotiques dont le manuscrit a été présenté à l'Institut, et que son auteur va bientôt publier. 
œil, une ligne transversale noire, et il y a une ligne longitudinale également noire au milieu du vcrtex, se terminant au sommet de la cavité dans laquelle sont insérées les antcnnes. Cellcs-ci ont la forme ordinaire des antennes de mouches; leurs deux premiers articles sont courts, à peu près égaux; le troisième est presque trois fois aussi long que les deux premiers réunis, arrondi au bout, ct portant vers sa base une soie allongée, précédée de deux petits articles, un peu renflée à sa base, et finement tomentense; le dcrnier article de l'antenne n'attcint que la moitié de l'espace compris entre l'insertion de celle-ci et le sommet de l'ćpistome. La trompe est aussi longue que la tête, coudée, avec les palpes un peu moins longs.

Lc corselet est tronqué carrément en avant, un peu élargi en arrière, avec un grand écusson arrondi postérieurement, et garni de longs cils roides et noirs; sa couleur est d'un brun vert, mais il a quelques portions, sur les côtés, qui offrent une couleur fauve brunàtrè à reflets verts; en avant, ce corselet est légèrement garni de duvet soyeux blanchâtre, et parsené de cils noirs et rọides; il offre quatre lignes longitudinales brunes, peu marquées, et qui n'atteignent pas l'écusson. Le dessous est vert, taclié de noir, et garni de duvet cendré. Les ailes sont grandes, incolores et transparentes, à nervures d'un brun noirâtre, avec une tache transversale noirâtre placée près de leur base. Les cuillerons sont grands, blanchâtres. Lcs pattes sont noircs et velues. L'abdomen est luisant, vert, couvert de poils noirs, avec le bord postérieur des segments, en dessus et en dessous, fincment liséré de noir, et garni de cils longs et roides de la même couleur. Le dernier segment est sans tache; les trois premiers ont une faible bande longitudinale noirc au milieu. La base de chaque segment, en dessous surtout, est garnie d'un fin duvet blanc et soyeux.

Cette grande mouche vient du Port-Jakson.

La figure I. A. représente la tête de notre Musca regalis très-grossie; I. B. idem vue de profil; r. C. les antennes grossies et en place; r. D. E. l'un des tarses vu de profil et en dessus.

La Rutilia Australasice de G. R. Gray (Anim. Kingd., pl. × x4, fig. I) semble être très-voisine de celle-ci; mais, d'après la figure que nous citons, elle en différerait par son abdomen, qui semble noir avec des taches vertcs, très-grandes aux deux premiers segmcnts, plus pctites et rondes aux troisième et quatrième.

Enfin la Musca splendida de Donovan (Epitome Ins.) vient encore près de celle-ci; mais elle semble s'en distinguer par la tête, qui est d'un beau jaune doré dans la figure que nous citons.

MOUCHE ADMIRABLE, Musca mirabilis. Gúk. - Viridi-nitens. Capite lateribus, griseo, vitta longitudinali nigra. Thorace lineis interruptis nigris, intermediis brevibus. Abdonine fasciis nigris, dorso emarginatis. Segmento anali subtruncato emarginato rufobrunneo. Alis flavidis, basi subobscurioribus. Pedibus nigris. - Long. 16 mill. Enverg. 35 mill. — Rutilia mirabilis. Atlas, Ins., pl. 20, fig. 2. 
Sa tête est d'un vert luisant; le vertex présente une ligne grise, partant du point de contact des yeux, et se terminant à l'insertion des antennes. On voit, au-dessous des yenx, une bande grise qui va, en s'élargissant, se terminer au bord de l'épistome et de la cavité antennaire. Le corselet est d'un bean vert brillant à reflets dorés et bleus, garni de cils noirs et roides, ainsi que l'écusson; il y a derrière la tête quatre lignes noires interrompues et formées chacune de deux points allongés; les latérales sont les plus longues, mais n'atteignent pas le bord postérieur du corselet. Les ailes sont d'une teinte jaunâtre sale, transparentes, à nervures brunes, avec la base tachée de jaune brunâtre peu foncé. Les pattes sont noires, velues. L'abdomen a le premier segment tout noir, un peu brun au milieu en dessous; les trois autres sont également noirs, mais ils ont à la base, dessus et dessous, une bande verte qui n'occupe pas la moitié de lcur largeur, et qui se termine près du milieu en s'élargissant et en s'arrondissant. En outre, le quatrième et dernier segment est échancré en arrière, avec cette partie d'un brun roussàtre.

Cette espc̀ce vient d'Offak.

CALLIPHORE PAPOUE, Calliphora papua. GuÉR. - Lutea; oculis brunneis; thorace lineis tribus longitudinalibus, scutello, fascïs tribus abdominalibus, cruris tarsisque, nigris. Alis hyalinis, costa obscura. - Long. 14 mill. Enverg. 25 mill. - Atlas Ins., pl. 2r, fig. 3.

Sa tête est d'un jaune orangé assez vif, avec les yeux bruns. Le corselet est de la même couleur, velu, avec trois lignes noires qui partent du bord antérieur, n'atteignent pas le bord postérieur, et sont réunies en arrière. L'écusson est noir, garni de cils roides. Les ailes sont transparentes, un peu enfumées vers la côte, à nervures noirâtres. Les pattes sont noires avec les cuisses jaunes. L'abdomen est d'un blanc jaunâtre avec trois larges bandes transverses noires. Cette mouche vient d'Offak, Terre des Papous. Sa tête est représentée grossie, fig. 3, A.

SARCOPHAGE MOUCHE, Sarcophaga Musca. GuÉn. - Grisea, pubescens; oculis brunneis. Thorace lineis tribus longitudinalibus nigris. Alis hyalinis; pedibus nigris. Abdomine nigro tessellato, ano atro nitido. - Long. 12 mill. Enverg. 20 mill. Myophora Musca. Rов. Desvoid. - Atlas Ins., pl. 21, fig. 4 .

Cette mouche cst décrite par MI. Robineau Desvoidy à la page 3oo de son grand ouvrage sur les Myodaires; elle a beaucoup de rapports avec la Sarcophaga princeps de Wiedemann, et peut-être sera-t-on ol,ligé de réunir ces deux espèces, quand on ponrra les comparer en nature. Notrc individu a été pris à Offak, Terre des Papous. La figure 4 A reprẻsente sa tête grossie.

SOPHIE A BANDES, Sophia vittata. Guér. - Nigra, villosa; fronte albo-sericeo. ro age de la Coquille. - Z. Tom. II, Part. II. I re Div. 
Thorace lineis duabus longitudinalibus argenteis. Alis nigris. Segmentis abdominalibus basi, argenteo-maeulatis. Pedibus nigris villosis. - Long. I9 mill. Enverg. 36 mill. Atlas Iıs., pl. 21, fig. 5 .

Cette espèce est très-voisine de la Sophia punctata de Rob. D. Mais elle s'en distingue par sa face qui n'est pas brune, et par les ailes et l'abdomen qui n'ont pas de violet. Sa tète est noire, avec la face et les côtés couverts d'un très-fin duvet blanchâtre et soyeux; les yeux sont rougeâtres. Le corselet est noir, velu et hérissé, avec l'angle des ćpaules blanc et deux lignes longitudinales de la même couleur, placées au milieu et ne s'étendant pas au delà du milieu de sa longueur. Les ailes sont d'un brun obscur plus foncé vers la côte, à nervures très-noires. Les pattes sont grandes, noires et velues. Les cuillerons sont bruns. L'abdomen est grand, aplati, noir et velu avec des poils noirs plus forts et roides; il y a à la base des second, troisième et quatrième segments deux taches d'un blanc jaunàtrc, luisantes, formées d'un duvet fin, plus visibles à certains jours. - De l'île Sainte-Catherine, sur la côte du Brésil. La fig. 5 A représente la tête grossie et vue de profil.

M. Macquart a changé le nom de Soplia, donné par M. Robineau Desvoidy, en celui de Scotiptera. Il n'a pas fait connaitre les motifs de ce changement.

LUCILIE A TĖTE DORÉE, Lueilia ehrysoeephala. Gúr. - Viridi-nitens; eapite aurantiaeo, pilis nigris; oeulis brunneis; alis subhyalinis antiee obseuris. Pedibus nigris. Abdomine viridi-eceruleseente. - Long. 13 mill. Enverg. 22 mill. — Atlas Ins., pl. 2 I, fig. 6 .

Sa tète est d'un jaune orangé assez vif, avec quelques poils noirs et roides. Les antennes sont noires, et les yeux d'un brun foncé. Le corselet est d'un beau vert luisant, garni de poils noirs et raides, dirigés en arrière, surtout au bord de l'écusson. Les ailes sont un pcu enfumées avec la moitié antérieure ou la côte d'un brun noirâtre. Les cuillerons sont blanchâtres, bordés de brun. Les pattes sont noires, velues. L'abdomen est d'un vert plus bleuâtre que le corcelet, avec le bord postérieur des segments bleu pur.

Du Port-Praslín, à la Nouvelle-Irlạde.

PROSÈNE CONIQUE, Prosena coniea. GuÉn. - Capite thoraeeque nigro-yriseis, villosis, fronte albo-argenteo; antennis luteis. Sentello nigro apiee fulvo. Alis hyalinis, nervulis brunneis, pedibus nigris, femoribus luteis. Abdomine eonieo, albo-luteseente, faseïs tribus nigris. - Long. I I mill. Enverg. 20 mill. - Atlas Ins., pl. 2 I', fig. ๆ.

Sa tête est grise avec lcs côtés et la facc d'un blanc argenté. Les antennes sont jaunes. Le corselet est gris, velu, avec des poils noirs et roides, et quelques parties un peu obscures. L'écusson est noir avec le bout rougeàtre. Les ailes sont transparentes, à ner- 
vures d'un brun jaunâtre. Les cuillerons sont blancs. Les pattes sont assez grandes, noires, avec les cuisses d'un fauve pâle jaunâtre. L'abdomen est étroit, cylindrique et conique, d'un jaune assez pâle à reflets soyeux blanchâtres: chaque segment est bordé de noir, et le milieu de cette bordure s'étend sur la ligne médiane en une assez grande tache triangulaire qui va atteindre le segment supérieur. Il y a des poils noirs et roides sur les côtés de chaque segment.

- Cette espèce vient du, Port-Jakson. La fig. 7 A représente sa tête vue de profil.

PROSÈNE A BANDES, Prosena vittata. GuÉr. - Grisea, fronte albo-argenteo; antennis luteis. Scutello nigro, apice flavo. Alis sub-infuscatis, nervulis brunncis. PCdibus nigris. Abdonine ovato, flavo, fasciis tribus latis nigris. - Long. 8 mill. Enverg. 15 mill.

Cette espèce est assez voisine de la précédente; sa tête est grise, avec les yeux rougeâtres et lc front couvert d'un duvet blanc argenté. Les antennes sont jaunes. Le corselet est d'un gris-jaunâtre soyeux. L'écusson est noir avec le bord postérieur jaune. Les ailes soltt un peu brunâtres, transparentes, à nervures brunes. Les cuillerons sont blanchâtres, les pattes entièrement noires. L'abdomen est ovalaire allongé, un peu aplati, velu et soyeux. Le premier segment est noir, les autres sont d'un beau jaune vif, avec la moitié postérieure noire.

Cette jolie espèce vient aussi du Port-Jakson.

PLATYSTOME A ALLES TACHETÉES, Platystoma maculipennis. Gứn. - Grisca; capite lnteo. Alis brunneo-punctatis, macula antica in medio posita, nigra, pedibus nigris, cruribus intermediis et posticis brunneo-fulvis, articulo primo tarsorum luteo. - Long. I I mill. Enverg. 23 mill. - Atlas, Ins., pl. 2 I , fig. 8.

La tête est d'un jaune testacé, avcc le vertex un peu rougeâtre; les antennes sont brunes ainsi que la trompe et les yeux. Il y a sur le devant de la facc deux lignes noirâtres qui partent de l'épistome et vont se terminer vers l'endroit où aboutit l'extrémité des antennes. Le corsclet est gris avec quelques lignes brunes peu marquées et les bords latéraux roussâtres, ainsi que le bord postérieur de l'écusson. Les ailes sont transparcntes, à nervurcs brunes, avec une assez grande tache noire à la côte, vers le milieu de lcur longueur, et un grand nombre de points bruns sur toute leur surface. Les cuillerons sont d'un blanc jaunàtre avec les balanciers fauves. Les pattes sont noirâtres, avec les jambes des intermédiaires et des postćrieurcs roussâtres; les tarses ont le premier article jaune. L'abdomen est d'un gris jaunâtre un peu soyeux.

Du Port-Jakson. La figure $8 \mathrm{~A}$ offre la tête de cette espèce grossie. $8 \mathrm{~B}$, idcm, vue de profil. $8 \mathrm{C}$, son aile.

PIATTSTOHE CEINTE, Platystoma cincta. Guér. - Flavo-rufa; capite thorace- 
que supra obscurc-rufis, infra luteis. Thorace lateribus nigro-flavoque cinctis. Alis hyalinis, flavidis, macutis numerosis obscuris. Pcdibus flavis, tarsis apicc nigris. Abdomine obscuro, vitta flava. - Long. 9 mill. Enverg. 20 mill. - Atlas Ins., pl. 21 , fig. 9.

Sa tête est d'un jaune roussâtre plus obscur en-dessus, avec une saillie transverse sur le front; les yeux sont bruns, l'épistome est bordé de jaune; les antennes sont de la même couleur. Le corselet est roux brunâtre en-dessus, avec une bordure jaune qui entoure l'écusson, et au-dessous une large bande noire qui se termine à l'insertion des ailes. Le dessous du thorax et les pattes sont d'un jaune pâle, celles-ci ont seulement le bout des tarses d'un brun noirâtre. Les ailes sont demi-transparentes, jaunâtres, à nervures brunes, avec des taches brunes formant des bandes étroites et transversales un peu obliques. L'abdomen est d'un brun noirâtre avec une petite bande transverse jaune vers l'extrénité.

Du Port-Jakson. - Les figures 9 A, B, C, représentent sa tête vue sous différents aspects.

PLATYSTOME AGRÉABLE, Platystona lata. Guér. - Fulva; oculis nigro-lineatis; thorace vitta lata longitudinali cyanea, altera antica grisea in medio secta; scutello abdomineque supra cyaneis. Alis hyalinis, basi costaque flavis, maculis quatuor anticis nigris. Pcdibus finlvis, tarsis apice nigris. - Long. 12 mill. Enverg. 28 mill.

Cette espèce est l'une des plus belles dı genre. Sa tête est d'un rouge fauve, avec le vertex un peu plus obscur. Les yenx ont chacun deux raies longitudinales noires. Le corselet est fauve, avec une large bande longitudinale violette au milieu, marqués au centre d'une ligne grise qui la coupe en deux. L'écusson est également d'un beau violet luisant. Les ailes sont transparentes, à nervures jaunes, avec la base et la côte d'un jaune clair; elles ont quatre taches noires touchant à la côte; la première est la plus grande, elle est placée près de la base, de forme irrégulière, et s'étendant au delà du milieu de la largeur de l'aile; la seconde, grande, arrondie, placée au milieu de sa longueur; la troisième, la plus petite, arrondie, et la dernière, au bout, un peu allongée. Les pattes sont fauves, avec le bout des tarses noirâtre. L'abdomen est d'un beau violet luisant endessus et sur les côtés, avec le dessous jaune-rougeâtre, marqué d'une bande longitudinale bleue au nilieu.

Cette espèce vient du Port-Jakson.

\section{Genre BACTROCĖRE, Bactrocera. Guér.}

Ce genre est voisin des Dacus. Mais il en diffère surtout par la saillie de l'épistome, la petite éminence du milieu $d u$ front, les dimensions respectives des articles des antennes, et la disposition des nervures des ailes. Voici les caractères à l'aide desquels on peut le distinguer: 
Palpes saillants, dilatés en spatules ovales; épistome saillant; front à petite éminence au milieu. Antennes plus longues quc la face; premier article un peu allongé, conique, dirigé horizontalement; dẹxième un peu plus long quc le premier, incliné, cylindricoconique; troisième, au nooins double du deuxième, linéaire, comprimé. Ailes à première nervure transversale très-oblique, rapprochće de la deuxième; cellule basilaire interne assez grande.

BACTROCÈRE LONGICORNE, Bactrocera longicornis. Gún. - Nigra, opaca; capite, maculis thoracis et scutelli, vitta abdominali anoque, ferrugineis. Pedilus Ravis, genubus obscuris. Alis hyalinis, vittis obliquis brunneis. - Long. 8 mill. Enverg. 16 mill.

Elle est d'un noir mat. Les palpes sont d'un jaune pâle ; la face est jaunâtre, avec une tache noire de chaquc côté. Le front est fauve, ainsi que les deux premicrs articles des antennes; le dernier est brun. Le corselet a un duvct gris, il a en dessus six taches fauves ainsi placées, une aux épaules, une autre plus pctitc devant l'insertion des ailes, et une très-mince de chaquc côté entre les ailes. Ses côtés en présentent deux autres plus grandes, l'une placée un peu avant l'attache des ailes, et l'autre au bord postérieur. L'écusson est fauve avec une tache noire au milicu. Les ailes sont transparentes, à nervures bruncs, avec le bord extéricur et quatre bandes très-obliques et transversales brunes. Les pattes sont jaunes, avec les genoux et le bout des tarses bruns. L'abdomen est noir avec le bord postérieur de son.deuxième segment et l'anus fauves. Il est jaunâtre en dessous.

Cet insectc curieux vicnt du Port-Jakson.

CALObaTE INDIENNE, Calobata Indica. Guér. - Atra opaca. Alis sub-hyalinis, nervulis fascusque tribus obscuris. Abdomine lateribus pallido; pedibus urunneis, femoribus quasi apice flavo annulatis. - Long. 12 mill. Enverg. 18 mill. - Neria Indica. Roв. Desv. - Atlas Ins., pl. 2 I, fig. 10.

Tout son corps est d'un noir terne; les yeux sont brunâtres. Les ailes sont demitransparentes, avec trois bandes brunes, l'une à la base, la seconde, la plus large, au delà du milieu, et la dernièrc au bout. Les pattes sont de la couleur du corps, avec lat bisc des cuisses et leur extrémité marquées d'un petit anneau jaune. Les jambes sont d'un brun un peu plus pàle. L'abdomen est allongé, avec les côtés d'un jaunâtre trèspâle.

Cet insecte vicnt d'Offak. La fig. Io A représente sa tête vue de profil. ıo B, son aile.

NÉRIE VIOLET, Ncrius cyaneus. Gux́n. - Cyancus, nitidus; capite brunneo. Scutello bispinoso. Abdomine clavato, segmento primo elongato, coarctato, basi bispinoso et clevato. Alis lyalinis, nervulis brunneis, costa nigra. Pedibus branneis femoribus basi lutcis. - Long. I3 mill. Enverg. 24 mill. - Atlas, Ins., pl, 2 I, fig. Ix. 
La place de eet insecte n'est pas encore bien fixée, ear le seul individu que nous avons étudié avait la têtc mangée, cc qui nous a cmpêché de connaître les antennes et les palpes. Peit-êtrc devra-t-on le ranger avee les Sepsis quand on le connaîtra mieux. En attendant, voici la description que nous en avons faite : Le corps est d'un beau bleu luisant, la tête est brune, au moins en arrière, sans poils. Le corselet est très-bombé, précédé d'un cou étroit, arrondi et un peu échaneré en avant; l'écusson est assez saillant, armé en arrière et de chaque eôté d'une petite épine courte. Les ailes sont grandes, transparentes, irisées, à nervures d'un brun noirâtre avee la eôte et une très-petite taehe à l'extrémité noirâtres. Les pattes sont longues, grêles, brunes, avec la base des cuisses d'un jaune pâle. L'abdomen est allongé, en massue, avee le premier artiele rétréei à la base, presque aussi long que les autres, armé à sa naissanee de deux petites épines divergentes, et ensuite d'une élévation assez saillante; son extrémité est ovalaire.

Ce joli inseete vient de Dory, à la Nouvelle-Guinée. La figure i I A le représente vu de profil. i I $\mathrm{B}$ donne son aile.

ORNITHOMYIE AUSTRALE, Ornithomyia australis. GuÉr. - Nigro-brunnea. Capite thoraceque infra flavo-viridibus. Oculis fulvis, thorace antice rufo, lateribus producto. Abdomine depresso, brunneo-griseo; alis sub-obscuris, nervulis nigris. Pedibus brunne-nigris, femoribus basi infraque flavo-viridibus. - Long. I I mill. Enverg. 25 mill. - Atlas Ins., pl. 2 I , fig. I 2.

Cette grande espèee ressemble beaueoup à la deseription que Fabrieius a donnée de. son Hipobosca Australasice, et pourrait bien n'en être qu'une variété; mais elle en diffère par les eôtés de son eorselet qui sont fauves, surtout si l'on s'en rapporte à la deseription donnée par M. Macquart d'un indivirlu qu'il a vu dans la eolleetion de Bosc. Notre Ornithomyie a la tête brune-noirâtre, avec le chaperon et les yeux fauves. Son corselet est très-luisant, noirâtre, avec lcs eôtés et les deux saillies antérieures fauves. Le dessous dc la tête et du eorselet est d'un jaune verdâtre. Les hanehes et la base des euisses ainsi quc toute lenr tranehe inférieure sont de la même eouleur; leur dessus, les jambes et les tarses sont d'un brun-noirâtre. Les ailes sont demi-transparentes, d'un brun enfumé, avee les nervures de la eôte noires. L'abdomen est d'un brun grisâtre.

Du Port-Jakson. 


\section{TABLE DES MATIERES}

CONTENUES

DANS LA PREMIERE DIVISION DE LA DEUXIÈME PARTIE

DU SECOND VOLUME

DE LA

\section{ZOOLOGIE DU VOYAGE AUTOUR DU MONDE,}

exéCuté pendant LeS ANNÉES $1822-$ I 825 .

CHAPITRE XII. Crustacés et Arachnides, par M. F. E. Guérin.

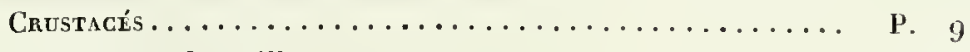

Ocypode de d'Urville...................... 9

Gélasime tétragone (G. de Duperrey, Atlas)........... Io

Trapézie cymodoce.................... Ir

Cyclocarcin (n. g.) pinnothéroïde.............. 12

Pimmothère villosıle.................... 3

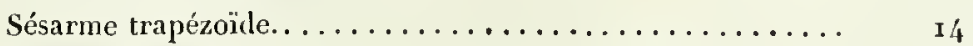

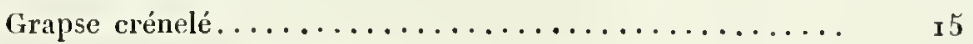

Criocarcin (n. g.) à sourcils. ................ \9

Hyménosome de Gaudichaud, 20. - Hym. de Leach....... 2 I

Eurypode (n. g.) de Latreille.................

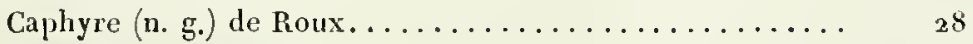

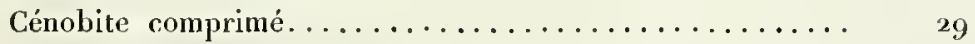

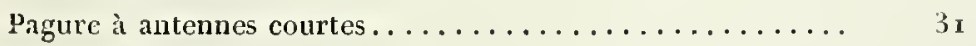

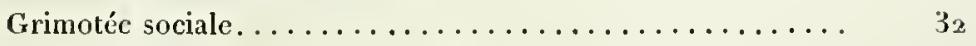

Porcellane violette..................... 33

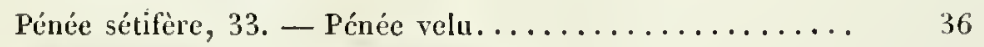

Palémon orné, 36. - Palémon austral............ 37

Hippolyte de Leach.................... 37

Alphce de Lottin, 38. - Alphće lisse............. 38

Squille de Cérisy (Squille de Lesson P!.)............. 40

Erich the narwal, 4 x. - Erichthe de Latreille........... 4 \&

Alime tétracantlure................... 42 
Phyllosome de Freycinet, 43. - Ph. à larges cornes, 44. Ph. ponctué, $1,6 .-$ Ph. de Duperrey ............ 46

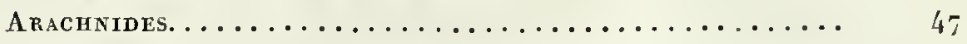

Androctone varié, 47. - Buthus du Pérou, 48. - Buthus cran, $49 .-$ Buthus à bandes............... 50

Ségestrie à tête ronge..................... $5_{1}$

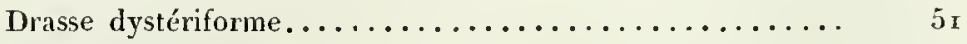

Ëpeire gracieuse.................... $5 \mathrm{r}$

Gastèracanthe de Lepelletier, 52. - Gast. à épines rouges, 53. - Gast. fascice, 53. — Gast. de Theïs, 54. - Gast. rhomboïde, 54. - Gast. en croissant, 55. - Gast. d'Audouin.

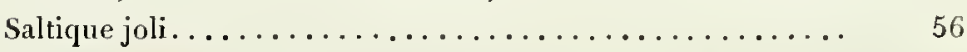

CHAPITRE XIII. Insectes, par M. F. E. GuÉrin.

Coléoptères....................... 57

Cicindèle de Latreille, 57. - Cic. à dix gouttes, 58. - Cic. de d'Urville, 58. - Cic. tortueuse, 58. - Cic. tuberculée.

. .......................... 58

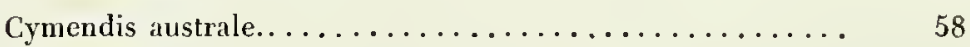

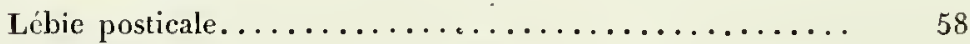

Antarctie brillante, 59 . - Ant. aimable, 59 . - Ant. à pattes jarmes, 59. - Ant. Malachite............... 59

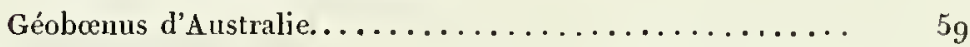

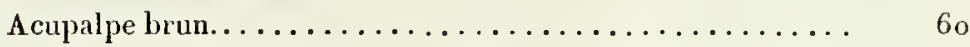

Tréchus de la Solédad, 6o. — Tréchus d'Audouin........ 60

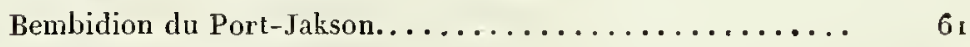

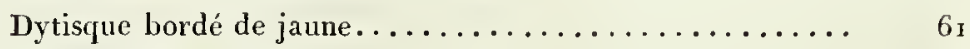

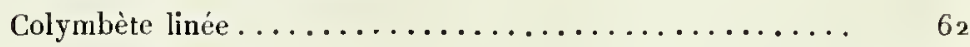

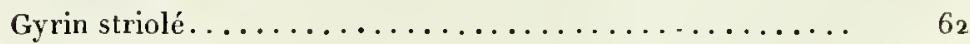

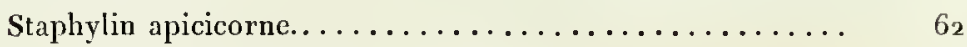

Pédère à élytres violettes, 62 . — Pédère austral......... 63

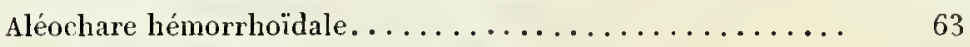

Bupreste brillant, 63. - Bup. à fossettes dorées, 6/4. - Bupr. à douze gouttes, 65. - Bupr. à élytres cuivrées, 65. Bupr. de Kirby, 65. - Bupr. Chilien, 66. - Bupr. joli... Ptérotarse (n. s.) marbré....................

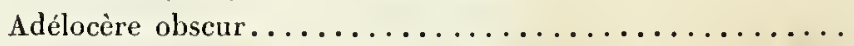

Taupin à épaulettes, 69. - Taup. clairvoyant, 69. - Taupin

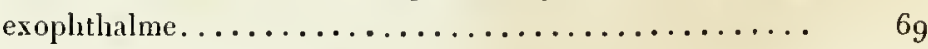

Cébrion à élytres rougeâtres................. 70

Callirhipis de Dejean.................... 70

Lycus apical, 72. - Lyc. parallèle, 72, - Lyc. porte-selle, 73. - Lyc. funeste, 73. - Lyг. beau, 73 - Lyc. sutıral, 73. - Lyc. à cou roux , $7^{3}$ - Lyc. à cou aune... 
TABLE DES MATIÈRES.

Lampyre de Panzer, 73. - Lamp. aplati, 73. - Lamp. de Delaporte, 74. - Lamp. latéral, 74. - Lamp. austral, 74. - Lamp. marginipcnne, 74. - Lamp. à col rouge, 75.

— Lamp. à bout brûlé....................

Téléphore à bout brúlć, 75. - Téléph. à élytres pointues, 75 . — Téléph. de Schæffer, 76. - Téléph. du Chili, 76. Télćph. à antennes dilatées, 76 . - Téléph. transversal, 76 .

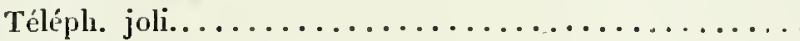

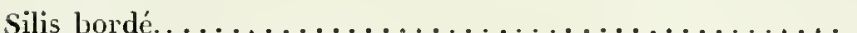

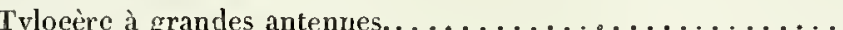

Laius $(n, t)$ bleu.

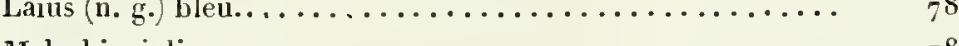

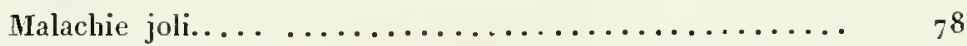

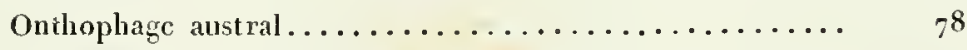

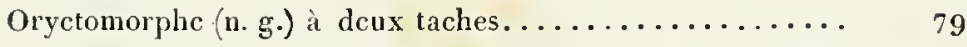

Scarabée Gédéon, 80. - Scar. Egéon, 80. - Scar. à pattes larges, 80. - Sear. court................ $8 \mathrm{~s}$

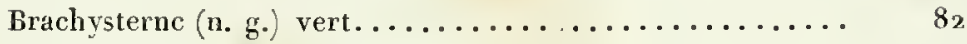

Hadroeère $(n . g)$ à élytres marron............... 83

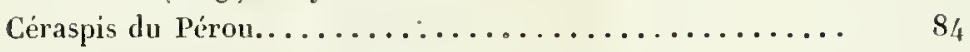

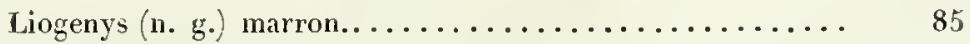

Hétćronyx (n. g.) austral. ................ 86

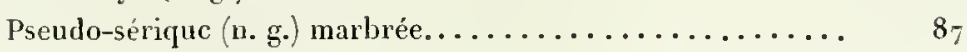

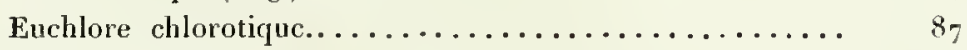

Euchlore lucidule...................... 88

Anisoplic du Pérou...................... 88

Diphucéphale colaspidioïde............... 88

Diphucéphale fourchue $. \ldots \ldots \ldots \ldots \ldots \ldots \ldots \ldots \ldots \ldots . \ldots \ldots$

Liparetrus (n. g.) discipenne................ 90

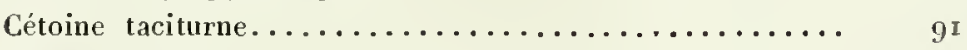

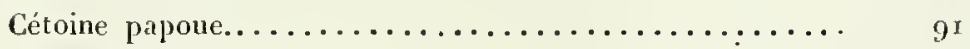

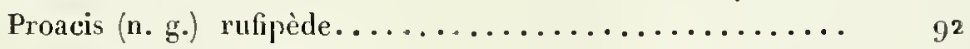

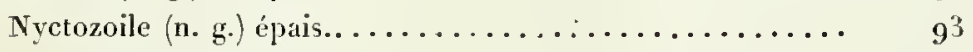

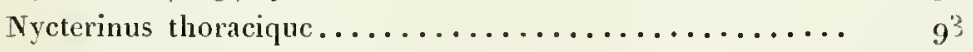

Ammophore $($ n. g.) du Pérou.................... 94

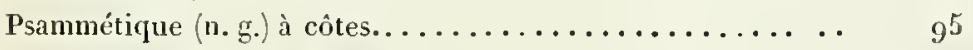

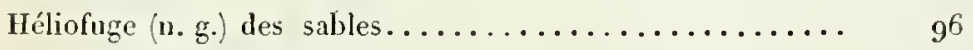

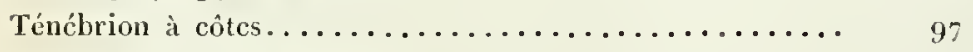

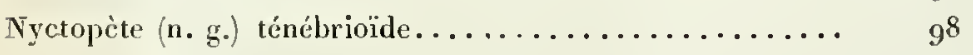

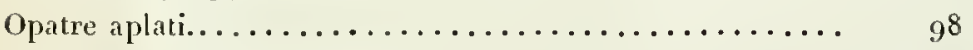

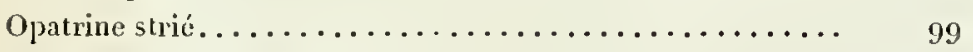

Phytophile (n. g.) hélopioïde................ r... roo

Adélic à col dilaté....................... roo

Amarygme changeant.................... Ior

Amarygme à col violet..................... Ior 


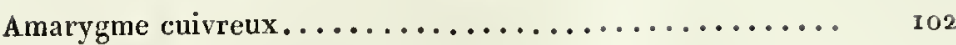

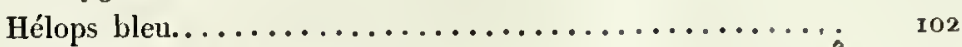

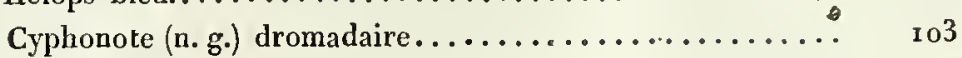

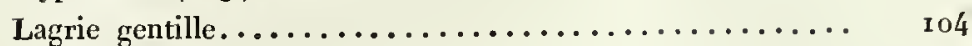

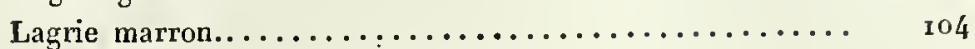

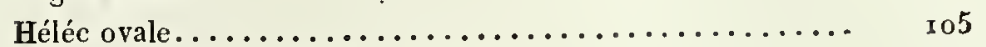

Cilibe échancré........................... n

Notoxe à quatre taches................... 106

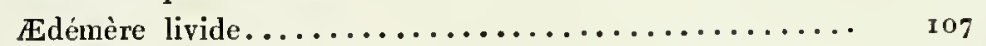

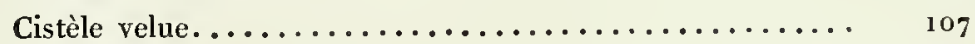

Cistèle jaune.............................. ${ }_{10}$

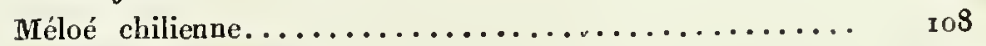

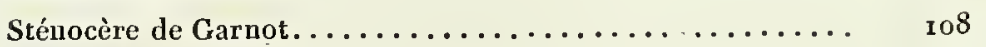

Bélus brun........................... 108

Brenthe bicolore...................... 109

Brenthe de la Nouvelle-Guinée............... 109

Leptorhynque (n. g.) étroit.................. II

Myrmaciçle (n. g.) bistrié................. II2

Aterpe à sourcils....................... 112

Géonémus à stries ponctuées................ 113

Euphole (n. g.) de Gcoffroy-Saint-Hilaire, 115; de Schonherr, I16; de Chevrolat, I 17 ; de Cuvier.......... 118

Cylydrorhinc (n. g.) rubané................... 1 I9

Psomèle (n. g.) en deuil...................... 120

Amyctère grenu.......................... 120

Amyctère à verrues........................... 121

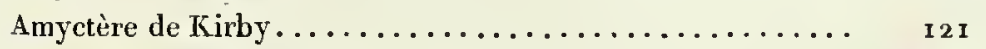

Acantholophe hérissć.................... I21

Splıæroptère (n. g.) à lignes blanches.............. ${ }_{12} 3$

Alcide bout brúlé...................... $1_{23}$

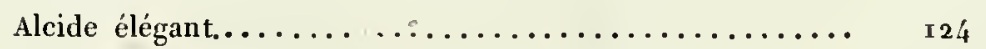

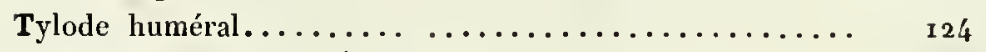

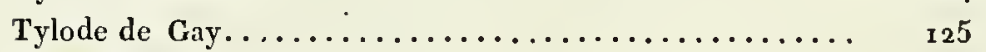

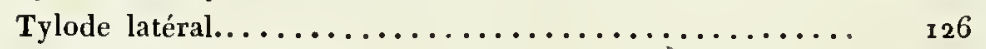

Mécopus à trois lignes.................... ${ }_{12} 6$

Arachnope (n. g.) à bande.................... ${ }_{12} 8$

Prione de Lima.......................... ${ }_{12} 8$

Distichocère ferrugineuse................. 129

Tmésisterue à trois bandes, r3o; marbré, r3 1 ; uniponctué.. $\quad$ I3 3

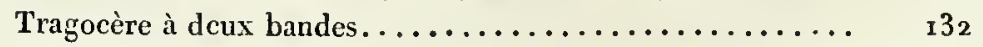

Lamie granuleuse ...................... 133

Lamic de d'Orbigny..................... 134

Lamie rugosule..................... 134

Gnome girafe......................... 135 
TABLE DES MATIÈRES.

Gnome scmblable.....................

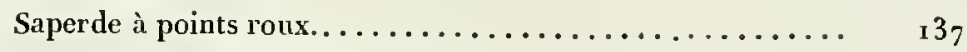

Saperde à bords blancs..................... I 3 ?

Saperde de Lefebvre...................... I 38

Saperde gracieuse...................... I 39

Criocère de Gory ........................ $\quad$ I39

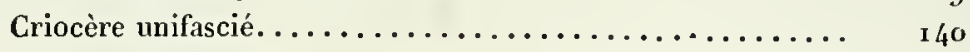

Hispe de Fabricius .................... 140

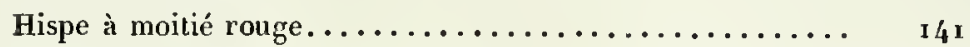

Hispe d col rouge......................... I4I

Hispe gentille.......................... 14

Oxycéphale (n. g.) cornue.................. 142

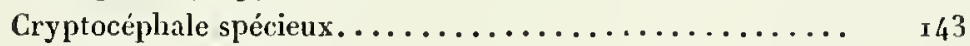

Cryptocéphale rudc.............................. I 43

Cryptocéphalc de Jakson.................. 143

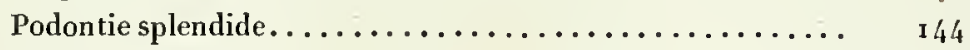

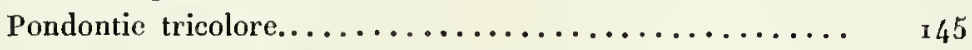

Phyllocharis à deux bandes....................... 145

Chrysomèle dc Percheron.................... $\quad$ I 46

Adorie subhémisphérique. - Adorie basale ......... I 146

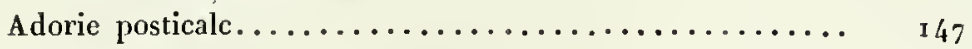

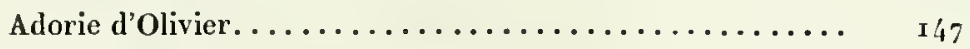

Adorie de Diard et A. de Duvaucel.............. I I/4

Calleruque partagée.................... I 48

Galleruquc de Buquet................... 148

Galleruque termince de rouge................ I 49

Galleruque posticale.................... I $_{50}$

Gallcruque de Carteret................... I50

Casside à un point..................... ${ }_{150}$

Altise de Chevrolat. .................... ${ }_{152}$

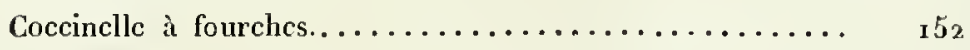

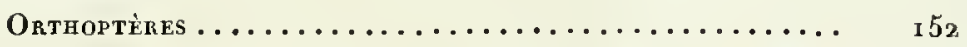

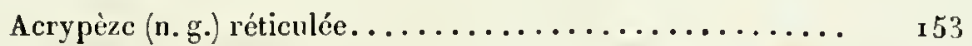

Listroscèle à pcignes.................... ${ }_{153}$

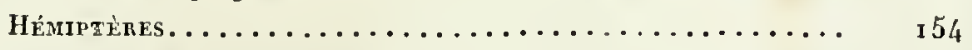

Scutellère de Labillardière.................. ${ }_{154}$

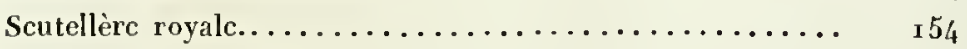

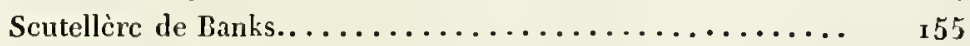

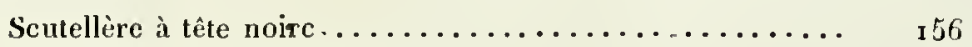

Scutcllère païcnnc......................... 156

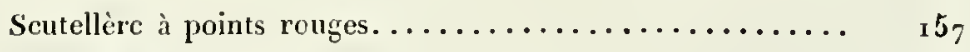

Scutellère des Papous................... ${ }_{15} 5_{7}$

Scutellèrc de Baudin..................... ${ }_{1} 58$

Scutellère de Praslin..................... ${ }_{\text {I } 60}$ 
Scutellc̀re latćrale..................... 160

Scutellère de Stoker...................... 16 I

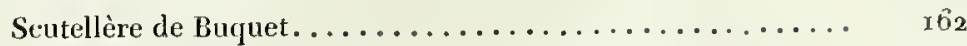

Scutellère dorée....................... ${ }_{1} 63$

Scutellère excavée......................... 163

Scutellère à corsclet dilaté. ................. ${ }_{1} 64$

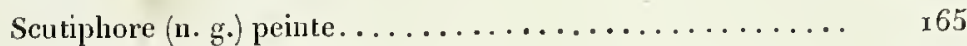

Pentatome de Fallcn...................... 165

Pentatome de Schellemberg................. 166

Pentatome de Wolf..................... 166

Pcntatomc de Germar...................... 167

Pentatome du Port-Jakson................. ${ }_{16} 6_{7}$

Pentatome aplatie.................... ${ }_{16} 67$

Pentatome raccourcie..................... 68

Agapophyte (n. g.) à deux points............... ${ }_{\mathbf{1}} 68$

Platycoris (n. g.) bordée dc rouge, - à deux points...... 1 go

Halys à points jannes.................... 170

Halys de Winthem.................... 170

Tessaratome à antennes jaunes............... $\quad$ $7 \mathrm{I}$

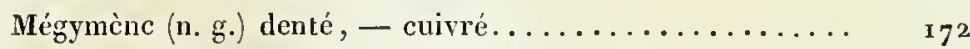

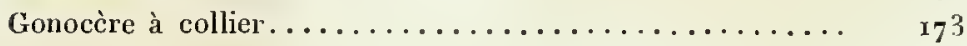

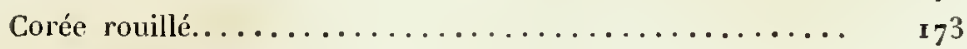

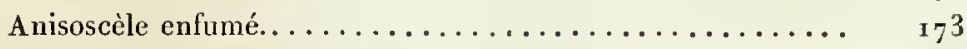

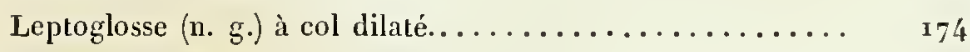

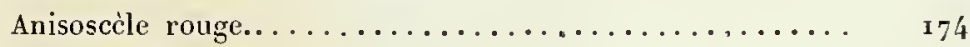

Anisoscèle fémoré..................... ${ }_{7} ; 5$

Anisoscèle à grosses cuisses.................. I 76

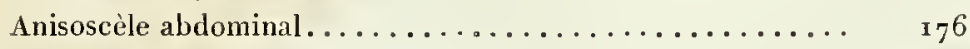

Anisoscèle à élytres bleues................. $\quad{ }_{77}$

Nématope à tête jaune................... I 77

Alyde à cornes annelćes.................. ${ }^{177}$

Leptocorise jaunâtre....................... $7_{7} 8$

Lygée rougc-noir . ...................... ${ }_{17} 8$

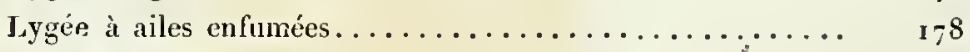

Lygée de Taïti........................... ${ }_{1} 8$

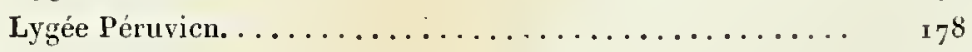

Réduve tubcrculé.................... 179

Réduve à ventre bleu.................... $\quad 179$

Réduve à ćlytres blanchâtres.................. 179

Cigale à poche........................ 18o

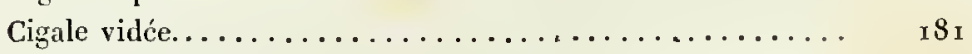

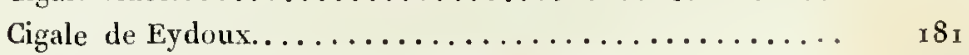

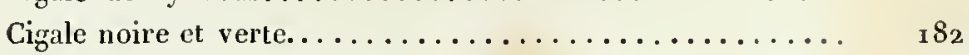

Cigale couleur de safran................... ${ }_{\mathbf{1}} \mathbf{S}_{2}$ 
Cigale à col taehé....................... ${ }_{1} 83$

Cigale thalassine...................... ${ }_{1} 83$

Cigale de Duvaucel...................... $\quad{ }_{18}$

Aphène (n. g.) rcmbrunie, - à points noirs, - jolie ..... $\quad{ }_{\text {I } 86}$

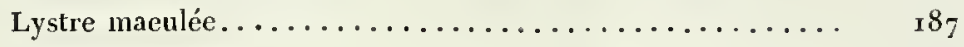

Lystre de Serville....................... ${ }_{1} 8_{7}$

Lystre pâle........................ ${ }_{1} 88$

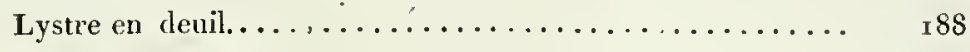

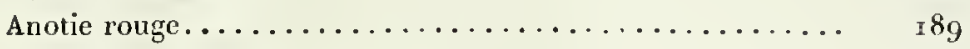

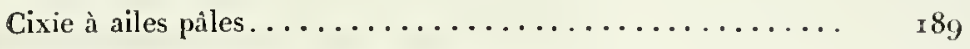

Cixie transparent... . . . . . . . . . . . . . $\quad{ }_{1} 8_{9}$

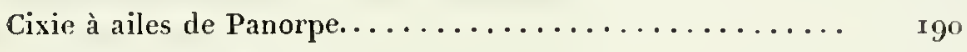

Ricanie trimaculée.................... 190

Ricanie à ailes violettes................... I $^{\mathrm{I}}$

Ricanie splendide..................... 191

Ricanie oculée....................... $19^{2}$

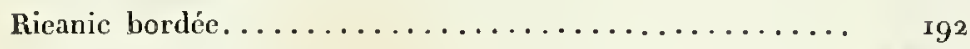

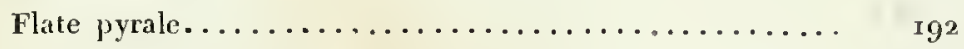

Eurybrachys raecourci................... $19^{3}$

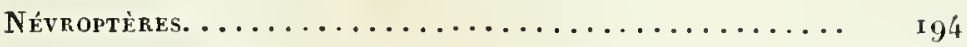

Libellule élégante...................... I94

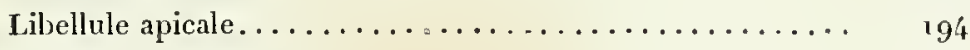

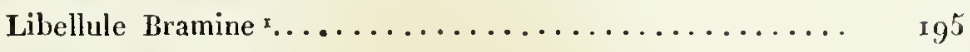

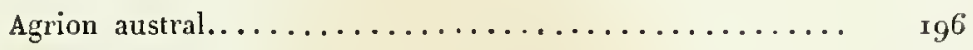

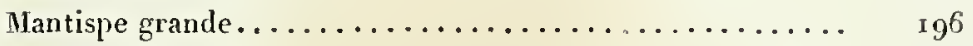

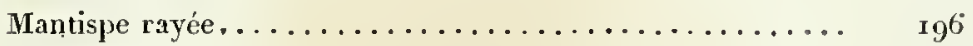

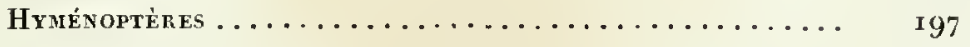

Iehneumon de Gravenhorst................. 197

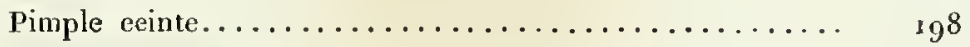

Joppe peinte........................ 198

Bracon trieolore........................ 199

Bracon épincux........................ 199

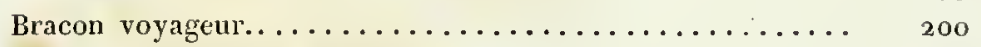

Trachypète (n. g.) en massue................. 202

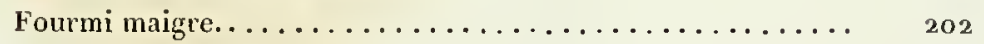

Fourmi à ventre noir................... 203

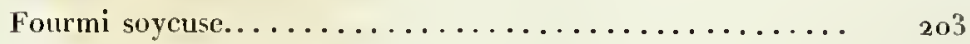

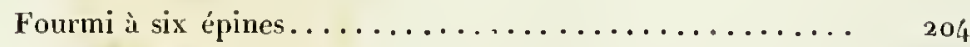

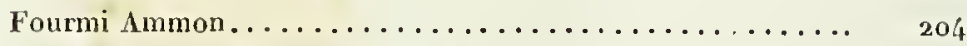

Fourmi de Latreille................... 205

(3) Ayant depuis vu l'individu qui a servi à M. Boisduval, nous avons reconnu que sa Lib. Manadensis et notre L. Bramina ne font qu'une même espèce. 


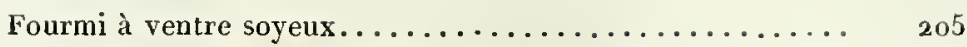

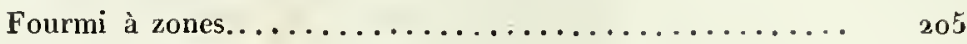

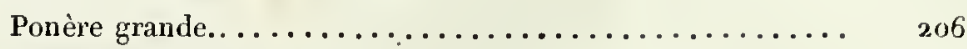

Myrnice de Lund....................... 206

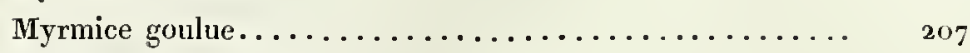

Rhagigastre (n. g.) unicolore................. 214

Téléphoromyie $(\mathbf{n}$. g. $)$ à pieds rouges............... 2 I 6

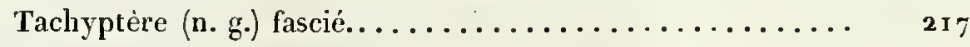

Agriomyie (n. g.) maculée.................... 2 8

Thynne (n. g.) denté, 222. - zoné, 222. - variable, 223. semblable, 226. - à ailes obscures, 227. - à ventre roux, 227. - annelć, 228. - austral, 228. - à ventre jaune, 229. échancré, 229. — abdominal, 229. - entier, 229. à taches jaunes, 230. - aptère, 230. - pédestre, 231. -

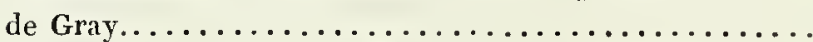

Thynnoïde (n. g.) à pieds fauves, 233. - à pieds rouges, 233. - blessé........................ 234

Diamma (n. g.) bicolore, - éphippigère.......... 235

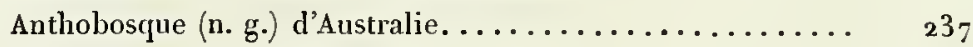

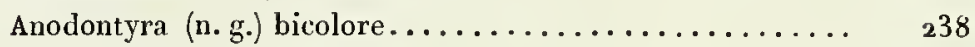

Ornepète $(\mathbf{n}$. s.) à tête noire....................... $\quad 239$

Élaphroptèrc (n. g.) mi-partie, 240. - à ailes pâles, $24 \mathrm{I}$. noire, $24 \mathrm{I}$. - fasciée, 242. - cornue, 243. - ả ailes

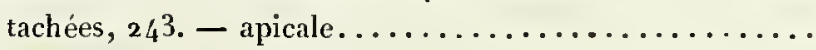

Ammodrome (n. g.) frontal, 245. - rufipède, 245. - à forme

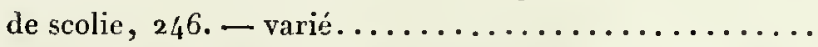

Scolie partagée, 247. - à tête orangée, 248 . - chilienne, 249. - de Petit, 249. - de Serville, 250. - brillante, 251. - thoracique, 25 r. - belle, 252. - apicicorne, 253. à bandes et points, 254 . - apicale, 254. - maculće..... Pepsis de Petit. - Pepsis à bordure.............. Pompile doré-soyeux..................... Pompile de Lepelletier. - Pompile du Chili........... Pompile à deux tubercules. - Pompile ichneumoniforme... Pompile noir-bleu. — Pompile à tête velue.......... Pompile à jambes jaunes....................

Pompile agrćable. - Pompile austral. ............

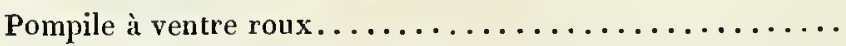

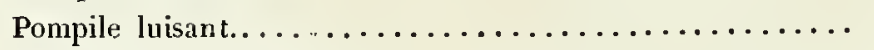

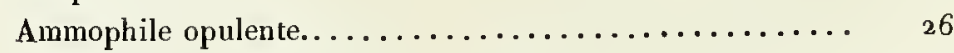

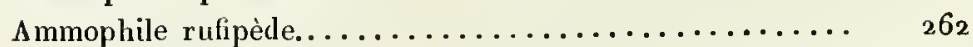

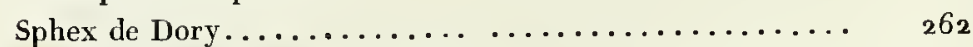

Sphex du Port-Praslin.................... $\quad 229$

Pélopée à ventre bleu.................... ${ }_{2} 63$ 
TABLE DES MATIĖRES.

Bembex de Brullé....................... 263

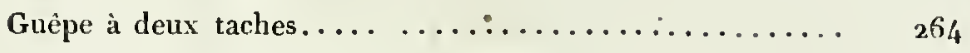

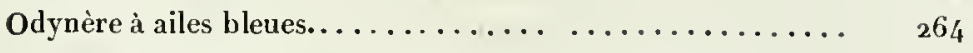

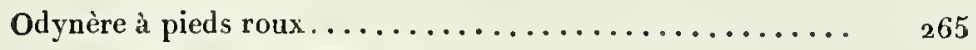

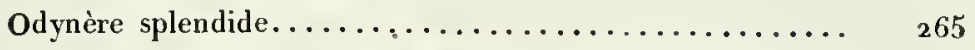

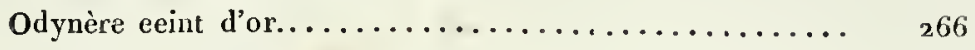

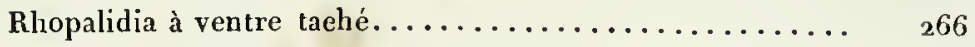

Eumène du Port-Praslin.................... ${ }_{26} 6_{7}$

Ischnogastre (n. g.) à ailes brillantes.............. ${ }_{26} 69$

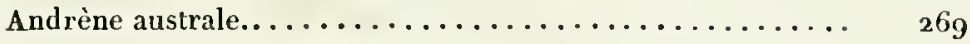

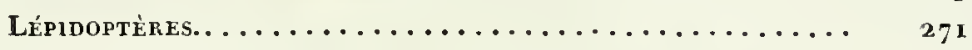

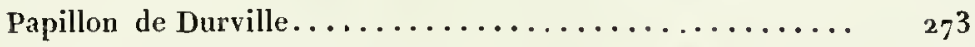

Papillon Axion. - Papillon sévère............... ${ }_{27} 73$

Papillon Ormenus....................... 274

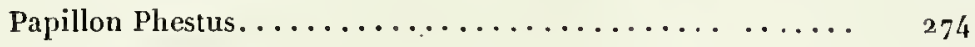

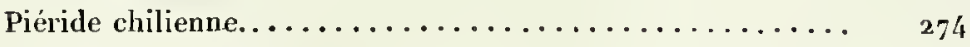

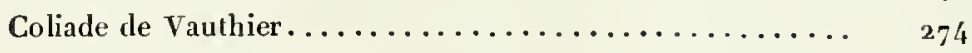

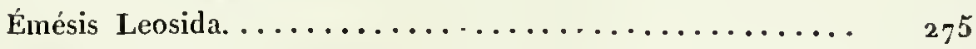

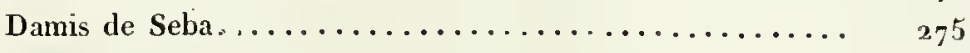

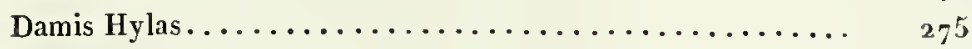

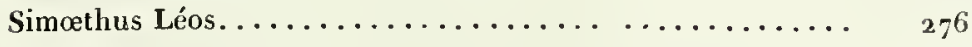

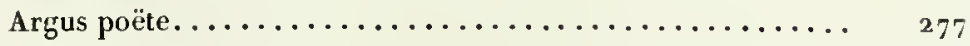

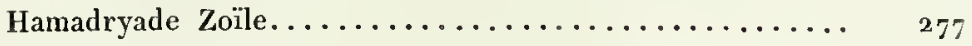

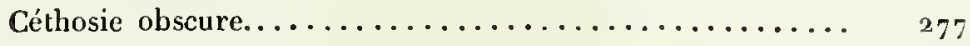

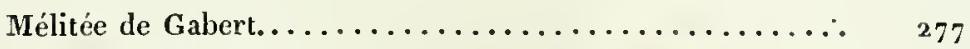

Vanesse Amélie. ........................... ${ }_{27} 8$

Nymphale de Geoffroy.................... ${ }_{279}$

Mynes Leucis.......................... $\quad 279$

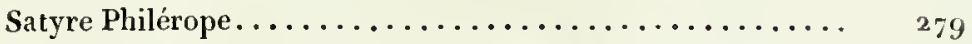

Satyre de Dory. - Satyre cyamite. - Satyre du Chili.... ${ }_{2} 80$

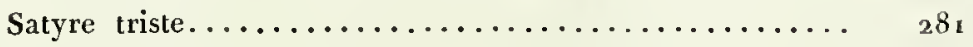

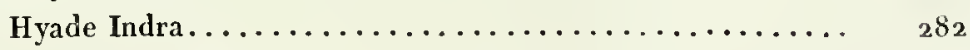

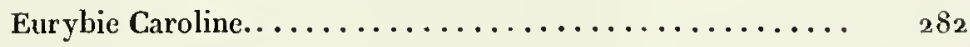

Thymèle $\operatorname{Odyx} . \ldots \ldots \ldots \ldots \ldots \ldots \ldots \ldots \ldots \ldots \ldots{ }_{2} 8_{2}$

Thymèle à deux eouleurs.................... ${ }_{2} 8_{2}$

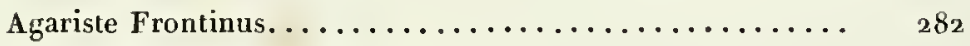

Agariste hémorrhoïdale................... ${ }_{2}^{2} 83$

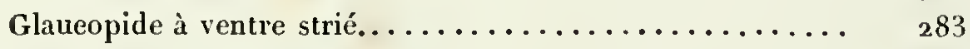

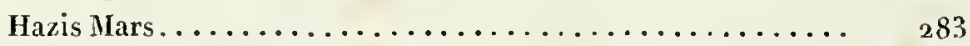

Phaloé (u. g.) ensanglantée.................. ${ }_{28} 84$

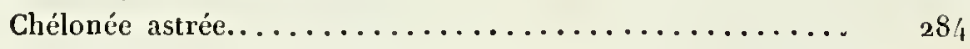

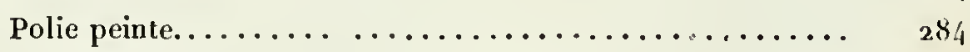

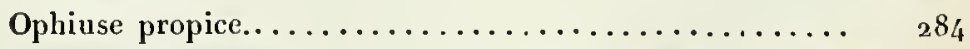

Damias Melaxanthe................... ${ }_{2} 86$ 


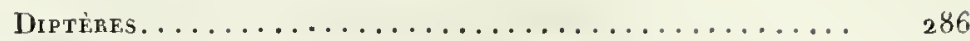

Leptotaise (n. g.) de Macquart................. 286

Évanioptèrc (n. g.) fasciće................... $\quad 287$

Pangonie du Port-Jakson. . . . . . . . . . . . . . . ${ }_{2} 88$

Pangonie de Macquart.................... ${ }_{2} 88$

Pangonic à ailes noires.................... ${ }_{2} 88$

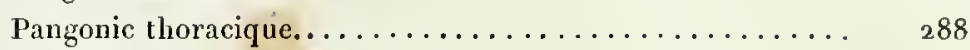

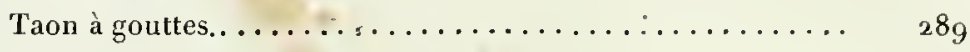

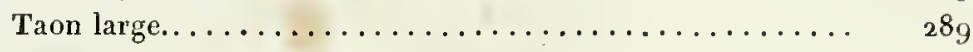

Agapophyte (n. g.) austral. .................. 290

Hermétie ceinte...................... $\quad \mathbf{2 9}^{\mathbf{2}}$

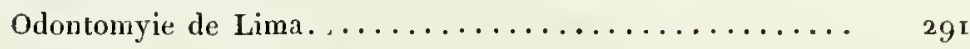

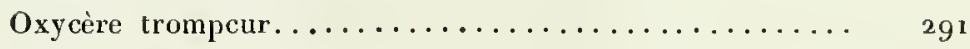

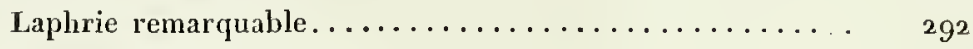

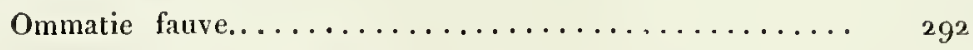

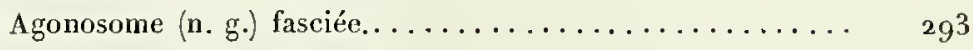

$\Lambda$ gonosome à ailes tachées $(\mathbf{r}) \ldots \ldots \ldots \ldots \ldots \ldots \ldots \ldots \ldots . \ldots \ldots 4$

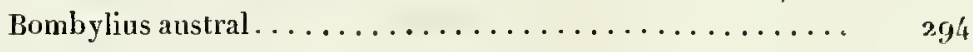

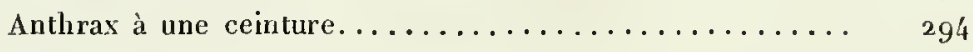

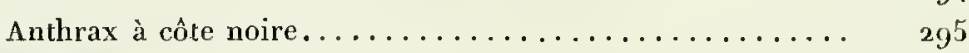

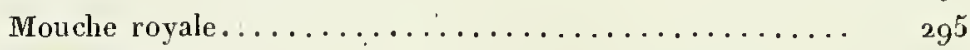

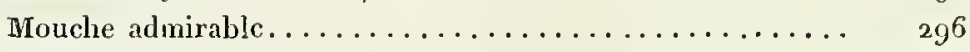

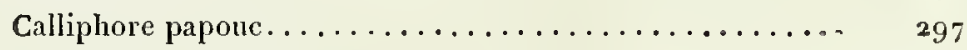

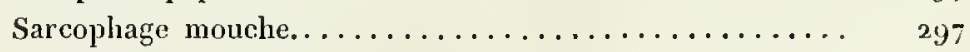

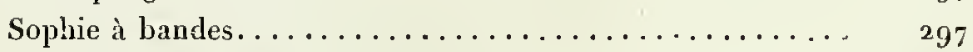

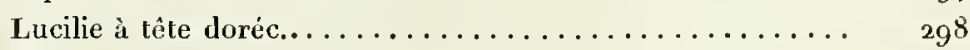

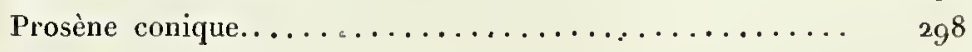

Prosène à bandes. . . . . . . . . . . . . . . . . . . . 299

Platystome à ailcs tachetées................... 299

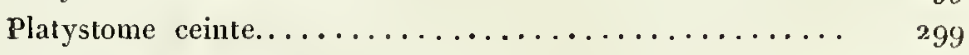

Platystome agréablc.................... 300

Bactrocère (n. g.) longicorne................. 3 oI

Calobate indienne..................... 30 I

Néric violet. . . . . . . . . . . . . 301

Ornithomyie australe.................. 302

(r) C'est par erreur qu'on a laissé à cet insecte le nom générique de Clırysosome.

FIN DE L'INDEX DE LA PREMIÉRE DIVISION DE, LA DEUXIËre PARTIE DU SECOND VOLUME. 


\section{TABLE DES PLANCHES DE L'ATLAS}

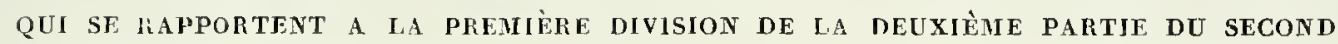
VOLUME.

CRUSTACÉS

Pl. I. Fig. r. Oeypode de Durville, Ocypode Urvillii, Gú̇́r.

P. 9

Fig. 2. Gélasime de Duperrey, Gelasimas Duperreyi, Gứr. (Gélas. tétragone, texte).

Fig. 3. Serre du Gélasime semblable, Gelasimus affrnis, Guér. (Gélas. tétragone, texte).

Fig. 4. Trapézie eymodoee, Trapezia cymodoce, Lark.

Pl. 2. Fig. I. Eurypode de Latreille, Eurypodius Latreillii, Gún.

Fig. 2. Hyménosome de Gaudichaud, Hymenosoma Gaudichaudï, Gứr.

Pl. 3. Fig. 1. Grimotée sociale, Grinotea gregaria, Lенен.

Fig. 2. Poreellane violette, Porcellana violacea, Gứr.

Fig. 3. Alphée de Lottin, Alpheus Lottini, Gú́r. 38

Pl. 4. Fig. I. Squille de Lesson, Squilla Lessonii, Guḱr. (Squille de Cerisy, texte). 40

Fig. 2. Érychte narwal, Erychtus narwal, Gứk.; 3 et 4 , détails.

Fig. 5. Éryehte de Latreille, Erychtus Latreillii, Gứr.; 6 et 7, détails. 42

Fig. 8. Alime tétracanthure, Alima tetracanthura, Latr.; 9 à 13 , détails. $\quad 42$

Pl. 5. Fig. 1. Phyllosome latieorne, Phillosoma laticorne, LeAeн. 44

Fig. 2. Phyllosome de Duperrey, I C. Phyllosoma Duperreyi, Guḱr. $\quad 46$

Fig. 3. Phyllosome de Freycinet, Phillosoma Freycinetü, Gúk. 43

\section{INSECTES.}

Pl. צ. Fig. 1. Cicindèle à dix gouttes, Cicindela decem-guttata, FAe. 58

Fig. 2. Cicindèlc de Durvillc, C. Urwillï, DEs.

Fig. 3. Cieindèle tortneusc, C. tortnosa, DEs.

Fig. 4. Cicindèlc tuberculée, C. tubcrenlata, FaB. 58

Fig. 5. Cicindèle de Latreille, $C$. Latreillii, Gứr.

Fig. 6. Thératc basalc, Theratcs basalis, D'Unr. 58

Fig. 7. Cyminde anstrale, Cymindis australis, DEs. $\quad 58$

royage de la Coquille.-Z. Tom. II, Part. II. $\mathrm{r}^{\mathrm{re}}$ Div. 
Fig. 8. Lebie posticale, Lebia posticalis, Gứr, 58

Fig. 9. Antarctie aimable, Antarctia blanda, Des. $\quad 59$

Fig. 10. Antarctie brillante, Antarctia nitida, GuÉr. $\quad 59$

Fig. I I. Géobène d'Australie, Geobœenus Australasia. Gứr. $\quad 59$

Fig. 12. Acupalpe couleur de poix, Acupalpus piccus, Guḱr. 60

Fig. I3. Antarctí à pattes jaunes, Antarctia flavipes, Gúkr. $\quad 59$

Fig. I4. Antarctie malachite, Antarctia malachitica, DeJ. $\quad 59$

Fig. 15. Tréchus de la Solcdad, Trechus Soledadinus, Guér. 60

Fig. 16. Tréchis d'Audouin, Trcchus Audouinii, GúÉr. 60

Fig. 17. Bembidion (Leia) du Port-Jackson, Leía. Jacksoniensis, Guḱr. 61

Fig. I 8. Dytiquc bordć de jaune, Dyticus flavocinctus, GuḱR. 6 I

Fig. 19. Colymbc̀te linée, Colymbetes lineatus, Guér. $\quad 62$

Fig. 2o. Gyrin striolé, Gyrinus striolatus. Guḱr, $\quad 6 \mathbf{2}_{\mathbf{2}}$

Fig. 21. Staphylin fulgipenne, Staphilinus fulgipennis, Guḱr. (Staph. apicicorne du texte.)

Fig. 22. Pédère à ćlytres violettes, Paderus cyanipennis, Guḱr. $\quad 62$

Fig. 23. Pćdère austral, Pcederus australis, Goḱn.

Fig. 24, Aléochare hćmorrhoïdale, Aleochara hemorrhoïlalis, Guḱr. $\quad 63$

Pl. 2. Fig. I. Bupreste joli, Buprestis bella, Guŕr. 66

Fig. 2. Buprestc à fossettes dorées, Buprestis auro-foveatus, GuÉr. $\quad 64$

Fig. 3. Galba marbré, Galba marmorata, Guér. (Ptérotarse marbré, texte). $\quad 68$

Fig. 4. Callirhipis de Dejean, Callirhipis Dejeanï, Latr. 7o

Fig. 5. Télćphore à antcnnes dilatćes, Telephorus dilaticomis, Gux́k. $\quad 76$

Fig. 6. Cordylocc̀re à grandes antennes, Cordylocera antennata, Guér. (Tylocère à grandes antcnnes, texte).

Fig. 7. Adélocèrc gris, Adelocera grisea, Guḱr. (Adćl. obscur, texte).

Fig. 8. Lycus (cladophorc) à col roux, Cladophorus ruficollis, Gúk.

Fig. 9, Lycus (cladophore) mi-parti, Cladophorus dinidiatus, Gú̉r. (Cladoph. formosus, texte).

Fig. хо. Laïus bleu, Laius cyaneus, Gú́r.

Fi. Scarabée à pattes larges, Scarabceus latipes, GuEr

Fig. 2. Scarabéc Egćon, Scarobreus Egeon, Far. So

Fig. 3, Oryctomorphe à dcux taches, Oryctomorphus bimaculatus, Guḱr. $\quad$ So

Fig. 4. Brachystene vert, Erachysternus prasinus, Gúḱr. $\quad \mathbf{8}_{2}$

Fig. 5. Sérique marbrée, Serica marnorea, Guḱr. (Pseudo-sćrique marbré, textc).

Fig. 6. Liogenys marron, Liogenys castanerı, Guḱr. 85

Fig. 7. Céraspis du Pérou, Ceraspis peruvianus, Guḱr. $\quad 84$

Fig. 8, Pachycc̀re à élytres marron, Pachycerus castaneipennis, Gứr. (Hadrocc̀re à élytres marron, texte).

Fíg. 9. Hétéronyx austral, Heteronyx australis, Guḱr.

Fig. 10. I,iparetrus discipcnne, Liparetrus discipennis, Guér. $\quad 90$

Fig. 11. Cétoine papouc, Cetonia papua, Gứr.

Fíg. 12, Cćtoinc taciturne, Cetonia tacituma, Guér. $\quad 91$ 
Pl. 4. Fig. I. Proacis rufipède, Proacis rufipes, Еsсн. $\quad \mathbf{9 2}^{2}$

Figr. 2. Noctozoïlc ćpais, Noctozoilus obesus, Gux́R. $\quad 9^{3}$

Fig. 3. Nycterinus thoracique, Nycterinus thoracicus, Еsсн. $\quad 93$

Fig. 4. Ammophore du Pérou, Armophorus peruvianus, GuÉr. $\quad 94$

Fig. 5. Ténébrion à côtes, Tenebrio costatus, Guḱr. 97

Fig. 6. Héliofugre des sables, Heliofugus arenosus, GuÉr. $\quad 96$

Fig. 7. Nyctopète ténébriö̈de, Nyctopetus tenebrioüdes, Guér. $\quad 9^{8}$

Fig. 8. Psammétique à côtes, Psammeticus costatus, Gún. $\quad 9^{5}$

Fig. 9. Phytophilc hélopioïde, Phytophilus helopioides, Guér. I

Fig. го. Opatre aplati, Opatrum complanatum, Guḱr. $\quad 98$

Fig. I I. Adélie à col dilaté, Adelium dilaticollis, Guḱr. 100

Fig. 12. Blapstine strić, Blapstinus striatus, Gú́r. (Opatrine strié, texte). 99

PI. 5. Fig. 1. Amarygme changeant, Anarygmus mutabilis, Gứr. IoI

Fig. 2. Amarygme cuivreux, Amarygnus cupreus, Guḱr. $\quad 102$

Fig. 3. Hélops bleu, Helops carulescens, Gúk. 102

Fig. 4. Cyphonotc dromadaire, Cyphonotus dronedarius, Gúr. 103

Fig. 5. Lagrie gentille, Lagria pulchella, GứR. $\quad 104$

Fig. 6. Lagrie marron, Lagria castanea, GuÉr. $\quad$ I04

Fig. 7. Hélée ovalc, Heloeus opatus, Guér. 105

Fig. 8. Notoxe ì quatre taches, Notoxus quadrimaculatus, Gú́r. Io6

Fig. 9. OEdémère soyeuse, OEdemera sericea, Gú́R. (OEdémère livide, texte). 107

Fig. Io. Cistèlc velue, Cistela pilosula, Guér. 107

Fig. I I. Cistèle jaune, Cistela luteola, Gó́r. 107

Fig. 1 2. Méloć chilienne, Meloe ćhiliensis, Guéa. 108

PI. 6. Fig. I. Aterpe à sourcils, Aterpus superciliosus, Latk. 112

Fig. 2. Géonémns à stries ponctuécs, Geonemus striato-punctatus, GuÉr. I 13

Fig. 3. Géonémus de Geoffroy, Geonemus Geoffroy ï, Guér. (Euphole de Geoffroy, texte). 115

Fig. 4. Géonćmus de Cuvier, Geonemus Cuvierii, Guér. (Euphole de Cuvier, texle).

Fig. 5. Criptorhynque à bande, Cryptorynchus striga, LaTr. (Arachnope à bande, teste).

Fig. 6. Alcide élégrant, Alcides elegans, Gứr.

Fig. 7. Rhynolaccus fourmi, Rhynolaccus formicarius, Latr. (Myrmacicelus bistrié, texte.)

Fig. 8. Cryptorhynque humćral, Cryptorhynchus humeralis, Laтn. (Tylode huméral, texte).

Fig. 9. Cryptorhynque latéral, Cryptorynchus lateralis, Gúér. (Tylode latẻral, texte).

Fig. ro. Pachyrhynque cuivré, Pachyrynchus aneus, Gú́r., Oriv.

Fig. I1. Brenthe bicolore, Brenthus bicolor, Gú́r.

Fig. I2. Brente étroit, Brenthus angustatus, Gứr. (Leptorhynque étroit, texte). I I I

Fig. 13. Brenthe de la Nouvclle-Guince (tête du Brenthus nost-guinensis), Gứl?. 
Pl. 7. Fig. x. Prione de Lima, Prionus Lima, Guḱr. 128

Fig. 2. Saperde de Lefebvre, Saperda Lefebrï, Gún. 338

Fig. 3. Tragocère à deux baudes, Tragocerus bifasciatus, Gvér. $\quad \mathbf{I 3 2}$

Fig. 4. Lamie à points roux, Lamia rubropunctata, Guḱr. (Saperde à points roux, texte).

Fig. 5. Saperde gracieuse, Saperda venusta, GuÉr.

Fig. 6. Lamie de d'Orbigny, Lamia Orbignyi, Gú̇r.

Fig. 7. Lamie à bords blancs, Lamia albicincta, Gú́r. (Saperde à hords blancs, texte.)

Fig. 8. Lamie granuleuse, Lamia granulosa, Gú́r.

Fig. 9. Lamie rugosule, Lamia rugosula, Gú̉r.

Fig. זo. Gnome semblable, Gnoma affinis, Guśr.

Fig. I I. Gnome girafe, Groma girafa, Guér.

Fig. 12. Tmésisterne à trois bandes, Tmesisternus trivitutus, GuÉ

Pl. 8. Fig. I. Fourmi maigre, Formic macra, GuĖn. 202

Fig. 2. Fourmi soyeuse, Formica sericata, Gut́r. 203

Fig. 3. Fourmi à six épines, Formica sexpinosa, var., Goḱn. $\quad 204$

Fig. 4. Fourmi à ventre noir, Formica nigriventris, GuÉr.

Fig. 5. Pimpla ceinte, Pimpla cinctata, Guér. $\quad 198$

Fig. 6. Ichneumon de Gravenhort, 7chneunon Gravenhorstii, Guḱn. 197

Fig. 7. Traclıypète en massue, Trachypetus clavatus, Guér. $\quad 202$

Fig. 8. Scolie de Serville, Scolia Servillei, Guér. 250

Figg. 8 D. Extrémité de l'abdomen du noâle de la Scolia Urrillei, Lepell. de Saint-Fargeau (Scolie brillante, texte). 25 i

Fig. 9. Thynnoïle à pieds rouges, Thynnus? rubripes, Gvér. (Thynnö̈des rubripes, texte).

Fig. ro. Myzine d'Australie, Myzine Australasice, Guḱn. (Anthobosque d'Australie, texte).

Fig. I I. Tête du Thyunus dentatus, Fав. ${ }^{x}$.

Fig. I 2. Pompile du Chili, Pepsis Lepelletierii, Gú́K.

Fig. 13. Pepsis ichneumoniforme, Pepsis ichneumoneus, Guḱr. (Pompile ichneumoniforme, texte).

Fig. I 4. Sphex du Port-Praslin, Sphex praslinius, Guḱr.

137

$3 y$

34

\section{7}

133

34

36

35

$3{ }^{2}$
98

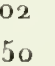
5

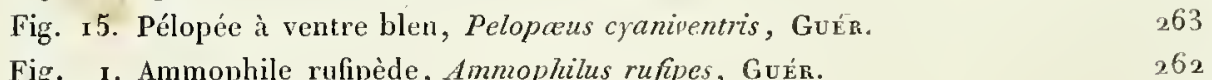

$\begin{array}{rrr}\text { Pl. 9. Fig. 1. Ammophile rufipède, Amnophilus rufpes, Gúr. } & 262 \\ & \text { Fig. } & 2 \text {. Pompile de Lepelletier, Pompilus Pelletierï. Guér. }\end{array}$

$\begin{array}{llr}\text { Fig. 2. Pompile de Lepelletier, Pompilus Pelletierï. Guḱr. } & 257 \\ \text { Fig. } & 263\end{array}$

Fig. 4. Odynère ceint d'or, Oclynerus aurocinctus, Guḱr.

Fig. 5. Odynère à ailes bleues, Odynerus cyanipennis, Gứr. 264

Fig. 6. Guèpe à deux taches, Vespa Alduini, Guér. (Vespa bimaculata, texte). 264

Fig. 7. Eumènc du Polt-Praslin, Eumenes praslinio, Guér.

(1) Ciest la tète du Thynnus variabilis, p. 223 . 
TABLE DES PLANCIES.

Fig. 8. Rhopalidie à ventre taehé, Rhopalia maculiventris, GuÉr.

Fig. 9. Sténogastre à ailes brillantes, Stenogaster fulgipennis, Gứr. (Ischnogastre ì ailes brillantes, texte).

Fig. 1o. Andrène australe, Andrena australis, Gứr.

Fig. I I A. Andreaa australis, Gú́r.

Fig. 12. Ailes de l'Andreaa flessa, FAB.

Fig. I. Listrocèle ì peignes, Listrocelis pectinata, Gó̀r.

Fig. 2. Acripèze rétieulée, Acripeza reticulata, Gứr. $\quad 753$

Fig. 3, Libellule élégante, Libellula elegans, Guér.

Fig. 4. Mantispe grande, Mantispa grandis, Gú̉r.

Fig. 5. Cigale à poche, Cicada perulata, Gú́r.

Fig. 6. Cigale vidée, Cicada exhausta, Gứr.

Fig. 7. Aphène rembrunie, Apheena fuscata, Guḱr. 18 ,

Fig. 8. Lystre de Serville, Lystra Servillei, Guḱr. $\quad$ I 87

Fig. 9. Rieanie oeulée, Ricania oculata, Gứr. I 92

Fig. Io. Rieanie splendide, Ricania spleadicla, Guḱr.

Fig. I I. Flate pyrale, Flata pyralis, Gúr. $\quad$ I92

Pl. I I. Fig. I-2. Seutellère de Labillardière, Scutellera Labillardierï; F FB: 154

Fig. 3. Seutellère de Praslin, Scutellera Praslinia, Gúr. $\quad 160$

Fig. 4. Seutellère de Péron, Scutellera Peronii, Gúk. $\quad$ I56

Fig. 5. Seutellère païenne, Scutellera pagaaa, FAв. $\quad$ i56

Fig. 6. Scutellère des Papous, Scutellerc papua, Goúr.

Fig. 7. Seutiphore marquée de rouge, Scutiphora rubromaculata, Gún. (Scutiphore peinte, texte).

Fig. 8. Pentatome de Fallen, Pentatoma Falleni,

Fig. 9. Pentatome de Seliellemberg, Pentatoma Schellenbergii, Gúkr. $\quad$ I66

Fig. Io. Pentatome de Wolf, Pentatoma Wolfi, GuEr. IGG

Fig. I I. Pentatome de Germar, Pentatoma Germarii, Guér. 167

Fig. 12. Pentatome du Port-Jakson, Pentatoma jaksoaiensis, Guir. $\quad 167$

Fig. I3. Pentatome aplatie, Pentatoma complanata, Guḱr. I67

Fig. I/. Pentatome raccoureie, Pentatoma crassula, Guḱr. I68

Fig. 15. Agapophyte à deux points, Agapophyla bipunctata, Guér. I68

Fig. 16. Platycoris bordée de rouge, Platycoris rubromarginata, Gón.

Fig. 17. Halys à points jaunes, Halys flaropunctata, Guír. I70

Fig. I 8. Halys de Wintlem, Halys IVinthemii, Gós. I . I

Pl. 12. Figg. 1. Mégymène denté, Megymenum dentatum, Guḱr. 172

Fig. 2. Tessaratome il antennes jaunes, Tessaratone flavicornis, Guḱr. I $\mathbf{r}$

Fig. 3. Platyeoris à deux points, Platycoris bipunctatus, Guír.

Fig. 4. Gonoec̀re à collier, Gonocerus collaris, Gó́n. 173

Fig. 5. Anisoscèle enfumé, Anisoscelis infumatus, Guxr. 173

Fig. 6. Anisosechle de Stoll, Aaisoscelis Stollii, Gún. (Anisoscrlis femoratus, texte).

Fig. 7. Anisosec̀le rougc, Anisoscelis rubricatus, Gox́n.

Fig. 8. Anisosec̀le sural, Anisoscelis suralis, Guḱr. (Anis. fémolé, texte.) I 75 
Fig. 9. Leptoglosse à col dilaté, Leptoglossus dilaticollis, Gú́r. $\quad$ I74

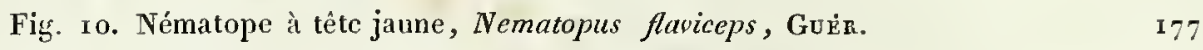

Fig. I I. Alyde à cornes annelées, Alydus annulicornis, Guḱr.

Fig. 12. Lcptocorise jaunâtre, Leptocorisa flavida, Guk̉r.

Fig. 13. Lygéc rouge-noir, Lygceus atrorufus, Guk̇. $\quad$ I 78

Fig. I 4. Lygée à ailes enfumées, Lygaeus fuscipennis, Gúr. 178

Fig. I 5. Lygée de Taïti, Lygous taitense, Gú́r. $\quad 178$

Fig. 16. Dysdercus péruvien, Dysdercus peruvianus, Guḱr. (Lygaus peruvianus). $\quad 178$

Fig. 17. Réduve tuberculé, Reduvius tuberculatus, Gǘr.

Fig. 18. Rćduve à ventre bleu, Rerluvius cyaniventris, Guغ̉r. $\quad 179$

Pl. 13. Fig. 1-2. Papillon de d'Urville, Papilio Urvillianus, Gúrr. 273

Fig. 3. Papillon Euchenor, Papilio Euchenor, Guk̇r. (P. Axion, texte). $\quad 273$

Pl. I4. Fig. 1. Papillon sévère, Papilio severus, GuẺr.

Fig. 2 A. B. Papillon Phestus, Papilio Phestus, GuER. $\quad 174$

Fig. 3. Papillon Ormcnus, Papilio Ornenus, Guḱr. 274

Pl. 14 bis Fig. I. Vanesse Amélie, Fanessa Amelia, Gü̇r. $\quad 278$

Fig. 2. Eurybic Caroline, Eurybia Carolina. Godart. $\quad 282$

Fig. 3. Satyre de Bazoehe, Satyrus Bazochii, Gú̉. (Satyrus cyanites, tcxtc). $\quad 282$

Fig. 4. Nymphale australe, Nymphalis rustralis, Guḱz. (Mynes Leucis, texte). 279

Pl. 15. Fig. I. Piéride du Chili, Pieris chiliensis, Guk̇r. (Antochuris chiliensis, texte). 174

Fig. 2. Coliade de Vauthier, Colias Vauthierii, Guỉn. 274

Fig. 3. Nymphale Nä̈, Nymphalis Nä̈s, Gứr. (Hamadryas zoilus, texte). 277

Fig. 4. Céthosie obseure, Cethosia obscura, Gúkr. 277

Pl. I6. Fig. I. Nymphale de Geoffroy, Nymphalis Geoffroyii, Gǘr. 299

Fig. 2-3. Argynne belle, Argynnis pulchra, Gú́r. (Emesis Leosida, texte). $\quad 27^{5}$

Fig. 4. Argynne de Gabert, Argynnis Gabertii, Guir. (Melitoea Gabertii,
textc).

Fig. 5. Argynne triste, Argynnis tristis, Guغ́r. (Satyrus tristis, texte). $\quad 28$ I

PI. I7. Fig. 1. Morphon à deux yeux, Morpho bioculatus, Guźr. (Hiades Indra, texte).

Fig. 2. Satyre de Klug, Satyrus Klugii, Gủ̇r. (Satyrus Philerope, tcxte). $\quad 280$

Fig. 3. Satyre de Duponehel, Satyrus Duponchelii, Gú́r. (Satyrus Dorycus, texte).

Fig. 4. Satyre du Chili, Satyrus chiliensis, Gú́r.

PJ. IS. Fig. I-2. Polyommate Damis, Polyommatus Danis, Gúkr. (Damis Sebce, texte).

Fig. 3. Polyommate coritus, Polyonmatus coritus, Gú́r. (Damis hylas, texte).

Fig. 4. Polyommate Cléotas, Polyommatus Cleotas, Gử. (Argus poeta, texte).

Fig. 5. Cléïs posticale, Cleïs posticalis, Gứr. (Damias Melaxantha, texte).

Fig. 6. Hespėric critomédia, Hesperia critomedia, Gủin. (Thymele odix, texte).

Fig. 7. Hespérie antipode, Hesperia antipodes, Gů̉. (Thymele dichroa, texte).

Fig. 8. Syméthus Léos, Symethus Leos, Gurir.

Pl. 19. Fig. I. Agariste hémorrhoïdale, Agarista haemorrhoüdalis, Gủ̇r.

Fig. 2. Noctuelle scapulaire, Noctua scapularis, Guغ̇r. (Agarista frontinus, textc). 
TABLE DES PLANCHES.

Fig. 3. Deileptène de Poey, Deileptena Poeyii, Guḱr. (Hazis Mars, texte). $\quad 28$ ?

Fig. 4. Phaloé ensanglantéc, Phaloe cruenta, GuÉr.

Fig. 5. Lithosie d'Arthus Bertrand, Lithosia Arthus Bertrand, Gúr. (Chelonia astrea, texte).

Fig. 6. Noctuelle propice, Noctua propitia, Guḱr. (Ophiusa propitia, texte). 285

Fig. 7. Noctuelle peinte, Noctua picta, Guḱn. (Polie peinte, texte).

Fig. 8. Glaucopide à ventre strié, Glaucopis strigiventris, Gú́n. $\quad 283$

Pl. 2o. Fig. I. Leptotarse de Macquart, Leptotarsus Macquartii, Guḱr. 286

Fig. 2. Caloptère fasciée, Caloptera fasciata, GuÉr. (Évanioptère faseiée, texte). ${ }_{2} 87$

Figr. 3. Pangonie du Port-Jakson, Pangonia jaksoniensis, Guḱn. 288

Fig. 4. Bombylius austral, Bombylius australis, Gúnr. $\quad 294$

Fig. 5. Chrysosome à ailes tachées, Chrysosoma maculipennis, Gú́r. (Agonosome à ailes tachées, texte).

Fig. 6. Chrysosome faseiée, Chrysosoma fasciala, Guér. (Agonosome faseiée, texte (I).

Fig. 7. Laphrie splendide, Laphria splendida, Guén. (Laphria spectabilis, texte).

8. Asile de Garnot, Asilus Garnotii, Guér. (Ommatius fulvidus, texte). $\quad 292$

Fig. 9. Anthrax à une ceinture, Anthrax unicincta, Guḱr. $\quad 294$

Fig. Io. Taon à gouttes, Tabanus guttatus, Dovov. $\quad 289$

Fig. I I. Agapophyte austral, Agapophytus Australasia. Guḱr. $\quad 290$

Fig. 12. Odontomyie de Lima, Odontonyia Lima, Guér. 29 I

Pl. 21. Fig. 1. Rutilie royale, Rutilia regalis, Gú́r. (Mouche royale, texte). $29^{5}$

Fig. 2. Rutilie admirable, Rutilia mirabilis, Gú́r. (Mouehe admirable, texte). $\quad 296$

Fig. 3. Calliphore papoue, Calliphora papua, Guér. 297

Fig. 4. Myophore mouehe, Myophora musca, Roв. Desv. (Sarcophaga nuisca, texte.)

Fig. 5. Sophie à bandes, Sophia vittata, Guḱr.

Fig. 6. Lucilie à tête dorée, Lucilia chrysocephala, Guḱr.

Fig. 7. Prosène eonique, Prosena conica, GuÉr.

GUÉr.

Fig. ro. Nérie indienne, Neria indica, Roe. Desv. (Calobate indienne, Icxte). 30 I

Fig. I 1. Nćric violet, Neria cyanea, Gú́r.

$30 \mathrm{I}$

Fig. I 2. Hyppobosc australe, Hyppobosca australis. GuÉr. (Omithomyia australis, texte).

(1) Il y a un rentersement de chiffres à la planche.

FIN DE LA TABLE DES PLANCHES. 



\section{DEUXIEI M DIVISION.}

\section{ZOOPHYTES, \\ Par R.-P. Lesson.}





\section{VOYAGE}

\section{AUTOUR DU MONDE,}

PENDANT LES ANNÉES

I $822, \quad$ I $823, \quad$ I 824 et I 825 .

\section{ZOOLOGIE.}

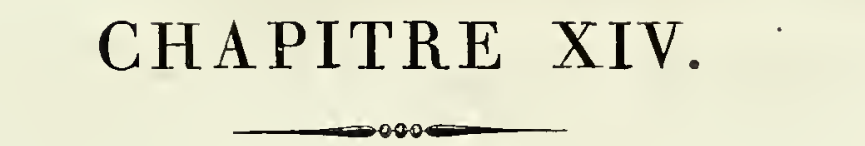

DESCRIPTION DES ZOOPHYTES ÉCHINODERMES.

$\oint 1$.

Genre OURSIN, Echinus, L.

I. OURSIN PORTE-HOULETTE.

Echinus pedifer, Less.; DE Blainv., Dict. sc. nat., t. XXXVII, p. 97 .

Cet oursin, que nous avons découvert sur les rivages de l'ile d'Oualan, et que nous avons communiqué, en 1825 , à 
M. le professeur de Blainville, se rapproche de l'oursin artichaut, echinus atratus, de Linné. Son test est ovale, subcirculaire, déprimé, convexe en dessus, plan et un peu concave en dessous, couvert d'un grand nombre de mamelons presque égaux, sur deux rangs serrés dans les ambulacraires, sur six dans les anambulacraires. Les ambulacres sont trèsfestonnés, chaque feston de onze ou douze paires de pores un peu alternants et comme percés à l'extrémité d'un demitube intermédiaire; les piquants du disque très-courts et plats à l'extrémité, comme dans l'oursin artichaut. Les périphériens bien plus grands, aplatis et élargis à leur extrémité en forme de houlette. Les auricules 'sont inconnues. Sa couleur générale est un vert bleuâtre; les mamelons sont verts, et les épines sont livides.

\section{OURSIN A BAGUETTES CARÉNÉES.}

Echinus carinatus, DE Blainv., Dict. sc. nat., t. XXXVII, p. $9^{8 \text {. }}$

Cette espèce d'oursin a été découverte par nous sur les rivages d'O-Taïi, elle se rapproche de l'oursin trigonaire, echinus trigonarius, Lamk.

Son test est ovalaire, couvert de gros mamelons, placés sur deux rangs dans les aires ambulacraires; à peu près sur quatre, dont les extrêmes sont bien plus petits et plus incomplets, dans les anambulacraires. Les ambulacres sont fortement sinueux, et chaque sinuosité a de deux à cinq paires de pores fort rapprochées. Les épines sont épaisses, assez longues, subcylindriques, obtuses au sommet, avec une carène plus ou moins marquée dans toute leur face inférieure. La couleur du test est jaunâtre, et celle des épines est violacée. 
SII.

Genre HOLOTHURIE, Holothuria, L.

\section{HOLOTHURIE (PHALIUSIE) QUADRANGULAIRE.}

Holothuria (phallusia) quadrangularis , I.ess., Cent. zoo!., pl. XXXI, fig. I.

Cette holothurie a de longueur totale 9 pouces et plus : elle est régulièrement quadrilatère, et les deux angles de la face dorsale sont hérissés d'éminences épineuses, allongées, à pointe mousse, légèrement recourbées, et régnant accolées deux a deux sur toute la longueur du corps, depuis la bouche jusqu'à l'anus, et colorées en rouge-brun à leur sommet. Les faces dorsale et latérales sont recouvertes par une peau dense, cartilagineuse, coriace et très-solide, mais en mème temps très-lisse, et colorée en bleu glauque très-brillant. La face ventrale ou inférieure est molle, plate, et recouverte d'innombrables papilles courtes, arrondies, n'affectant aucune attache particulière, mais confusément implantées sur toute la surface de cette partie. Ces papilles sont colorées en rouge brun. La bouche est ovalaire, arrondie, bordée d'environ vingt faisceaux membraneux que terminent des tentacules pressés, ramassés et comme globuleux, frangés. L'ouverture postérieure ou anale, est ovalaire, arrondie, sans aucun sphyncter, et occupe le point déelive et aminci du corps.

Cette holothurie se trouve sur les rochers que la mer abandonne à marée basse, sur la côte méridionałe de la grande baie d'Offack, dans l'île de Waigiou, l'une des terres de la Nouvelle-Guinée, où nous l'avons découverte en septembre, I 823 . 
4. HOLOTHURIE (PHALLUSIE) TIMAME.

Holothuria (phallusia) timama, Less., Cent. zool., pl. XLIII.

Cette holothurie atteint jusqu'à 2 pieds de longueur, sur 6 pouces et plus de circonférence. Son corps en dessus est convexe, ridé transversalenient et recouvert par une enveloppe cartilagineuse, très-dure, très-coriace. C'est donc à tort que dans la planche XLIII de notre Centurie M. Prêtre a prêté à cette holothurie une ondulation dans le sens de sa longueur qu'elle ne peut avoir. La face inférieure ou ventrale est aplatie, sillonnée au milieu et dans le sens longitudinal par une rainure profonde, entièrement recouverte de papilles vermiculaires, très-courtes, arrondies et coniques. Cette face ventrale est d'un blanc pur, tandis que le dessus du corps dense et cartilagineux, partout recouvert de papilles vermiculaires de couleur marron, est d'un gris rougeâtre, sillonné de rouge de brique, et marqué de taches losangées et irrégulières d'un noir profond, qu'encadre une légère bordure d'un jaune blanchâtre clair.

Les tentacules de la bouche, au nombre de vingt, sont courts, aplatis, lancéolés et en rayons. Leur coloration est un jaune pâle. L'anus placé au milieu de l'extrémité postérieure, est circulaire, large, et sans sphyncter.

Nous pêchâmes fréquemment cette holothurie sur les fonds de sables et de corail, à quelques brasses de profondeur, dans la vaste baie d'Offach, dans l'île de Waigiou, faisant partie de la terre des Papous. Les nègres de cette région du monde lui donnent le nom de Timame, que nous lui avons conservé. 
5. HOLOTHURIE TRÉPANG.

Holothuria (phallusia,) edulis, Less., Cent. zool. pl. XLVI, fig. 2.

Célèbre depuis long-temps dans le commerce de l'Inde sous le nom de trépang que lui ont consacré les Malais, ou de priape marin que lui donnent les Européens, cette holothurie est l'objet d'un immense commerce de toutes les îles indiennes de la Malaisie avec la Chine, le Camboge et la Cochinchine. Des milliers de jonques malaises sont armées chaque année pour la pêche de ce zoophyte, et des navires anglais ou anglo-américains se livrent eux-mêmes à la vente de cette denrée, généralement estimée chez tous les peuples polygames, qui lui accordent les propriétés aphrodisiaques les plus énergiques et les plus efficaces. La forme de cette holothurie aurait-elle contribué à cette réputation si généralement établie chez les Malais, les Chinois et les Indiens? ou bien la matière gélatineuse qui constitue en entier l'animal, avivée par le principe salin de la mer, serait-elle assez efficace pour restaurer les forces et par conséquent permettre de satisfaire à des désirs qui, pour les Orientaux, sont une des nécessités de la vie? Souvent nous avons mangé de ce zoophyte préparé de plusieurs manières, et toujours nous ne lui avons trouvé aucun goût particulier, il est vrai, masqué qu'il était par l'énorme dose d'épices ou d'aromates dont est surchargée la cuisine de ces peuples. Les trépangs ou sualas des habitants de Sumatra, les sea slugs des Anglais établis aux Indes, se vendent 45 dollars le piccul, et forment une des branches les plus considérables du commerce de cabotage entre Bornéo, Sumatra, les Moluques, les terres papoues de la Malaisie avec la Chine. Leur préparation consiste, après leur pêche, à les faire dégorger dans de la chaux de corail, et a les dessécher à la fumée. 
L'holothurie trépang est cylindrique, arrondie, mince et longue d'environ huit pouces. La surface du corps est légèrement rugueuse, onduleuse, consistante et recouverte en dessous de papilles courtes, éparses, rangées sans symétrie. La partie supérieure du corps est d'un noir fuligineux intense, tandis que la partie inférieure et les côtés sont d'un rose agréable moucheté de points noirs. lua bouche est arrondie, entourée de six à huit paquets de tentacules arrondis, floconneux. L'anus est médian, terminal, et dę forme ovalaire, imitant un cylindre droit et assez mince.

Le trépang est excessivement commun sur les banes que forment les coraux à peu de profondeur sous la mer, entre les îles Moluques, dans le nord de la Nouvelle-Hollande, dans les îles Philippines et Carolines. C'est le condiment aphrodisiaque de tout repas malais ou chinois.

\section{HOLOTHURIE (PHALLUSIE) IMPUDIQUE.}

Holothuria (phallusia) monacaria, Less. Cent. zool. pl. LXXVIII.

Cette holothurie a plus de sept pouces de longueur totale, sur un diamètre de 24 lignes. Sa partie supérieure et les côtés sont coriaces, résistants, assez solides, et hérissés de petits crochets recourbés. Sa couleur est d'un rouge brun foncé sur le dos, et chaque papille est entourée d'un cercle blanc, nettement dessiné. Sa surface inférieure est aplatie, souple, garnie d'une prodigieuse quantité de papilles molles servant de pieds, et colorées en rouge brun. Cette surface inférieure est elle-même d'un rouge ferrugineux, mais deux raies d'un jaune clair se dessinent sur toute sa longueur. L'anus est terminal, arrondi, nu, et l'extrémité antérieure est ovalaire, charnue, garnie d'une rangée de tentacules plissés ( 6 à 20), élargis et évasés à leur sommet, ce qui leur donne l'aspect.d'un godet à bords fléchis, 
plissés et onduleux. Cette dernière partie du zoophyte est d'un rouge caunelle agréable.

L'holothurie impudique ressemble à un grossier phallus. Elle habite les rivages des îles d'O-Taiti et de Borabora dans l'océan Pacifique.

7. HOLOTHURIE (HOLOTHURIE) PÉRUVIENNE.

Holothuria (holothuria) peruviana, Less., Cent.zool. pl. XLVI, fig. I.

Cette holothurie est longue de près de 6 pouces, cylindrique, plus amincic vers son extrémité buccalc, et légèrement renflée à l'extrémité opposée. Sa surface est molle, peu consistante, et couverte dans tout son diamètre de papilles cylindriques, courtes, érectiles et placées sans aucun ordre, c'est-à-dire éparses quoique rapprochées sur la surface du corps. La bouche est arrondie, petite, au milieu d'un cercle légèrement convexe, d'où partent huit parquets de tentacules buccaux, portés chacun sur un pédoncule arrondi, puis garni de franges épaisses et serrées, formant une sorte de louppe dense au sommet. L'anus est placé à la partie postérieure, et s'ouvre en formant un trou ovalaire, médian et nu à son pourtour. Quelques filaments blanchâtres s'élèvent çà et là sur le corps, sans que leurs fonctions nous soient connues. La couleur de cette holothurie flasque et mollasse est en entier d'un rouge violet éclatant et foncé. Nous l'avons recueillie sur les rivages de Payta, par douze degrés de latitude sud, sur la côte du Pérou.

\section{HOLOTHURIE (INTESTINAIRE) OCÉANIENNE.}

Holothuria(intestinaria)oceanica, Less., Cent.zool. pl. XXXV.

Cette holothurie a de longueur jusqu'à 3 pieds, mais comme 
elle est éminemment contractile, elle se raccourcit souvent en se boursouflant de manière à n'avoir que i 2 ou i 5 pouces. Elle est cylindrique, à enveloppe mince, intestiniforme, pellucide. Six brides membraneuses s'étendent de l'extrémité antérieure à la postérieure, et servent de point d'appui aux contractions des parois tégumentaires qui se froncent et se boursouflent dans le mouvement de raccourcissement du zoophyte. L'épiderme du corps est abondamment recouvert de crochets peu apparents, rudes comme du chagrin, jaunes, jouissant des propriétés accrochantes à un haut degré et retenant vivement les corps qui sont mis en contact arec l'animal; un liquide âcre et corrosif lubrifie la surface du corps et fait naître un prurit intolérable sur la peau lorsquion touche cette holothurie sans précaution; aussi les naturels de la mer du Sud témoignent-ils la plus grande répugnance à sa vue. Des reuflements égaux, simulant des sortes de nodosités parfaitement symétriques, occupent les intervalles des brides membraneuses. La couleur générale du corps est un gris rougeâtre à teinte douce et uniforme que relèvent six raies brun foncé, bordées latéralement de petites raies blanches argentées, côtoyant les brides membraneuses longitudinales. Les renflements sont d'un gris plus intense.

L'extrémité antérieure se compose d'un disque cónvexe au milieu duquel s'ouvre une bouche arrondie, et d'ou partent dix longs tentacules buccaux aplatis, à tige graduellement amincie, et pectinée sur ses bords de manière à imiter les barbes d'une plume. L'anus est arrondi, nu, et placé tout-à-fait à l'extrémité du corps. Nous avons trouvé cette holothurie dans les criques de la baie de Matavai dans l'île d'O-Taïti en mai ı 823 . Eile y était fort commune. Elle se décompose aisément dans l'esprit-de-vin, lorsqu'on essaie de la préserver pour l'étude. Tout porte à croire que les crochets nombreux qui sont épars sur le corps ont pour fonctions de retenir le zoophyte sur les 
rochers, et de s'opposer par leur résistance aux agitations que les vagues apporteraient à l'existence d'un animal éminemment fragile, et qui se plait cependant dans les endroits où la mer brise avec force.

9. HOLOTHURIE (INTESTINAIRE) ANDOULLLE.

Holothuria (intestinaria) hilla, Less., Cent. zool., pl. LXXIX.

Longue de I o à I I pouces, cette holotlıurie est peu épaisse, cylindrique, allongée, d'un diamètre à peu près égal, et à cnveloppe mince, membrencuse, pellucide. Son cxtrémité postérieure est amincie, conique, terminée par un sphincter arrondi et nı; l'extrémité antérieure est ample, percée d'une bouche ovalaire qu'entourent deux rangs de tentacules pressés, serrés, dilatés à leur sommet et festonnés sur les bords. Chaque rang parait avoir dix tentacules dont la coloration est un gris tendre mélangé de blanc.

La surface supéricure est d'un gris légèrement rougeàtre qui se dégrade sur les côtés, et le dessous est uniformément blanchâtre. Mais des bandes circulaires entourent, de distance en distance, le corps et sont d'un gris rougeâtre plus foncé que celui du dos. La surface de cette holothurie, sur tous les points de son épiderme membraneux, extensible et très-contractile, est hérissée de crochets papilleux, placés avec régularité, d'un jaune vif, qu'entoure à leur base un cercle d'un blanc satinć.

Cette holothurie vit sur les récifs qui entourent l'ile de Borabora dans l'archipel de la Société.

so. HOLOTHURIE (CHIRIDOTE) PURPURINE.

Holothuria (chiridota) purpurea, Less., Cent. zool., pl. LII, fig. 2.

Cette holothurie appartient au petit genre chiridota de 
M. Eschscholtz, qui a pour principal caractère les tentacules digités à leur sommet, la peau assez dense, mais privée de tubes rétractiles. Les trois espèces décrites par le naturaliste russe ont les plus grands rapports de forme avec la nôtre, bien que cette dernière s'en distingue par sa vive coloration.

L'holothurie purpurine a de longueur environ i 8 lignes. Elle est mince, cylindrique, très-lisse, très-contractile, et munie d'un à trois petits tubes sur le dos. L'anus est placé à l'extrémité pointue du corps. La bouche est arrondie, entourée de dix tentacules de longueur inégale et qui sẻmblent placés sur deux rangs. Chacun d'eux est arrondi à sa base et digité au sommet, ou plutôt pétaloïde et profondément lacinié, de manière à imiter un pétale d'ocillet : les laciniures au nombre de six. La couleur des tentacules est un rose pâle, mais celle de tout le corps est d'un rouge carmin velouté et très-éclatant.

Cette holothurie, assez rare, se tenait dans les crampons des fucus pyriferus, à cinq brasses de profondeur, dans la baie de la Soledad aux îles Malouines.

i. HOLOTHURIE (CONCOMBRINE) ORANGÉE.

Holothuria (cucumaria) crocea, Less., Cent. zool., pl. LII, fig. I.

Cette jolie petite holothurie appartient à la tribu des concombres de mer, cucumaria, tribu que caractérise un corps pentagonal avec dix rangs de tentacules ou deux rangs sur chaque angle du zoophyte.

Cette holothurie s'est présentée à nous par centaines d'individus le 20 novembre 1822 . Lorsqu'elle est contractée, elle affecte nue forme ovoïde, renflée et terminée par une éminence conique au milieu de laquelle est percé l'anus. Cinq còtes sail- 
lantes partent du pourtour de la bouche et se rendent à l'extrémité opposée, en laissant dans leur intervalle un sillon assez prononcé. Sur chaque côté est placé un double rang de tentacules courts, réguliers, cylindriques. Les tentacules buccaux sont au nombre de dix, assez longs, d'abord simples, puis ramifiés par petits faisceaux dichotomés à leur sommet. Ces tentacules sont blancs tandis que le corps de l'holothurie est d'in jaune orangé fort vif, se décolorant parfois et passant à la couleur jaune pâle.

Cette holothurie est molle, gélatineuse, sans grande consistance. Elle exhale une odeur d'huitre caractérisée. Elle vit par essaims innombrables sur les frondes de fucus pyriferus et sur les autres fucacées qui encombrent certaines parties de la baie de la Soledad aux îles Malouines. Elle doit, sans aucun doute, servir de pâture alı phoques et aux oiseaux marins qui se plaisent au milieu de ces lits de goémons.

×2. HOLO'THURIE (MYNIADE) AZUR.

Holothuria (mynias) carnlea, Less., Cent. zool., pl. LXII, fig. I.

Le genre Mynias fut établi pour la première fois (I 8 I 7 ) par M. Cuvier dans la première édition du Règne animal, pour un zoophyte marin rapporté par Péron, et qui y est représenté pl. XV, fig. 8. Les myniades sont placées par M. Cuvier à la suite des molpadies (molpadia, Cuv.) dans l'ordre des échinodermes sans pieds, et avant les priapules, à la suite toutefois des holothuries. Les caractères assignés à ce genre par M. Cuvier sont ceux-ci : Corps sans pieds et ouvert aux deux bouts, ayant la forme d'un sphéroüde déprimé aux pôles et sillonné comme un melon. Point d'armure à la bouche. "La seule espèce connue, ajoute ce savant, est très-belle, d'un bleu foncé, et se trouve 
dans l'océan Atlantique. M. de Blainville adoptant l'opinion de M. Lesueur place ce genre près des actinies.

Le genre mynias nous parait devoir rentrer évidemment dans le genre holothurie, et ne devoir former qu'un sous-genre qui établira les rapports des vraies holothuries aver les actinies. Nous précisons ainsi ses caractères. Corps méloniforme, très-déprimé aux pôles dans son état de contraction, à bouche antérieure, large, arrondie, bordée de trois rangs de suçoirs courts, vermiculaires, cylindriques, blancs: anus oblong, nu, ouvert dans une surface déprimée, arrondie et plane. Lorsque l'animal erre sur la surface de la mer, pour saisir sa proie, il est convexe en dessus, renflé, étranglé et rétréci à l'extrémité buccale qu'entourent des suçoirs nombreux pressés les uns à côté des autres.

La myniade azur est, ainsi que l'indique son nom, d'un bleu azur céleste que relèvent des points papilleux blancs sur les côtes qui parcourent régulièrement le corps dans le sens longitudinal. Les suçoirs sont d'un blanc pur, et les organes internes d'un rose tendre. La surface extérieure jouit d'une grande contractilité, mais en même temps d'une densité remarquable. Sur les côtes sont placées des rangées de papilles cornées solides et très-accrochantes, ainsi qu'on le remarque sur beaucoup d'espèces d'holothuries.

Nous avons rencontré la myniade bleue, què nous avions nommée Peronia, le 19 décembre 1824 , dans les mers du cap de Bonne-Espérance. Elle voguait à l'aventure sur la surface de l'océan atlantique méridional, dans les jours de calme, si rares sur le banc des Aiguilles. 
§III.

Genre OChétostome, Ochetostoma, Leuch., It. Ruppel..

\section{ı3. OGHÉTOSTOME ÉAOUARI.}

Ochetostoma eaouari, Less.

Holothuria eaouari, Less., Cent. zool., pl. XXXI, fig. 8.

Les ochétostomes, bien voisins des siponcles, ont le corps allongé, membraneux, contractile, strié dans le sens longitudinal, et terminé en avant par un cylindre aminci, percé au sommet par un orifice simple et complètement nu. L'anus s'ouvre près de la partie postérieure et sacciforme du corps, et non loin des organes de la génération.

L'espèce que nous décrivons est très-voisine de l'Ochetostoma erythrogrammon de MM. Leuchart et Rüppell. Les habitants de Borabora, l'une des îles de la Société, lui donnent le nom d'Eaouari que nous lui conservons, et la recherchent pour la manger toute crue. Ils la regardent comme un aliment exquis, et la grande quantité de liquide d'un pourpre vif qu'elle contient teint leurs lèvres, à la manière du fruit des mûriers. Cette holothuride est très-commune sur le rivage de l'îlot de Tuboï; elle est éminemment contractile, fusiforme, lombrisciforme, arrondie, et terminée en pointes coniques aux deux extrémités. Sa surface est uue, lisse, charnue, molle, recouverte seulement de papilles lisses vers les extrémités et principalement sur le pourtour de l'ouverture orale. Un rose carné tirant sur le violâtre, passant ensuite au bleuâtre, forme le fond de sa coloration. Dix bandelettes longitudinales purpurines vont d'une extrémité a l'autre. La bouche s'ouvre au bout d'un long tube cylin- 
drique, jaune-verdâtre transparent. L'anus est rouge, circulaire, petit, et bordé de courts tubercules.

\section{\IV.}

Genre SIPONCLE, Sipunculus, Gm.

\section{SIPONCLE LOMBRISCIFORME.}

Sipunculus lumbrisciformis, Less., Cent. zool., pl. LIII fig. 3.

Le genre Siponcle, Sipunculus, a été caractérisé ainsi par Lamarck (An. sans vertèb., t. III, p. 77 ):

"Corps allongé, nu, se rétrécissant postérieurement par un petit renflement terminal, et ayant antérieurement un colétroit, cylindrique, court et tronqué. Bouche orbiculaire, terminant le col. Une trompe cylindrique, finement papilleuse à l'extérieur, rétractile, sortant de la bouche. Anus latéral, placé vers l'extrémité antérieure.»

Le siponcle lombrisciforme est mince, arrondi, long de 5 pouces, très-contractile et le plus souvent renflé sur lui-même. Son extrémité postérieure est plus volumineuse, et se termine en un mamelon conique. L'antérieure fusiforme, s'allonge en une trompe conique, munie sur ses côtés de trois petits renflements épatés et ovalaires. La surface du corps est lisse, plissée circulairement, mince, colorée en bistre parfois clair, parfois foncé, et souvent mélangé de teintes fauves. La bouche est d'un jaune orangé.

Nous avons souvent rencontré ce siponcle au milieu des fucus pyrifères jetés sur les côtes de la baie de la Soledad, l'une des îles Malouines, en novembre I 822 . 


\section{CHAPITRE XV.}

DESCRIPTION DE LA FAMILLE DES CYSTISOMES ET DES ESPÈCES OBSERVÉES PENDANT LE VOYAGE DE LA COQUILLE.

La famille des eystisomes, Cystisoma, comprend les animaux que la plupart des naturalistes eonnaissent sous le nom de physalides ou physales, et que les voyageurs sur mer appellent, les Franęais, Galères, Petites frégates, et les Anglais Man of war. Pison semble affirmer que leur nom brésilien est Moucieu. Les caractères de eette famille sont les suivants:

L'animal eonsiste en un plateau eharnu, épais au centre, perforé, ayant un tube digestif disposé en eanal, et garni en dessous de trois sortes de tentaeules; les premiers courts, museuleux, dilatables, sacciformes, munis d'une bouche à leur sommet, et destinés à absorber et sucer la proie dont se nourrit le zoophyte; les deuxièmes très-longs et très-contractiles, tubuleux, munis sur le côté de glandes hexagonales, ouvertes au milieu, suintant un liquide âcre, corrosif, destiné à stupéfier les êtres que les bouches stomacales doivent dévorer; les troisièmes formés de disques minces, vibrants, ont l'aspect des branchies de salpas. Au-dessus du corps réel s'élève une large vessie composée de deux tuniques, de forme cylindrique, atténuće aux deux bouts, munie d'une ouverture que ferme une soupape à l'extrémité antérieure. Une crête plissée oceupe la face supérieure de la partie dilatable et vésiculeuse. 
La définition que nous donnons de cette famille la caractérise parfaitement. Elle se rapproche de celle des physophorées et ne comprend qu'un genre, le genre physalia, auquel, par conséquent, on devra transporter les caractères que nous avons consacrés à la famille.

Toutefois les animaux cystisomes, les physalies, ne nous paraissent pas être de vrais zoophytes. Bien quon ne leur ait point encore trouvé une organisation assez complexe pour les élever au rang de mollusque, toujours est-il que leurs divers systèmes se rapprochent notablement de ceux de quelques genres de mollusques ${ }^{\mathrm{r}}$.

En se rappelant la ligne horizontale de l'eau, et par conséquent la vie essentiellement marine que reçurent en partage les physalies, on ne peut se refuser à admettre que ces animaux ne soient des êtres renversés. Ainsi, nul doute que la crête ne soit le pied, la partie vésiculeuse le prolongement du pied, le plateau qui porte les tentacules le corps réel, et les tentacules les bras ou cirrhes et les branchies qui enveloppent le prolongement oral de la cavité digestive.

Le corps est donc placé entre la partie vésiculeuse qui le surmonte et le faisceau des tentacules de diverses sortes qui partent de la surface inférieure. Sa forme est irrégulière, sa consistance dense et cartilagineuse, solide : il semble composé de quatre gros tubercules inégalement renflés, charnus, et donne en dessous immédiatement attache aux tentacules stomacaux. En dessus s'étend la vessie qui semble, au premier coup d'œil, constituer la plus grande partie de l'animal. Cette vessie est de

I Quant à l'antériorité des idées émises dans ce chapitre, nous rappellerons que les notes manuscrites rédigées le 19 septembre I $_{22}$, en mer, comminniquées, avec tous nos dessins, à l'Institut, en 1825 , ont été insérées en partie dans le tome XI, année 1827, p. $163, \mathrm{n}^{\circ}$ 1 10 du Bulletin des sciences naturelles de M. de Férussac. 
forme allongée, variable, dilatée au centre, se terminant en avant par un cône obtus, finissant en arrière par un cône fréquemment nuamelonné. Sa capacité, au reste, varie singulì̀rement, suivant la quantité d'air qui en distend les parois, et de là viennent ces boursouflures inégales qui donnent à ces êtres une si grande variabilité dans les formes, et ce qui fait que presque toutes les figures qu'on en a données sont si différentes et si fautives dans leurs contours. L'extrémité antérieure qui s'allonge en une sorte de rostre cylindrique est percée à sa partie terminale par un trou que ferme solidement une soupape oblique. Par cette ouverture parfaitement circulaire s'échappe l'air qui distendait la vessie, et par suite l'animal peut, en diminuant la résistance que cette vessie opposait à sa pesanteur spécifique, descendre au fond de l'eau. Il est très-aisé de démontrer la présence de cette ouverture en pressant une vessie gonflée de physalie, et en mettant la main devant, au bas de l'extrémité antérieure : l'air qui est comprimé se fait jour en forçant la soupape oblique membraneuse qui en fermait l'issue, et la colonne d'air, en sortant, dévie de la ligne droite en se brisant à angle aigu. Enfin, le plus souvent le côté droit est plus renflé que le gauche, ct cela tient à ce que, ce dernier soudé à la partie cartilagineuse du corps, est peu susceptible de dilatation.

Les proportions de cette vessie varient suivant les espèces; mais chez toutes elles restent uniformément les mêmes. Sa surface la plus externe est me tunique membraneuse, brillante, de nature satinée, n'offrant pas la moindre trace de vaisseaux, mais parcourue par des sortes de brides musculaires disposées en cercles, et au point d'attache de la base de la vessie avec le corps on remarque des paquets solides de fibres concentriques qui semblent avoir pour but d'augmenter la solidité de leurs moyens de jonction. Sur le devant du corps souvrent deux orifices principaux où viennent aboutir les matières absorlies 
par les tubes buccaux, ouvertures où commence un réservoir général, cloisonné, remontant sur la ligne moyenne de la vessie, et sur la partie supérieure, à l'endroit même où naît la crête. Nous avons souvent trouvé ce canal rempli d'un chyme abondant, coloré en rouge lie-de-vin, de consistance de bouillie, et nous pensons qu'il se termine un peu au-dessus et au-devant du trou de l'extrémité antérieure; du moins nous ne l'avons pas suivi au-delà. Les parois internes de cette vessie sont formées par une membrane mince, très-transparente, striée, de nature séreuse, dont la surface forme un sac sans ouverture, adapté aux anfractuosités des cellules de la crête, cellules qu'elle tapisse par des duplicatures. Cette membrane se rétrécit pour se coller au tube de l'extrémité antérieure, et se soude aux rebords de l'ouverture dont nous avons parlé. La séreuse interne se sépare très-aisément de celle qui constitue la tunique extérieure et qui est fibreuse. Elle parait avoir pour principale fonction dẹ former un sac que l'air remplit et qui protége le système digestif. Or, ce système digestif ne peut pas exister sans des bouches, des conduits, et une ouverture de déjection?

La partie qu'on nomme crête ou voile, surmonte donc la vessie dilatable, et constitue une portion accessoire, épaisse à la base, mince au sommet, et taillée en carène, qui s'élève sur la partie dorsale de la vessie. Les deux extrémités de celle-ci offrent à peine 12 à 18 lignes de son cylindrequi soient libres. Cette voile, crête, pied, ainsi qu'on voudra nommer cette portion accessoire et terminale de l'ensemble vésiculaire, a jusqu'à un pouce de largeur à son insertion, et s'amincit successivement pour former à son bord terminal un biseau nince et arrondi. Cette crête est divisée dans sa partie interne en dix cloisons ou cellules, subdivisées elles-mêmes, et chacune en deux loges, chaque loge en deux cavités, chaque cavité en deux méats très-petits. Ies parois de séparation entre toutes ces loges 
forment à l'extérieur des sortes de rainures, ou des lignes roses, puis fréquemment colorées en violàtre foncé. Ces piliers semblent être des muscles droits très-eontractiles, et qui distendent les parois minces et diaphanes des cavités, lorsqu'elles se remplissent d'air, et les compriment lorsqu'il s'agit d'expulser les gaz et de les vider. Lintérieur de toutes ces cellules est tapissé par des replis de la menbrane interne ou séreuse, qui double en totalité le dedans de la vessie. Le sommet de la crête est arrondi, ainsi que nous l'avons dit; mais il est remarquable par une bordure de bouillonnement eolorée très-vivement d'une sorte d'écume toute brillante, car nous ne savons comment nommer cette manière d'être des cellules aériennes qui paraissent se diviser à l'infini pour offrir la particularité dont nous parlons.

Sousle plateau charnu qui constitue le corps naissent en groupes, ou en faisceaux, les trois sortes d'organes qui servent à la trituration des aliments, aux moyens de saisir la proie, et très-probablement à la respiration.

Les tubes stomacaux ou bouches uourricières sont renflés à leur base, rétrécis au sommet, sacciformes, dilatables, delongueur variable, ouverts à leur terminaison, et munis d'une bouche propre à opérer une succion rapide. Ces tubes sont évidenment musculeux, formés de fibres concentriques, disposés de manière à rejetcr dans le canal central alimentaire le résultat de leur trituration première et de leur grossière élaboration. Rétrécis dans leur état de vacuité, ils sont susceptibles de se renfler considérablement.

Un nombre très-variable de chapelets branchiaux se prolonge sous for'me de filaments ténus et déliés du milieu des tentacules buccaux. Ces chapelets ne sont pas, ainsi qu'on les représente, des grains enfilés; ils sont généralement droits, délicats, trèsfragiles, composés d'un fil capillacé, supportant les cils ou rondelles qui sont minces, trc̀s-mobiles et empilés sur l'axe central, 
comme le seraient les plaques d'une pile voltaïque, en supposant qu'au milieu des rondelles passât un fil de fer qui les réunirait toutes. Ces disques très-minces sont très-irritables, sans cesse en mouvement. Il nous répugne de les regarder comme des ovaires ou des grappes reproductrices. Il nous paraît plus naturel de les considérer comme analogues aux rayons branchiaux de quelques mollusques, ou comme jouant le rôle des cils vibratoires de certains zoophytes, de ceux notamment de la famille des béroides. Il eșt très-probable que la fonction de cette sorte de pile pulmonaire est de décomposer l'eau, pour fournir à l'animal l'air nécessaire à l'excitabilité des tissus, et par suite à l'entretien de la vie. Est-ce cet air respirable qui gonfle la vessie? est-ce cet air qui pressant l'eau contenue souvent dans cette vessie lorsque l'animal veut abandonner la surface de la mer, la chasse par l'ouverture terminale d'où la soupape de sûreté éloigne tout corps étranger? Ou bien, l'eau que fréquemment noas avons vu remplir les deux tiers de la vessie, ne s'était-elle introduite dans son intérieur que par suite de fatigue musculaire, de malaise ou d'inertie dans les soupapes? car les individus qui nous présentèrent uniformément cette particularité élaient soumis depuis quelques jours à la captivité dans des vases pleins d'eau de mer, renouvelée, il est vrai, mais non dans des proportions convenables à leur existence, car ils ne tardèrent pas à mourir. Peut-être enfin cette eau, qui filtre dans la vessie, devient-elle un lest nécessaire pour que la physale puisse vaincre la résistance qu'oppose au liquide qui la supporte sa pesanteur spécifique.

Il serait très-intéressant d'analyser chimiquement l'air contenu dans la vessie, et renfermé dans la membrane séreuse qui lui forme une enveloppe imperméable? Est-ce de l'oxigène? A ces questions, aujourd'hui sans solution, nous ajouterons que cet air, quelle que so it sa nature, s'introduit dans les cellules de 
la crête, les gonfle, et leur donne cette apparence de voile si remarquable, et qui a fixé l'attention de tous les navigateurs: crête qu'ils supposent avoir été donnée à la physale, comme une voile de vaisseatu, pour se tendre au vent et permettre à l'asimal d'évoluer à la manière des navires. Il est bien certain que cette crête a pour principal but d'accroitre la légèreté du corps qu'elle surmonte, lorsque la mer est un peu houleuse, et que, sans cela, arriveraient de nombreux chavirements, et par suite interruption de fonctions. Il est certain aussi que, par les beaux jours de calme des tropiques, cette crête, donnant prise aux vents alisés, il doit en résulter accélération de progression lorsque les phyalies, unies en troupes, s'abandonnent aux émigrations de parages, qui paraissent toutefois n'avoir lieu que sous des latitudes données et circonscrites, et sous l'influence de certains courants.

11 nous reste à parler des moyens de défense ou d'industrie qui furent donnés aux physales pour protéger ou entretenir leur existence. Sous la portion moyenne du corps, et entouré de suçoirs, est placé un organe pyriforme assez consistant, c'est-à-dire, dilaté à son attache, puis rétréci à son extrémité, le plus souvent coloré en bleu vert, et qui pourrait bien être l'analogue du foie. Cet organe, de nature glanduleuse apparente, sécrète une matière très-âcre, très-fugace et très-vénéneuse, qui s'écoule dans de long canaux rubanés, minces, trèscontractiles, canaux multipliés jusqu'à vingt dans la grande pliysale, tandis que toutes les autres espèces n'en ont quiun seul, ample, et proportionnellement plus gros dans les petites pliysalies. Ce réservoir. de fluide hépatique se trouve donc bordé à sa portion interne, puis terminé par un tube qui atteint depuis dix jusqu'à trente pieds dans les grandes espèces. Ces tubes, formés de doubles membranes musculeuses, éminemment contractiles, sont aussi composés d'anneaux dont 
les fibres sont circulaires. Mais sur une ligne, et distantes, s'ouvrent des centaines de bouches arrondies, fermées par un froncement relevé de leur bordure ou par une sorte de sphyncter épaissi; or, de ces bouches suinte, lorsque le tentacule vient embrasser un corps quelconque, le liquide vénéneux dont nous avons parlé. Ces bouches vont jusqu’à l'extrémité ténue du tentacule, et par leur épaisseur elles ressemblent aux glandes des végétaux rosacés, chargées d'élaborer la matière que leurs abords fournissent, et qui devient définitivement vénénense en sortant des mailles de leur tissu.

Certes, le système nerveux des physales, encore inconnu, doit avoir une action bien énergique; car, au moindre contact, au moindre choc, les tentacules musculaires se contractent, et tels d'entre ceux qui flottaient sur la surface de la mer, ou à quelquues pieds de profondeur sous l'eau, frappent instantanément de stupeur la proie qui va donner dans leurs réseaux dangereux, et l'enveloppent de plis en se contractant au point de n'avoir plus que quelques pouces, lorsque, distendus, leurs dimensions sont de quinze à vingt pieds.

Ce liquide si corrosif est coloré en bleu, sa consistance est légèrement sirupeuse; il se dissout instantanément dans l'eau ou l'alcool, et les tentacules d'une physale qui mourut dans mn bocal de 6 litres rempli d'eau de mer, où nous la tenions en captivité, suffirent pour colorer toute cette masse d'eau dans l'intervalle d'une nuit, en beau bleu azur, et sans laisser paraitre les plus légers vestiges de trame organisée. Lorsque ce liqnide est appliqué sur quelque endroit du corps humain que ce soit, et il agit avec d'autant plus de violence que les parties sont plus délicates, il occasionne aussitôt le sentiment le plus vif d'une urtication intense, appréciable pendant quelques jours, si le contact a été de peu de durée, et si la peau a reçu peu de matière corrosive; mais suivi d'inflammation érysipélateuse, 
avec fièvre, syncope, puis délire, si le contact a été prolongé. Malgré nos précautions nous tonchâmes légèrement des tentacules (et il faut arouer que ces filaments semblent s'entortiller et se cramponner avec avidité aux corps qu'ils approchent, ) et nous éprouvâmes des donleurs atroces. Un officier de la corvette la Coquille, M. de Blois de la Calande, eut des accidents assez formidables après avoir saisi une physale. Le remède le plus actif à employer aussitôt l'urtication, $110 u$ s a paru être l'ammoniaque liquide un peu étendue d'eau, ou une solution d'acétate de plomb.

"La vessie de mer, dit le P. Feuillée, cité par Chanvallon (Voy. à la Martinique, in- $4^{\circ}$, p. 107, 1763), moccasionna, en la touchant, des douleurs si vives que jen eus des convulsions par tout le corps. »

Nous extrairons d'un mémoire de M. Ricord-Madiana, médecin à la Guadeloupe, sur les propriétés toxiques de la physale, une série de citations importantes et de faits curieux, moins connus qu'ils ne mériteraient de l'ètre.

Oı lit dans Dutertre (Voy. aux Antilles):

"Un jour que je gouvernais un petit canot, ayant aperçu en mer une de ces galères, je fus curieux de voir la forme de cet animal, et je recherchai attentivement si j'y pourrais rencontrer quelque chose de remarquable; mais je ne l'eus pas plutôt pris, que tous ses fibres m'engluèrent la main, et à peine en eus-je senti la fraicheur (car elles sont froides au toucher), qu'il me sembla avoir plongé mon bras, jusqu'i l'épaule, dans une chaudière d'huile bouillante, et. cela avec de si étranges douleurs, que quelque violence que je pusse faire pour me contenir, de peur qu'on ne se moquast de moy, je ne pus ní empècher de crier par plusicurs fois à pleine teste: Miséricorde, mon Dieu, je brusle! je brusle! De bonne fortune pour moi, cela n'arriva à deux lieures après midy; car sil arrive que l'on 
tombe dans cet accident au matin, la douleur croist toujours jusquà midy; et diminue à mesure que le soleil décline, et le soleil se cachant sous l'horizon, l'on est entièrement guéri. ”

Leblond (Voyage aux Antilles, t. I, p. 350), donne une figure de physale et dit:

" Un jour je me baignais avec quelques amis dans une grande anse, devant l'habitation où je demeurais; pendant qu'on pêchait de la sardine pour le déjeuner, je mnamusais à plonger, à la manière des Caraibes, dans la lame prête à se déployer; parvenu de l'autre côté, je gagnais au large et revenais sur une autre vague, m'échouer sur le rivage. Cette prouesse, que les autres ne s'avisaient pas de tenter, faillit me coûter la vie. Une galère, dont plusieurs s'étaient échonées sur le sable, se fixa sur mon épaule gauche, au moment oú la lame me rapportait à terre : je la détachai prompiement; mais plusieurs de ses filamcnts restèrent collés à ma peau jusqu'au bras; bientôt je sentis à l'aisselle une douleur si vive que, prêt à m'évanouir, je saisis un flacon d'huile qui était là et j’en avalai la moitié, pendant qu'on me frottait avec l'autre; mais la douleur s'étendant au cocur j’eus un évanouissement. Revenu à moi, je me sentis assez bien pour retourner à la maison, où deux heures de repos me rétablirent, à la cuisson près, qui se dissipa dans la nuit. ”

On lit dans la narration du naufrage de la Méduse, par Savigny, "qu'une espèce de mollusque, connu à bord des vaisseaux sous le non de galère, était quelquefois poussée sur le radeau en très-grand nombre, et lorsque leurs longues expansions se reposaient sur des membres dépouillés, elles occasionnaient les souffrances les plus cruelles. »

Beancoup d'habitants des Antilles, et plusieurś des médecins qui les habitent, disent que les galères sont un poison violent, et que les nègres s'en servent, après les avoir fait sécher et pulvérisées, pour empoisonner les hommes et les bestiaux. Les 
pêcheurs des îles croient aussi que lorsque les poissons avalent des galères, ils deviennent délétères et empoisonnent ceux qui les mangent. Ce préjugé a été adopté par beaucoup de voyageurs, et a même trouvé place dans un grand nombre de livres scientifiques. Nous allons voir, par l'expérience, que la galère peut bien brûler la main ignorante qui touche ses tentacules, mais que lorsqu'elle est séchée et pulvérisée au soleil, ce n'est plus quiune substance inerte qui ne produit aucun effet sur l'économie animale. Voici cependant ce qu'on lit dans les ouvrages des voyageurs les plus célèbres : "Il ze fant pas manger la bécune sans précaution, ditle P. Labat (vol. 2, p. 3 I), car ce poisson est sujet à s'empoisonner et à empoisonner ceux qui le mangent quand il est dans cet état. Comme il est extrêmement vorace, il dévore goulument tout ce qui se présente dedans et dessus l'eau, et il arrive très-souvent qu’il s'y rencontre des galères ou des pommes de mancenillicr, qui sont des poisons très-violents et très-canstiques. La bécune n'en meurt pas, quoiqu'elle en ingère; mais sa chair contracte le venin, et fait monrir ceux qui la mangent, comme s'ils avaient avalé de ces méchantes pommes ou des galères.»

"Il y a tout lieu de croire, dit M. Leblond (ouvrage cité), que la sardine, après avoir mangé des filaments ou tentacules de galères, acquiert une qualité vénéneuse, ainsi que plusienrs autres espèces de poissons. Me trouvant à souper, continuet-il, dans une auberge avec d'autres personnes, on servit une bécune, dont les gastronomes sont très-friands, et qui d'ordinaire ne fait aucun mal; cinq en mangèrent, et ćprouvèrent bientôt après des symptômes dé poison qui sc manifestèrent par une chaleur brûlante à la région de l'estomac. J'en saignai deux : l'un fut guéri par le vomissement, l'autre ne voulut rien prendre que du thé et quelques cuillerées d'huilc. La colique dura toute la nuit, s'apaisa le matin; mais il lui resta une horreur de l'eau, 
telle qu'en la voyant seulement dans un verre, il en pâlissait comme quelqu'un prêt à se trouver mal. Cette incommodité se dissipa d'elle-même. " Et M. Leblond conclut de ce fait que les poissons qui mangent des galères deviennent un poison pour ceux qui s'en nourrissent; et cependant rien n'avait prouvé à M. Leblond que cette bécune eût mangédes galères ou toute autre substance réputée vénéneuse. Mais les livres scientifiques, dont un bon nombre ne sont que des échos, répètent aussi tout ce qui a été publié de vrai ou de fanx par les voyageurs ' qui, la plupart, n’ont fait que répéter, à leur tour, ce qu'on leur avait raconté dans les pays qu'ils avaient visités.

Écoutons celui-ci : «Je ne vois pas pourquoi on veut élever des doutes sur la possibilité de l'empoisonnement des poissons dans lạ mer des Indes par la coralina opuntia, le fruit du mancenillier, les méduses et les holothuries, dont malheureusement plusieurs poissons sont friands. Remarquons, à l'occasion de I'holothurie ou galère, qu'elle a de tout temps passé pour vénéneuse, et quil est rapporté par plusieurs voyageurs que quelques Espagnols d'Amérique la font sécher et la mettent en poudre pour s'en servir comme d'un poison actif mêlé avec du chocolat." (Dict. des Sciences médicales, art. Toxicologie, vol. 55, p. 434, par le docteur Fodéré.) Mais il en est du Dic-

I A Carthagène dans l'Amérique espagnolc, le botaniste danois Van-Rohr', qui avait résidé quelque temps dans cette ville, assurait (dit le docteur Chisholm), dans une communication faite à son ami, M. John Ryan-de-Sainte-Croix, que les Espagnols faisaient nsage de la galère (Holothuria physalis) conme d'un poison. Pour cet effet l'animal est desséché et rérluit cn poudre très-fine, qu'ils mettent dans lc chocolat de la victime qu'ils venlent empoisonncr, ce qui la fait périr infailliblement. Il cst de coutume dans cette partie de l'Amérique du sud, de prendre une tasse de chocolat tous les matins, et lorsque l'on soupçonne qu'une persomne a été empoisonnée, ou dit proverbialement qu'elle a eu sa galère ce matin-là. Ce qui est très-probable, ajoute le docteur Chisholn, et il fait remarqucr que cette infàmc coutume a été propagée par les Espagnols d'Europe eux-mêmes. (Chisholm, on the poison of fish, p. 406.) 
tionnaire des Sciences médicales comme de tous les grands ouvrages scientifiques rédigés par plusieurs savants, on y trouve du vrai et du faux. Voyons encore ee qu'un collaborateur du même Dietionnaire, mieux informé sur cette matière que le doeteur Fodéré, nous dit relativement à la gálère, puis rapportons nos expéricnces. "Si l'on ajoute foi à l'assertion de eertains marins, les méduses brûlantes peuvent servir d'aliment aux liommes, qui, dans plusieurs occasions, les ont appropriées à leur nourriture sans en éprouver aucune incomnodité. Ce fait semble prouver que ees animaux, malgré les fâcheux effets de leur eontaet; n'exereent point leur action délétère lorsquion les a préparés par la coction. Comment done deviendraient-ils l'origine du principe empoisonné des poissons?" (Dict. des Sciences médicales, t. 43, p. 67o, par Hipp. Cloquet. )

"Première remarque. J'avais mis une galère au soleil pour la faire sécher et la pulvériser. Les fourmis s'y mirent et la dévorèrent en entier. Beaucoup de personnes, dans les îles, pensent que ces insectes ne touchent pas aux poissons vénéneux.”

"Deuxième remarque. Une autre galère, que j’avais laissée sur une table dans mon laboratoire, fut assaillie par un nombre de grosses mouches qui y déposèrent leurs oenfs, d'où les vers ćelorent et se nourrirent du zoophyte pourri. ”

"Première expérience. Le 12 juillet 1823 , me trouvant à la Guadeloupe, sur le bord de la mer, dans une anse entre SainteMarie et la Goyave, je.vis beaueoup de galères, réeemment échouées sur le sahle. Ayant avec moi un chien, comme cela m’arrive souvent pour mes expériences, je lui fis tenir la gueule ouverte par mon domestique, et j’y introduisis, avee un petit bâton, la galère la plus fraiche parmi eelles qui se trouvaient auprès de moi, avec toutes ses tentacules filiformes qu'il avala, non sans quelques difficultés. Cing minutes après, il 
sembla éprouver une vive douleur sur le bord des lèvres et à la gueule; il bavait et se frottait cette partie dans lc sable, sur les herbes, en faisant des sauts à droite et à gauche; passant sans cesse ses pattes sur sa gueule, ou il ressentait certainement une vive douleur. Je remontai à cheval, et, malgré sa souffrance, le pauvre animal continua de me suivre; après vingt minutes de marche, il sembla ne presque plus rien souffrir. J'avais un morceau de pain que je lui donnai, et il le mangea avec appétit, sans qu’il parût avoir aucune difficulté pour avaler. Son mal n'avait eu lieu que sur les bords de la gueule. Il fut bien toute la journée, n'ayant eu aucune évacuation extraordinaire qui pût indiquer que l'ingestion de cette galère avait eu quelque action sur les organes de la digestion. Le lendemain et les jours suivants, l'animal était aussi bien portant que de coutume, sans qu'il parût aucune trace d'inflammation, ni dans la gorge ni dans la gueule.»

"Deuxième expérience. Le 20 du même mois, je pris deux galères sur le bord de la mer, je les coupai en morceaux; puis, avec une cuiller, je les fis avaler à un très-jeune chien qui tétait encore sa mère, et cette forte dose de galère n'eut aucun effet sur lui, les tentacules ayant probablement été enveloppées avec le corps de la galère en la coupant en morceaux, ne lui touchèrent point la gueule, ce qui fit qu'il n'y éprouva aucune douleur. Ne serait-il pas possible que les muqueuses intcrnes supportassent l'application de certaines substances caustiques sans éprouver le même degré d'irritation que ces membranes exposées à l'air ressentent lorsqu'on leur applique ce même caustique?"

"On avale quelque chose à un degré de chaleur qu'on ne pourrait supporter dans la bouchê si l'objet brûlant y restait. »

"Troisième expérience. Je me suis procuré plusieurs galères, puis les ayant placées sur un carreau de vitre, je les ai fait sé- 
cher et les ai pulvérisées. Vingt-cinq grains de cette poudre, administrés à un très-jeune chien, nont produit aucun effet délétère. Deux fois cette quantité, administrée à un jeunechat, n'a rieu produit non plus. Et cela ne m'a point surpris; car, puisque la galère fraîche n'empoisonne point, comment pourrait-on supposer que la dessiccation de ce zoophyte pût augmenter ses qualités vénéneuses, sil en avait réellement? bien au contraire, il est plutôt raisonnable de croire que, par sa dessiccation, le principe délétère provenant de n'importe quel animal, tout comme des holothuries ou galères, doit perdre infiniment de son activité par l'évaporation et les autres changements que l'air et la chaleur produisent avant qu'il soit entièrement desséché.»

"Quatrième expérience. Je coupai une galère en morceaux, et je les fis avaler à un jeune poulet gras. Il n'en fut uullement incommodé. Trois heures après, je le fis tuer et rôtir; puis je le mangeai et en fis manger à mon domestique, ce qui ne nous fit mal ni à l'un ni à l'autre: prenve bien certaine que ce n'est. point pour avoir mangé des galères que les poissons deviennent vénéneux ; car si c'était ainsi, le poulet nous aurait bien certainement empoisonnés. »

"Cinquième expérience. Je mis vingt-cinq grains de galère pulvérisée dans un peu de bouillon; javalai cette dose sans la moindre crainte, et je n'en fus nullement incommodé.»

“D'après ces expériences, qui bien certainement sont concluantes, que penser de l'histoire qu'on rapporte à la Guadeloupe, d'un monsieur Tébé, gérant de l'habitation de M. B., dans le quartier du Lamantin, lequel fut la victime de son cuisinier, qui, dit-on, après avoir cherché en vain à l'empoisonner avec un peu de râpure de ses ongles qu'il avait soin de répandre sur le poisson rôti qu'il lui servait tous les jours à son dimer, se décida, voyant qu'il ne réussissait pas par ce moyen, 
à mettre dans sa soupe une galère pulvérisée? Une heure après son repas, ce monsieur se rendit au bourg du Lamantin, à une petite distance de son habitation, et là, en entrant chez un de ses amis, il fut saisi de douleurs atroces dans l'estomac et dans les intestins, qui le rongeaient comme aurait pu le faire le poison le plus corrosif. Le mal alla en augmentant de plus en plus jusqu'au lendemain matin qu'il mourut dans les tourments les plus affreux. A l'examen de son cadavre, on trouva l'estomac et les intestins enflammés et corrodés, comme s'il eût été empoisonné avec de l'arsenic, et je n'ai presque aucun doute que ce fut avec cette substance, ou avec tout autre poison corrosif, que le cuisinier de M. Tébé commit ce crime. Ce malfaiteur, pour ne point faire connaître le poison dont il s'était servi, voulut laisser croire à ceux qui l'accusèrent et le firent brûler vivant que c'était avec une galère pulvérisée qu'il avait empoisonné son maître. "

"Les nègres ne font jamais connaitre la substance dont ils se sont servis pour commettre un empoisonnement; ils avoueront tout ce qu'on voudra leur faire avouer, excepté la vérité, qu’ils ont juré de ne jamais faire connaitre sur l'article des empoisomnements. »

Tels sont les faits les plus avérés de l'action vénéneuse des physales. Nous les croyons bien propres à servir de point de départ pour une nouvelle étude des propriétés fort remarquables de ces zoophytes douteux, ou plutôt de ces mollusques tronqués, sortes de céphalopodes retournés. Cette dernière opinion peut sembler hypothétique à quelques savants, et cependant nous ne pouvons nous dispenser de reconnaître qu’il y a peut-être plus de ressemblance qu'on ne le croit entre un poulpe et une physale, ou, pour parler plus correctement, que la physale n'est qu'une répétition obscure et incomplète des anomalies d'un poulpe, l'un et l'autre placés 
à de grandes distances dans une même série d'organisation. Un céphalopode commencerait une chaine d'animaux dont la physale serait le dernier anneau, mais un anneau qui se lierait au premier. Peut-être serons-nous un jour en position dẹ revenir sur ce sujet très-intéressant et de l'appuyer par des aperçus détaillés.

Les physales se réunissent pour former des essaims dont les habitudes sont encore inconnues. Sur la surface unie de la mer, par les beaux jours de calme, entre les tropiques, soit dans l'océan Atlantique, soit dans la mer Pacifique, on les voit entraînées par les courants ou poussées par les vents alisés, trainant derrière elles leurs longs tentacules détendus. Mais c'est une erreur d'admettre qu'elles n'apparaissent que par les beaux temps; fréquemment nous en observâmes que chaviraient les vagues heurtées et qui résistaient à une très-grosse mer. Les marins croient que la crête mince qui surmonte le corps vésiculeux fait foffice, chez les physales, de voiles latines, et que ces animaux s'en servent 'pour serrer le vent, et, ainsi qu'ils le disent, naviguer au plus près. C'est, comme on le voit, ajouter une explication un peu forcée à la théorie des causes finales.

Souvent dans notre longue navigation les physales vinrent récréer nos regards errants sur la surface de la mer. Ces animaux nous offrirent toujours un problème que notre intelligence n’a pu résoudre; ils cheminent parćs des plus riches couleurs; la partie vésiculeuse et la crête rémplies d'air sont d'un blanc nacré argentin auquel s'unissent les teintes les mieux fondues de bleu, de violet et de pourpre. Un carmin vif colore le bouillomnement du biseau de la crête, et le bleu d'outremer le plus suave teint les trois sortes de tentacules dont nous avons parlé. Certes nous concevons qu'une imagination poétique ait pu comparer les formes sveltes d'une physale au vaisseau le 
plus fin voilier, et que pour elle sa vessie ait été une carène gracieuse présentant aux vents une voile de satin, et laissant trainer derrière elle des guirlandes trompeuses frappant de mort l'être qui se serait laissé entrainer à leur séduction.

La manière dont se nourrissent les physales est très-remarquable. Nous avons observé mainte et mainte fois les faits dont nous allons parler. Les longs tentacules qui laissent suinter une humeur vénéneuse deviẹnnent, par leur relâchement et lorsque le zoophyte les abandonne vaguement derrière lui, des sortes de conducteurs nerveux. Les poissons qui nagent avec imprévoyance viennent-ils à les heurter, chaque tentacule, par un mouvement aussi rapide 'que l'éclair, aussi brusque qu'une décharge électrique, les frappe de stupeur par la matière vénéneuse qu'il recèle, et se roule sur eux en s'y attachant de manière à comprimer leur enveloppe aussi instantanément et plus vivement centfois que ne le fait un serpent qui entortille sa victime. Souvent une physale à peine grosse comme une noix tue un poisson beaucoup plus fort qu'un hareng; mais ce sont principalement les poissons volants qui deviennent leur proie journalière, conjointement avec les poulpes. L'animal ne se débattant plus entre les tentacules qui le serrent est alors ramené, par la contraction puissante de ceux-ci, au niveau des bouches absorbantes. Là, toutes les ventouses dont nous avons parlé s'appliquent sur les chairs, s'y incrustent, et par un mode de succion qui leur est spécial, décomposent ces mêmes chairs, les transforment en une bouillie liquide, s'en gorgent jusqu'au point d'en acquérir une distension énorme, et versent ensuite cette sorte de chyme dans le réservoir commun de lappareil digestif. C'est ce chyme que nous avons vu affecter la couleur et l'aspect de la lie de vin, qui est transporté dans le canal central qu'on suit au milieu et entre les deux membranes de la vessie, et qui s'abouche à des tubes latéraux d'anastomose. 
Il n'est pas aisé de se rendre compte des procédés par lesquels une physale remplit d'air la capacité de sa portion vésiculeuse: Seulement nous savons, à ne pouvoir en douter, qu'au moment où ce zoophyte veut chasser l'air qui le fait surnager, il obtient ce résultat par la grande contractilité des parois musculaires de sa vessie dont les fibres concentriques, en opérant un mouvement de pression d'arrière en avant, forcent la soupape antérieure à s'ouvrir; c'est alors que la crête ramenée jusque sur la vessie semble annulée, et c'est dans cet état que les marins disent que la physale a serré sa voile.

La patrie des physales n'est point aisée à circonscrire. Trèsabondantes entre les tropiques, elles sont parfois tout aussi communcs dans les zones tempérées de l'un et l'autre hémisphère; ce n'est toutefois qu'accidentellement qu'on les voit perdues ou égarées par les hautes latitudes. Ces zoophytes sont essentiellement de haute mer, et lorsqu'ils se rapprochent des terres, c'est quils y sont portés par les courants, et surtout par la persistance de certains vents. C'est ainsi qu'à la suite des tempètes d'automne dans le golfe de Gascogne, on en voit de gisants sur les côtes de France. C'cst dans l'hivernage qu'ils jonchent les sables des Antilles ct qu’ils périssent, abandonnés quils sont, par les flóts qui les ont vomis sur la grève.

On ne peut se dispenser d'admettre plusieurs espèces de physales. Les quatre que nous avons figurées se sont offertes à nous constamment revêtues des mêmes attributs, toujours isolées entre elles, c'est-à-dire n'habitant que des parages donnés; et cependant, bien que nous ayons vu des milliers d'individus de chacune d'elles, on ne peut se servir pour les spécificr de caractères précis, de phrases qui peignent avec exactitude leurs dissemblances. 
16. PHYSALIE DE L'A'TLANTIDE.

Physalia atlantica, Less.

$$
\text { (pl. IV, 3/4 g. n.) }
$$

Cette physale est évidemment la physalia arethusa de Chamisso, pl. 1 du Voy. pittoresque de Choris. C'est très-certainement aussi la physalia caravella de la planche 14, fig. 1, d'Eschscholtz. II parait què cette espèce doit réunir les synonymes suivants: Physalia pelagica, Lamck., t. 2, p. 480; physalis arethusa, Tilésius, $9^{1}$; urtica marina, Hans Sloane, Jam. t. 1 , pl. 4, f. 5 ; arethusa, Brown, Jam. p. 386; medusa caravella, Gm.; holothuria physalis, L., Am. ac., pl. 3, f. 6, t. IV, p. 254. C'est la medusa caravella, Muller, pl. 9, f. 2 ; la thalia de Brug. ,.pl. 89 de l'Encyclopédie.

Cette physale se distingue de toutes les espèces du genre par des caractères zoologyiques très-précis. Elle est la seule qui n'ait point d'extrémité postérieure garnie de verrues charnues; elle est aussi la seule qui ait sous le corps plusieurs tentacules à glandes vénénifères. Sa taille, et quelques autres particularités, la distinguent aussi facilement dès la première vue.

La physale de l'Atlantide a son corps charnu, solide; la bouche subcentrale entourée d'épais mamelons denses et comme cartilagineux. I a vessie est cylindrique, assez régulière, plus dilatée à son milieu, atténuée et arrondie à ses deux extrémités. La postérieure est courte et mamelonnée. L'antérieure est amincie, allongée. Cette vessie a jusqu'à I I ou 12 pouces de longueur sur 2 à 3 pouces de largeur. Son aspect est vitré, transparent. Sa coloration est celle d'un pourpre dégradé passant au riche violet, puis à l'azur en dessous. La crête qui surmonte la vessie est verticale, haute de 12 à 20 lignes, et 
s'arrête à un pouce de l'extrémité postérieure, et à dix-huit lignes ou 2 pouces de l'extrémité antérieure. La'largeur de sa base est d'un pouce, et son sommet est en biseau mince, coloré en rouge très-vif. Cette crête est brillante et limpide comme le cristal, et seulement les rainures droites qui la sectionnent sont colorées en pourpre rutilant, en violet dégradé, et en azur-elair. Les gros mamelons du corps sont d'un bleu glauque tirant au vert-bleu, tandis que tous les tentaeules sont d'un bleu-eéleste de la plus grande beauté. Les tentacules à cils sont transparents, eeux à godets sont bleu-pâle; mais les glandes vénéneuses qui en occupent la frange sont d'un bleu-indigo foncé.

Les tentaeules stomaeaux sont longs d'un pouce, tandis que eeux que nous soupegonnons être affectés à la respiration, au nombre de 3o à 40 , sont fragiles, délicats, eapillacés et longs de plusieurs pieds. Quant aux grands tentaeules, ils sont au nombre de 20 , et acquièrent en longueur de io à 30 pieds. Un peu plus larges et plus solides à leur point d'attache, ils diminuent graduellement et finissent en pointe déliée. En se raccoureissant par la eontraction, ces tentacules ressemblent à une corde qui serait garnie de nouds à se toucher, nouds que simulent les rosettes en spirale des glandes vénénifères formant alors des cereles pressés. Le sue que distillent ces glandes est très-âcre, et se dissout eomplétement dans l'eau, qu'il eolore en bleu d'outremer, et qu'il rend vénéneuse. Alors il laisse exhaler une odeur très-désagréable, et si on y verse un acide, il passe instantanément au rouge comme la teinture de tournesol.

Cette physale se nourrit de poissons tels que scombres, naquereaux et exocets: Ses ventouses stomacales agissent sur les chairs que leur bouche presse eomme celle des sangsues quand elles font le vide pour tirer du sang. La matière vénéneuse 
des grands tentacules agit en frappant de stupeur l'animal, et aussi très-probablement pour en dissoudre les parties solides, à la manière du venin des serpents.

La physale de l'Atlantide habite exclusivement l'Océan atlantique entre les tropiques qu'elle ne franchit qu'accidentellement. C'est par troupes considérables que nous la rencontrâmes en septembre $8_{2} 3$, par les 7 degrés de lat. N., et par les 23 de long. occidentale.

i7. PHYSALIE DE L'OCÉAN PACIFIQUE AUSTRAL.

Physalia australis, Less. '.

$$
\text { (Pl. V, fig. I, } 2 / 3 \text { g. n.) }
$$

Cette physalie, ainsi que toutes les autres espèces qui vont suivre, est caractérisée par de petits appendices charnus, ventrus, placés en dessous de l'une des extrémités, distinct's des suçoirs et des tentacules réunis en un faisceau sous le disque du corps.

La physalia australis est bien caractérisée, comme espèce. Primitivement décrite par Péron, pl. 59, fig. 1, de l'atlas du Voyage aux terres australes, sous le nom de physalis megalista, on a eu tort de la confondre avec la physale d'Osbeck de Tilésius, qui nous parait être celle que nous décrivons sous le nom de physalie de l'Océan atlantique austral.

La physalia australis est reconnaissable à son tentacule glanduleux et vénénifère presque cylindrique, unique, attaché à une poche hépatique centrale, ample et très-développée. La forme de sa vessie est cylindrique, atténuée et conme pointue

I L'Urtica marina soluta, oblonga, cirrhis longissimis, ou $A$. caravella, de Hans Sloane, Lond., 1707 , Jamaica, fig. 5, pag. 7, qu'on retrouve dans Brown pl. 48, fig. 1, est bien l'espèce précédente. 
aux deux extrémités. La postérieure est mamelonnée, courte, garnie en dessous de deux rangées de petits corps charuus, cylindriques, perforés, et pouvant servir de sucoirs. Les bouches stomacales sont allongées, peu amples, cylindriques, et entourent en un seul paquet le vaisseau central du foie. La vessie est surmontée d'une crête droite, peu large, occupant toute la longueur de sa partie renflée et dilatée, et légèrement colorée en bleu aigue-marine. Le bouillonnement lui-même est azuré. La vessie est légèrement irisée, et bleu-azuré, mais teintée de rose en dessous aux deux extrémités. Ies tentacules stomacaux sont bleu aigue-marine avec la bouche jaunâtre-fauve. Le foie est vert glauque-intense ainsi que le grand tentacule et les glandes dont la teinte est moins foncée. Les conduits monoliformes ou aériens sont ell petit nombre, très-grêles, et très-courts.

Cette physalie a au plus 4 pouces de longueur sur 15 à 18 lignes de diamètre.

Nous la rencontrâmes sur les côtes de la Nouvelle-Galles du Sud, au moment d'eutrer dans le vaste port Jackson. Nous n'en vimes qu'un petit nombre d'individus.

18. PHYSALIE DE L'OCÉAN ATLANTIQUE AUSTRAL.

Plysalia antarctica, Liess.

$$
\text { (Pl. V, fig. 2, g. n.) }
$$

Cette pliysalie nous parait être celle figurée par La Martinière, ( I'oj. de La Pérouse, pl. 20, fig. i 3 et I 4 ), et la même que représente le colonel Bory de Saint-Vincent, atlas, pl. 54, fig. 5. Ce serait alors la physalis Lamartinieri, de Tilésius, la physalia utriculus, d'Eschscholtz. La figure que nous donnons de cette espèce a été copiée par M. Vauthier pour l'atlas du Dict. classiq. d'hist. nat., livraison 15, et on a conservé le nom de physalis cystisoma qu'elle portait écrit au crayon. 
Cette espèce a au plus 2 pouces 6 lignes de longueur totale. Elle est subovalaire, également arrondie partout, et atténuée aux deux extrémités en deux cônes cylindriques raccourcis. L'extrémité antérieure plus mince est garnie en dessous d'un paquet de suçoirs assez courts, gros, bleus et repliés sur euxmêmes. La crête qui surmonte la vessie est médiocre; toutes les deux sont d'un blanc nacré très-brillant, à peine teinté de vert-bleu glaucescent sur les cloisons et les parties saillantes des extrémités. Le foie allongé et pyriforme, ne se divise point. Il donne naissance à un long et unique tentacule bleu à glandes vénénifères, entouré au plus de 4 tentacules à cils vibratoires, tous quatre de médiocre longueur et d'un bleu clair. Les sacs stomacaux de forme allongée, sont colorés en rose pâle, ponctués de rose foncé, teintés de bleuâtre au rétrécissement de leur extrémité qui porte la bouche. Celle-ci et son rebord sont colorés en jaune pur. A la base des tentacules nait une rangée d'appendices simples, courts, analogues à ceux des vélelles, et d'un beau bleu d'outremer.

Nous rencontrâmes un grand nombre d'individus de cette espèce par une belle mer, dans l'Océan atlantique méridional.

Elle se présenta à nos regards par le $\mathrm{I}^{\text {er }}$ degré de lat. sud et les 25 degrés dế long. occidentale, sans cesser chaque jour de se montrer jusque par les 35 à 38 degrés de latitude australe, après que nous eûmes doublé le cap de Bonne-Espérance.

\section{ig. PHYSAlie TUBERCULEUSE.}

Physalia tuberculosa, Lамк.

$$
\text { (Pl. V., fig. 3, g. n.) }
$$

La physalie tuberculeuse primitivement décrite par James Forbes (Mém. Or.), n'existe point, dit M. de Chamisso, ou est 
ZOOLOGIE.

confondue avec les espèces que cet auteur a décrites ${ }^{\mathbf{}}$. Nous ne doutons pas qu'elle ne soit distincte.

La physalia tuberculosa se rapproche de l'espèce précédente. Elle en diffère en ce qu'elle est plus grêle, trigone en arrière, à parois très-minces, d'un blanc nacré translucide, à crête médiocre et courte. Le côté gauche de cette physale se renfle

' MM. de Chamisso et Eysenhardt ont adopté dans le genre physale les espèccs suivantes. ( $D c$ animalibus quibustam, etc., Nov. act.phys. med.ac. Coe. Leop. nat. cur., tom. X, I82 I, 343.)

I. Physalia arcthusa, Tilés., Cham., pı. 35, figs. 1.

Vcsica integra; brachia basi ramosa, æqualia, omnia approximata, appendicibus genitaïbus instructa.

Physalia arethusa et physalia glauca, Tilésius, fig.

Pliysalia pelagica, Lamk., An. sans vertèb.

Holothuria physalia, L., Blum.

Medlusa caravella, Müllcr, Beschãft. d. Bcrl. natur forsch. ges. II, avec fig.

2. Physal in Lamartinierii, Tilés.

Vcsica integra ; brachia basi sinplicia(?) eorumque alterum cæteris majus, omnia approximata, appendicibus genitalibus instructa.

Physalia Lamartinierii, Tilésius, avcc fig. copiée dc celle de La Pérouse, atl.

Physalia pelagica, Bory St-Vincent, fig. atlas.

Physalia, La Pérouse, atlas fig.

Medusa utriculus, Lamk., Journ. physiq., I 787 , tom. 2 (d'après Tilésius.)

3. Physalia Osbeckii, Tilés.

Vesica appendiculata; brachia basi simplicia (?) eorumque altcrum cæteris majus, omnia approximata, appendicibus genitalibus instructa.

Phrsaliz cornuta, afra et Osbeckii, Tilésius, avcc fig.

Physalia megalista, Péron, atlas pl.

Holothuria phrsalis, Osbeck, Voy. en Chine, avec fig.

Doit-cllc étrc róunic à la précédentc?

4. Physalia pelagica, Bosc, Cham., pl. 35, fig. 2.

vesica integra; brachia basi simplicia; in acervos duos disposita (deux paquets) : in acervo altcro omnia appendicibus genitalibus instructa, brachiumque unum vel duo cæteris majora; in acervo altcro appcndices genitales desunt.

Physalia pelagica, Bosc, fig.; Tilésius, fig.

Physalia tuberculosa, Lumk., An. sans vertèb.

Arellusa caravella, Oken's zoologie.

Voyage de la Coquille. - Z. Tom. II, Part. II. ${ }_{2}{ }^{e}$ Div. 
en un gros mamelon conique d'où partent les tentacules, et sous lequel est le corps. Le côté droit forme aussi un cône, mais moins considérable, bien que recouvert de deux petites rangées de tentacules azurés, très-courts et vermiculés.

Le foie simule une poche peu développée, d'où part un seul tentacule vénénifère, très-grêle et cepeadant long de cinq pieds. Les sacs stomacaux entourés de tentacules simples et renflés à leur naissance, sont médiocres, courts et d'un blanc rose trèspâle. Les tentacules ciliaires sont au nombre de 4 et petits.

Nous rencontrâmes des troupes de quelques centaines d'individus de cette espèce le $\mathbf{I}_{2}$ octobre $\mathbf{1} 822$, alors que la corvette la Coquille se trouvait par les 27 degrés de lat. sud et longeait la côte d'Amérique. Tous se ressemblaient. Il est possible cependant que cette physalie ne soit qu'une variété de l'antarctica, bien que plusieurs motifs nous portent à l'en distinguer.

Le liquide vénéneux sécrété par le tentacule central avait peu d'énergie. Appliqué sur la peau, il occasionnait à peine un léger prurit, mais il n'en était pas de même lorsqu'on s'en frottait la muqueuse de la bouche et des yeux, il faisait alors naître des phlyctènes. Ce peu d'énergie tient à deux causes, la première est la petite taille de l'espèce, et l'autre les zones plus refroidies qu'elle habite.

20. PHYSALIE DES AÇORES.

Physalia azoricum, Less.

$$
\text { (PI. V, fig. } 4 \text {, g. n.) }
$$

Cette physalie est-elle la trigona de Lamarck? Il est au reste certain que c'est la plysalia utriculus d'Eschscholtz (pl. IV, fig. 3, mais non la fig. 2), mais surtout la physalia pelagica de Bosc (Vers, pl. I6, fig. I et 2), et sans aucun doute la physalia 
pelagica de Chamisso, pl. 35, fig. 2 de son Mémoire de animalibus, etc. (Act. de Bonn, X, $182 \mathrm{I}$ ).

Cette très-petite pliysale a sa partie vésiculeuse légèrement renflée au milieu, à parois minces, d'un blanc très-argenté. En avant la vessie finit en un petit cône pointu. En arrière elle forme deux renflements tuberculeux, partant du corps atténué. et divisé lui-même en deux faisceaux à peine distincts. La crète qui surmonte la vessie est convexe, très-courte et d'un blanc nacré. Le foie est placé au-dessous du lobe gauche de la vessie: il constitue un sac allongé, coloré en vert-noirâtre. Le tentacule qu’il supporte, a jusqu’à i pied de longueur, lors même qu'il est tortillé en replis serrés. 4. tentacules à cils l'entourent, 2 très-courts, grêles, monoliformes, et 2 presque aussi longs que lui, en spirale. Les sacs stomacaux sont peu nombreux, médiocres, placés sous le tuberculè droit, et entourés à leur base de tentacules simples, filiformes, d'un bel outre-mer. Ces sacs sont bleus nuancés de rose, et sillonnés de petits vaisseaux anastomosés. Ils se terminent par des godets jaunes.

Nous primes un très-grand rombre d'individus de cette physale, le 4 sept. I 822 , par les $26^{\circ}$ de lat. nord et les $20^{\circ}$ de longitude occidentale, au milieu des îles Canaries, et en quittant celle de Ténériffe. Depuis en revenant en Europe après notre circumnavigation, nous en trouvâmes la mer couverte dans les parages des Açores. Ce serait donc une espèce des latitudes tempérées de l'hémisphère boréal. Sa taille varie de 12 à 18 lignes au plus.

DESCRIPTION DE IA FAMHLE DES PHYSSOPHORES.

Cette famille, très-voisine de celles des physales, renferme aujourd'hui quelques petits groupes proposés dans ces dernières 
années: elle semble faire le passage des vraies physalies aux autres genres de la classe des acalèphes.

Le type de cette famille, le genre physsophore, physsophora, établi par Forskahl, doit avoir pour caractères lcs suivants: Corps musculeux (pl.XVI), disposé cn cercle, supportant tout à l'entour de l'espèce de couronne qu'il simule, 'un grand nombre de sacs stomacaux, arrondis, tubuleux, ventrus au milieu, atténués à leur extrémité qui est renflée et perforée au centre; ces sacs sont dilatablcs, élastiques et intimement soudés au rebord du corps (fig. A), au-dessus d'unc rangée régulière, et formant aussi couronne, de tentacules courts, arrondis, très-irritables, et qui paraissent avoir pour but de s'opposer à l'introduction des corps étrangers sous le disque central où aboutit un canal (fig. B). Le corps charnu est surmonté à son milieu par une tige membraneuse, cylindrique, renflée en haut, perforéc d'un trou au sommet; trou qui conduit à la séreuse qui double la dilatation ou le renflement, et qui se remplit d'air par l'ouverture médiane du corps, ou le chasse par cette issue, de la même manière qu'on l'observe chez les physales. Sur la tige vésiculeuse s'insèrent de chaque côtć, et en s'opposant, trois très-courts pédoncules supportant trois paires de vessies latérales à trois lobes chacune; les deux latéraux arrondis, aveugles; le moyen tronqué en avant, ouvert circulairement; mais à demi fermé par une soupape membraneuse (fig. C).

Dans la figure gravée dans l'atlas de Péron (pl. 59, fig. 4), de la physsophora muzonema, on observe une grande quantité de productions cirrhiformes très-diverses qui manquaient aux individus que nous avons étudiés. Ces appareils tentaculiformes, ces linéaments, appartiennent-ils aux organes générateurs? 
2. PHYSSOPHORE DISTIQUE.

Physsophora disticha, Less.

$$
\text { (Pl. XVI, fig. 3, g. n.) }
$$

Le portrait de la plysssophora muzonema de Lesueur donne une idée très-médiocre de ce zoophyte. La figure que nous publions de la $p h$. disticha a été faite d'après plusieurs individus, et nous pouvons répondre de son exactitude. Il nous sera moins aisé toutefois d'assurer que l'animal était bien complet; car ses diverses parties se désagrègent avec une facilité extrême, et notre espèce n'avait aucun des organes accessoires qu'on remarque à celle décrite par Péron.

La physsophore distique est frêle, délicate, d'une absolue diaphanéité, comme nuageuse dans l'eau, se décomposant avec la plus grande facilité. Le corps musculeux buccal circulaire soutenant les sacs stomacaux, est d'un rose-foncé, ainsi que les sacs dont le sommet est blanchâtre. La tige et le renflement vésiculeux sont d'un blanc-nacré, et le trou terminal est coloré en rose-vif. I.es vessies latérales et natatrices sont légèrement nuancées de jaune-citron.

Le 19 décembre $18_{2} 3$, par une belle mer, nous rencontrâmes plusieurs individus de ce zoophyte par les 28 degrés de lat. Sud, et les $9^{2}$ de longitude orientale.

22. PONTOCARDE CRUCIÉ.

Pontocardia cruciata, Less., Mem. de la Soc. d'Hist. nat. t. 3, p. 4i 7 , pl. X, fig. B.

(PI. V, fig. 6, des mollusques.)

Ce corps, dont nous avons donné deux figures, l'une quand il est encore dans l'eau, l'autre quand il en est sorti, n'est 
point une vésicule de physsoplore ainsi que le pensaient plusieurs naturalistes de Paris. D'après un dessin, on peut le croire; mais ce doute était impossible pour celui qui avait observé l'un et l'autre à la surface même de la mer, en les touchant. Depuis que notre planche a paru, nous avons retrouvé une figure rigoureusement semblable dans la pl. ı3, f. ı, D. C. du Système des acalèphes d'Eschscholtz publié en 1829 ; et ce n'est qu'une partie d'un animal inédit que l'auteur russe nomme agalma Okenï. Nous ne serions pas surpris que ce corps ne soit encore le type du genre cuneolaria de M. Eysenhardt.

Ce genre agalma parait intermédiaire aux physsophores d'une part, et aux pléthosomes de l'autre, et peut-être appartient-il exclusivement à cette dernière famille. Voici textuellement la description que nous en avons donnée, et surtont les caractères que nous avions assignés au genre pontocardia: Corps libre, simple, gélatineux, consistant, ovalaire, échancré profondément à sa partie supérieure, cordiforme, aminci et rétréci inférieurement; point de nucléus ni de viscères apparents. Canal translucide, creusé, occupant tout l'intérieur et composé d'une branche plus longue et transversale, et d'une seconde, plus courte, placée verticalèment au milieu, et dont l'extrémité présente une issue correspondant à une autre ouverture de la partie inférieure du zoophyte. Aspect liyalin parfait.

La place que ce nouveau genre doit occuper, disions-nous, doit être près des diphyes, dans les acalèphes libres; mais il est si facile de prendre des portions de zoophytes pour des animaux entiers, que, malgré l'exactitude de notre dessin, nous ne répondons pas de l'existence réelle de ce genre : ce. pendant on ne peut point le confondre avec une vésicule de stéphanomie détachée, parce que ces dernières sont faciles à reconnaitre et lui ressemblent peu.

I. pontocarde croisé, ou vésicule d'agalma, s'était offert à 
nos recherches comme un zoophyte de consistance mollasse, d'un blanc cristallin et de forme dense hors de la mer, nuageux, ne paraissant que comme une croix délicate dans l'eau. Le pourtour de la bouche se trouva coloré en un jaune-pâle. On ne reconnaissait aucune trace de viscères; seulement on pouvait distinguer de très-petits tubes entortillés, de couleur albine, sillonnant les deux branches cruciées de l'intérieur.

Ce corps était à peu près de la grandeur d'une pièce d'un franc; ses bords étaient arrondis, et son épaisseur de plus de quatre à cinq lignes et assez régulièrement cordiforme. L'échancrure supérieure était profonde, et ses bords concaves.

Nous le prîmes le i 8 septembre 1823 , par 27 degrés $3 o^{\prime}$ de lat. S. dans l'Océan indien, dans notre traversée de Waigiou à Bourou, une des Moluques, et au milieu des îles de Ruib, de Siang et de Guebé.

DESCRIPTION DE LA FAMILLE DES VÉLELLES.

Les vélelles forment une famille naturelle très-caractérisée par l'espèce de squelette qui en remplit l'intérieur, et cette famille ne renferme que le seul genre $V$ élelle .

' M. De Haan (Verhandeling over de rangschikking der velellen, porpiten, en physaliën; Bïdragen tot de Nat. Wetenschappen, $\mathrm{n}^{\circ} 3$, p. 489), donne le tableau suivant des espèees du genre velella.

A. Vela sinistra, Cham. et Eys.

x. Velella australis, Esehscholtz, eap B.-Espér.; Columna , Aq.et Terr., p. 20, ch.X, pl. 22 , fig. I et 2 ; Imperati, Hist. Nat., p. 688, fig. I.

Porpite vélelle, Bory, Voy., pl. 54, fig. 2.

Velella scaphidia, Péron, atl., pl. 3o, fig. 6 .

Felella scaphiclia, Lamk.

Felella sinistra, Cham. et Eys., pl. 32, fier. I.

2. Felella pacifica, Eschscholtz, mer du Sud.

B. Vela dextra, Cham. ct Eys. 
La charpente solide des vélelles se trouve formée de deux feuillets ex trêmemcnt minces et intimement soudésl'un à l'autre. Cette sorte de squelette affecte aussi deux systèmes opposés par leur direction : l'un cst horizontal et se présente sous l'aspect d'une lame convexe en dessus, concave en dessous, qui semble être le résultat de la soudure de quatre fragments unis par des bords taillés en biseaux; l'ajustement de ces quatre pièces donne naissance à quatre rainures ou à deux seulement, l'une longeant obliquement de gauche à droite ou de droite à gauche et dans toute la longueur, cette lame horizontale; l'autre coupant la première à angle"plus ou moins aigu, est beaucoup plus courte qu'elle, puisqu'elle ne s'étend que dans le sens transversal. La deuxième lame est verticale, son bord inférieur occupe le sillon de la grande rainure, et le supérieur, qui est libre, est ordinairement arrondi; cette lame, qu'on nomme crête ou voile, est le résultat de deux feuillets très. minces, très-diaphanes, d'un nacré brillant, qui sont appliqués l'un sur l'autre. Coupé en segment de sphère à son bord libre, cette crĉte présente dans sa partie moyenne une pièce cunéiforme plus large au sommet, qui y est enclavée. La forme du bord supérieur de cette pièce, omise dans une foule de figures, varie depuis l'angle pointu, 'la coupe rectiligne jusqu'à la forme échancrée ou concave. La partie inférieure de cette crête ver-

3. Radackiana, Eschscholtz.

Velella oblonga, Cham. et Eys., pl. 32, figr. 2 ; Radack.

4. Sandwichiana, Eschscholtz.

Velella lala, Cham. et Eys., pl. 32, fig. 3.

Vélelle échancrée, Quoy et Gaim., Zool., pl. 86, fig. 9 .

C. Incertoe sedis.

5. Velella mutica, Lamk., Mcdusa velella, Gm., Phyllidoce, Brown. Jam. 387, pl. 48, fig. I (F. Limbosa, Lamk.); Holothuria spirans, Forsk. Eg., p. 104, pl. 26, fig. K.; Ency. pl. $9^{\circ}$, fig. 1 et 2. 
ticale se trouve ajustée sur la pièce horizontale basale, audessus du grand sillon dont la direction sénestre ou dextre constitue, relativement à une ligne droite qui couperait l'animal par le milieu et dans son plus grand diamètre, un angle d'au moins vingt-trois degrrés. Les deux portions, soit verticale, soit horizontale de cette sorte de squelette, présentent une identité parfaite de construction. Chaque pièce, dans son ensemble, est formée par deux parois minces, parcheminacées, garnies en dedans de ressauts disposés en lignes, qui s'entrecroisent de telle sorte, que les uns se dirigent dans le sens longitudinal, et les autres daus le sens transversal (f. A et $\mathbf{A}^{\prime}$ ). Ces ressauts sont eux-mêmes de petites lamelles creusées en demi-canaux. Or, comme chaque pièce des deux parois offre parfaitement la même symétrie, il en résulte que ces demi-canaux, en s'ajustant par leurs bords libres, constituent des tubes ou conduits entiers, hernıétiquement fermés et dans lesquels l'air circule, et c'est à cet appareil fort simple que les vélelles doivent de voguer sur la surface de la mer sans ètre submergées. Très-certainement par un mécanisne qui nous est inconnu, ces animaux peuvent chasser l'air contenu dans ces canaux et se laisser couler à une certaine profondeur pour éviter les perturbations dont les grains des tropiques frapperaicnt leur existence. Ces tubes aérifères sont donc le moyen par lequel une vélelle augumente ou diminue sa pesanteur spécifique.

Une membrane cellulaire assez épaisse enveloppe et déborde le système horizontal de la charpente en dessus comme en dessous. Un épiderme pellucide éminemment nacré et trèsbrillant revêt seul le système vertical ou la crête. En dessous de la lame horizontale sont logés tous les viscères; d’abord dans la rainure profonde et oblique qui traverse tout le grand diamètre de sa face inféricure est logé l'appareil digestif (f. B.), qui se compose d'un tube ventru et d'une bouche au centre 
rétrécie en deux cylindres qui se prolongent en branches et se ramifient aux deux extrémités du zoophyte, en se perdant dansle tissu cellulaire, de manière à ce qu'on ne puisse s'assurer de ce qu'ils deviennent. Sur le pourtour de cette ouverture moyenne et protégée par la lame cartilagineuse horizontale dont elles occupent toute la surface, sont placées en grande quantité des poches stomacales musculaires (fig. C) très-contractiles, prèsque globuleuses quand elles sont remplies par les aliments, et munies à leur sommet d'une bouche destinée à opérer la succion; la membrane où s'implantent tous les suçoirs est beaucoup plus épaisse que celle du pourtour, et au point où finit la lame horizontale du squelette elle donne attache à une série régulière de tentacules cylindriques, pointus, très-élastiques et rangés avec une parfaite symétrie. Ces organes de tact, d'une texture délicate et fragile, fréquemment tortillés sur euxmêmes, sont munis à leur pointe qui est aiguë, de sept à huit petites glandes qui paraissent très-sensibles (fig. D). Ce sont ces tentacules qui saisissent les petits animaux dont se nourrissent les vélelles, et qui les retiennent pendant que les ventouses stomacales en digèrent la substance. Le résultat de la digestion est presque inmédiatement transporté dans le grand canal digestif à parois membraneuses que nous avons mentionné; et c'est alors qu'on le trouve rempli d'un chyme rouge imitant parfaitement la lie de vin.

Le tissu cellulaire de la partie dorsale du corps est granuleux, de texture muqueuse, et se dissout avec beaucoup de facilité.

Les vélelles se réunissent par grandes troupes qui flottent par les beaux jours sur la surface de la mer, entre les tropiques. Leur nourriture consiste en petits mollusques, en petits poissons qu'elles saisissent avec leurs tentacules en passant près d'eux. Elles n'ont point de matière toxique apparente pour 
frapper leur proie. Elles-mêmes sont dévorées par une foule d'autres animaux, tels que des planaires, des crabes, etc. Elles n'ont aucune saveur comme aliment pour l'homme. Les espèces que nous avons étudiées sont au nombre de deux ${ }^{\mathrm{r}}$. M. Eschscholtz en caractérise $\mathbf{~} 0$.

'MM. dc Chamisso et Eysenhardt ont admis trois espèces dans leur travail (Actes de Bonn, t. X), et publié à leur sujet les détails suivants :

Medusa chondrophorae.

Velella, Bosc.

MI. Cuvier a dit, avce juste raison (Règ. animal), que les caractères spćcifiques assignés aux vélelles par Laınarck et d'autres, n'étaient point suffisants pour les classer. Il paraît toutefois ètre dans l'erreur, en mettant en doute si on ue doit ceconnaîtrc qu'une seule espèce de vélelle. Tìois espc̀ces sont aisémcnt reconnaissables, cn comparant la direction de la voile et la longueur du corps relativ cment à sa larycur. La voile, en elfet, est toujours oblique; ce quc tous les auteurs ont rcconnu: mais cllc s'oblique de deux manières; de sorte que la voile se dirige ou de droite ou de ganche, ou de l'avant à l'arrière et vice-versâ.

Vella sinistra (Velella sinistra), Vella dextra (Velella oblonga etlata), dircction dans le sens du diamètre longitudinal, ce qui pormet de reconnaître les espèces suivantes:

I. Velella sinistra, Ch. et Eys., pl. 32, fig. 1.

Voile yauchc: longueur du corps excédant trois fois la largeur du cartilage; les tentaculcs latéraux, qui sont blcus dans toutes les vélelles, sont dans les individus de celle-ci, prise au cap de Bonnc-kspérance, orangés à l'extrémité, ainsi qu'on le voit dans la figure que nous en avons donnée; les individus suivants étudiès dans la mer Pacilique avaient leurs tentacules bleus.

2. Velella oblonga, Cl. et Eys., pl. 32, fig. 2, a , b, c.

Voile droite : longucur du corps excédant 4 fois et demie la largeur du cartilagc.

3. Velella lata, Ch. ct Eys., pl. 32, fig. 3, a, b.

Voilc droite : longueur du corps excédant 2 fois la largeur du cartilagc.

Soit d'après les descriptions, soit d'après les figures de la plupart des auteurs quc nous avons compulsés, nous n'avons pu trouver aucune mention de la direction de la voile; aussi la synonymie qu'on pourrait tirer de ce caractère cst-clle complètcment à désirer.

L'espícc figuréc par Péron (Allas, pl. 3o, fig. 6), n'a pu être rapportée par nous à aucune dcs espèces que nous avons décrites. Ia Velella Forshaelii, pl. 26 , fig. 4, semblc appartenir à la Velella sinistra, Clam.; la planchc de Fabius Columna (de aquatil. et terrest.) urtica marina, pl: 22, semble ètre notre Velella lata, ou la Veletla obliqua.

Les vélelles se trouvent dans toutes les mers des rigions les plus chaudes, et jamais dans lcs «oncs froides. Elles abondent principalcment daus la mer Pacifique scptentrionale. Le plus son-vent des essaims nc sont formés quc d'ure scule espèce, les individus adultes mélangés aux jeuncs, ct janais réunis à d'autres espèces. 
23. VÉLELLE MUTIQUE.

Velella mutica, LamarcK.

(Pl. VI, fig. I, vue en dessus, fig. 2, vue en dessous ; g. n.)

A, cartilages internes; B, bouche et tube stomacal ; C C, suçoirs buccaux; D, tentacule isolé; $\mathrm{E}$, jeune âge.

Cette vélelle a de grands rapports avec l'espèce figurée et décrite par M. de Chamisso, sous le nom de Velella oblonga (pl. 32, fig. 2); peut-être se distingurue-t-elle même de la Velella mutica de Lamarck, bien que nous lui ayons appliqué ce synonyme; elle se rapproche beaucoup de l'espèce que représente Eschscholtz, pl. I5, fig. 3, sous le nom de Velella oblonga (système des acalèphes, p. I 7 I), et de la vélelle tentaculée de Bosc, bien que des différences assez notables puissent être signalées. Peut-être eussions-nous bien fait de conserver le nom de Velella atlantica que nous avions donné sur nos dessins manuscrits à cette espèce.

Cette vélelle est longue de 4 pouces sur 18 lignes de largeur. Sa forme est oblongue, arrondie aux extrénités, à bords presque droits. Sa crête est mince, blanc-nacré, dirigée de gauche à droite, et très-reconnaissable à la pièce tronquée qui surmonte sa partie moyenne et qui est enclavée entre les deux lobes, antérieur et postérieur, qui la composent; lobes qui sont convexes en dessus et taillés en ligne déclive à leur terminaison. Cette crête repose sur la charpente cartilagineuse basale, et que recouvre un tissu cellulaire épais, sinueux aux bords droit et gauche, et traversé par des sillons qui divergent du centre à la circonférence. Un large ruban charnu, lisse, granuleux, déborde la charpente cartilagineuse, et se trouve coloré en bleu-glaucescent assez intense en dessus comme en des- 
sous. La surface inférieure du disque est revêtue d'une épaisse membrane musculeuse colorée en jaune-rougeâtre foncé, couverte de ventouses minces, blanchâtres, cylindriques, dilatables (fig. C. C.). Au rebord du disque nait une ligne circulaire de tentacules allongés, cylindriques (fig. D.), musculaires, pouvant se contracter, et terminés au sommet par deux séries de petits pores. Au milieu des ventouses stomacales est placée une bouche subcentrale, ouverte au milieu d'un sac prolongé de chaque côté en un canal digestif qui finit par se diviser à ses deux extrémités en plusieurs petits canaux nourriciers (fig. B.) que nous trouvâmes remplis de matière rougge.

Cette vélelle se distingue de plusieurs autres espèces, parce que les tentacules sont assez allongés pour dépasser les bords. Elle se nourrit de petits crustacés lucifuges, de petits poissons qu'elle saisit avec ses tentacules en les enlaçant et en les ramenant sous les suçoirs mêmes, ainsi que nous avons eu très-fréquemment occasion de nous en assurer. Souvent des vers planaires, des éolides s'attachent à elle et dévorent sa substance. Nous en rencontràmes des troupes considérables le 26 septembre ı 828, par 2 degrés de lat. S., dans l'Océan atlantique équatorial. Nous essayâmes de faire frire ce zoophyte pour servir d'aliment : nous ne lui trouvâmes qu'un goût de poisson un peu nauséeux et horriblement salé. Bien que l'action du venin des glandes terminales des tentacules ne soit pas sensible à nos organes, nul doute qu'il n'ait des propriétés assez appréciables' pour les petits animaux qui doivent servir de pâture aux vélelles, et qu'il les frappe de stupeur.

La fig. I, lettre E, représente, de grandeur naturelle, une très-petite vélelle que nous croyons être le jeune àge de celle que nous venons de décrire, du moins nous la rencontrâmes flottant au milieu des grands individus par 27 degrés de lat. boréale non loin de l'île de Fer, la plus méridionale des îles Ca- 
naries. Sous son disque bleuâtre était cachée la pointe des tentacules. Nous en remarquâmes deux seulement très-longs, filiformes, fragiles. Sa crête était terminée par un long cône pointu; son disque était presque circulaire. Serait-ce une espèce?

\section{VÉLELLE BLEUE.}

Velella cyanea, LEss.

(Pl. VI, fig. 3, vue en dessus, fig. 4, vue en dessous; g. n.)

Cette petite vélelle n'a guère que 20 lignes de longueur sur 1 o de largeur. Sa forme est ovalaire; ses bords sont légèrement sinueux et recouvrent entièrement les tentacules préhenseurs qui ne les dépassent point.

La crête argentine de cette espèce est peu élevée, dirigée de droite à gauche, légèrement convexe, à lame intercalaire obtuse au sommet, et à bord des deux lobes frangé par un repli azuré et légèrement épidermoïque. Le dessus du disque est d'un beau bleu azuré, à lignes concentriques plus colorées, traversées par d'autres sillons divergents. En dessous le disque est revêtu d'une mémbrane jaunâtre où sont implantés des sacs stomacaux nombreux, jaunes, à pourtour de la bouche blanc, ayant son ouverture subcentrale et lactée. Au rebord de la membrane jaune est placée la rangée régulière de tentacules préhensiles. Ceux - ci sont minces, grêles, arrondis, et occupent une zone bleue très-claire, et n'atteignent point le pourtour de la vélelle, rebord qui est d'un riche azur-foncé et très-étroit.

Nous rencontrâmes cette vélelle dans le Grand-Océan, par 23 degrés de lat. méridionale, et I 79 degrés de longitude occidentale, le 26 juin I 822 . 
DESCRIPTION DE LA FAMILLE DES PORPITES.

Nous trouvons dans les physales un ensemble d'organes fort remarquable que nous suivons dans les vélelles, et par suite dans les porpites. Les vélelles ont en effet le canal digestif des physales, avec une bouche subcentrale entourée de sacs ou suçoirs nombreux, entremêlés eux-mêmes d'une série marginale de tentacules. Il est vrai que ces tentacules ne sont plus chez les vélelles que d'une sorte, et beaucoup moins compliqués sans doute que ceux des physales. Enfin la partie vésiculeuse de ces dernières est remplacée par des tubes assez consistants chiez les vélelles, et quant à la crête cloisonnée de celles-là, elle a chez celles-ci son analogue dans une crête à 2 parois aréolées. Chez les porpites nous voyons à peine une légère modification de l'organisation des vélelles. Le disque central résulte également de 2 lames avec des tubes aérifères seulement, il est enveloppé de toute part et sans crête. Mais il y a toujours un canal alimentaire s'allongeant au milieu en une bouche supportée par un tube, puis enveloppée de suçoirs et enfin de tentacules préhenseurs et glanduleux. Seulement ceux-ci sont toutit-fait attachés par une insertion marginale. Les porpites nous conduisent donc aux cyclolithes, dont l'axe calcaire doit avoir en dessous des suçoirs en ventouses comme ceux des physales, puis de là il n'y a plus qu'un pas pour atteindre les fongies qui appartiennent à cette grande division et les actinolithes qui conduisent les actinies charnues et diversiformes, simples ou agrégées aux madrépores.

Les porpites ont leur disque interne parfaitement arrondi. Il parait à la vue simple aréolé en dessus et lamelleux en dessous; mais il est composé de deux lames cartilagineuses très- 
minces soudées intimement à leur bord, puis garnies en dcdans de demi-tubes élevés, très-courts, qui s'ajustent pour former des canaux cntiers que parcourt l'air qui y est introduit, et qui peut cn être chassé, par où et comment, c'est ce que nous ignorons encore. Ce disque très-mince, d'un blanc nacré-pellucide, est complètement enveloppé par le tissu cellulaire. Mais il semble toutefois formé de cercles arrondis et rapprochés, coupés par des rayons divergents espacés et comme ponctués. Le dessus du disque est à peu près lisse, tandis qu'en dessous un tissu musculeux, épais, supporte une grande quantité de ventouscs ou suçoirs irrégulièrement rangés tout à l'entour de la bouche subcentrale, dont la forme est celle d'une bouteille (pl. 7, fig. 3, lettre C). Une portion membraneuse déborde ce disque en forme de feston circulaire plus ou moins étroit, et donne attache à une couronne de tentacules régulièrement pressés les uns près des autres, et tous cylindriques et en massue, c'est-ä-dire plus épais à leur extrémité libre qui est garnie de glandes miliaires pédicellées ou sessiles.

La manière de vivre des porpites est parfaitement analogue à celle des vélelles. Les tentacules à glandes ont pour fonctions de se saisir de la proie que les suçoirs doivent digérer, et dont lc produit circule dans le canal digestif. Leur locomotion sur la mer est purement passive, du moins en apparence, et leur disque couché à plat sur la ligne des caux, laisse flotter librement, et dans le sens horizontal, les bras irritables disposés à l'entour, et voguant comme une petite couronme de passiflore bleue.

On n'est point d'accord sur le nombre des espèces de porpites qu'il faut admettre. M. de Chamisso, en parlant de la Porpita gigantea de Péron, dit: "Nous ne devons citer qu'une espèce de porpite, suivant l'opinion de M. Cuvier, et on doit rejeter les 4 espèces de M. de Lamarck: la Porpita gigantea 
s'est présentée à nous dans toutes les mers intertropicales. "II est inutile d'ajouter que cette opinion, que rien n'appuie, est complètement erronée ${ }^{x}$. Eschscholtz, dans son mémoire sur les Acalèphes, les place dans la famille des vélelles, où il classe les genres rataria, velella, porpita, et dans ce dernier genre il admet cinq espèces.

Un très-grand nombre d'animaux marins se nourrissent de porpites; notamment un pinnothère pélagien minime et des planaires. Aussi n'est-il pas rare de rencontrer des disques entièrement nus que leur légèreté spécifique soutient sur la mer, ou des disques dont les parties musculeuses sont très-diversement déchiquetées. Ces fragments mutilés, très-abondants sur la mer, ont donné lieu à quelques auteurs de créer des espèces fictives telles que la Porpita nuda, et la porpite appendiculée représentée par Bosc, pl. ı 5 , fig. 5 et 6 de son histoire des vers.

La zone équatoriale des deux océans semble être la patrie exclusive des porpites. Il est rare en effet de les rencontrer hors des limites de la Torride.

Nous établirons dans cette famille trois petites coupes génériques, qui sont fondées sur des caractères assez précis : Les vraies porpites, porpita, les radeaux, ratis, et les prunelles, acies.

'M. De Haan admet les espèces suivantes:

1. Porpita Reinwardtii, D. H., esp. nouv., Moluques.

2. Porpita Forstahli, D. H.

Holoth. denudata, Forsk., pl. 26, f. L. I.

Holoth. nuda, Gin., Encycl., pl. 9o, f. 6 et 7.

Porpita glandifera, Lmk.

3. Porpita Kuhlii, D. H. (Porpita disticha, Kuhl, M. S.)

4. Porpita gigantea, Péron, Lmk., pl. 3ı, f. 6 (Porpite radiée, Bory, pl. 5, f. 2 ).

royage de la Coquille. - Z. Tom. II, partic II. $2^{\mathrm{C}}$ Div. 
25. PORPITE AUX CHEVEUX D'OR.

Porpita chrysocoma, Less.

$$
\text { (Pl. VII, fig. I, et I', g.n.) }
$$

Le disque de cette espèce est de I I à I 2 lignes : les stries rayonnées de sa face supérieure sont légères, peu marquées; et la couleur de cette partie est d'ùn bleu-violâtre faible, tandis que la membrane charnue qui l'entoure forme un cercle régulier assez large d'un jaune d'or pâle uniforme. Les tentacules sont légèrement inégaux entre eux, plus épais à leur extrémité libre qui est en massue (fig. I, lettre A). Chaque tentacule est dans presque toute son étendue recouvert de glandes qui sont éparses et supportées par des pédicelles grêles et assez allongés. La surface inférieure du disque est recouverte de ventouses petites, pressées, de couleur de chair passant au violâtre dans certains cas. La bouche subcentrale est pyriforme, parfaitement blanche.

Nous rencontrâmes eette porpite le 28 août ${ }_{1} 823$, sur les côtes de la Nouvelle-Guinée, non loin de la terre, et dans le grand océan Pacifique. C'est jusqu'à présent la seule qui ait le pourtour de son disque et ses tentacules jaunes.

26. PORPITE ATLANTIQUE.

Porpita atlantica, Less.

$$
\text { (Pl. VII, fig. 2, g. 11.) }
$$

Cette porpite a 14 lignes de diamètre au disque et à son rebord; ses tentacules sont courts, pressés, cylindriques, puis arrondis et renflés à leur sommet. Les glandes qui les terminent sont globuleuses, subsessiles, et en très-petit nombre à leur sommet seulement. Le disque est rayonné; les lignes qui 
partent du centre se rendent au bord, sont légèrement rugueuses, c'est-à-dire hérissomnées et âpres. Des points ou sortes de renflements d'une extrême petitesse s'élèvent sur ehaque ligne qu'ils rendent noueuse. Le dessus du disque est d'un bleu indigo noirâtre. Le cercle membraneux eharnu qui l'entoure est régulier, étroit, lisse, et coloré en vert glaueescent, ainsi que les tentacules préhenseurs. En dessous les ventouses stomacales et la bouehe sont blanehâtres.

Nous rencontrâmes cette porpite le 25 septembre $\mathrm{r} 822$, dans la zone équatoriale de l'océan Atlantique.

27. PORPITE DU GRAND OCEAN.

Porpita pacifica, Less.

( Pl. VII, fig. 3, et $3^{\prime}$ vue en dessous. )

C. la bouche subcentrale cntourée de ventouses stomacales ou suçoirs.

Le disque de cette porpite a 15 lignes de diamètre, sans y comprendre les tentacules, et avee ceux-ci 2 pouces 6 lignes. Elle est de la taille de la porpita gigantea de Péron.

Son disque est en dessus très-finement rayonné et possède un éclat argentin ou nacré très-brillant. Le repli membraneux qui l'entoure est régulièrement sinuolé par de légers festons, exeessivement étroit, et paraît peu. Sa couleur est un bleu céleste clair très-transparent. Les tentacules, très-pressés et trèsminees, sont eylindriques et complètement garnis de petites glandes sessiles pressées sur les deux lignes latérales. Ces tentacules sont azur clair, et les glandes sont bleu indigo.

Le dessous du disque a sa bouche subcentrale pyriforme, petite, entourée de nombreux suevoirs ou ventouses stomacales pressées, minimes, et toutes d'un blane hyalin parfait.

Cette belle porpite s'offrit à nos regards par essaims très- 
nombreux sur la surface de la mer, alors unie comme une glace, par i 6 degrés de latitude sud et 79 degrés de longitude occidentale, à peu de distance des rivages du Pérou.

28. RADEAU DE LA MÉDUSE.

Ratis Medusa, Less.

Ce petit groupe se distingue des vraies porpites par les particularités suivantes : Le disque est charnu, petit, à lignes concentriques en dessus, terminées en dessous par un sac large, conique, percé par la bouche à son sommet, et muni de suçoirs en petit nombre à sa base. Les tentacules sont distants, très-allongés, capillacés, et partent d'un cercle membraneux entourant le dessous du disque, et sont recouverts à leur origine par un deuxième cercle membraneux, ou repli supérieur de la membrane du disque.

Nous ne connaissons qu'une espèce de ce genre; et nous en possédons la figure dans nos dessins inédits. Le disque en dessus est bleu-noir, cerclé de bleu avec des traits rayonnés. La membrane du pourtour est bleu-clair. En dessous, le sac médian est blanc-bleuâtre, entouré à son origine d'une membrane rouge de sang, membrane d'où partent les suçoirs ou ventouses. Ceux-ci sont épars, allongés, cylindriques, bleus; mais terminés de jaune d'or à leur ouverture. Le deuxième repli qui donme attache en dessous aux tentacules, est d'un beau bleu; mais les tentacules sont bleu clair.

Cette espèce, dont le disque a au plus 6 lignes de diamètre, a des tentacules longs à eux seuls de 12 lignes. Nous la trouvâmes le I I octobre 1822 , par 26 degrés de lat. Sud, dans l'océan Atlantique. 
29. PRUNELLE CILLANT.

Acies palpebrans, Less.

Les porpites de ce petit sous-genre sont remarquables en ce que leur disque est petit, lisse, musculeux et très-finement rayonné en dessus. Toute la surface inférieure est occupée par une cavité musculeuse, en cône, et terminée à sọn extrémité libre qui est la pointe du cône par une petite bouche centrale et arrondie. Il n'y a point de suçoirs latéraux, le cône charnu occupant tout l'espace du disque, dont le pourtour est garni de tentacules serrés, filiformes, médiocres, très-nombreux et trop minces pour qu'on puisse distinguer s'ils sont munis de glandes.

Le seul individu que nous rencontrâmes de ce zoophyte était complet, et flottait par les 27 degrés de lat. N. et les 20 de long. occidentale dans l'océan Atlantique. Son diamètre était de 2 lignes, et chaque tentacule pouvait avoir jusqu'à 5 lignes de longueur. Le dessus du disque est bleu, un point bleu-indigo en marque le centre. Les tentacules sont bleu clair, et le grand sac conique qui pend au-dessous est d'un blanc-bleuâtre, excepté la bouche qui est plus foncée; un canal très-marqué part de celle-ci, et se rend au disque.

DESCRIPTION DE LA FAMILLE DES PLÉTHOSOMES.

Cette famille doit être divisée en trois tribus : $\mathbf{I}^{\circ}$ les DIPHYEs, avec les nouveaux genres calpés, abyles, cuboïdes, navicules, eudoxies, ersœa, aglaisma, cucubales, capuchon, cymba, cnnéagone, amphiroa, galéolaire, rosace, etc. bien que plusieurs de ces genres reposent sur des pièces isolées des pléthosomes; $2^{\circ}$ les Polytomes, comprenant les genres polytomus, 
agalma, apolemia, plethosoma; et $3^{\circ}$ les StÉPhanonies, n'ayant que le genre stephanomia, et une seule espèce, la $S$. amphitritis de Péron.

Les animaux de cette famille sont gélatineux, très-transparents, composés de pièces accolées les unes à côté des autres, ou s'unissant par des cônes emboîtés dans des ouvertures taillées en facettes, et s'engageant par des surfaces planes finissant à angles, se groupant tantôt 2 par 2 , tantôt en cylindres ou en ovoïdes, ou parfois s'articulant sur 2 rangs et sur les côtés, de manière à s'étendre en largeur, Ces diverses pièces forment un tout; mais au moindre choc, elles se désagrégent et errent sur la surface de la mer, où elles paraissent se conserver par une vie propre, et ne pouvoir plus jamais se rejoindre aux autres pièces qui constituaient l'animal sous sa forme naturelle primitive. Toutes ces pièces, variables de formes, suivant leur position dans l'animal, laissent apparaître dans leur intervalle des canaux aériens, des cloisons et des cellules, et par suite de nombreux prolongements cirrhigèrets, frondescens, à petits rameaux terminés par des utricules.

Les pléthosomes se soutiennent sur l'eau à l'aide de cavités qui se remplissent d'air pour diminuer leur pesanteur spécifique. Leur nourriture parait être absorbée par une ouverture buccale, aboutissant à un grand canal musculaire tortillé sur lui-même. M. de Blainville admet que dans l'état parfait de ces zoophytes, il y ait un nucléus à la partie antérieure de la masse totale, et que ce nucléus est surmonté d'un osophage probosciforme que termine une bouche faite en espèce de ventouse, qui aboutit à un estomac entouré de granules hépatiques, et quelquefois dans un canal rempli d'air. Les productions cirrhigères seraient donc des ovaires annexés au tube musculaire digestif?

La locomotion s'exécute par des mouvements bornés de con- 
traction et de distension, et les animaux agrégés flottent à quelques pouces sous la surface de la mer dans une position presque verticale, dans toute la zone équatoriale des grands océans, et dans la mer Méditerranée où ils sont aussi abondants que variés.

3o. DIPHYE JUMELLE.

\section{Diphyes dispar.}

Cette diphye que nous avons figurée pl. 56, fig. 4 de notre Centurie zoologique, est bien évidemment la même quont représentée MM. de Chamisso et Eysenhardt, pl. 34, fig. 4. Cependant nous avons observé quelques particularités d'organisation que ne mentionnent point les naturalistes qui ont écrit sur ce sujet. La substance propre de ce zoophyte est dense, rénitente, d'un blanc hyalin, imitant un morceau de cristal taillé. Elle est de même consistance ferme et subcartilagineuse que celle des firoles et des salpas. Toutefois on ne découvre aucune trace de nucléus coloré, ni de vaisseaux. Dans l'eau, le cordon musculaire, rouge intense, apparait seul, à la manière des renflements vasculaires des pléthosomes proprement dits, en linéaments qui se dessinent vaguement dans l'eau; et au moindre choc les deux pièces de la diphye se séparent. Hors de l'eau, ces deux pièces sont denses, sillonnées à leur surface, ayant à leur milieu une cavité large, séparée au centre de chaque portion du zoophyte par un diaphragme vertical et mince, que personne n'a encore indiqué. Notre dessin est analogue, quant à la manière dont il reproduit la diphye, à celui de MM. Chamisso et Eysenhardt, et diffère beaucoup sous ce rapport de la diphye Bory de MM. Quoy et Gaimard. Tout autorise à penser qu'il existe une ouverture au sommet conique antérieur de la pièce supérieure de la diphye, laquelle ouver- 
ture se trouve aboutir à un canal étroit, filiforme, qui se dilate en une cavité oblongue, à l'extrémité de laquelle part le ruban musculaire coloré en rouge carmin que l'on voit étendu en cordon tortillé sur lui-même, au milieu des deux pièces, et se dirigeant de l'une à l'autre. Or, ce chapelet est très-probablement un tube digestif musculaire, car il n'est pas probable que les diphyes soient alimentées par les pores seulement de la surface et par une sorte d'imbibition, et dans la figure qu'en a donnée M. de Chamisso, on voit même un canal zigzagué bien marqué où viennent aboutir des ventouses buccales. Suivant cet auteur, les diphyes se nourriraient donc: à la manière des porpites, vélelles ou physales par la succion des matières animales. Les cavités du parenchyme agissent sur l'eau qui les remplit, et leurs mouvements de contraction en chassant ce liquide et en le pressant accélèrent la locomotion. La diphye jumelle se soutient aussi à la surface de l'eau, à l'aide de l'air qui remplit des cellules ovalaires placées à son sommet. Nous la rencontrâmes fréquemment dans l'océan Atlantique après avoir doublé le cap de Bonne-Espérance, soit dans les mers des Moluques, soit dans l'océan Indien, par 29 degrés de lat. Sud et $9^{2}$ de longitude orientale. Peut-être n'avons-nous pas su distinguer dans les individus que nous avons aperçus plusieurs espèces qu'un examen comparatif aurait peut-être isolées.

\section{PLÉTHOSOME HYALIN.}

Plethosoma cristaloides, Less.

$$
\text { (Pl. XIV, fig. 2, g. n.) }
$$

A. A., pièce inférieure; B. C. fragments latéraux désarticulés.

Le genre Pléthosome peut être caractérisé aussi : zoophyte agrégé, résultant d'un grand nombre de pièces subcartilagi- 
neuses, diaphanes, rénittentes, diversiformes, soudées par des faces régulièrement ajustées, et formant par leur réunion un corps composé, cylindrique, atténué aux extrémités qui sont obtusément arrondies, flottant librement, traversé au centre par un canal allongé que remplit un tube musculaire, tortillé sur lui-même de distance en distance, ce qui imite des renflements ou des noeuds, tube qui est évidemment le canal digestif. Les pièces sont toutes plus épaisses à la partie qui doit être extérieure, plus amincies à leur extrémité interne. Celles des côtés, tantôt en petits cônes, tantôt en lames (fig. B. C.), celle d'en bas ou d'enclavement pentagonale, conique, allongée (fig. A.), ayant une issue à sa terminaison, que ferme un petit còne mobile (fig. $A^{\prime}$ ), puis à cinq angles aigus en haut pour supporter les pièces latérales qui viennent la recouvrir en s'accrochant à ces éminences.

Les pièces diverses des pléthosomes ont sans aueun doute servi à établir de petits groupes dans les diphyes. Ainsi les genres pramis d'Otto, et calpé de Quoy et Gaimard, sont évidemment établis sur la pièce basale, composée elle-même d'un long fragment et d'un petit. La facilité excessivement grande avec laquelle leurs diverses pièces se désagrégent au premier choc, rend compte de la difficulté qu'il y a d'observer avec exactitude ces animaux. C'est même le hasard qui nous mit sur la voie de leur texture, un jour qu'assis sur des récifs nous dessinions des actinies. Un pléthosome passa près de nous, en le saisissant avec un filet en gaze, nous ne trouvâmes plus au fond de l'instrument que des fragments nombreux et de toute forme. Avertis par cette première rencontre, nous étudiâmes quelques autres pléthosomes, et tous se désagrégèrent de la même manière en les touchant, et leurs pièces avaient constamment les mêmes coupes et les mêmes surfaces à facette. Il reste donc beaucoup à faire dans l'examen de cette curieuse et intéres- 
sante famille, et les voyageurs futurs ne sauraient trop s'en occuper, car de nombreuses découvertes les dédommageront. amplement de leurs peines.

Le plethosoma cristaloides vogue sur la surface de la mer, et nous le rencontrâmes dans les parages de la Nouvelle-Guinée, au Port-Praslin, et très-abondamment aux attérages de l'ile de Waigiou. Dans I'eau, on ne voit que le tube digestif, qui apparaît sous forme d'une bandelette déliée, d'un rose purpurin très-éclatant, et semblable à un collier, parce que de distance en distance, s'élèvent comme des perles les gros renflements ou les paquets vasculaires qui résultent du tortillement sur lui-même du tube. Nous n'observâmes aucun prolongement cirrhigère. La limpidité des pièces articulées est telle que dans l'eau on ne peut en apercevoir aucun yestige. Mais élevé avec les précautions les plus grandes sur une feuille de papier mouillé passée sous l'animal lorsqu'il nageait encore, on le voit conserver quelques instants sa forme cylindrique, ovalaire oblongue, de consistance un peu ferme, d'une parfaite transparence, puis la vie qui cesse assez vite, laisse les pièces s'affaisser à leurs articulations, et se séparer aussitôt.

Très-fréquemment nous avons rencontré dans l'océan Atlantique équatorial la pièce basale (fig. A.) flottant avec son bouchon terminal et conique, s'adaptant sur l'ouverture ronde à l'aide d'une charnière, et dont nous avions fait le genre Pentagonus, avant d'avoir rencontré l'animal complet.

Le genre Pléthosome n'a jusqu'à présent que deux espèces : La première, le plethosoma cristaloides, est longue de 3 à 5 et même 6 pouces : elle est blanche translucide, mais le chapelet entortillé est d'un rose vif. La $2^{\mathrm{e}}$, que nous nommerons plethosoma cartulea, n'a que i 5 à 18 lignes de longueur, une circonférence mince, des pièces petites et blanc-bleuâtre, et un tube ou chapelet d'un bleu-indigo foncé. Ces zoophytes sont éminemment phosphorescents. 


\section{CHAPITRE XVI.}

DESCRIPTION DES ANIMAUX DE LA FAMILLE DES ACTINIÉES.

La famille des Actiniées ou des Actinozoaires, comme la nomme M. De Blainville, comprend non-seulement l'ordre $\mathrm{I}^{\mathrm{er}} \mathrm{de}$ M. Cuvier, c'est-à-dire ses polypes.charnus, mais encore un grand nombre de genres de l'ordre des polypes à polypiers, de la section des Lithophytes du règne animal. La division de M. De Blainville est donc parfaitement naturelle, tandis que celle de M. Cuvier est des plus imparfaites, car cet auteur n'a eu égard qu'au squelette, et nullement à la disposition actiniforme du zoophyte, pour opérer des coupes entièrement artificielles.

Les espèces d'actiniées que nous aurons à décrire nous permettent, par leur étude, de proposer un tableau méthodique des tribus qu'on peut reconnaître parmi elles et des genres qu'on doit distribuer dans ces groupes divers. Ce tableau aura l'avantage de les présenter dans l'ordre de leurs rapports naturels, et de citer les noms des genres récemment admis. Nous ne décrirons toutefois que ceux qui font partie de nos propres découvertes. 
FAMILLE DES ACTINIÉES.

$\S$ г. Point de squelettc ou d'axe interne solide: les ACTINIES.

A. Enveloppe cxtérieure de l'animal dure et subcartilagineuse.

i ${ }^{\text {re }}$ tribu. Actinies holothuriées : g. actinecte ou mynias (voy. page 13 ).

Sarcophinanthe; lucernaire; moscate? et actineria?

$2^{e}$ tribu. ACtinies Contrcifères : g. corticifera, maminilifera.

$3^{\mathrm{e}}$ tribu. actinits zoanthimes $\left\{\begin{array}{l}\mathrm{I}^{\mathrm{re}} \text { race : racémides : g. racemides. } \\ 2^{\mathrm{e}} \text { race : zoanthes : g. zoanthus. }\end{array}\right.$

B. Enveloppe extérieure de l'animal molle et charnue.

$4^{\mathrm{e}}$ tribu. Actinies multifines: g. actinodendron, metridium, thalassianthus.

$5^{\text {e }}$ tribu. Actinies SARCodermes: g. actinia $\left\{\begin{array}{l}\mathrm{I}^{\mathrm{re}} \text { race: vraies actinies : actinia. } \\ { }_{2}^{\mathrm{e}} \text { race : actinocères : cereus. }\end{array}\right.$

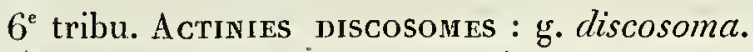

$7^{\mathrm{e}}$ tribu. Actinies en ventouses: g. lagena.

$8^{\text {e }}$ tribu. ACTINIES eUMénIdes : g. eumenides.

$\S 2$. Un squelette ou un axe interne calcaire : les ACTINOLITHES.

$9^{\mathrm{e}}$ tribu. Actiñes MadéPHy llies : g. cyclolithe; fongie; fabelline, lithartinie, etc., etc.

\section{SARCOPHINANTHE FLEURI.}

Sarcophinanthus sertum, Less.

$$
\text { (Pl. VIII, fig. I, 3/4 g. n.) }
$$

Sä̈-ï, dans la langue des.habitants de l'île de Waigiou.

Les zoophytes que nous avons réunis sous le nom de sarcophinanthus, sont des actinies qui se rapprochent singulièrement des holothuries : à bien dire, ce seraient des holothuries fixées par la base. Les deux espèces que nous décrivons seraient peut-être susceptibles d'être chacune le type d'un genre. Nous 
les avons dessinées toutes les deux en place, ayant de l'eau sur les récifs jusqu'à la ceinture. Les caractères que nous assignerons à ce genre, sont les suivants :

Corps adhérent par la base qui est dilatée en plateau, trèscoriace extérieurement, cylindrique et atténué au nilieu, élargi au sommet en un disque concave, à bords festonnés ou presque entiers, couvert en dessus de papilles diversiformes, accrochantes ou appendiculées, coniques ou multifides. Bouche centrale, supérieure, exerte, protégée par 6 ou plusieurs tentacules courts, gros, droits, s'accolant entre eux.

Le tube digestif qui part de la bouche et se rend au plateau basal est divisé à sa terminaison en paquets d'intestins trèsentortillés et de couleur ardoisée, munis de nombreux cœcums d'un blanc nacré et d'aspect tendineux.

Le sarcophinanthe fleuri est représenté aux deux tiers de sa grandeur naturelle. Mais il n'est pas rare d'en rencontrer des individus dont la taille est beaucoup plus considérable. Son corps est aussi haut que large; avec cette différence que les deux extrémités sont évasées en disques assez régulièrement orbiculaires, tandis que le milieu est très-aminci, bien que parfaitement arrondi. L'enveloppe extérieure est consistante, coriace, mais cependant marquée de stries ou plissures longitudinales et de nombreuses rides circulaires dans la partie la plus rétrécie. Cette enveloppe est lisse inférieurement et légèrement squameleuse et à écailles comme imbriquées sous l'élargissement discoïde supérieur. Sa couleur est un blanc-jaunâtre fade.

Le plateau inférieur ou d'attache est très-évasé, et s'applique sur les corps en s'accommodant à leurs formes. Le disque supérieur est comme divisé en deux larges lobes semi-circulaires vers le milieu. Au centre s'élève un douzaine de tentacules collés les uns à côté des autres, et formant par leur réunion un 
cône solide à l'extrémité duquel s'ouvre la bouche. Ce cône est d'un blanc lacté. Tout à l'entour, et sur toute la surface supérieure du disque, se pressent un grand nombre de paquets de granules, portés sur un pédicelle, granules ou globules arrondis, pressés à se toucher et formant comme une sorte de grappe ou de houppe; chaque grappe, mi-partie lactée, mi-partie marron-foncé, touche sa voisine, et chaque globule est surmonté d'un petit crochet qui retient vivement tout ce qu'il touche. La forme de ces petites grappes accrochantes rappelle parfaitement et les tentacules buccaux de beaucoup d'holothuries, et les petits corps spinescents qui hérissent l'épiderme des fistulaires. Enfin, le pourtour du disque, sur son rebord, qui est d'ailleurs mince, est garni d'une rangée de palmettes multifides, sortes de petits tentacules laciniés et colorés rougemarron. Ces tentacules sont placés à une faible distance les uns des autres et d'une grande délicatesse.

Nous observâmes ce zoophyte en août $\mathrm{r} 823$, sur les récifs du Port-Praslin à la Nouvelle-Irlande. Il y est beaucoup plus rare que l'espèce suivante.

\section{SARCOPHINANTHE A PAPILLES.}

Sarcophinanthus papillosus, Less.

$$
\text { (Pl. VIII, fig. } 2, \mathbf{I} / 2 \text { g. n.) }
$$

Sä̈-̋̈, dans la langue des Papous de Waigiou.

C'est encore sur les récifs de l'île aux Marteaux, dans le PortPraslin de la Nouvelle-Irlande, qu'en août 1823 , nous étudiâmes le zoophyte qui fait l'objet de cette description. Bien que semblable par l'ensemble de ses caractères au précédent, il s'en distingue cependant par une foule de particulari- 
tés, qui pourraient autoriser à en faire le type d'un petit genre.

En effet, le sarcophinanthe papilleux, quoique dilaté aux extrémités en deux disques, et enveloppé d'une peau coriace, a le pôle supérieur à six lobes réguliers, et beaucoup plus petit que le plateau basal. Puis le pourtour des lobes supérieurs se trouve épaissi, arrondi, et couvert de verrues subglobuleuses, tandis que toute la surface supérieure du disque est, ainsi que le corps, recouverte de papilles épaisses.

Ce sarcophinanthe, peint demi-grandeur naturelle, forme très-souvent sur les récifs de coraux que la mer n'abandonne jamais (bien qu'il n'y ait sur eux que 12 à 18 pouces d'eau à marée basse) des rosettes considérables. Le plus ordinairement il a la taille de l'individu type de notre planche. Le disque basal est assez épaté, puis il dininue de largeur, et le corps est cylindracé, blanc-jaunâtre, et couvert de papilles distantes, par rangées assez régulières d'un fauve-clair. Le disque supérieur est comme tronqué, dilaté, un peu sinuolé en dessus, à pourtour lobé, les lobes, au nombre de six, épais à leur milieu, renflés, flexueux, couverts de petits grains miliaires, globuleux. Ce pourtour est d'un blanc pur, tandis que la surface supérieure du disque est d'un fanve-brunâtre avec quelques taches blanchâtres, et les nombreuses papilles érectiles qui le recouvrent sont brun-marron. La bouche est simple, d'un blanc-neigeux, ouverte au bout d'un petit cône, ou trompe, formé de 6 tentacules soudés.

34. CORTICIFÈRE AGRÉGÉE.

Corticifera aggregata, Less.

$$
\text { (Pl. VIII, fig. 3, g. n.) }
$$

Le genre corticifère a été établi par M. Lesueur, le compa- 
gnon et l'ami de Péron, pour une espèce de l'île de la Guadeloupe, bien voisine de celle que nous avons figurée, et que ce voyageur a nommée corticifera glareola (Ac. de Phil., pl. 8, fig. 6). Ce genre a les caractères suivants : zoophytes agrégés, fixes, composés d'une réunion plus ou moins nombreuse d'individus à enveloppe coriace, soudés par les côtés et par la base les uns aux autres et formant une agrégation commune qui gazonne sur les récifs et s'accommode à leurs inégalités. Corps cylindrique, parfois déformé par la pression, à disque supérieur tronqué, à bouche petite, perforée dans une membrane à stries rayonnées qu'entourent de petits tentacules trèscourts disposés en couronne, et bouche garnie sur ses côtés de plissures étroites. Ce genre, ainsi que le dit avec juste raison M. de Blainville, conduit aux astrées.

La corticifère agrégée est de la nature d'un cartilage solidifié, et s'étend en couche épaisse de 6 à 8 lignes, sous forme de tapis blanc-jaunàtre, sur la surface des coraux que les eaux abandonnent quelques instants à marée basse. Cette couche animalisée s'accommode aux aspérités des rochers madréporiques que les vagues brisent et triturent en déferlant sur les jetées avancées qu'ils forment autour des îles de la mer du Sud. Mais c'est surtout sur la barre à l'entrée de Borabora, dans l'Archipel de la Société, que la corticifère couvre de ses zoophytes tenaces et robustes de vastes espaces. Le corps de chaque individu est court, cylindrique, intimement soudé par le pied et les côtés avec celui de son voisin. Il est blanchâtre, intérieurement vide à sa base, de sorte qu'en enlevant la partie supérieure d'une partie des zoophytes, il ne reste plus qu'une masse de cellules solides, parfaitement analogues à celles d'un gâteau de miel, mais arrondies au lieu d'être anguleuses. Ces aréoles sont toutefois remplies par un liquide aqueux, très-âcre et corrosif, et leurs rebords sont solidifiés par des piliers fibreux. Le 
disque supérieur se compose donc d'une surface tronquée, obarrondie, ayant une petite couronne simple de.tentacules trèscourts, très-minces, au nombre de 12 à 18 , enveloppant une membrane perforée au milieu pour la bouche, qui est fendue en ligne droite et bordée sur les côtés de petites fissures.

\section{LAGÈNE A LÈVRES VERTES .}

\section{Lagena chlorostoma, Less.}

Le genre Lagena aura pour caractères diagnostiques les suivants : Corps cylindrique, unique, de forme de gourde de pélerin, ou ovale-oblong, charnu, mou, élargi à la base, souvent fixé, pouvant être erratique, ou maintenu sur les branches de coraux; bouche simple en fente, ouverte au sommet qui est aminci, garnie sur son pourtour d'un petit rebord membraneux festonné, sans aucuns tentacules.

La seule espèce de ce gemre est une actinie longue de io lignes sur 5 de diamètre environ. Dilatée à l'extrémité inférieure, et mème renflée, elle se rétrécit au sommet et devient conique. Sa surface extérieuré est rousse, molle, couverte de petites rangées de points rouge-foncé, bien qu'au toucher l'épiderme paraisse lisse. La bouche, percée en fente tout-à-fait au sommet, est étroite, bordée d'une membrane verte-émeraudine qui lui forme un petit rebord sinuolé.

Nous rencontrâmes ce zoophyte très-abondamment sur les pâtés de corail recouverts par la mer, près l'île aux Mar-

I Le Zoophyte Lagènè semble composé d'un seul sac stomaeal, tandis que les Lithactinies sont formées d'un grand nombre de sacs stomacaux de même forme, mais aboutissant à une issue subeentrale et eommune. Consultez la description que nous avons donnée de ee dernier genre, pl. 6 de nos Illustrations de Zoologie, avec une belle figure de la Lithactinia nova-hybernice que nous avons découverte à la Nouvelle-Irlande.

rojage de la Coquille. - Z. Tom. II. Parlie $11.2^{\circ}$ Dir. 
teaux à la Nouvelle-Irlande; les individus étaient tantôt isolés sur les rochers, tantôt fixés par leurs pieds et adhérents sur les branches des antipathes à l'aide d'un mucus tenace.

\section{ACTINIE DE SAINTE-HÉLÈNE.}

Actinia Sancta-Helenc, Less.

$$
\text { (Pl. II, fig. I, g.n.) }
$$

Cette actinie de grande taille est beaucoup plus large que haute, ear elle est très-déprimée. Elle se fixe en s'évasant sur les rochers basaltiques de l'entrée de James's-town à l'île SainteHélène, où nous l’observâmes en janvier i 825 . Sa bouche est ample, d'un rouge de sang, et bordée par une membrane onduleuse couleur de chair. Un limbe rouge-brun lui sert d'entourage, et donne naissance, à son bord externe, à des tentacules médiocres, épais, comme en double rangée, cylindriques, et pointus à leur sommet. Ces tentacules sont rouge-brunâtre très-velouté, de même que l'aíre buccale. A leur base, en-dessous s'élèvent de gros tubercules, disposés en une rangée circulaire, d'un rouge de sang. L'enveloppe externe du corps est au toucher douce, veloutée, bien qu'elle soit couverte de petits tubercules d'un rougeâtre brun-foncé, tandis que sa teinte propre est un rouge-brun très-obscur.

\section{ACTINIE DE SAINTE-CATHERINE.}

Actinia Sanctc-Catherince, Less.

$$
\text { (Pl. II, fig. 2, g. n.) }
$$

Cette actinie est obarrondie, déprimée, étalée par la base et fortement adhérente. Sa surfaee est lisse, assez consistante, très-douce au toucher, d'un brun marron-foncé velouté, et 
marquée de lignes verticales brunes, qui de la base remontent au sommet, et sont régulièrement espacées entre elles. La bouche est simple, bordée de deux rangs de tentacules trèscourts, cylindriques, et d'un rouge fulgide. Les tentacules de cette espècc partagent avee ceux des autres actinies une grande contractilité. Il suffit du moindre choc pour les fairc rentrer vivement, et les parois de la bouche se contractent aussitôt, chassant avec énergie l'eau qu'elles renfermaient.

Cette actinie est très-commune sur les rochers de granite qui forment des barrières puissantes à la mer, soit sur la côte du Brésil, soit sur les rivages de l'île de Sainte-Catherine, et principalement sur l'îlot d'Anato-Mirim, au pied du fort de Santa-Cruz. Nous l'observâmes le I 7 octobre I 822 .

38. ACTINIE DU PÉROU.

Actinia peruviana, Less.

$$
\text { (Pl. II, fig. 3, g. n.) }
$$

Cette actinie est cylindrique, plus évasée au sommet qu’à son pied, à peau lisse, nue, d'un vert-pré agréable, avec quelques plissurcs brunâtres à la base. L'extrémité supérieure est donc aplatie, dilatée; à son milieu est percée la bouche qui est ample, à lèvres boursouflées couleur de chair. La membrane qui l'enveloppe est d'un vert-clair, et finement couverte de lignes régulières brunes. Les tentacules forment deux rangées circulaires. Ils sont médiocrcs, arrondis à leur naissance, pointus et grêles à l'extrćmité, et tous de couleur blanc-rosée.

Cette actinie se loge dans les anfractuosités des rochers et même dans les sables des côtes du Pérou, à Payta, où elle est commune. 
39. ACTINIE CAPENSIENNE.

Actinia capensis, Less.

$$
\text { (PI. II, fig. 4, g. n.) }
$$

Cette actinie a été recueillie sur les rochers du cap de Bonne-Espérance, et dessinée par M. le docteur Garnot. Renflée et arrondie au sommet, elle est étranglée au milieu. Son enveloppe externe est de couleur fauve bistrée, avec des rangées régulières de très-petites verrues brunâtres. Ces verrues sont plus nombreuses vers l'ouverture de la bouche. Celle-ci est grande, à verrués d'un rouge de cinabre sur son bord, et à tentacules courts, petits; arrondis et azurés. Une membrane rouge de sang dépasse sa partie basale et tapisse lintérieur.

\section{ACTINIE CHILIENNE.}

Actinia chilensis, Less.

$$
\text { (PI. II, fig. 5, g. n.) }
$$

Cette actinie est mamellée, subconique, ayant des sortes de côtes ou stries élevées de distance en distance, à peau d'un vert tendre, très-finement rayée de vert foncé. La bouche est en fente oblongue, percée dans une membrane jaunâtre, bordée de tentacules: les premiers formant une couronne simple, médiocre, aurore, et tous grêles et flexueux; les seconds trèslongs, espacés, filamenteux et blanc de neige. .

Cette actinie se loge dans les crevasses des rochers où la mer se brise avec force, sur le bas-fond placé à l'entrée de la baie de Talicahuano, dans la province de la Concepcion, au Chili, et aussi sur les rivages de l'île de Quiriquine. 
4. ACTINIE DOUTEUSE.

Actinia dubia, Less.

(Pl. II, fig. 6, g. n.)

Cette espèce qui est représentée au trait sur une valve de moule a été découverte par M. Garnot au cap de Bonne-Espérance. Elle est courte, tronquée, ayant un rebord dilaté et plissé au sommet, des tentacules courts, sur 2 rangs, et rougèàtres, tandis que son enveloppe légèrement rayée, est vertnoirâtre.

42. ACTINIE DE LA NOUVELLE-IRLANDE.

Actinia Nowa-Hybernia, Less.

$$
\text { (Pl. III, fig. I, g. n.) }
$$

Saz-i, dans la langue des Papous de Waigiou.

Bata, dans le langage de quelques nègres du Port-Pràslin de la Nouvelle-Irlande.

Guerou, en malais.

Palaï, nom des habitants de la Nouvelle-Bretagne et de la Nouvelle-Irlande.

C'est en août r 823 que nous observâmes au Port-Praslin, de la Nouvelle-Irlande, cette belle espèce d'actinie, allongée, conico-cylindrique, portée sur une base un peu moindre que l'axe du corps, s'adaptant par une surface plane avec des vides rayonnés sur les rochers de l'îlot aux Marteaux. L'enveloppe du corps est plissée circulairement, très-lisse, très-veloutée au toucher, et colorée en rouge-aurore d'un brillant éclat, mais qui se dissont aisément après quelques instants d'immersion de l'animal dans de l'eau douce. La bouche est en fente allongée 
au milieu d'une membrane fauve. Les tentacules sont courts, cylindriques, plus gros à leur base, pointus et minces à leur extrémité libre, colorés en jaune mordoré ou tachetés de brun et ponctués de jaune.

\section{ACTINIE PAPILLEUSE.}

Actinia papillosa, Less.

$$
\text { (PI. III, fig. 2, g. n.) }
$$

Cette actinie est mamelonnée ou semi-globuleuse, très-évasée par le bas. La bouche est médiocre, arrondie, entourée de cinq renflements, de couleur de chair ainsi que la membrane du pourtour. Les tentacules sont très-courts, pressés sur 3 rangs, cylindriques, pointus, un peu renflés à leur base et d'un rougebrun très-foncé. L'enveloppe externe est assez ferme, totalement papilleuse ou verruqueuse, mais les verrues sont grenues et pressées, vert-émeraude, et chacune d'elles, encadrée d'une ligne d'un rouge vif. Cette actinie vit attachée aux rochers sousmarins schisteux de la baie de Talcahuano au Chili, et remonte le long de la côte du Pérou jusqu'à Lima, où on la retrouve. Elle est commune sur le bas-fond placé près de l'ìle de Quiriquine.

44. ACTINIE BICOLORE.

Actinia bicolor, Less.

(Pl. III, fig. 3,g. n. )

Cette actinie, plus haute que large, est de la forme d'un vase, c'est-à-dire ayant un pied discoïde aplati, puis étranglé, et le corps grossissant légèrement et se renflant à l'extrémité tentaculée. Sa circonférence est assez parfaitement 
cylindrique, son enveloppe est lisse, d'un blanc de neige. La bouche est petite, en fente avec un pourtour un peu épaissi et vert-tendre. Les tentacules forment deux rangées très-touffues; ils sont minces, grêles, médiocres et d'un beau vert-émeraude.

Cette actinie est très-comnune sur le pourtour de la baie de Payta sur la côte du Pérou.

\section{ACTINIE DES MALOUINES.}

Actinia macloviana, Less.

$$
\text { (Pl. III, fig. 4, g. n.) }
$$

Cette actinie est ćylindrique, courte, attachée aux rochers schisteux de l'îlot aux Pingoins dans la baie Française de l'île Soledad, la plus orientale des Malouines. Elle a de 9 à 12 rangées de petites verrues placées en lignes verticales, de même couleur que le fond de l'enveloppe extérieure, c'est-à-dire un rouge sombre mélangé de beaucoup de vert. La bouche est petite, transversale, fendue au milieu d'une membrane rougebrun. Les tentacules sont placés sur deux rangs. Ils sont assez allongés, arrondis, pointus, colorés vivement en rouge-brun, ponctués de gouttelettes albines. Nous l'avons observée en décembre 1822 . Le dessin en représente deux individus; l'un en mamelon, les tentacules repliés, le deuxième entièrement ouvert.

46. ACTINIE OCELLÉE.

Actinia ocellata, Less.

$$
\text { ( Pl. III, fig. 5, g. n.) }
$$

Cette actinie est semi-globuleuse, arrondie, convexe, à base élargic, à enveloppe extérieure couverte de petits points trèsrouges, rapprochés, pressés; la bouche est en fente étroite, 
rouge-brun, percée au milieu d'une membrane brunâtre ayant une aire rougeâtre marginale. Les tentacules sont courts, fins, pressés, capillacés d'un brun-rouge vif.

Cette espèce, très-rare, se tient dans les crevasses des rochers de la côte de Payta au Pérou.

47. ACTINIE PEINTE.

Actinia picta, Less.

$$
\text { (Pl. III, fig. 6, g. n.) }
$$

Cette actinie est sub-égale aux deux pôles qui sont déprimés. Elle est arrondie, à enveloppe très-lisse, verte, mais finement striée de lignes verticales rapprochées et d'un vert un peu plus foncé; la bouche est ovalaire, bordée de tentacules courts, rouge-brun; sur le disque buccal aplati est une zone rougeâtre couverte d'ovales d'un jaune d'orpin, placés à côté. les uns des autres, et se touchant par leur base ou seulement séparés sur les côtés par une petite raie rouge-brunâtre.

Cette espèce est peu commune, et vit comme la précédente sur la còte de Payta au Pérou.

48. ACTINJE ERRANTE.

Actinia vagans, Less.

$$
\text { (Pl. III , fig. 7, g. n.) }
$$

Cette petite actinie appartient au genre Cereus, par ses tentacules aplatis et placés sur un seul rang. Dilatée à la base, son corps se rétrécit assez brusquement et devient cylindrique. Il est couvert de petites cannelures longitudinales, sinuolées sur le bord des anģles qui en composent les côtés. La bouche est petite, en fente, au milieu d'une aire ovalaire. Les tentacules sont allongés, spatuliformes, amincis à leur sommet et grêles 
à leur naissance. Cette actinie est en entier d'une couleur olivâtre glaucescente. Nous la trouvâmes fixée sur un test flottant de spirule aux attérages de la Nouvelle-Guinée.

49. ACTINIE NEIGEUSE.

Actinia nivea, Less.

(Pl. III, fig. 8, g. n., et fig. A et B, B, B.)

Cette actinie est remarquable par la blancheur éblouissante de toutes ses parties, et par les diverses formes qu'elle affecte dans ses mouvements de contraction. Dilatée à la base, puis conique, souvent elle se rétrécit inférieurement et se renfle supérieurement de manière à imiter un vase à fleurs(fig. B'.) Sa partie supérieure peut aussi rentrer avec les tentacules et se cacher dans l'ampleur moyenne du corps. Enfin, l'enveloppe est très-lisse, très-douce au toucher et seulement marquée de quelques ondes ou plissures verticales. La bouche est petite, arrondie, percée au milieu d'une aire ayant 4 renflements (fig. A). Les tentacules sont très-nombreux, serrés, fins, courts et implantés sur le rebord d'un plateau.

Cette actinie est très-commune à Payta, sur la côte du Pérou. Nous en trouvâmes des milliers d'individus fixés-sur les pieux du pont débarcadère vis-à-vis la ville.

5.o. EUMÉNIDES TISIPHONE.

Eumenides ophiseocoma, LEss. (P]. I, fig. I, au $1 / 4$ de g. n.)

Les euménides formeront dans la famille des actinies un genre parfaitement caractérisé par les cinq quartelles convexes qui renflent le corps, tandis que les intervalles ou fosses qui les 
séparent sont couverts, du sommet à la base, de larges ventouses dilatables, membraneuses, perforées à leur extrémité, et parfaitement analogues aux sacs stomacaux des physales. Ce genre euménides peut donc recevoir les caractères diagnostiques suivants : Corps charnu, mou, évasé, plus large que haut, adhérent aux rochers par une large surface basale, et muni d'une bouche centralc encadrée d'un bourrelet épais, sans tentacules au pourtour. Enveloppe du corps dilatée en cinq lobes convexes, composée de fibres verticales et de sillons horizontaux, séparés par cinq dépressions assez profondes, donnant naissance dans toute leur étendue à de larges ventouses membraneuses, cylindriques, sacciformes, dilatables, perforées au sommet.

L'Euménides tisiphone que nous avons représenté au quart des dimensions qu'offrait l'individu que nous avons étudié, est un des géants de la famille des actinies. Son corps est convexoobovalaire, un peu déprimé, un peu plus large que haut. Il s'attache aux rochers par une large surface plane, et son tissu est fortement contractile. Les cinq côtes arrondies, saillantes, sont légèrement sinueuses ou ondulées, douces au toucher et colorées en vert olivâtre mélangé d'une nuance fauve. La membrane interne de la bouche est d'un vert pré, et le pourtour en bourrelet de celle-ci est blanc. Les nombreux tentacules qui hérissent la surface du corps dans les intervalles des cinq renflements convexes, sont allongés, à membrane peḷlucidc dilatable, vcrmiformes, cylindriques, amincis au sommet et perforés. Ces tentacules sont sans cesse en mouvement, se dilatent considérablement quand le zoophyte est repu, et sont cylindriques ct atténués dans leur état de vacuité. Ils sont colorés en blanc-rosé diaphane avec des reflets violâtres et d'autres irisés. Le pourtour de l'ouverture terminale est d'un carmin vif, et quelques-uns sont entièrement fauves jaunâtres. 
Ce singulier zoophyte établit donc un point de contact entre les actinies et les oursins, c'est-à-dire qu'il rappelle la disposition qu'affectent ceux-ci d'avoir des piquants dans les intervalles des démarcations verticales qui partagent le corps en se dirigeant d'un pôle à l'autre. Nous rencontrâmes l'euménides tisiphone sur les récifs de corail du havre de Dorey, à la Nouvelle-Guinée, formant de gigantesques rosettes dont tous les tentacules, sans cesse agités, rappelaient à l'esprit la tête à chevelure de serpents des Euménides. 


\section{CHAPITRE XVII.}

DESCRIPTION DE LA FAMILLE DES POLYPACTINIES.

Les zoophytes actiniformes, mous, ou munis d'un squelette calcaire, à tentacules simples ou ramusculeux, bordant l'aire buccale ou recouvrant le corps, nous conduisent sans saccades aux polypes de la classe des zoophytaires de M. de Blainville, à ceux dont l'enveloppe est charnue, coriace ou même calcaire, et dont la bouche est garnie de tentacules frangés sur les bords, rétractiles comme ceux des actinies dans la partie supérieure de l'enveloppe externe ou dans le tube calcaire lorsqu'il existe. Cette famille est doncle passage des actinies aux polypes alcyons ou aux polypes multibrachidés et octobrachidés, dont les bras sont simples et l'enveloppe aussi variable de formes que de nature.

Les polypactinies sont créées sur le même type que les actinies, avec cette différence que leurs animaux sont des polypes de transition, aussi à ovaires internes; à tentacules pouvant se cacher dans l'enveloppe partielle ou commune. Leur corps est toujours cylindrique, arrondi, charnu ou coriace, et parfois se trouve empaté dans des cellules calcaires, ainsi que cela se voit dans les tubipores.

La première section, ou celle des polypactinies charnues, à corps basal simple, à polypes nombreux, comprendra notre genre actinantha, et celui de Lamarck, nommé anthelia, dont 
nous possédons un portrait inédit de la figure type de Savigny : Il est possible, cependant, que le genre anthelia reste distinct, ainsi que le xenia de Savigny. La $2^{\mathrm{e}}$ section recevra les lobulaires, lobularia; la $3^{\mathrm{e}}$ section, le genre ammothea; la $4^{\circ}$ enfin, notre genre zoantha, pour exprimer sa grande analogie de forme générale avec celui nommé zoanthus dans la famille des actinies.

Les polypactinies jouissent d'une vive sensibilité, sous la nappe d'eau qui les recouvre constamment. A la moindre agitation, lors même qu'on en est encore à plusieurs pieds, et même à 2 ou 3 toises, on les voit se contracter assez vivement, et leurs polypes s'abriter de telle sorte, que le zoophyte simule une masse coriace ou charnue, à la manière des actinies. Souvent nous sommes restés des heures entières à les faire se contracter, puis à attendre l'entier épanouissement de leurs tentacules ordinairement bordés de 4 rangs de pinnules. Chaque polype se contracte isolément ou s'épanouit seul; et en s'ouvrant, les 8 tentacules s'allongent les uns après les autres. Ces animaux sont d'une rare élégance sur les rochers de corail des mers échauffées, où ils forment souvent de vastes pelouses de la plus grande fraicheur. Ils se tiennent principalement dans les fonds des baies, sur des bancs où, à marée basse, il reste encore I à 2 pieds d'eau. En les pressant, ils vomissent de l'eau comme on l'observe aussi chez les actinies simples.

5r. ACTINANTHE BOUQUET.

Actinantha florida, Less.

$$
\text { (Pl. I, fig. 3, g. n.) }
$$

Saï:̈, dans la langue des naturels de l'île Waigiou.

Le genre actinantha est bien distinct de ceux qui composent la famille des polypactinies. Les polypes sont très-nombreux, 
arrondis, cylindriques, ayant 8 bras oblongs, à 4 rangs de cils sur chacun, et tous implantés sur une masse commune, cylindrique, basale, charnue; perforée au centre et communiquant par un canal commun avec tous les polypes par leur base. Ce corps est nu sur les côtés, et terminé par une surface plane, s'adaptant avec ténaeité sur les roches qui reçoivent le zoophyte.

C'est en août 1823 que nous observâmes sur les récifs du pourtour du Port-Praslin, à la Nouvelle-Irlande, l'actinanthe bouquet. Cet animal y était extrêmement abondant. Son eorps basal est arrondi, charnu, assez élevé, parfaitement lisse ou seulement marqué de plissures circulaires. Par sa face inférieure, il s'adapte aux rochers; sa coloration est d'un incarnat très-pâle, et son sommet est couronné d'un assez grand nombre de polypes allongés, renflés à leur base, cylindriques, à extrémité supérieure obtuse, membraneuse, perforée au centre par une ouverture parfaitement arrondie, garnie de 8 bras minces, aplatis, linéaires, oblongs, couverts en dessus de deux rangées de petits cils très-fins, et bordés sur leur lame de deux autres rangées pareilles. Ces polypes sont implantés sur la masse commune, par leur partie inférieure et renflée, les uns à côté des autres. Leur coloration est carnée-pâle; mais comme leurs cils marginaux sont d'un bleu glauque, il en résulte une teinte générale lilas: les deux rangées de cils du limbe de la lamelle sont marron.

Les actinanthes se réunissent souvent en très-grand nombre d'individus, c'est-à-dire en corps complet surmonté de polypes, et se placent près les unes des autres. Elles forment sur les rochers, où il ne reste que peu d'eau pendant la basse mer, des sortes de parterres d'une magnificenee étonnante. Les polypes sont presque toujours en mouvement; et leurs cils, en vibrant, agitent l'eau paisible, forment des courants qui précipitent vers 
eux les petits animaux dont ils se repaissent. Notre dessin, fait sur les récifs, est d'une grande exactitude.

52. ZOANTHA DES MOLUQUES.

Zoantha thalassanthos, I.Ess.

(Pl. I, fig. 2, g. n.)

Les polypes du genre zoantha sont portés sur des sortes de racines fibreuses, comme les actinies du genre zoanthus des auteurs, et les caractères de nos zoantha pourront être groupés dans la diagnose suivante : Enveloppe extérieure du corps disposée en tube membraneux, coriace, à demi-solide, oblong, légèrement ventru, rétréci à la base, et se continuant en une sorte de racine flexueuse, ramusculeuse, arrondie, amincie, anastomosée et entrelacée ou plutôt soudée avec celles qui supportent les polypes avoisinants, racines décurrentes, couchées, servant de crampon sur la roche où se fixe l'animal. La partie supérieure de cette enveloppe est amincie, soudée avec un prolongement musculeux, contractile, arrondi, à peu près égal dans tout son diamètre, tronqué au sommet où s'ouvre une bouche circulaire, entouré de 8 bras unis à leur base, très-pectinés ou frangés sur leurs bords. Ces tentacules ou bras très-coutractiles, et pouvant, avec leur limbe musculaire, se reployer en entier et se cacher dans le tube crétacéo-membraneux qui leur est inférieur et que soutient la racine.

La polypactinie zoantha thalassanthos forme de larges touffes gazomnantes et touffues, sur les roches de corail de la partie orientale de la baie de Cajéli, dans l'île de Bourou, l'une des Moluques. Les animaux imitent à faire illusion des corolles épanouies sous les eaux, corolles dont les pétales seraient sans cesse en mouvement, formant dans leur atmosphère aqueuse divers petits courants dans l'oscillation desquels 
sont précipités comme dans un torrent, les animalcules qui leur servent d'aliments. Au moindre mouvement de progression dans l'onde par les jours de calme, ces zoophytes sont avertis d'un danger, et aussitôt on les voit replier successivement leurs tentacules, et se presser de manière à imiter un clou dont la tête serait formée par le repli des bras. Lorsqu'on les touche, il en résulte un prurit assez persistant sur les parties nues, qui annonce une action vénéneuse, peut-être, de leurs franges.

Les sortes de racines traçantes qui se cramponnent aux roches sont d'un blanc pur. L'enveloppe renflée et fusiforme du corps est d'un rouge-brun foncé, marqué de stries plus colorées longitudinales. Sa consistance est ferme et parcheminacée. Le tube arrondi musculaire est rougeâtre clair, et surtout trèscontractile, et les 8 bras qui le couronnent sont allongés, marqués au centre, chacun, d'une nervure jaune. Ils sont rougeâtres; leurs pinnules marron clair, et leur sommet est jaune pur.

DESCRIPTION DE LA FAMILLE DES NEPHTHÉEs, nephthce.

Les deux espèces de zoophytes gravées pl. 2 et fig. 5 et 6 de l'ouvrage de la commission d'Égypte sans autre indication que le nom de nephthées écrit au bas de la planche, laissent des doutes très-grands sur la place qu'on doit leur assigner. M. de Blainville les a placés dans ses zoophytaires sarcinoïdes ou alcyonnaires, entre les xenia et les anthelia de M. Savigny, et proche les alcyons et les éponges. Notre opinion est que les nephthées doivent former une famille bien distincte, conduisant des actinies, des polypactinies et des isaures aux polypes à 8 bras et aux éponges.

Ce sont des actinies et des polypactinies par une enveloppe extérieure assez consistante, renfermant un polype interne à 8 
divisions soudées et engagées dans une aire membraneuse, percée au centre par une bouche, garnie de 8 mamelons dus au renflement des bras polypiformes. Puis, comme les isaures, ces zoophytes sont supportés par une masse commune lobée ou rameuse, et enfin, comme les éponges, le tissu qui entre dans la texture des ramifications est celluleux ou rayonné, en même temps que des spicules charnus hérissent sa surface; spicules musculaires, il est vrai, et externes, tandis que dans les éponges ils sont internes et calcaires ou siliceux.

Les nephthées ne comprennent, dans l'état actuel de nos connaissances, que deux genres: celui nommé par Savigny nephthcea, et celui que nous avons établi dans nos Illustrations de zoologie sous le nom de spongode, spongodes, pl. 2 I.

Les animaux dugenre nephthée sont polypiformes, à 8 bras ténus, fixés dans une membrane circulaire percée au milieu par un trou parfaitement rond, bras renflés, mamelonnés, renfermés dans une enveloppe ou corps subglobuleux, composé de 8 côtes falciformes soudées par les hords, ouvertes au sommet, entourées et portées par des spicules carnoso-tendineux, groupés sur des ramuscules coniques, soutenus par une masse commune celluleuse, fixée par la base et ramifiée au sommet, formée intérieurement de cellules anguleuses, cloisonnées, et aboutissant à un ou plusieurs centres.

Notre genre spongodes doit en être différencié par les caractères suivants : Animanx à 8 bras, simples, mamelonnés, unis, renfermés dans un corps oviforme, petit, régulier, formé de 8 côtes spiculifères soudées par les bords, un peu renflé au sommet ou existe au milieu de 8 petits mamelons une ouverture arrondie. Ces corps, façonnés en clochette, se rétrécissent à leur base, et s'attachent à des faisceaux de spicules cylindracés, très-alténués aux deux extrémités, hérissonnés de petits mamelons à leur surface, et formant par leur réunion des épis ser- 
rés, groupés en petits pompons coniques sur les branches membraneuses, au nombre de cinq ordinairement, d'une masse commune celluleuse, fixée par la base aux rochers, et composée de cellules aboutissant à un axe central, et toutes séparées par des cloisons rayonnantes.

Par ses caractères généraux, ce genre est bien distinct, quoique voisin des nephthées. La seule espèce connue est la spongode crête de coq.

\section{SPONGODE CRETE DE COQ.}

Spongodes celosia, Less., Illust. de Zool., pl. 2 I.

Ce zoophyte se compose d'un corps cylindrique, dilaté, fixé par la base sur les récifs de corail, de texture molle, membraneuse, pellucide, blanche, légèrement et à peine striée, stries qui paraissent être des spicules d'une extrême délicatesse. La base paraît former adhérence à la roche sur laquelle elle s'attache par des replis membraneux. Ce corps, long d'environ un pouce, se divise bientôt en 4 à 5 troncs assez courts, gros à proportion, aussi membraneux. Leur intérieur est comme vide ou du moins rempli par des cellules dont les cloisons, au nombre de $\mathbf{2}$ environ, rayonnent du centre à la circonférence, et forment au milieu un axe dù à la soudure de toutes les lames des cloisons. Parfois il y a de ces cloisons qui s'oblitèrent ou qui se réunissent lorsque le corps donne naissance à uu tronc. Sur les rameaux que nous venons d'indiquer, sinsèrent abondamment, bien que d'une manière éparse, de petits chatons vivement colorés en rouge-ponceau, qui paraisseut à la vue simple comme de petites houppes serrées, informes, et qui sont le résultat du tassement d'un grand nombre de spicules 
musculaires, supportant les animaux proprement dits, c'est-àdire les petites clochettes percées au sommet, formées de 8 lamelles soudécs qui renferment le polype avec ses 8 tentacules inembraneux. Un court pédoncule fixe cette clochette ou plutôt ce polype méloniforme sur les tiges charnues nommées par analogie avec les axes des éponges, spicules. Mais ici, ces spicules sont simples, presque droits, renflés au milieu, puis atténués aux extrémités qui s'allongent en pointe grêle. Leur surface est couverte de petits points granuleux, et semble hérissonnée.

La spongode est donc un zoophyte qui semble être façonné sur le type des éponges par sa texture celluleuse, ses spicules; mais c'est près des polypes qu'elle doit prendre place par ses animaux. Nous devons dire cependant que nous avons rencontré des éponges dont les ccllules et le corps étaient enveloppés par une nembrane charnue, épaisse, très-irritable, et le moment n'est peut-être pas loin où les animaux qui vivent dans ces corps obscurs seront découverts. Quant aux axes calcaires ou spicules qui sont logés dans les cellules, ils sont le résultat du dépôt et de la cristallisation des matières minérales, de la même manière qu'on retrouve ce phénomène dans les végétaux à mailles du tissu cellulaire lâches.

La spongode imite à faire illusion une panicule de Celosia crista-galli. Sa tige blanche, ses ramelets rouges, fixés sur les rocher's de corail à quelques pieds sous l'eau, en font un zoophyte des plus remarquables. Nous le trouvâmes au fond de la baie de Cajéli, une des Moluques les plus rapprochées de la terre des Papous. 
DESCRIPTION DE LA FAMILLE DES POLYPES.

\section{SARCOPHYTE LOBULÉ.}

Sarcophyton lobulatum, LEss."

Nous avons donné une figure réduite de moitié de ce nouveau genre, à la pl. 2 des zoophytes du Voy. aux Indes-Orientales de M. Bélanger, figure dessinée d'après nature à la Nouvelle-Irlaude, et sur le polypier lui-même encore attaché au rocher, et recouvert par les eaux de la mer.

Les sarcophytes sont des animaux polypes à 8 bras simples, arrondis, grêles, libres excepté à la base où ils sont enchâssés dans une membrane perforée au milieu, couronnant un corps membraneux, cylindrique, extensible, à 8 côtes verticales trèsmarquées, aboutissant aux 8 bras. Ce corps est rarement exsertile, et le plus habituellement caché dans une cellule arrondie, bordée de 8 points correspondants aux 8 côtes longitudinales du polype. Les cellules sans nombre qui logent les polypes, sont toutes rapprochées, placées à distance les unes des autres dans une masse charnue, molle, de nature gélatinoso-musculeuse, abondamment lubrifiée par un enduit onctueux de consistance de mucilage; masse attachée aux rochers par un pédicule court, s'évasant en simulant un large champignon dont le chapeau serait ondulé, bien que plane, et la circonférence très-diversement lobée et lobulée. Ce disque agariciforme est peu épais, à rebord arrondi ; et notre dessin le représente avec exactitude, mais réduit de moitié.

Le sarcophyte lobulé forme très-fréquemment de larges rosettes ou touffes, à deux pieds et plus sous l'eau, sur les récifs de corail du Port-Praslin à la Nouvelle-Irlande. La masse char- 
nue est olivâtre sur tous les points. Le cercle de pores qu'on remarque sur le pourtour de chaque cellule est noir. Les bras du polype sont d'un jaune d'or vif, et le corps est rougeâtre avec les 8 côtes longitudinales rouge-brun foncé. Ces dernières seraient-elles les ovaires?

\section{TUBASTRÉE ÉCARLATE.}

\section{Tubastraa coccinea, Less.}

Le nombre des planches qui nous avait été accordé, ayant été outre-passé, il nous a fallu saisir l'occasion de figurer ce polypier madréporique de la fainille des Astrées, dans l'atlas zoologique du Voyage aux Indes-Orientales de M. Bélanger, pl. I des Zoophytes.

Ce polypier retrace assez bien la disposition de certaines caryophyllies sareinules, et ne s'éloigne de la famille des Actinolithes que par le petit nombre de divisions brachiales de l'animal. Cette tubastrée se eompose de tubes cylindriques assez eourts, enehâssés par leur base dans une pâte commune, encroûtante, gravitant vers la forme arrondie, c'est-à-dire que les tubes, toujours courts lorsqu'ils sont distincts, très-souvent enchâssés jusqu'à leur terminaison ouverte, affectent une grande tendanee à former des roches libres, semi-arrondies, ou, lorsque leur base est attachée, des têtes subglobuleuses. Ces tubes sont distants, séparés par des sillons plus ou moins profonds, parfois rapprochés, accolés et même soudés, arrondis sur leur surface libre, qui est très-finement striée de cannelures verticales. Chaque tube est complètement ouvert au sommet en cellule ronde, unique, creusée en soucoupe conico-concave forméc de 6 ou 8 grandes lamelles et de 6 ou 8 plus petites, ou en les eomptant toutes de 12 à 16 loges. Ces lamelles rayonnantes et partant du fond de la loge sont verticales, étroites, et se 
terminent au rebord ou cercle marginal mince, sans le dépasser, bien distinctes en cela de celles des caryophyllies, et surtout leur bord étant en biseau, et nullement relevé en bourrelet.

Les stries verticales qui marquent la surface externe des cylindres de ce polypier sont guillochées, c'est-à-dire très-rapprochées, très-fines et comme ponctuées. Les lamelles des cellules terminales sont étroites, et aboutissent à l'axe basal du cylindre. Une épaisse enveloppe charnue, colorée en rouge de sang des plus éclatants, recouvre toute la matière calcaire qui est friable, cellulense ou du moins peu compacte. Cette teinte brillante disparait aussitôt que les polypes sortis de l'eau viennent à mourir, et passe au noir. Chaque cellule est donc tapissée d'un repli de cette membrane animalisée rutilante, et se trouve occupée par un polype attaché à ses parois par la base, de forme arrondie, courte, terminée par une petite aire subhénisphérique percée d'un trou exactement rond et bordée de 8 bras simples, allongés, médiocres, filiformes, libres dans toute leur étendue, excepté à leur base, légèrement arrondis, et un peu renflés à leur terminaison. Ces polypes sont en entier d'un jaune très-brillant, et les 8 bras sont étendus dans les grandes cloisons qu’ils dépassent un peu.

La tubastrée écarlate constitue des sortes de têtes globuleuses fréquemment supportées par des parties dépouillées, qui ont dû être les premières formées, et dont les animaux ont péri par des causes accidentelles. Nous la croyons très-rare, car nous n'en trouvâmes que quelques échantillons maigres sur l'immense récif qui découvre à mer basse, à l'entrée de la baie de Beula, et qui sert de ceinture à Borabora, l'une des îles de l'Archipel de la Société. Nous ne l'avons rencontrée nulle part ailleurs. 


\section{CHAPITRE X VIII.}

DESCRIPTION DE LA FAMILLE DES bÉRoÏDES.

Les animaux de cette famille nommée Ciliogrades ou Vibrantes par quelques auteurs, conduisent aux médusaires par des véritables béroés sans cils. Les cténophores, en effet, ont constamment un canal vertical ouvert en haut et en bas, et enveloppé de parties musculaires très-diversiformes à lignes garnies de cils vibratoires, disposés tantôt horizontalement, tantôt verticalement. Ces zoophytes assez compliqués dans leur organisation, paraissent même énettre à certaine époque de leur croissance des prolongements cirrhigères qui sont probablement des organes reproducteurs. D'autres, par une organisation plus compliquée, semblent même conduire à quelques ptéropodes, et à certains mollusques nucléobranches, et présenter une analogie assez remarquable avec les salpas ou biphores. On ne peut même les rejeter loin de ces derniers que par le manque apparent de nucléus.

Tels que nous avons étudié les animaux de cette famille, ils nous semblent organisés de la manière qui suit : corps très-diversiforme, mucilagineux, diaphane, peu consistant et se brisant aisément par la pression, présentant sur sa surface des lignes toujours droites qu'elles soient verticales ou horizontales, partant toujours d'une extrémité qu'on pourrait appeler ciligère, et se perdant vers le pôle opposé qu'on pourrait nommer aquifère. Ces lignes sont formées par un canal fin, droit, parfois 
dentelé sur les bords, et garni au milieu ou sur les côtés de petites lignes régulières de lames branchiales, minces, courtes, attachées par les bouts sur un support capillacé, comme le sont les lanıes de bois des volets, dits jalousies ou persiennes, et se mouvant de haut en bas en demi-cercle, absolument de la même manière que des volets. Ces lames qu'on nomme cils sont trèsirritables, très-mobiles, assez analogues à celles des cordons respiratoires des physales, et décomposent la lumière qui traverse leurs interstices, en isolant les rayons lumineux, et produisant l'irisation.

L'extrémité aquifère, quel que soit le diamètre de son ouverture, parait avoir pour but de recevoir la colonne d'eau sur laquelle agissent ses parois pour assurer la locomotion, en même temps que parfois, et rarement cependant, l'eau qui passe dans le canal central fournit à la respiration de l'animal, et par suite en entraínant des corps étrangers dissous, à sa nourriture. On remarque, en effet, que protégé au milieu du canal médian traversé par l'eau, se trouve le tube digestif, formant tantôt un seul conduit droit, tantôt un canal composé d'entonnoirs accolés sommet à sommet, ou séparés dans quelques cas par un étroit tuyau de communication. Quelquefois enfin le tube digestif ne va que jusqu'au milieu du corps, et là se divise en conduits égaux en nombre aux rangées respiratoires ou ciliaires, et s'y joint pour disparaître dans le canal central de chaque rangée. Enfin, dans une espèce, nous avons trouvé près du sac stomacal des grains nombreux qui seraient peut-être des ovaires. Toujours cependant existe-t-il deux ouvertures aboutissant au canal de l'axe du corps, l'une plins petite, souvent ciliée sur sou pourtour ou la bouche, l'autre grande où viennent aboutir les prolongements cirrhigères quand ils existent et l'anus, reçoit aussi dans l'ampleur de sa cavité l'eau que ses parois conprimeut, et celle-là est véritablement l'organe locomoteur par ex- 
cellence, lorsque les prolongements latéraux et musculaires viennent à manquer. Fréquemment enfin, la bouche semble être multiple, c'est-à-dire avoir une ouverture commune d'où partent quatre conduits nourriciers, dont deux se dirigent verticalement et deux latéralement, ainsi que cela s'observe dans les callianires.

Les béroïdes ont été jusqu'à ce jour assez mal étudiés. Ce sont des zoophytes qui conduisent aux méduses, et les méduses elles-mêmes sont les êtres les plus simples de tout le règne animal, sans en excepter les éponges. Comme les méduses, les béroïdes se trouvent dans toutes les mers du monde, nageant entre deux eaux à l'aide de l'élasticité contractile de leur tissu cutané, et surtout par le moyen des mouvements ondulatoires des nageoires quand ils en ont, ou par l'entonnoir postéricur ou aquifère. Dans l'eau, leur position est très-oblique et presque horizontale, ce que l'on conçoit d'autant mieux, que l'ean qui passe dans la cavité de l'axe doit servir elle-même à la locomotion. Ces animaux se nourrissent-ils du frai et des matières graisseuses dont la mer est parfois couverte dans l'intervalle de plusieurs milles?

Leurs cils, par leurs brusques mouvements et leurs rapprochements, opèrent le phénomène d'irisation très-connu. Souvent aussi les béroides produisent une phosphorescence des plus-vives.

Nous avions eu le projet de rédiger une liste systématique et descriptive des béroïdes décrits, mais ce travail nous eût entrainé beaucoup trop loin, et nous avons dû nous borner à dresser un tableau des familles, tribus et genres que nous avons adopté après une étude sérieuse. A la suite de l'esquisse de cette famille, nous donnerons purement et simplement les descriplions des zoophytes qui lui appartiennent, et qui ont été figurés dans notre atlas. 


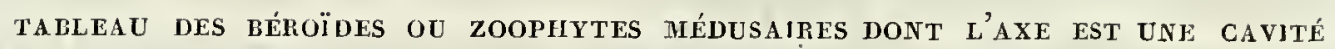
S'ouvrant en haUt ET EN bas dU CORPS, MUUN OU PRIVÉ de CILS.

I $^{\text {re }}$ fam. Les Ciliobranches.

Corps ovalaire, ou symétrique et diversiforme, de substance muqueuse, traversé par des lignes à lamelles nommćes cils.

$$
1^{\text {re }} \text { tribu : les Cestes. }
$$

Corps transversal, très-large, peu haut, mince. Deux rangées de cils sur le rebord supérieur, parfois des prolongements cirrhigères sortant par 2 orifices sur le bord de l'extrémité aquifère.

$1^{\text {er }}$ genre. Ceste, Cestum, Lesueur, csp.; C. veneris; C. naïadis, Eschs.

$2_{2}^{\mathrm{e}}$ genre. Lcmnisque, Lemniscus, Quoy et Gaim.

type : Lemnisque bordé de rouge, Quoy et Gaim., pl. 86, fig. I.

\section{$2^{\mathrm{e}}$ tribu : lcs Callianires.}

Corps transversal, plus lraut que large, ayant des nageoires latérales, et parfois des folioles natatrices isolées. Les cils par doubles rangées verticales sur les bords des nageoires.

$3^{\mathrm{e}}$ genre. Callianire, Callianira, Péron.

C. diploptère, Péron, Ann. mus., tom. I5, pl. 2, fig. I6.

C. d'Amboine, Q. et G.; C. triploptère, Lam.

$4^{\mathrm{e}}$ genre. Polyptère, Polyptera, Less.

Type : Callianira heteroptera, Eys. et Cham.; pl. 3 , fig. I, $a, b, c{ }^{\mathrm{I}}$.

1 MM. de Chamisso et Eysenhardt déerivent ce Zoophyte ainsi qu'il suit:

"Callianira heteroptera, Ch. et Eys., pl. 3ז, fig. 3, a.b,c.

"Animal hyalin, très-fragile; corps tubuleux, eylindrique, dilaté antérieurement; bouehe " transversale? (II nous a été impossible de pénétrer dedans toutefois.) Une seule aile de chaque " eôté, grancle, large, eestö̈de, ciliée sur ehaque bord, à eils irisés, toujours en monvement. "Ailes intermédiaires plus petites, au nombre de six, 4 supérieures laneéolées, soudées au eorps 
$5^{\text {e }}$ genre. Calymma, Calymma, Eschsch.

Types : C. Trevirani, Esch., pl. 2, fig. 5 ; C. Reynaudï, ou callianira bucephalon, Ray., in Lcsson Cent., pl. 28.

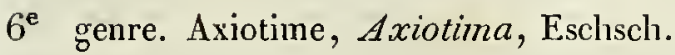

Typc : A. Gaedei, Esch., pl. 2, fig. 6.

$3^{\mathrm{e}}$ tribu : les Neis.

Corps comprimé, mince, plus haut que large. Deux rangées de cils entourant lc milieu du corps. Quatre rangées de cils sur les côtés.

$7^{\mathrm{e}}$ genre. Neïs, Neis, Less.

Type : Neis cordigera, Tess., pl. 16, fig. 2.

$8^{\text {e }}$ genre. Mnemia, Mnemia, Eschsch.

Types : M. Schneiggeri, Esch.; M. Kuhlii, Eschsch; M. Chamissonis, Esch.

$4^{\text {e }}$ tribu : les Ocynó́s.

Corps vertical, peu haut; ailes ou appendiccs étendus horizontalement, et munis au milieu et en dessus de rangées transversalcs de cils.

$9^{\mathrm{e}}$ genre. Alcinoé, Alcinoe, Rang.

Type : Alcinoé verniculée, Rang., Mem. hist. nat., tom. 4, pl. 8.

$10^{\mathrm{e}}$ genre. Ocyroć, Ocyroe, Rang.

Types: Ocyroé cristalline, Rang.; Ocyroé tachée, Rang.; Ocyroé brtune, Rang., Mem. Soc. hist. nat., tom. 4, pl. 19.

"par leur base, eiliées sur leurs bords : 2 inférieures, différant des 4 premières, ayant les plus "grands rapports avee les grandes ailes latérales, cestoïdes et ciliées sur leurs bords:

"Le eap de Bonne-Espérance, rade de Table-Bay."

Fig. 3. $a$ et $b$. Le Zoophyte. $c$. Les eils des ailes.

"Genre obseur, qu'on doit plaeer suivant Lamarek eutre les Béroés et les Cestes, eomme un " type distinet, mais qu'on ne doit pas réunir aux Béroés, ainsi que le veut M. Cuvier, ni diviser " en deux genres (Callianira et Janira), ainsi que le pense M. Oken. Les eils des bords des ailes "peuvent étre comparés aux raugćes de eils des Búroés, mais non à des branchies ainsi que le eroit "Péron. 
$5^{\mathrm{e}}$ tribu : les Eucharis.

Corps ovalaire ou subdéprimé, à 8 ou 9 rangées de cils s'étendant d'un pôle à l'autre. Tube digestif formé de deux entonuoirs unis par un canal étroit ; deux prolongenents cirrhigères partant du milieu en dedans du corps, peut.être des ovaires.

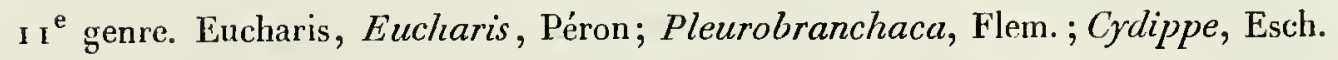

Types : $\mathrm{I}^{\circ}$ Eucharis pileus ou Beroe pileus, L., Encycl., pl. 9o, fig. 3 et 4 ; Scoresby, pl. I6, fig. 5 Bosc, pl. 15 ;

$2_{2}^{\circ}$ E. ovum ou Medusa ovum, L.;

$3^{\circ}$ Beroe densa, Forsk. ;

$4^{\circ}$ Beroe cucullus, Fab.

${ }_{12}{ }^{\mathrm{e}}$ genre. Mertensie, Mertensia, Less.

Types : Mertensia groenlandica, Less.; Mertens, pl. P, fig. G, tom. 2, pag. 122 des Voy. au Nord, èt Scoresby, pl. 16, fig. 4 .

I $3^{\mathbf{e}}$ genre. Janire. Janira, de Fréminv., Oken.

Type : Béroé hexagone, Encycl., pl. 9o, fig. 6.

$$
6^{\mathrm{e}} \text { tribu : les BÉROÏDEs. }
$$

Corps ovalaire, cylindrique, à 8 ou 9 rangées de cils se dirigeant d'un pôle à l'autre; canal subcentral, large et simple. Nul appendice.

(Nota.) On pourrait classer ici le genre Allas de Lestueur et notre s. g. Dubreuillia. L'un et l'autre font le passage des Béroés aux mollusques.

I $4^{\mathbf{e}}$ genre. Béroé, Beroe, Müller.

Types : Beroe ovata, Encycl., pl. 9o, fig. 2 ; Beroe Basteri, Less., pl. ı6, fig. I; Beroe, Scoresb., pl. 16, fig. 6, et Mertens , pl. P., fig. H; Beroe, Scoresb., pl. 16 , fig. 5 .

$15^{\mathrm{e}}$ genre. Idye, Idya, Oken.

Types : Beroe macrostomus, Péron, Atl., pl. 6r , fig. I ; Less., pl. г 5, fig. 2 ; Beroe ovata, Chan. et Eys., pl. 3o, fig. 3 ; Beroe, 
Scoresby, pl. I6, fig. 7; Beroe punctata, Ch. et Eys., pl. 3 I, fig. I ; Beroe capensis, Ch. et Eys., pl. 3o, fig. $4^{1}$.

${ }_{16}$ e genre. Médée, Medea, Esch.

Type : Beroe constricta, Cham. et Eys. ${ }^{2}, \mathrm{pl} ., 3 \mathrm{r}$, fig. 2 ; et Medea rufescens, pl. 3 , fig. 3 ; Beroe, Scoresby, pl. 16, fig. 8 .

$17^{\mathrm{e}}$ genre. Pandore, Panclora, Esch.

Type : Pandora Flemingii, Esch., pl. 2, fig. 7 .

$18^{\mathrm{e}}$ genre. Cydalise, Cydalisia, Less.

Type : Beroe mitraformis, Less., pl. r 5 , fig. 3.

' Ces 3 espèces de MMI. de Chamisso et Eyscnhardt, sont ainsi déerites :

I -Beroe orata, Bosc, C. icone. Brownii, Jam., page 384 , tab. 43 , fig. 2 , pl. 30 , fig. 3.

Dans l'océan Atlantique équinoxial.

$z$ Beroe capensis, Ch. et Eys., pl. 3o, fig. 4, $a, b$.

Forme oblongue, différente du précédent : les individus pris n'ont jamais été trouvés entiers. 8 côtes ciliées rougeâtres, dont la disposition est rendue par la fig. $a$. Réseau vaseulaire de la surface extérieure du corps brunâtre, ce qui n’a pas lieu dans l'espèce précédente.

Le eap de Bonne-Espérance à Table-Bay.

3-Beroe punctata, Ch. et Eys. Pl. 3 1 , fig. I. $a, b, c$ :

Corps ponetué, atténué vers la bouche, diffère de l'ovata par la série de cils qui s'arrêtent devant la bouche.

A. animal vu de côté. B. bouche. C. extrémité.

Océan $\Lambda$ tlantique équinoxial, observé par Eschseholtz.

Ces auteurs le déerivent de la manière qui suit :

"Beroe constricta, Ch. et Eys. Pl. 3 I, fig. 2.

Zoophyte long d'un demi-pouce, légèrement fauve, plus dense que les autres espèces observées par nous. Corps ovalaire, déprimé, rétréci vis-à-vis l'ouverture. Bonche ample, bilabiée. 8 rangécs de eils irisés, partant de l'ouverture buecale, et se terminant au sommet en pinceaux doubles. L'animal ouvre et ferme son ouverturc pour donner passage à l'eau, d'où résulte un mouvement de vic et de locomotion. La mer des Indes. 


\section{$2^{\mathrm{e}}$ fam. Les Acils.}

Corps sacciforme, biforé, de substance muqueuse. Nulles traces de cils.

Obs. : famille conduisant aux Méduses.

$$
7^{e} \text { tribu : les BÉrosomes. }
$$

$19^{\mathrm{e}}$ genre. Doliole, Doliolum, Otto.

Type : Doliolum Mediterraneum, Otto, fig. 13.

${ }_{20}{ }^{\mathbf{e}}$ genre. Epomis, Epomis, Less.

Type : Beroe gargantua, Less., pl. I5, fig. I.

$2 \mathrm{I}^{\mathrm{e}}$ genre. Bourse, Bursarizs, Less.

Type : Bursarius Cytherce, Less., pl. I4, fig. I.

$22^{\mathrm{e}}$ genre. Bougainvillie, Bougainvillia, Less.

Type : Cyanea Bougainvillii, Less., pl. ז4, fig. 3.

\section{LEMNISQUE (CESTE?) BORDÉ DE ROUGE.}

Lemniscus marginatus, Q. et G., Zool. Ur., pl. 86, fig. I.

La plupart des zoologistes de notre époque regardent le genre lemnisque de MM. Quoy et Gaimard, comme un fragment de ceste. Cette opinion est très-probable, car nous n'en avons rencontré nous-mêmes qu'un morceau long de 2 pieds et large d'un pouce, n'ayant aucune trace de vaisseaux, ni même de cils.

C'est le 24 juillet 1824 , sur les attérages de la Nouvelle-Guinée, que nous trouvâmes le lemnisque flottant à la surface de la mer par un beau jour de calme, et ayant l'aspect d'un large ruban blanc satiné bordé de deux lisérés roses. Le fragment que nous examinâmes était arrondi à ses extrémités, mince, formé 
de deux feuillets accolés, ayant au milieu une ligne médiane transversale d'un blanc mat. Sa consistance, d'une grande fragilité, n'a point permis qu'on l'examinât, car au moindre choc il se brisait, et sorti de l'eau les parcelles se dissolvaient aussitòt.

57. NEIS BOURSE DE MER.

Neis cordigera, Less.

$$
\text { (Pl. XVI, fig. 2, g. n.) }
$$

Ce nouveau genre de zoophyte à cils est remarquable par son corps aminci sur ses deux faces en coin, obcordé au pôle supérieur, et largement ouvert au pôle natateur. L'axe cavitaire est allongé, étroit, bordé sur ses 2 faces de cils unis en haut, et libres en bas, et de 2 rangées sur tous les bords, soit des pôles, soit des côtés.

C'est le 18 mars 1824 , que nous observâmes dans le petit golfe nommé Port-Jackson, dans la Nouvelle-Galles du Sud, ce zoophyte, que notre dessin représente de grandeur naturelle. La forme qu'il affecte est celle d'un coin dont le biseau serait échancré en forme de cœur. Au milieu de ce biseau que garnissent deux rangées de cils placées à se toucher, dans l'enfoncement et au milieu de l'animal existe une très-petite ouverture. Si le biseau échancré est mince, le corps s'épaissit successivement jusqu’à sa terminaison, terminaison rétrécie et munie d'une très-longue ouverture dont les bords membraneux sont garnis chacun de cils irisés. Deux rangées de cils garnissent les angles aigus des côtés dont la face est plane, ainsi que les faces antérieures et postérieures. Mais celles-ci ont chacune une double rangée de cils rapprochés, libres, près la grande ouverture, et réunis en un demi-cercle près l'échancrure de l'extrémité cordiforme. 
La consistance de la neïs est d'une grande nollesse. Le tissu qui la compose se brise aisément. Sa coloration, sur les deux grandes faces planes, est un blanc hyalin, parsemé d'un grand nombre de veinules anastomosées, et celle des côtés est un jaune mordoré linéolé de traits enlacés jaune clair. Les cils, saus cesse en mouvement, possèdent la propriété irisante à un haut degré. Les lèvres de la grande ouverture, servant d'ailes natatoires, sont minces, et très-contractiles.

58. BÉROÉ DE BASTER.

Beroe Basteri, Less.

(Pl. XVI, fig. I, g. n., fig. I, A, vu de côté, et fig. I, B, vu par le pôle buccal.

Ce zoophyte de la tribu des vrais béroés, a la forme d'un petit melon, c'est-ì-dire qu'il est assez régulièrement ovalaire. Sa surface extérieure est marquée par 9 lignes de cils très-fins, très-blancs, et sans éclat irisé, mais très-mobiles dans leur acte vibratoire. Toutefois les cils ne sont pas extérieurs, car une membrane nuageuse enveloppe tout le zoophyte comme dans une deuxième tunique (fig. I, B). Le pôle supérieur s'ouvre au nilieu par une bouche petite et arrondie, où aboutissent sur les côtés des tubes digestifs qui se contournent sur eux-mêmes, en se tortillant et descendant au pôle inférieur où s'ouvre l'anus. L'axe cavitaire est occupé par un canal cylindrique, qui envoie un petit canal à chacume des rangées de cils. Des grains nombreux réunis en paquets garnissent les côtés du tube digestif.

Ce béroé, d'organisation assez conıliquée pour être sans contredit classé avec les mollusques, est d'une transparence parfaite. Sa couleur est un blanc de cristal, qui s'efface dans 
l'eau, au point que l'animal n'apparait plus que sous la forme de linéaments nuageux, et il ne devient opaque que sorti de l'eau.

Ce béroé a été pris par un ealme sur les côtes du Pérou, non loin de Callao dans l'océan Pacifique.

59. BÉROÉ (IDYA) MACROSTOME.

Beroe (idya) macrostomus, Péron.

$$
\text { (Pl. XV, fig. 2, g. n.) }
$$

Nous avons dû rapporter le béroé gravé pl. I5, fig. 2 de notre atlas, au B. macrostomus de Péron (Voy. aux terres australes, atlas, pl. 6I, fig. 2), car les deux dessins se rapportent entre eux par les contours, le nombre des rangées de cils, la forme des ouvertures, et ne diffèrent que par les proportions relatives.

Nous rencontrâmes un assez grand nombre d'individus semblables de ee béroé, le 2 septembre 1823 , alors que la corvette la Coquille longeait les côtes de la Nouvelle-Guinée, sous l'équateur même. La forme de ee zoophyte est celle d'un sac à deux ouvertures, cylindrique, mou, peu ouvert à l'extrémité arrondie ou orale, et largement fendu au pôle opposé qui est tronqué. Le pourtour de l'ouverture orale est eerclé de rose, puis donne naissance à huit rangées de cils, rangées qui sont espacées, régulièrement verticales, et qui cessent vers les lèvres simples et minces de la gुrande ouverture ou du pôle natatenr et aquifère. Ces cils jouissent du plus grand éclat métallique, et produisent une irisation des plus brillantes. Quant au parenchyme en lui-même, c'est une substance mollasse, d'un blanc mat, plus ou moins fortement linéolée de stries rosées, enlaeées et enchevêtrées les unes dans les autres. Souvent la 
teinte rosée des dessins est remplacée par des lignes roses blafardes ou même tout-ì-fait albescentes.

Ce béroé est beaucoup moins compliqué dans son organisation que le précédent. Ce serait une médusaire sans ses rangées de cils et ses deux ouvertures. Ses mouvements de contraction et de distension sont très-vifs, et sa locomotion s'opère en poussant d'arrière en avant le corps qui est obliquement suspendu dans l'eau.

6o. BÉROÉ (CYDALISE) MITRE.

Beroe (cydalisia) mitraformis, Less.

$$
\text { (Pl. XV, fig. 3, g. n.) }
$$

Les béroés du genre $c y$ dalise de notre tableau, se distinguent des idya dont ils se rapprochent par la simplicité de leur organisation, parce que leur extrémité orale est conique, presque pointue, et qu'au lieu d'avoir une seule ouverture, elle en a deux, petites, arrondies, presque jointes, et couronnées, chacune, d'une petite frange de cils d'où partent les 8 rangées longitudinales.

Nous rencontràmes communément le béroé en forme de mitre le 23 mars i 823 par 6 degrés de lat. Sud, à cinquante lieues au large de la côte du Pérou. Dans l'eau sa teinte est diaphane, rosée; ses mouvements sont pleins de vie, et il chemine avec grande prestesse à l'aide de l'ouverture assez large, arrondie, de son pôle natateur. Sa forme est celle d'un cône allongé, à base tronquée largement ouverte; puis soll diamètre qui est cylindrique, se renfle un peu, et finit en s'atténuant graduellement par une pointe obtuse. Les 8 rangées de cils d'abord très-rapprochées au sommet, s'éloignent ensuite et s'arrêtent à un cercle rosé qui enceint la grande ouverture. Ces cils sont très-brillants et éminemment irisateurs, car les teintes 
roses, violettes, pourpres, bleucs métallisées se succèdent avec la rapidité du jet de lumière qui les produit en se décomposant. A peine sorti de l'eau, la vie, chez ce béroé, cesse, et on le voit alors se dissoudre en un mucus blanchâtre, qui ne laisse après lui aucune trace.

6. BÉROÉ (ÉPOMIS) GARGANTUA.

Beroe (epomis) Gargantua, Less.

$$
\text { (Pl. XV, fig. I, g. n.) }
$$

Païpaï, dans la langue des habitants d'O-Taïti.

Le genre épomis (d'气̇ंopis, chansse de docteur) établit le passage des béroés et des idya, aux bursarius et aux vraies méduses. C'est en effet par sa forme allongée, ses deux pôles ouverts, un béroé; mais c'est une méduse par son tissu rénittent, sans aucune trace de cils. Le genre epomis aura pour caractères les suivants: Corps cylindrique; extrémité orale, arrondie, percée par une bouche à 4 angles, à substance charnue, cristalliniforme, composée de fragments accolés; nulle trace de cils. Le pôle natateur tronqué, large, ayant une grande ouverture bordée d'une membrane mince, tendue sur le pourtour, et renforcée en dehors par 4 pilicrs denses, rénittents, épais.

Le béroé gargantua a été figuré de grandeur naturelle. Nous le trouvâmes en mai 1823 dans les criques de la baie de Matavai de l'île d'O-Taiti. Les insulaires nous firent signe que c'était une substance susceptible de servir d'aliment, mais comme ils éprouvèrent de la répugnance, lorsque nous les engageâmes à la manger, nous devons raisonnablement douter de cette proprićté. Les O-Taïtiens sont naturellement gais et moqueurs, et il se pourrait que les naturels qui nous accompagnaient au moment où nous rencontrâmes ce zoophyte, aient voulu se jouer 
de notre empressement à leur faire des questions, auxquelles très-souvent ils répondent de travers.

Ce zoophyte est de consistance charnue, muqueuse, d'une transparence parfaite, sans aucune trace de conduits vasculaires, ni de tubes digestifs. Sa surface est comme cannelée, ce qui est dù à des sortes de piliers renflés, convexes, soudés par leurs bords et séparés par des sortes de rainures très-inégales : les piliers sont épais, courts et enchevêtrés inégalement les uns avec les autres. L'ouverture natatrice est grande, ovalaire, bordée tout à l'entour d'une membrane mince, striée, plissée, tandis que son bord est arrondi, épais, formé de pièces convexes, solidifiées par quatre forts piliers distants, carénés, comprimés sur les côtés, élevés en pointe conique et recourbée au sommet, et composés eux-mêmes de plusieurs pièces engrenées. L'ouverture du pôle rétréci, est petite, circulaire, bien que son limbe soit marqué par quatre petits angles saillants qui répondent aux quatre piliers du grand pôle. Sa forme est cylindrique, et l'eau qui traverse l'animal aide à sa locomotion.

62. BOURSE DE VÉNUS.

Bursarius Cythera, Less.

$$
\text { (Pl. XIV, fig. I, g. n.) }
$$

Le zoophyte qui nous occupe a cela de remarquable, qu'il conduit des Bérosomes acils aux Médusaires vraies. Ce genre est bien distinct du précédent, et l'animal type présente les particularités suivantes : son corps est sacciforme, arrondi au sommet, dilaté à la base qui est largement ouverte, boṛdée d'une membrane diaphane plissée, et dont la circonférence est munie de 4 piliers d'une seule pièce, subcomprimés, les deux du milieu terminés par deux très-longs tentacules cylindracés. L'ou- 
verture de la partie arrondie du sommet est submédiane, petite et percée dans un enfoncement conique.

La mer était parfaitement calme, la journée chaude, lorsque nous capturâmes un grand nombre d'individus de la bourse cythéréenne, près de l'île de Rawach, sur la côte d'Ouarido ou de Waigiou, au milieu des archipels morcelés de la Papuasie. Ses nouvements de contraction étaient vifs et rapides, et l'animal paraissait animé par une vitalité des plus grandes.

La consistance de la Bourse est charnue, muqueuse : sa transparence est parfaite; sa liyaléinité des plus luisantes. Sa forme est un cylindre recouvert de granules à l'extrémité arrondie, qui est excavée au milieu, puis perforée. De cette ouverture partent quatre rubans assez larges formés de lignes placées les unes à còté des autres, ces 4 rubans sont régulièrement espacés entre eux. La grande ouverture a son bord renforcé par des portions convexes, arrondies. Une membrane est tendue circulairement sur le pourtour de ce pôle le plus large. Cette membrane est couverte de stries régulières, et laisse au milieu un grand espace pour la cavité natatrice. Vis-à-vis les 4 rubans, sur le péristome, s'attachent quatre piliers élevés et consistants. Les deux latéraux sont comprimés sur les côtés, obconiques. Les deux du milieu sont élargis, et finissent en petits cônes surmontés chacun d'un très-long filament tentaculaire, partout d'égale grosseur, et de couleur carıée ou rosée, tandis que le zoophyte entier est d'un blanc de cristal.

Un individu que nous saisîmes, le 3 septembre ı 823 , surles côtes de la Nouvelle-Guinée était de petite taille, d’un blanc mat, et nous sémble être le jeune âge de l'espèce que nous venous de décrire. On ne lui trouvait aucune trace de lignes vasculaires. Des quatre piliers de la grande onverture, trois étaient minces, terminés en une petite tête semi-globuleuse, et un seul finissait en un tentacule médiocre. Sa consistance était mucilagineuse, mollasse. 
DES MÉdUSES OBSERVÉES DANS LE VOYAGE DE LA COQullle.

La famille des méduses a été long-temps obscurcie par le vague de l'histoire des êtres qui lui appartiennent. Les travaux de Rondelet, d'Aldrovande, de Baster, de Borlase, de Moeder, de Pallas, de Forskal, de Pennant, de Bruguière, de Macri, de Réaumur, de Slabber, de Müller, de Fabricius et autres, n'apportèrent que successivement, et avec des degrés de mérite fort différents, de nouvelles connaissances. C'est à partir des publications de Péron et Lesueur, qu'on peut signaler des découvertes neuves et vraiment philosophiques sur ces zoophytes. C'est au beau mémoire intitulé : Histoire générale et particulière de tous les animaux qui composent la famille des médluses, enrichi d'un très-grand nombre de planches gravées sur cuivre, dont quelques exemplaires seulement ont été distribués à divers naturalistes, que date l'ère nouvelle qui vint enrichir cette famille de recherches nombreuses et d'un haut intérêt. Les coordinations des Lamarck, Cuvier, de Blainville, les découvertes de MM. Eysenhardt et Chamisso, Quoy et Gaimard, celle de Scoresby, les savantes anatomies de plusieurs auteurs allemands, et enfin, le grand travail d'Eschscholtz (System der acalephen), publié en I 829 , rendent l'étude des méduses bien plus lucide, sans que pour cela les bases en soient définitivement fixées, car trop de faits manquent encore pour préciser d'une manière solide leurs caractères zoologiques. Un grand travail accompagné de figures coloriées est donc devenu d’une impérieuse nécessité.

Nos planches avaient déjà vu le jour, et nos descriptions étaient rédigées, lorsque nous avons eu connaissance de l'ouvrage de feu Eschscholtz. Nous n'avons donc pas pu entrer dans les vues de cet auteur, en discutant la valeur de ses genres, et 
en établissant des rapports synonymiques. Par suite, il nous a été impossible de rédiger des généralités sur une famille dont nous n'avions à faire connaître qu'un petit nombre d'individus. C'est ce qui nous autorise à conserver les noms qui sont gravés au bas des planches de notre atlas, et que les monographes pourront changer suivant le système de nomenelature qu'ils préféreront.

Nous nous bornerons à dire que les méduses vivent rarement solitaires; c'est le plus souvent par essaims considérables qu'on les rencontre dans les parages que leurs espèces fréquentent. Sous ce rapport on ne voit point leur préférence se porter sur des latitudes données, ear elles sont aussi eommunes sous l'équateur que dans les zones glaeées. "Les méduses ou sea-blubber "des Anglais, dit Scoresby (Arct. reg., t. I, p. I79), se ren" contrent en grande abondance dans les mers arctiques, et pa" raissent être le principal aliment des animaux marins des ré"gions du pôle.

"La quantité des espèces est peu variée sans doute, mais " eelle des individus est immense. Le nombre de méduses dans " la mer Verte est incalculable : nous avons mesuré qu'un pouce " cube d'eau en renfermait 64, un pied cube ı ro,592, et une " brasse eube $23,887,872$, et un mille eube 23,888, ooo,ooo,ooo, " ooo!!!! La mer, en cet endroit, a un mille de profondeur, " et on ne peut apprécier la couche d'eau jusqu'où ees animaux " parviennent. On ne pense pas qu'ils aillent au-delà de 250 "brasses."

63. PÉLAGIE PANOPYRE.

Pelagia panopyra, Péron, Less., Cent. Zool., pl. LXII, fig. 2.

De toutes les espèces de méduses connues, il n'en est pas de plus commune que la panopyre; il n'en est point aussi qui ait 
été plus souvent figuréc. Bosc, dans son histoire des vers, a représenté la panopyre sous le nom de méduse pélagique, et c'est à tort que Péron et Lesueur en ont fait une espèce distincte sous le nom de pelagia denticulata (Méduses, page 38). Chamisso a de nouveau gravé la panopyre à la pl. 2, fig. 3 et 4 du Voy. pittoresque de Choris.

La pélagie panopyre dont Lamarck a fait sa Dianea panopyra (Anim. sans vertèbres, t. 2, p. 507), est remarquable par son ombrelle en demi-sphère, légèrement déprimée ou comme ombiliquée au milieu, un peu étranglée ou rétrécie sur ses bords, à surface hérissée de petites verrues denses et allongées, à bord entier, mais marqué de festons apparents. Le milieu de l'ombrelle est occupé par quatre paquets de vaisseaux entortillés, nuageux, qui surmontent le corps ou le pédoncule qui s'allonge au-dessous de l'ombrelle pour se diviser en quatre bras foliacés, épais au centre et amincis, frangés et comme découpés sur leurs bords. Huit tentacules, très-minces, trèsgrêles, arrondis, dépassant les bras, sont espacés sur le pourtour de l'ombrelle.

La méduse panopyre est d'un rose tendre uni à une grande diaphanéité. Le rose est plus foncé sur les petites verrues de sa surface, sur les ovaires, et lesrebords des bras. Nous en a vons gardé assez long-temps des individus vivants en les plaçant dans des vases pleins d'eau de mer. Ils manifestaient la plus grande irritabilité lorsque pendant l'obscurité on approchait une lumière. Notre dessin la représente à peu près de grandeur naturelle, son ombrelle a jusqu'à 4 pouces de diamètre. La nuit elle jouit de propriétés phosphorescentes à un haut degré.

Cet te méduse est extraordinairement commune dans l'océan Atlantique équatorial. C'est par bancs épais que nous la rencontrâmes le i 6 septembre 1827 par les $7^{\circ}$ de lat. $N$. et $22^{\circ}$ de longitude occidentale, de même que par $4^{\circ}$ de lat. S. Nous la re- 
trouvẩmes tout aussi commune dans l'océan Pacifique jusque par les i 8 degrés de longitude.

L'individu que nous avons figuré pl. 63 de notre Centurie zoologique parait être le jeune âge de l'espèce qui nous occupe. Cependant il en diffère par plusieurs détails, bien que rien ne puisse autoriser à l'en séparer spécifiquement. Nous croyons d'ailleurs que les méduses, dans le premier temps de leur croissance, s'éloignent de l'âge adulte par leur coloration, et qu'elles éprouvent ainsi divers changements dans l'ensemble de leur texture, et peut-être même de leurs formes. Il résulterait de ce fait que certains zoophytes, à l'exemple de ce qu'on nomme livrées chez les oiseaux, subiraient dans leur aspect extérieur des modifications successives.

Le 15 septembre 1822 , par 7 degrés de lat. boréale et par 22 degrés de long. occidentale, naviguant au milieu de bancs épais de pélagies panopyres, nous pèchâmes un grand nombre d'individus semblables à la figure 63 de notre Centurie.

L'ombrelle est hémi-sphérique, hyaline ou diaphane, d'une certaine densité hors de l'eau, translucide, molle et nuageuse dans ce liquide, et formée de sortes de pièces isolées par compartiments que hérissent quelques éminences papilleuses. Le pédoncule est surmonté par 4 paquets de vaisseaux entortillés, couleur lic de vin, et se divise au-dessous de l'ombrelle en 4 bras foliacés. Nous avons vu cette méduse aspirer l'air contenu dans l'cau par des pores placés sur les bords flexueux des bras, et remonter tout le long de ces bras, sous forme de globules aussi brillants que ceux de mercure, et à aboutir aux 4 gros paquets vasculaires ramifiés au sommet élargi du pédoncule. La portion videde l'ombrelle nous parait être évidemment remplie d'air pour diminuer la densité du corps lorsqu'il doit rester à la surface de la mer, et ce mème air doit trouver quelque issue ménagée sur le pourtour de l'ombrelle lorsqu'il devient né- 
cessaire pour la sûreté de l'animal, qu'il descende à une certaine profondeur. Entre les 4 bras foliacés existe une ouverture centrale, et 4 autres occupent leur base. Toutes sont recouvertes par une membrane pellucide. C'est par ces ouvertures que doivent sans aucun doute s'échapper les gemmules animalisés ou les jeunes méduses. Huit tentacules capillacés, blancs, peu apparents, naissent sur le bord de l'ombrelle qui est légèrement sinuolé.

La couleur de cette méduse est un blanc laiteux. Les vaissaux du corps et ceux des bords des bras foliacés sont d'un rose vineux qui s'affaiblit sur les bras, mais qui est très-foncé sur le pédoncule.

\section{CHRYSAORE DE GaUdichaud.}

Chrysaora Gaudichaudü, Less.

$$
\text { (Pl. XIII, fig. I, g. n.) }
$$

Cette méduse peinte de grandeur naturelle est de consistance gélatineuse, assez ferme. La contractilité de son ombrelle est énergique, et son nager èst toujours oblique, c'està-dire l'ombrelle en avaut, pressant l'eau par son rebord, et traînant derrière elle les 4 larges divisions foliacées et respiratoires qui terminent son pédoncule. Sa coloration est d'un blanc teinté généralement de rouille, et ses conduits vasculaires apparaissent de nuance roux-fauve très-prononcé, tandis que les tentacules ombrellaires sont marron.

C'est dans la baie de la Soledad, aux îles Malouines, qu'on rencontre cette méduse en nombreux essaims, dont les individus s'avançaient jusque par les hautes latitudes du cap Horn, et même par 55 degrés de latitude australe.

Son ombrelle forme une demi - sphère régulière, très-lisse, parfaitement convexe. Une calotte arrondie en constitue la voûte. 
Du cercle qui la circonscrit, partent des lignes verticales régulièrement espacées qui se rendent au rcbord de l'ombrelle. Ces lignes sont des vaisseaux assez larges, colorés en rouge-brun, ayant 2 quartelles, séparées elles-mêmes à leur milieu par une ligne plus pâle, où viennent aboutir des traits obliques, rangés sur la ligne moyenne comme les barbes d'une plume sur leur rachis. Douze très-grands festons réguliers, intersectés par 12 très-petits, forment le rebord festonné de l'ombrelle. Du sommet de ces 12 lobes partent i 2 faisceaux de tentacules trèslongs, très-simples, capillacés, faisceaux larges à leur base, et qui diminuent successivement, de manière à devenir filiformes à leur extrémité, et leur longueur dépasse trente pouccs. Leur couleur est rouge vineux clair, tirant au fauve jaunâtre. Le pédoncule ou corps est large, évasé, ouvert au milieu par une bouche quadrilatère, renforcée par des piliers qui donnent attache à 4 larges divisions mcmbranacées, blanchâtres, foliolées, pointues à leur sommet, à limbe planc et strié et seulèment à petits vaisseaux aériens courts, rougeâtres, entortillés et peu apparents sur leurs bords. Quatre grandes ouvertures latérales, entourées de membranes minces, striées, et renforcées par des épaississements du pédoncule, surmontent l'ouverture médiane et inférieure.

65. CHRYSAORE DE BLOSSEVILLE.

Chrysaora Blossevillii, Less.

(Pl. XIII, fig. 2, I/2 g. n.)

Cctte méduse est représcntéc moitié grandcur naturelle; son ombrelle est subhémi-sphérique, à pourtour garni d'une premic̀re rangée de festons arrondis, surmontés d'une deuxième rangée de festons oblongs, nombreux et arrondis à leur extrémité libre. Sa surface est lisse, d'un blanc légèrement teinté de 
jaune paille, et est couverte de taches ferrugineuses petites, et semées sur toute la surface de l'ombrelle. Vingt-quatre tentacules environ partent de chaque groupe de deux festons du rebord ombrellaire, et naissent en dedans aux angles des lobes arrondis de la première rangée. A l'intérieur de l'ombrelle, et à sa partie moyenne, se dessinent des cordonnets entortillés et recourbés sur eux-mêmes de vaisseaux ou de conduits ovariés.

Le corps est de forme tronçonnée, court, gros, épais, et présente sur ses côtés 4 ouvertures oblongues, ouvertes, solidifiées par des piliers charnus. Sa bouche est terminale, médiane, assez grande, et abritée par quatre bras foliolaires, allongés, terminés en pointe, et qui forment les cinq divisions du corps. Ces bras ont une ligne médiane très-marquée, où viennent se rendre les ondulations et les sortes de crispures ou franges pulmonaires qui couvrent leur limbe applati. Leur couleur est un fauve ferrugineux très-clair, tandis que les vaisseaux sont colorés en jaune d'ocre très-intense.

Nous rencontrâmes cette méduse en octobre I 822 , à l'entrée de la baie de Sainte-Catherine, sur la côte du Brésil méridional, et elle y est commune.

\section{CYANÉE AUX BEAUX CHEVEUX.}

Cyanea plocamia, LEss.

(Pl. XII , I/2 g. n., fig. I, jeune âge, fig. 2, âge adulte.)

Cette cyanée s'offrit à notre examen par les 13 degrés de lat. S., et les $79^{\circ}$ de long. occidentale dans l'océan Pacifique sur les côtes du Pérou. Nous la retrouvâmes ensuite à Payta et à San-Gallan, où elle cachait la mer, tant les individus se pressaient dans certains espaces.

Dans son jeune âge cette méduse (fig. I) a son ombrelle 
hémi-sphérique, lisse, à pourtour marqué par un canal très transparent, sous lequel se dessinent de 3 o à 32 festous arrondis, peu séparés, et finement frangés sur leur rebord. Dans l'intervalle de chaque feston est attaché un tentacule cylindrique, simple, pointu au sommet, médiocre, d'un jaune d'or à sa naissance, puis d'un beau rouge dans le reste de son étendue.

L'ombrelle est d'un blanc de cristal translucide, que relèvent deux traits jaune d'ocre, libres au pourtour, et unis en un demianneau vers la calotte de l'ombrelle, qu'ils ne dépassent point. Dans leur intervalle se dessinent des lignes blanches perpendiculaires. Au-dedans de la voûte de celle-ci, apparaît une croix de Malte à branches arrondies, et légèrement teintée en rouille.

Le corps est court, tronçonné, cylindracé, à piliers musculeux. A sa troncature s'ouvre la bouche qui est médiane terminale, et de forme quadrilatère. Quatre ouvertures étroites, oblongues, occupent latéralement les parois de ce même corps, qui, au niveau de la bouche, donne naissancc à quatre bras allongés, ayant jusqu’à deux pieds de longueur, mesentériformes, c'est-à-dire composés d'une membrane plissée, divisée à linfini en membranes plus petites, arrondies, repliées cent fois sur elles-mêmes, et dont le rebord est strié et porte le réseau pulmonaire. Ces bras sont d'une hyalanéitć parfaite, excepté lcs franges, qui, sur le liséré, sont nuancées de jaune peu décidé.

Cettc méduse nage couchée horizontalement, et possède une grande vitalité. Nous en rencontrâmes le 23 févricr I 823 , près de l'île San-Gallan, à 3 lieues dc la terre du Pérou, par 13 degrés de lat. S., des millions d'individus, nageant pressés les uns à còté des autres, et tous ayant l'ombrelle dirigée au 
Nord, et les bras au Sud. La mer alors était parfaitement calme, et la journée sereine.

Dans l'àge adulte (fig. 2), cette espèce a la calotte de son ombrelle plus convexe, colorée en jaune rouille assez intense, et le parenchyme de l'ombrelle, lui-même, est ponctué de taches faibles de jaune ocreux. Enfin, les traits vasculaires forment un encadrement oblong à bords jaune-brun, à intérieur jaune ferrugineux pâle, ponctué; de plus, foncé, et divisé en fourche sur le pourtour dentelé, qui reste blanc de cristal.

Les vieux individus se trouvaient mêlés aux jeunes, et ont cela d'intéressant de prouver que les couleurs des méduses varient suivant des influences encore complètement inconnues, soit qu'elles tiennent à l'âge, au sexe, aux saisons, à la climature ou à certains parages. Nous retrouvâmes la cyanée de la figure $n^{\circ}$ 2, à Payta, au nord de Lima; mais cet endroit ne nous offrit aucun jeune individu.

\section{CYANÉE DE BOUGAINVILLE.}

\section{Cyanoa Bougainvillii, Less.}

$$
\begin{aligned}
& \text { (Pl. XIV, fig. 3, g. n.) } \\
& d^{\prime} d^{\prime \prime} d^{\prime \prime \prime} \text { vue sous plusieurs aspects. }
\end{aligned}
$$

C'ette méduse n'est point une cyanée. Nous en faisons le type d'un petit genre de médusaire, que nous nommerons Bougainvillie, Bougainvillia, en appliquant à l'espèce le nom trivial de macloviana.

Ce zoophyte est oviforme, arrondi en haut, tronqué et ouvert en bas. Son enveloppe extérieure consiste en une membrane transparente, pellucide, légère, parfaitement lisse. A l'intérieur apparaissent les ovaires disposés en croix simple, de 
couleur noire, mais granuleux et jaunes sur leur rebord. Quatre petits vaisseaux blancs se rendent des sommets cruciés et descendent sur le rebord de l'ouverture qui est ovalaire, et munie, à égale distance les unes des autres, de 4 glandes triangulaires, saillantes, d'un jaune foncé, ponctué de noir. Chacune de ces glandes est hérissée de petits filaments formant houppe, tous grêles, minces, simulant des cils, et chacun d'eux partant d'un point noir; une membrane mince est l'enveloppe de la cavité intérieure.

Dans l'eau la Bougainvillie est nuageuse, vague; hors de l'eau, sa consistance est mucilagineuse, molle, d'aspect hyalin, excepté les ovaires et les glandes qui sont vivement colorées. L'ouverture est à parois très-contractiles; aussi cette méduse est-elle pleine de vivacité, et resserre ou dilate sa tunique extérieure par des mouvements aussi brusques que rapides.

Cette médusaire couvre parfois, tant elle est abondante, la surface de la mer dans la grande baie française de l'île de la Soledad, l'une des Malouines. Le plus ordinairement on la rencontre au milieu des fucus pyrifêres qui encombrent les rivages. Son nom rappelle le fondateur de l'établissement des Français sur ces terres antarctiques.

68. AURELLIE PISSINÉBOQUÉ.

Aurellia clausa, Less.

Pissinéboqué, dans la langue des Papous du Port-Praslin à la Nouvelle-Irlande.

Cette méduse a trois pouces et demi de diamètre ombrellaire. Elle est hémi-sphérique, à pourtour mince, strié en rose, membraneux, garni de très-courtes franges capillacées et nombreuses; quatre ovaires lie de vin dessinent au centre de l'om- 
brelle une ample croix de Malte. Le dôme que forme eelle-ei est lisse, blanc mat, mais rayonné de lignes roses trifurquées sur le rebord, et finissant à une ligne rosée circulaire. En dessous, ces lignes roses radiées se dessinent de la même manière. Le pédoncule est sessile, pereé d'un trou au milieu, divisé $\mathbf{~}^{\circ}$ en 4 bras rubanés minees, étroits, et frangés sur leurs bords qui sont sinueux, et $2^{\circ}$ en 4 lobes épais, applatis, obovalaires pointus. Ces 4 lobes soudés à leur base, libres à leur sommet, ferment hermétiquement ou laissent un libre passage pour 4 ouvertures parfaitement rondes, ouvertes dans 4 dépressions en ereux placées à égale distanee les unes des autres en dessous de l'ombrelle, cerclées de rouge vineux foncé. Dans l'état normal, les 4 soupapes de sûreté s'appliquent sur elles avec exactitude, et s'opposent à ee que rien ne puisse y pénétrer.

Cette méduse est blanche mais relevée par les lignes rose vif et le rouge vineux qui forment des veinules ou les cereles des ovaires de son parenchyme. Nous l'observâmes le I 3 août I 823 dans le Port-Praslin de la Nouvelle-Irlande, où les naturels nous la nommèrent pissinéboqué.

\section{RHIZOSTOME AUX LONGS BRAS.}

\section{Rhizostoma brachyura, LEss.}

Cette méduse ( figurée pl. 8o de notre Centurie zoologique, sous le nom de Melitea brachyura), est remarquable par son ombrelle hémi-sphérique, arrondie, à pourtour lisse, à surface aréolée par plaques pentagonales. Des sortes de plissures verticales, régulières, occupent le bord de l'ombrelle, qui est sans tentaeules. Quatre ovaires jaunîtres forment à travers le parenehyme du corps, et à son sommet, une croix de Malte. L'on:brelle a jusqu'à 6 pouces de largeur, sur 7 à 8 de hauteur, et les bras n'ont pas moins de trois pieds de longueur. Quatre pi- 
liers occupent la partie inférieure de l'ombrelle; ils sont arrondis, épais au milieu, amincis sur le pourtour ombrellaire. Au centre est placée la bouche de forme quadrilatère, et recouverte de franges cylindriques, nombreuses et flottantes. Quatre ouvertures latérales occupent l'intervalle des piliers et s'étendent jusqu'au bord de l'ombrelle, à demi cachée par des séries de franges qui naissent des bords des piliers charnus. De ceux-ci part, à leur extrémité, un pied évasé, bifurqué, servant d'attache à deux bras, ce qui porte à 8 le nombre total de ceux-ci. Chaque bras est cylindrique, disposé en forme de corde, et s'amincit successivement jusqu'à l'extrémité qui est pointue. Il est composé de franges, sinuées, serrées et pressées.

Cette méduse a l'ombrelle d'un blanc hyalin, à ovaires cruciés jaunâtres; ses bras sont d'un rouge ocreux foncé, et le rebord de l'ombrelle est légèrement teint de rouille.

Nous avons découvert cette méduse dans le Havre de Dorey à la Nouvelle-Guinée.

\section{RHIZOSTOME CROISÉE.}

Rhizostoma cruciata, Less.

$$
\text { (Pl. XI, fig. I, g. n.) }
$$

Mouge, dans le langage créole des Portugais brésiliens.

C'est en octobre 1822 que nous trouvâmes cette méduse échouée sur les rivages de l'île de Sainte-Catherine sur la côte du Brésil. Son ombrelle est régulièrement hémisphérique, et son pourtour est formé par une sorte de ruban de dentelle à mailles excessivement fines et régulières, et garni de dents aiguës, obtriangulaires et nombreuses. La voûte de l'ombrelle est parfaitement lisse; sa couleur ẹst uniformément blanc fade, légèrenent liıé de jaune pâle. Une large croix grecque, à bords 
roses, occupe toute la face supérieure. Chacune des extrémités de la croix, au lieu d'être arrêtée en lignes droites, se trouve être cordiforme. Un cercle rosé fait aussi le tour de l'ombrelle à la naissance de la partie aréolée du pourtour; le corps est épais, court, perforé au milieu, ayant sur sa circonférence quatre larges ouvertures dont les parois sont renforcées par les piliers charnus. Le corps se termine en huit bras folliolaires, assez allongés et couverts, dans toute l'étendue de leurs limbes, d'ondes vasculaires disposées en cercle, et qui, par leur ensemble, donnent aux bras une disposition imbriquée.

\section{I. CÉPHÉE DES PAPOUS.}

Cephea papua, Less.

(Pl. XI, fig. 2, g. n.; fig. 3, la même dans son jeune âge.)

Kangoune, dans la langue des Papous de la Nouvelle-Guinée. Semaï, chez les Papous de Waigiou.

Cette méduse est voisine de celle figurée dans Séba (t. III, pl. I, fig. 2). Nous la rencontrâmes daus la baie d'Offack de l'íle de Waigiou, et dans le Havre Dorey de la Nouvelle-Guinée. Elle est un nouvel exemple des modifications, qu'éprouvent les méduses suivant les diverses périodes de leur croissance. Car on ne peut raisonnablement se refuser à admettre l'identité des deux individus de notre onzième planche.

Cette céphée adulte (fig. 2 ) a son ombrelle demi-globuleuse, à pourtour parfaitement entier ou à peine sinueux et sans aucun tentacule. Cette ombrelle est lisse, marquée d'une croix à branches étroites au sommet. Sa couleur est un bleu glauque peu foncé, que relèvent des taches arrondies, éparses, albescentes, et sur le pourtour un rebord jaune ferrugineux. La croix, elle-même, est de teinte ocracée, côtoyée dans le con- 
tour de ses divisions par un trait bleu-clair. Quelques lignes verticales azurées coupent la periphérie de l'ombrelle.

Le corps est peu épais et directement attaché à la base de l'ombrelle; il s'ouvre en dessous en une bouche très-étroite, très-régulièrement fendue en croix, à l'extrémité des branches de laquelle partent quatre bifurcations qui sont la naissance des huit bras. Intimement soudés à l'extérieur à leur origine, ces bras sont recouverts par des paquets membraneux, mésentériformes, formant une épaisse masse de plis ondulés sur euxmêmes et dont les bords porteut les vaisseaux aériens disposés en franges d'une extrême ténuité. Chaque bifurcation de la bouche donne attache à un bras épais, massif, charnu, fragile, long de 3 pouces, façonné en massue, un peu comprimé sur les côtés, conico-pointu au sommet, et couvert de verrues. Ces bras sont vert-glauquic, teintés de rougeâtre sur les angles, les verrues et la pointe, tandis que le corps est carné et que les replis mésentériformes de sa membrane sont rouge-brunâtre.

Nous n'observâmes que deux individus de l'âge adulte nageant obliquement par une mer très-calme, et une température trés-chaude dans la grande baic d'Offack dans l'ile de Waigiou.

Dans son jeune âge (fig. 3) la céphée papone a son ombrelle d'un bleu glaucescent pâle sans aucune trace de teintc rouille ni sur la croix ni sur le pourtour. Sa bouche en fente cruciée ne diffère en rien quant à la division des bras et quant à sa forme de l'âge adultc. Seulement les bras ont la membrane enroulće de leur origine empilée en forme de cônes, cônes au nombre de huit, et du milieu desquels partent huit bras cylindriques, minces, d'un égal volume dans toute leur longueur, et façonnés en bâtons au lieu de l'être en massue. 
72. DIANÉE CÉRÉBRIFORME.

Dianea cerebriformis, Less.

$$
\text { (Pl. X, I/4 g. n.) }
$$

Nous rencontrâmes cette méduse le 25 septembre 1822 , sous l'équateur même dans l'océan Atlantique. La température était chaude, la mer très-belle, et nous nous trouvions alors par 25 degrés de longitude occidentale.

L'ombrelle de cette espèce, au lieu d'être en parasol comme chez la plus grande partie des méduses, est au contraire creusée au centre de manière à imiter un vase antique. Cette ombrelle est donc concave supérieurement ou est infundibuliforme, se relevant sur les bords qui sont convexes, puis se surbaissant pour se découper en festons, festons ou lobes qui occupent l'épaisseur d'une membrane circulaire étroite, et qui sont eux-mêmes découpés en quatre ou cinq festons plus petits. Le parenchyme de l'ombrelle est sur toute sa surface, qui est d'un blanc mat, parsemé de stries rayounantes d'un blanc hyalin et rapprochées par faisceaux de six, faisceanx séparés par un intervalle assez grand. Ces stries n'occupent que le cercle de la portion moyenne de l'ombrelle, et communiquent sur le pourtour avec un vaisseau de mème couleur qu'elles et qui les réunit toutes. De chaque dentelure de la circonférence naissent en dessous des festons membraneux, et en s'attachant sous le vaisseau aérifère circulaire, les tentacules qui sont excessivement nombreux, parfaitement blancs, très-longs, très-greèles et arrondis. Ces tentacules paraissent creux à l'intérieur, ou du moins à travers leur parenchyme d'un blanc mat, se dessine un tube capillaire d'un blanc nacré très-brillant; ce tube parait même décrire une légère spirale. 
L'ombrelle est done entièrement hyalino-albide, tandis que les stries qui rayonnent sur sa surface sont du blanc argentin le plus brillant. Dans la concavité et au centre même de la périphérie de l'individu que nous prímes, était attaché par un pédoncule soudé avec la substance propre de la méduse un paquet de mollusques de la famille des Anatifs, et que nous avons figuré sous le nom de Triton fasciculatus (Mollusques, pl. XVI, fig. 6), et que nous avons décrit t. II, p. 442.

Le corps de la dianée cérébriforme est court, évasé sous l'ombrelle et assez brusquement tronqué; il est percé à sa partie moyenne d'une large ouverture, régulièrement arrondie, autour et au-dessus de laquelle le corps se divise en quatre trones bifurqués d'où partent huit bras. Ces bras sont formés par des canaux rubanés excessivement entortillés, d'une délicatesse extrême, membraneux, colorés en gris au milieu, tandis quïls sont côtoyés par deux tubes d'un blane nacré dans lesquels montaient des bulles d'air ayant le même aspect que des globules de mercure descendant dans un tube capillaire de verre. Sur ces rubans s'attache une membrane singulièrement ténue, froncée, plissée sur elle-ńĉme, de manière à donner une imitation parfaite des plis mésentériques des intestins ou plutôt simulant les anfractuosités de la surface pulpeuse du cerveau. Clacun de ces bras, dont la longueur est considérable lorsqu'ils sont détendus, ce qui arrive très-rarement, se termine par un épi allongé de tubes cylindriques subulés à leur sommet et plus épais à leur attache. Ces tubes qui pourraient bien être des organes de tact sont très-irritables, car il suffit de les toucher pour faire opérer de suite une contraction de tout le bras, et dans ce mouvement ils sont entièrement cachés dans les replis qui simulent une boule encéphalique.

Quant à sa coloration générale, cette méduse, de grande taille, est d'un blanc de porcelaine que relèvent les stries na- 
crées ou cristallines du corps et de l'ombrelle; les contours des bras sont au contraire nuageux ou vaporeux.

Liombrelle est très-épaisse, et son diamètre est de dix-huit pouces et au-delà. Le zoophyte entier pesait plus de trente livres. Le tissu des bras se déchire avec la plus grande facilité, et nous ne parvînmes, qu'avec des peines infinies à en conserver pendant quelques jours un individu vivant dans une baignoire remplie d'eau de mer renouvelée plusieurs fois. Nous n'en rencontrâmes pendant tout le voyage que trois individus: Le premier avait les anatifs membraneux que nous avons indiqués, attachés sur son ombrelle, et le second tenait captifs dans ses bras plusieurs petits poissons déjà à moitié digérés. Ces poissons, enlacés dans le réseau de la méduse, n’y avaient-ils été portés que par hasard? ou les méduses se nourriraient-elles de chair animale à la manière des physales ou autres zoophytes?

\section{3. ÉQUORÉE DES ILES CAROLINES.}

\section{Aquorea carolinarum, Less.}

Cette petite équorée s'offrit à notre étude le 30 mai I 824 , alors que la Coquille naviguait au milieu des îles plates de l'Archipel des Carolines.

Son ombrelle est hémisphérique, large au plus de 9 lignes de diamètre, à pourtour presque entier, régulier, ayant 8 tentacules assez gros, finissant en pointe. Ces tentacules et l'ombrelle sont blanc rosé, excepté le pourtour qui est bleuâtre, marqué d'un gros point marron ayant sous lui un chevron jaune d'or, à la naissance de 8 tentacules. Sa surface inférieure est creusée au milieu en une seule grande ouverture arrondie, fermée par des cils capillacés et groupés en 4 faisceaux principaux qui s'allongent en dessous. 
74. ÉQUORÉE MITRE.

Equorea mitra, Less.

$$
\text { (PI. XIV, fig. 4, g. n.) }
$$

Cette médusaire est cylindracée, pyramidale et d'un blanc translucide. Son sommet est subconique, rétréci, et son ouverture ou rebord est tronquée, largement ouverte, simple, et munie de 8 tentacules médiocres, courts, tortillés sur euxmêmes, capillacés à leur sommet et dilatés et échancrés à leur base. Ces tentacules sont rouge carmin, puis rouge ocracé. $\mathbf{A}$ l'intérieur les ovaires forment une masse oblongue, cylindracée, composée de 4 lobes allongés, à réseau imbriqué sur les côtés ( fig. 4, lettre E), et coloré en jaune d'ocre très-foncé. Ces ovaires sont comme liés entre eux, et soudés par un renflement. Quelques lignes jaunâtres se dirigent verticalement du sommet au pourtour de l'ouverture.

Nous rencontrâmes cette médusaire le 6 septembre 1823 , aux attérages de l'île de Waigiou. Ses mouvements de contraction avaient beaucoup d'énergie, et nous vimes plusieurs fois ce zoophyte retirer les tentacules du pourtour à l'intérieur, et froncer les bords de l'ouverture, en les repliant en dedans.

75. EUDORE EAU-CONDENSÉE.

Eudora hydropotes, Less.

$$
\text { (Pl. IX, fig. 2, g. n.) }
$$

A. Vue horizontalement. B. vue en dessus.

Nous observâmes cette eudore le 6 septembre $\mathbf{~} 823$, aux attérages de Waigiou. Parfaitement blanche, ou de ce blanc que le cristal peut seul rappeler à l'esprit, elle est presque réniforme 
ou plutôt simule un disque épais, renflé sur ses contours et à peu près plane sur deux faces. C'est donc une méduse compacte, toute charnue, sans bras, sans tentacules, sans bouche, sans ovaires apparents. Seulement au centre un cercle de vaisseaux rayonnés se dessine sur la face supérieure, et tous partent d'un vaisscau parfaitement circulaire qui les unit par la base. Souvent on voit l'air cheminer dans ces tubes, sous forme et avee l'aspeet de petits globules de mercure. Lorsqu'on sort ce zoophyte de la mer, et qu'on essuie avec un linge fin sa surface, on le voit dégorger une très-grande quantité d'eau par la face inférieure, et sans qu'on puisse reconnaître les ouvertures et encore moins les déchirures par où elle s'écoule.

\section{EUDORE ROSACE.}

Eudora rosacea, Less.

C'est le I 7 octobre I 822 , sur les côtes de Sainte-Catherine du Brésil, que nous rencontrâmes cette médusaire; complètement hyaline, assez épaisse au milieu, bordée sur sa circonférence d'une membrane mince, sinueuse, légèrement oblongue, convexe et renflée en dessus, et concave en dessous. Un large cercle de mamelons élevés forme un anneau très-marqué sur la face dorsale.

\section{EUDORE DISQUE.}

\section{Eudora discoides, Less.}

$$
\text { (Pl. IX, fig. 3, g. n.) }
$$

Cette méduse est prodigieusement abondante sur les côtes du Pérou, aux attérages de Lima et de Payta. Elle sert de pâture aux animaux marins qui pullulent dans ces mers, et surtout à ce crustacé nommé Grimotée sociale (pl. III, fig. I ) 
Cette méduse est excessivement bombée sur ses deux faces, qui sont épaisses, régulièrement convexes, très-rénittentes ou d'un tissu solide. Son aspect est vitré ou blanc de cristal. Les surfaces renflées sont lisses, puis s'amincissent successivement sur les bords pour donner attache à une membrane entière un peu épaissie, légèrement festonnée. La circonférence est à peu près parfaitement ronde, et à peine dessine-t-elle 4 grands systèmes delobes qui festonnent et terminent la partie moyenne de la méduse, lobes très-peu marqués, et qui disparaissent sur la membrane annexée au pourtour.

D'un cercle qui envelopperait la partie renflée et médiane de chaque face, partent très-serrés et régulièrement rayonnants, les vaisseaux respiratoires sous forme de lignes ponctuées et ciliées. Ces lignes aboutissent sur le rebord à un lacis très-fin de petits vaisseaux qui occupent la marge du disque et son épaisseur. La membrane du pourtour possède la même distribution dans les vases aérifères. On ne reconnaît à cette méduse aucune cavité gastrique, ni ovaires, ni pores. Son aspect est celui d'un orbe qui serait muni d'une lame en carène sur la circonférence. Sa consistance est ferme; sa saveur parfaitement identique avec celle de l'eau salée. Fortement pressée dans un linge elle se résolvait en eau, en laissant pour résidu la simple pellicule membraneuse ou épidermique qui enveloppait le tissu cellulaire. Chauffée, elle se résolvait entièrement en liquide.

L'individu, figuré d'après notre dessin, avait 4 pouces $\mathbf{I} / 2$ de diamètre, mais il n'est pas rare d'en trouver de beaucoup plus grands. Nous en rencontrâmes des essaims nombreux le 9 mars 1823 , et la plupart étaient à demi rongés par les morsures des animaux marins. 
78. MICROSTOME AMBIGU.

Microstoma ambigua, Less.

$$
\text { (Pl. XIV, fig. } 5 \text { et } 5^{\prime} \text {, g. n.) }
$$

Nous rejetons à la fin des médusaires le zoophyte que représente la fig. 5 de notre pl. XIV, car nous ignorons vraiment à quelle tribu il appartient, et où serait sa vraie place. Il s'est offert à nous, le $\hat{6}$ septembre 1823 , sur les côtes de Waigiou, nageant au milieu de beaucoup de zoophytes. Nous l'observâmes long-temps dans un verre d'eau de mer. Dans le liquide, il imitait un gros globule d'air à parois nacrées, surmonté d'un corps épais, exsertile, d'un jaune d'orpin. A la partie inférieure qui est fendue et largement ouverte, pendent quatre petits tentacules placés à égale distance les uns des autres, colorés en jaune, renflés à leur sommet, et munis de cils latéraux.

Hors de l'eau il était, ainsi que le représente la fig. 5', oviforme, ayant un vide intérieur, et marqué au sommet d'un petit carré coloré.

Serait-ce une espèce de béroïde? En tout cas, nous avons dù figurer ce petit corps singulier, pour appeler l'attention des voyageurs futurs sur son existence, et les engager à l'étudier avec soin.

79. EULYMÈNE CADRAN DE MONTRE.

Eulymena heliometra, LEss.

Cette médusaire complètement transparente est bombée en dessus, concave en dessous, et parfaitement ronde sur les bords. Son diamètre est celui d'une pièce de six francs; sa consistance est mollasse et sa transparence parfaite. A travers l'enveloppe 
externe, on voit dans sa portion centrale une large ouverture circulaire, entonrée d'une membrane frangée sur les bords ; un conduit vasculaire assez large décrit un cercle entier, d'où partent des vaisseaux aériens excessivement nombreux et rayonnant du centre à la circonférence, en s'ạrêtant et se recourbant à une faible distance du pourtour; ces vaisseaux apparaissent avec la couleur nacrée qui les caractérise, et qui les distingue si éminemment de la substance blanche du zoophyte.

Nous rencontrâmes, le 7 février I 823 , non loin des côtes $d u$ Pérou, cette médusaire qui a les plus grands rapports avec l'eulymène cyclophile de Péron.

DE QUELQUES ZOOPHYTES OBSCURS.

8o. EUCOELIUN DE BORABORA.

Eucolium boraboriensis, Less.

$$
\text { (Pl. VIII, fig. } 4 \text {, g. n.) }
$$

Ce corps adhère sur les rochers de corail à l'entrée de la baie de Beula, dans l'ile de Borabora. Il se présente sous une forme oblongue, arrondie aux extrémités, peu épaisse et revêtue d'une couche grrisâtre, dense, solide, percée par quatre ouvertures distantes; ouvertures qui ne consistent qu'en petites fentes occupant une légère élévation. Le tissu intérieur est homogène, jaunâtre, abondamment gorgé d'un liquide jaune.

8r. ÉPONGE VERSICOLORE.

Spongia versicolor, LEss.

Nous rencontrâmes, rarement il est vrai, sur les rivages des îles Malouines, attaché aux valves de la moule de Magellan ou 
aux rochers schisteux des rivages, un corps spongieux, celluleux, oblong, élevé au centre en un tube ayant une large ouverture. Le tissu qui le compose est formé de cellules régulières à parois veloutées et flexibles, presque toujours gorgées d'eau; la portion élevée du milieu ressemble à un cône tronqué à ouverture du sommet parfartement arrondie; en pressant ce corps, l'eau qu'il renferme jaillit par le tube dont nous venons de parler. Un épiderme d'un purpurin des plus gracieux et de couleur très-fugace, puisqu'il suffit de quelques instants d'immersion dans l'eau douce pour la faire disparaittre, sert d'enveloppe, très-irritable de sa nature, à la partie externe de ce corps. Dans l'état de vie, cette enveloppe animalisée prend toutes sortes de nuances depuis le rose, le gris, le violet et le blanc, jusqu'au jaune le plus pur.

82. ÉPONGE GALCANÉUM.

Spongia calcaneum, Less.

C'est avec quelque doute que nous rangeons dans les éponges le corps dont il s'agit ici, et bien que nous en ayons observé plus d'une centaine d'individus, nous n'avons pu nous fixer sur sa nature. C'est un corps imitant par le volume et la forme l'os calcanéum de l'homme. Son tissu est fibreux et.aréolaire et uniformément d'un vert herbacé muqueux qui paraît être animalisé.

Des centaines d'échantillons de ce corps jonchaient les rivages des îles Malouines, en novembre ı 822 . 
DE QUELQUES CORPS incerta sedis.

\section{TURBINELLE EN GRAPPE.}

\section{Turbinella racemosa, Less.}

Ce corps rappelle tout-à-fait par sa forme le fucus turbiné. Mais sa consistance est molle, mucilagineuse; sa texture est très-fragile. C'est une tige cylindrique, grosse comme une plume à écrire, d'où partent alternativement pour former une grappe des sortes de portions turbinées, résultat de l'épaississement des pédoncules partiels qui, minces à leur attache, s'accroissent successivement, et forment un disque tronqué au sommet trèsfinement ponctué. Ce corps est uniformément d'un vert glaucescent très-pâle; il a au plus vingt lignes de longueur, il flottait sur la mer aux attérages de l'ìle de Waigiou.

Serait-ce un fucus gélatineux? serait-ce une réunion d'oufs de quelque mollusque?

84. BÉROSOME TENTACULÉ.

Berosoma tentaculata, Less.

$$
\text { (Pl. IX, fig. I, I/5 de g. n.) }
$$

Le corps dont nous avons reproduit la figure $\left(\mathrm{n}^{\circ}\right.$ I de notre pl. IX), a été dessiné et pris en mer par M. le lieutenant de vaisseau Bérard; il flottait le long de la Coquille, naviguant alors par vingt degrés de latitude sud et les cent soixante-dix degrés de longitude orientale, dans le grrand Océan équinoxial. La journée était très-chaude et la mer parfaitement calme. Lorsque M. Bérard qui était de quart s'en aperçut, il fit mettre le petit canot ì la mer, et s'y précipita afin de s'en emparer. Ce 
corps n'avait pas moins de deux pieds et demi de longueur sur huit pouces environ de largeur, et se brisa en cent morceaux lorsqu'on voulut le tirer hors de l'eau. Ce que nous en dirons est donc entièrement emprunté au récit de l'officier que nous avons nommé.

La forme du bérosome est cylindrique; il nageait obliquement penché à la surface de la mer; arrondi à son sommet, il était largement ouvert à l'extrémité postérieure, et muni sur le pourtour de cette ouverture de longs filaments cylindriques dont le nombre, suivant M. Bérard, était de huit. Il était parfaitement creux à l'intérieur; son tissu consistait en un mucilage abondant, très-gluant et à moitié liquide. Ce tissu se brisait au moindre choc. Sa coloration générale était d'un blanc mat relevé par des amas de points rouges disposés en lignes régulières et droites d'un pôle à l'autre. Ces points roses étaient eux-mêmes des corps animalisés, ovoïdes, sacciformes, terminés par une tête ayant cinq pointes mucronées rouges et un point rouge au milieu. Ces corps d'une extrême petitesse avaient en propre des mouvements contractiles très-apparents, et le tissu de la masse elle-même possédait une irritabilité qui se manifestait par des ondulations successives.

Ce corps serait-il, ce qui est fort probable, une réunion d'embryons de mollusques? D'un autre côté, quel serait l'animal qui pourrait mettre au jour un corps aussi fragile ayant deux pieds et demi de longueur sur huit pouces environ de diamètre?

85. OEUFS DE MOLLLUSQUE INCONNU.

$$
\text { (Pl. XVI, fig. 4, g. n.) }
$$

A. Un œuf isolé terminé par une aile membraneuse.

Lorsque la corvette la Coquille sortit de la baie de Callao sur la còte du Pérou, la mer était couverte de corps en tire-bou- 
chons en tous points semblables entre eux, et au portrait que nous donnons d'un individu. On ne peut douter un seul instant que ce cordon spiral ne soit une longue grappe d'ovaires à féconder. Disposé en massue au sommet, cylindrique dans le reste de son étendue, vivement coloré dans toute sa partie supérieure, son rouge de saturne finit par pâlir et faire place à la couleur blanchâtre indécise à son extrémité. Ce corps se conservait quelques instants intact dans l'eau de mer; mais dans l'eau douce son mucus se dissolvait, et tous les petits oufs qui en formaient l'ensemble se désagrégéaient aussitôt. Les oufs sont ovalaires, aplatis, peu épais, colorés en rouge de saturne, avec des linéaments vasculaires intérieurs colorés en rouge carmin; ils sont encadrés sur leur bord d'une petite membrane blanche, membrane allongée en forme d'aile à la partie postérieure; ces petits œufs tenus dans l'eau douce contractaient leurs parois, pirouettaient sur eux-mêmes, et l'irritabilité ne tardait pas à s'éteindre. 


\title{
APPENDIX
}

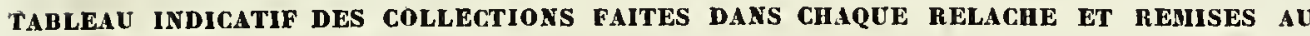 IUSÉU M D'histoire Na'TURELLE a Paris.}

\author{
I ${ }^{0}$ SAINTE-CatheRINE, AU BHÉSIL.
}

(Du 16 octobre 1822 au 28 du mème mois.)

GÉOLOGIE : Douze échantillons de roches granitiques ordinaires de l'île Sainte-Catherine et du Brésil. Savoir : des granites des côtes au niveau de la mer, de l'île et du continent, des montagnes et du cap de Punta-Grossa, de lîle d'Anato-Mirim; le quartz des sommets de Punta-Grossa; les granites en décomposition de Saint-Michel et des îles Ratones. Eau de mer prise, le $\mathbf{I} 2$ octobre $\mathbf{I} 822$, à 200 brasses de profondeur, par 26 degrés de lat. S. - Zoophrtes : Pyrosome jaune; salpas divers; triton fasciculé; diphyes dispar; vélelles; physales; 2 astéries; actinies; rénille américaine, deux individus ayant près de 6 pouces de diamètre; oursins; sertulaires.—Crustacés : crabe; portune ; pénée. - Moluusques : Glaucus; buccin avec son animal; tonne avec son animal; solen; bulime à bouche rose et granuleux; cabochon; huîtres; casque. - Porssovs : Tétraodon; engraulis edentulus; belone timucu; batrachoïde; umbrine grêle; pristipome poreux ; caranx; vomer; stromatée; et divers autres poissons. - Reptrles : Tupinanıbis teguixin; lopliyre; couleuvre; rainette squelette.-Oiseadx : Vautour aura; émerillon de SaintDomingue; pie-grièche tachot; tyran à gorge grise; moucherolle rubin; manakin aux longues pennes; fauvette nouvelle; hirondelle ruffine; chardonneret à front d'or, pitpit vert; sucrier commun; oiseau-mouche jacobine; oiseau-mouche tout vert ; le modeste; le saphir et deux espèces nouvelles; tangaras à ventre marron, tricolore, houpette, écarlate; moineau chingolo; ani mineur.

Cet appendix est une sorte d'aperçu de géographie zoologique, qui pourra derenir utile aux voyageurs futurs, el appeler leur attention sur un grand nombre d'animanx que nous n'a vons pas décrits ou qui ont été égarés cll France. Les échantillons que nous avons recueillis étaient fréquemmeut en nombre. Dans ce tableau ne sont pas comprises les enllertions qui furent perdues dans le naufrage de M. Garnot au cap de Bonue-Espérance. Le calalogue du Muséum d'histoire naturelle est signé par MM. Laugler et VaLengiennes.

Vogage de la Coquille. - Z. Tom. II, Part. II. $2^{\mathrm{e}}$ Div. 


\section{$2^{\circ}$ îles MaLOdINes.}

(Du 18 novembre 1822 au 18 décembre suivant.)

GÉoLogiE : Trente-cinq échantillons de roches intermédiaires. Savoir : Les phyllades des alentours du Port-Louis, du banc de l'Uranic, du port Duperrey, de l'île aux Pingoins; les schistes argileux qui couvrent la phyllade; les grès purs ou avec impressions de spirifères de la surface du sol. Les quartz amorphes du mont Chatellux; les grès quartzeux des montagnes dites des Monuments de Pernetty; les concrétions calcaires des rivages; les plaques de quartz amorphe recouviant les rochırs de grès; les roches de l'Ile-aux-Manchots; les tourbes sèches et marécageuses; les troncs enlacés des glayeuls, de Pernetty, gramen remarquable par son port; enfiń, des ocres ronges et des argiles de l'Ile-aux-Pingoins. - Zoophytes : Holothuria crocea; H. purpurea; actinie des Malouines; oursin; astéries; diverses éponges; éponge versicolore; alcyons; polypier nullipore; sertulaires. - CrustacÉs : Maïa; galathée; sphéromes.-- AnnéLides : Nereïs cirrhigère; spirorbe antarctique. - MoundsQues : Chiton géant; autre chiton; patelle avec son animal; fissurelle avec son animal; calyptrée trochiforme avec son animal; calyptrée; murex avec son animal; solen gaîne; solen radié ; mactre; patelle géante; patelle cymbuloide; siphonaire de Lesson et autres patelles, la deaurata; fissurelle radieuse ; trophon magellanique; balane; salpa divers; ascidies trois espèces; doris; $b o l$. tenia legumen; holozoa cylindrique; polyzoa raquette de mer; sycozoa sigillinoide; cynthie sociale; anatif strié; tćrébratule des Malouines; turbo bicolore; moule de Magellan ; moule édule; vénus ; mitres.-Porssons : Stomias varié; éléginus des Malouines. —OIseadx : Vautour à calotte rousse; caracara funèbre; vautour aura; grive rousse; fauvette; bruant mélanodère ; étourneau des tcrres magellaniques; fournier brun; vanneau à écharpe; huîtrier noir; huîtrier à pieds blancs; bihoreau pouacre; bécassine à long bec; grèbe Roland; grèlse aux belles joues; chionis blanc; goëland au manteau noir; mouette à tête brunc; stercoraire austral; sterne caugeck; cormoran à gorge variée; oie de Magellanie; canard aux ailes courtes; canard à ventre noir; sarcelle soucrourette. - Mamafrìnes: Otarie molosse; lapin des Malouines, delphinaptère de Péron.

$3^{\circ}$ Chili, province de la concepcion, port de talcahuano.

(Du 20 janrier 1823 au 13 février suivant.)

GÉologre : Dix échantillons de roches talqueuses phylladiformes de la presqu'île de Talcahuano, ce sont: Des phyllades noires de la côtc occidentale de la baie de la Concepcion. Des mica-schistes de la même côte, du niveau de la mer au sommet des coteaux qui bordent le Havre, à Castillo-Galvès, dans l'île de Quiriquine et à Talcahuano; les 
quartz disposés en veine dans les roches de mica-schistes; les gròs et les argiles durcies avec oxide de fer de l'île de Quiriquine.

Six échantillons de granitc ordinaire de la côte continentale de Penco, des mamelles du Biobio, de la montagne de la Concepcion, et surtout de la chaîne qui domine cette ville, et un de sable noir micacé et ferrugineux des plages de Quiriquine.

Trois échantillons du lignite stratiforme, voisin de la houille des mines de Penco, avec des morceaux de sel gemme du Chili. - Zoophytrs : Actinie, diverses espèces; polypiers nullipores; oursins; astéries, diverses espèces. - Crustacés : Crabe azur; autre crabe maia ; pagure; axies du rio de Penco, uniâs de la mar, ou rémipède. - lNsecte: Scolopendre verte. - Molcusques : Dans la liqueur, doris, chiton poilu; quatre espèces de patelles; fissurelle radieuse; trois espèces de calyptrées; auricula Dombeyana des eaux douces du rio de Penco; concholepas avec son animal, deux individus; licorne géante; mytila lata; pourpres cancellée et cordelée; troclıus; balane picos; moules striées; moule très-petitc ; cinq espèces d'oscabrions; ascidie; éolide de Lottin; corbule; mactre; solen; balane. - Porssoss : Pastenague ; climère antarctique; scrran rayonnant; pristipone; scombre; ésoce; muge.-Rertress : Tortuc de la Californie; lézard; agame du Chili; scinque à quene bleue; couleuvre; autre couleuvre; crapaud thaul; crapaud verruqueux; grenouille.-Oisfaux : Faucon chimango; moucherolle clignot; autre moucherollc; troglodyte; farlouze de Monte-Video; étourneau Chopi ; fournier Lesson; oiseau-mouche sephaniodes; pic chilien; arara de la Patagonie; colombe araucanienne; autre colombe; vanneau armé; alouette de mer; pétrel fulmar; prion blcu; mouette à tète grise; mouette à nuque grise; bec-en-ciseaux à bec noir.

\section{$4^{\circ}$ Callao et lima, côte du PÉrou. \\ (Du 26 février 2823 all 4 mars suivant.)}

Gŕologie : Des échantillons de phtanite gris de l'île de San-Lorenzo, à l'entrée de la baie de Callao; de granitc des environs de Lima. - Ciustacés : Crabe violet, une deuxième espèce vivement bariolée.-Mourusques : Calmar; onychoteuthe; piléopsis; concholepas du Pérou, avcc son animal; peigne de Callao; chiton péruvien; la vaginule du mont San-Clıristoval. - Poissons : Liche. - Repriles : Iguane belliqueux. OIseaux : Vautour urubu; moucherolle nouveau; moineau olivarez; bouvreuil télasco; ani de Las-Casas ; oiseau-mouche amazili ; oiseau-mouche cora ; colombe cocotzin ; petite maubèche, sterne des Incas; cormoran de Gaimard ; cormoran nigaud.

$5^{0}$ PAYTA, CÓTE DU PĹROU.

(Du zo mars 1823 ali 22 du mème mois.)

GÉoLogIE : Six échantillons des roches talqucuses pliylladiformes de la basc du terrain de Payta. Des échantillons de gypse fibreux formant des losanges dans les sables 
agglutinés des coteaux. Sept échantillons d'argile plastique. Quarante échantillons du calcaire grossier qui est rempli de moules testacés de diverses espèces de coquilles marines, tels que : huîtres, peignes, cérithes, troques, etc., etc., avec des ossements triturés à la surface. Enfin, un échantillon de catucho, pierre merveilleuse à laquelle les Péruviens accordent par superstition les plus grandes propriétés. - ZoopHyres : Diverses actinies; gorgone; astérie hélianthe; autres astéries; antipathes; ophiure; oursin à baguettes violettes; holothurie de Payta. - CRdstacśs : Squille; ocypode; grapse fleuri; crabe; pagure.-Annéunde : Néréide.-MolnusQues : Calmar; aplysie de Lesson; ascidies ; phyllidies ; patelles ; vis ; balane ; calyptrées ; murex; fissurelle; natice glauque; natice blanche; monocéros; huîtres; vénus, cythérée lupanar; corbule; solen; perne; pholade; ponce-pied élégant.-Porssons : Pastenague Thouin; saurus; vomer; serran.OIsEadX: Farlouze grise; aigrette; spatule rose; pélican de la mer du Sud.

$6^{\text {o }}$ ÎLE D'O-TAÏTr, ARCHIPEL DE LA SOCIÉTÉ.

(Du 3 mai r 823 au 22 du même mois.)

Gíologie : Roches basaltiques avec péridot de la surface de l'île et de la cascade intérieure. Divers fragments de laves. - OnJEts divers : Bois d'hibiscus tiliaceus avec lequel les insulaires allument du feu par le frottement; fruits du mapé, inocarpus edulis. Fucus érimou ou turbiné. - Zoophytes : Holothuries; oursin ena à pointes blanches et rosées; vétoué ou cydarite à baguettes, très-commun; astéries à cinq rayons étroits; fongies ; madrépores rameux, lamelleux, etc., etc.; seize espèces nommées pouboupa, paya et farira.-Irsecres : Diverses araignées. - Crustacḱs : Langouste; mante à bandes; cypaye ou crabe de cocotier, birgus latro; ocypode, deux espèces des bords des rivières; pagure; palémon; pénée, rémipède.-Mourusques : Onychoteuthe; aplysies souris et Kéraudren; ptérocère avec son animal; cadran poupou; vis tachetée; vis bleuàtre; olive de Taïti ; néritine à couronne ou ehii ; pourpre; volute; patelles ; turbo mahaoua; pour poutaratara chicorée ; païao, nurex ; triton ; porcelaines nombreuses; telline; tirana ou pintadine mère-perle; pinna saccata; tridacne ou paoua; moules; lime avec son animal; huîtres. - Porssoss : Anguille toréa; anguille marbrée thoura; ophiure éounè ; deux sphagebranches; cyclogaster; exocetus exiliens; holocentrum tiéré; grammistes rayé; dules; serran; kurte touréréa; chœtodon, plusieurs espèces; lepidopus; acanthures; prionure; girelle aoupa ; girelle pao; sciène; gomphose bleu, ou poou; eleotris; spare eou; scare eouvou; acinacée du Grand Océan.-—Reprines : Gecko hémidactyle; autre gecko; scinque à queue bleue à raies dorées; autre scinque; autre scinque. - OIsEardx Gobe-nıuche Ponaré ; fauvette ; todiramphe, deux espèces ; perruche ari-manou; perruche vini; tourterelle kuru-kuru, d'O-Taïti; héron monogrammique; chevalier.-MА MPĖ̀E : Musaraigne. 


\section{$7^{\circ}$ île de borabora, ARCHIPEl de la société.}

(Du 18 mai 1823 au 9 juin.)

GÉologıE : Huit échantillons de basalte avec péridot de l'ossuaire de l'île; des scories rouges pesantes; le calcaire madréporique des côtes; la belle dolérite qui forme le mont Paya et l'île de Maupiti._Zoophyтes : Holothuries, diverses espèces; ochétostome eaouari; actinies; astéries discoïdes; oursin; ophiure; tubastrcea coccinea; nombreux madrépores; halymède tuna. - CRustacḱs : Crabe; portunes diverses; grapse; ocypode toupa; calope; pagure latro; palémon ; squille; eoua ou Bernard-Ermite rouge à points blancs._Mourusoues : Poulpe neigeux; ascidie; dolabelle; ocea ou partule; patelle; cône; bronte; vis bleuâtre; vis tigre ; natice ; mitre ; monodonte ; strombe; deux tellines; cythérée gourgangine; came; trois espèces d'arches ; pinna saccata ; vénéricarde; corbule; huître; tridacne; hippope._Porssovs : Balistes, plusieurs espèces; le noir et le très-orné; ostracion quadricorne momoa; ostracion peintade; ophisures, plusieurs espèces; ophisure alternant; ichthyophis tigré ; ophidie ; murénophis; sébaste nain ; synancée; holocentre diadème, holoccntre anguleux; serran, plusieurs espèces; serran myriaster; pomacentres, l'émamo; chétodon à housse; chétodon cocher; caranx; acanthure; esclave.-Reptines : Gecko; emo, ou scinque à queue bleue.-Oiseaux : Coucou d'O-Taîti ; sterne blanc; petite frégate toute noire; canard nouveau.

\section{$8^{\circ}$ PORT-PRASLIN DE LA NOUVELLE-IRLANDE.}

(Du I2 août 1823 au 2 du mème inois.)

GÉoLogIE : Cinq échantillons du calcaire madréporique tantôt grossier, tantôt avec grains spathiques du pourtour du Port-Praslin; puis les calcaires grossiers durs, avec des coquilles modernes superficielles de l'île aux Marteaux. -Zoophytes : Actinie novæhyberniæ ; sarcopliyton lobulatum ; sératopore ; corail tubipore; halymède; éponge; astéries cicinbone.-1nsecte: Spectre noir._CrustacÉs : Maïa; cạlope; langouste ornée. —Mourusques: Phyllidie; scarabe; nautile pompilius; argonaute; pyrène fluviatile ; pourpres ; troque pagode; néritines; patelle; vis; cônes; haliotide; balane; crassatelle; solécurte? donaces ; vénus; cardite; arche; tridacne; placune vitrée; lingule; huître édule._Porssons : Pastenague de Halgan; requin à ailerons noirs; baliste rayé ; alutère; murénophis, diverses espc̀ces; pleuronecte émaillé; pélor; myripriste; térapon queue rayée; serran; kurte; perchot; glyphysodon; cæsio azuror; cirrhiptère; chétodon; holacanthe gćométrique; scombre loo ; caranx; salarias crête de coq; périopthalme kalolo. Reptiles : Tupinambis; gecko de Pandang ou vittata; couleuvre dendrophis; autre coulcuvre.-Oiseaux : Gobe-1nouche télescopthalme; stourne métallisé; corbeau à duvet 
blane; souï-manga aspasie; coucal atralbin; perruche de Latham; colombe muscadivore; colombe puella.-Mamnifìnes : Couscous tacheté; couscous à grosse queue.-OBJEts D'ART : Cassc-tête en bois dur; nattes et flèches; poivrière et salic̀re malgaches; coussins des Papous sculptés avec des sphinx; idoles des Papous.

$9^{\circ}$ île de waigiou, terre des papous.

(Du 6 septembre 1823 au 16 du mème mois.)

GÉologie : Vingt échantillons des roches de serpentine, qui constituent l'ossuaire de l'île de Waigiou, avec des basaltes et des pierres ponces qui flottent aux attérages.Zoophytes: Holothuries, diverses espèces; scutelle; spatangue; oursin diadème; porite ; flustres; fongies; lithactinies; ćponge jaune._CnustacÉs : Scyllare; palémon; langouste; crabe honteux; parténope horrible.-Moldusques : Dans la liqueur : cérithe; cône damier; cône linéolé; autres cônes; anatif grenu; balane ; scarabes, deux espèces; nérite; néritines; sigaret; turbinellc ; trochus; troque épcron; murex; patelle; apole; hippocrène; hélicc, plusieurs espc̀ces ; peintadine; placune selle; huîtres diverses; tridacne; vénus; came; arche; oscabrion; coronule des tortues; pollicipes. - Porssoxs : Roussette; requin à ailerons noirs; diodon; tétraodon; balistes écharpe et praslin; nason; anguille; murénophis; leptocćphale; échéneïs à vingt-cinq plaques; saurus; platycéphale rude; plusieurs insidiator; pélor marbré; bar waigien ; holocentre; serran ; denté ; pomacentre; acanthopode; acanthure, plusieurs espèces; trigle enop ; scorpène à anternes. - ReptiLEs : Tupinambis: rainette de Waigiou. - Orseadx : Gobe-mouche; philédon à oreilles jaunes; souï-manga zénobie; souï-manga chcvalier ; guépier à gorge jaune ; martin-chasseur Gaudichaud; perroquet Geoffroy ; psittacule Desmarest; lori ; édienême à gros bec ; sternc; paradisier rouge femelle dans l'alcool. - Mammrères : Couscous blanc; péramèle kalubu (perdu.)

Io îlE de botrou, L'UNe des moluQues.

(Du 23 septembre 1823 au ${ }^{\text {er }}$ octobre suivant.)

Gíologre : Trois échantillons de roches talqueuses carburées phylladiformes des collines de la baie de Cajéli; deux autres de talcitc quartzifère, avec des fragments de quartz formant des veines puissantes et épaisses d'un pied dans les couches précédentes. -Zoophytes : Actinie; oursin ovalaire; actinanthe; zoantha; madrépores, diverses espèces; gorgone verruqueuse; isis hippuris avec son écorce ; ophiures; astéries; fongies 
-_Crustacés : Pagure; palénıon; pénée.-Moldusques : Dans la liqueur; aronde avec son animal; cône marbré avec son animal; nérites; mélanies; volutes ; sanguinolaire ; crassatelle; cardite; huître; vénus déflorée; anatine; modiole papoue; solécurte ; arche; placune selle et vitre. - Porssors : Baliste rayé; autres balistes; ostracion quadricorne; sphagebranche; échéneis rémora; échéneïs naucrate; monochire; sardine; hémiramphe; plotose ikapor; platycéphale ; apogon ; gerres; kurte; caranx ; sidjan ; scombre, fistulaire pétimbe. - Reptiles : Crocodile biporcatus; agama; gecko; scinque rayé; dragon volant, trois espèces; couleuvre des Célèbes; deux autres couleuvres des Célèbes. - OrSEAUX : Aigle malais; pie-grièche; langrayen à ventre blanc; philédon moine; gros-bec vermiculé; dicée ensanglanté; soui-manga; martiı-chasseur; alecthélie d'Urville, de Guébé; colombe phasianelle; canard radjah. - MaMmifìres : Têtes de babirussa.

$$
\text { I I }{ }^{\circ} \text { ÎLE D'AMBOINE: }
$$

( Du 3 octobre ${ }^{82} 3$ au 27 du mème mois.)

GÉoLogie : Plusieurs échantillons du calcaire grossier madréporique des collines qui dominent la ville d'Amboine, et qui peuvent avoir de 300 à 450 pieds de hauteur. Zooннттеs : Holothuries diverses. - Insecres : Scolopendre; phasme; mante-feuille, très-commune.-Crustacḱs : Langouste; scyllare; crabes, etc. - Annélide : Sangsue d'Amboine. - Molucseves : Nautile; argonaute papyracé, hians et haustelium; la plus grande partie des coquilles ordinaires des collections, telles que volutes, porcelaines, cônes, olives, grimaces, etc., qu'on trouve par boîtes chez les marchands chinois. Porssovs : Diodon; syngnathe; échéneïs; priacanthe; caranx; gasterostée; temnodon ; amphacanthus; scombres.-Reptines : Tortue à boîte; dragon volant; scinque à queue azur; geckos; plusieurs couleuvres; dendrophis; grenonille bicolore.-Orseavx : Perroquet Geoffroy; colombe Reinwardt; divers moineaux.-MLanmifìres : Couscous gris.

I $2^{\circ}$ PORT-JACKSON DE LA NOUVELLE-GALLES DU SUD.

(Du I 7 janvier 1824 au 22 mars suivant.)

GÉologiE : Trente échantillons des grès de la côte et de la première rangée des montagnes Bleues. Douze fragments de granites et de syénites quartzifères; six de porphyre pétro-siliceux noirâtre quartzifère des montagnes Bleues; deux morceaux de dolérites de Paramatta ; douze de grès souvent ferrugineux, avec fer hydraté colorant et fer oligiste en écailles brillantes disséminées, sur lc pourtour de la rivière Nepean et sur les côtés du bassin de la Weragambia; des stalactites calcaires de la caverne de Bathurst. 
Nous nous procurâmes une trentaine d'échantillons des roches de la terre de Diémen, savoir : des pegmatites; des roches d'un terrain tertiaire; des spirifères; des roches serpentineuses, des asbestes; d'un calcaire intermédiaire; etc., etc. —Zoopнyт́̇s: Divers polypiers encroûtants. - Crustacés : Pinnothère. - Moluusques : Olive avec son animal; physe de la rivière Macquarie avec son animal; huîtres; trochus; pyraze Baudin; patelles; bulle.-Porssons : Squale de Phillipp; tétraodon; baliste verruqueux et autres; maquaria austral et grystes de la rivière Macquarie ; térapon à six raies.-RepriLes : Émyde au long col, espèce non décrite; agame jacksonien; gecko; scinque jaune et noir des montagnes Bleues; scinque rayé; python de Péron; acantophis tortor; couleurre de Botany-Bay; grenouilles de Swamp et de la rivière Macquarie.-Oiseadx : Faucon de la Nouvelle-Hollande; autour id.; pie-grièche; cassican flûteur; cassican gris des montagnes Bleues : trois espèces de muscicapa ; la moucherolle à pourtour de l'œil membraneux; grive écaillée; grive ponctuée; philédon grivelé; philédon à front blanc ; philédon varié; philédon cap nègre; philédon nouveau; fauvette; pouillot; moineau astrild; moineau webbung; sittelle aux ailes dorées; sucrier? à front roux; séricule prince régent; épimaque royal; nartin-chasseur géant; coucou chalcite; scythrops ; platycerquedePennant, la rose-hell ou l'omnicolore; perruche moineau; cacatoës de Banks; caille australe; colombe magnifique; colombe lumachelle. - Mammirères : Kangourou oualabat ; phalanger volant; échidné dans la liqueur; ornithorhynque.

\section{I $3^{\circ}$ BAIE-DES-î́LES DE LA NOUVELLE-ZÉLANDE.}

(Du 3 avril 1824 au 17 du mème mois.)

GÉoLogie : Quatre échantillons de basalte écailleux passant à la phonolithe; des obsidiennes ordinaires; des pépérites avec lesquelles les habitants se peignent le corps en rouge et aussi leurs constructions; une argile bleue, nommée paraka-oua-io, avec laquelle les femmes se font des mouches sur le visage. - Zoopнттеs : Astéries; le polypier flexible kolinou-limou. - CRustacés : Portune; dorippe; grapse peint; palémon; squille rubanée. - AnnéLide : La serpule patouka-touka. - Moldusques : Haliotide australe; trochus de Cook ; patelles; trois turbo korano ; calyptrée; crassatelle de Roissy; vénus; moule; solen.-Porssons : Stomias de la rivière de Kiddi-Kiddi; uranoscope kouripoua; pélor brun; perche colias; pentapode tilé; daurade des eaux douces; caranx; acanthure; labre poréquirikiri , éléotris ; hippocampe kioré; trigle kumu-kumu. —RepTILE : Scinque rayé à queue bleue.-OIscaux : Gobe-mouche, deux espèces nouvellcs ; rhipidure flabellé ; étourneau à barbillons; philédon Duméril ; traquet queue gazée; pouillot nouveau ; farlouze ; alouette ; stourne ; martin-chasseur ; perruche d'Edwards ; perroquet nestor; colombe spadicée; pluvier à collier; prion bleu; sterne à bec noir ; cormoran monogramme; cormoran à bec court. - M MMmirk̀ne : Le chien austral. 
$14^{\circ}$ île d'ounlan et archipel des earolines.

(Juin $1824 \cdot$ )

GÉologie : Des roches basaltiques eotsé, et le caleaire madréporique grossier des eôtes. Des coquilles de tridacne spathisées avee lesquelles les insulaires font leurs haehes. -Zoophytes : Ophiures; oursin inescha; oursin noir; oursin à baguettes vertes annelées; oursin à baguettes acieulées noires; le madrépore flabelliforme eoka à polypes jaunes, à huit bras; éponge eylindrique; poly pier opuntia ou mouai; sakène, polypier flexible diehotome ; loume sertulaire; astérie pentagone; astérie bleue. - CrustaeÉs : Palémon; erabes divers; l'ixos. - Molrusours : Aplysie; calmar; cône; unieorne d'Oualan; huître feuille; vénus ; eorbeille; telline._- Porssoss : Baliste a mérieain; anguille et murénophis, plusieurs espèces; apiste noir; eheilodyptère einq raies; priaeanthe earolin ; serran ; gerres; kurte argenté ; pomacentre ; eirrhiptère des eaux saumâtres ; ehétodon , diverses espèces; aeanthure, diverses espèees ; girelle, plusieurs espèees ; seiène ; gomplose bleu; périopthalme; le mulet à trois bandes ou tiléà dos bleu, et à eôtés argentés et roses. - Reptiles : Deux scinques; geeko. - Oiseaux : Stourne des eolombiers; fauvette; hirondelle salangane; cisse ou einnyris rubrater; mouleux ou eolombe océanique; chevalier bécasseau; pétrel désolé (dans les Carolines); fou des îles Carolines; aigrette lougoulap; héron gris; sterne noddi ou palé.-MaMmifères : Roussette Kéraudren; phyllostome; rats; tête de dauphin à seapulaire noir.

\section{I $5^{\circ}$ NOUVELLE-GUINÉE.}

(Du 26 juillet 1826 au 9 aoút suivant.)

GÉologis : Caleaire madréporique des eôtes; quelques échantillons de quartz et de granite roulés de l'in térieur. - Zoophytes : Spongode Célosie; divers polypiers; astérie. -Crustacés : Crabe; grapse; pagure.—MoLLusques : Dans la liqueur; pyrosome jaune; sépioteuthe de Lcsson; onehidies, diverses espèees; harpe avec son animal; aurieule oreille de Midas avec son animal; anatifs; onehidlies; eônes ; vénus; trochus; fuseau; ovule; etc. - Porssoss : Tétraodon géographique; balistcs, sept espèces; deux alutères; ostraeions; murénophis ; éehéricìs à vingt-cinq plaques; diacope maeolore ; toxote areher; chétodon bieorne; holaeanthe à bandes; trois aeanthurcs; genre voisin des aeanthures et nouveau; lophie.-ReptıLEs : Hydre bicolore; conleuvre ikahı̀que; autres eouleurrcs. - Orseaux : Autour longicaude; vanga eap-gris, éehınilleur karou; eassiean varié; eassiean Quoy; clalybé; phonygame Kćraudren; museicapa ornoir; eurylaime de Blainville;

royage de la Coquille. - Z. Tom. II, partie II. $2^{\mathrm{e}}$ Div. 
gobe-mouches, deux espèces; đlrongo moucheté; pie de paradis ou astrapie, deux individus; philédon corbicalao; deux autres philédons; martinet à moustaches; hirondelles; corbeau gris; corbeau vieillard; rolle; mino de Dumont; paradisiers émeraude, adulte, jeune et femelle, un dans l'alcool; manucode adulte et sa femelle; certhia; cinnyris; martin-pécheur dea, adulte et jeune; syma; martin-chasseur de Gaudichaud; cejx bleu; calao, deux espèces; coucou jaune; coucal mênebiki; psittacule Desmarest; perroquet lori, tricolore, émeraude, à collier; cacatoës rouge, huppé; ara à trompe; mégapode de Duperrey; talégalle de Cuvier; mégapode Freycinet; pigeon goura; pigeon nicombar; tourterelle puella; colombe zoë; colombe pinon; colombe turvert; etc.; pluvier doré ; héron phaëton; sterne à nuque noire; et un grand nombre d'autres. - Mammirìres : Le cochon des Papous; le podin (perdu) espèce de kangourou; plusieurs crànes d'alfourous, habitants de l'intérieur.

I $6^{\circ}$ SOURABAYA; îlE DE JAVA.

( Du 28 août I 824 au II septembre suivant).

GÉologie : La corvette la Coquille était ancrée au fond de la vaste baie de Madura, et au milieu des terrains bas de cette partie du sol javanais. - Reprizes: Gecko à verrues azur; caméléon nez fourchu.-Orseadx : Aigle malais; hibou ketupa; loriot couliawan ; mainate religieux; deux hirondelles de mer; fou des îles de la Sonde; casoar éneu; sterne de Panay.

\section{I $7^{\circ}$ îLe Mathice.}

( Du 3 octobre 1824 au 16 novembre suivant).

GÉoLogre. Quatorze échantillons de basalte passant à la dolérite.-Zoophytes : Diver's coraux qui forment la ceinture de plusieurs des havres de l'île de France. Quelques astéries. Insectes : Scorpion des Seychelles; mante; forficule. - Crustack: : Squille rubanée. Annélide : Amphitrite.—Molussques : Dans la liqueur : agathine kouroupa avec son animal. - Porssons : 'Triodon macroptère; élops saurus; mégalope filament; exocet exilient; dorade à trois lobes; carpe des ealıx douces; sébaste nain; perche nébuleuse; doule des rochers; cirrhite panthérin; daurade des eaux douces; amphyprion à bandes; lichia; sidjan; girelle; crénilabre de Chabrol; lâbres divers; cheiline queue verte; girelle à demi-parée; gobie; éléotris. - Reprites : Caméléon de Madagascar; l'uroplate des Seychelles; gecko inunguis. - Orseaux : Martin gryllivore; foudi; calfat; tisserin; bouvreuil à sourcils jaunes; serin gris; gros-bec domino.-Mammipères : 'Tanrec de Madagascar; squelette du maki mococo de Madagascar. 
$18^{\circ}$ îLE DB SAINTB-HÉLÈNE.

(Du 3 janvier au r2 du même mois.)

GŕoLogre: Cinq échantillons de porphyres trachytiques de la vallée de James, de Rupert's hill; la pouzzolane de James's town.-Zoophytes: Actinia Sanctoe-Helence; mynias bleu; oursin à baguettes aciculaires...Moluusques : Diverses janthines avec leurs mollusques; patelle bleue.-Poissons : Priacanthe boops; scombre ; caranx.-Oiseaux : Pétrel damier; fou.

$$
\text { I } 9^{\circ} \text { îLe de L'Ascencion. }
$$

( Du $x 8$ janvier au 28 du même mois.)

GÉoLOGIE : Dix-huit échantillons des roches basaltiques de la montagne de Green-Hill; des clapers; laves; scories; cinq fragments d'obsidienne; un agrégat calcaire moderne qui encroûte les basaltes des côtes où la mer déferle. - Zoophytes : Actinies; éponges. - Crustacé : Grapse peint. - Mollusques : Patelles; littorines; colombelle; huître en tulipe.-Porssons : Balistes divers; baliste bleu; baliste vieille; alutère.-RepTILE : Tortue verte de très-grande taille.-Orsearx: Squelettes de fous; frégate à tête blanche; paille en queue à brins blancs; fou manche de velours. - MLamifènes : Oryctère du cap (M. Garnot); antitope spring-bock du cap (M. Garnot); musaraigne.

FIN. 



\title{
TABLE DES MATIËRES
}

\author{
Contrnuts bans La $2^{\mathrm{e}}$ Division
}

DE LA DEUXIÈME PARTIE DU SECOND VOLUME

DE LA

\section{ZOOLOGIE DU VOYAGE AUTOUR DU MONDE,}

EXÉCUTÉ PENDANT LES ANNÉES 1822-1825.

ZOAPH Y'T RS; Par R.-P. Lesson.

CHAPITRE XIV. Description des Zoophytes échinodermes.. P. 3

Oursin porte-houlette, 3. - Oursin à baguettes carénées, 4 .

- Holothuric (phallusie) quadrangulaire, 5. - Holothurie timamc, 6. - Holothurie trépang, 7. - Holothurie (phallasic) impudique, 8. - Holothurie péruvienne, 9.-Holothurie (intestinaire) océanienne, 9. - Holothurie (intestinaire) andouille, I 1. - Holothurie (chiridote) purpurine, I r. - Holothurie (concombrinc) orangée, 12. - Holothurie (myniade) azur, 13. - Ochétostome eaouari, i 5. - Siponcle lombrisciforme.................. 6

CHAPITRE XV. Description de la famille des Cystisomes, et des espèces observées pendant le voyage de la Coquille. 17

Physalic de l'Atlantide, 36.-Physalie de l'ocćan Pacifique austral, 38. - Physalie de l'océan Atlantique austral, 39. Physalic tuberculeusc, 40. - Physalie des Açorcs....... 42 
Description de la famille des Physsophores........ 43

Physsophore distique, 45. - Pontocarde crucié...... 45

Description de la famille des Vélelles........... 47

Vélelle mutique, 52. - Vélelle bleue........... 54

Description de la famille des Porpites........... 55

Porpite aux cheveux d'or, 58. - Porpite atlantique, 58.

- Porpite du grand Océan, 56. - Radeau de la Méduse, 6o.

- Prunelle cillant................... 6 I

Description de la famille des Pléthosomes......... 6 I

Diphyc jumelle, 63. — Pléthosome hyalin......... 64

CHAPITRE XVI. Description des animaux de la famille des Ac-

tiniées.................................67

Sarcophinanthe fleuri, 68. - Sarcophinanthe à papilles, 70. - Corticifere agrégée, 71. - Lagène à lèvres vertes, 73 . - Actinie de Ste. - Hélène, 74. - Actinie de Ste. - Catherine, 74. - Actinie du Pérou, 75. - Actinic capensienne, 76. Actinie du Chili, 76. - Actinie douteuse, 77. - Actinie de la Nouvellc-Irlande, 77. - Actinie papilleuse, 78. - Actinie bicolore, 78. - Actinie des Malonines, 79. - Actinie ocellée, 79. - Actinie peinte, 8o. - Actinie crrante, 8o. - Actinie neigeuse, 8ı. - Euménide tisiphone........... 8,

CHAPITRE XVII. Description de la famille des Polypactinies.. 84

Actinanthe bouquet, 85. - Zoantha des Moluques..... 87

Description de la famille des Nephthées.......... 88

Spongode crête de coq.................. go

Description de la famille des Polypes.......... $9^{2}$

Sarcophyte lobulé, $9^{2}$. - Tubastrée écarlate....... $9^{3}$

CHAPITRE XVIII. Description de la famille des Béroïdes...... 95

Lemnisque (ceste?) bordé de rouge, ro2. - Neis bourse de mer, ı3. - Béroé cle Baster, ı oł. - Béroé (idya ) macrostome, I05. - Béroé (cyclalise) en nitre, ı o6. - Béroé (épomis) gargantua, ro7. - Bourse de Vénus........... ro 8

Des Méduses observées dans le voyage de la Coquille. I I Pélagie panopyre, I I I. - Chrysaore de Gaudichaud, I I 4. - Chrysaore de Blosseville, i I5. - Cyanée aux beaux cheveux, i I6. - Cyanée de Bougainville, i 18 - Aurellie pissinéboqué, r I9. - Rhizostome aux longs bras, I20. - Rhizostome croisée, 121. - Céphée des Papous, 122. Dianéc cérćbriforme, 12/. - Equorée des îles Carolines, I 26 . - 
TABLE DES MATIÉRES.

Equorée mitre, I27. - Eudore eau condensée, r27. - Eu-

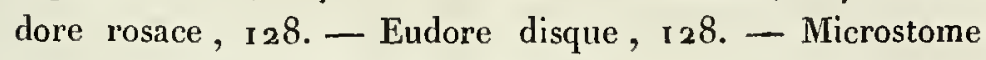
ambigu, I3o. - Eulymène cadran de montre........ 13o

De quelques zoophytes obscurs........... I3 r

Eucclium de Borabora, I3 г. - Éponge versicolore, I 3 г.

Éponge calcanéum.................. $1 \mathbf{3}_{2}$

De quelques corps incertce sedis........... I33

Turbinelle en grappe, I33. - Bérosome tentaculé, 133.

OEufs de mollusque inconnu............... 134

Appendix....................... 137

FIN DE L'INDEX DE LA DEUXIĖE PARTIE DU SEcoND VOLUME. 


\section{TABLE DES PLANCHES DE L'ATLAS}

QUi SE RAPPORTENT a LA $2^{\mathrm{e}}$ DIVISION DE LA DEUXIÈME PaRTIE DU SECOND VOLUME.

\section{ZOOPHYTES.}

Pl. 1. Fig. I. Euménide Tisiphone, Eumenides ophiseocoma, Lrss.

P. 8 I

Fig. 2. Zoantha thalassanthe, Zoantha thalassanthos, Less.

Fig. 3. Actinanthe bouquet, Actinantha florida, Less.

Pl. 2. Fig. I. Actinia Sancte-Helence, Less.

Fig. 2. Actinia Sancte-Catherince, Less.

Fig. 3. Actinia peruviana, LEss.

Fig. 4. Actinia capensis, Isss.

Fig. 5. Actinia chilensis, Less.

Fig. 6. Actinia dubia, Less.

Pl. 3. Fig. 1. Actinia Nove-Hybernice, Less. 77

Fig. 2. Actinia papillosa, Less. 78

Fig. 3. Actinia bicolor, Less. $\quad 78$

Fig. 4. Actinia macloviana, Lrss. $\quad 79$

A. la même ayant les tentacules repliés.

Fig. 5. Actinia ocellata, Lrss. $\quad 79$

Fig. 6. Actinia picta, Less. $\quad 80$

Fig. 7. Actinia vagans, Less. $\quad 80$

Fig. 8. Actinia nivea, Less. $8 \boldsymbol{I}$

A. La même vue de face.

B. La même en divers états.

PI. 4. Physalie de l'Atlantide, Plyysalia atlantica, Lrss.

A. Ventouses grossies.

Pl. 5. Fig. I. Physalie de l'océan Pacifique, Plıysalia australis, Less.; $P$. megalista, Péron et Lesueur.

Fig. 2. Physalie de l'océan Atlantique austral, $P h$. antarctica, L.s.s. 
Fig. 3. Physalie tuberculeuse, Ph. tuberculosa, Laмk. 40

Fig. 4. Physalie des Açores, Ph. azoricum, Less. 42

PI. 6. Fig. r. Vélelle mutique, Velella mutica, La rк.
A. Cartilages internes.
B. Bouche et tube stomacal.
C. C. Suçoirs buccaux.
D. Tentacule isolé.
Ł. Jeune âge.

Fig. 2. La même vue en dessous.

Fig. 3. Vélelle bleue, Velella cyanea, Less.

Fig. 4. La même vue en dessous.

P!. 7. Fig. I. Porpite aux cheveux d'or, Porpita chrysocoma, Isiss. 58

Fig. 2. Porpite atlantique, Porpita atlantica, Less. 58

Fig. 3. Porpite du Grand Océan, P. pacifica, Less. 56

3'. La même vue en dessous.

C. Sa bouche entourée de suçoirs.

PI. 8. Fig. 1. Sarcophinanthe fleuri, Sarcophinanthus sertum, Less.;

Nouv.-Irlande.

Fig. 2. Sarcophinanthe à papilles, S. papillosus, ILess.; Nouv.Irlande.

Fig. 3. Corticifère agrégée, Corticifera agregata, Less.; île de Borabora.

Fig. 4. Eucoelium de Borabora, Eucœelium Boraboriensis, Less.; île de Borabora.

PI. 9. Fig. I. Bérosome tentaculé, Berosoma tentaculata, Less.

Fig. 2. Eudore eau-condensée, Eudora hydropotes, Less.

A. Vue horizontalement.

B. La même vue en dessus.

Fig. 3. Eudore disque, Eudora discoides, Less.

Pl. ro. Dianée cérébriforme, Diance a cerebriformis, Isess.; Océan Atlantique.

Pl. I I. Fig. I. Rhizostome croisée, Rhizostoma cruciata, Læss. ; côtes du Brésil.

Fig. 2. Céphée des Papous, Cephea papua, Less.

Fig. 3. La même dans son jeune âge. Côtes de l'île de Waigiou.

Pl. 12. Fig. I. Cyanée aux beaux cheveux, Cyanea plocamia, Less.

Fig. 2. La même complètement adulte. Côtes du Pérou.

Pl. r3. Fig. I. Chrysaore de Gaudichaud, Chrysaora Gaudichaudii, I_ess., côtes des îles Malouines. 
TABLE DES PLANCHES.

Fig. 2. Chrysaore de Blosseville, C. Blossevilii, Less.; côtes du Brésil.

11. 14. Fig. 1. Bourse de Vénus, Bursarius Cytherce, Less.

Fig. 2. Pléthosome hyalin, Plethosoma crystaloides, Liss.

A. A'. Pièce inférieure.

B. C. Fragments latéraux désarticulés.

Fig. 3. Cyanée de Bougainville, Cyanea Bougainvilli, Lrss.

118

D. D'. D'. D'". La même vue sous plusieurs aspects.

Fig. 4. Équorée mitre, AEquorea mitra, Liss.

Fig. 5. 5'. Microstome ambigu, Microstoma ambigua, Less. $\quad 130$

Pl. 15. Fig. I. Béroé gargantua, Beroe gargantua, Less.

Fig. 2. Béroé macrostome, B. macrostomus, Péron.

107

I 05

Fig. 3. Béroé mitre, B. mitrceformis, Less.

106

Pl. ı6. Fig. I. Béroé de Baster, B. Basteri, Less.

A. Vu de côté.

B. Vu par le pôle inférieur.

Fig. 2. Neïs bourse de mer, Neis cordigera, Less.

Fig. 3. Physsophore distique, Physsophora disticha, Less.

A. Suçoir isolé.

B. Disque inférieur des suçoirs.

C. Vessies vues de face et de profil. Celle du milieu ouverte et à demi fermée par une valvule.

Fig. 4. OEufs de mollusque inconnu.

A. Un œuf isolé, terminé par une aile membraneuse. 




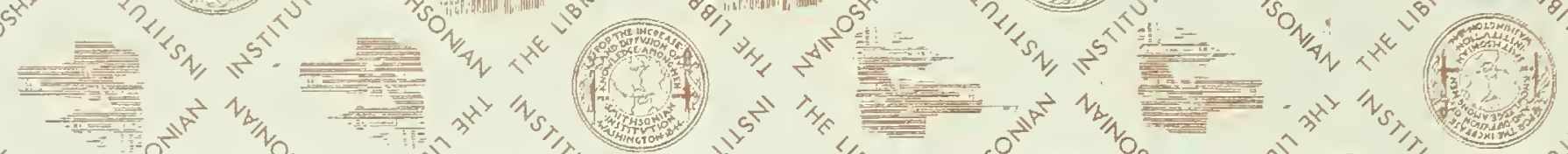

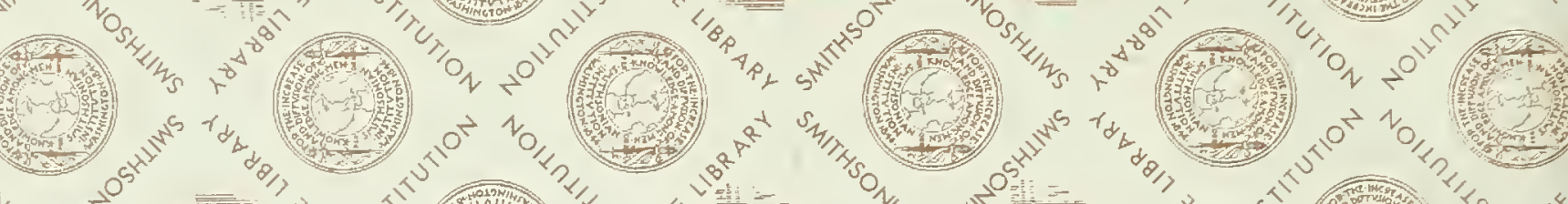

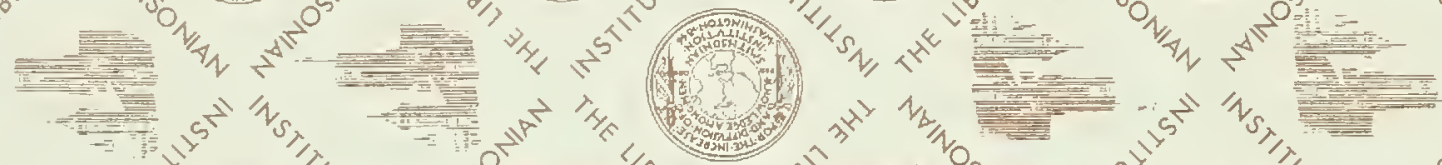

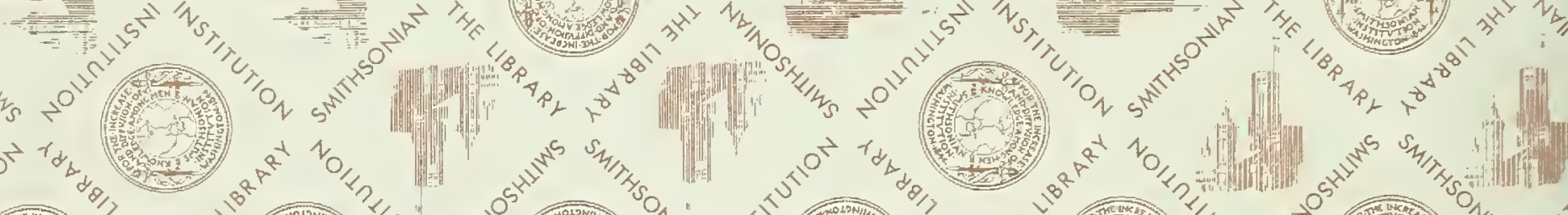

(1)

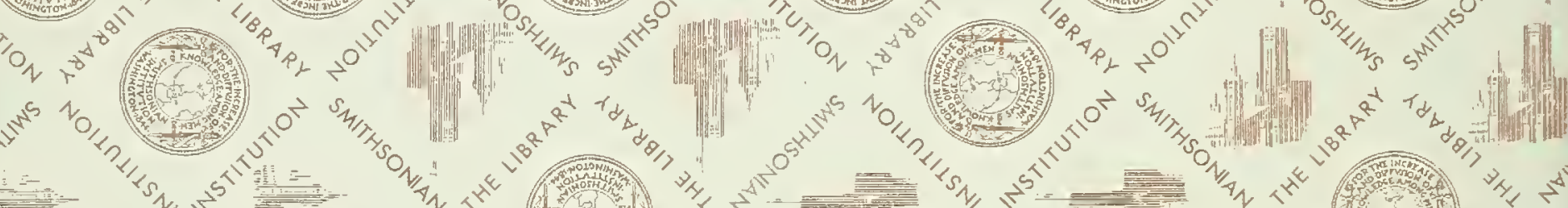

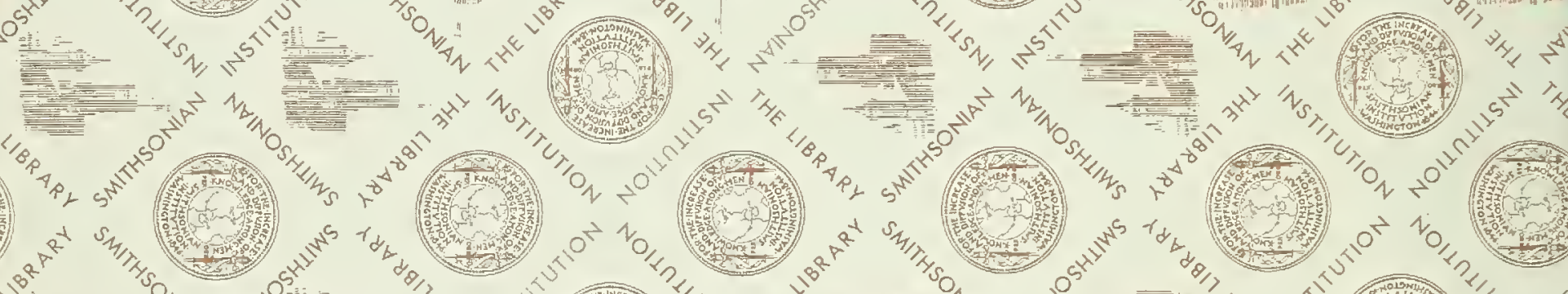

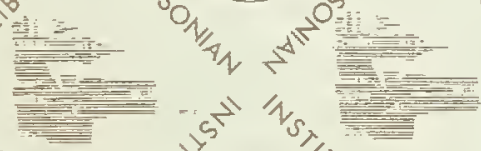

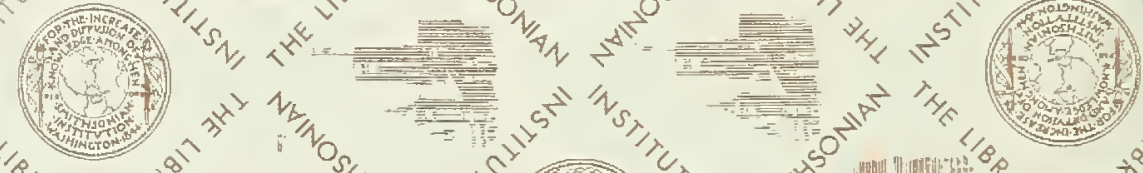

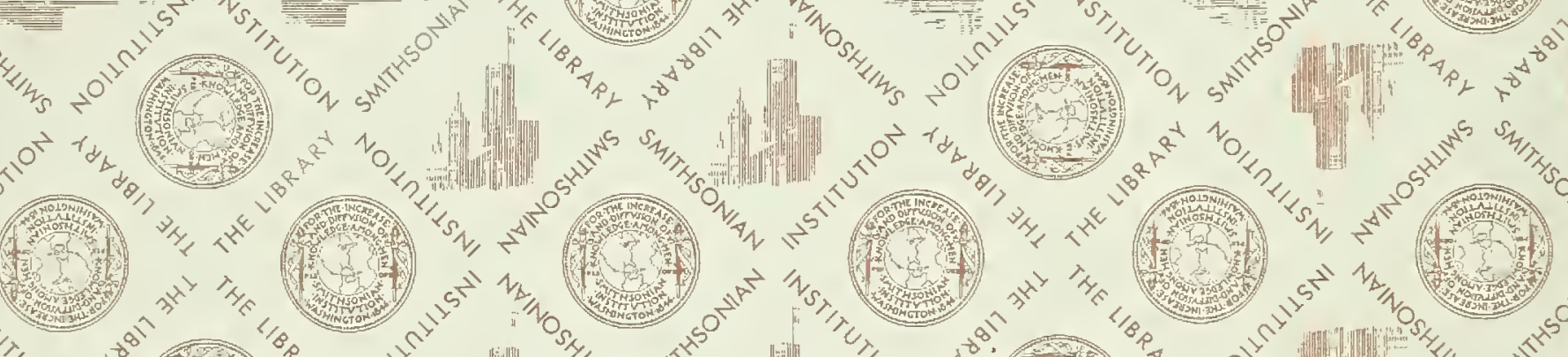

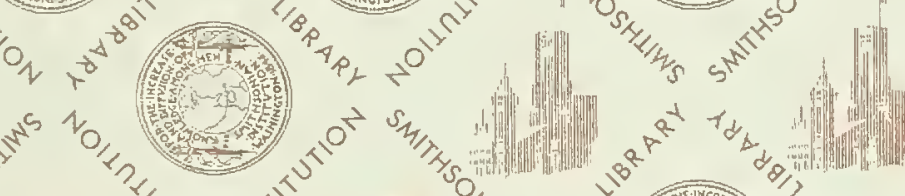

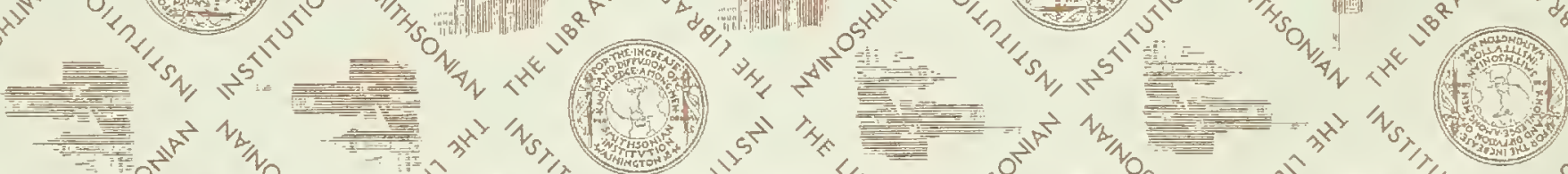

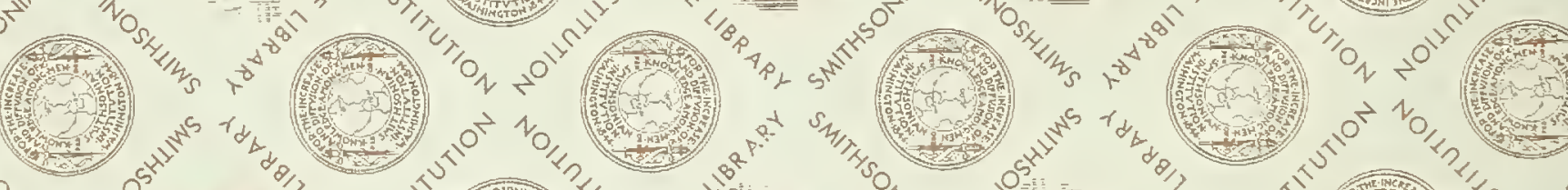

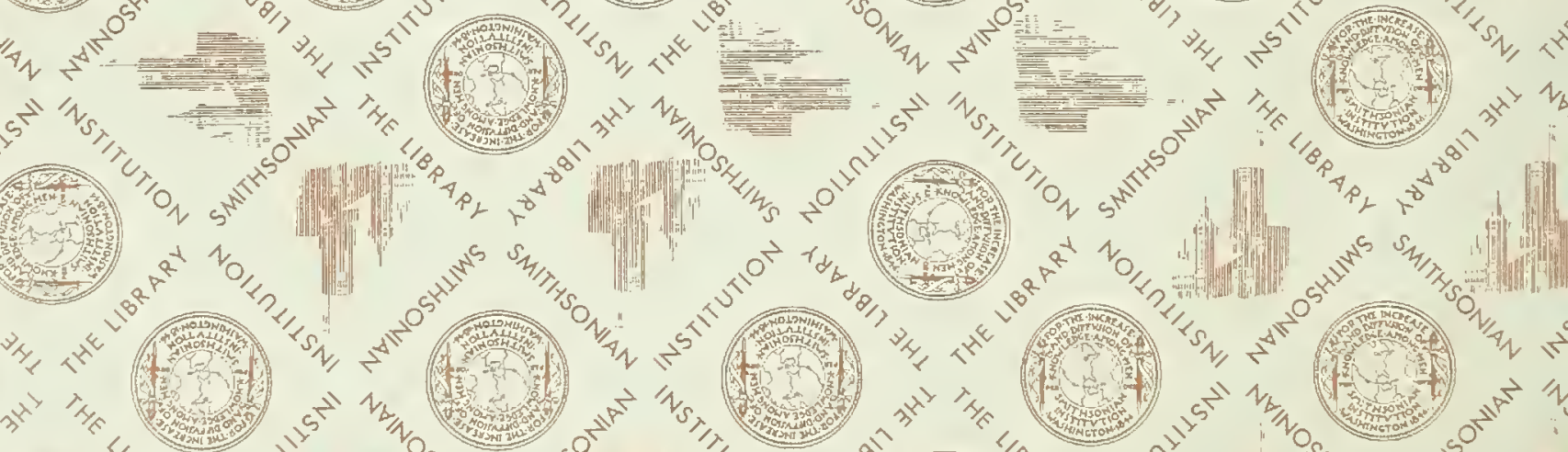

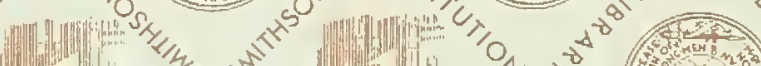


